\title{
AVALIAÇÃO GEOLÓGICO-GEOTÉCNICA DA ÁREA DO LIXÃO DE POÇOS DE CALDAS (MG): PROBLEMAS AMBIENTAIS, MODELAGEM DE FLUXO E DE TRANSPORTE DE POLUENTES E MEDIDAS DE REMEDIAÇÃO
}

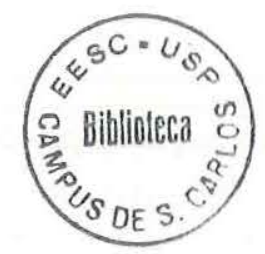

JANAINA BARRIOS PALMA

Dissertação apresentada à Escola de Engenharia de São Carlos da Universidade de São Paulo, como parte dos requisitos para obtenção do título de Mestre em Geotecnia.

ORIENTADOR: Prof. Dr. Lázaro Valentin Zuquette 
Class. $\frac{\text { TESE -EESU }}{\text { cutt. } \frac{}{4160}}$

ins 1063233

Ficha catalográfica preparada pela Seção de Tratamento da Informação de Serviço de Biblioteca da EESC-USP

P171a

Palma, Janaina Barrios

Avaliação geológico-geotécnica na área do lixão de Poços de Caldas (MG) : problemas ambientais, modelagem de fluxo e de transporte de poluentes e medidas de remediação / Janaina Barrios Palma. -- São Carlos, 1999.

Dissertação (Mestrado) -- Escola de Engenharia de São Carlos-Universidade de São Paulo, 1999.

Área: Geotecnia.

Orientador: Prof. Dr. Lázaro Valentin Zuquette.

1. Geotecnia ambiental. I. Título. 
Ao meu pai, José Carlos Palma, e minha mãe Odete Barrios Palma pela possibilidade de nascer $e$ pelo apoio e amor que me permitiu existir 


\section{AGRADECIMENTOS}

Ao prof. Dr. Lázaro Valentin Zuquette, pela orientação, estímulo e amizade.

À Coordenadoria de Aperfeiçoamento de Pessoal de Nível Superior-CAPES, pela bolsa de estudo concedida e à FAPESP pela concessão de verba através do Projeto 98/11320-4.

À Prefeitura do Município de Poços de Caldas pelo dados cedidos.

Aos professores, funcionários e colegas do Departamento de Geotecnia da EESCUSP pelo auxílio durante a elaboração deste trabalho.

As amigas Joseli Ferreira e Vanessa Madrucci pelo companheirismo e estímulo.

A Adriano Akiossi pelo respeito, paciência e apoio durante todos os momentos.

As minhas irmãs Daniela e Tatiane, e ao meu sobrinho Rogério Jr. pelo amor e compreensão durante minha ausência em tantos momentos.

E a todos que, direta ou indiretamente, contribuíram para a realização desta etapa, em especial aos amigos da sala de mapeamento. 


\section{SUMÁRIO}

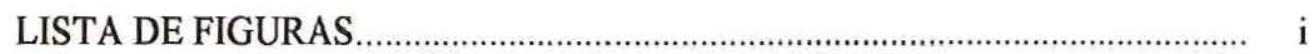

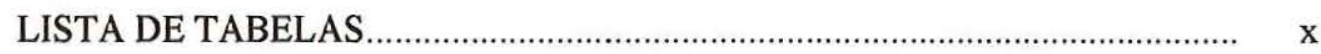

LISTA DE SÍMBOLOS.................................................................................

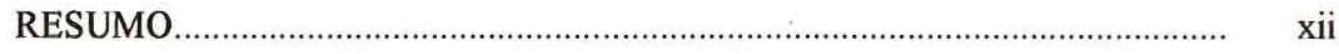

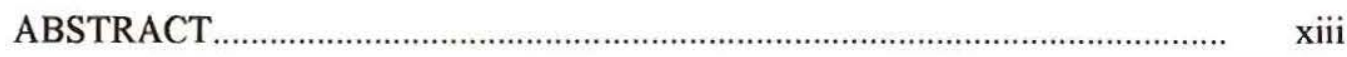

CAPÍTULO I: Introdução..................................................................................... 1

CAPÍTULO II - Revisão Bibliográfica.............................................................. 5

1. Modelagem de Água Subsuperficial............................................................. 5

1.1 Revisão dos Modelos de Fluxo Subsuperficial.......................................... 6

1.1.1 Modelos Analíticos...................................................................... 6

1.1.2 Modelos de Meios Porosos............................................................. 6

1.1.3 Modelos de Fluido Viscosos.............................................................. 8

1.1.4 Modelos de Membrana................................................................... 8

1.1.5 Modelos de Analogia Elétrica....................................................... 8

1.1.6 Modelos Empíricos..................................................................... 9

1.1.7. Modelos de Balanço de Massa........................................................ 9

1.1.8 Modelos Numéricos.................................................................... 9

1.2 Erros Associados a Modelos Numéricos.............................................. 12

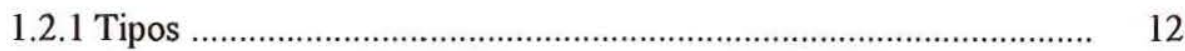

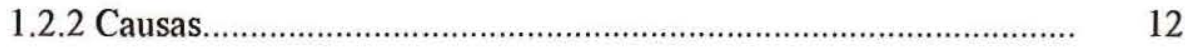

1.2 .3 Controle

2. Técnicas de "Cleanup" ................................................................................ 14

2.1 Técnicas Demostradas ou Comprovadas.............................................. 15

2.1.1. Extração por Vapor........................................................................... 15

2.1.2. Bioremediação "in situ"............................................................... 17

2.1.3. Bioventilação............................................................................. 18

2.2. Técnicas em Desenvolvimento............................................................. 20

2.2.1. Bombeamento Intermitentes....................................................... 20

2.2.2. Bioremediação - "in situ" ................................................................ 20

2.2.3. "Air Sparging" - Aeração "in situ"................................................ 21

2.2.4. Soil Flushing - Lavagem de Solo.................................................... 22

2.2.5. Tratamento Químico “in situ"......................................................... 23 
2.2.6. Técnicas Termais "in situ"

A "Steam Enchanced Extraction" - Extração por Vapor Quente...... 25

B "Radio Frequency Heating" - Aquecimento por Ondas

Eletromagnéticas......................................................................... 26

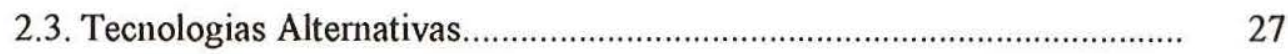

2.3.1. Bioremediação Intrínseca.............................................................. 27

2.4. Técnicas de Contenção.......................................................................... 28

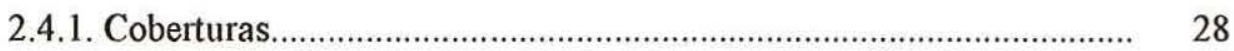

2.4.2. Barreiras Verticais / Paredes Flexíveis / Slurry Walls..................... $\quad 30$

2.4.2.1. Interação Solo - Slurry (lama de preenchimento no estado plástico)

2.4.2.2. Material para Slurry............................................................... 32

2.4.3. Barreiras Inferiores - Liners....................................................... 33

2.4.3.1. Classificações......................................................................... 33

2.5. Poços de Bombeamento..................................................................... 34

2.6. Atributos do meio físico que afetam a seleção do método........................ 35

2.7. Processo de seleção.................................................................................. 38

2.8 Considerações sobre as técnicas................................................................. 40

CAPÍTULO III - Metodologia...................................................................... 43

1. Construindo o Modelo Numérico........................................................................ 43

1.1 Compilação e Interpretação dos Dados de Campo....................................... 44

1.2 Criação do Modelo que represente o Sistema Natural.................................. 45

1.3 Selecionando o Modelo Numérico........................................................... 45

1.4 Calibração e Validação do Modelo.......................................................... 46

1.5 Aplicação do Modelo.............................................................................. 47

1.6 Apresentação dos Resultados................................................................... 47

2. Emprego da Metodologia no caso do Lixão de Poços de Caldas....................... 48

CAPÍTULO IV . Materiais e Métodos ............................................................... 50

1 Equações Governantes do Fluxo de Água Subsuperficial................................... 50

2 Transporte e Atenuação de Solutos em Meio Poroso............................................ 55

2.1. Classificação dos Contaminantes em função do Comportamento de

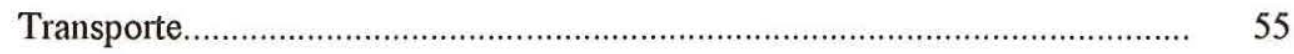

2.2. Mecanismos de Transporte e atenuação dos Solutos.................................. 55

2.2.1 . Advecção ......................................................................... 56

2.2.2. Dispersão Hidrodinâmica ………………………………..... 56 
2.2.4. Decaimento ……....................................................................... 61

2.2.5. Hidrólise, Volatilização, e Biotransformação........................... 62

3 Descrição do Modelo Computacional - Modflow.................................................. 64

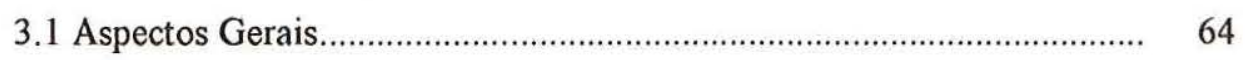

3.2 Processo de Entrada de Dados (Input)................................................ 64

CAPÍTULO V. Características Gerais da área......................................................... 70

1. Aspectos Globais..................................................................................... 70

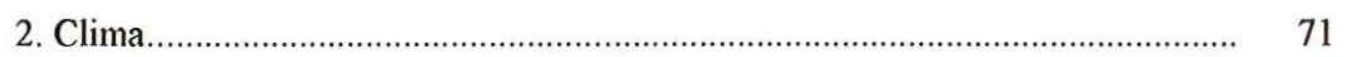

3. Cobertura Vegetal................................................................................. 72

4. Aspectos Geomorfológicos............................................................................... 72

5. Geologia Regional - Modelos Geológicos......................................................... 73

5.1. Estruturas do Maciço Alcalino de Poços de Caldas................................. 75

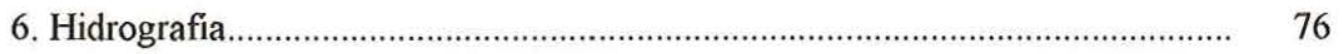

6.1. Recursos Hídricos Superficiais...................................................... 77

6.2. Águas Subterrâneas....................................................................... 78

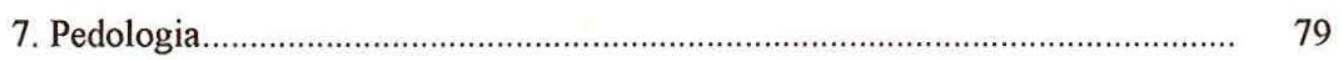

CAPÍTULO VI . Coleta de Dados......................................................................... 81

1. Características do Meio Físico............................................................................. 81

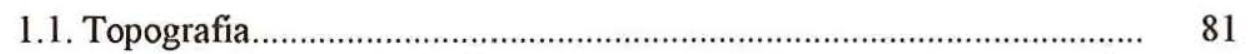

1.2. Substrato Rochoso ........................................................................ 81

1.3. Materiais Inconsolidados................................................................ 85

1.4 - Ensaios Laboratoriais....................................................................... 87

1.5 - Sondagens Geofísicas......................................................................... 88

1.6. Características Hidrogeológicas....................................................... 91

2 Dados Sobre o Aterro........................................................................................... 95

3 Dados sobre a pluma de Contaminação............................................................ 100

CAPÍTULO VII - Modelagem e Análise dos Resultados Obtidos........................ 103

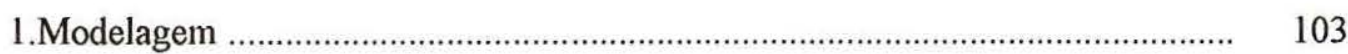

1.1. Delimitação da Área de influência............................................................ 103

1.2. Representação dos Dados em Forma Digital........................................ 103

2. Análise dos Resultados das Simulações................................................................ 118

$1^{\circ}$ Simulação Modelagem da Situação Atual............................................. 120

Simulação da Situação Real utilizando-se a Isoterma de Sorção Linear 134

$2^{\circ}$ Simulação: Extração dos Resíduos......................................................... 136 
$3^{\circ}$ Simulação: Utilização de Cobertura.

$4^{\circ}$ Simulação: Paredes a Montante na Camada número 1.

$5^{\circ}$ Simulação: Utilizando-se de Paredes Frontais......

$6^{\circ}$ Simulação: Utilizando-se de parede única a montante. 195

$7^{\circ}$ Simulação: Parede a montante e cobertura. 209

$8^{\circ}$ Simulação: Paredes frontais e cobertura. 223

$9^{\circ}$ Simulação: Utilizando Poços de Bombeamento. 236

CAPÍTULO 8 - Conclusões. 249

CAPÍTULO 9 - Referências Bibliográficas. 


\section{LISTA DE FIGURAS}

FIGURA 01A - Uso e ocupação Antrópica da Bacia do Rio das Antas (Modificado de LAGE FILHO, 1996)

FIGURA 01 B- Área Afetada pelo Projeto de Construção da Barragem.

FIGURA 02 - Exemplos de Modelos de Água Subsuperficial (Fonte: SPITZ \& MORENO, 1996).......

FIGURA 03 - Esquema do Processo de Extração de vapor do Solo (Fonte: NATIONAL ACADEMY PRESS. 1995)........................................................... 16

FIGURA 04 - Esquema do Processo de Bioremediação (Fonte: NATIONAL ACADEMY PRESS. 1995)

FIGURA 05 - Componentes do sistema de bioventilação. (Fonte: NATIONAL ACADEMY PRESS. 1995).

FIGURA 06 - Possibilidades de configuração do método de "Air Sparging". (Fonte: NATIONAL ACADEMY PRESS. 1995)

FIGURA 07 - Esquema do sistema de Lavagem de Solo. (Fonte: NATIONAL ACADEMY PRESS. 1995).

FIGURA 08 - Esquema do tratamento Químico (Fonte: NATIONAL ACADEMY PRESS. 1995)...

FIGURA 09 - Camadas que constituem um Sistema de Cobertura (Fonte: Modificado de DANIEL, 1995).

FIGURA 10a - Distribuição Vertical (Fonte SHARMA \& LEWIS, 1994)................... 30

FIGURA 10b - Distribuição Vertical (Fonte SHARMA \& LEWIS, 1994)................... $\quad 30$

FIGURA 11a - Distribuição Horizontal (Fonte SHARMA \& LEWIS, 1994)................ 31

FIGURA $11 \mathrm{~b}$ - Distribuição Horizontal (Fonte SHARMA \& LEWIS, 1994)................ 31

FIGURA 11c - Distribuição Horizontal (Fonte SHARMA \& LEWIS, 1994).................. 31

FIGURA 12 - Formação do "Filter Cake" (Fonte SHARMA \& LEWIS, 1994)............. 32

FIGURA 13a - Esquema de Situação de Bombeamento (FREEZE \& CHERRY, 1979).. 35

FIGURA 13b - Esquema de Situação de Bombeamento (FREEZE \& CHERRY, 1979).. 35

FIGURA 14 - Fluxograma das principais etapas para a seleção do método de remediação........................................................................................................ 39

FIGURA 15 - Fluxograma do Procedimento de Construção de Modelos Numéricos para o Lixão de Poços de Caldas.......................................................................... 49

FIGURA 16 - Discretização espacial de um aqüífero (Fonte: MATSUZAKI, 1998)..... 52 
FIGURA 17 - Mapa de Localização da Área de Interesse (Fonte: Modificado de LIPORACI, 1996)

FIGURA 18 - Mapa Geológico do Maciço Alcalino de Poços de Caldas (Fonte: LIPORACI, 1996).

FIGURA 19 - Mapa Topográfico da Região (Fonte: Modificado de Prefeitura do Município de Poços de Caldas, 1995)

FIGURA 20 - Mapa do Substrato Rochoso. 83

FIGURA 21 - Mapa do Material Inconsolidado. 86

FIGURA 22 - Localização dos ensaios na área de Poços de Caldas (MG). 89

FIGURA 23 - Mapa de fluxo das águas subsuperficial. (Modificado de ELIS, 1998)... 90

FIGURA 24 - Posição dos perfis na área de influência da Pluma de contaminação....... 91

FIGURA 25 - Perfil 1 das Unidades Hidrogeológicas................................................... 92

FIGURA 26 - Perfil 2 das Unidades Hidrogeológicas..................................................... 92

FIGURA 27 - Mapa Potenciométrico........................................................................... 93

FIGURA 28 - Gráfico da Isoterma Linear.................................................................... 94

FIGURA 29 - Gráfico da Isoterma de langmuir (Para solo argiloso + 5\% de bentonita) 94

FIGURA 30- Vista Geral da Área (1996)...................................................................... 95

FIGURA 31 - Vista Geral da Área (1991) ................................................................. 96

FIGURA 32 - Área ao Sul - Presença de Matacões........................................................ 96

FIGURA 33 - Detalhe do Solo - Presença de Matacões.................................................. 97

FIGURA 34 - Vista Atual de lixão (1998).................................................................... 97

FIGURA 35 - Detalhe do Lixão............................................................................... 98

FIGURA 36 -.Camada de Argila Compactada.............................................................. 98

FIGURA 37 - Detalhe da Camada de Argila Compactada - Presença de Trincas........... 99

FIGURA 38 - Início do Processo Erosivo......................................................................... 99

FIGURA 39 A- Delimitação da Pluma de Contaminação por Geofísica - Outubro de 1995 (Fonte: ELIS, 1998).............................................................................. 101

FIGURA 39 B- Delimitação da Pluma de Contaminação por Geofísica - Setembro de 1997 (Fonte: ELIS, 1998)............................................................................. 102

FIGURA 40 - Mapa Topográfico da área de Influência ................................................ 105

FIGURA 41 - Modelo Tridimensional da área da influência.......................................... 106

FIGURA 42 - Mapa do Nível de Água da área de influência....................................... 107

FIGURA 43 - Modelo tridimensional do nível de água da área de influência............... 108

FIGURA 44 -.Mapa do topo do Saprolito da área de influência...................................... 109

FIGURA 45 - Modelo tridimensional do Topo do Saprolito da área de influência........ 110 
FIGURA 46 - Mapa da Superfície do Sienito na área de influência.............................. 111

FIGURA 47 - Modelo Tridimensional do Topo do Sienito da área de influência......... 112

FIGURA 48 - Localização dos pontos de observação utilizados para a calibração....... 114

FIGURA 49 - Gráfico de erro médio para o Modelo de Fluxo. .................................... 116

FIGURA 50 - Gráfico de erro médio para o Modelo de Transporte. ................ 116

FIGURA 51A - Localização dos perfis paralelos ao eixo X (perfis em Linha),

longitudinal a direção de maior espalhamento da pluma de poluição.................... 118

FIGURA 51B - Localização dos perfis paralelos ao eixo Y (perfis em coluna), transversal a direção de maior espalhamento da pluma de poluição..................... 119

FIGURA 52 - Modelo de Fluxo das águas subsuperficiais na área de influência (S1)... 121

FIGURA 53 - Trajetória das Partículas S1 ................................................................... 122

FIGURA 54 - Modelo de Transporte. Camada 1 Tempo 1825 dias. S1.......................... 122

FIGURA 55 - Modelo de Transporte. Camada 1 Tempo 3650 dias.S1........................... 123

FIGURA 56 - Modelo de Transporte. Camada 1 Tempo 7300 dias S1.......................... 123

FIGURA 57 - Modelo de Transporte. Camada 2 Tempo 1825 dias.S1........................... 124

FIGURA 58 - Modelo de Transporte. Camada 2 Tempo 3650 dias.S1........................... 124

FIGURA 59 - Modelo de Transporte. Camada 2 Tempo 7300 dias.S1 .......................... 125

FIGURA 60 - Modelo de Transporte. Camada 3 Tempo 1825 dias................................. 125

FIGURA 61 - Modelo de Transporte. Camada 3 Tempo 3650 dias................................. 126

FIGURA 62 - Modelo de Transporte. Camada 3 Tempo 7300 dias................................ 126

FIGURA 63 - Perfil Longitudinal a direção de maior espalhamento da pluma (Linha) -

Tempo 1825 dias.......................................................................................... 128

FIGURA 64 - Perfil Longitudinal a direção de maior espalhamento da pluma (Linha) no Tempo 3650 dias.......................................................................................... 129

FIGURA 65 - Perfil Longitudinal a direção de maior espalhamento da pluma (Linha) Tempo 7300 dias.

FIGURA 66 - Perfil Transversal a direção de maior espalhamento da pluma (Coluna) no Tempo 1825 dias...

FIGURA 67 - Perfil Transversal a direção de maior espalhamento da pluma (Coluna) no Tempo 3650 dias.

FIGURA 68 - Perfil Transversal a direção de maior espalhamento da pluma (Coluna) no Tempo 7300 dias.................................................................................... 133

FIGURA 69A - Modelo de Transporte. Camada 1 Tempo 1825 dias. (1L)................... 134

FIGURA 69B - Modelo de Transporte. Camada 1 Tempo 3650 dias. (1L)................... 135

FIGURA 69C - Modelo de Transporte. Camada 1 Tempo 7300 dias. (1L)..................... 136 
FIGURA 70 - Modelo de Fluxo das águas subsuperficiais na área de influência. (S2)... 137

FIGURA 71 - Trajetória das Partículas (S2) ………................................................. 138

FIGURA 72 - Modelo de Transporte. Camada 1 Tempo 1825 dias. 138

(S2).

FIGURA 73 - Modelo de Transporte. Camada 1 Tempo 3650 dias.

(S2).

FIGURA 74 - Modelo de Transporte. Camada 1 Tempo 5475 dias.

FIGURA 75 - Modelo de Transporte. Camada 1 Tempo 7300 dias. (S2).

FIGURA 76 - Modelo de Transporte. Camada 2 Tempo 1825 dias. (S2).

FIGURA 77 - Modelo de Transporte. Camada 2 Tempo 3650 dias. (S2).

FIGURA 78 - Modelo de Transporte. Camada 2 Tempo 5475 dias. (S2).

FIGURA 79 - Modelo de Transporte. Camada 2 Tempo 7300 dias. (S2)

FIGURA 80 - Modelo de Transporte. Camada 3 Tempo 1825 dias.(S2)

FIGURA 81 - Modelo de Transporte. Camada 3 Tempo 3650 dias.(S2).

FIGURA 82 - Modelo de Transporte. Camada 3 Tempo 5475 dias.(S2)

FIGURA 83 - Modelo de Transporte. Camada 3 Tempo 7300 dias. (S2)

FIGURA 84 - Perfil Longitudinal a direção de maior espalhamento da pluma (Linha) .-

Tempo 1825 dias. (S2)

FIGURA 85 - Perfil Longitudinal a direção de maior espalhamento da pluma (Linha) -

Tempo 3650 dias. (S2).

FIGURA 86 - Perfil Longitudinal a direção de maior espalhamento da pluma (Linha) -

Tempo 5425 dias. (S2).

FIGURA 87 - Perfil Longitudinal a direção de maior espalhamento da pluma (Linha) -

Tempo 7300 dias. (S2).

FIGURA 88 - Perfil Transversal a direção de maior espalhamento da pluma (Coluna) -

Tempo 1825 dias. (S2)

FIGURA 89 - Perfil Transversal a direção de maior espalhamento da pluma (Coluna) -

Tempo 3650 dias. (S2)......

FIGURA 90 - Perfil Transversal a direção de maior espalhamento da pluma (Coluna) -

Tempo 5425 dias. (S2).

FIGURA 91 - Perfil Transversal a direção de maior espalhamento da pluma (Coluna ) -

Tempo 7300 dias. (S2) ............................................................................. 152

FIGURA 92 - Modelo de Fluxo de água subsuperficial na área de influência. (S3)...... 154

FIGURA 93 - Trajetória das Partículas (S3) .............................................................. 155 
FIGURA 94 - Modelo de Transporte. Camada 1 Tempo 1825 dias.(S3)........................ 155

FIGURA 95 - Modelo de Transporte. Camada 1 Tempo 3650 dias (S3)......................... 156

FIGURA 96 - Modelo de Transporte. Camada 1 Tempo 7300 dias.(S3)......................... 156

FIGURA 97 - Modelo de Transporte. Camada 2 Tempo 1825 dias. (S3)........................ 157

FIGURA 98 - Modelo de Transporte. Camada 2 Tempo 3650 dias. (S3)......................... 157

FIGURA 99 - Modelo de Transporte. Camada 2 Tempo 7300 dias. (S3)........................ 158

FIGURA 100 - Modelo de Transporte. Camada 3 Tempo 1825 dias. (S3)..................... 158

FIGURA 101 - Modelo de Transporte. Camada 3 Tempo 3650 dias. (S3)..................... 159

FIGURA 102 - Modelo de Transporte. Camada 3 Tempo 7300 dias. (S3)..................... 159

FIGURA 103 - Perfil Longitudinal a direção de maior espalhamento da pluma de poluição (Linha) no Tempo de 1825 dias. (S3)..................................................... 161

FIGURA 104 - Perfil Longitudinal a direção de maior espalhamento da pluma de poluição (Linha) no Tempo de 3650 dias. (S3).................................................. 162

FIGURA 105 - Perfil Longitudinal a direção de maior espalhamento da pluma de poluição (Linha) no Tempo de 7300 dias. (S3).......................................................

FIGURA 106 - Perfil Transversal a direção de maior espalhamento da pluma de poluição (Coluna) no Tempo de 1825 dias. (S3).

FIGURA 107 - Perfil Transversal a direção de maior espalhamento da pluma de poluição (Coluna) no Tempo de 3650 dias. (S3).

FIGURA 108 - Perfil Transversal a direção de maior espalhamento da pluma de poluição (Coluna) no Tempo de 7300 dias. (S3) ................................................. 166

FIGURA 109 - Modelo de Fluxo de água subsuperficial na área de influência (S4)..... 168

FIGURA 110 - Trajetória das Partículas (S4),............................................................. 169

FIGURA 111 - Modelo de Transporte. Camada 1 Tempo 1825 dias. (S4)....................... 169

FIGURA 112 - Modelo de Transporte. Camada 1 Tempo 3650 dias.(S4)....................... 170

FIGURA 113 - Modelo de Transporte. Camada 1 Tempo 7300 dias.(S4)....................... 170

FIGURA 114 - Modelo de Transporte. Camada 2 Tempo 1825 dias.(S4)....................... 171

FIGURA 115 - Modelo de Transporte. Camada 2 Tempo 3650 dias.(S4)..................... 171

FIGURA 116 - Modelo de Transporte. Camada 2 Tempo 7300 dias.(S4)....................... 172

FIGURA 117 - Modelo de Transporte. Camada 3 Tempo 1825 dias.(S4)....................... 172

FIGURA 118 - Modelo de Transporte. Camada 3 Tempo 3650 dias.(S4)....................... 173

FIGURA 119 - Modelo de Transporte. Camada 3 Tempo 7300 dias.(S4)...................... 173

FIGURA 120 - Perfil Longitudinal a direção de maior espalhamento da pluma de poluição (Linha) no Tempo de 1825 dias. (S4)...................................................... 175

FIGURA 121 - Perfil Longitudinal a maior direção de espalhamento da pluma de 
poluição (Linha) no Tempo de 3650 dias. (S4).

FIGURA 122 - Perfil Longitudinal a direção de maior espalhamento da pluma de poluição (linha) no Tempo de 7300 dias. (S4)...

FIGURA 123 - Perfil Transversal a direção de maior espalhamento da pluma de poluição (Coluna) no Tempo de 1825 dias. (S4).

FIGURA 124 - Perfil Transversal a direção de maior espalhamento da pluma de poluição (Coluna) no Tempo de 3650 dias. (S4).

FIGURA 125 - Perfil Transversal a direção de maior espalhamento da pluma de poluição (Coluna) no Tempo de 7300 dias. (S4).

FIGURA 126 - Modelo de Fluxo da água subsuperficial na área de influência (S5).....

FIGURA 127 - Trajetória das Partículas (S5).

FIGURA 128 - Modelo de Transporte. Camada 1 Tempo 1825 dias. (S5)... 183

FIGURA 129 - Modelo de Transporte. Camada 1 Tempo 3650 dias. (S5) 184

FIGURA 130 - Modelo de Transporte. Camada 1 Tempo 7300 dias. (S5) 184

FIGURA 131 - Modelo de Transporte. Camada 2 Tempo 1825 dias.(S5) 185

FIGURA 132 - Modelo de Transporte. Camada 2 Tempo 3650 dias.

(S5).

FIGURA 133 - Modelo de Transporte. Camada 2 Tempo 7300 dias. (S5) 186

FIGURA 134 - Modelo de Transporte. Camada 3 Tempo 1825 dias. (S5) 186

FIGURA 135 - Modelo de Transporte. Camada 3 Tempo 3650 dias.9S5). 187

FIGURA 136 - Modelo de Transporte. Camada 3 Tempo 7300 dias. (S5) 187

FIGURA 137 - Perfil Longitudinal a direção de maior espalhamento da pluma (Linha) Tempo de 1825 dias. (S5)

FIGURA 138 - Perfil Longitudinal a direção de maior espalhamento da pluma de poluição (Linha) no Tempo de 3650 dias. (S5).

FIGURA 139 - Perfil Longitudinal a direção de maior espalhamento da pluma de da Linha no Tempo de 7300 dias. (S5).....

FIGURA 140 - Perfil Transversal a direção de maior espalhamento da pluma de poluição (Coluna) no Tempo de 1825 dias. (S5).

FIGURA 141 - Perfil Transversal a direção de maior espalhamento da pluma de poluição (Coluna) no Tempo de 3650 dias. (S5).

FIGURA 142 - Perfil Transversal a direção de maior espalhamento da pluma de poluição (Coluna) no Tempo de 7300 dias. (S5).

FIGURA 143 - Modelo de Fluxo das águas subsuperficial na área de influência. (S6)... 196

FIGURA 144 - Trajetória das Partículas (S6). 
FIGURA 145 - Modelo de Transporte. Camada 1 Tempo 1825 dias. (S6)...................... 197

FIGURA 146 - Modelo de Transporte. Camada 1 Tempo 3650 dias. (S6)...................... 198

FIGURA 147 - Modelo de Transporte. Camada 1 Tempo 7300 dias. (S6)....................... 198

FIGURA 148 - Modelo de Transporte. Camada 2 Tempo 1825 dias. (S6)....................... 199

FIGURA 149 - Modelo de Transporte. Camada 2 Tempo 3650 dias. (S6)...................... 199

FIGURA 150 - Modelo de Transporte. Camada 2 Tempo 7300 dias. (S6)...................... 200

FIGURA 151 - Modelo de Transporte. Camada 3 Tempo 1825 dias. (S6)...................... 200

FIGURA 152 - Modelo de Transporte. Camada 3 Tempo 3650 dias. (S6)...................... 201

FIGURA 153 - Modelo de Transporte. Camada 3 Tempo 7300 dias. (S6)...................... 201

FIGURA 154 - Perfil Longitudinal a direção de maior espalhamento da pluma de poluição (Linha) no Tempo de 1825 dias. (S6)........................................................ 203

FIGURA 155 - Perfil Longitudinal a direção de maior espalhamento da pluma de poluição (Linha) no Tempo de 3650 dias. (S6).................................................. 204

FIGURA 156 - Perfil Longitudinal a direção de maior espalhamento da pluma de poluição (Linha) no Tempo de 7300 dias. (S6)..................................................... 205

FIGURA 157 - Perfil Transversal a direção de maior espalhamento da pluma de poluição (Coluna) no Tempo de 1825 dias. (S6).

FIGURA 158 - Perfil Transversal a direção de maior espalhamento da pluma de poluição (Coluna) no Tempo de 3650 dias. (S6).

FIGURA 159 - Perfil Transversal a direção de maior espalhamento da pluma de poluição (Coluna) no Tempo de 7300 dias. (S6).................................................. 208

FIGURA 160 - Modelo de Fluxo de água subsuperficial na área de influência (S7)..... 210

FIGURA 161 - Trajetória das Partículas (S7)................................................................. 211

FIGURA 162 - Modelo de Transporte. Camada 1 Tempo 1825 dias. (S7)...................... 211

FIGURA 163 - Modelo de Transporte. Camada 1 Tempo 3650 dias. (S7)...................... 212

FIGURA 164 - Modelo de Transporte. Camada 1 Tempo 7300 dias. (S7)..................... 212

FIGURA 165 - Modelo de Transporte. Camada 2 Tempo 1825 dias. (S7)...................... 213

FIGURA 166 - Modelo de Transporte. Camada 2 Tempo 3650 dias. (S7)...................... 213

FIGURA 167 - Modelo de Transporte. Camada 2 Tempo 7300 dias. (S7)...................... 214

FIGURA 168 - Modelo de Transporte. Camada 3 Tempo 1825 dias. (S7)..................... 214

FIGURA 169 - Modelo de Transporte. Camada 3 Tempo 3650 dias. (S7)..................... 215

FIGURA 170 - Modelo de Transporte. Camada 3 Tempo 7300 dias. (S7)..................... 215

FIGURA 171 - Perfil Longitudinal a direção de maior espalhamento da pluma de .poluição (Linha) no Tempo de 1825 dias. (S7).................................................... 217

FIGURA 172 - Perfil Longitudinal a direção de maior espalhamento da pluma de 
poluição (Linha) no Tempo de 3650 dias. (S7).

FIGURA 173 - Perfil Longitudinal a direção de maior espalhamento da pluma de poluição (Linha) no Tempo de 7300 dias. (S7).

FIGURA 174 - Perfil Transversal a direção de maior espalhamento da pluma de poluição (Coluna) no Tempo de 1825 dias. (S7).

FIGURA 175 - Perfil Transversal a direção de maior espalhamento da pluma de poluição (Coluna) no Tempo de 3650 dias. (S7).

FIGURA 176 - Perfil Transversal a direção de maior espalhamento da pluma de poluição (Coluna) no Tempo de 7300 dias. (S7)

FIGURA 177 - Modelo de Fluxo de água subsuperficial na área de influência(S8)...... 223

FIGURA 178 - Trajetória das Partículas (S8).................................................................. $\quad 224$

FIGURA 179 - Modelo de Transporte. Layer 1 Tempo 1825 dias. (S8).......................... 225

FIGURA 180 - Modelo de Transporte. Layer 1 Tempo 3650 dias. (S8)........................ 226

FIGURA 181 - Modelo de Transporte. Layer 1 Tempo 7300 dias. (S8)........................ 226

FIGURA 182 - Modelo de Transporte. Layer 2 Tempo 1825 dias. (S8)......................... 227

FIGURA 183 - Modelo de Transporte. Layer 2 Tempo 3650 dias. (S8)......................... 227

FIGURA 184 - Modelo de Transporte. Layer 2 Tempo 7300 dias. (S8)........................ 228

FIGURA 185 - Modelo de Transporte. Layer 3 Tempo 1825 dias. (S8)........................ 228

FIGURA 186 - Modelo de Transporte. Layer 3 Tempo 3650 dias. (S8)........................ 229

FIGURA 187 - Modelo de Transporte. Layer 3 Tempo 7300 dias. (S8)........................ 229

FIGURA 188 - Perfil Longitudinal a direção de maior espalhamento da pluma de poluição (Linha) no Tempo de 1825 dias. (S8)................................................... 230

FIGURA 189 - Perfil Longitudinal a direção de maior espalhamento da pluma de poluição (Linha) no Tempo de 3650 dias. (S8).................................................. 231

FIGURA 190 - Perfil Longitudinal a direção de maior espalhamento da pluma de poluição (Linha) no Tempo de 7300 dias. (S8).

FIGURA 191 - Perfil Transversal a direção de maior espalhamento da pluma de poluição (Coluna) no Tempo de 1825 dias. (S8).

FIGURA 192 - Perfil Transversal a direção de maior espalhamento da pluma de poluição (Coluna) no Tempo de 3650 dias. (S8).

FIGURA 193 - Perfil Transversal a direção de maior espalhamento da pluma de poluição (Coluna) no Tempo de 7300 dias. (S8)..................................................... 235

FIGURA 194 - Modelo de fluxo de água subsuperficial na área de influência (S9)..... 237

FIGURA 195 - Trajetória das Partículas (S9)................................................................ 238

FIGURA 196 - Modelo de Transporte. Camada 1 Tempo 1825 dias. (S9)...................... 238 
FIGURA 197 - Modelo de Transporte. Camada 1 Tempo 3650 dias. (S9). 239

FIGURA 198 - Modelo de Transporte. Camada 1 Tempo 7300 dias. (S9) 239

FIGURA 199 - Modelo de Transporte. Camada 2 Tempo 1825 dias. (S9) 240

FIGURA 200 - Modelo de Transporte. Camada 2 Tempo 3650 dias. (S9) 240

FIGURA 201 - Modelo de Transporte. Camada 2 Tempo 7300 dias. (S9) 241

FIGURA 202 - Modelo de Transporte. Camada 3 Tempo 1825 dias. (S9) 241

FIGURA 203 - Modelo de Transporte. Camada 3 Tempo 3650 dias. (S9) 242

FIGURA 204 - Modelo de Transporte. Camada 3 Tempo 7300 dias. (S9) 242

FIGURA 205 - Perfil Longitudinal a direção de maior espalhamento da pluma de poluição (Linha) no Tempo de 1825 dias. (S9) 243

FIGURA 206 - Perfil Longitudinal a direção de maior espalhamento da pluma de poluição (Linha) no Tempo de 3650 dias. (S9).

FIGURA 207 - Perfil Longitudinal a direção de maior espalhamento da pluma de poluição (Linha) no Tempo de 7300 dias. (S9).

FIGURA 208 - Perfil Transversal a direção de maior espalhamento da pluma de poluição (Coluna) no Tempo de 1825 dias. (S9).

FIGURA 209 - Perfil Transversal a direção de maior espalhamento da pluma de poluição (Coluna) no Tempo de 3650 dias. (S9)

FIGURA 210- Perfil Transversal a direção de maior espalhamento da pluma de poluição (Coluna) no Tempo de 7300 dias. (S9). 


\section{LISTA DE TABELAS}

TABELA 01 - Relação entre o tipo de poluentes e o tratamento químico mais adequado. (Modificado de DESTRIBATS et al. 1994)............................ 24

TABELA 02 - Síntese das características das principais técnicas de "cleanup"......... 40

TABELA 03 - Seqüência de eventos dos modelos. Modificado de GARDA (1990),

ULBRICH \& ULBRICH (1992) apud LIPORACI (1996)...................... 74

TABELA 04 - Dados sobre as bacias hidrográficas do Planalto de Poços de Caldas... $\quad 76$

TABELA 05: Características e Composição das Águas Superficiais (AS) e das Fontes de Circulação Superfícial (FCS) em mg/l. Modificado de CETEC (1987) apud LAGES (1996)...

TABELA 06 - Correlações entre os valores de resistências e os valores de concentração (mg/l). 


\section{LISTA DE SÍMBOLOS}

$\mathrm{c}_{\mathrm{o}}=$ concentração em um tempo 0 (concentração inicial ou concentração fonte) $\left[\mathrm{M} / \mathrm{L}^{3}\right]$

$\mathrm{c}_{\mathrm{a}}=$ concentração de adsorvidos medidos como massa de contaminante por massa de material de matriz seca [1]

$\mathrm{c}=$ concentração $\left[\mathrm{M} / \mathrm{L}^{3}\right]$

$\mathrm{h}=$ carga hidráulica $(\mathrm{L})$;

$\mathrm{K}_{\mathrm{d}}=$ coeficiente de distribuição $\left[\mathrm{L}^{3} / \mathrm{M}\right]$

$\mathrm{K}_{\mathrm{xx}}, \mathrm{K}_{\mathrm{yy}}, \mathrm{K}_{\mathrm{zz}}=$ valores da condutividade hidráulica ao longo das coordenadas espaciais $\mathrm{x}, \mathrm{y} \mathrm{e}$ $\mathrm{z}\left(\mathrm{LT}^{-1}\right)$;

$K_{H}=$ constante da lei de Henry (atm $\left.\mathrm{m}^{3} / \mathrm{mol}\right)$

$K_{o w}=$ coeficiente de partição de octanol-água $\left[\mathrm{L}^{3} / \mathrm{M}\right]$

$\mathrm{n}=$ porosidade tota $[1]$

$\mathrm{n}_{\mathrm{e}}=$ porosidade efetiva $[1]$

$q=$ Fluxo de Darcy $[\mathrm{L} / \mathrm{T}]$

$R=$ fator de retardamento [1]

Ss = armazenamento especifico $\left(\mathrm{L}^{-1}\right)$;

$\mathrm{t}=$ tempo $[\mathrm{T}]$

$\mathrm{T}_{1 / 2}=$ meia-vidas de isótopos radioativos ou de contaminantes degradados [T]

$\mathrm{v}=$ velocidade de transporte advectivo $[\mathrm{L} / \mathrm{T}]$

$v=$ velocidade média de transporte $[\mathrm{L} / \mathrm{T}]$

$\mathrm{x}=$ coordenada espacial na direção $\mathrm{X}[\mathrm{L}]$

$\mathrm{y}=$ coordenada espacial na direção $\mathrm{Y}[\mathrm{L}]$

$z=$ coordenada espacial na direção $Z$ [L]

$\lambda=$ taxa constante que caracteriza o decaimento $\left[\mathrm{T}^{-1}\right]$

$\Delta \mathrm{Rj}=$ largura das células nas direções das linhas [L]

$\Delta \mathrm{Ci}=$ largura das células da direção das colunas [L]

$\Delta \mathrm{Vk}=\mathrm{a}$ espessura das células em uma dada camada $[\mathrm{L}]$ 


\section{RESUMO}

O presente trabalho apresenta os resultados obtidos na avaliação dos problemas ambientais relacionados a lixiviação de poluentes do lixão próximo ao Ribeirão dos Moinhos na cidade de Poços de Caldas (MG).

O estudo considera as características geológicas - geotécnicas e climáticas da área e os vários tipos de técnicas de "cleanup".

O software Visual Modflow foi usado para desenvolver simulações em termos de fluxo de água subsuperficial e de transporte de poluentes.

Palavras Chaves: Modelagem numérica, Modelagem de fluxo de água superficial e de transporte de poluentes, Lixão, Poços de Caldas, Visual Modflow, Técnicas de remediação. 


\section{ABSTRACT}

This work presents the results obtained from assessment of the environment problems related to the pollutant lixiviation from the urban wastes disposed near the Moinho River in Poços de Caldas (MG) city.

The study considered the geological - geotechnical and climatic characteristics of the area and the main kinds of cleanup techniques.

The software Visual Modflow were used to developed the simulation in terms of groundwater flow and pollutant transport.

Key words: Numerical Modeling, Groundwater flow and pollutant transport Modeling, Wastes, Poços de Caldas, Visual Modflow, "cleanup". 


\section{CAPÍTULO I - INTRODUÇÃO}

A maioria das atividades humana tendem a gerar resíduos, e estes muitas vezes são dispostos de maneira inadequada trazendo sérias conseqüências para o meio ambiente. $\mathrm{O}$ crescimento da população e do índice de desperdício resulta em uma quantidade cada vez maior de resíduos agravando a situação.

Existem, no Brasil, mais de 20.000 locais utilizados como depósitos de algum tipo de resíduo e/ou rejeito, não incluídos neste número postos de combustíveis, tanques de armazenamento e barragens de rejeito. Segundo IPT (1995), cerca de 76\% dos resíduos sólidos urbanos produzidos são dispostos a céu aberto (lixões) e apenas os $24 \%$ restantes recebem um tratamento mais adequado, sendo que 13\% são depositados em aterros controlados, $10 \%$ para aterros sanitários, $0,9 \%$ para usinas de compostagem e $0,1 \%$ para usinas de incineração. Observa-se que a maior parte desses resíduos são depositados sem a observância de critérios técnicos de proteção dos recursos hídricos subsuperficiais e do meio ambiente como um todo.

A locação, o manejo e o controle dos aterros sanitários no Brasil só tiveram normas legais a partir de 1979. Até então, na maioria dos casos, o fator preponderante para equacionar o problema da eliminação dos resíduos foi o menor custo imediato. Na maioria dos municípios brasileiros os resíduos sólidos são depositados em locais impróprios, como depressões naturais ou escavações já existentes, em contato direto com o meio físico e muitas vezes com a zona saturada (MATSUZAKI, 1998).

O Lixão de Poços de Caldas pode ser considerado como um depósito de resíduos urbanos e hospitalares do município e vêm sendo regularmente compactados e recoberto por 
material terroso. Este lixão está em atividade desde 1985 e, atualmente, a quantidade de resíduos que ele recebe esta próxima dos seguintes valores:

- 60 ton./dia - resíduos urbanos residenciais;

- 5 ton./dia - resíduos decorrentes dos serviços da saúde; e

- 15 ton./dia - resíduos das industrias comuns e do comercio.

Considerando-se estas quantidades diárias pode-se estimar a necessidade de espaços diários da ordem de 70 a $75 \mathrm{~m}^{2}$ para a disposição dos resíduos urbanos residenciais / industriais e comerciais e de $5 \mathrm{~m}^{2}$ (considerando profundidade de $5 \mathrm{~m}$ ), com condições especiais, para os resíduos oriundos da saúde (Dados da Prefeitura do Município de Poços de Caldas, 1997).

Considerando o crescente índice de geração de resíduos, a modelagem matemática de fluxo de água subsuperficial e de transporte de solutos tornou-se uma ferramenta importante na gestão da qualidade dos recursos hídricos.

Um modelo matemático numérico - computacional pode ser idealizado para resolver um problema especifico ou ter um caracter genérico que the permite ser aplicado a várias situações distintas (MATSUZAKI, 1998). No segundo grupo enquadra-se o programa conhecido pela sigla MODFLOW, desenvolvido pelo USGS e de domínio publico. Posteriormente foi adaptado para uso em microcomputadores em ambiente Windows, denominado Visual Modflow e de propriedade da Waterloo Hydrogeologic Software.

Neste trabalho a técnica de modelagem foi utilizada para a simulação de alternativas de remediação para o Lixão de Poços de Caldas (MG), para este fim realizou-se um estudo sobre as técnicas existentes. As formas de tratamento e manejo de áreas contaminadas são agrupadas em um termo em inglês denominado "cleanup" que é conceituado por SUTHERSAN (1997) como o desenvolvimento e implantação de estratégias que visam a restituição das características originais do local pela remoção dos contaminantes perigosos. Em NATIONAL ACADEMY PRESS (1995), considera-se que também fazem parte deste conjunto os métodos de contenção, estes utilizam-se de barreiras físicas e/ou químicas para manter o contaminante isolado em um local específico.

A presente dissertação tem como objetivo realizar um estudo de caracterização da área do Lixão de Poços de Caldas (MG) e considerando os métodos de "cleanup", suas vantagens e limitações, sugerir uma ou mais técnicas consideradas mais adequadas ao local. A modelagem tem como finalidade predizer o comportamento do fluxo de água subsuperficial e o transporte dos líquidos poluídos oriundos do lixão, incluindo a área circunvizinha (região de influência da pluma). 
O interesse por este Lixão é devido a sua localização na principal bacia da região, a Bacia do Ribeirão das Antas (FIGURA 1A), além disto oferece recreação de contato primário no reservatório "Bortolan" e é a última opção de abastecimento de água para a população de Poços de Caldas a médio prazo.

Além destes pontos um fato torna este estudo ainda mais relevante. Existe um projeto de construção de uma barragem com eixo próximo ao local do lixão e com lago de influência que prevê inundação da área onde encontra-se o lixão. $\mathrm{O}$ eixo previsto assim como a cota de inundação do lago estão representados na Figura 1B. Como pode-se observar o simples fato de rebaixar a cota de influência não adiantaria, devido a proximidade do eixo da barragem com a área do lixão, e a mudança da localização do eixo diminuiria consideravelmente o volume de água represado.

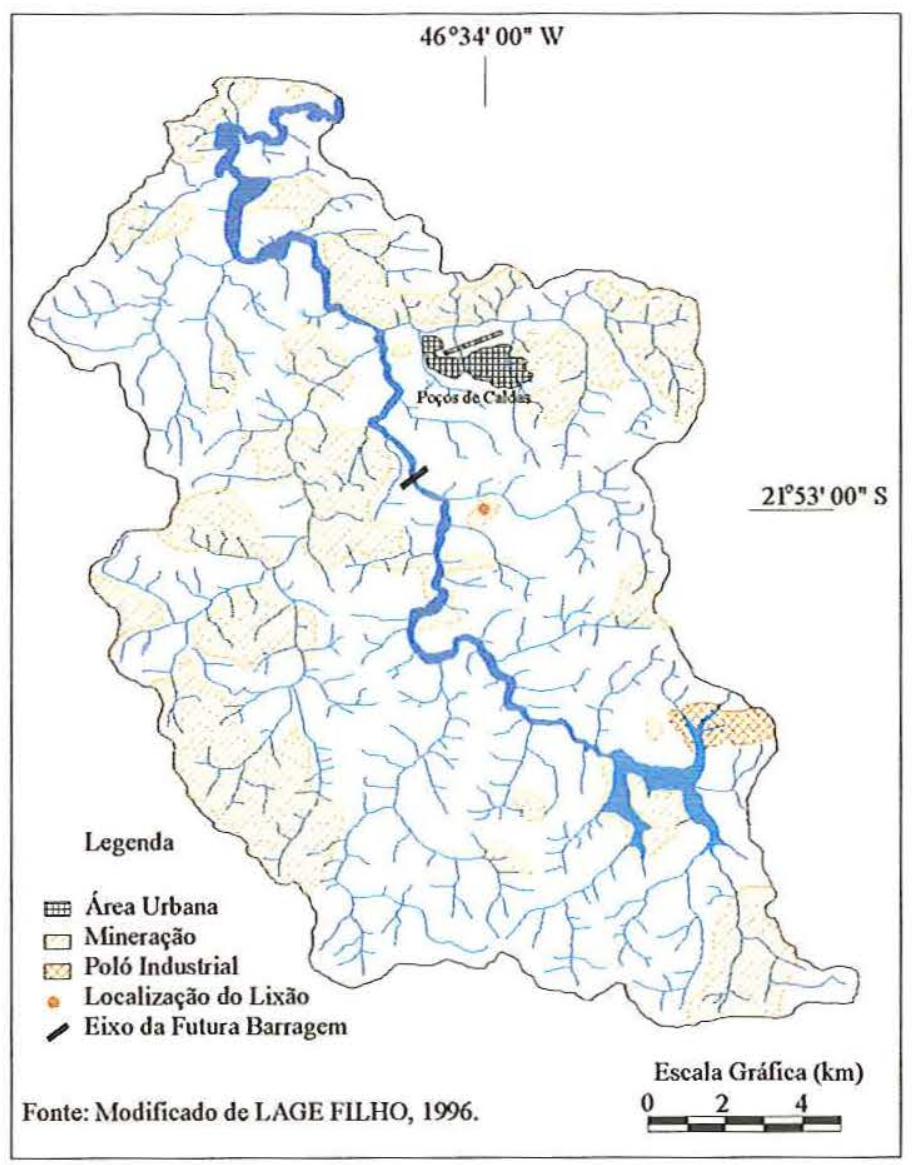

FIGURA 1A - Uso e ocupação antrópica da Bacia do Rio das Antas (Modificado de LAGE FILHO, 1996). 
Área Afetada pela Represa

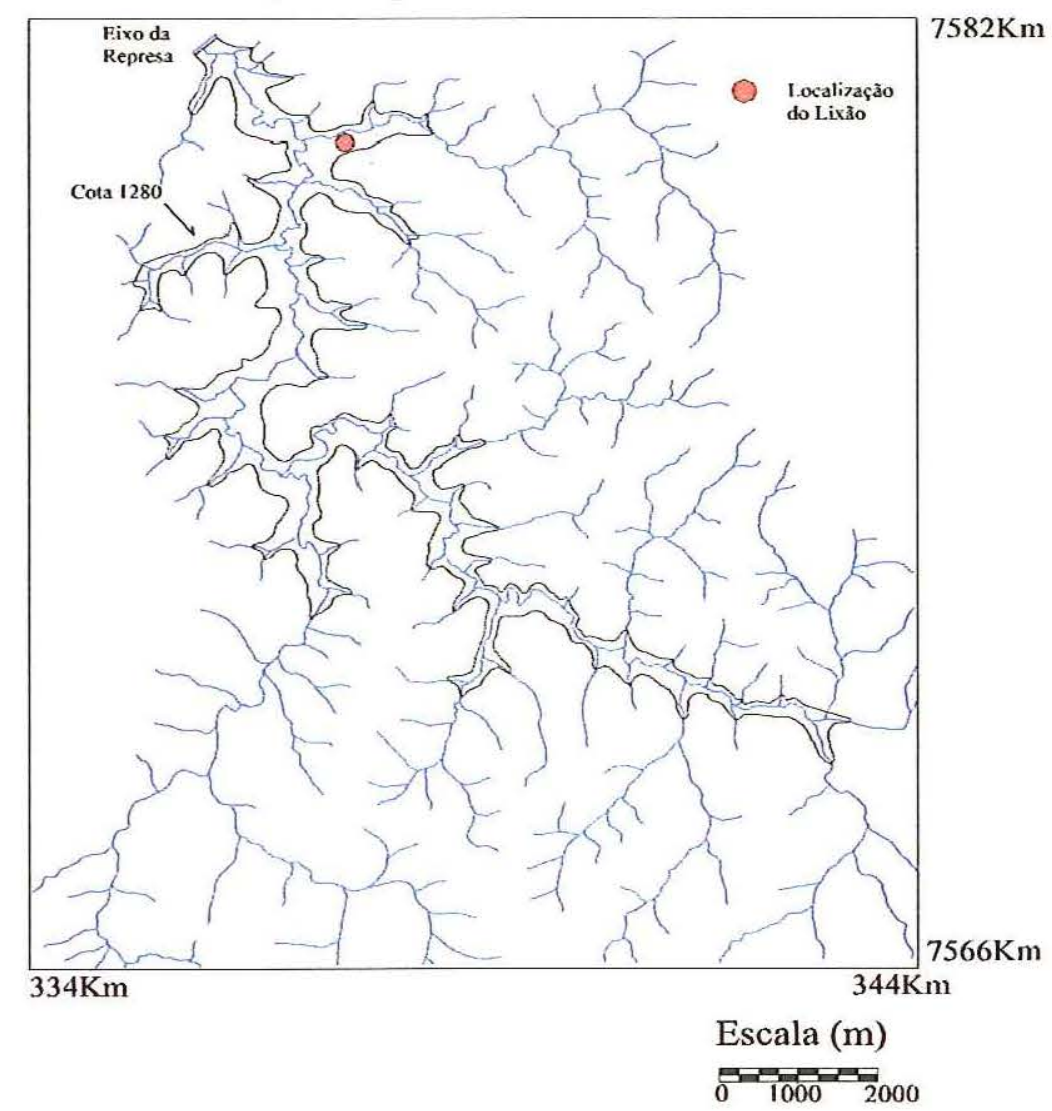

FIGURA 1B - Área Afetada pelo Projeto de Construção da Barragem. 


\section{CAPÍTULO II - REVISÃO BIBLIOGRÁFICA}

A presente revisão bibliográfica engloba dois aspectos principais, no primeiro apresenta-se os principais pontos da modelagem de fluxo de água subsuperficial e de transporte de soluto, com ênfase na modelagem numérica em função do objetivo do trabalho e em uma segunda parte são mostradas as principais técnicas de "cleanup" utilizadas.

\section{Modelagem de Fluxo de Água Subsuperficial e de Transporte de Soluto}

\section{Introdução}

Os modelos numéricos, por apresentarem uma aproximação mais versátil dos problemas de fluxo subsuperficial, estão tendo maior destaque que os demais modelos de fluxo subsuperficial, no entanto, deve-se atentar para isto não induzir a uma super estimativa do seu potencial.

Para uma análise do problema de fluxo subsuperficial são exigidas suposições e simplificações. Um modelo, por mais complexo, nunca descreverá o sistema de fluxo subsuperficial real, consequentemente é importante entender as implicações das simplificações propostas.

Modelos numéricos são uma ferramenta para resolver problemas mas não a própria solução, estes não oferecem respostas precisas a problemas insuficientemente definidos. Consequentemente modelar não é essencialmente uma pergunta de compreensão as técnicas numéricas mas de aplicação de modelo de compreensão. 


\subsection{Revisão dos Modelos de Fluxo Subsuperficial}

O papel dos modelos de fluxo subsuperficial na análise das características do local e de transporte é um tópico de interesse para diversos profissionais. Entre os vários modelos desenvolvidos, destacam-se:

$\checkmark$ Modelos analíticos

$\checkmark$ Modelos de meios porosos

$\checkmark$ Modelos de fluidos viscosos

$\checkmark$ Modelos de membrana

$\checkmark$ Modelos de Analogia Elétrica

$\checkmark$ Modelos empíricos

$\checkmark$ Modelos de equilíbrio de massa

$\checkmark$ Modelos numéricos.

A seguir são apresentadas as principais vantagens e desvantagens de cada modelo de acordo com SPITZ \& MORENO (1996):

\subsubsection{Modelos Analíticos}

O uso de soluções analíticas tradicionais é limitado devido às grandes simplificações necessárias, no entanto, quando possível de ser aplicado este modelo apresenta bons resultados. O método possibilita o estudo da influência de parâmetros individuais, além de ser freqüentemente simples e rápido. Soluções analíticas acham larga aplicação na descrição do fluxo bidimensionais e em sistemas de fluxo homogêneo. Uma vantagem é o fato da equação de Laplace, a equação que governa o fluxo, ser uma equação diferencial muito estudada entre os matemáticos e físicos.

\subsubsection{Modelos de Meios Porosos}

Este modelo é muito usado em Engenharia Hidráulica e tem a vantagem de poder ser representado em escala laboratorial, como mostrado para fluxo unidimensional na Figura 2, que também ilustra exemplos dos modelos de fluido viscoso, de membrana, de sistema de analogia elétrica, de balanço de massa e do modelo numérico discutidos nas subseção seguintes. Neste caso as propriedades hidrogeológicas são distribuídas em espaço e magnitude de acordo com o sistema natural, o modelo é então manipulado e as respostas do sistema de fluxo são registradas e comparadas com o sistema real. 
Modelos de Meios Porosos

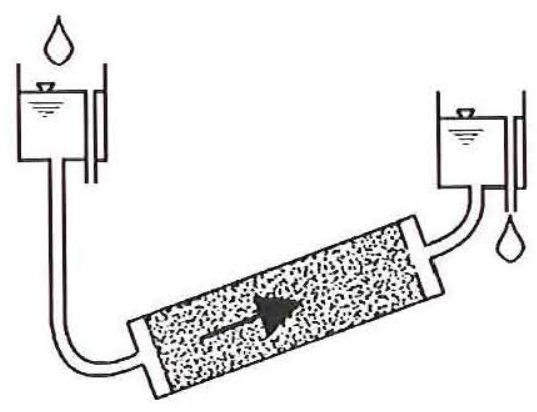

Modelos de Membrana

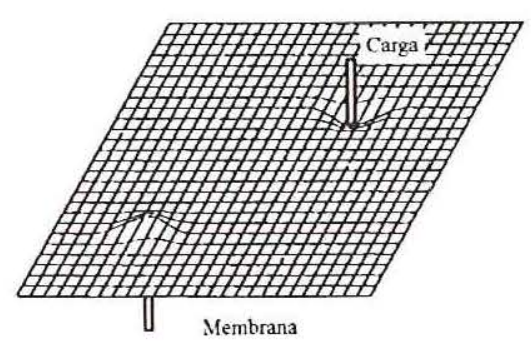

Modelo de Balanço de Massa

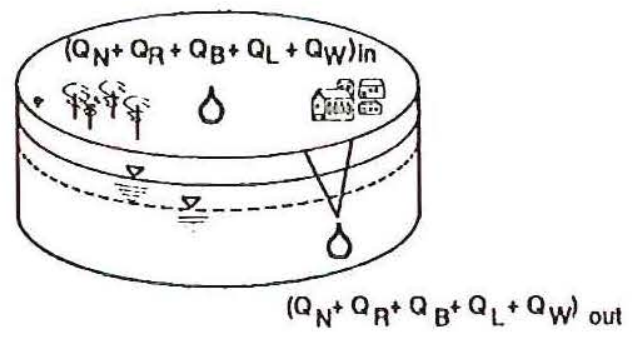

Modelo de Fluido Viscoso

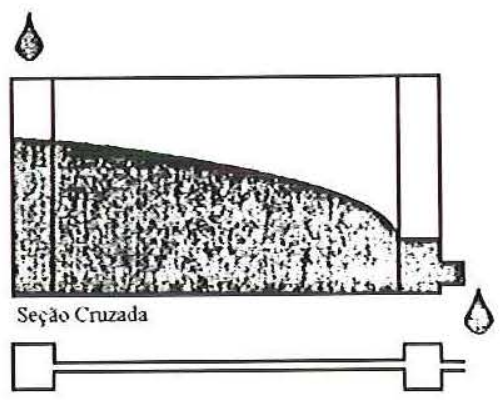

Modelo de Analogia Elćtrica

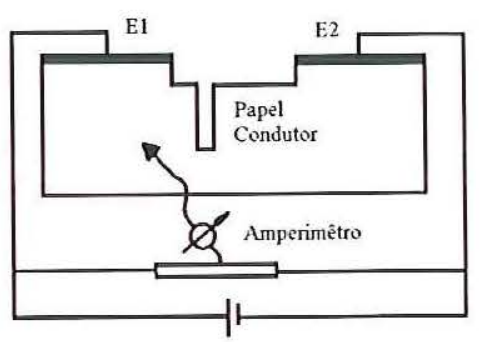

Modelo Numérico

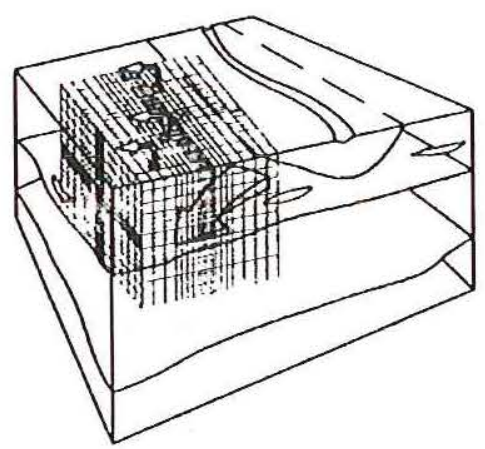

FIGURA 2 - Exemplos de Modelos de Água Subsuperficial (Fonte: SPITZ \& MORENO, 1996). 


\subsubsection{Modelos de Fluido Viscosos}

"Hele-Shaw" ou modelos planos paralelos são sinônimos para o modelo de fluido viscoso, a Figura 2 mostra um exemplo deste modelo em sua forma mais simples. O modelo de "Hele-Shaw" faz uma analogia ao movimento do fluido viscoso, como glicerina, entre dois planos paralelos de pequeno espaçamento. Uma analogia semelhante é a lei de $\mathrm{Ohm} \mathrm{em}$ um sistema elétrico e a Lei de Fourier em um sistema térmico. A equação mais utilizada deste tipo é a lei de movimento de Newton.

Foram introduzidos modelos de "Hele-Shaw" para estudar fluxos, intrusão de água salina e outros fenômenos. Estes modelos foram aplicados por SCHWILLE (1988) para modelar o fluxo subsuperficial e o transporte de soluto por fraturas de rochas. A permeabilidade apresentada pelos modelos planos e de fluido viscosos é isotrópica, mas variações locais de permeabilidade ou podem ser representadas pela variação da largura interespacial ou colocando obstruções entre os planos. O armazenamento pode ser simulado conectando reservatórios pequenos entre os planos (SPITZ \& MORENO, 1996).

\subsubsection{Modelos de Membrana}

O modelo de membrana consiste no mecanismo de aplicar uma pressão sobre uma membrana colocada em um dispositivo para medir as deformações. Por exemplo, para representar um único poço, uma pressão pontual pode ser aplicada para deprimir a membrana a um ponto discreto, a intensidade do bombeamento do poço pode ser ajustada variando-se a pressão. Para um poço de bombeamento a membrana estará rebaixada, enquanto para um poço de injeção o ponto formará uma saliência, como mostrado na Figura 2 (SPITZ \& MORENO, 1996).

\subsubsection{Modelos de Analogia Elétrica}

Esse modelo é baseado na relação entre o fluxo elétrico e o fluxo de água subsuperficial. O meio no qual o fluxo elétrico é estudado pode ser um papel, um tanque de eletrólise ou uma série de resistências elétricas. O papel condutor é uma ferramenta para simular o fluxo bidimensional de água subsuperficial. Uma voltagem equivalente (E) é aplicada em ganchos de cobre descascados conectados ao papel condutor, assim as linhas de queda de potencial, que representam linhas de frentes constantes, podem ser facilmente medidas. Um esquema simples deste modelo é mostrado na Figura 2. 


\subsubsection{Modelos Empíricos}

Os modelos empíricos são usados para representar os processos físicos ou químicos mais gerais ou simplificações e representações em escala maior que o próprio processo. Os modelos empíricos são de dois tipos: modelos que representam processos individuais ou mecanismos e modelos que representam um problema geral de água subsuperficial.

Este método é mais aplicado em circunstâncias limitadas.

\subsubsection{Modelos de Balanço de Massa}

Modelo de balanço de massa, também conhecido como caixa preta (black box) ou modelo de célula única, é considerado como um modelo numérico na sua forma mais simples. Os fluxos de massa, de água subsuperficial (balanço de água) ou de outro componente (balanço de soluto) são balanceados com base em grandes volumes como mostrado esquematicamente na Figura 2. Apesar de sua simplicidade, este modelo é muito útil para se conduzir a um exame do equilíbrio de massa global. Modelos de células unitária são bons para complementar a modelagem de modelos numéricos e provêem uma comparação de balanço de massa nas fases anteriores aos cálculos.

\section{人〔1.1.8 Modelos Numéricos}

Os modelos computacionais que tratam da modelagem numérica podem ser divididos em duas categorias: modelos de fluxo da água subsuperficial e modelos de transporte de solutos. Os primeiros fornecem a distribuição das cargas hidráulicas no domínio enquanto o segundo grupo fornece a distribuição das concentrações de soluto afetada pelos mecanismos de transporte, neste caso antes deve ser realizada a modelagem de fluxo.

O Internacional Groundwater Modeling Center do Holocomb Institute na Universidade de Butter em Indianapolis, Indiana, catalogou mais de 400 modelos de fluxo e transporte existentes (VANDER HEJDE, 1984, apud RAMOS et al. 1989), destes, em 1984, existiam no mínimo 100 modelos considerados como eficientes na modelagem de fluxo de água subsuperficial. Para modelagem Bi ou Tridimensional os modelos conhecidos como MODFLOW, desenvolvido no USGS por McDonald e Harbaugh (1988) e o AQUIFEM, são os mais utilizados, o primeiro usa o método de diferenças finitas e o segundo o de elementos finitos (ANDERSON et al., 1992). Existe uma diferença conceitual entre os dois métodos: o método das diferenças finitas calcula um valor para a carga hidráulica que é uma média das cargas nas células vizinhas e nenhuma hipótese é feita sobre a forma de variação da carga de uma célula para a vizinha. No método dos elementos finitos é definida uma lei de variação 
por meio de funções de interpolação e o gradiente hidráulico é definido em qualquer posição por meio destas funções.

Existem várias equações para esquematizar os mecanismos de movimento de fluxo de água subsuperficial e de transporte dos solutos, no entanto, para a maioria dos casos práticos estas equações não tem solução analítica, desse modo, métodos numéricos são utilizados para sua resolução.

Cinco métodos numéricos são utilizados para a solução das equações: diferenças finitas, elementos finitos, diferenças finitas integradas, método da integral de contorno e método dos elementos analíticos, sendo os dois primeiros mais comumente empregados.

\section{Procedimentos da Modelagem}

Após a coleta de dados, a próxima etapa do trabalho é a elaboração de um modelo conceitual ou modelo físico. Nessa etapa as informações sobre a geologia da área devem ser compiladas e as camadas confinantes e semiconfinantes são definidas usando-se o conceito de unidades hidroestratigráficas, que são formações geologicamente distintas mas com características hidrogeológicas similares.

Como resultado do modelo físico o fluxo de água subsuperficial resultante poderá ser classificado em termos de dimensões espaciais em bidimensional, quase tridimensional ou totalmente tridimensional. Os modelos bidimensionais e quase tridimensionais adotam o enfoque hidráulico, ou seja, fluxo horizontal por camadas, nesses casos, ao invés da condutividade hidráulica, utiliza-se a Transmissividade que é o produto da condutividade hidráulica pela espessura da camada considerada. Convém ressaltar que o enfoque hidráulico não significa a inexistência de fluxo na direção vertical como ficou demonstrado por CONNTORNO (1985), apud CONTIN, (1987).

Modelos tridimensionais são utilizados em situações nas quais o gradiente vertical pode vir a ser relevante, estes devem ser usados também para representar a extração de água de camadas confinantes em fenômenos de compactação (LEAKE, 1990).

O método de interpolação mais utilizado é o método denominado de Krigagem. MARSILY (1986) fornece uma boa explanação sobre este método aplicado em problemas de água subsuperficial; PUCCI \& MURASHIGE (1987) utilizaram esse método para interpolar valores de gradiente hidráulico. Existem outros programas geoestatísticos utilizados além da Krigagem, como o Inverso da Distância, Curvatura Mínima, Regressão Polinomial, Função Radial, Método de Shepard e Triangularização com Interpolação Linear.

Pode-se distinguir contornos físicos e hidráulicos para o modelo, sendo os físicos produzidos por rochas impermeáveis e grandes corpos de água superficial, enquanto os 
hidráulicos são geralmente invisíveis tais como divisores de água subsuperficial e linhas de corrente.

A escolha do intervalo de tempo e do espaçamento nodal de discretização espacial influi nos resultados da simulação. É desejável o uso de pequeno espaçamento nodal e pequenos intervalos de tempo para que a representação numérica melhor se aproxime da equação diferencial parcial. A maioria dos programas computacionais adotam intervalos de tempo crescentes a medida que o tempo de simulação aumenta, utilizando-se geralmente o esquema de progressão geométrica com relação de 1,2 a 2,5. O programa MODFLOW utiliza esse esquema.

Os modelos computacionais, em casos especiais, podem ser testados pela comparação de seus resultados numéricos com a solução analítica, a finalidade desse teste é demonstrar que a solução numérica é relativamente independente de erros de truncamento $\mathrm{e}$ de arredondamento. O conjunto de equações algébricas que representa o movimento é resolvido usando-se métodos diretos, indiretos ou uma combinação entre eles (MATSUZAKI, 1998).

A validação do modelo é obtida quando o mesmo é capaz de reproduzir com precisão os dados de campo. Outro procedimento desejável é a análise de sensibilidade, o objetivo desta fase é quantificar as incertezas no modelo calibrado, causada na avaliação dos parâmetros. FREEZE et al (1990), discutem a necessidade de se desenvolver a análise de sensibilidade em face do grande número de parâmetros envolvidos nas simulações de modelos de fluxo de água subsuperficial. COOLEY et al. (1986), elaboraram mapas de sensibilidade para ilustrar as áreas do modelo mais sensíveis a mudanças em um dado parâmetro. SYKES et al. (1985); TOWNLEY \& WILSON (1985) mostram metodologias para calcular a sensibilidade para os parâmetros em todos os nós da discretização espacial (no Capítulo III as fases da modelagem serão detalhadamente explicadas).

Os modelos discutidos anteriormente supõem que o meio poroso é constituído por um espaço poroso continuo interconectado. Meios porosos fraturados necessitam de um tratamento matemático diferenciado. Um meio fraturado consiste em uma rocha que tem uma porosidade primária a qual se superpõe um sistema de fraturas que cria uma porosidade secundária geralmente muito maior que a porosidade primária. Os sistemas fraturados são modelados usando basicamente três modelos conceituais: meio poroso equivalente; sistema de fraturas discretas e porosidade dual.

Na modelagem de fluxo de água subsuperficial e de transporte, o modelo numérico mais simples considera o sistema de água subsuperficial como um único volume de controle. A partir do balanço de água global, apresenta-se o modelo de múltiplas células, o modelo de 
diferença finita (DF), e o modelo de elemento finito (EF) para fluxo de água subsuperficial.

\subsection{Erros Associados a Modelos Numéricos (SPTIZ \& MORENO, 1996)}

\subsubsection{Tipos}

A aplicação de modelo numéricos está sujeita a vários tipos de erros, descritos a seguir:

$\checkmark$ Erros na coleta e interpretação de dados - Utilização de dados que não representem o sistema real ou simplificações incorretas;

$\checkmark$ Erro de mutilação. São criados erros de mutilação quando se expressa uma função complexa como a distribuição de frente potenciométrica como uma série de funções mais simples. O erro é embutido na teoria numérica.

$\checkmark$ Erro de "Roundoff". Este tipo de erro sempre está presente e é devido à limitação do computador em representar dígitos. O acúmulo pode causar eventualmente instabilidade numérica.

$\checkmark$ Dispersão numérica relacionada a distância. A Dispersão numérica relacionada a distância origina erros em modelos de DF porque as concentrações nas malhas só são conhecidas nos nós que representam a célula inteira.

$\checkmark$ Dispersão numérica angular. Este tipo de erro está relacionado a variação angular entre os planos axiais e a discretização.

$\checkmark$ Oscilação. Este é um problema comum observado em situações com concentração simulada mais alta que a concentração de fonte ou concentração menor que zero (undershoot).

$\checkmark$ Instabilidade, este é um problema comum em casos de grande variação no tamanho nodal.

$\checkmark$ Repetição erro residual. Esta relacionado ao cálculo utilizando valores com erros imbutidos.

\subsubsection{Causas}

Para reduzir os erros numéricos, deve-se entender os parâmetros em aplicação no modelo, que podem causar erros. As principais causas e tipos de erros associados são:

$\checkmark$ Grade inadequada - gera dispersão numérica. 
Grandes intervalos de tempo estimulam a oscilação.

$\checkmark$ Extrapolações para tempos anterior (esquema implícito) tende a dispersão numérica.

$\checkmark$ Extrapolações para tempos posterior (esquema explícito) está sujeito a instabilidade.

$\checkmark$ Não linearidade alta em fluxo ou processos de transporte podem causar instabilidade.

$\checkmark$ Relação entre comprimento e largura alta (relação de aspecto de célula) também pode introduzir erros de "Roundoff".

$\checkmark$ Mudanças abruptas de tempo ou discretização espacial geram instabilidade.

$\checkmark$ Discretização espacial grosseira em áreas onde são esperadas respostas diferentes, por exemplo, em áreas onde as propriedades hidrogeológicas mudam abruptamente, ou em áreas onde o limite condicionante muda rapidamente, causam dispersão numérica e podem resultar em soluções instáveis.

\subsubsection{Controle}

Erros numéricos podem ser influenciados pela discretização espacial e temporal. Os seguintes controles existem para diminuir os erros numéricos e assegurar resultados precisos:

$\checkmark$ Critério de Peclet - O critério de Peclet controla o discretização de espaço em cada uma das direções das coordenadas.

$\checkmark$ Critério de Courant - O critério de Courant controla intervalo de tempo (dt) da modelagem.

$\checkmark$ Critério de Neumann - O critério de Neumann restringe o fluxo dispersivo permissível dentro de um intervalo de tempo.

Outros aspectos que podem minimizar os erros são:

$\checkmark$ Orientação da malha ao longo da direção principal de fluxo;

$\checkmark$ Assegurar variação gradual de tempo e discretização espacial;

$\checkmark$ Números reais decrescentes em resultados de operações numéricos reduz perda de dígitos significantes;

$\checkmark$ Manter a relação de tamanho da célula dentro de pelo menos uma ordem de magnitude;

$\checkmark$ Diminuir o intervalo de tempo para melhorar estabilidade; e

$\checkmark$ Aumentar a discretização em áreas com mudanças rápidas das propriedades do meio hidrogeológico ou de respostas diferentes esperadas. 


\section{TÉCNICAS DE "CLEANUP"}

Existem diversas propostas para se sub-agrupar os métodos de "cleanup". HARRIS \& HERBERT (1994), separam os métodos em função do local onde o tratamento é aplicado, dividindo em remediações "ex situ" e "in situ". DESTRIBATS et a (1994), sugerem duas abordagens possíveis, o confinamento e a despoluição do local, para estes autores as ações podem ser classificadas em quatro domínios:

1. Técnicas de Características Físicas: Este conjunto abrange a maioria dos processos empregados atualmente. São aproveitadas as propriedades físicas do sistema (interação contaminante e solo) como o potencial de adesão dos contaminantes ao vapor.

2. Técnicas de Características Térmicas: Estes tratamentos consideram o comportamento do sistema em função de variações de temperatura. Vários autores incluem neste conjunto o processo de incineração, gaseificação e pirólise a altas temperaturas.

3. Técnicas de Características Químicas: Englobam reações químicas que são induzidas com o objetivo de destruir, fixar ou neutralizar os componentes considerados tóxicos

4. Técnicas de Características Biológicas (bioremediação ou biodegradação):

Consiste na degradação de poluentes devido a atividade de microorganismos.

Existem outras propostas de classificação, como por exemplo a de ATTEWELL (1993) e a de FAILEY \& SCRIVENS (1994). O Comitê de Alternativas de "Cleanup" para Águas Subsuperficiais (NATIONAL ACADEMY PRESS. 1995) tem dividido os sistemas de tratamento em três categorias: técnicas demostradas (comprovadas), técnicas em desenvolvimento e técnicas alternativas. Neste trabalho será adotado a proposta do Comitê por se considerar esta a mais abrangente.

O grupo de técnicas demostradas ou comprovadas corresponde a um conjunto de procedimentos que vem sendo sistematicamente utilizado em campo obtendo resultados satisfatórios, existindo um número significativo de trabalhos publicados sobre estas técnicas, comprovando sua eficiência. Seu uso abrange desde as fases iniciais de ocupação e contaminação até a fase de abandono do projeto do empreendimento, sendo sua infraestrutura preservada concomitantemente com o monitoramento da área.

As técnicas em desenvolvimento são aquelas em fase de análise, estes tratamentos vem sendo testados em laboratórios e em controles de campo, no entanto, estudos mais 
aprofundados, principalmente em campo, ainda são necessário para se fazer generalizações. Existem poucas publicações que comprovem a eficiência destes procedimentos.

Das técnicas alternativas fazem parte o conjunto de métodos que vem demostrando bons resultados tanto em estudos laboratoriais como em aplicações de campo, no entanto, não há comprovações de seu comportamento ao longo do tempo.

\subsection{Técnicas Demostradas ou Comprovadas}

\subsubsection{Extração por Vapor}

A extração de contaminantes utilizando-se de vapor ("Soil Vapor Extraction" SVE) é uma técnica com poucas inovações que vem ganhando importância devido aos sucessivos resultados positivos que vem alcançando. O processo consiste na extração de contaminantes, principalmente orgânicos, por injeções de vapor (com temperatura variando em função do objetivo do tratamento e das propriedades do contaminante), em zonas não saturadas. $\mathrm{O}$ transporte por este sistema ocorre por adesão do contaminante do solo para o vapor.

Conceitualmente, a eficiência da remoção do contaminante depende do estado físico deste, no caso por exemplo do NAPL, os contaminantes devem ser transferidos da fase líquida para a fase vapor para assegurar a eficácia do sistema. No caso dos contaminantes estarem adsorvidos ao solo, então a transferência deve ocorrer na interface solo-ar de modo que o contaminante passe para a fase gasosa. Finalmente, se os contaminantes estão dissolvidos na água dos poros do solo, a transferência de massa deve ocorrer na interface água-ar. O SVE deve superar a atração das massas, que pode inibir a retirada de material.

Neste trabalho será utilizada a sigla NAPLs, abreviatura de "Nonaqueoous - Phase Liquid', que corresponde aos compostos orgânicos não completamente miscível com a água, estes materiais podem ser formados por um ou mais componentes. Os NAPLs pode ser de dois tipos: DNAPLs (Denser than water Nonaqueous Phase Liquid) e LNAPLs (Less dense than water Nonaqueous Phase Liquid), contaminantes, respectivamente, mais densos e mais leves que a água.

As propriedades do contaminante, do sistema natural e o arranjo do projeto afetam a performance do tratamento. As principais propriedades do contaminante são a pressão de vapor, a constante da Lei de Henry, a hidrofobicidade e suas características de difusão. A eficiência deste método está relacionada com o ponto de ebulição do contaminante, se este 
for menor que $150^{\circ} \mathrm{C}$ ou se a pressão de vapor for maior que $5.10^{-4}$ atm o tratamento terá uma probabilidade maior de sucesso (HUTZELER et al. 1989, JOHNSON et al. 1990).

As propriedades dos solos que influenciam na eficácia do sistema são as características físicas do solo (por exemplo a distribuição da granulometria, permeabilidade e porosidade), a presença de material orgânico, a mineralogia e a umidade. A permeabilidade do meio em relação ao ar é importante, para as condições mais favoráveis esta deve ser maior que $9,66 \cdot 10^{-6} \mathrm{~m} / \mathrm{s}$ (1 Darcy).

O projeto pode variar, alterando o número de poços de extração, a direção do fluxo de ar, a profundidade destes poços e a abrangência da área a ser atingida. Em alguns casos, a superfície é coberta com uma capa impermeável para melhorar a performance do sistema, controlando a direção do fluxo de ar e assegurando a captura próxima do total do material mobilizado. A Figura 3 mostra um esquema deste método.

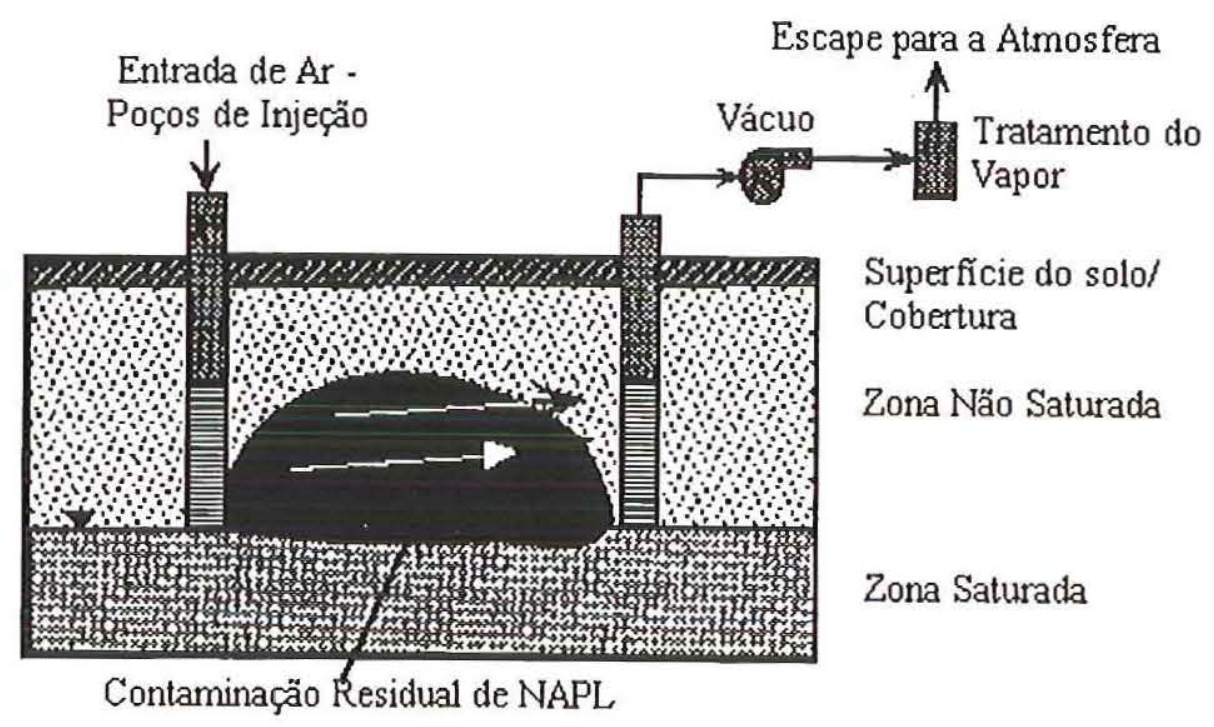

FIGURA 3 - Esquema do Processo de Extração de vapor do Solo

(Fonte: NATIONAL ACADEMY PRESS. 1995)

Descargas de ar no substrato estão sujeitas a muitas limitações. De uma certa forma, todos os fatores que inibem a liberação de contaminantes durante o sistema convencional de bombeamento também afetam este sistema.

A maior vantagem deste método em relação a descarga de água é a alta corrente que este fluxo possibilita, permitindo que uma grande quantidade de volume de poros sejam atingidos em pequeno espaço de tempo, possibilitando aumentar a taxa de recuperação em 
um determinado intervalo de tempo. Outras vantagens são sua competitividade em termos de custo, sua performance e sua adaptabilidade. BUSCHECK \& PEARGIN, 1991 salientam que o sistema vem mostrando sucessivas recuperações de voláteis orgânicos a profundidades superiores a $60 \mathrm{~m}$.

A técnica também é conhecida como a retirada "in situ" de ar do solo, extração de vácuo, solos ventilados ou superfícies ventiladas. O tratamento de aspiração de ar é passível de ser realizado por oxidação térmica, por oxidação catalítica, por condensadores, refrigeradores ou por adsorsão ácida de carvão ativo.

\subsubsection{Bioremediação "in situ"}

O termo Bioremediação abrange o processo de transformação do contaminante em um material não tóxico pela ação microbiológica. Este tratamento pode ser aplicado em uma grande gama de contaminantes e locais devido a possibilidade de se escolher a espécie mais apta a situação, esta versatilidade é uma das vantagens deste processo.

Neste sistema os microorganismos são estimulados a se proliferar rapidamente transformando o contaminante em um produto inofensivo como o dióxido de carbono e a água. Os estímulos principais são a entrada de oxigênio ou outro receptor de elétrons (como os nitratos ou sulfatos) e nutrientes (como nitrogênio ou fosfatos) no meio natural. A atividade metabólica resultante pode ser de dois tipo: Aeróbica ou Anaeróbica, sendo a primeira mais eficaz e de mais fácil controle.

As principais vantagens deste sistema são:

- Transforma o contaminante em material inofensivo no próprio local onde este se encontra;

- As necessidades de bombeamento são em comparação com o sistema convencional menores, sendo necessário em alguns casos apenas para se iniciar a circulação mais continua da água subsuperficial;

- É em geral mais rápido que o sistema convencional; e

- Capacidade da população de microorganismos de se moverem para outras regiões com concentrações maiores de contaminantes, auxiliando a expansão da zona biodegradada e assim completando o tratamento (BOSMA et al., 1988). 
As principais limitações do processo são:

- Existem poucos contaminantes inorgânicos que são transformados por esta técnica, e neste caso estes poluentes podem ser tóxicos para os microorganismos;

- Podem existir diferentes contaminantes nos solos, e a população bacteriológica pode biodegradar um e não alterar as características tóxicas dos outros; e

- É difícil precisar com exatidão o tempo necessário para a descontaminação efetiva, podendo levar vários anos para o tratamento se completar .

Este método foi aplicado com sucesso pela primeira vezes em um vazamento em um oleoduto em Amblu, Pensilvânia em 1972, desde então esta técnica tem sido usada em derrames subsuperficiais de refinarias de óleo bruto (cru) e combustíveis. É também aplicado no tratamento de outros contaminantes orgânicos como Fenóis, acetona e resíduos de celulose.

Um esquema deste método é ilustrado na Figura 4.

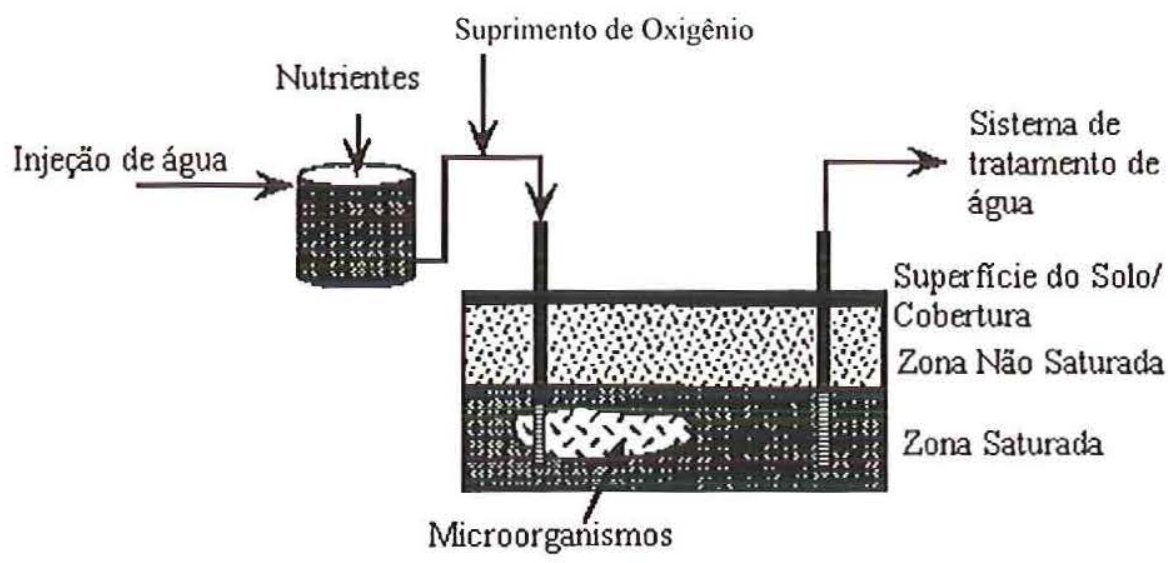

FIGURA 4 - Esquema do Processo de Bioremediação

(Fonte: NATIONAL ACADEMY PRESS. 1995)

\subsubsection{Bioventilação}

Este processo pode ser aplicado em zonas não saturadas e tem como objetivo suprir as necessidades de oxigênio do meio, sendo útil como complemento a outros métodos que necessitem deste elemento, como por exemplo a bioremediação. Cabe ressaltar que este sistema não altera o estado físico do contaminante.

O sistema pode funcionar apenas com poços de injeção, como também com poços de extração. A Figura 5 mostra um esquema deste tratamento. 


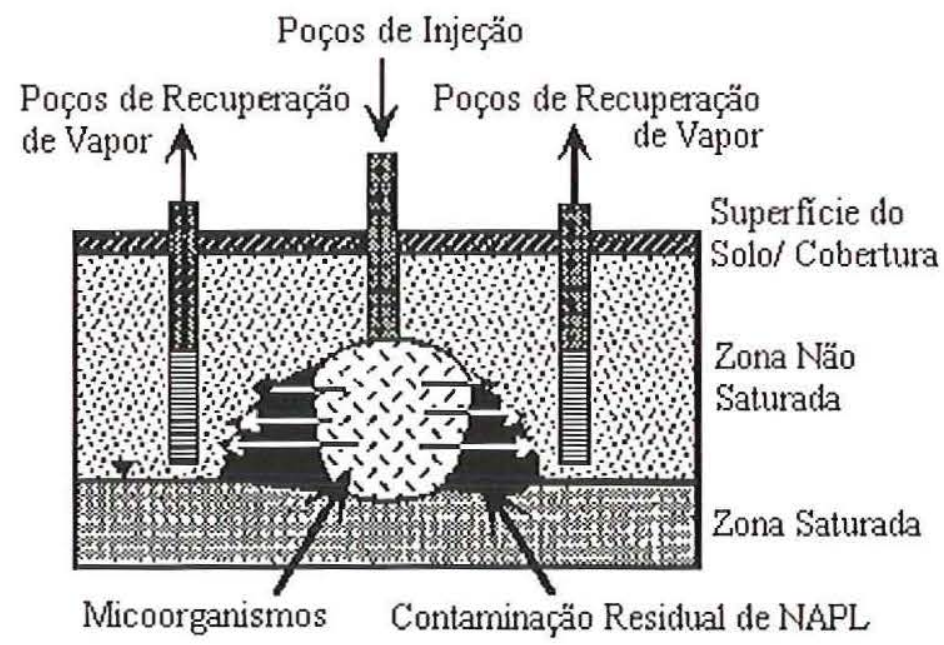

FIGURA 5 - Componentes do sistema de bioventilação.

(Fonte: NATIONAL ACADEMY PRESS. 1995)

A bioventilação é utilizada principalmente para hidrocarbonetos de petróleo e alguns solventes clorinatados.

Uma limitação do sistema é a possibilidade do material injetado transportar o contaminante da zona não saturadas para a zona saturada. Para evitar a migração, enquanto o material é injetado, o sistema de circulação de ar é operado por períodos determinados para a remoção física dos contaminantes mais voláteis e auxiliar a biodegradação; além disto, a injeção de material pode afetar a capacidade de suporte do solo. Este método apresenta as mesmas limitações mencionadas na técnica de Extração por Vapor.

Uma das vantagens da bioventilação é a maior facilidade do ar em circular no meio em comparação com facilidade encontrada pela água, estudos demostram que a permeabilidade do solo para o ar é 2 a 3 vezes a ordem de grandeza encontrada pela água (WILSON \& CLARKE, 1994). A $15^{\circ} \mathrm{C}$ o ar pode transportar $280 \mathrm{mg}$ de $\mathrm{O}^{2} /$ litro enquanto a água transporta somente $10 \mathrm{mg}$ de $\mathrm{O}^{2} /$ litro, assim é possível se ter uma relativa mobilidade do oxigênio transportado por este sistema em solos com moderada permeabilidade. 


\subsection{Técnicas em Desenvolvimento}

\subsubsection{Bombeamento Intermitentes}

Este método é semelhante ao sistema convencional de bombeamento, ou seja, consiste na remoção do líquido (contaminante + água) por meio de poços de extração, neste caso porém, com a variação na frequiência do bombeamento, utilizando-se de pulsação. Esta variação tem o intuito de aumentar a massa de contaminante removido por unidade de volume de água bombeado

Semelhante ao processo convencional, este é afetado pelas condições geológicas e hidrogeológicas sendo mais efetivo em zonas homogêneas, com condutividade hidráulica maior que $10^{-5} \mathrm{~cm} / \mathrm{s}$, podendo ser aplicados em zonas com menor permeabilidade e heterogêneas, aumentando-se o tempo de "cleanup".

Este tratamento tem a vantagem de reduzir as necessidades de bombeamento do método convencional e seu custo, embora ainda esteja em desenvolvimento e a eficiência sendo avaliada.

\subsubsection{Bioremediação aplicada a determinados contaminantes}

Este procedimento de "cleanup" é semelhante aos processos tradicionais de bioremediação, estão contudo incluído no grupo de métodos em desenvolvimento devido aos poucos dados que comprovem a eficácia para os seguintes contaminantes:

- Solventes Clorinatados - Este caso é muito semelhante ao descrito para a bioremediação de hidrocarbonetos, no entanto o processo de metabolismo é mais complexo, o que dificulta a redução a níveis aceitáveis.

- Metais - Semelhante ao procedimento anterior, porém necessita que se retire o material decantado resultante da ação microbial. Microorganismos podem afetar a dissolução e precipitação dos metais através de um ou mais dos seguintes mecanismos: (1) Redução enzimática dos metais; (2) Alteração bioquímica das condições que influenciam o estado de oxidação dos metais; (3) Excreção do metabolismo dos microorganismos ou produtos de decomposição que podem quelar ou arrastar os metais; (4) Bioacumulação e liberação de metais em outras partes do substrato. 


\subsection{3. "Air Sparging" - Aeração "in Situ"}

O sistema de "Air Sparging", também conhecido como aeração "in situ", se utiliza da circulação de ar para remoção dos contaminantes voláteis. O principio é semelhante ao utilizado no método de extração de vapor de solo, no entanto, neste caso, o tratamento é aplicado em zonas saturadas.

Conceitualmente esta técnica promove a remoção dos contaminantes por mecanismos físicos e biológicos. A dissolução dos componentes voláteis segue a Lei de Henry, onde os compostos, são volatilizados para o sistema de extração do ar. O sistema vem sendo efetivo na remoção de quantidades substanciais de voláteis aromáticos e hidrocarbonetos. A eficácia do método dependerá muito das características geológicas do local, tais como sua heterogeneidade e características químicas.

O tamanho dos grãos do solo também é importante. Geralmente se o tamanho médio dos grãos excede $1 \mathrm{~mm}$ (areia média segundo ABNT:7250/82) e estiverem bem selecionados, os bolsões de ar tendem a subir para a superfície, neste caso o raio de influência de cada poço será menor, no entanto, esta situação não é comum (JOHNSON et al., 1990). Em contrapartida em solos com grãos muito menores que $1 \mathrm{~mm}$ (principalmente argilas), o fluxo pode formar canais que agiriam como desvios (atalhos).

Outro fator importante é o comportamento químico do contaminante, a retirada dos poluentes é mais efetiva quando a constante da Lei de Henry é superior a $10^{-5} \mathrm{~atm}-\mathrm{m}^{3} / \mathrm{mol}$ e a solubilidade aquosa é menor que $20.000 \mathrm{mg} / \mathrm{l}$ (BROWN, 1992).

A performance também depende do projeto do sistema, os parâmetros mais importantes são a pressão de injeção de ar, o número e espaçamento dos poços de injeção, o volume de ar a ser injetado, a profundidade de injeção do ar e o tamanho da seção do poço.

Existem várias possibilidades de configurações para a disposição dos poços de injeção, um exemplo é observado na Figura 6. 


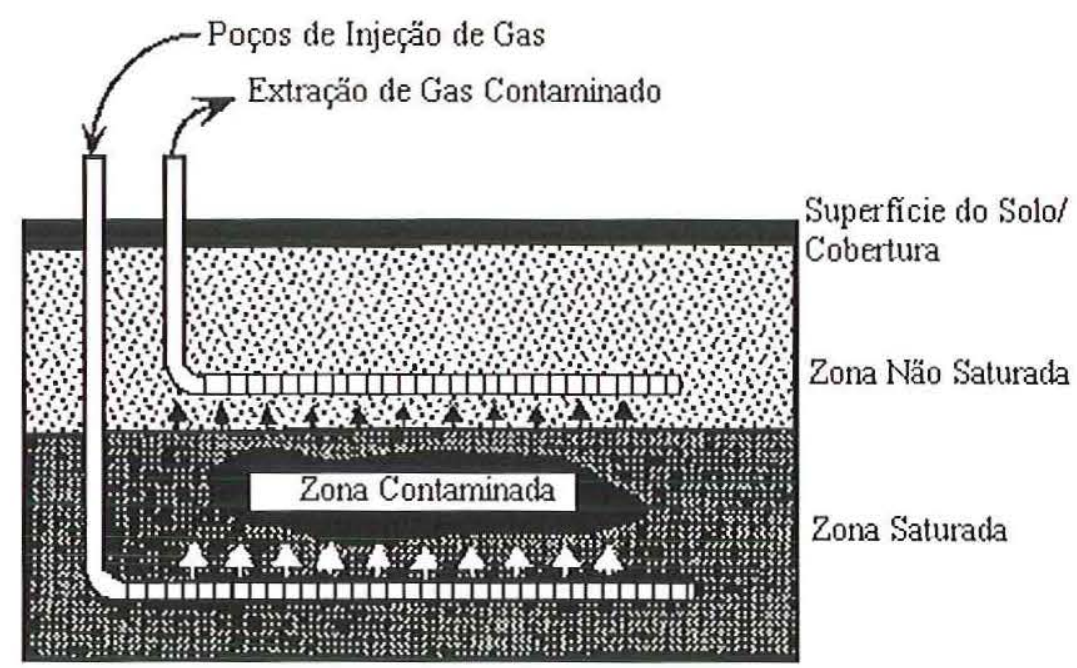

FIGURA 6 - Possibilidades de configuração do método de "Air Sparging".

(Fonte: NATIONAL ACADEMY PRESS. 1995)

Uma limitação deste procedimento é a extração de misturas com multicomponentes, por exemplo, a mistura de gasolina. O uso de "air sparging" em grandes profundidades $(>100 \mathrm{~m})$ é complicado, pois o caminho a ser percorrido pelo fluxo é difícil de ser identificado, neste caso, o não controle da saída do ar pode dificultar a captura dos poluentes. O sistema pode provocar a dissolução do ferro e sua precipitação resultando no entupimento da cortina do poço, ocasionando uma falha no sistema.

Este processo tem a vantagem de estimular a bioremediação e de não ser oneroso, pois o bombeamento de ar é mais eficiente e mais barato que o de água.

\subsection{4. "Soil Flushing" - Lavagem de Solo}

O processo consiste na injeção de materiais que propiciem o aumento na recuperação dos contaminantes pelo sistema convencional de bombeamento, este acréscimo é devido ao incremento da quantidade de poluentes transportados pela água.

Dois agentes químicos são utilizados neste processo, os cosolventes e os surfactantes. A injeção pode mobilizar os contaminantes pelo aumento no gradiente hidráulico, pela redução da tensão na interface entre NAPLs e água, pelo incremento da solubilidade do contaminante, e/ou pela redução da viscosidade do NAPLs. A Figura 7 mostra um esquema do sistema. 


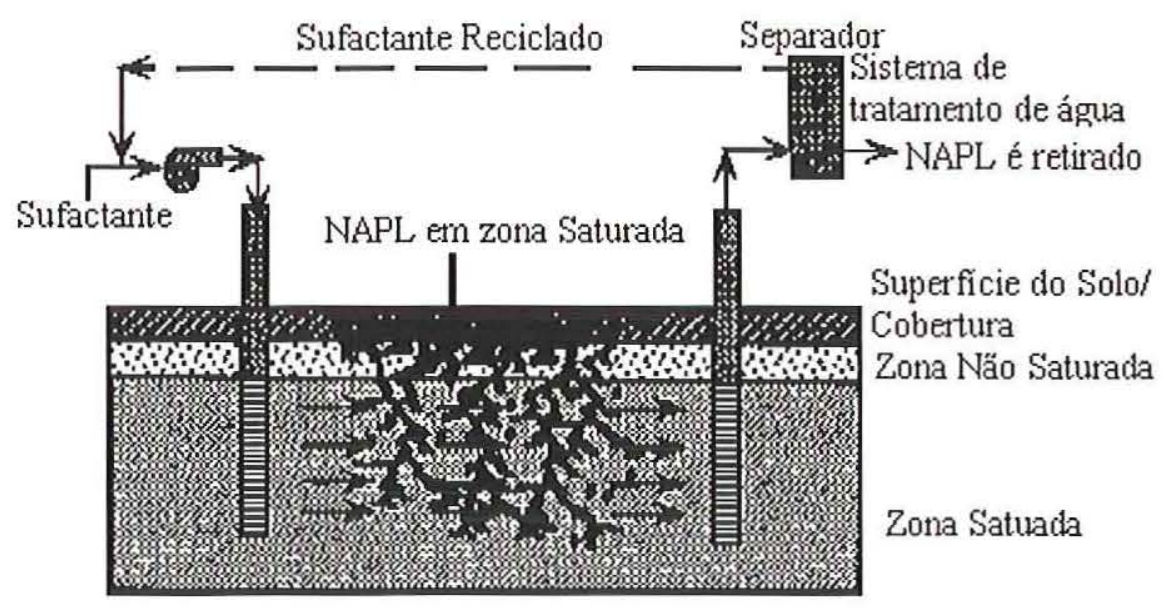

FIGURA 7 - Esquema do sistema de Lavagem de Solo.

(Fonte: NATIONAL ACADEMY PRESS. 1995)

A quantidade de contaminantes orgânicos mobilizados durante a lavagem de solo depende da estrutura química e da concentração do contaminante, da temperatura e das condições geoquímicas do meio.

A performance do processo depende das características geológicas do subsolo, o sistema de lavagem de solo será mais efetivo quanto melhor as condições de permeabilidade e uniformidade do substrato.

Este sistema apresenta outras limitações, um exemplo é observado na remoção do fluido com NAPLs, uma vez que este tem densidade e viscosidade muito diferentes da água, o comportamento do transporte é complicado, sendo necessário empregar técnicas (geralmente o bombeamento de grande volume de água subsuperficial) para controle do fluxo.

A principal vantagem do tratamento é o aumento da mobilidade do NAPLs. Este sistema reduz o tempo de "cleanup" para se obter um objetivo mais eficiente de "cleanup".

\subsubsection{Tratamento Químico "In Situ"}

Neste método são usados compostos químicos para transformar os contaminantes, convertendo-os para formas não tóxicas ou inertes. Possíveis agentes oxidantes incluem peróxido de hidrogênio, ozônio e permanganato de potássio. São agentes redutores os sulfatos, dióxidos, ferro e zinco metálicos. A Figura 8 apresenta um esquema deste tratamento. 


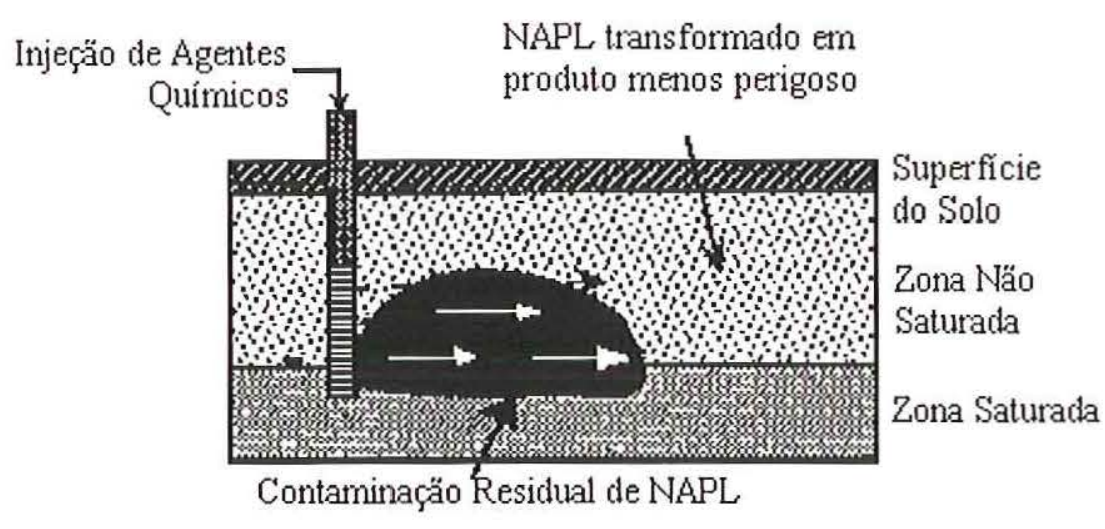

Figura 8 - Esquema do tratamento Químico

(Fonte: NATIONAL ACADEMY PRESS. 1995)

A maioria dos procedimentos exigem que os solos estejam saturados visto que o reagente deve estar em contato com o contaminante para que ocorra a reação. A Tabela 1 apresenta uma relação entre os tratamentos químicos e a natureza dos poluentes (Modificado de DESTRIBATS et al. 1994)

TABELA 1 - Relação entre o tipo de poluentes e o tratamento químico mais adequado. (Modificado de DESTRIBATS et al. 1994)

\begin{tabular}{|c|c|c|}
\hline Poluentes & Líquidos & No solo \\
\hline Não & B, I, J & I, J \\
Orgânicos & & \\
\hline Orgânicos & A, B,C, E, & E,F,G,I \\
& F,G,I,L,K & \\
\hline Metálicos & H,I,J,L,D & \\
\hline
\end{tabular}

Sendo:
A -Ozone/ $\mathrm{H}_{2} \mathrm{O}_{2} /$ Oxidação
G - Extração SCF
B - Oxidação úmida
C - Oxidação Ultra Violeta
H - Extração ácida
D - Redução
I - Neutralização
E - Declorificação Química
J-Precipitação lust lijo 8
F - Extração por Solvente
K-Hidrólise
L - Processos Eletroquímicos 
O tratamento tem severas restrições, cabendo destacar:

-O método é limitado pelas heterogeneidades geológicas que complicam o espalhamento dos componentes químicos;

- As reações químicas não são restritas, podendo o oxidante reagir com Fe (II), Mn (II) e $\mathrm{H}_{2} \mathrm{~S}$ e outros componentes orgânicos e inorgânicos do solo. Como conseqüência é necessário adicionar material em excesso para se ter certeza que o reagente entrara em contato com todo contaminante;

- A adição química pode alterar as condições de pH local e seu potencial redox, em conseqüência a adição química pode causar precipitação de metais que podem entupir os canais e os poços de injeção e extração. Existe também a alternativa de agir de forma a aumentar a mobilidade de certos compostos e precipitar outros.

A vantagem deste tratamento é a redução do volume de material a ser bombeado. $\mathrm{O}$ sistema pode transformar contaminantes que resistam a biodegradação, além do tratamento químico não ser específico e passível de ser aplicado em tratamentos de contaminantes misturados.

\subsubsection{Técnicas Termais "In Situ"}

Todos os fenômenos físicos, químicos e biológicos que são exigidos para a remoção dos contaminantes, direta ou indiretamente dependem da temperatura. A adição de calor pode mobilizar ou transportar os contaminantes, ou mesmo, em casos extremos, utilizando-se de temperaturas altas fazer com que estes permaneçam inertes, pelo processo de vitrificação.

A medida que se aumenta a temperatura, os compostos orgânicos são mobilizados mais rapidamente, aumenta-se a volatilização e reduz-se a viscosidade. Altas temperaturas também podem acelerar certas transformações abióticas ou reações de decomposição. Dos vários processos cabe ressaltar o "Steam Enchanced Extraction" e o "Radio Frequency Heating".

\section{A - "Steam Enchanced Extraction" - Extração por Vapor Quente}

Conceitualmente este método se utiliza de vapor quente para aumentar a mobilidade dos contaminantes, e é aplicado através de poços verticais a profundidades e pressões adequadas. 
HUNT et al. (1988a, b), citam que o método obteve 100\% de eficiência na remoção de DNAPLs e de LNAPLs em laboratório, no entanto devido as heterogeneidades do meio geológico e hidrogeológico, os testes em campo não apresentam os mesmos resultados laboratoriais.

O incremento da temperatura aumentam a eficiência do sistema de injeção do vapor, visto que compostos orgânicos com baixo ponto de ebulição e compostos semivoláteis são parcialmente evaporados. O processo potencialmente pode diminuir o tempo necessário para o "cleanup", além de apresentar vantagens em relação a custo.

\section{B - "Radio Frequency Heating" - Aquecimento por Ondas Eletromagnéticas}

$\mathrm{O}$ aquecimento neste caso envolve ondas eletromagnéticas geralmente com freqüência variando de $45 \mathrm{~Hz}$ a $10 \mathrm{GHz}$ (freqüências comumente utilizadas por industrias, cientistas e pelo setor médico), sendo que modificações nas transmissões servem para alterar a energia.

Neste tratamento temperaturas próximas a $80^{\circ} \mathrm{C}$ podem ser facilmente atingidas, este calor afeta a água nos poros do solo que produzem vapores em um efeito semelhante ao do forno de microondas.

Os parâmetros chaves para o sucesso do tratamento são as características dos contaminantes, a mistura do solo e a velocidade a ser empregada.

O processo é aplicado primeiramente para remover contaminantes com ponto de ebulição menor que $80^{\circ} \mathrm{C}$ em zona não saturada, exemplos incluem hidrocarbonetos aromáticos e alifáticos. Os resultados obtidos indicam uma eficiência de $90 \%$.

Este método também sofre influência da permeabilidade e das características geológicas de maneira semelhante as citadas nos processos anteriores. Semelhante a extração de vapor, este método tem a vantagem de aumentar a razão de remoção dos contaminantes aumentando a velocidade de volatilização e a desorção. 


\subsection{Tecnologias Alternativas}

\subsubsection{Bioremediação Intrínseca}

O processo chamado bioremediação intrínseca, é basicamente a bioremediação "in situ", sem a intervenção humana. Neste contexto, os microorganismos nativos transformam contaminantes em outros materiais, sem a adição de receptores de elétrons e nutrientes.

A extensão de seu uso depende da afinidade do componente contaminante com os organismos e das características hidrogeológicas e geoquímicas do local. Esta estratégia é aplicada especialmente em níveis superficiais do solo e em problemas mais localizados. ATTEWELL (1993), cita que em um solo normal existem $10^{6}$ a $10^{7}$ bactérias por grama de solo.

Em geral, há quatro tipos de características hidrogeológicas e geoquímicas do local que determinam a viabilidade deste processo (NATIONAL ACADEMY PRESS. 1995): (1) A direção de fluxo da água subsuperficial e a sazonalidade do fluxo devem ser observadas; (2) O local deve ter a concentração de receptores de elétrons - como o Oxigênio, Nitrato, Sulfato ou íons férricos - suficientes para o desenvolvimento da ação microbiológica; (3) O solo deve ter capacidade de tamponamento, para reter o material; (4) O local deve ter suprimento natural de nutrientes (principalmente Nitrogênio e Fósforo) necessários para o metabolismo dos microorganismos.

Os compostos alifáticos halogenados têm recebido uma particular atenção no tratamento de contaminantes orgânicos. Para ocorrer a biodegradação desses contaminantes necessita-se de uma cultura de mistura de bactérias que cresçam por oxidação do metano e que possa co-oxigenar os compostos alifáticos halogenados (WILSON \&WILSON, 1994, FOGEL et al 1985 apud DOMENICO \& SCHWARTZ, 1990). 


\subsection{Técnicas de Contenção}

Devido as limitações dos sistemas de remoção, as técnica de contenção têm se desenvolvimento muito. Estes métodos consistem em procedimentos que visam o isolamento do contaminante em relação a área. Estas técnicas vem sendo amplamente aplicadas tanto em locais em fase de preparação para a disposição do resíduo, como em locais em fase de atividade e exauridos. Basicamente, o processo consiste no "envelopamento" dos resíduos por um material com menor permeabilidade por uma associação das 3 estruturas seguintes:

1 - Cobertura (Cover);

2 - Barreiras Verticais (Slurry Walls); e

3 - Barreiras Inferiores.

\subsubsection{Coberturas}

Segundo DANIEL (1995), o sistema de cobertura final tem uma variedade de funções a saber:

\# Minimizar a quantidade de infiltração;

\# Promover o controle do material remanescente;

\# Diminuir/Dificultar o Contato com as raízes;

\# Separar o resíduo das plantas e animais;

\# Prevenir a migração de lixiviantes e escorregamentos de material; e

\# Controlar a liberação de gases.

A cobertura deve permanecer com suas caraterísticas inalteradas por um longo período de tempo e o projeto deve considerar a natureza do contaminante e a hidrogeologia local.

O projeto de cobertura deve considerar vários fatores ambientais, que incluem:

- Ciclos úmidos/secos;

- Penetração de raízes de plantas, escavações de animais e insetos;

- Deposição total e diferencial causando a compressão do material ou fundação de solo;

- Sobrecarga temporária ou permanente;

- Escorregamento ou arraste de taludes;

- Movimentos de veículos em ruas sobre ou perto do local; 
- Erosão pluvial ou eólica;

- Deformação causada por terremotos e atividades sísmicas na área;

- Temperaturas extremas, possibilitando inclusive o congelamento / descongelamento; e

- Alterações causadas pelos gases derivados e compostos voláteis do resíduo ou produtos decompostos.

A maioria dos sistemas de cobertura são compostos por um sistema múltiplo de componentes. Na Figura 9 observa-se um conjunto de 5 componentes:

\begin{tabular}{|c|c|c|c|}
\hline & Nivel & Principal(s) Função (s) & Materiais Utilizados \\
\hline & $\begin{array}{l}\text { 1. Nivel } \\
\text { Superficial }\end{array}$ & $\begin{array}{l}\text { Promover o Crescimento da } \\
\text { vegetação, promover a } \\
\text { evapotranspiração, previnir a } \\
\text { erosão. }\end{array}$ & $\begin{array}{l}\text { Solos, Cobbles e } \\
\text { geosintéticos para } \\
\text { controlar a erosão }\end{array}$ \\
\hline & $\begin{array}{l}\text { 2. Nível de } \\
\text { Proteção }\end{array}$ & $\begin{array}{l}\text { Proteger os níveis } \\
\text { inferiores de intrusões de } \\
\text { plantas e animais e de } \\
\text { grandes variações de } \\
\text { temperatura. }\end{array}$ & $\begin{array}{l}\text { Misturas de solos e } \\
\text { Cobbles }\end{array}$ \\
\hline 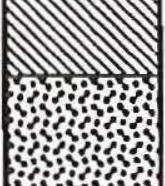 & $\begin{array}{l}\text { 3. Nivel de } \\
\text { Drenagem }\end{array}$ & $\begin{array}{l}\text { Drenar a água que infiltra, } \\
\text { diminuindo o tempo de } \\
\text { contato com o nivel de } \\
\text { barreira. }\end{array}$ & $\begin{array}{l}\text { Areias, cascalhos, } \\
\text { geonets, geotêxteis e } \\
\text { geocompostos }\end{array}$ \\
\hline \%ifi:j & $\begin{array}{l}\text { 4. Nível de } \\
\text { Barreira }\end{array}$ & $\begin{array}{l}\text { Minimizar a infiltração e } \\
\text { previnir o escape de gás } \\
\text { para fora da área. }\end{array}$ & $\begin{array}{l}\text { Liner Argiloso Compac. } \\
\text { Liner Geosint. Argilosos } \\
\text { Geomembranas }\end{array}$ \\
\hline 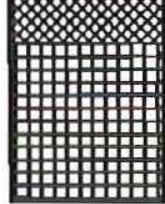 & $\begin{array}{l}\text { 5. Nivel } \\
\text { Coletor de } \\
\text { Gas }\end{array}$ & $\begin{array}{l}\text { Transportar o gás para } \\
\text { pontos de coleta. }\end{array}$ & $\begin{array}{l}\text { Areias, Geonets e } \\
\text { geotêxteis. }\end{array}$ \\
\hline
\end{tabular}

FIGURA 9 - Camadas que constituem um Sistema de Cobertura

(Fonte: Modificado de DANIEL, 1995) 


\subsubsection{Barreiras Verticais / Paredes Flexíveis / Slurry Walls}

Barreiras Verticais são estruturas que têm como objetivo controlar a migração lateral de poluentes, estas retêm, capturam ou redirecionam a água subsuperficial e o fluxo do poluente (SHARMA \& LEWIS, 1994).

A efetividade da estrutura irá depender, dentre outras coisas da distribuição vertical e horizontal das barreiras (USEPA, 1984). Distribuição vertical refere-se as características da parede em profundidade em relação ao nível de água da zona saturada e a permeabilidade do material subjacente. Distribuição horizontal refere-se a disposição das paredes em relação a origem do contaminante e a direção do fluxo da água subsuperficial.

Baseado na distribuição vertical, as exigências sobre as paredes podem ser menor quando se atinge um nível com permeabilidade baixa, ou o posicionamento pode ser de tal forma que intercepte a porção superior do nível de água e ocorra um bombeamento anterior do contaminante, estes tipos de barreiras são mostrados nas figuras $10 \mathrm{a}$ e $10 \mathrm{~b}$, respectivamente. O primeiro caso é usado quando o contaminante é miscível ou mais denso que a água e segundo caso é aplicado quando o contaminante é mais leve que a água e não é miscível, exemplo deste caso são os LNAPLs.

Baseado na distribuição horizontal, as paredes podem ser classificadas como circunferencial, com aumento ou decaimento de gradiente. Estes métodos são apresentados nas figuras $11 \mathrm{a}, 1 \mathrm{lb}$ e $1 \mathrm{lc}$ respectivamente.
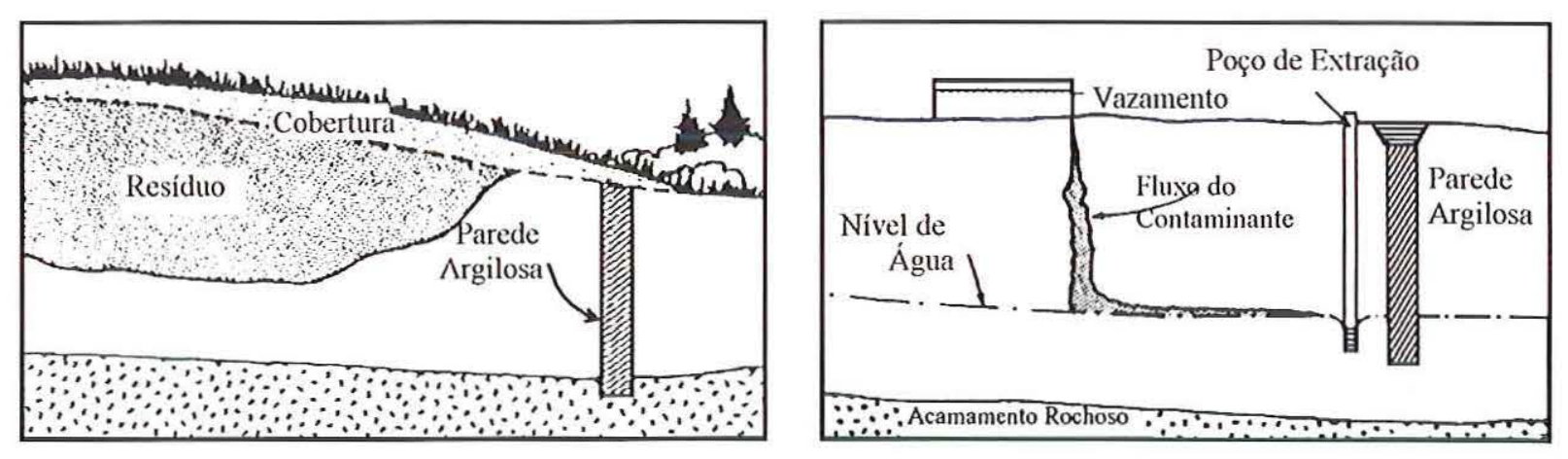

FIGURA 10a e FIGURA 10b - Distribuições Verticais (Fonte SHARMA \& LEWIS, 1994). 

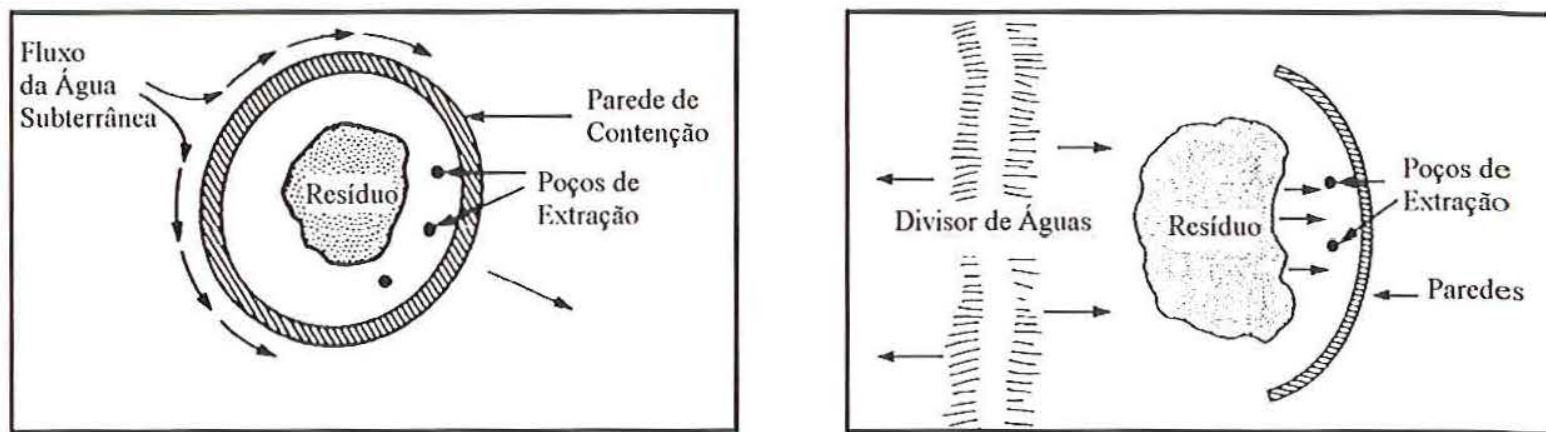

FIGURA 11a e FIGURA 11b - Distribuições Horizontais das paredes (Fonte SHARMA \& LEWIS, 1994)

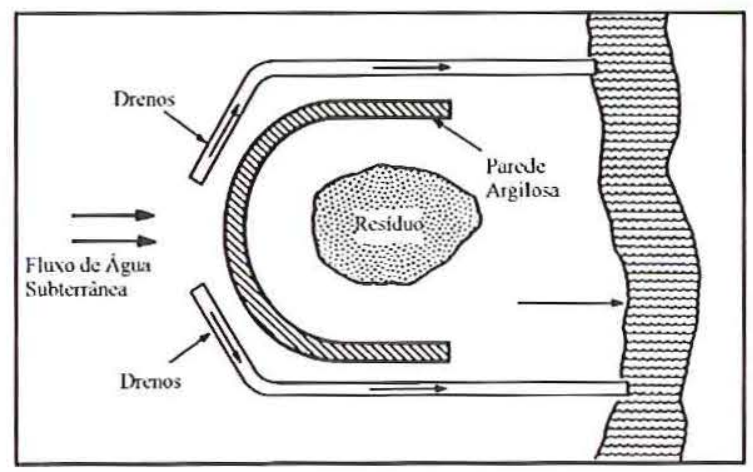

FIGURA $11 \mathrm{c}$ - Distribuição Horizontal da parede (Fonte SHARMA \& LEWIS, 1994)

A disposição em círculo das paredes de contenção retêm totalmente a migração do fluxo. A disposição das paredes de tal forma que aumente o gradiente hidráulico é utilizado em situações onde o objetivo é desviar o fluxo para diminuir o seu contato com os resíduos. Paredes dispostas de tal modo que diminua a condutividade hidráulica são usadas, principalmente, em locais próximos a divisores de água, isto é, áreas onde exista um fluxo de água subsuperficial com alto gradiente hidráulico (USEPA, 1984).

\subsubsection{Interação Solo - "Slurry" (lama de preenchimento no estado plástico)}

Assume-se que na zona de interação entre o solo e a lama de preenchimento ocorra a formação de uma zona impermeabilizada. SHARMA \& LEWIS (1994) citam que devido a densidade do slurry ser maior que a densidade do fluido dos poros, a diferença de pressão causa uma migração das partículas sólidas do "slurry" para os espaços vazios dos solos. Com 
a continuidade deste processo um pacote compacto, chamado de "filter cake" é formado próximo a face da parede e em um período curto de tempo o "filter cake" pode ser coberto por uma fina camada de partículas de bentonita, chamada de filme de proteção. Neste estágio a face da parede fica vedada, resultando em uma superfície onde o valor da condutividade hidráulica irá depender entre outras coisas da concentração de bentonita (XANTHAKOS, 1979).

A Figura 12 exibe o processo de penetração das partículas coloidais vedando os poros do material granular.

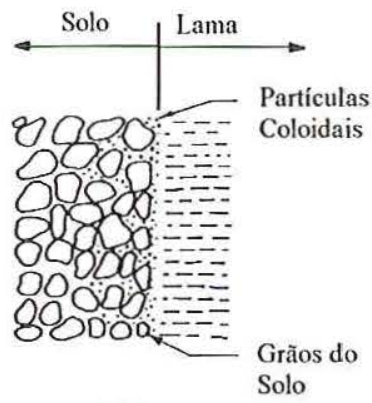

(A)

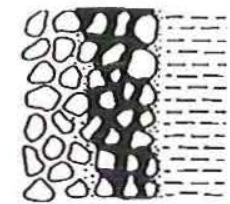

(B)

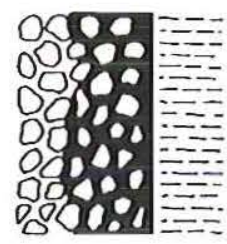

(C)

FIGURA 12 - Formação do "Filter Cake" (Fonte SHARMA \& LEWIS, 1994).

A quantidade de perda de bentonita depende principalmente da concentração na parede e posteriormente do tipo de solo e de bentonita selecionada para o local. Esta seleção deve ser feita para as condições específicas de cada área.

\subsubsection{Material para "Slurry"}

SHARMA \& LEWIS (1994) classificam os tipos de barreiras baseados nos materiais de preenchimento utilizado, como:

1. Preenchimento Solo - Bentonita $\rightarrow$ Preenchimento mais comum, de fácil construção. Apresentam uma homogeneidade boa, permeabilidade razoável e torna a parede flexível;

2. Preenchimento Solo- Atapulgita $\rightarrow$ Preenchimento utilizado em situações onde a bentonita não pode ser empregada devido as características químicas do contaminante (em soluções salinas a bentonita pode flocular alterando sua permeabilidade). Sua 
construção requer equipamentos especiais onerando o processo, além deste limitante a atapulgita não é encontrada no Brasil;

3. Preenchimento Solo - Cimento $\rightarrow$ Este tipo de mistura confere rigidez a parede;

4. Preenchimento de Concreto Plástico $\rightarrow$ É aplicado em situações onde se necessite de uma parede flexível e ao mesmo tempo que possa suportar um stress. Geralmente esta mistura fornece resistência maiores que $1400 \mathrm{psi}$ e permeabilidade menor que $1.10^{-7} \mathrm{~cm} / \mathrm{s}$;

5. Mistura de Bentonita - Cimento $\rightarrow$ Diferente dos três casos anteriores, esta mistura não é empregada como preenchimento, mas utilizado como aditivo para endurecer o material de preenchimento;

6. Barreiras Compostas $\rightarrow$ Este tipo de construção é formado pela combinação dos preenchimentos anteriores de acordo com as exigências específicas de cada local.

\subsubsection{Barreiras Inferiores - Liners}

As barreiras inferiores têm longa história de uso, drenos e diques protegidos por betume foram utilizados na Mesopotânia, há aproximadamente 3.200 anos AC, FOLKES, 1982 apud LEITE, 1996. Inicialmente estas estruturas tinham como objetivo somente a diminuição da permeabilidade, a fim de diminuir o volume infiltrado e a conseqüente contaminação da água subsuperficial.

Os liners referem-se tanto a estruturas de materiais naturais (solos argilosos compactados ou argilas) como a materiais artificiais que servem com barreiras, objetivando o controle da contaminação através de mecanismos de atenuação.

Existem vários tipos de liners e a escolha de um determinado tipo é influenciada segundo LEITE (1996), pela química da solução percoladora e da água subsuperficial; vida útil do projeto; taxa de infiltração e restrições físicas.

\subsubsection{Classificações}

Existem várias classificações para liners, como a Classificação de VIRARAGHAVAN (1986), que dividem os materiais utilizados em duas classes, os materiais naturais como o solo compactado e os materiais obtidos através de síntese, como o Polietileno clorosulfurado (Hypalon), o Cloreto Polivinílico (PVC) e o Polietileno (PE). 
Outra classificação é a de DANIEL (1993), para este autor os tipos de liners argilosos são: os liners argilosos naturais $\left(\mathrm{k} \leq 10^{-6}-10^{-7} \mathrm{~cm} / \mathrm{s}\right)$ e os liners argilosos compactados (LAC).

A classificação proposta por ROWE (1995) divide os liners em cinco categorias:

A - Depósitos argilosos naturais - Estes depósitos tem como objetivo a redução do gradiente hidráulico e a atenuação do processo de migração por mecanismos tais como sorção, biodegradação, precipitação, etc;

B- Liners argilosos compactados: camadas argilo-arenosas ou areno-argilosas compactadas, com espessuras variáveis. Em uma barreira de argila compactada bem projetada, o mecanismo principal de transporte de soluções se processa geralmente por difusão molecular efetiva;

C - Cortinas com Envoltório Permeável: Normalmente são utilizadas como medidas reparadoras em sítios não projetados adequadamente;

D - Depósito de Rochas Naturais: Trata-se de depósitos escavados em rochas, ou situados diretamente sobre estas.

E - Liners argilosos geossintéticos: Além do material argiloso contém na sua estrutura materiais sintéticos.

\subsection{Poços de Bombeamento}

Este processo consiste na remoção do contaminante por poços de extração. É aplicado em condições variadas, no entanto, o ambiente hidrogeológico adequado para o sistema de bombeamento apresenta um nível de condutividade hidráulica maior que cerca de $10^{-5} \mathrm{~cm} / \mathrm{s}$ e um coeficiente de retardamento menor que 10 . O grau de fraturamento e as características químicas do substrato (como por exemplo um ambiente kárstico) afetam a facilidade de bombeamento.

Para que este processo obtenha sucesso é necessário se ter dados sobre o contaminante, principalmente seu tipo, propriedades e distribuição. Estas características vão influenciar, por exemplo, a tendência do contaminante (orgânico e/ou inorgânicos) a ser sorbido pelo meio físico e a tendência de certos compostos orgânicos em permanecerem indissolúveis. São também importante a capacidade de degradação e de volatilização. . Os compostos orgânicos voláteis, tem pressão de vapor alta e a constante da Lei de Henry maior que $10^{-3} \mathrm{~atm} . \mathrm{m}^{3} / \mathrm{moles}$ (USEPA, 1990).

De acordo com a solubilidade do contaminante pode-se visualizar três possíveis 
situações; (1) Contaminantes dissolvidos em água, (2) soluções com LNAPL, (3) soluções com DNAPL. O primeiro caso é relativamente fácil de ser removido pelos poços de bombeamento, a remoção de LNAPL é mais complicada, e deve contemplar principalmente o desenvolvimento do cone de depressão sobre o nível de água.

O tratamento do caso de DNAPL é muito complexo. FREEZE \& CHERRY (1979), estudaram a eficiência deste sistema em duas situações, uma onde a remoção do contaminante inicia-se pela base da pluma de contaminação e outra, onde uma bomba submersível foi instalada para aumentar o cone de depressão, em ambos os casos o resultado não foi satisfatório, pois a concentração não diminuiu de maneira efetiva.

Muitas vezes devido a extensão e distribuição da pluma, um único poço de bombeamento não é suficiente, deste caso um número maior de poços é necessário. Exemplos destes casos são ilustrados nas figuras 13a e $13 \mathrm{~b}$.

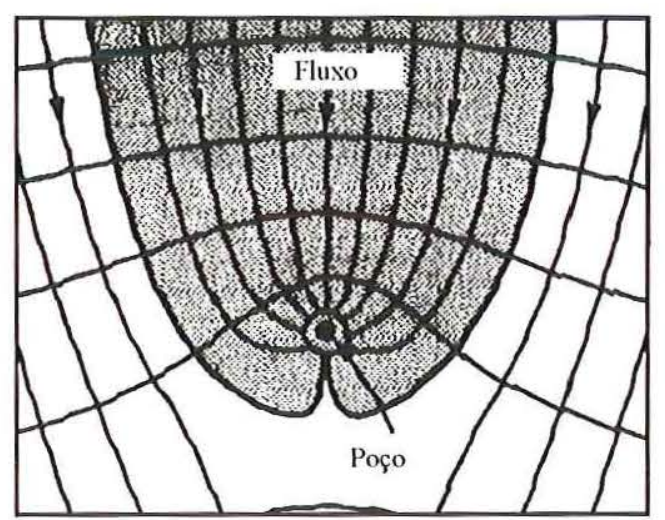

Zona de Captura

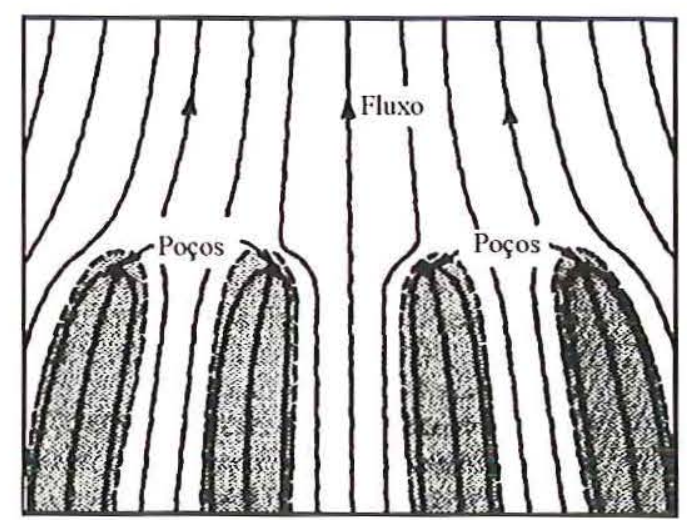

雃过 Zona de Captura

FIGURA 13a e FIGURA 13b - Esquemas de Situações de Bombeamento (FREEZE \& CHERRY, 1979)

Além destas técnicas apresentadas pelo Comitê de Alternativas de "Cleanup" para Águas Subsuperficiais (1995), cabe ressaltar outros métodos existentes de importância:

- Tratamento por flotação (DESTRIBATS et al, 1994): Este processo foi desenvolvido pela mineração e adotado nos tratamento de solos muito poluídos.

Para ser aplicado necessita que o solo seja escavado, e que, as vezes, receba um tratamento ácido prévio. É aplicado em uma enorme gama de poluentes, como por exemplo hidrocarbonetos, compostos clorados e pesticidas. 
O princípio consiste na preparação de uma mistura de água, solo peneirado e agentes químicos, neste material é injetado ar que aderem aos poluentes e quando este é removido forma uma espuma que é então recuperada.

- Extração do poluente aproveitando suas Características Elétricas (DESTRIBATS et al, 1994): O princípio consiste na circulação de uma corrente elétrica em um solo para induzir a migração das partículas carregadas para os eletrodos porosos. A solução contaminada é então recuperada por bombeamento ou por sinfonagem.

A eficiência do método depende de vários fatores, como por exemplo, o poder de tamponamento do solo; a concentração de íons, o fluxo osmótico diferenciado; a densidade de carga por eletrodo e o espaçamento entre estes.

- Tratamentos térmicos a altas temperaturas - Inclui processos como a incineração, a desorção termal, e a vitrificação. São empregados para descontaminação de solos poluídos por substâncias facilmente oxidadas e facilmente convertidas em $\mathrm{CO}_{2}$ e $\mathrm{H}_{2} \mathrm{O}$. O procedimento térmico tem a desvantagem de precisar de 3 estágios para a execução e a vantagem de reduzir o volume do material.

- Extração do Material para outra área mais adequada - O processo de remoção do resíduo para outro local, além de ser um método altamente oneroso, também apresenta grande risco de contaminação. Este processo é limitado tanto pela quantidade de material a ser transportado como pela distância necessária de deslocamento.

- Solidificação - Utiliza-se agentes cimentantes para estabilizar (fixar) o material. Os possíveis agentes cimentantes incluem o cimento pozzolan-portland, termoplásticos, polímeros orgânicos e asfalto. Pode-se também empregar silicatos aditivados combinados com cimento. Da homogênea mistura destes agentes com o solo vai depender o sucesso do processo.

A solidificação também pode ser feita utilizando-se de altas temperaturas, podendo chegar a temperaturas entre 1.600 e $2.000^{\circ} \mathrm{C}$. Nesta temperatura os compostos orgânicos sofrem pirólise e os vapores são capturados na superfície para serem tratados. 


\subsection{Atributos do Meio Físico que Afetam a Seleção do Método}

A seleção da técnica de "cleanup" mais adequada depende da relação entre vários critérios, como por exemplo a aplicabilidade do método, as exigências específicas da situação, as limitações de cada alternativa em função da relação contaminantes/meio, a praticabilidade de sua aplicação, o custo, os impactos ambientais, as exigências operacionais e de instalação, o tempo necessários para o confinamento, a possibilidade de monitoramento, o potencial de integração, o planejamento e avaliação das necessidades e a segurança necessária.

Cada local apresenta características físicas e químicas inerentes. Além disto, geralmente existe uma variação lateral e vertical do solo que afeta a distribuição do contaminante e a facilidade que este é transportado e removido.

As condições do meio físico limitam a seleção dos processos de remediação, algumas características podem ser ajustadas em função da necessidade do tratamento, no entanto, outros parâmetros não podem ser alterados fazendo que um determinado tratamento seja descartado.

O Comitê de Alternativas de "Cleanup" para Águas Subsuperficiais (1995) avalia os locais baseados nas seguintes informações:

1. Descrição das camadas geológicas, com dados sobre o substrato rochoso e o material inconsolidado. Devem envolver entre outras informações as variações laterais e verticais, textura, espessura, presenças de matacões, coesão e heterogeneidades que afetem o comportamento do fluxo subsuperficial (como por exemplo o grau de cimentação);

2. Características hidrogeológicas, devem conter informações principalmente sobre a permeabilidade e a condutividade hidráulica dos níveis, direção e sentido do fluxo de água subsuperficial e profundidade do nível de água;

3. Geologia estrutural, especialmente informações sobre falhas, juntas e fraturas. Devem envolver dados sobre abertura, espaçamento, conecção entre descontinuidades, etc;

4. Características químicas do substrato, que vão influenciar por exemplo a capacidade de tamponamento e a capacidade de troca catiônica; e

5. Estimativa da distribuição química do substrato, incluindo a atual ou potencial presença de LNAPLs ou DNAPLs.

O nível de caracterização para selecionar uma ação de remediação deve ser 
suficiente além de determinar as características do local, estabelecer a extensão da contaminação e a restauração potencial de cada sub-área do local. Em termos simples os dados necessários devem conter:

- Informações para definir ou estimar a extensão horizontal e vertical da contaminação;

- Informações sobre a localização da área fonte em relação a bacia hidrográfica;

- Informações que descrevam as condições locais; e

- Informações para estimar a restauração potencial do local.

Estes dados devem ser suficientes para formular um modelo conceitual do local para servir como base na análise das questões sobre a contaminação da área.

\subsection{Processo de Seleção}

Este procedimento tem como objetivo identificar o(s) método(s) mais adequado(s) para uma situação específica, isto é feito através de uma avaliação individual de cada estratégia e posterior comparação entre as várias possibilidades a fim de se chegar a melhor relação entre eficiência e custo.

Dentro do processo de seleção pode se atribuir pesos para um ou outro fator de acordo com a importância do critério.

Em alguns casos uma estratégia baseada em um método único pode ser suficiente para o objetivo de remediação, em outras situações métodos combinados formam uma estratégia de remediação integrada capaz de obter resultados mais satisfatórios.

O fluxograma da Figura 14 sintetiza um grupo de etapas para a seleção do método de remediação. 


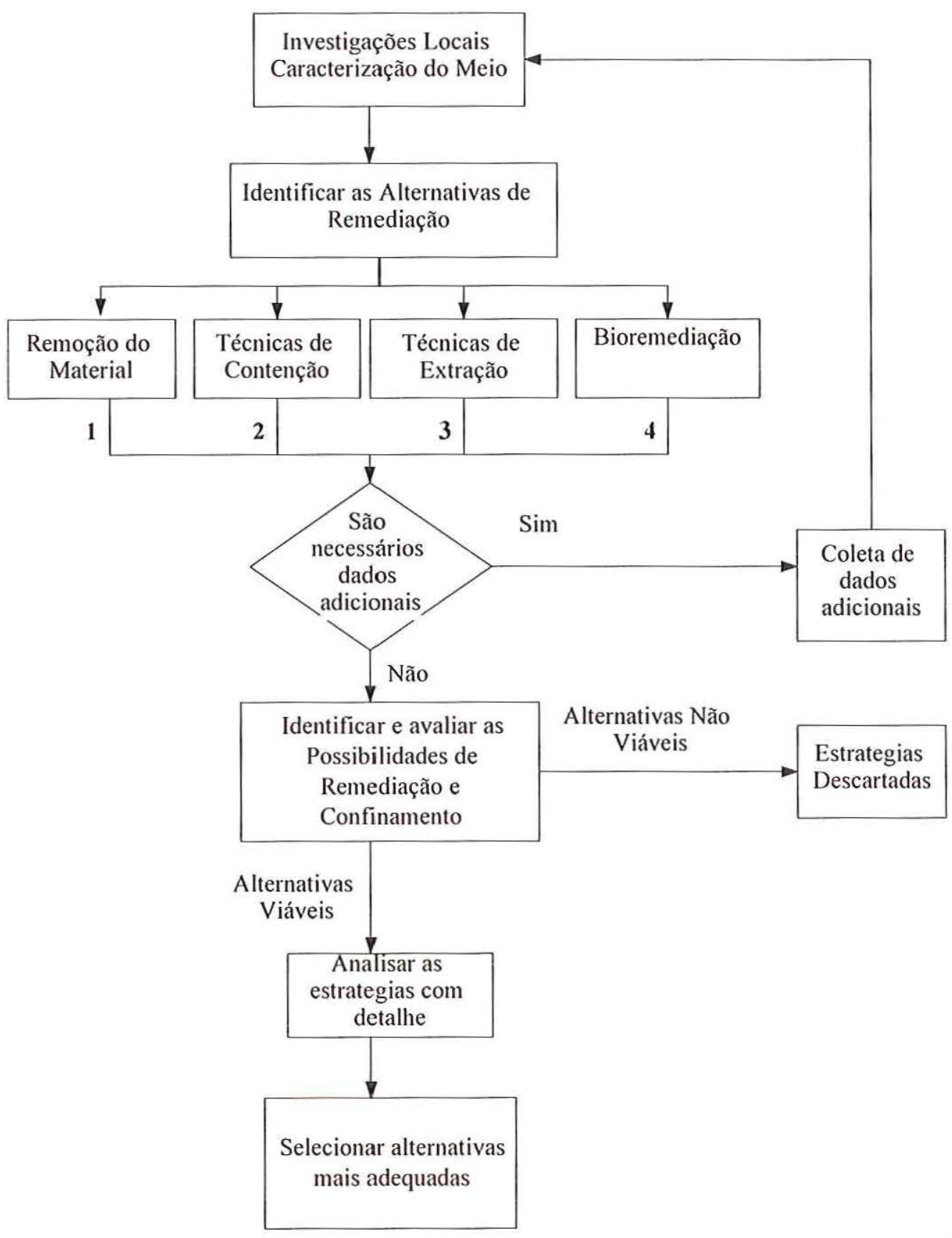

Figura 14 - Fluxograma das principais etapas para a seleção do método de remediação.

Os número 1 a 4 representam uma série de fatores limitantes para cada conjunto $\mathrm{e}$ que devem ser considerados:

1: Volume de material depositado e existência de local próximo disponível para disposição do resíduo;

2:Caracteristicas que condicionam a condutividade hidráulica, nível de água, direção do fluxo subsuperficial e material disponível para ser utilizado para a estrutura de 
contenção;

3:Condutividade hidráulica, transmissividade, capacidade de tamponamento do solo, características do contaminante, tamanho e distribuição da pluma de contaminação.

4:Presença de nutrientes e de receptores de elétrons. Características do contaminante e profundidade da contaminação.

\subsection{Considerações Sobre as Téenicas}

A tabela 2 apresenta uma síntese das principais técnicas de "cleanup" e suas características principais.

TABELA 2 - Síntese das características das principais técnicas de "cleanup".

\begin{tabular}{|c|c|c|c|c|}
\hline Técnica & Princípios & $\begin{array}{c}\text { Limitações do } \\
\text { Meio Físico }\end{array}$ & $\begin{array}{c}\text { Produtos x } \\
\text { eficiência }\end{array}$ & Custo * \\
\hline $\begin{array}{l}\text { Extração de } \\
\text { Vapor do solo }\end{array}$ & $\begin{array}{l}\text { Sucção do vapor } \\
\text { (ar }+ \\
\text { contaminante). }\end{array}$ & $\begin{array}{l}\text { Capacidade de } \\
\text { tamponamento do } \\
\text { solo; nível d'água } \\
\text { permeabilidade. }\end{array}$ & $\begin{array}{l}\text { Extração de } \\
\text { contamin. voláteis } \\
\text { acima do nível } \\
\text { d'água, eficácia } \\
\text { comprovada. }\end{array}$ & $\begin{array}{l}\$ 10.00 \mathrm{a} \\
\$ 50.00 / \mathrm{m}^{3} \\
\text { de solo } \\
\text { tratado (1) }\end{array}$ \\
\hline Bioremediação & $\begin{array}{l}\text { Degradação de } \\
\text { contaminantes } \\
\text { pela ação } \\
\text { microbial }\end{array}$ & $\begin{array}{l}\text { Presença de } \\
\text { nutrientes e } \\
\text { receptores de } \\
\text { elétrons, } \\
\text { profundidade. }\end{array}$ & $\begin{array}{l}\text { Material resultante } \\
\text { não é tóxico. A } \\
\text { eficiência dependerá } \\
\text { do tipo de } \\
\text { contaminante }\end{array}$ & $\begin{array}{l}\$ 30.00 \text { a } \\
\$ 100.00 \\
/ \mathrm{m}^{3} \text { de solo } \\
\text { tratado (2) }\end{array}$ \\
\hline Bioventilação & $\begin{array}{l}\text { Injeção de } \\
\text { oxigênio }\end{array}$ & $\begin{array}{l}\text { Permeabilidade, } \\
\text { anisotropia, } \\
\text { heterogeneidades e } \\
\text { nível d' água.. }\end{array}$ & $\begin{array}{l}\text { Auxilio no processo } \\
\text { de bioremediação. } \\
\text { Eficiência } \\
\text { comprovada. }\end{array}$ & $\begin{array}{l}\$ 10.00 \mathrm{a} \\
\$ 70.00(3)\end{array}$ \\
\hline $\begin{array}{l}\text { Bombeamento } \\
\text { em ritmo } \\
\text { variável }\end{array}$ & $\begin{array}{l}\text { Bombeamento } \\
\text { alterando a razão } \\
\text { de extração. } \\
\text { Permite a } \\
\text { dissolução, } \\
\text { desorção, difusão } \\
\text { em áreas estagn. }\end{array}$ & $\begin{array}{l}\text { Condutividade } \\
\text { hidráulica, } \\
\text { transmissividade, } \\
\text { capacidade de } \\
\text { tamponamento do } \\
\text { solo. }\end{array}$ & $\begin{array}{l}\text { Remoção de NAPLs } \\
\text { e outros } \\
\text { contaminantes via } \\
\text { poços de extração. } \\
\text { Técnica em } \\
\text { desenvolvimento. }\end{array}$ & $\begin{array}{l}\text { Não se } \\
\text { obteve } \\
\text { dados. }\end{array}$ \\
\hline
\end{tabular}




\begin{tabular}{|c|c|c|c|c|}
\hline "Air Sparging" & $\begin{array}{l}\text { Injeções de } \\
\text { material abaixo da } \\
\text { zona contaminada } \\
\text { e captura acima. }\end{array}$ & $\begin{array}{l}\text { Capacidade de } \\
\text { suporte do solo, } \\
\text { nível d'água e } \\
\text { permeabilidade. }\end{array}$ & $\begin{array}{l}\text { Extração de } \\
\text { contaminantes } \\
\text { voláteis da zona } \\
\text { saturada. Técnica em } \\
\text { desenvolvimento. }\end{array}$ & $\begin{array}{l}\$ 371.000 \text { a } \\
\$ 865.000 \\
\text { /hectare de } \\
\text { pluma } \\
\text { contaminad } \\
\text { o }\end{array}$ \\
\hline $\begin{array}{l}\text { Desorção } \\
\text { térmica }\end{array}$ & $\begin{array}{l}\text { Aumento da } \\
\text { temperatura } \\
\text { provocando a } \\
\text { volatilização do } \\
\text { contaminante }\end{array}$ & $\begin{array}{l}\text { Características que } \\
\text { dificultem a } \\
\text { distribuição } \\
\text { uniforme do calor. }\end{array}$ & $\begin{array}{l}\text { Retirada de } \\
\text { contaminantes } \\
\text { voláteis por } \\
\text { aquecimento. }\end{array}$ & $\begin{array}{l}\$ 30.00 \mathrm{a} \\
\$ 130.00 \\
/ \mathrm{m}^{3} \text { de solo } \\
\text { tratado }\end{array}$ \\
\hline $\begin{array}{l}\text { Tratamento } \\
\text { químico }\end{array}$ & $\begin{array}{l}\text { Transformação do } \\
\text { contaminante em } \\
\text { material não } \\
\text { tóxico pela reação } \\
\text { com compostos } \\
\text { químicos }\end{array}$ & $\begin{array}{l}\text { Capacidade de } \\
\text { Tamponamento do } \\
\text { solo, nível d'água, } \\
\text { permeabilidade e } \\
\text { heterogeneidades. }\end{array}$ & $\begin{array}{l}\text { Compostos menos } \\
\text { perigosos e a } \\
\text { eficiência depende de } \\
\text { vários fatores. }\end{array}$ & $\begin{array}{l}\$ 190.00 \text { a } \\
\$ 660.00 \\
/ \mathrm{m}^{3} \text { de solo } \\
\text { tratado (4) }\end{array}$ \\
\hline $\begin{array}{l}\text { Contenção } \\
\text { física }\end{array}$ & $\begin{array}{l}\text { Isolamento do } \\
\text { contaminante } \\
\text { através de } \\
\text { estruturas físicas }\end{array}$ & $\begin{array}{l}\text { Material disponível } \\
\text { para a construção } \\
\text { da estrutura, } \\
\text { permeabilidade da } \\
\text { camada subjacente. }\end{array}$ & $\begin{array}{l}\text { Previne a migração, e } \\
\text { a eficiência após } \\
\text { longo tempo é } \\
\text { incerta }\end{array}$ & $\begin{array}{l}\$ 540 \mathrm{a} \\
\$ 750 / \mathrm{m}^{2} \mathrm{de} \\
\text { estrutura } \\
\text { instalada. } \\
(5)\end{array}$ \\
\hline
\end{tabular}

* Dados obtidos via internet: http://frtr.gov/matrix/section1/toc.html (05/03/98)

Nota:

(1)- A variação é função do local, área contaminada (tamanho), natureza e tipo de contaminante, seção hidrogeológica, número de poços e tratamento final do vapor.

(2)- A variação é função, principalmente da natureza e profundidade do contaminante.

(3)- Função do tipo de contaminante e concentração, permeabilidade do solo, espaçamento e número de poços, razão de bombeamento e tratamento final do gás.

(4)- Função da Natureza e periculosidade do contaminante e do método de escavação, este preço inclui a remoção, transporte e disposição do material.

(5)- Depende do tipo e distribuição do contaminante; da profundidade, comprimento e largura da parede; das características geológicas e hidrogeológicas e do tipo de lama utilizada. 
Muitas vezes as características do contaminante e do meio físico fazem com que uma estratégia baseada em um único processo de remediação não seja suficiente para se conseguir alcançar o objetivo estipulado para o "cleanup". Neste contexto é importante a utilização de processos combinados, no qual cada técnica deve ser tratada como parte de uma sequiência.

Devido ao custo relativamente alto dos processos, à evolução destes serem recentes e à tecnologia não ser bem difundida, o Brasil não tem grande experiência na utilização destas técnicas, sendo necessário maiores estudos sobre sua aplicação nas condições brasileiras. Atualmente os processos mais utilizados são as técnicas de contenção, utilizandose de barreiras físicas e de poços de bombeamento. 


\section{CAPÍTULO III - METODOLOGIA}

A simulação de fluxo de água subsuperficial e transporte de solutos, considerando os modelos numéricos, é relativamente recente, ganhando importância na década de 70 . Atualmente os modelos numéricos dominam o estudo de problemas de água subsuperficial e representam basicamente uma série de muitos modelos de célula unitárias. Grandes avanços na tecnologia computacional auxiliaram neste processo, hoje muitos programas computacionais estão disponíveis para a maioria dos problemas de fluxo e de transporte de soluto.

O Capítulo sobre metodologia está dividido em 2 tópicos, o primeiro apresenta uma base bibliográfica sobre as etapas da modelagem e uma segunda onde são mostrados os passos utilizados no caso específico do Lixão de Poços de Caldas.

\section{Construindo o Modelo Numérico (SPITZ \& MORENO, 1996)}

As principais fases da modelagem são:

* Compilação e interpretação dos dados de campo;

* Representação do sistema natural;

* Seleção do modelo numérico;

* Calibração e validação do modelo (Análise de Sensibilidade);

* Aplicação do modelo; e

* Apresentação dos resultados.

A seguir são apresentados os principais aspectos sobre cada fase de construção dos modelos numéricos. 


\subsection{Compilação e Interpretação dos Dados de Campo}

Os dados de campo são essenciais para a representação do sistema natural, já que o modelo numérico é desenvolvido a partir dos parâmetros reais do campo. A precisão dos resultados da modelagem não é função da sofisticação do programa computacional, do tempo de cálculo, da boa discretização ou de grandes memória computacional, a qualidade das simulações depende em grande parte da validade dos dados do modelo físico e do modo que se entra com os dados.

Muitos dos dados entram no programa na forma de mapas. Exemplos destes são:

- Mapa topográfico em uma escala satisfatória que pode servir como o mapa básico no qual são sobrepostos outros dados.

- Mapa hidrológico que mostra todos os corpos de água de superfície como lagos, fluxos, lagoas, ou canais, além de poder incluir fontes e pântanos. O mapa deve prover um quadro claro do sistema de drenagem de superfície

- Mapas que mostram a distribuição do fluxo de água subsuperficial medido em momentos diferentes. A superfície potenciométrica interpretada, a localização de poços de monitoramento são incluídos nestes mapas.

- Mapa geológico junto com seções cruzadas Os mapas geológicos devem mostrar informações como falhas, espessura dos estratos e mudanças dos tipos rochosos. Esta informação pode ser relacionada então a ocorrência e movimento de água subsuperficial e permitir a identificação das possível unidades hidrográficas.

- Mapa de uso da terra que mostra áreas agrícolas, áreas recreativas, áreas industriais, canais de irrigação etc. Este mapa pode ser usado junto ao mapahidrológico para delinear áreas de recarga / descarga.

- Mapas adicionais de interesse para o caso específico.

Estes mapas são sobrepostos como camadas para formar o modelo hidrogeológico do local.

Muitos parâmetros necessários não são obtidos diretamente de coletas em campo, como por exemplo, a Transmissividade que é produto da condutividade hidráulica e da espessura da camada. O tempo necessário para desenvolver um modelo dependerá principalmente do tempo exigido para coletar e preparar os dados do modelo. 


\subsection{Criação do Modelo que represente o Sistema Natural}

Para assegurar a precisão de um modelo, deve-se fazer uma boa representação do sistema natural. Em alguns casos o usuário pode aplicar o modelo geral de água subsuperficial de modo simular ao fluxo ou transportar para escala de detalhes, no entanto, simplificações são, geralmente, necessárias. O modelo deve ser simples bastante para facilitar sua compreensão, sem excluir características dominante do problema a ser investigado. Em resumo, o sistema natural deve ser bem entendido para se projetar o modelo mais representativo.

Um dos primeiros pontos na modelagem de água subsuperficial é a identificação da área de influência do modelo e seus limites, este é a interface entre a área do modelo e o ambiente circunvizinho. As condições nos limites devem ser especificadas, muitas vezes representam influências externas, como rios e divisores de água.

Os critérios de decisão para selecionar as condições de limite hidráulico são principalmente a topografia, hidrologia e geologia. A topografia, geologia, ou ambos, podem gerar limites como estratos impermeáveis ou superfície potenciométricas que controlam a água de superfície, ou as áreas de recarga/descarga. O sistema de fluxo permite a especificação de limites em situações onde limites naturais estão a uma grande distância (chamado aqüíferos infinito).

Os problemas são maiores para a aproximação na modelagem de transporte de soluto. Neste caso, além de simplificar o fluxo, os processos de transporte do soluto atuantes são reduzidos a alguns mecanismos de transporte considerados dominantes, tais como a advecção e a sorção .

\subsection{Selecionando o Modelo Numérico}

Nesta fase do estudo do deve-se decidir qual programa computacional é o mais adequado para ser usado no cálculo do problema particular de água subsuperficial, considerando o objetivo da modelagem, os critérios técnicos e os fatores de implementação.

A maioria dos modelos numéricos são semelhantes no que se refere a subdividir a área investigada em segmentos poligonais. A manipulação na entrada e saída de dados (chamado de pré e pós-processamento) determinam a adequabilidade dos softwares ("user friendly"). 


\subsection{Calibração e Validação do Modelo}

São exigidas calibrações e validações no modelo para superar uma deficiência na entrada de dados.

Para se calibrar um modelo entra-se com um conjunto de dados medidos em campo, este valores serão utilizados como referência no modelo.

A validação do modelo tem vários significados e é necessária para demonstrar se o modelo pode ser usado com confiança. Não existe atualmente um critério absoluto para demonstrar a exatidão do modelo. A discrepância entre os dados previstos e os observados deve ser menor que aproximadamente $10 \%$ do intervalo de observações. $\mathrm{O}$ desvio padrão entre os dados previstos e observados deve situar-se em um intervalo de 0.7 a 1.0 dependendo do número e da qualidade dos dados. Se o modelo de fluxo de água subsuperficial e de transporte de contaminantes depois de calibrado não reproduz os resultados precisos o modelo deve ser revisto.

\section{Discretização de um Modelo no Espaço e no Tempo}

Esta discretização tem o objetivo de:

* Aumentar a resolução do modelo.

* Minimizar a dispersão numérica.

* Minimizar as exigências computacionais para memória, armazenamento e tempo de execução.

\section{Orientação da Grade do Modelo}

Em quase todos os casos a melhor orientação da grade não coincide com direções principais da bússola, estradas, ou limites cartográficos. Os seguintes fatores afetam a orientação da malha (em ordem de importância):

- Características geológicas, hidrológicas e hidrogeológicas do local. A representação de características chaves como rios, fluxos, falhas e outros limites naturais podem ser simplificados através da orientação apropriada da malha. Por exemplo, uma zona de falha que afeta o fluxo de água subsuperficial é melhor representada por células orientadas paralelamente e perpendicularmente à falha.

- Direção de fluxo predominante da água subsuperficial. Se a direção de fluxo 
varia dentro do domínio do modelo, o alinhamento da malha da grade com a direção de fluxo na área de interesse é mais adequada.

- Anisotropia de propriedades hidráulicas. Considerando que a condutividade hidráulica é expressa no modelo como componentes alinhados com os planos axiais da malha, os erros são reduzidos escolhendo uma malha orientada coincidente com o tensor de condutividade.

\subsection{Aplicação do Modelo}

A aplicação do modelo é a parte do estudo no qual o modelo numérico demonstra suas vantagens sobre todos os outros modelos, pois permite que sejam avaliadas várias simulações alternativas para uma determinada área.

A análise de sensibilidade neste ponto é muito importante, pois auxilia na ordenação dos dados de entrada em termos de sua influência no modelo e oferece respostas a várias perguntas. Uma prática comum é a comparação do modelo com um conjunto de dados não usados na calibração, este procedimento é mais útil quando as condições simuladas diferem significativamente da usada na calibração.

O objetivo da análise de sensibilidade é quantificar as variações no modelo calibrado causadas pelas incertezas na avaliação dos parâmetros. Durante a análise de sensibilidade os valores utilizados como condutividade hidráulica, coeficiente de armazenamento e a condição de contorno são alterados dentro de uma gama plausível de valores e são computados os novos valores da modelagem. COOLEY et al. (1986), elaborou mapas de sensibilidade para ilustrar as áreas do modelo mais sensíveis a mudanças em um dado parâmetro. SYKES et al. (1985); TOWNLEY \& WILSON (1985) propuseram metodologias para calcular a sensibilidade para todos os parâmetros em todos os nós da discretização espacial.

\subsection{Apresentação dos Resultados}

A saída das simulações pode ser de forma numérica ou na forma de linhas de mesmo potencial, como nos mapas de superfície potenciométrica onde as medidas são apresentadas como isolinhas (por exemplo, contornos de concentração relativo a uma concentração de fonte de 1.0) .

Os resultados podem ser apresentados em muitas formas e podem ser incluídos gráficos tridimensionais, seções cruzadas verticais, ilustrações de vetor de fluxo de água 
subsuperficial ou comparação de esquemas de alternativas de remediação. Idealmente cada figura deve ser auto - explicativa.

\section{Emprego da Metodologia no caso do Lixão de Poços de Caldas}

Para o caso particular do Lixão a seqüência metodológica utilizada pode ser resumidamente visualizada no fluxograma da Figura 15.

Nota:

1 - O Visual Modflow considera que os contaminantes que entram no sistema sejam totalmente miscíveis com a água, no caso, por exemplo de orgânicos, este programa não é recomendado.

2 - O Visual Modflow admite que na zona não saturada o único mecanismo de transporte efetivo seja a advecção. Esta suposição não é verdadeira para a maioria dos casos, o que faz com que em áreas com uma zona não saturada com espessura grande sejam gerados resultados incorretos.

3 - Qualquer programa de modelagem tem uma limitação quanto ao número de células, a capacidade do programa deve ser tal que permita representar as características do meio importantes da área.

4 - Observar se o nível de exigência é compatível com o tipo de resultado. 
FIGURA 15 - Fluxograma dos procedimentos utilizados na construção do modelo numérico para o lixão de Poços de Caldas. 
NÃO LOCALIZADO NO EXEMPLAR IMPRESSO 
Este capítulo enfoca três pontos considerados importantes, as equações que governam o fluxo de água subsuperficial, os processos de transporte dos solutos e uma descrição básica do programa selecionado.

\section{1 - Equações Governantes do Fluxo de Água Subsuperficial}

O movimento tridimensional de água subsuperficial, através de meios porosos pode ser descrito pela equação diferencial parcial:

$$
\frac{\partial h}{\partial x}\left(K_{x x} \frac{\partial h}{\partial x}\right)+\frac{\partial}{\partial y}\left(K_{y y} \frac{\partial h}{\partial y}\right)+\frac{\partial}{\partial z}\left(K_{z z} \frac{\partial h}{\partial z}\right)-W=S_{S} \frac{\partial h}{\partial t}
$$

onde:

$\mathrm{K}_{\mathrm{xx}}, \mathrm{K}_{\mathrm{yy}}, \mathrm{K}_{\mathrm{zz}}=$ valores da condutividade hidráulica ao longo das coordenadas espaciais $\mathrm{x}$, y e $\mathrm{z}\left(\mathrm{LT}^{-1}\right)$;

$\mathrm{W}=$ vazão por unidade de volume correspondente a fontes e/ou sumidouros;

Ss = armazenamento especifico $\left(\mathrm{L}^{-1}\right)$; e

$\mathrm{t}=$ variável tempo. 
A equação anterior juntamente com as condições iniciais e de contorno constituem a representação matemática do fluxo de água subsuperficial em um domínio especificado. No entanto, exceto para sistemas muito simples, não é possível encontrar uma solução analítica para esta equação devido as condições de contorno complexas do sistema. Faz-se, então, uso de métodos numéricos para obtenção de soluções.

Entre os mais utilizados, destaca-se o método das diferenças finitas. Nesse método o meio continuo é substituído por um conjunto discreto de pontos no espaço e no tempo e as derivadas parciais são substituídas por termos calculados através de diferenças entre as cargas hidráulicas nesses pontos. O processo resulta em um sistema de equações lineares simultâneas cuja solução fornece os valores dos gradientes hidráulicos em pontos e tempos especificados.

\section{Esquema da discretização.}

Na Figura 16 apresenta-se o esquema de discretização adotado pelo programa MODFLOW, que mostra uma discretização espacial de um aquífero com uma malha de blocos denominadas células, cuja locação é descrita em termos de linhas, colunas e camadas. Utilizam-se os índices i, j, k, onde i é o índice relativo as linhas, j refere-se as colunas e k refere-se as camadas. Denotando-se, a largura das células nas direções das linhas é designada por $\triangle \mathrm{Rj}$; a largura das células da direção das colunas por $\Delta \mathrm{Ci}$ e a espessura das células em uma dada camada é designada por $\Delta \mathrm{Vk}$. Assim, por exemplo, uma célula com as coordenadas $(i, j, k)=(4,8,3)$ terá um volume expresso por $\Delta R_{4} \Delta C_{8} \Delta V_{3}$. (MATSUZAKI, 1998). 


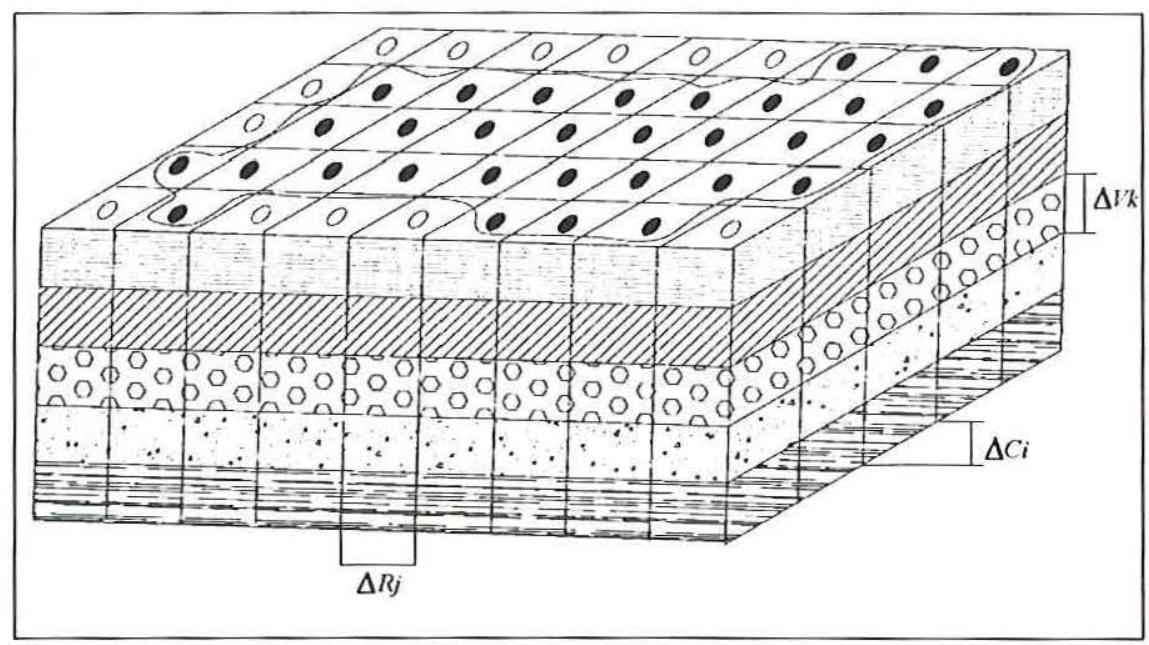

FIGURA 16 - Discretização espacial (Fonte: MATSUZAKI, 1998)

onde:

$\mathrm{O}=$ células inativas

- = células ativas

$I$ = contorno do aqüífero

Em cada uma das células pode se formular a equação do movimento aplicando-se a equação de Darcy estendida para um meio anisotrópico e pela equação da continuidade. Adota-se a convenção de positivo para o fluxo que entra em uma célula e negativo para o fluxo que sai da célula. Desse modo a vazão que entra na célula $i, j, k$ vinda da célula i, j-l, $k$ é dada pela equação:

$q_{i, j-1 / 2, k}=K R_{i, j-1 / 2, k} \Delta C_{i} \Delta C_{k} \frac{h_{i, j-1, k}-h_{i, j, k}}{\Delta R_{j-1 / 2}}$

onde $\mathrm{KR}_{\mathrm{i}, \mathrm{j}-1 / 2, \mathrm{k}}$ é a condutividade hidráulica ao longo da linha entre os nós i,j, k e i, j$\mathrm{I}, \mathrm{k}$ e $\Delta \mathrm{R}_{\mathrm{j}-1 / 2}$ é o valor da largura da célula entre os nós j-1 e j. Expressões análogas podem ser escritas para as outras cinco faces remanescentes da célula i, j, k.

A notação pode ser simplificada introduzindo-se a grandeza denominada condutância hidráulica que engloba a condutividade hidráulica e as dimensões da malha. Assim da equação anterior tem-se: 


$$
C R_{i, j-1 / 2, k}=\frac{K R_{i, j-1 / 2 k} \Delta C_{i} \Delta V_{k}}{\Delta R_{j-1 / 2}}
$$

onde $\mathrm{CR}_{\mathrm{i}, \mathrm{j}-1 / 2, \mathrm{k}}$ é a condutância na linha i e camada $\mathrm{k}$ entre os nós $\mathrm{i}, \mathrm{j}-\mathrm{I}, \mathrm{k}$ e i,j,k. A condutância é então o produto da condutividade hidráulica pela área transversal à direção do fluxo, dividida pelo comprimento longitudinal.

Dessa forma a equação (2) pode ser escrita como:

$$
q_{i, j-1 / 2, k}=C R_{i, j-1 / 2, k}\left(h_{i, j-1, k}-h_{i, j, k}\right)
$$

De maneira similar tem-se para as outras cinco faces do bloco i, j, $\mathrm{k}$.

É preciso elaborar outros termos para se considerar os fluxos resultantes de processos externos ao aqüífero tais como rios, drenos, recarga, evapotranspiração e poços. O termo geral que leva em conta essas contribuições é expresso por:

$Q S_{i, j, k}=P_{i, j, k} h_{i, j, k}+Q_{i, j, k}$

onde $\mathrm{P}_{\mathrm{i}, \mathrm{j}, \mathrm{k}}$ é a vazão de uma fonte externa que depende da carga na célula $\mathrm{i}, \mathrm{j}, \mathrm{k}$ (por exemplo, na interação entre rio e aqüífero) e $Q_{i, j, k}$ é a vazão de uma fonte externa que não depende da carga na célula (por exemplo, recarga proveniente de precipitação).

Acrescentando-se as contribuições $\mathrm{QS}_{\mathrm{i}, \mathrm{j}, \mathrm{k}}$ aos escoamentos expressos pelas equações que representem as seis faces do bloco, pode-se escrever a equação 6:

$$
\begin{aligned}
& C R_{i, j-1.2, k}\left(h_{i, j-1, k}-h_{i, j, k}\right)+C R_{i, j+1 / 2, k}\left(h_{i, j+1, k}-h_{i, j, k}\right)+C C_{i-1 / 2, j, k}\left(h_{i-1, j, k}-h_{i, j, k}\right) \\
& +C C_{i+1 / 2, j, k}\left(h_{i+1, j, k}-h_{i, j, k}\right)+C V_{i, j, k-1 / 2}\left(h_{i, j, k-1}-h_{i, j, k}\right)+C V_{i, j, k+1 / 2}\left(h_{i, j, k+1}-h_{i, j, k}\right)+ \\
& P_{i, j, k} h_{i, j, k}+Q_{i, j, k}=S S_{i, j, k}(\Delta r j \Delta c i \Delta r k) \frac{\Delta h_{i, j, k}}{\Delta t}
\end{aligned}
$$


onde $\mathrm{S}_{\mathrm{S}, \mathrm{j}, \mathrm{k}}$ representa o armazenamento do aqǘf́ro na célula $\mathrm{i}, \mathrm{j}, \mathrm{k}$. O termo $\Delta \mathrm{h}_{\mathrm{i}, \mathrm{j}, \mathrm{k}} / \Delta \mathrm{t}$ pode ser aproximado pela expressão:

$$
\left(\frac{\Delta h_{i, j, k}}{\Delta t}\right)_{m}=\frac{h_{i, j, k}^{m}-h_{i, j, k}^{m-1}}{t_{m}-t_{m-1}}
$$

A equação (6) pode então ser escrita em termos das cargas no tempo (m) e no tempo (m-1), rearranjada de tal forma que no lado esquerdo apareçam os termos que contém gradiente hidráulico no tempo $(\mathrm{m})$ e no lado direito estejam agrupados os termos no tempo $(\mathrm{m}-1)$. A equação resultante pode ser escrita como (8):

$$
\begin{aligned}
& C V_{i, j, k-1 / 2} h_{i, j, k-1}^{m}+C C_{i-1 / 2, j, k} h_{i-1, j, k}^{m}+C R_{i, j-1 / 2, k} h_{i, j-1, k}^{m}+h_{i, j, k}^{m} \\
& \left(-C V_{i, j, k-1 / 2}-C C_{i-1 / 2, j, k}-C R_{i, j-1 / 2, k}-C R_{i, j+1 / 2, k}-C C_{i+1 / 2, j, k}-C V_{i, j, k-1 / 2}+H C O F_{i, j, k}\right) \\
& +C R_{i, j+1 / 2, k} h_{i, j+1, k}^{m}+C C_{i+1 / 2, j, k} h_{i+1, j, k}^{m}+C V_{i, j, k+1 / 2} h_{i, j, k+1}^{m}=R H S_{i, j, k}
\end{aligned}
$$

Onde:

$$
\begin{aligned}
& \operatorname{HCOF}_{\mathrm{i}, \mathrm{j}, \mathrm{k}}=\mathrm{Pi}, \mathrm{j}, \mathrm{k}-\mathrm{SCl}_{\mathrm{i}, \mathrm{j}, \mathrm{k}} /\left(\mathrm{T}_{\mathrm{m}}-\mathrm{T}_{\mathrm{m}-\mathrm{l}}\right) ;\left(\mathrm{L}^{2} \mathrm{t}^{-1}\right) \\
& \mathrm{RHS}_{\mathrm{i}, \mathrm{j}, \mathrm{k}}=-\mathrm{Qi}, \mathrm{j}, \mathrm{k}-\mathrm{SCl}_{\mathrm{i}, \mathrm{j}, \mathrm{k}} \mathrm{h}^{\mathrm{m}-1}{ }_{\mathrm{i}, \mathrm{j}, \mathrm{k}} /\left(\mathrm{t}_{\mathrm{m}}-\mathrm{t}_{\mathrm{m}-\mathrm{l}}\right) ;\left(\mathrm{L}^{3} \mathrm{t}^{-1}\right) ; \mathrm{e} \\
& \mathrm{SCl}_{\mathrm{i}, \mathrm{j}, \mathrm{k}}=\mathrm{SS}_{\mathrm{i}, \mathrm{j}, \mathrm{k}} \Delta \mathrm{Rj} \Delta \mathrm{Ci} \Delta \mathrm{Vk} .
\end{aligned}
$$

A equação (8) na realidade representa um sistema de equações ( $i, j, k)$ que pode ser colocada na forma matricial

$$
[\mathrm{A}]\{\mathrm{h}\}=\{\mathrm{q}\}
$$

onde $[\mathrm{A}]$ é a matriz dos coeficientes dos gradientes hidráulicos; $\{$ h $\}$ é um vetor incógnito (carga no final do tempo considerado) e $\{q\}$ é o vetor nos termos constantes.

As células de carga constante tem o valor do gradiente hidráulico especificado anteriormente e seu valor permanece constante durante toda a simulação. As células inativas são aquelas externas ao domínio considerado. O contorno real do meio físico é irregular; a aproximação produzida pelo retículo resulta em um domínio cujos limites são linhas retas; as células externas ao retículo são consideradas células inativas. 


\section{2 - Transporte e Atenuação de Soluto em Meio Poroso}

\subsection{Classificação dos Contaminantes em função do comportamento de Transporte}

Os contaminantes podem atingir a água subsuperficial tanto dissolvidos em água (miscíveis) como em uma fase líquida que pode ser imiscível em água. Alguns contaminantes tais como os metais pesados também podem ser adsorvidos em partículas finas e ser transportados em suspensão, dependendo do tamanho da partícula, o transporte pode ser equivalente ao dos contaminantes dissolvido. Líquidos miscíveis (ou contaminantes dissolvidos) migram pelos poros dos materiais de forma diferente dos fluidos imiscíveis. Os fluidos miscíveis e a água subsuperficial natural formam uma fase cujo movimento pode ser expressado pela lei de Darcy (fluxo de fase única).

Os solutos que permanecem estáveis na água subsuperficial e não mudam devido a processos físicos, biológicos ou químicos são descritos como conservadores, estes solutos por não influenciar significativamente a viscosidade e a densidade da água podem ser utilizados como traçadores.

Uma pluma de contaminação de água subsuperficial geralmente contém vários contaminantes, estes podem migrar diferentemente e reagir entre si. Os estudos de transporte de soluto, normalmente concentram-se no contaminante que é considerado mais importante para o problema investigado. Muitas vezes é considerado a predição do espalhamento máximo de uma pluma.

\subsection{Mecanismos de Transporte e atenuação dos solutos}

Os principais mecanismos pelos quais os solutos são transportados são:

$\checkmark$ Advecção

$\checkmark$ Dispersão Hidrodinâmica.

Nesta seção também serão apresentados os processos de Difusão, Sorção, Decaimento, Hidrólise, volatilização e biotransformação. 


\subsection{1 . Advecção}

FREEZE \& CHERRY (1979) definem a Advecção como o componente do movimento do soluto atribuído ao transporte pela água em movimento, onde a taxa de transporte de soluto está diretamente relacionada a velocidade de água do meio poroso. A velocidade média de transporte (v) é calculada como no fluxo de Darcy:

$$
v=\frac{K i}{n_{e}}
$$

Durante a evolução da maioria das plumas, a advecção é o mecanismo de transporte mais importante. Se a advecção for um processo de transporte exclusivo, então as mudanças de concentração, numa relação de volume e tempo é igual à diferença entre a entrada e a saída de fluxos advectivos. A expressão (10) representa a equação de transporte unidimensional em sua forma mais simples, assumindo que o meio é homogêneo:

$$
\frac{\partial c}{\partial}=-v \frac{\partial c}{\partial x}
$$

onde:

$\mathrm{x}=$ direção de fluxo em [L]

$t=$ tempo em $[\mathrm{T}]$

$c=$ concentração em $\left[\mathrm{M} / \mathrm{L}^{3}\right]$

$\mathrm{v}=$ velocidade de transporte advectivo em $[\mathrm{L} / \mathrm{T}]$

O fluxo advectivo torna-se mais complexo quando a densidade e/ou a viscosidade da água mudam com a concentração do soluto. Solutos com densidade elevada, em comparação com a água, introduzem um componente vertical de movimento de fluxo.

\subsubsection{Dispersão Hidrodinâmica}

O espalhamento dispersivo, longitudinalmente e transverso à direção de fluxo principal, causa uma diluição gradual da pluma de poluição. 
O fenômeno da dispersão hidrodinâmica constitui-se na tendência ao espalhamento do soluto nos caminhos pelos quais este percorre. Os mecanismos principais deste espalhamento são a dispersão mecânica e a difusão molecular e, portanto o coeficiente hidrodinâmico $(\mathrm{Dh})$ considera estes dois fatores.

\section{Dispersão Mecânica}

A dispersão Mecânica é causada basicamente pelo movimento do fluido. O fluxo unidimensional de massa de uma espécie química por dispersão mecânica é descrita pela equação (11) (SCHACKELFORD, 1993). A equação (12) descreve Dm em termos também unidimensionais (CLEARY, 1991).

$$
\begin{gathered}
J m=-D m n \frac{\partial C}{\partial x} \\
D m=\alpha_{\mathrm{L}} \mathrm{V}
\end{gathered}
$$

Onde $\alpha_{\mathrm{L}}$ é o coeficiente longitudinal e $\mathrm{J} m$ é o fluxo de massa por dispersão mecânica.

Em algumas situações, quando as concentrações estão abaixo dos valores de concentração considerados prejudiciais aos humanos, a dispersão pode ser um benefício, mas freqüentemente a dispersão é um efeito indesejável devido ao espalhamento rápido dos contaminantes que aumenta o volume de água subsuperficial poluída. O espalhamento dispersivo conduzirá a um aumento na uniformidade da pluma com a distância.

\section{Difusão Molecular}

A difusão é o movimento de solutos de uma zona de alta concentração de soluto para uma zona de baixa concentração. A força motriz é o movimento aleatório dos constituintes iônicos e moleculares sob a influência de sua atividade cinética, denominado movimento Browniano. A difusão é irreversível, uma vez que duas soluções estejam misturadas sob condições naturais, elas formarão uma única solução uniforme. O transporte global de solutos ocorre na direção do gradiente de concentração e pode ser expressa pela lei de Fick: 


$$
q_{o}=-D_{o} \frac{\partial c}{\partial x}
$$

A lei de Fick simplifica o fluxo de massa difusivo $q_{o}$ como o produto do gradiente de concentração e um coeficiente $D o\left[\mathrm{~L}^{2} / \mathrm{T}\right]$ chamado de coeficiente de difusão. Valores típicos de coeficientes de difusão em solução livre são da ordem de $10^{-9} \mathrm{~m}^{2} / \mathrm{s}$. O coeficiente de difusão em materiais porosos é chamado de efetivo para distingui-lo do coeficiente de difusão medido em solução livre.

Incluindo o transporte difusivo de contaminante na equação de transporte unidimensional, encontra-se:

$$
\frac{\partial c}{\partial}=-v \frac{\partial c}{\partial x}+D_{o} \frac{\partial^{2} c}{\partial x^{2}}
$$

Os processos de difusão são processos de transporte relativamente lentos. Assumindo uma fonte de concentração constante limitada por uma camada argilosa, sem fluxo advectivo de água subsuperficial, mas com um coeficiente de difusão efetivo de $5 \times 10^{-9}$ $\mathrm{m}^{2} / \mathrm{s}$, a concentração à $10 \mathrm{~m}$ da fonte mostraria $10 \%$ da concentração de fonte depois de 500 anos de migração. Assim, o efeito da difusão será normalmente mascarado pelo efeito da advecção em água subsuperficial divida em áreas com velocidades de fluxo elevadas.

\subsubsection{Sorção}

A sorção refere-se a adsorção e a desorção das partículas. A adsorção descreve a adesão de moléculas ou íons à superfície da partícula no solo, a liberação da fase sólida é chamado desorção. A adsorção causa a diminuição da concentração na fase aquosa e um retardamento no transporte de contaminantes se comparado ao movimento da água subsuperficial. O grau de sorção depende de vários fatores, inclusive da concentração e das características do contaminante, do tipo de solo e sua composição, do pH da água e da presença de outro solutos na água. Cada um destes fatores pode variar no tempo e no espaço, e pode resultar em uma variação do retardamento no ambiente natural. Um termo " $\mathrm{S}$ " (fonte/esgotamento), representando a taxa à qual massa de soluto é perdida ou somada à fase aquosa (massa de soluto por volume de unidade de solução por unidade de tempo), é acrescentado à equação de transporte para representar a sorção: 


$$
\frac{\partial c}{\partial}=-v \frac{\partial c}{\partial x}+D_{L} \frac{\partial^{2} c}{\partial x^{2}}-S
$$

A equação 15 é a forma unidimensional da equação advecção-dispersão para o aqüífero homogêneo, modificado para responder os efeitos da sorção

As taxas de sorção do material sólido em relação à concentração na água subsuperficial é expressada através de cinéticas de sorção. Tais reações cinéticas são aplicadas e o modo de sorção é incorporado no termo fonte/esgotamento (S). Se os processos de sorção forem relativamente rápidos se comparados ao tempo de transporte advectivo dos contaminantes, o equilíbrio entre a concentração de adsorvidos $\left(c_{a}\right.$, ) e a concentração dissolvida $(c)$ pode ser assumida (sorção de equilíbrio). A relação entre a concentração de um soluto na fase sorvida e na fase de água, em equilíbrio, é chamada de isoterma de sorção. A depender do comportamento do solo, as isotermas podem ser lineares ou não lineares. Nas isotermas lineares o Kd pode ser obtido para uma determinada concentração (c) através da expressão:

$$
c_{a}=f(c)
$$

A relação de equilíbrio mais simples que pode ser encontrada em problemas de transporte com concentrações relativamente pequenas é a isoterma linear:

$$
c_{a}=K_{d} c
$$

onde:

$\mathrm{c}_{\mathrm{a}}=$ concentração de adsorvidos medidos como massa de contaminante por massa de material de matriz seca [1]

$\mathrm{c}=$ concentração dissolvida medida como massa de contaminante por volume de água em $\left[\mathrm{M} / \mathrm{L}^{3}\right]$

$\mathrm{K}_{\mathrm{d}}=$ coeficiente de distribuição $\left[\mathrm{L}^{3} / \mathrm{M}\right]$

Depois de algumas reestruturações este termo $S$ (fonte/esgotamento), para uma isoterma linear leva a uma equação de transporte unidimensional idêntica a equação de advecção-dispersão: 


$$
\frac{\partial c}{\partial}=-\frac{v}{R} \frac{\partial c}{\partial x}+\frac{D_{L}}{R} \frac{\partial^{2} c}{\partial x^{2}}
$$

Assim, a sorção de equilíbrio descrita pela isoterma linear causa um retardamento da migração do contaminante comparado ao transporte advectivo com a velocidade média de transporte. Tal retardamento é descrito pelo fator de retardamento adimensional $R$, definido como:

$$
R=1+\frac{(1-n) \rho_{s}}{n} K_{d}
$$

O modelo de $K d$ também pode ser aplicado para descrever o transporte com troca iônica ou sorção hidrofóbica, embora os mecanismos de sorção hidrofóbica ainda não sejam bem definidos. Experiências mostram que quanto maior o conteúdo orgânico no meio físico, maior é o potencial de sorção. Os orgânicos hidrofóbicos em uma solução aquosa deixarão a fase aquosa em preferência a fase sólida orgânica presente no solo quando aderidos ao material de solo. A solubilidade ou, alternativamente, o coeficiente de partição de octanolágua $K_{o w}$, é uma medida desta preferência.

As isotermas não lineares descrevem melhor o comportamento do solo para uma concentração qualquer. Os modelos matemáticos mais conhecidos para estas isotermas são os de Freundlich e de Langmuir. O modelo de Freundlich é empírico e é representado pela equação:

$$
c_{a}=K c^{a}
$$

No caso de adsorção linear, $a$ é igual a 1 . Além de causar um retardamento no movimento da pluma, as isotermas não lineares também criam uma assimetria na distribuição da concentração, neste caso, a previsão da migração da pluma de contaminação fica mais difícil.

O modelo de Langmuir descreve um processo onde há uma capacidade máxima de sorção pelo solo. A expressão (21) descreve este processo:

$$
C a=\frac{S_{m} b}{1+b c}
$$


Sendo $\mathrm{S}_{\mathrm{m}}$ a quantidade máxima sorvida pelo solo; b é a taxa cinética constante de saída e entrada de constituintes nos sítios de adsorção e c é a concentração de equilíbrio.

\subsubsection{Decaimento}

Nem todos o contaminantes que são sorvidos seguem o princípio de reações rápidas. Reações da primeira ordem seguem a relação:

$$
\frac{\partial c}{\partial t}=-\lambda c
$$

onde $\lambda$ é uma constante de decaimento $\left[\mathrm{T}^{-1}\right]$.

Reações de primeira ordem também são aplicadas para descrever o decaimento radioativo e/ou processos de degradação simples de poluentes biológicos:

$$
c=c_{o} e^{-\lambda t}
$$

onde

$\mathrm{c}=$ concentração em um tempo $\mathrm{t}\left[\mathrm{M} / \mathrm{L}^{3}\right]$

$\mathrm{c}_{\mathrm{o}}=$ concentração em um tempo 0 (concentração inicial ou concentração fonte) $\left[\mathrm{M} / \mathrm{L}^{3}\right]$

$\lambda=$ taxa constante que caracteriza o decaimento $\left[\mathrm{T}^{-1}\right]$

$\mathrm{T}_{1 / 2}=$ meia-vidas de isótopos radioativos ou de contaminantes degradados [T]

Visto que as reações da primeira ordem são lineares e não mudam as características da equação de transporte, elas podem ser utilizadas em simulações de transporte. Os valores de concentração obtidos sem considerar o decaimento são simplesmente multiplicados pelo fator exp. $(\lambda / t)$, onde $t$ é o tempo para o qual foram calculadas as concentrações. Os processos de degradação também diminuem a fonte de contaminação com o tempo. 


\subsubsection{Hidrólise, Volatilização e Biotransformação}

Existem outros processos que afetam o transporte do contaminante, como a dissolução, filtração, fotólise, hidrólise, oxidação, reações químicas com outra espécie, volatilização, bioacumulação e biotransformação e a biodegradação. Destes os processos mais importante são:

\section{Hidrólise}

A hidrólise é a reação do contaminante na água, normalmente com a introdução de um grupo hidróxila $(\mathrm{OH})^{-}$na estrutura da substância química contaminante e, geralmente, com a perda de um íon. A taxa de reação pode ser catalisada por metais, ácidos e/ou bases e microorganismos.

\section{Volatilização}

A volatilização de substâncias químicas orgânicas da água para a atmosfera pode ser um caminho importante para substâncias químicas com pressões de vapor elevadas. Esta reação é facilitada pela preferência de muitos contaminantes serem dissolvido na fase gasosa do que na fase aquosa. Os fatores que controlam a concentração de vapor na fase gasosa são a pressão de vapor $p$ do contaminante sob investigação (em atm.) e a constante da lei de Henry $K H\left(\mathrm{em} \mathrm{atm.} \mathrm{m}^{3} / \mathrm{mol}\right)$ :

$$
\mathrm{p}=\mathrm{K}_{\mathrm{H}} \mathrm{c}
$$

onde $c$ é a concentração do contaminante na fase aquosa (em moles $/ \mathrm{m}^{3}$ ). Assumindo o equilíbrio, a equação 24 , fornece a concentração do contaminante na fase gasosa se esta estiver em contato com a fase aquosa contaminada. Assim a constante de lei de Henry representa o equilíbrio entre as fases aquosa e vapor. A pressão de vapor ajuda a calcular a taxa de evaporação do contaminante. Quanto maior a pressão de vapor, mais volátil é o contaminante. 


\section{Biotransformação e biodegradação}

A biotransformação ou biodegradação é o resultado da transformação enzimacatalisada de um contaminante. As biotransformações são realizadas principalmente por micróbios, desta forma a taxa de biotransformação é uma função da massa microbiana no ambiente aquoso estudado. As populações de bactérias presentes no solo geralmente são multiespécies e é raro um contaminante ser tóxico a todos os micróbios. Também é usual uma adaptação rápida da comunidade de bactéria nativa em relação ao contaminante, devido a isto, todos o contaminantes orgânico são eventualmente biotransformados ou biodegradados em certas proporções, no entanto esta relação não é previsível, em um ambiente natural onde a biomassa é relativamente grande e a concentração de contaminante é baixa, a taxa de degradação segue uma pseudo reação de primeira-ordem. 


\section{3 - Descrição do Modelo Computacional - Modflow}

O Visual Modflow é um modelo tridimensional de diferença finita de fluxo de água subsuperficial, elaborado por Michael McDonald e Arlen Harbaugh - USGS, sendo, atualmente, o mais utilizado. Este programa integra um pré e um pós processador, o MODFLOW e o MODPATH, o Modpath é um modelo de trajetória de partículas que utiliza os gradientes hidráulicos gerados pelo Modflow; os dois modelos foram desenvolvidos pelo United States Geological Survey (USGS). O Visual Modflow é um software que contém um ambiente com menus totalmente integrados, possuindo assim uma boa interface com o usuário.

\subsection{Aspectos Gerais}

\section{Menu do Visual Modflow}

$\mathrm{O}$ ambiente integrado consiste de quatro partes principais: tela principal, entrada de dados (input), executar o programa (run) e saída.

\section{Tela Principal}

Ao se iniciar o Visual Modflow aparecerá na tela um menu principal que oferece acesso para seis opções na barra de menu que se localiza na parte superior da tela: [File], [Input], [Run], [Output), [SETUP), [HELP].

\subsection{Processo de Entrada de Dados (Input)}

Após a entrada do mapa base em formato .DXF, inicia-se a modelagem com a definição da discretização espacial da área de influência.

\section{Definições do Domínio da Malha ("grid")}

Para definição horizontal da malha inseri-se os valores correspondentes ao número de linhas e número de colunas do domínio, esta definição é importante porque afetará a precisão dos resultados.

\section{Suavizando o Espaçamento entre as grades}

Uma malha regular gera resultados mais precisos, especialmente em áreas de gradientes hidráulicos íngremes, porém, a exigência de capacidade de memória do 
computador, também aumentará. Para melhores resultados, deve-se mudar gradualmente os espaçamentos da grade, esta não deve aumentar mais que 50 por cento entre células adjacentes. Deve-se também respeitar a relação de dimensão entre as células; uma célula não deve ter 10 vezes o tamanho de uma outra direção.

O usuário poderá modificar a malha no item [Grid], alterando o número de linhas, colunas e camadas.

\section{Discretização vertical do domínio}

Para uma melhor discretização vertical, no Visual Modflow pode-se importar superfícies como a da topografia, nível de água e camadas adjacentes, em forma de arquivos ASCII ou adivindas do software SURFER (*.GRD).

\section{Orientação da Grade}

A orientação da grade com respeito às condições limite é útil. Embora o Visual MODFLOW não permita girar o modelo, o arquivo .DXF pode ser girado em AutoCAD e então pode ser importado para o Visual MODFLOW.

\section{Inserindo Poços}

A tela [Well] permite a locação de poços. Quando existe necessidade se adicionar algum poço, clica-se em [Add Well] e aparecerá uma janela onde se introduz os dados sobre os poços, como o nome, locação correta, filtro, quantos dias o poço devera bombear e vazão bombeada. Colocando uma vazão positiva, significa que o poço estará injetando água no aquífero e negativa quando o poço estiver bombeando, se necessário, pode-se também desativar o poço.

\section{Notas:}

- O MODFLOW considera um poço em uma célula como sendo localizado no centro da célula, independente das coordenadas atribuídas. São necessárias espaçamentos pequenos de linha e de coluna na redondeza de um poço para melhorar a precisão em pequena escala.

- O MODFLOW considera um poço como sendo desenhado na camada toda, apesar do intervalo de blindagem atribuído no Visual MODFLOW. São necessárias camadas de espessura menor para representar pequenos intervalos de blindagem. 


\section{Propriedades hidrogeológicas}

Para se adicionar propriedades hidrogeológicas, como a condutividade, recarga, evapotranspiração, armazenabilidade, porosidade total e efetiva, clica-se em [Properties].

\section{Condições de Contorno}

As condições de contorno estão na tela [Boundaries]. Pode-se entrar com os dados de: células com cargas hidráulicas constantes e diferenciada, rios e células que se comportam com uma barreira no meio.

\section{Carga Constante}

[Constant Head]: Atribui ou edita células com cargas constantes. Estas podem ser uma simples célula ao longo de uma linha ou um polígono demarcado.

\section{Rios}

Para inserir um rio, deve-se acessar a sub-Tela "Boundaries" e a função "Rivers". O ModFlow trata a condutância como o fluxo que sai do aqüífero e alimenta o rio ou viceversa.

\section{GHB (General Head Boundaries)}

Essas cargas consistem nas elevações das superfícies dos níveis d'água em torno da área ou bacia. Quando inicia-se um problema no Visual Modflow, as extremidades da área são consideradas regiões de fluxo nulo, para se evitar isto utiliza-se o G.H.B.. A função do GHB é matematicamente similar a dos rios e a evapotranspiração, na qual a vazão entrando ou saindo da célula $i, j, k$ por uma fonte externa é proporcional a diferença entre a carga na célula, $h_{\mathrm{i}, \mathrm{j}, \mathrm{k}}$ é a carga na fonte externa, $\mathrm{h}_{\mathrm{bi}, \mathrm{j}, \mathrm{k}}$.

\section{Drain (Dreno)}

O Visual Modflow considera os rios como sendo perenes, quando o rio é intermitente deve-se considerá-lo como sendo dreno.

\section{Paredes - "Wall" (Barreiras de fluxo horizontal)}

O Pacote de barreira de fluxo Horizontal (HFB), ou parede limite como se refere no Visual MODFLOW, foi desenvolvido para simular estruturas com espessura e profundidade variadas, baixa permeabilidade e outras características que impeçam o fluxo horizontal de água subsuperficial. Este pacote permite que não haja necessidade de reduzir o 
espaçamento da grade em um número excessivo de células do modelo e assim aumentar sua eficiência.

\section{Recarga ("Recharge")}

Para se inserir a precipitação ou a recarga efetiva no domínio deve-se clicar em "Recharge", pode-se adicionar recargas diferentes ao longo da área. Outros dados que são inseridos nesta janela são o tempo de simulação e a recarga, podendo inserir recargas diferentes para os vários intervalos de tempo.

\section{Evapotranspiração ("Evapotranspiration")}

Ao adiciona-se a precipitação deve-se inserir dados de evapotranspiração para que o problema se torne o mais real possível. Assim como para o caso da recarga, o programa permite adicionar diferentes valores de evapotranspiração ao longo do domínio.

A aproximação da evapotranspiração está baseado nas seguintes suposições:

- Quando o nível de água está sobre a superfície do solo (topo da camada 1), a perda de evapotranspiração do nível de água acontece à taxa de máximo especificada pelo usuário.

- Quando a elevação do nível de água está abaixo da elevação da superfície de "Extinction Depth", ou está abaixo da camada 1, a evapotranspiração do nível de água é reduzido.

- Entre estes Limites, a evapotranspiração do nível de água varia linearmente com elevação do nível de água.

\section{Caminhamento das partículas (MODPATH)}

A tela [Particles] é utilizada quando se quer verificar o caminhamento de uma ou mais partículas. Por exemplo: marcando-se uma linha onde existe alguma fonte de poluentes e também marcando-se aos poços nas imediações da área, pode-se verificar se os poços estão bombeando a água da fonte de poluentes ou simplesmente para onde caminham as partículas.

O MODPATH usa um esquema semi - analítico para localizar a partícula. O método está baseado na suposição que cada componente de velocidade direcional varia 
linearmente dentro de uma célula da malha em sua própria direção de coordenada. Esta suposição permite obter uma expressão analítica descrevendo o caminho de fluxo dentro da células da grade. Dado a posição inicial de uma partícula em qualquer lugar em uma célula, as coordenadas de qualquer outro ponto ao longo de sua linha de caminho dentro da célula, e o tempo de viagem pode ser computado (MATSUZAKI, 1998).

\section{Calibração}

A tela [Calibrate] é utilizada para adicionar valores conhecidos de campo.

Quando adiciona-se um ponto de observação, uma nova janela irá surgir, nesta inseri-se a locação do ponto de observação, o nome, a partir de que tempo deve ser observado e a carga conhecida.

\section{Zona de Balanço (Zone Budget)}

O balanço de massas é feito célula por célula ou em sub - domínios separados de acordo com o interesse do usuário.

\section{MT3D}

O MT3D é um modelo de computador para simular a advecção, dispersão e as reações de substância química de contaminantes em sistemas de Fluxo Tridimensional de água subsuperficial. O modelo foi projetado para ser utilizado no mesmo modulo do Modelo de Fluxo de diferença finita MODFLOW. O MT3D usa uma mistura de Eulerian-Lagrang e aproxima à solução da equação de advecção - dispersão, baseado em uma combinação do método de características (MOC) e no método modificado de características (MMOC).

\section{Entrada de Dados no MT3D ("Input")}

Os botões de "Input" do MT3D da tela é acessado quando é selecionado o [MT3D] da barra de "Menu" de topo no módulo "Input". Esta tela contém os seguintes itens de "Menu":

File - Conc Inicial. - Boundarys - Calibrate - Dispersion - Chem. Reação - Flow - Help 


\section{Concentração inicial}

Ao entrar na tela de MT3D pela primeira vez pede-se uma concentração inicial (background) para todas as células, esta pode ser zero.

\section{Limites}

No módulo MT3D a condição de limite é usada para fixar as mudança de transporte. Os tipos de condições de limite permitidos pelo MT3D são: concentração constante; concentração de recarga; concentração de evapotranspiração; e concentração do aponte da fonte - "Point Source".

\section{Calibração}

Podem ser adicionados poços de observação com dados de concentração em relação ao tempo em uma localização específica (células). As concentrações observadas são comparadas com as concentrações calculadas e ajudam na calibração do modelo. O modelo salva os valores de concentração para cada intervalo de tempo de transporte.

\section{Dispersão}

Depois de selecionar [Dispersion] pela primeira vez, do "Menu" de topo entra-se nos itens: "Dispersivity Longitudinal", "Horizontal Longitudinal Ratio" e "Vertical to Longitudinal Ratio" para todo o domínio, estes dados iniciais podem ser modificados posteriormente. A dispersividade longitudinal especifica é uma característica do tipo de solo, relacionado à tortuosidade dos poros interconectados. O MT3D requer que a dispersividade horizontal transversal (largura de pluma) e vertical transversal (espessura da pluma) sejam determinadas em relação a dispersividade longitudinal.

\section{Reações químicas}

Esta opção de Menu é usada para especificar os parâmetros de reação químicos usados por MT3D. O MT3D permitem sorção do contaminante e decaimento (radioativo ou biológico) do soluto dissolvido e a fase sorbida. O MT3D também permite escolher o tipo de isoterma de sorção (linear, Freundlich, ou Langmuir), especificando as constantes que definem a isoterma. 


\section{CAPÍTULO V - Características Gerais da área}

\section{Aspectos Globais}

A área estudada situa-se nas coordenadas geográficas $46^{\circ} 34^{\prime} 00^{\prime \prime}$ de longitude Oeste e $21^{\circ} 53^{\prime} 00^{\prime \prime}$ de latitude Sul, a cerca de $200 \mathrm{~m}$ da margem direita do córrego do Retiro dos Moinhos e do lado esquerdo da Rodovia BR-146, considerando-se o sentido Poços de Caldas - Andradas, sua localização pode ser visualizada na Figura 17. Inseri-se no contexto geológico-geomorfológico do Maciço Alcalino de Poços de Caldas, no extremo sul do Estado de Minas Gerais.

O Maciço Alcalino de Poços de Caldas está circunscrito pelas coordenadas geográficas $21^{\circ} 49^{\prime}-22^{\circ} 02^{\prime}$ de latitude Sul e $46^{\circ} 42^{\prime}-46^{\circ} 24^{\prime}$ de longitude Oeste, abrangendo terras dos municípios mineiros de Poços de Caldas, Caldas, Santa Rita de Caldas e Ibitiúra de Minas, além do município paulista de Águas da Prata. 


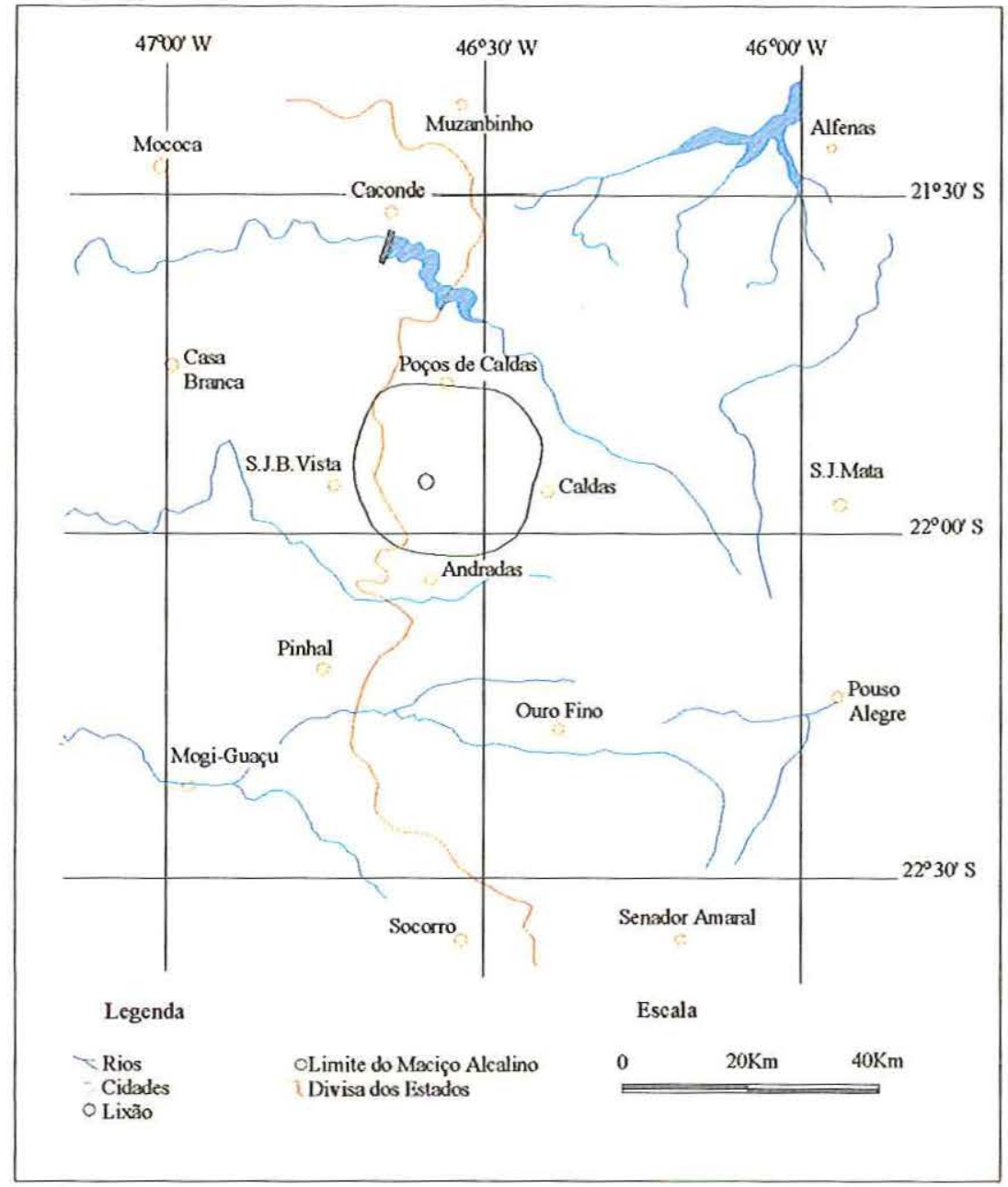

FIGURA 17 - Mapa de Localização da Área de Interesse

(Fonte: Modificado de LIPORACI, 1996)

\section{Clima}

O clima da região, segundo critérios de Köppen é do tipo Cwb, situando-se entre o grupo $\mathrm{A}$, dos climas tropicais quentes e o grupo $\mathrm{C}$ dos mesotérmicos com inverno seco e verão chuvoso. Segundo MINAS GERAIS, Secretaria de Ciências e tecnologia (1987) apud LAGE FILHO (1996), o clima no município apresenta as seguintes características:

•Precipitação Média Anual: 1.700mm;

-Temperatura Média Anual: $18^{\circ} \mathrm{C}$;

-Temperatura Mínima Média: $12,5^{\circ} \mathrm{C}$;

-Temperatura Máxima Média: $24,5^{\circ} \mathrm{C}$; 
-Umidade Relativa Média Anual: 76.5\%;

-Evapotranspiração Potencial Média Anual: $850 \mathrm{~mm}$; e

-Direção Preferenciais dos Ventos: N-NE.

Os ventos são moderados, de direção NE-SW e velocidade de 10 a $15 \mathrm{Km} / \mathrm{h}$, podendo variar devido à entrada de frentes frias no Planalto de Poços de Caldas e se inverter passando para SW-NE. As temperaturas mínimas e máximas já registradas foram $-6^{\circ} \mathrm{C}$ e $31.7^{\circ} \mathrm{C}$, respectivamente.

\section{Cobertura Vegetal}

Segundo LAGE (1996), o planalto de Poços de Caldas abriga formações vegetais bastante diversificadas, sendo a mais importante a Floresta Atlântica Subperenifólia, também denominada Floresta Semi-decídua que é constituída por espécies vegetais perenifólias entre outras. No extrato dominante, as plantas apresentam alturas entre 20 e 25 metros, alcançando, raramente, até 35 metros de altura.

\section{Aspectos Geomorfológicos}

Segundo CHRISTOFOLETTI (1970), o Planalto de Poços de Caldas está localizado na borda ocidental da Serra da Mantiqueira e em contato com os extremos orientais da Bacia Sedimentar do Paraná, formando um conjunto morfo-estrutural complexo e distinto.

O Maciço Alcalino de Poços de Caldas destaca-se como marcada feição positiva entre as rochas do embasamento da região oriental do Bloco de Pinhal. Tem forma subcircular, com diâmetro N-S da ordem de $33 \mathrm{Km}$ e E-W com $31 \mathrm{Km}$. Para SW, o contorno se desvia do padrão subcircular para formar característico abaulamento que constitui a chamada "estrutura de Água da Prata", considerada subsidiária da principal, conforme ULBRICH (1984).

O maciço encontra-se emoldurado por forte ressalto ou "Anel" topográfico, a $\mathrm{N} \mathrm{e} \mathrm{a}$ W e em parte do seu contorno meridional, com cotas variando de $1.400 \mathrm{~m}$ a $1.650 \mathrm{~m}$, os desníveis em relação às rochas encaixantes, pertencentes ao embasamento cristalino atingem 400 a $700 \mathrm{~m}$. 
Na parte interna dos anéis topográficos ocorre uma depressão, substituída mais para o centro do maciço por paisagens de morros em forma de meia laranja ou alongadas, com vertentes íngremes às vezes suavizadas e pequenas colinas ou colinas amplas em forma de meia laranja ou alongadas, com encostas íngremes ou suavizadas; nesta área predominam cotas entre 1.300-1.550m, enquanto que nos vales em V ou em U (amplas planícies aluvionares) as altitudes descem para $1.100-1.300 \mathrm{~m}$.

Predominam feições de relevo como morros alongados, colinas amplas e suaves, escarpas e feições do tipo mesa. O relevo é principalmente resultado do abatimento da cratera vulcânica associada as condições climáticas, apresentando feições bem variadas e diversificadas quanto analisadas em escalas locais.

\section{Geologia Regional - Modelos Geológicos}

O resumo da sequiência dos eventos que embasaram os modelos da origem propostos para o Maciço Alcalino de Poços de Caldas é apresentado na Tabela 3.

ELLERT (1959) apud LIPORACI (1996), propôs um modelo de gigantesca cratera vulcânica, que sofreu abatimento central, em que as serras circundantes seriam os vestígios do cone vulcânico; os demais autores tentam confirmar ou rejeitar este modelo. As relações de idade entre os vários eventos são as questões mais polêmicas, principalmente no que se refere às características dos corpos de nefelina sienitos, reconhecimento e definição das manifestações piroclásticas e das rochas sedimentares. 
TABELA $3 *$ - Sequiência de eventos dos modelos. Modificado de Garda (1990), Ulbrich \& Ulbrich (1992) apud LIPORACI (1996).

\begin{tabular}{|c|c|c|c|}
\hline Ellert (1959) & Fraenkel et al (1985) & $\begin{array}{c}\text { Motoki \& Oliveira } \\
\text { (1987) Motoki et al } \\
\text { (1988) }\end{array}$ & $\begin{array}{c}\text { Ulbrich (1984), Ulbrich \& } \\
\text { Ulbrich (1992) }\end{array}$ \\
\hline $\begin{array}{l}\text { Formação de diques } \\
\text { anelares, } \\
\text { concomitantes com } \\
\text { cristalização de rocha } \\
\text { fina. }\end{array}$ & $\begin{array}{l}\text { Intrusões de lujauritos } \\
\text { chibinitos e foiaítos, } \\
\text { atividade hidrotermal } \\
\text { (brechamento, ação águas } \\
\text { termais etc). } \\
\text { Formação de diques } \\
\text { anelares. }\end{array}$ & $\begin{array}{l}\text { Brechamento tardio } \\
\text { (faixa piroclásticas do } \\
\text { Vale do Quartel; vários } \\
\text { condutos etc). }\end{array}$ & $\begin{array}{l}\text { Vários brechamentos } \\
\text { tardio (piroclásticos de } \\
\text { conduto e supracrustais); } \\
\text { alteração hidrotermal e } \\
\text { mineralizações. } \\
\text { Intrusões de pseudoleucita } \\
\text { fonolitos e fonolito } \\
\text { tardios. }\end{array}$ \\
\hline $\begin{array}{l}\text { Cristalização de } \\
\text { tinguaítos, fonolitos e } \\
\text { foiaítos centrais, } \\
\text { superposição de } \\
\text { eventos; linha anterior } \\
\text { e posterior da coluna. }\end{array}$ & $\begin{array}{l}\text { Segunda fase de } \\
\text { soerguimento com } \\
\text { invasão de tinguaítos e } \\
\text { foiaítos centrais. }\end{array}$ & $\begin{array}{l}\text { Em parte, intrusão de } \\
\text { nefelina sienitos. }\end{array}$ & $\begin{array}{l}\text { Intrusão de nefelina } \\
\text { sienitos diferenciados e } \\
\text { não diferenciados. }\end{array}$ \\
\hline $\begin{array}{l}\text { Subsidência da parte } \\
\text { central e intrusão de } \\
\text { tinguaítos etc. }\end{array}$ & $\begin{array}{l}\text { Subsidência central, com } \\
\text { reajustes graduais, } \\
\text { brechamento e } \\
\text { milonização. }\end{array}$ & $\begin{array}{l}\text { Intrusões de fonolitos e } \\
\text { cristalização de nefelina } \\
\text { sienitos. }\end{array}$ & $\begin{array}{l}\text { Intrusão subvulcânica de } \\
\text { egerina fonolitos e } \\
\text { fonolitos porfiríticos, } \\
\text { formando-se também os } \\
\text { anéis topográficos. }\end{array}$ \\
\hline $\begin{array}{l}\text { Atividade vulcânica } \\
\text { inicial (lavas e } \\
\text { piroclásticas } \\
\text { intercaladas), derrames } \\
\text { fonolíticos a sul. }\end{array}$ & $\begin{array}{l}\text { Longo período de } \\
\text { atividade vulcânica - } \\
\text { piroclástica (lavas, } \\
\text { brechas, tufos etc). }\end{array}$ & & $\begin{array}{l}\text { Rochas piroclásticas e } \\
\text { derrames (Vale do Quartel } \\
\text { e Represa Bortolan). }\end{array}$ \\
\hline $\begin{array}{l}\text { Levantamento do } \\
\text { embasamento, falhas } \\
\text { escalonadas, Arenitos } \\
\text { Botucatu. }\end{array}$ & $\begin{array}{l}\text { Soerguimento do } \\
\text { embasamento e } \\
\text { sedimentos, formação de } \\
\text { falhamentos escalonados. }\end{array}$ & $\begin{array}{l}\text { Arenitos Botucatu e } \\
\text { Corumbataí. }\end{array}$ & $\begin{array}{l}\text { Não prevê domeamentos. } \\
\text { Arenitos Botucatu com } \\
\text { siltitos laminados. }\end{array}$ \\
\hline
\end{tabular}

* Em cada coluna foi utilizada a nomenclatura original do autor, no sentido base-topo, a seqüência dos eventos grada do mais antigo para o mais recente. Não há necessariamente correlação no sentido horizontal entre as colunas. 
A Figura 18 representa o Mapa Geológico do Maciço Alcalino de Poços de Caldas.
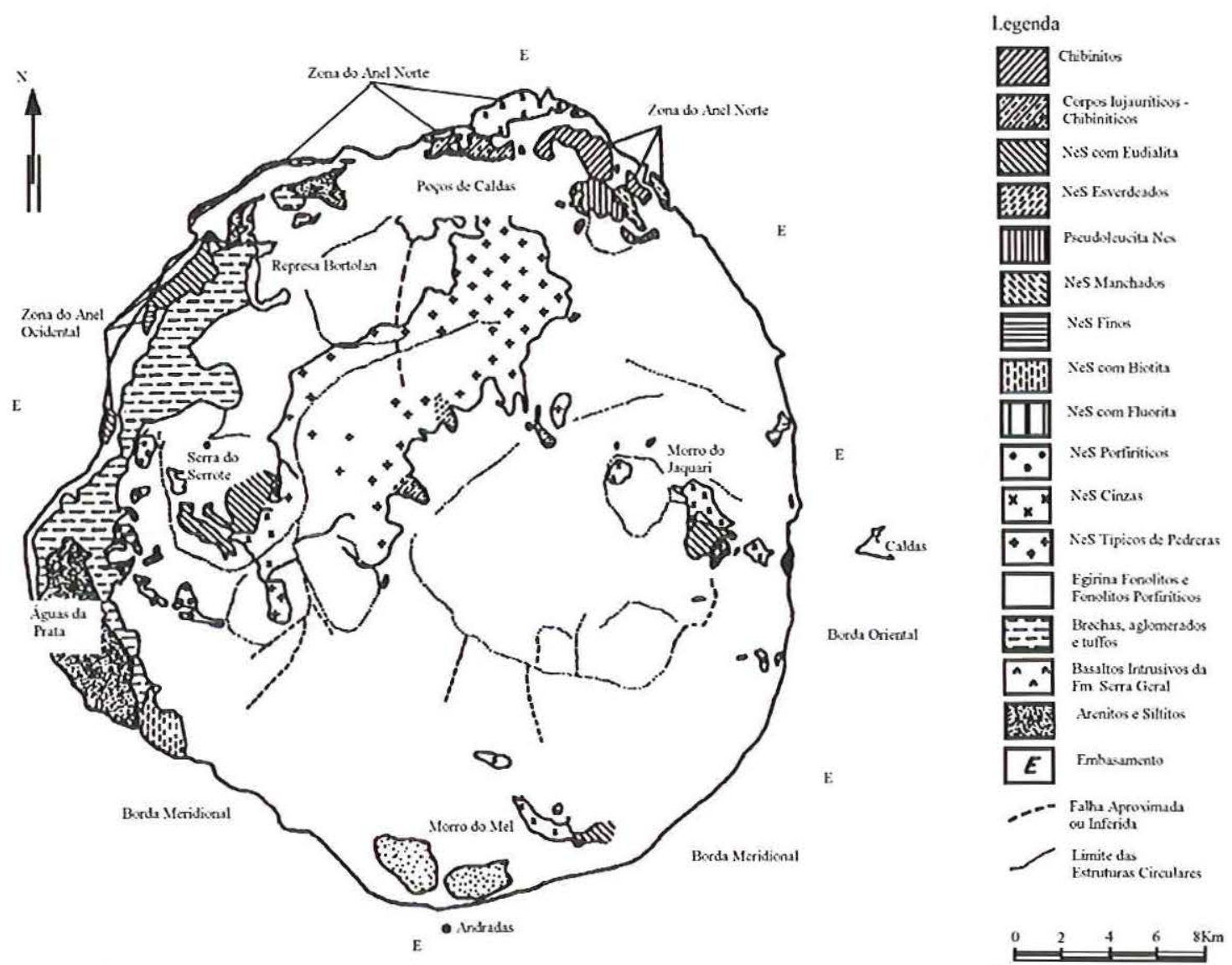

FIGURA 18 - Mapa Geológico do Maciço Alcalino de Poços de Caldas (Fonte: LIPORACI, 1996).

\subsection{Estruturas do Maciço Alcalino de Poços de Caldas}

Em termos regionais, conforme ALMEIDA FILHO \& PARADELLA (1977) através do estudo de imagens de satélite, podem ser destacados como o embasamento cristalino circunvizinho e a Bacia do Paraná. Os autores admitiram que os lineamentos interpretados como falhas de direção $N 70^{\circ}-80^{\circ} \mathrm{E}$, com extensões superiores a $100 \mathrm{Km}$, foram os que desempenharam papel mais importante no modelamento dos grandes traços de relevo da área e que o maciço alcalino se alojou em uma zona de fraqueza marcada pelo cruzamento de diversas falhas.

Com referência específica ao planalto, ALMEIDA FILHO \& PARADELLA (1977) demarcaram diversos lineamentos estruturais e algumas estruturas de conformação anelar. 
As extensas descontinuidades, bem como o intenso fraturamento de pequena extensão que está evidente nas rochas do interior do maciço, é segundo CETEC (1987) e confirmado por ETCHEBEHERE (1990) o principal fator que condiciona a recarga do aquiífero, bem como funcionam como caminhos preferenciais para o afloramento das fontes de águas frias e termais de Poços de Caldas.

\section{Hidrografia}

Segundo LAGE (1996) a principal bacia hidrográfica do Planalto de Poços de Caldas é a Bacia Hidrográfica do Ribeirão das Antas, às vezes citado como Rio das Antas. Alguns dados obtidos através da análise das bacias hidrográficas do Planalto de Poços de Caldas, por CHRISTOFOLLETI (1973), estão apresentadas na Tabela 4:

TABELA 4 - Dados sobre as bacias hidrográficas do Planalto de Poços de Caldas.

\begin{tabular}{|l|l|l|l|l|l|}
\hline Bacias Hidrográficas & Área $\left(\mathrm{Km}^{2}\right)$ & $\begin{array}{l}\text { Número de } \\
\text { rios }\end{array}$ & $\begin{array}{l}\text { Comprim. } \\
\text { Total }(\mathrm{Km})\end{array}$ & $\begin{array}{l}\text { Densid. } \\
\text { Hidrog. } \\
\left(\text { canais/Km }{ }^{2}\right)\end{array}$ & $\begin{array}{l}\text { Densid. } \\
\left(\mathrm{Km} / \mathrm{Km}^{2}\right)\end{array}$ \\
\hline Rio das Antas & 423.0 & 517 & 682.9 & 1.2 & 1.614 \\
\hline Rio Verde & 213.4 & 428 & 449.3 & 2.0 & 2.104 \\
\hline Córrego do Quartel & 66.7 & 146 & 138.2 & 2.2 & 2.071 \\
\hline Córrego P. Alegre & 103.7 & 162 & 165.3 & 1.5 & 1.593 \\
\hline Córrego Cachoeira & 16.9 & 16 & 25.0 & 0.9 & 1.478 \\
\hline Córrego das vargens & 35.1 & 51 & 62.8 & 1.4 & 1.790 \\
\hline Rio Verdinho & 54.3 & 131 & 143.6 & 2.3 & 2.644 \\
\hline Córrego Tamanduá & 22.4 & 29 & 37.8 & 1.3 & 1.719 \\
\hline Córrego Quartel* & 34.2 & 95 & 78.7 & 2.7 & 2.300 \\
\hline Córrego Grande & 68.9 & 66 & 98.1 & 0.9 & 1.425 \\
\hline
\end{tabular}

* Neste caso, refere-se à bacia do córrego do Quartel sobre rochas vulcânicas.

Os estudos sobre a densidade hidrográfica e da densidade de drenagens demonstra a importância assumida pelos diferentes tipos litológicos, bem como aos eventos geológicos que determinaram as estruturas circulares de origem e posicionamento destas rochas. Considera-se que a densidade hidrográfica representa a relação entre número de rios por unidade de área e a densidade de drenagem representa o comprimento dos canais por unidade de área. 


\subsection{Recursos Hídricos Superficiais}

O Ribeirão das Antas nasce a sul do planalto (altitude $1.400 \mathrm{~m}$ ), percorre $55 \mathrm{Km}$ dentro do planalto, saindo do mesmo a norte (altitude $1.180 \mathrm{~m}$ ) no local denominado de Cascata das Antas. A área total desta bacia é de $423 \mathrm{Km}^{2}$, sendo que o curso deste ribeirão é meandrante, com ampla planície de inundação.

Os principais afluentes da margem esquerda são: o Ribeirão do Cipó, os Córregos das Amoras e do Chiqueirão; já os da margem direita são: Córregos do Pilão e o do Retiro dos Moinhos, ressaltam-se ainda o Ribeirão das Vargens, o da Ponte Alta e o da Serra, os dois últimos após confluírem passam a se denominar Ribeirão dos Poços, o qual deságua no Ribeirão das Antas, logo à montante da Cascata das Antas. A drenagem apresenta tendência por padrões de drenagem dentríticos, pinados e treliças.

A Bacia do Ribeirão dos Poços drena a totalidade da área urbana de Poços de Caldas (MG), podendo-se destacar os seus afluentes pela margem esquerda, que são: Ribeirão da Ponte Alta e o Córrego do Vai e Volta, considerados como maior zona de recarga do aqüífero que alimenta as fontes frias e termais.

As características da Bacia Hidrográfica do Ribeirão das Antas, segundo CHRISTOFOLETTI (1970) são:

* Índice de Circularidade: 0.38;

* Declividade Média: $4.0 \mathrm{~m} / \mathrm{Km}$;

* Densidade Hidrográfica: 1.22 canais $/ \mathrm{Km}^{2}$; e

* Densidade de Drenagens: $1.62 \mathrm{Km} / \mathrm{Km}^{2}$.

O índice de circularidade de uma bacia tem valor máximo igual a 1 , quando o perímetro da bacia se aproxima de um círculo, quanto mais próximo a 1 , significa que as águas pluviais que atingem a bacia poderão se escoar mais rapidamente para o centro desta bacia, podendo provocar inundações. A Tabela 5 apresenta as características e as composições das águas superficiais e das fontes de circulação superficial. 
TABELA 5: Características e Composição das Águas Superficiais (AS) e das Fontes de Circulação Superficial (FCS) em mg/l. Modificado de CETEC (1987) apud LAGE (1996).

\begin{tabular}{|c|c|c|c|c|}
\hline \multirow{2}{*}{$\begin{array}{c}\text { Atributos } \\
\text { Característicos Analisados }\end{array}$} & \multicolumn{2}{|c|}{ Valores Mínimos } & \multicolumn{2}{|c|}{ Valores Máximos } \\
\hline & AS & FCS & AS & FCS \\
\hline Temperatura $\left({ }^{\circ} \mathrm{C}\right)$ & - & 18.4 & - & 24.5 \\
\hline $\mathrm{pH}$ & 6.2 & 5.4 & 7.4 & 6.9 \\
\hline Condutividade $\mathrm{em} \mu \mathrm{mho} / \mathrm{cm}$ & 10.50 & 10.0 & 60.0 & 105.5 \\
\hline Resíduo Seco & 4.26 & - & 27.2 & - \\
\hline Dureza em mg/lCaCO 3 & 2.0 & - & 34.0 & - \\
\hline $\mathrm{Ca}++$ & 0.16 & 0.40 & 8.0 & 10.80 \\
\hline $\mathrm{Mg}++$ & 0.13 & 0.20 & 3.36 & 0.92 \\
\hline $\mathrm{Na}^{+}$ & 0.26 & 0.80 & 0.91 & 7.50 \\
\hline $\mathrm{K}+$ & 1.19 & 0.80 & 2.27 & 6.50 \\
\hline $\mathrm{HCO}_{3-}^{-}$ & 6.10 & 6.10 & 18.30 & 34.70 \\
\hline $\mathrm{CO}_{3--}$ & - & - & - & - \\
\hline $\mathrm{Cl}-$ & 0.70 & 0.40 & 5.0 & 9.0 \\
\hline $\mathrm{SO}_{4^{--}}$ & - & 0.5 & - & 1.20 \\
\hline Fe Total & 0.11 & - & 2.0 & - \\
\hline F- & 0.10 & 0.08 & 1.41 & 0.38 \\
\hline
\end{tabular}

\section{2. Águas Subsuperficiais}

A utilização de águas subsuperficiais através de poços tubulares, no município de Poços de Caldas (MG), é ainda muito baixa e restrita à zona urbana. Nesta região só a partir de 1980, com o aumento da demanda de água provocada sobretudo pela implantação de indústrias e expansão de vilas e conjuntos habitacionais, é que o abastecimento através de poços tubulares tornou-se imperativo.

Conforme mapeamentos estruturais realizados pela NUCLEBRAS (1975), CETEC (1987) e ETCHEBEHERE (1990) e ETCHEBEHERE et al.(1992), foram detectados lineamentos estruturais de grande extensões com direções médias de $\mathrm{N} 30^{\circ}$ e $60^{\circ} \mathrm{E}$ e $\mathrm{N} 30^{\circ}-$ 
$60^{\circ} \mathrm{W}$. Além destas direções existem os fraturamentos de pequena extensão (menor que $2 \mathrm{Km}$ ) com direções preferenciais $\mathrm{N} 10^{\circ}-20^{\circ} \mathrm{E}$ e $\mathrm{N} 40^{\circ}-50^{\circ} \mathrm{W}$, estas fraturas de pequena extensão predominam com uma freqüiência de $75 \%$ em relação aos de grande extensão.

Segundo LIPORACI (1996), na Bacia do Ribeirão das Antas, as drenagens obedecem um forte controle estrutural determinado pelas direções citadas anteriormente. O alto curso do Antas acompanha as direções preferenciais $\mathrm{N} 30^{\circ}-60^{\circ} \mathrm{W}$, sendo que o baixo Antas, Ribeirão do Cipó e Córrego do Vai e Volta mostram-se controlados pelas fraturas de direções $\mathrm{N} 10^{\circ}-20^{\circ} \mathrm{E}$, já o curso do Ribeirão dos Poços está alinhado na direção E-W.

Uma efetiva circulação das águas subsuperficiais na Bacia do Ribeirão do Antas, é evidenciada pela quantidade de fontes frias e nascentes, localizadas nas cabeceiras das drenagens. Quase todos os afluentes do Ribeirão das Antas têm suas nascentes alimentadas por fontes, provenientes da surgência das águas subsuperficiais. A maioria das cabeceiras de drenagens associadas às direções de fraturas é alimentada por fontes difusas ou nascentes de vazões variáveis, a maioria de regime permanente.

A origem das águas termais está relacionada, segundo CETEC (1987) apud LAGE (1996) a um extenso e profundo sistema de fraturas abertas e detectadas em imagens e fotografias aéreas e confirmadas em campo, onde se observa pelo menos 3 direções preferenciais: $\mathrm{E}-\mathrm{W} ; \mathrm{N} 50^{\circ} \mathrm{E}$ e N $14^{\circ} \mathrm{E}$. A direção E - W coincide com o curso do Ribeirão dos Poços e se interconecta com outras fraturas secundárias em direção à Serra de São Domingos, que constituí uma zona de recarga.

As outras duas direções $\mathrm{N} 50^{\circ} \mathrm{E}$ e $\mathrm{N} 14^{\circ} \mathrm{E}$ estendem-se desde a Serra de São Domingos ao Norte, até o vale do Ribeirão das Vargens, a sul; todo o leito do Ribeirão Vai e Volta é encaixado e controlado por uma destas fraturas $\left(\mathrm{N} 14^{\circ} \mathrm{E}\right)$, devendo constituir uma zona preferencial de recarga, que se estende até o ribeirão das Vargens, com o qual se comunica através de fraturas secundárias.

\section{Pedologia}

Os solos da região do Planalto de Poços de Caldas são classificados como latossolos vermelho - amarelos e vermelhos escuros distróficos, cambissolos distróficos, terras bruno estruturadas e podzólicos vermelho - amarelados, todos álicos com baixa capacidade de troca catiônica (CAVALCANTE et al., 1979; BRASIL, Ministério das Minas e Energias, 1983; MINAS GERAIS, Secretaria de Ciências e Tecnologia, 1983 apud LIPORACI, 1996). 
Nas cotas mais baixas ocorrem os solos turfo argilosos, classificados por BRASIL, Ministério das Minas e Energia (1983) apud LIPORACI (1996) como glei húmicos a pouco húmicos. São pouco desenvolvidos devido ao ambiente anaeróbico, redutor e fruto de gleização holocênica. A drenagem imperfeita e a estrutura maciça desse solo faz com que aflore o lençol freático. Este solo hidromórfico é geralmente coberto por gramíneas e, próximo aos cursos d'água, por mata ou vegetação higrófila. 


\section{CAPÍTULO VI - Dados Coletados}

\section{Características da área}

\subsection{Topografia}

A Figura 19 representa o mapa topográfico da região com curvas de nível eqüidistantes de $10 \mathrm{~m}$, este documento foi feito com base no mapa 1:10.000 elaborado pela prefeitura de Poços de Caldas. Este mapa trás as principais drenagens da área e a localização do lixão.

\subsection{Substrato Rochoso}

As rochas que compõem o substrato, onde se insere a bacia hidrográfica do Ribeirão das Antas, como mostra a Figura 20 (Fonte: Prefeitura do Município de Poços de Caldas, 1997), são essencialmente nefelina - sienitos e fonolitos.

\section{Descrição dos tipos Litológicos}

Os termos fonolitos e nefelina sienitos identificam, respectivamente, as rochas vulcânicas a subvulcânicas e plutônicas do campo 11 da classificação de rochas ígneas propostas pelo Comitê petrográfico da IUGS. Devido aos diferentes modos de ocorrência, apesar de possuírem a mesma composição mineralógica, estas duas rochas apresentam perfis de alteração muito distintos e comportamentos geotécnicos bastante diferenciados. 
FIGURA 19 - Mapa Topográfico 
NÃO LOCALIZADO NO EXEMPLAR IMPRESSO 
FIGURA 20 - Mapa do Substrato Rochoso 


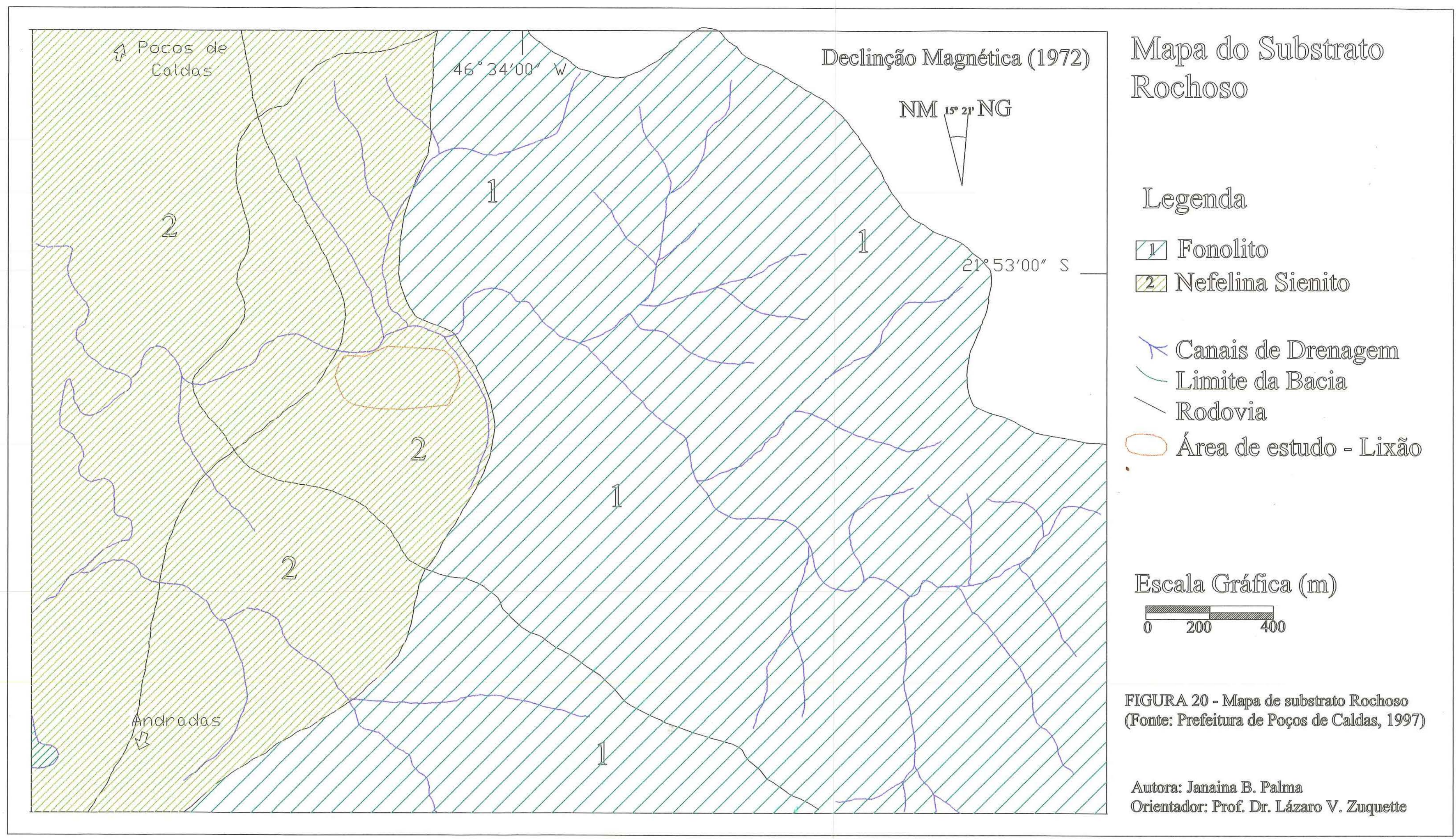


Rochas vulcânicas a Subvulcânicas: Estas rochas representadas pelos fonolitos, predominam na área. Do ponto de vista petrográfico, podem ocorrer os egerina fonolitos, fonolitos porfiríticos e pseudoleucita fonolitos.

A textura dos fonolitos vária de afanítica até fanerítica fina ou, raramente fina média. As variações com textura fina ou fina - média, seriam os tradicionalmente chamados "tinguaítos". Na maioria dos locais onde afloram os fonolitos, o relevo é acidentado (serras com altitudes de até $1.640 \mathrm{~m}$ e morros com altitudes variando entre $1.350 \mathrm{~m}$ até $1.500 \mathrm{~m}$ ), com declividades entre $10 \%$ e $20 \%$ ou maiores que $20 \%$, chegando a ser até maiores que $30 \%$.

Na área: Fonolitos: São variados, porém predominam os egerina-fonolitos, fonolitos-porfiros e pseudoleucita - fonolitos, com coloração variando de cinza esverdeado a preto. Mineralogicamente são constituídos por nefelina e as vezes analcima e sodalita, podendo predominar ainda as pseudoleucitas; os piroxênios ocorrem em porcentagens que podem atingir até $20 \%$ e os anfibólios são menos freqüentes. Os fonolitos são muito fraturados com descontinuidades oriundas do resfriamento do magma e condicionadas pela estrutura fluidas e tectônica. As juntas e fraturas decorrentes são verticais e sub-verticais com direções geológicas NE, EW e NS. Estas descontinuidades podem ser facilmente observadas em afloramentos e/ou fotos aéreas.

\section{Rochas Plutônicas:}

Nefelina Sienitos: Apresentam estrutura maciça, leucográficos, sendo constituídos quase exclusivamente por feldspato potássico e nefelina. O piroxênio (muito raramente acompanhado por biotita) aparece em pequenas proporções, são raras as rochas com mais de $10 \%$ de minerais máficos, muitos são hololeucográficos.

Os nefelinas sienitos apresentam um perfil de alteração típico, ou seja, superficialmente uma fina camada de colúvio $(0.10 \mathrm{~m}$ a $0.60 \mathrm{~m})$, constituída por concreções lateríticas envoltas em solo argilo-siltoso marrom avermelhado a acinzentado. Logo abaixo deste horizonte de solo transportado, encontra-se uma camada de solo residual (laterizado ou não), textura argilo-siltosa de coloração amarelo clara a esbranquiçada e/ou rosada. Abaixo deste horizonte residual aparece um solo saprolítico de textura também argilo-siltosa, coloração semelhante à do solo residual, envolvendo blocos e matacões métricas de rocha parcialmente intemperizadas e/ou sã, com formas arredondadas. 
$\mathrm{Na}$ área: Nefelina-Sienitos: Estes litotipos de coloração acinzentada são constituídos predominantemente por nefelina e ortoclasios, os minerais máficos (piroxenios, biotitas e acessórios) atingem no máximo $10 \%$. Na região onde os nefelina-sienitos ocorrem os perfis de alteração podem apresentar matacões com dimensões que perfazem até $100 \mathrm{~m}^{3}$.

\subsection{Materiais Inconsolidados}

De acordo com a proposta da Geological Society (1995), os materiais presentes na área podem ser classificados em 4 tipos, representados na Figura 21 (Fonte: Prefeitura do Município de Poços de Caldas, 1997).

\section{Tipo 1: Retrabalhado}

Este pacote esta associado aos talveques dos principais canais de drenagem, sendo constituído pela seguinte seqüência:

$\checkmark$ Retrabalhado: representado por aluviões e colúvios e em alguns locais com características de talus.

$\checkmark$ Residual: material oriundo da alteração das rochas, quase totalmente modificado, com raros blocos de rocha.

$\checkmark$ Reliquiar: material residual que mantém as características das rochas de forma reliquiar.

$\checkmark$ Rocha Alterada: As características da rocha são mantidas e as descontinuidades isolam muitos blocos.

$\checkmark$ Rocha Sã: Níveis de alteração insignificantes a não existentes.

A principal característica deste pacote é a ocorrência da porção superior retrabalhada, a denominação genética mais adequada do tipo 1 é o termo retrabalhado.

\section{Tipo 2: Reliquiar}

Este pacote, sobreposto aos materiais rochosos alterados, apresenta espessuras que podem chegar até $10 \mathrm{~m}$. Entre os dois materiais existe uma descontinuidade geotécnica importante. 
FIGURA 21 - Mapa do Material Inconsolidado 
NÃO LOCALIZADO NO EXEMPLAR IMPRESSO 


\section{Tipo 3: Residual / Reliquiar}

É constituído por um conjunto de materiais inconsolidados com grau de heterogeneidade alta, conforme esquema:.

$\checkmark$ Residual: material oriundo da alteração das rochas, quase totalmente modificado, com raros blocos de rocha.

$\checkmark$ Reliquiar: material residual que mantém as características das rochas de forma Reliquiar.

$\checkmark$ Rocha Alterada: As características da rocha são mantidas e as descontinuidades isolam muitos blocos.

\section{Tipo 4:}

A principal característica deste pacote é a porção superior ser um aterro. Este tipo ocorre nas áreas onde foi explorado o minério de alumínio (bauxita), as cavas decorrentes desse processo foram aterradas com blocos e materiais inconsolidados não aproveitados como minério ou importados de outras áreas.

$\checkmark$ Aterro - constituído basicamente por blocos e materiais inconsolidados.

$\checkmark$ Reliquiar - material residual que mantém as características das rochas de forma Reliquiar.

$\checkmark$ Rocha Alterada - As características da rocha são mantidas e as descontinuidades isolam muitos blocos.

\section{4 - Ensaios Laboratoriais}

Do Relatório da Prefeitura de Poços de Caldas (1997), obteve-se dados dos seguintes ensaios laboratoriais:

1) Analise granulométrica conjunta;

2) Ensaio de proctor normal;

3) $\mathrm{pH} \mathrm{em} \mathrm{H}_{2} \mathrm{O}$ e pH KCl;

4) Capacidade de troca catiônica;

5) Superfície especifica.

Estes ensaios realizados em amostras de materiais retirados a cada $50 \mathrm{~cm}$ até a profundidade de $11 \mathrm{~m}$ revelaram valores predominantes de $\mathrm{pH}$ entre 6 e 8 , capacidade de 
troca catiônica inferiores a $5 \mathrm{meq} / 100 \mathrm{~g}$ de material, superfície especifica $<50 \mathrm{~m}^{2} / \mathrm{g}$. A textura dos materiais é argilo-silto-arenosa para os 2 metros superiores e tipicamente siltoarenosa para os materiais coletados a profundidades maiores que $2 \mathrm{~m}$.

Os ensaios foram executados segundo as propostas metodológicas da ABNT, ASTM e PEJON (1992).

\section{5 - Sondagens Geofísicas}

A área é parte de uma tese com enfoque geofísico realizada na Unesp, de Rio Claro por ELIS (1999). Os ensaios foram executados em outubro de 1995 e setembro de 1997 e são descritos abaixo:

$\checkmark 6$ linhas de caminhamento elétrico dipolo-dipolo com espaçamento 10 metros, denominadas de $\mathrm{Cl}$ a $\mathrm{C} 6$;

$\checkmark$ Repetição, em dois períodos diferentes, das linhas C3 e C4; 10 sondagens elétricas verticais arranjo Schlumberger, com $\mathrm{AB}$ máximo de 300 metros, denominadas de SEV1 a SEV10;

$\checkmark 2$ sondagens dipolares axiais, com abertura n mínima de 90 metros, denominadas de SD11 e SD12;

$\checkmark 2$ linhas de caminhamento elétrico dipolo-dipolo com espaçamentos de 5 e de 20 metros, denominadas de $\mathrm{C} 4$ e $\mathrm{C} 7$ (a linha $\mathrm{C} 4$ é a mesma para o arranjo com espaçamento de 10 metros).

A localização desses ensaios na área em estudo é apresentada na Figura 22. Os resultados das SEVs possibilitaram a elaboração do mapa de fluxo subsuperficial, além da definição da espessura dos resíduos dispostos e dos diversos estratos existentes. Para essa área, as sondagens executadas podem ser divididas também em dois grupos: o primeiro representado pelos ensaios executados fora da área utilizada para disposição dos resíduos, e o segundo representado pelos ensaios da área de resíduos. Pelas SEVs do primeiro grupo foram obtidos a profundidade do nível d'água e das camadas da transição solo - rocha (ELIS, 1999).

As SEVs do segundo grupo definiram a camada de resíduos, com resistividades entre 5,6 e 11,2 ohm.m e cerca de 9 metros de espessura, uma camada com resistividades entre 25 e $87 \mathrm{ohm} . \mathrm{m}$, interpretada como solo saturado na base do aterro e uma camada de alta resistividade (maior que $1450 \mathrm{ohm} . \mathrm{m}$ ) interpretada como saprolito ou sienito, que aflora no córrego localizado nos limites da área preenchida com resíduos (ELIS, 1999). 


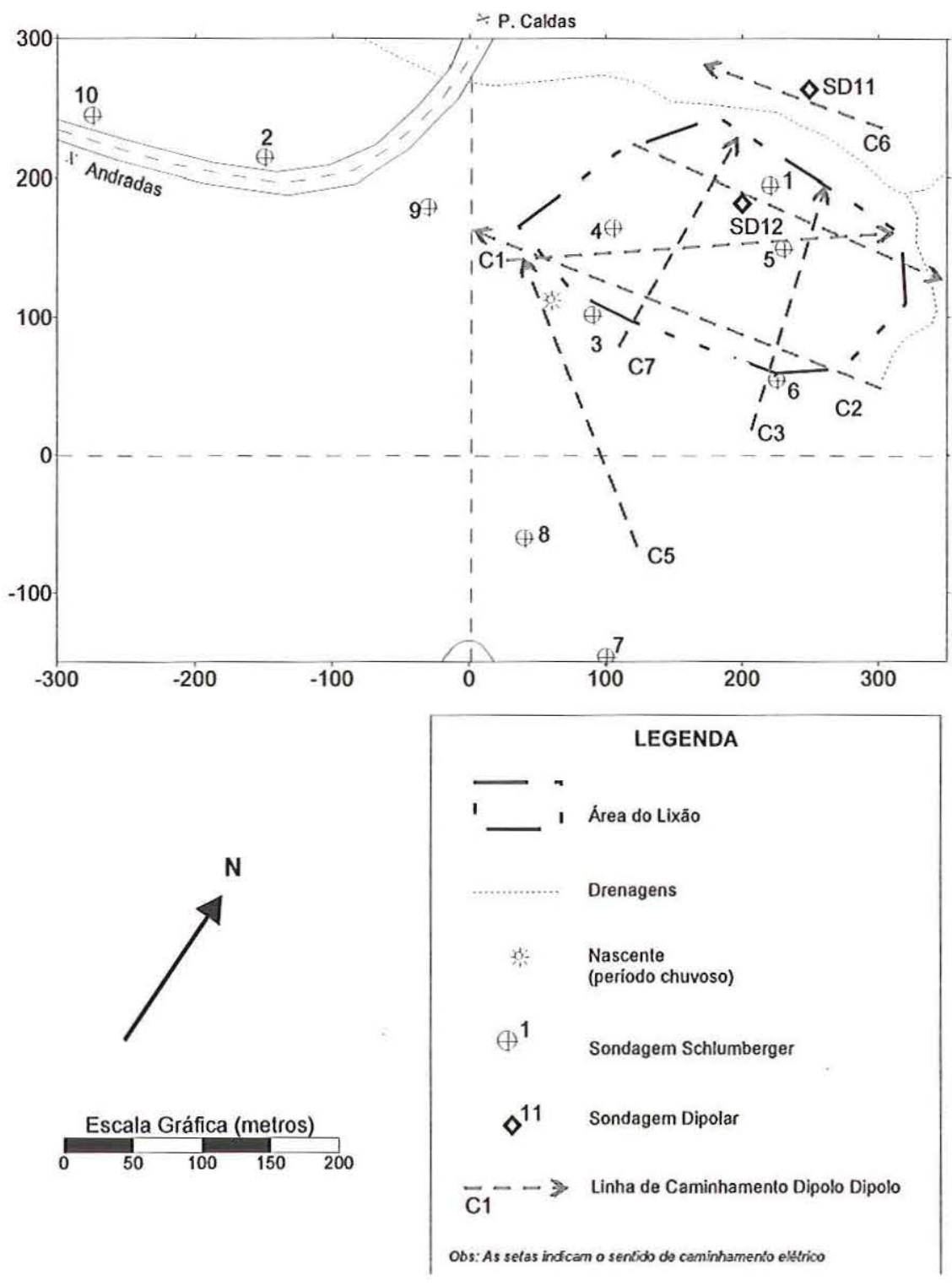

FIGURA 22 - Localização dos ensaios na área de Poços de Caldas (MG) (Modificado de ELIS, 1999).

O mapa de fluxo subsuperficial construído a partir dos dados fornecidos pelas sondagens elétricas é apresentado na Figura 23. 


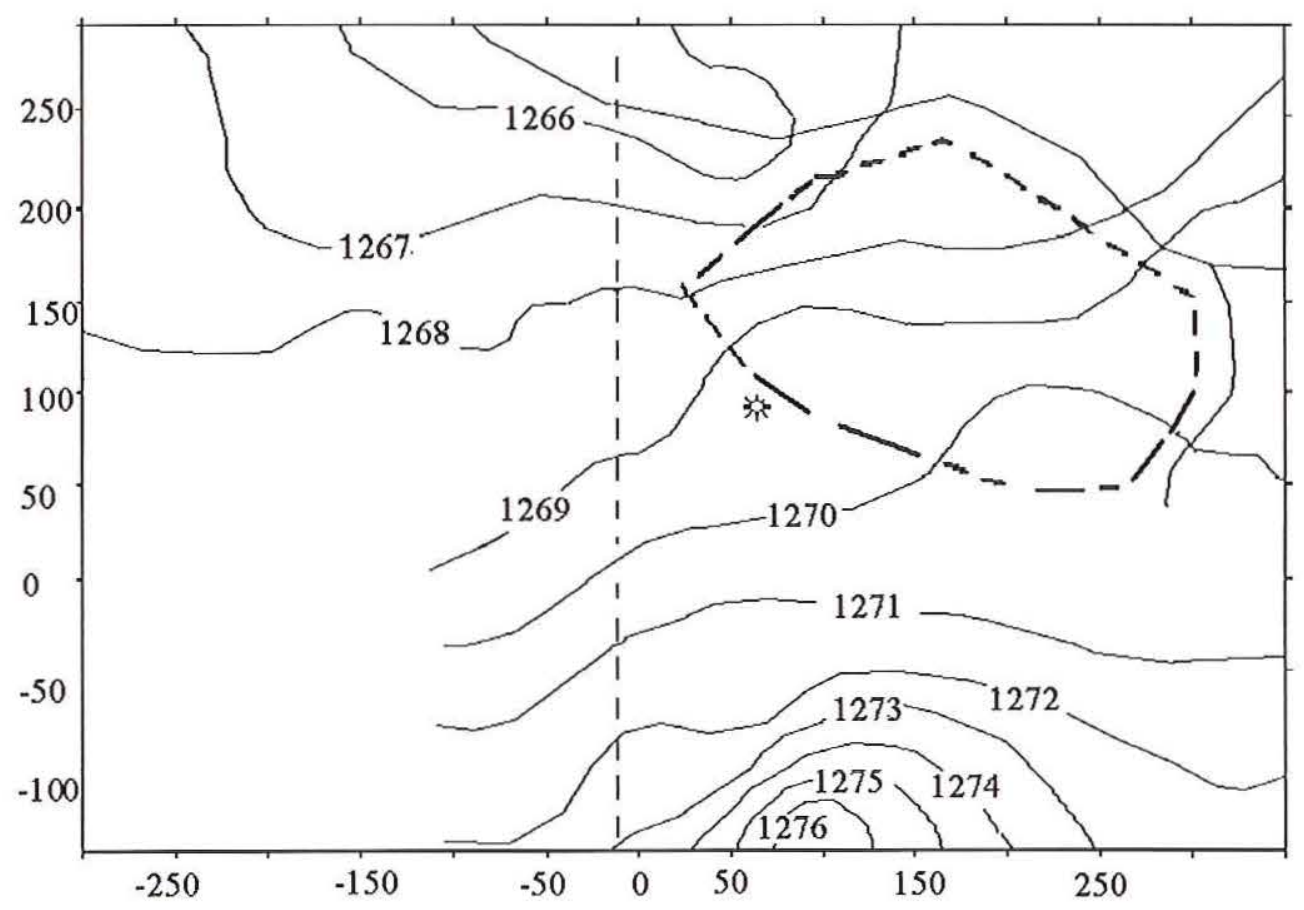

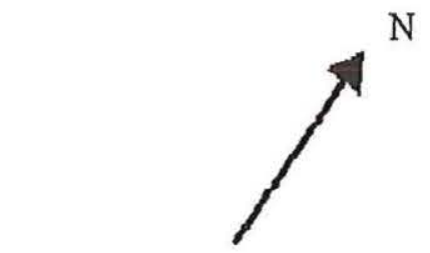

Escala gráfica $(\mathrm{m})$

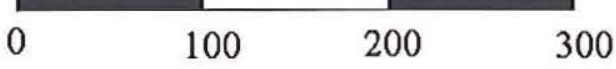

Legenda

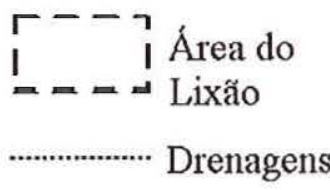

* Nascente

Nível

Potenciométrico

FIGURA 23 - Mapa de fluxo das águas subsuperficial (Modificado de ELIS, 1999).

Foram realizadas duas sondagens dipolares, uma (SD12) com o objetivo de obter a profundidade do nível d'água embaixo das cavas preenchidas com resíduos. Porém praticamente não existe separação entre a base dos resíduos e a zona saturada. Neste caso, a sondagem dipolar foi executada para confirmar essa interpretação, e seu resultado não mostrou uma separação entre a zona saturada e um estrato inferior com maior resistividade. A sondagem (SD11) foi realizada em uma área a norte do Lixão, na outra margem do córrego, com o objetivo de se obter a profundidade do nível d'água. Foi utilizada a sondagem dipolar devido a área apresentar uma vegetação fechada, e o espaço para abertura do arranjo Schlumbeger ser pequeno, nesse caso, a sondagem dipolar alcançou o objetivo 
(ELIS, 1999).

Através de sondagens dipolares observou-se que praticamente não existe separação entre a base dos resíduos e a zona saturada.

\section{Recarga do Aqüífero}

Adotou-se um valor constante e igual a $20 \%$ da precipitação (precipitação anual igual a $1700 \mathrm{~mm})$. Assim a recarga adquiriu um valor médio igual a $340 \mathrm{~mm} / \mathrm{ano}$.

\subsection{Características Hidrogeológicas}

As unidades hidrogeológicas sob a área do Lixão, em ordem do topo para a base são: resíduos, solo, saprolito e rocha.

$\mathrm{O}$ aterro recebe todo os tipos de materiais de origem doméstica. $\mathrm{O}$ solo é siltoso com presença de matacões na parte sul, estes matacões variam de poucos centímetros a alguns métricos. A espessura deste material varia de aproximadamente 2 a 20 metros. Abaixo encontra-se uma rocha desintegrada (saprolito) que é formado a partir de processos físico-químicos de desgaste, este material tem espessura muito variada, com média de 30 metros. A base é o nefelina sienito.

Os perfis das figuras 25 e 26 mostram as seqüências das Unidades Hidrogeológicas, a localização destes perfis pode ser visualizado na Figura 24 .

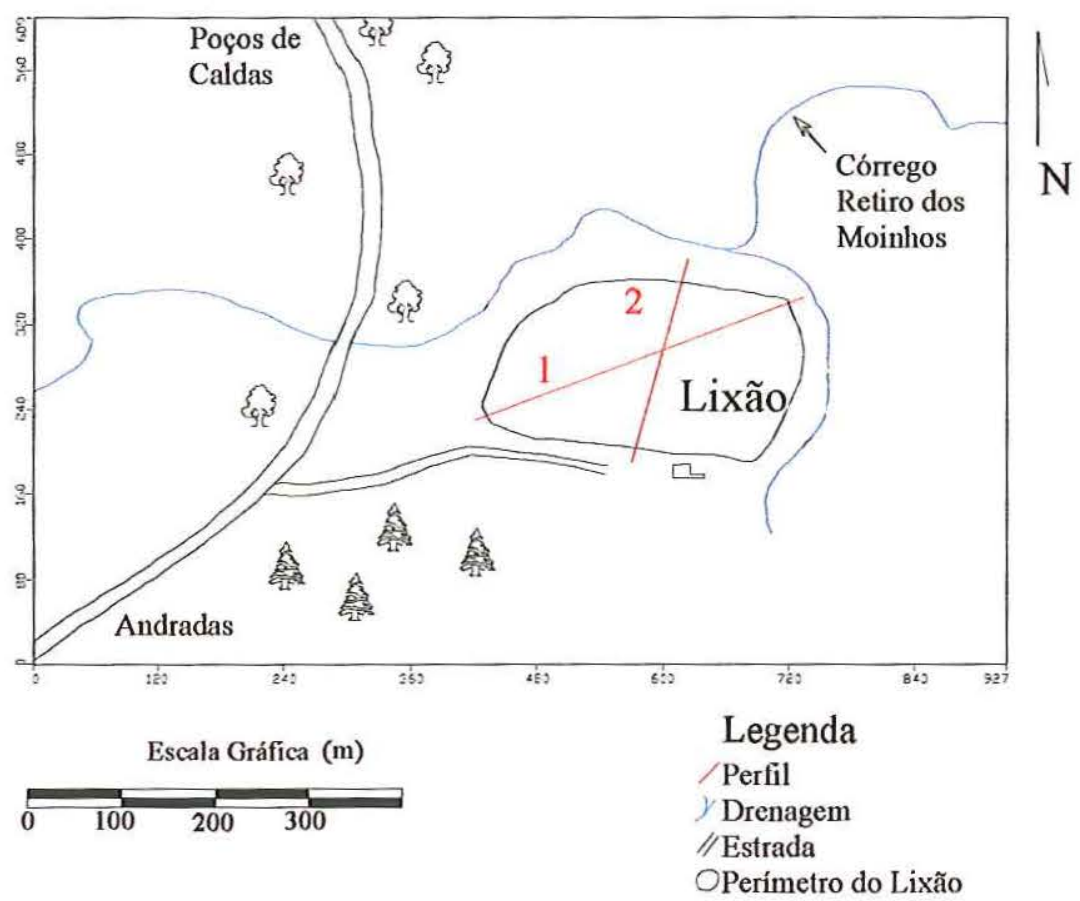

FIGURA 24 -. Posição dos Perfis na área de influência da Pluma de Contaminação 


\section{Perfil 1}

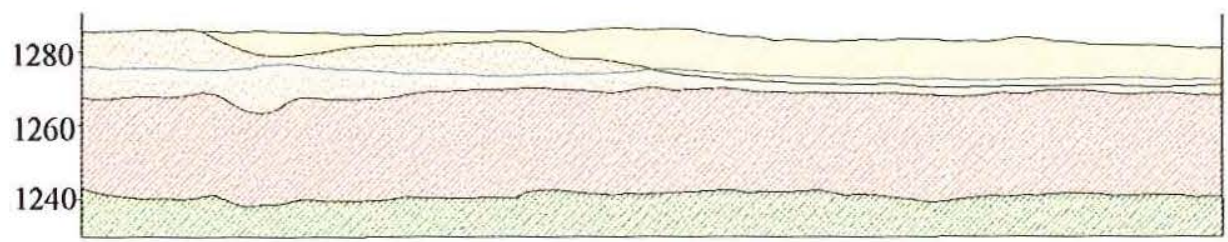

Escala

Resíduos - Lixão

$1: 1.000$

Solo - Material Silto-arenoso $-\mathrm{k}=1,2.10^{-4} \mathrm{~m} / \mathrm{s}$

Saprolito - Para a Modelagem 2 "layers" - $\mathrm{k}=1.10^{-5} \mathrm{e} 1.10^{-7} \mathrm{~m} / \mathrm{s}$.

Rocha Sã - Sienito. $\mathrm{k}=5,4 \cdot 10^{8} \mathrm{~m} / \mathrm{s}$.

- Limites entre as Unidades Hidrogeológicas

— Nível de Água

FIGURA 25 - Perfil 1 das Unidades Hidrogeológicas.

\section{Perfil - 2}

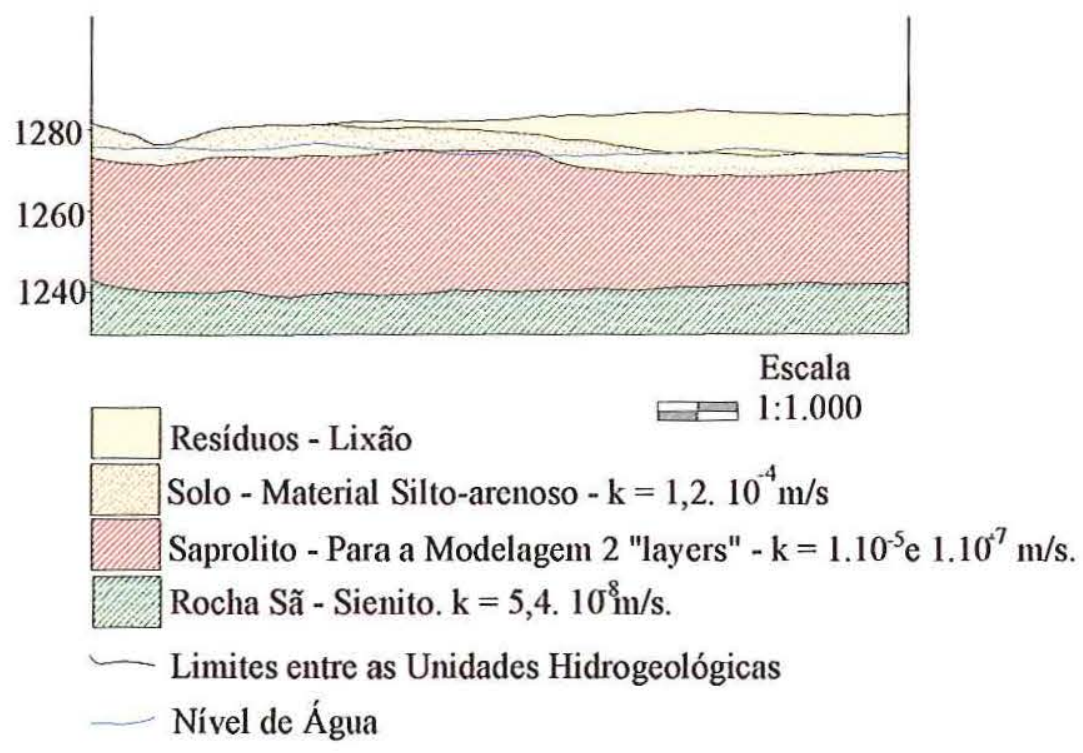

FIGURA 26 - Perfil 2 das Unidades Hidrogeológicas

O Mapa de superfície potenciométrica (Mapa PM) foi elaborado a partir dos dados de campo e dados geofísicos. Este mapa está representado na Figura 27 e mostra a direção e o sentido do fluxo. 


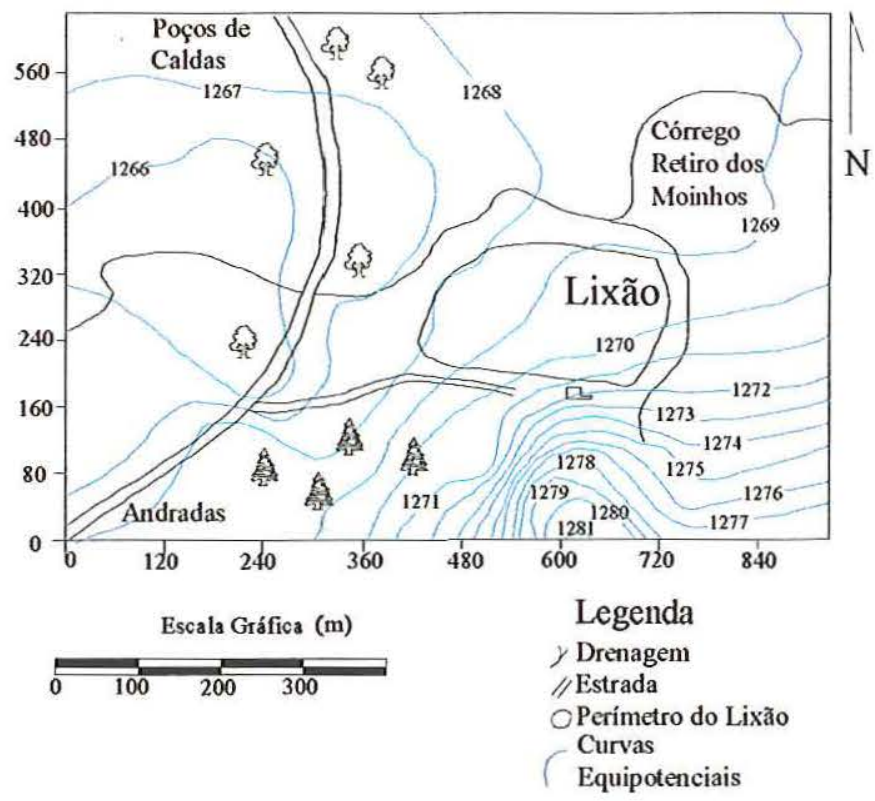

FIGURA 27 - Mapa Potenciométrico

CARLSTRON FILHO et al.(1978) desenvolveram um trabalho na Mina de Urânio Osamu Utsumi, próxima do Lixão, deste trabalho se obteve vários dados úteis sobre a área, principalmente sobre a condutividade hidráulica dos vários materiais. Os dados foram: solo $1,2.10^{-4} \mathrm{~m} / \mathrm{s}$., os ensaios realizados mostraram grande variação na condutividade hidráulica do saprolito, de $1.10^{-5}$ e $1.10^{-7} \mathrm{~m} / \mathrm{s}$., a condutividade hidráulica considerada para o sienito é de $5,4 \cdot 10^{-8} \mathrm{~m} / \mathrm{s}$. Através da mesma fonte se obteve a capacidade de campo para o solo, $19 \%$.

A porosidade efetiva adotada é de 0.20 e a porosidade total de 0.30 , com índice de vazio próximo a 0.80 .

Tendo em vista o modelo de transporte, realizou-se o cálculo da isoterma de sorção linear e a isoterma de sorção de Langmuir utilizando dados de LEITE (1997) para materiais com características semelhantes aos encontrados na área. Os gráficos gerados estão representados nas figuras 28 e 29 . 


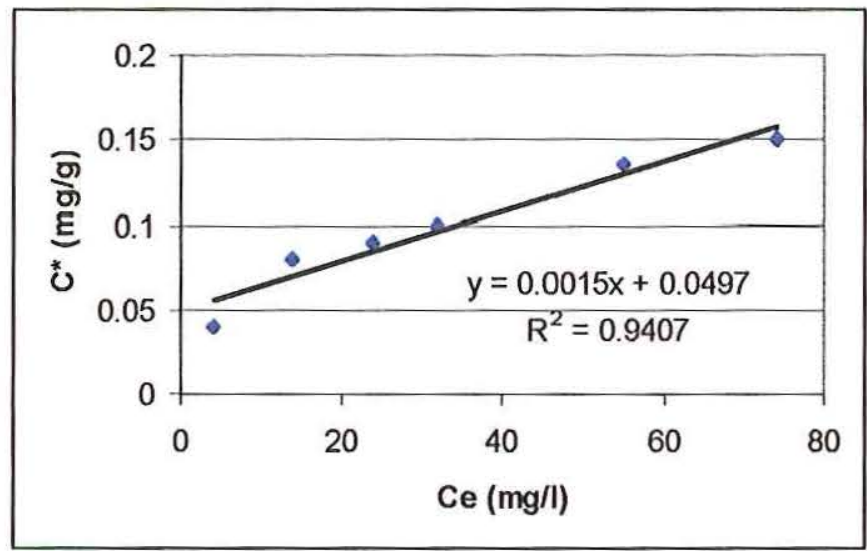

FIGURA 28 - Isoterma Linear (Solo Argiloso da Formação Serra Geral)

$\mathrm{O}$ valor obtido para a Isoterma Linear de $\mathrm{Kd}$ foi $0.0015 \mathrm{~m}^{3} / \mathrm{Kg}$
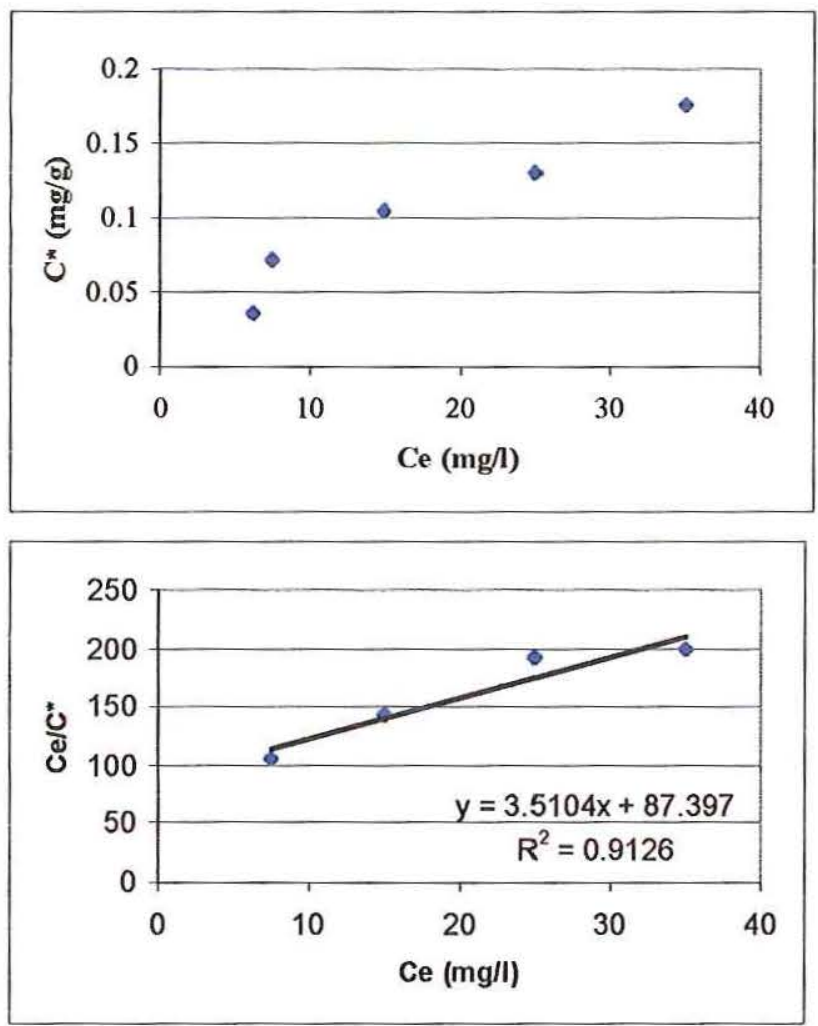

FIGURA 29 - Isoterma de Langmuir (Para solo argiloso da Formação Serra Geral + 5\% de bentonita)

Os valores obtidos para a Isoterma de Langmuir foram:

$\beta=0.0002848 \mathrm{Kg} / \mathrm{Kg}$

$\alpha=0.04016 \mathrm{~m}^{3} / \mathrm{Kg}$ 


\section{Dados sobre o Lixão}

O lixão está em funcionamento deste meados de 1985, com área recoberta de $33.081 \mathrm{~m}^{2}$ e volume aproximado de $248.107 \mathrm{~m}^{3}$, considerando uma espessura média de $7.5 \mathrm{~m}$.

Atualmente o lixão está sendo recoberto por uma fina camada de argila compactada (centimétrica). Não existe, porém, nenhum sistema de controle à poluição como um liner ou um sistema coletor.

O Lixão recebe resíduos urbanos residenciais; decorrentes dos serviços da saúde; e das industrias comuns e do comercio.

As figuras 30 a 38 mostram fotos de vários aspectos do Lixão.

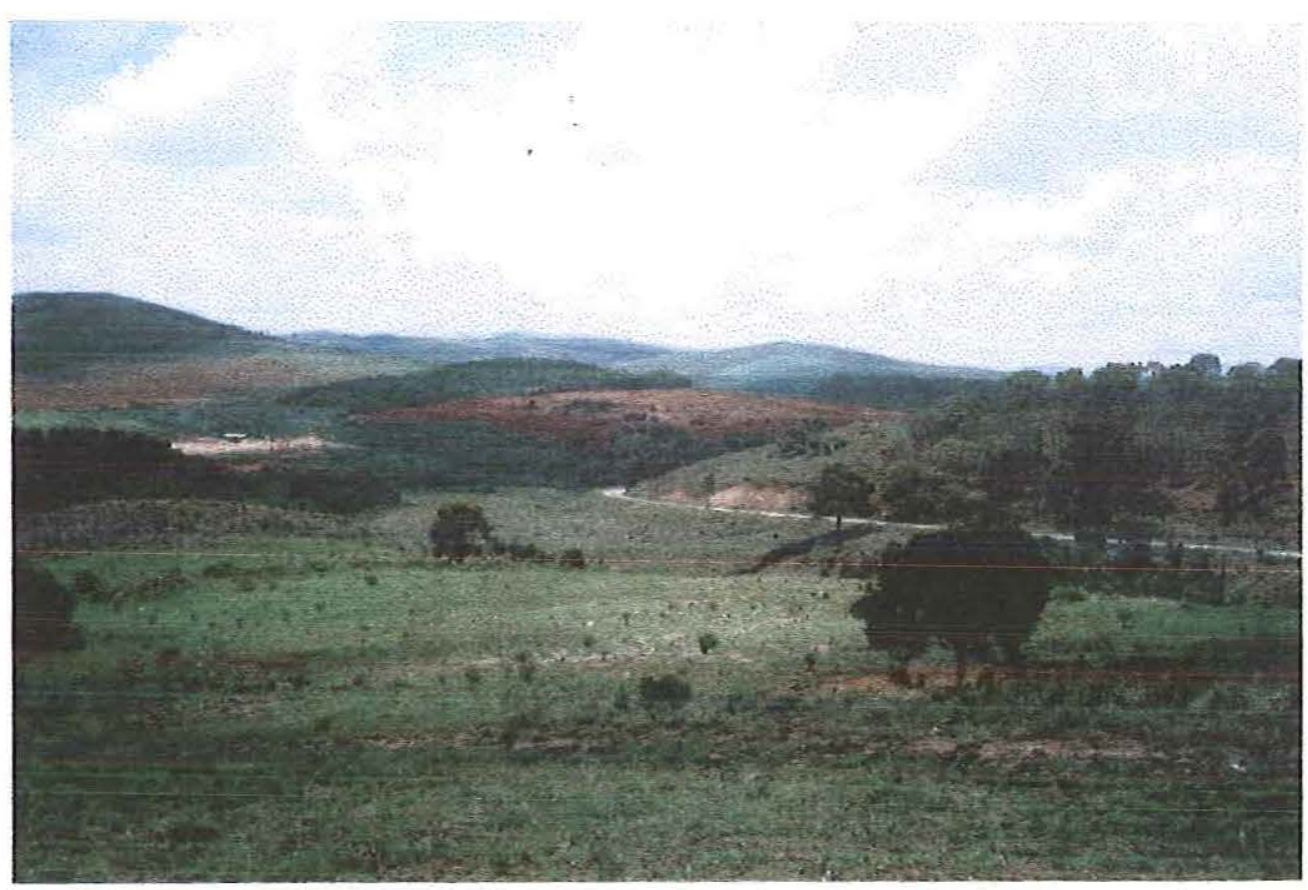

FIGURA 30 - Vista Geral da Área (1996) 


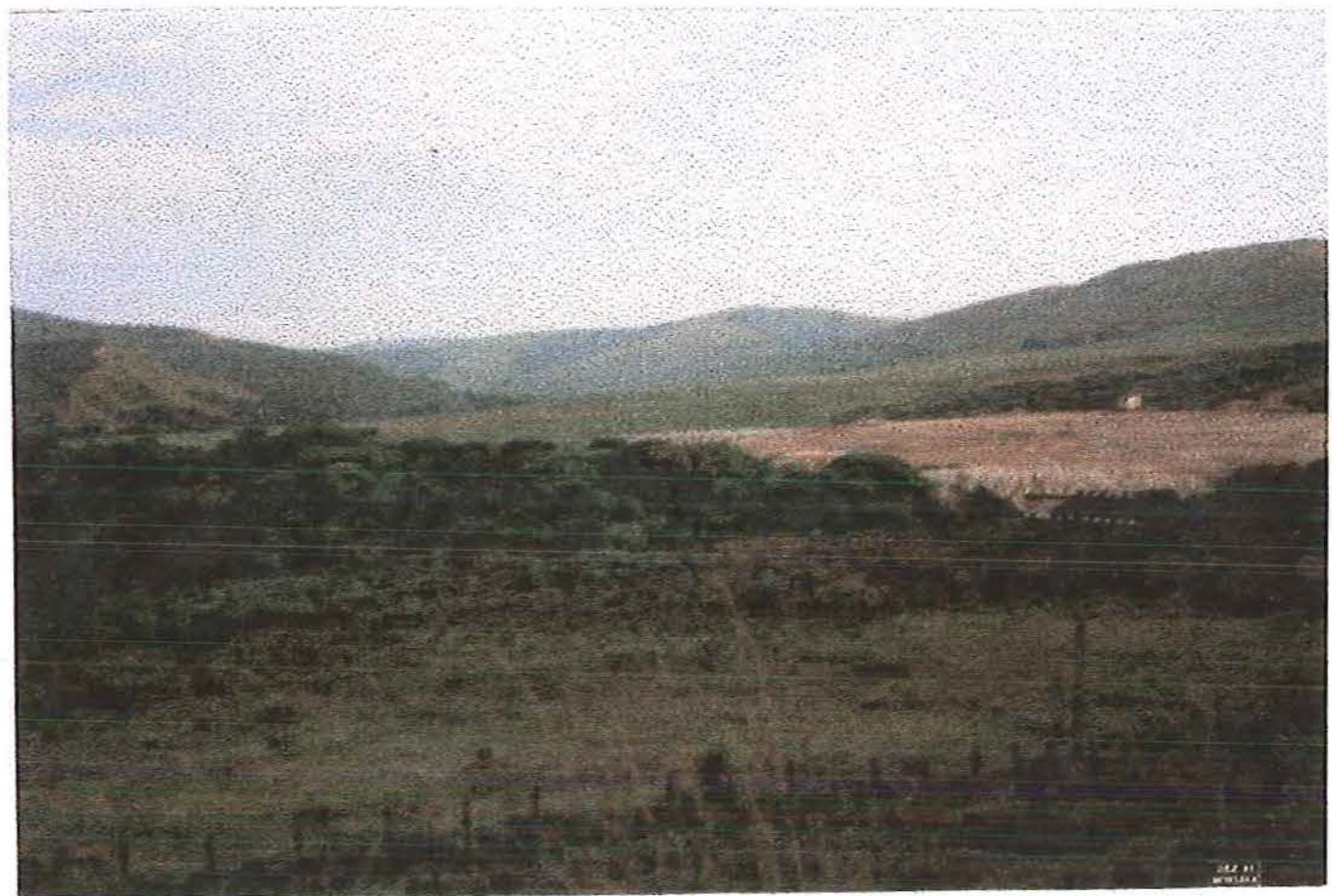

FIGURA 31 - Vista da área (1991)

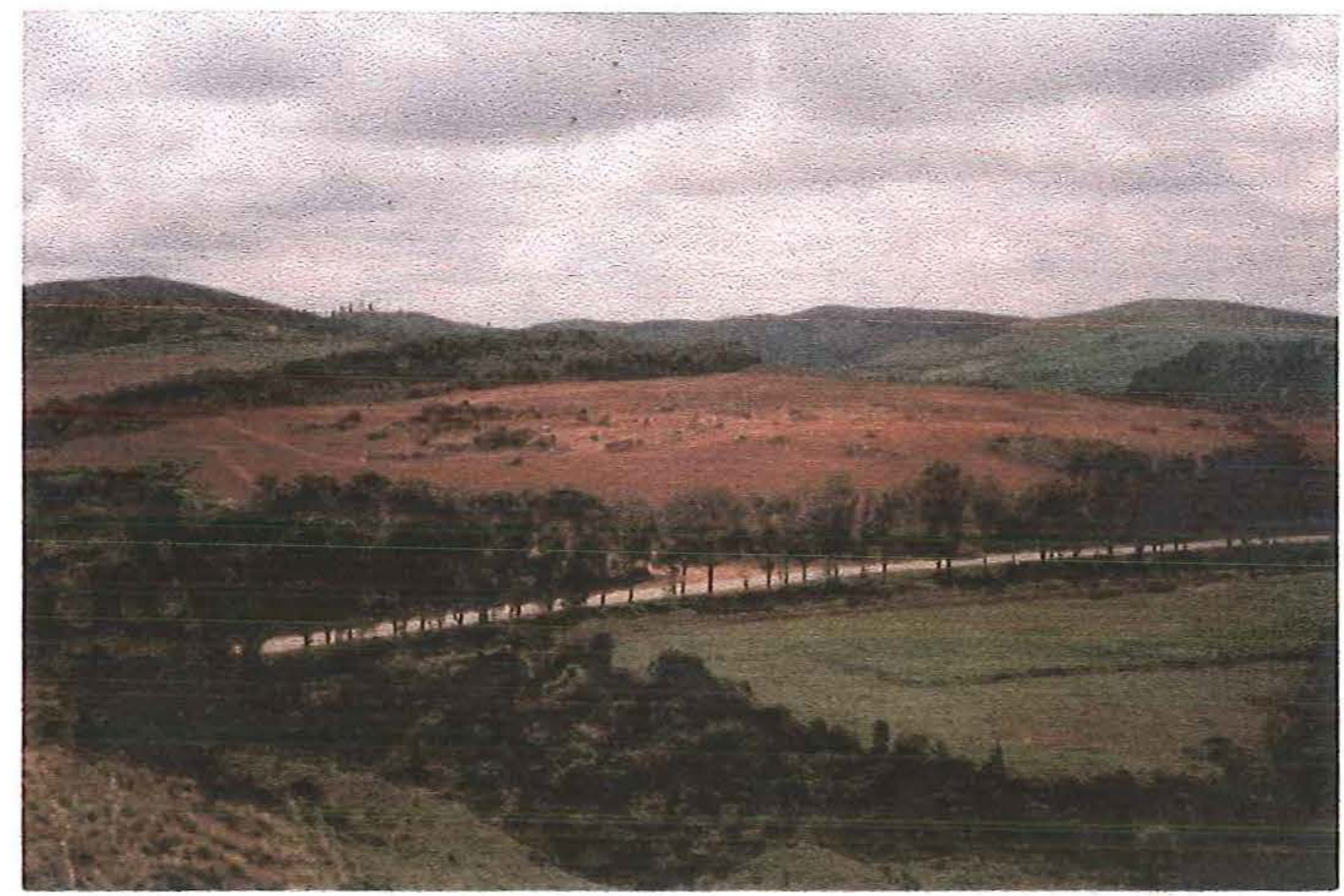

FIGURA 32 - Área ao sul do Lixão - Presença de Matacões 


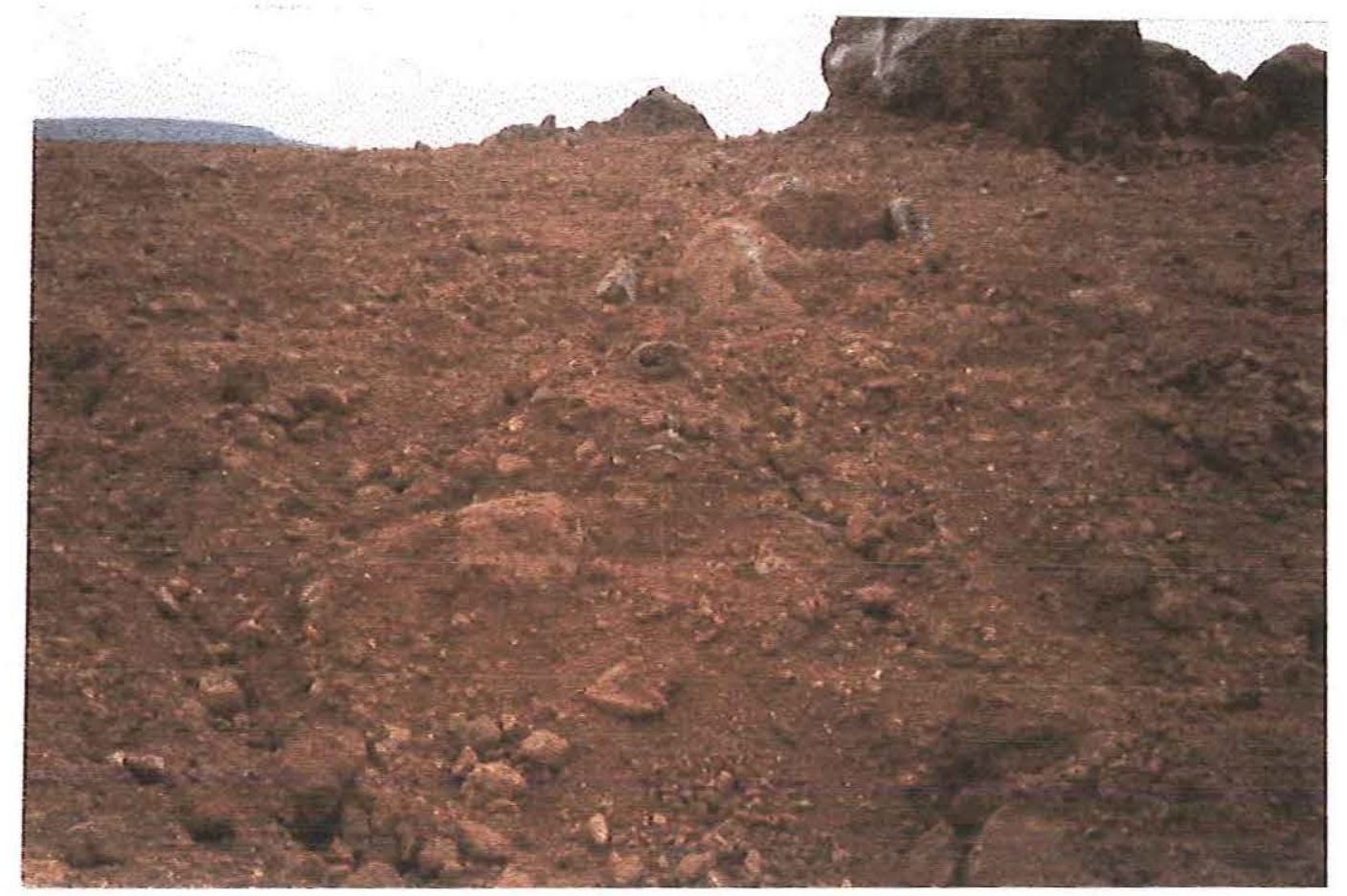

FIGURA 33 - Detalhe do Solo - Presença de Matacões

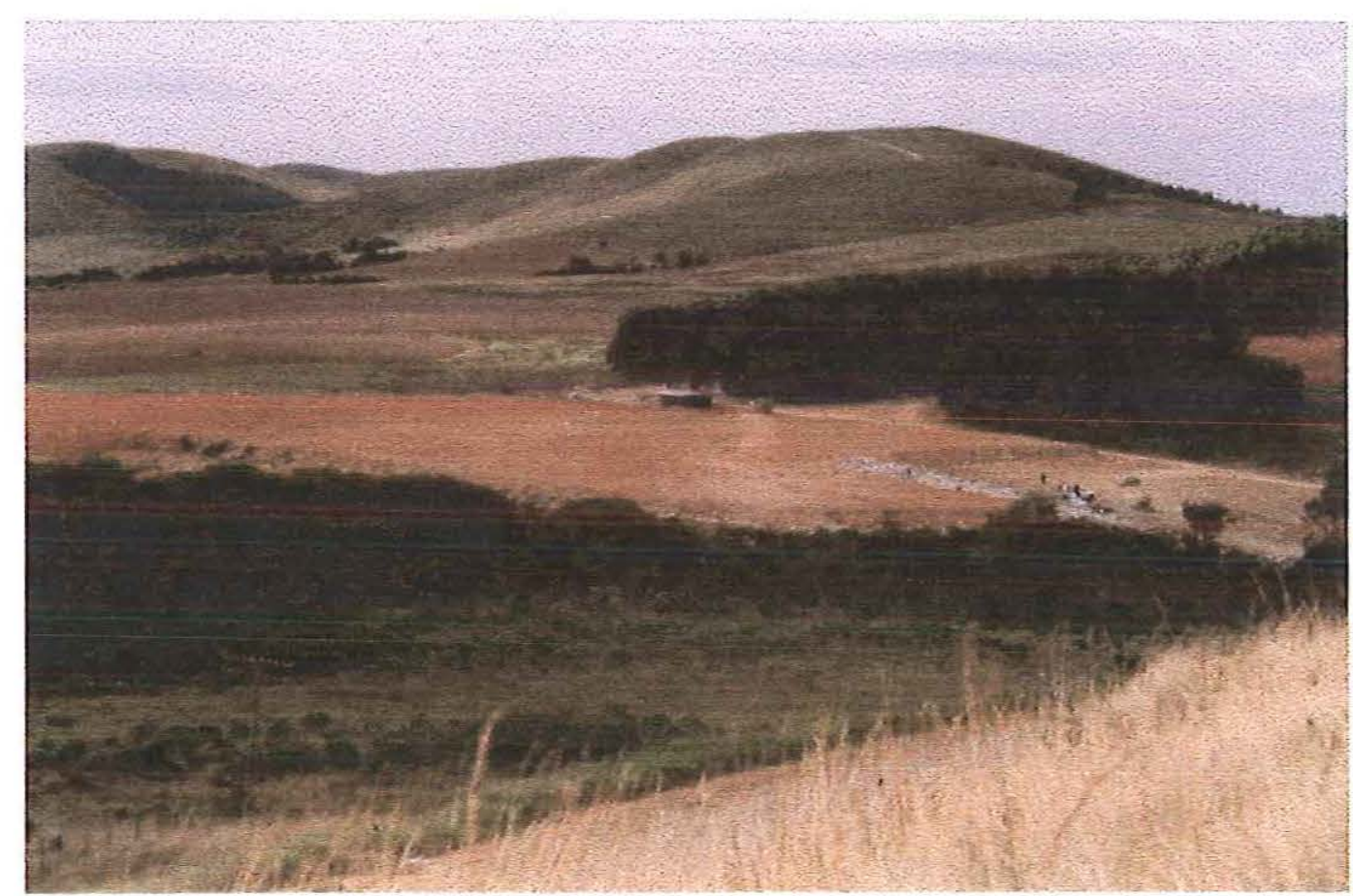

FIGURA 34 - Vista atual do Lixão (1998) 


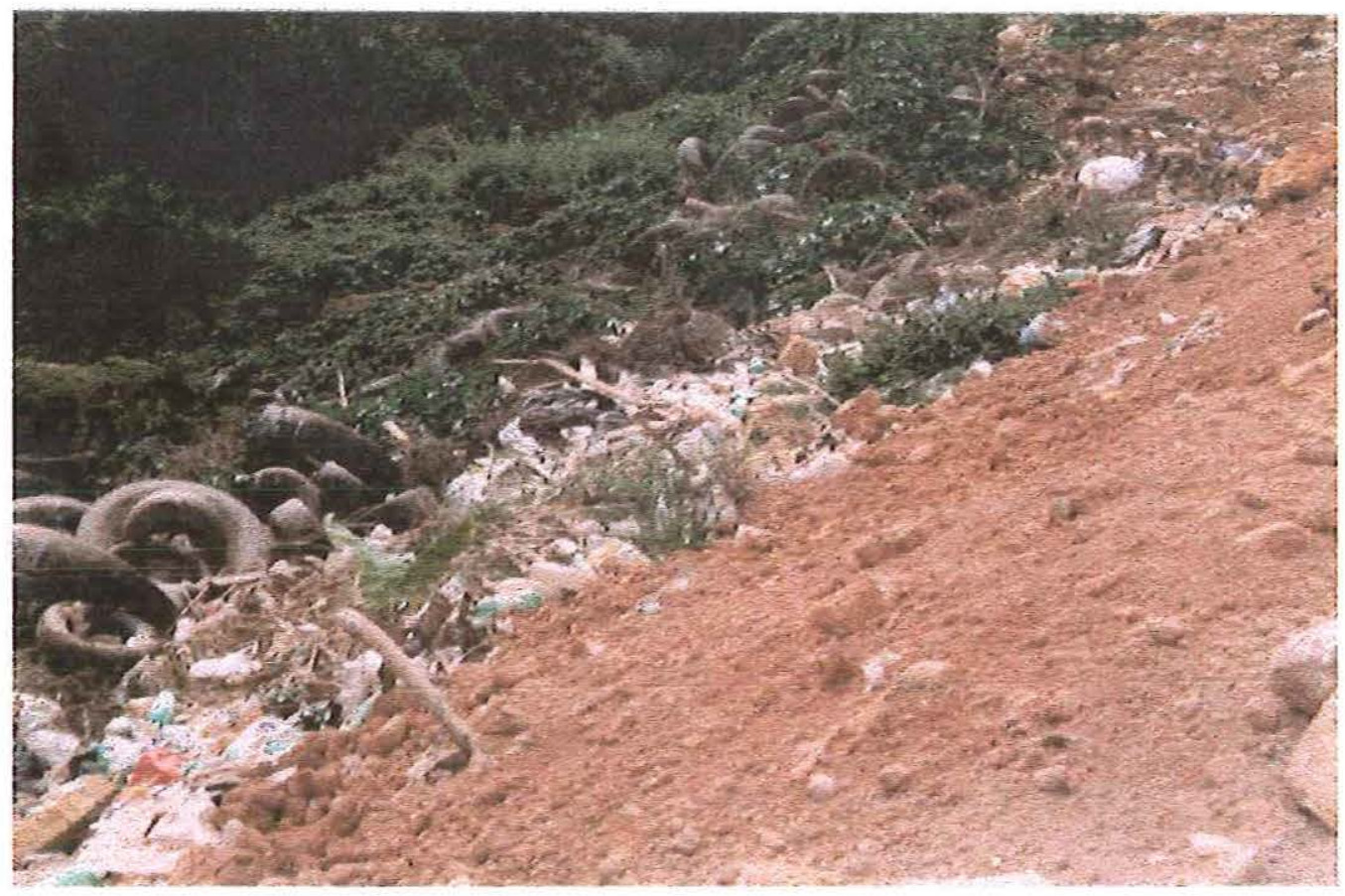

FIGURA 35 - Detalhe do Lixão

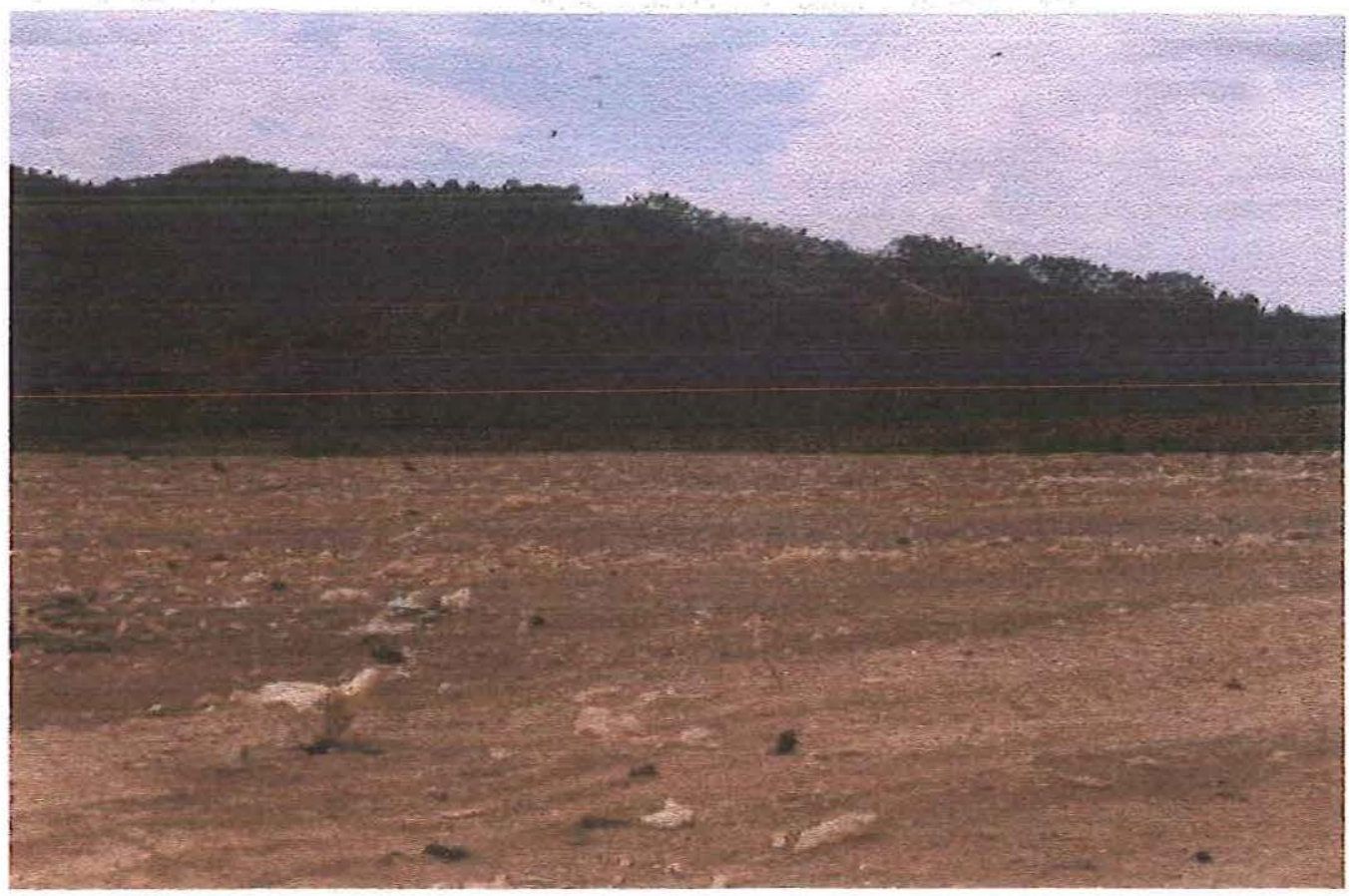

FIGURA 36 - Camada de Argila Compactada 


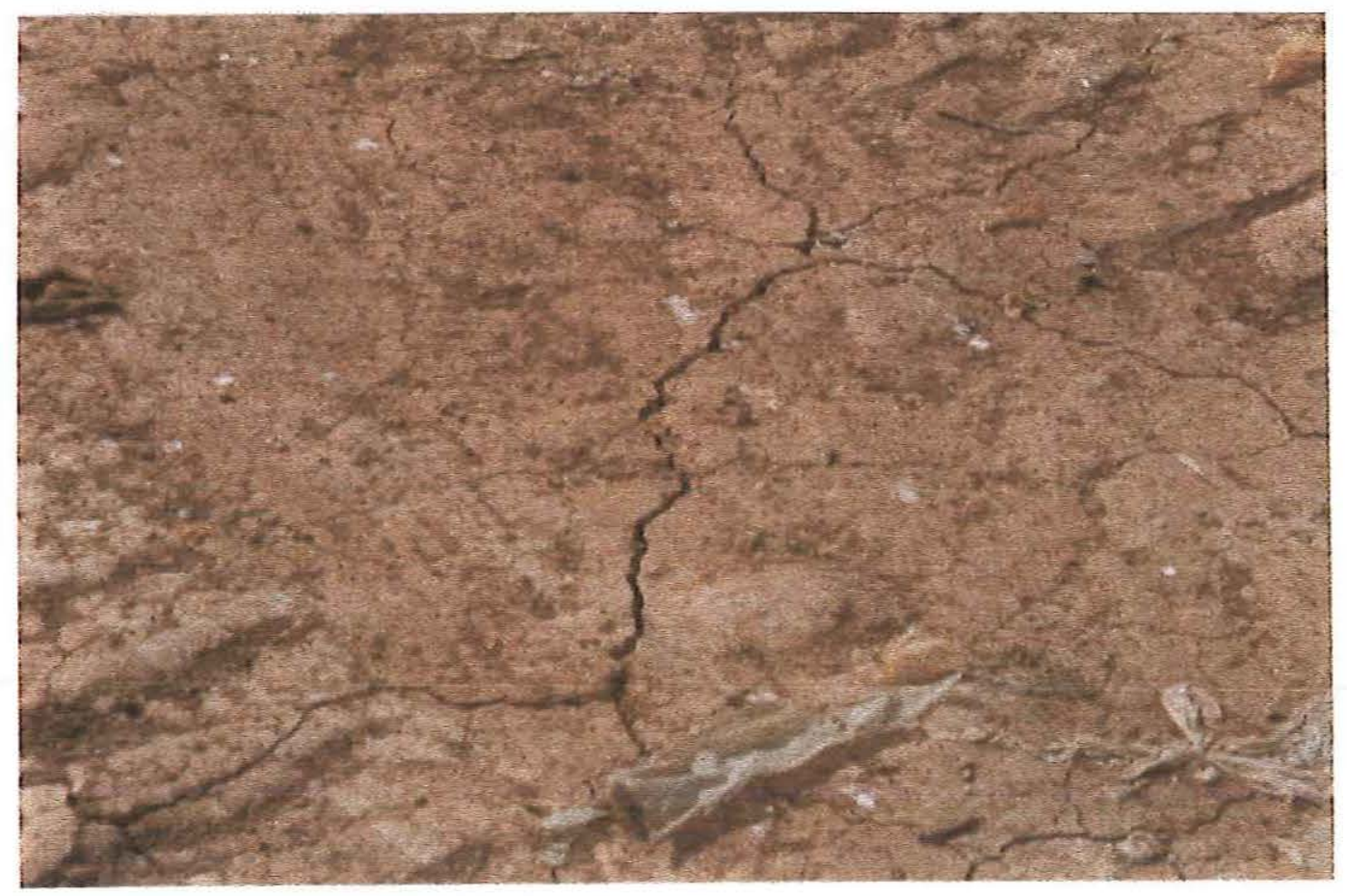

FIGURA 37 - Detalhe da Camada de Argila Compactada - Presença de Trincas

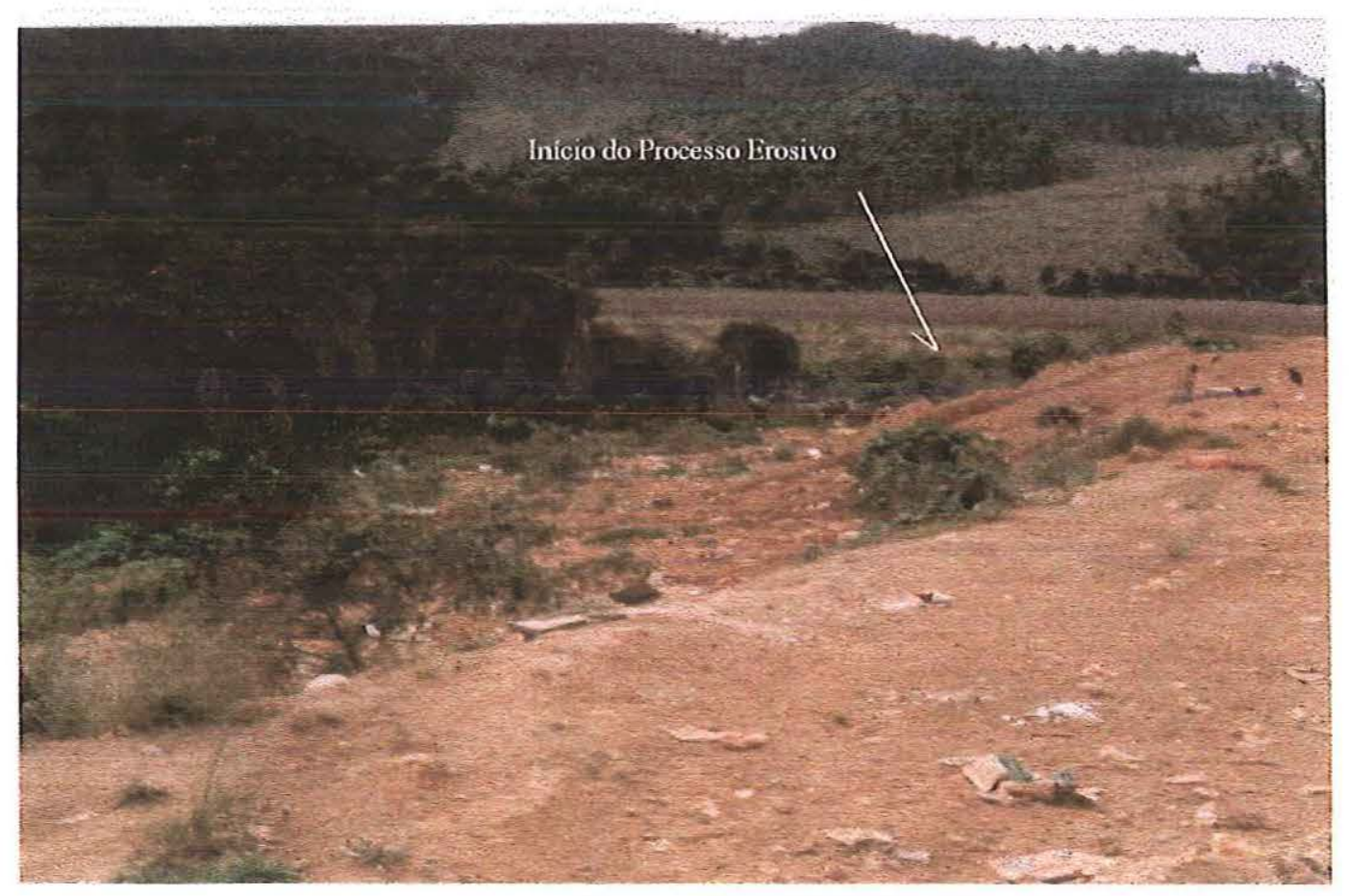

FIGURA 38 - Início de Processo Erosivo 


\section{Dados sobre a Pluma de Contaminação}

A pluma de contaminação foi delimitada através de levantamento geofísico realizado por ELIS (1999), juntamente com o levantamento das características do meio físico já citado neste trabalho. As figura 39A e 39B mostram a pluma de contaminação e sua diferente resposta de resistividade. 


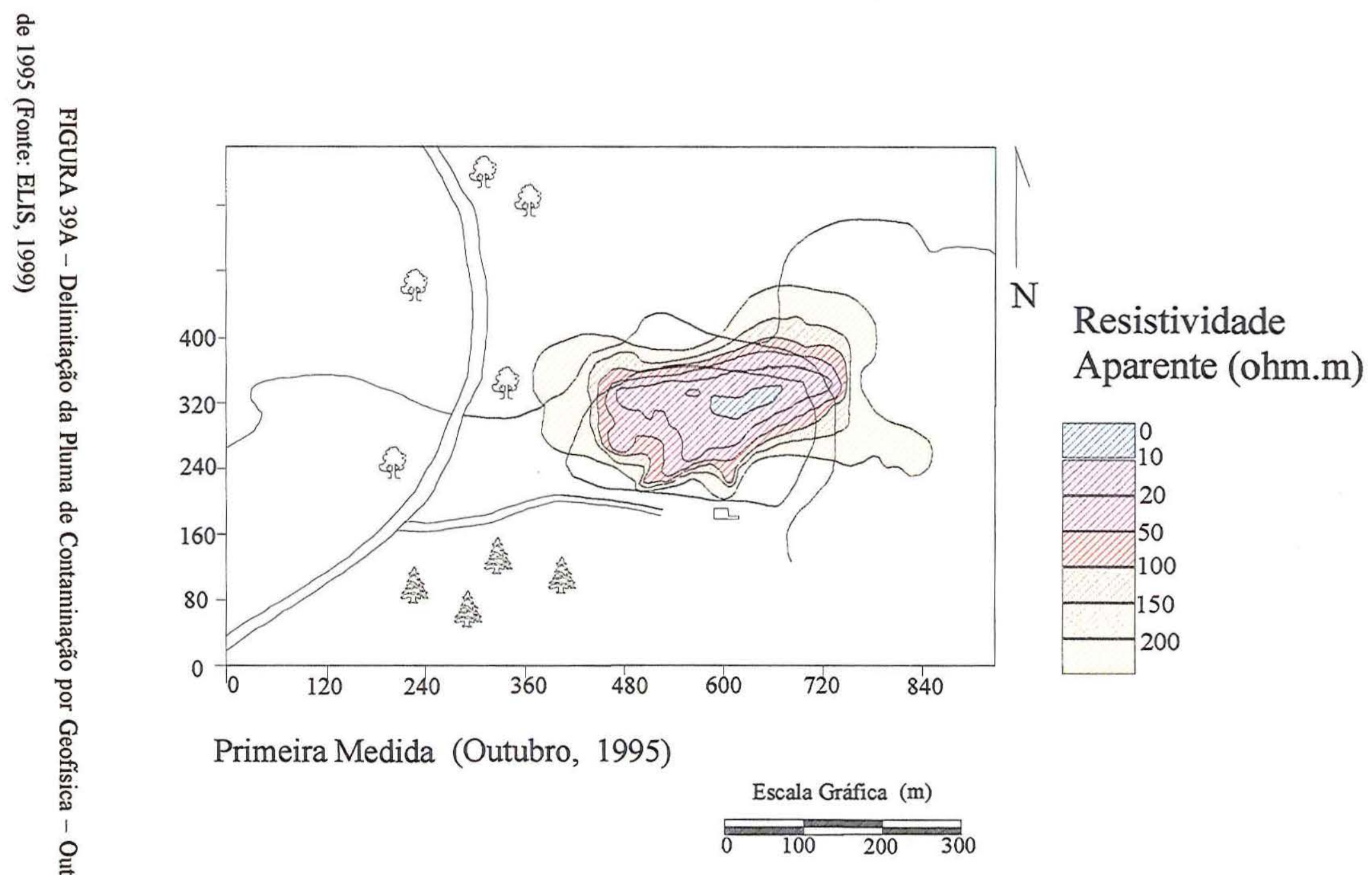



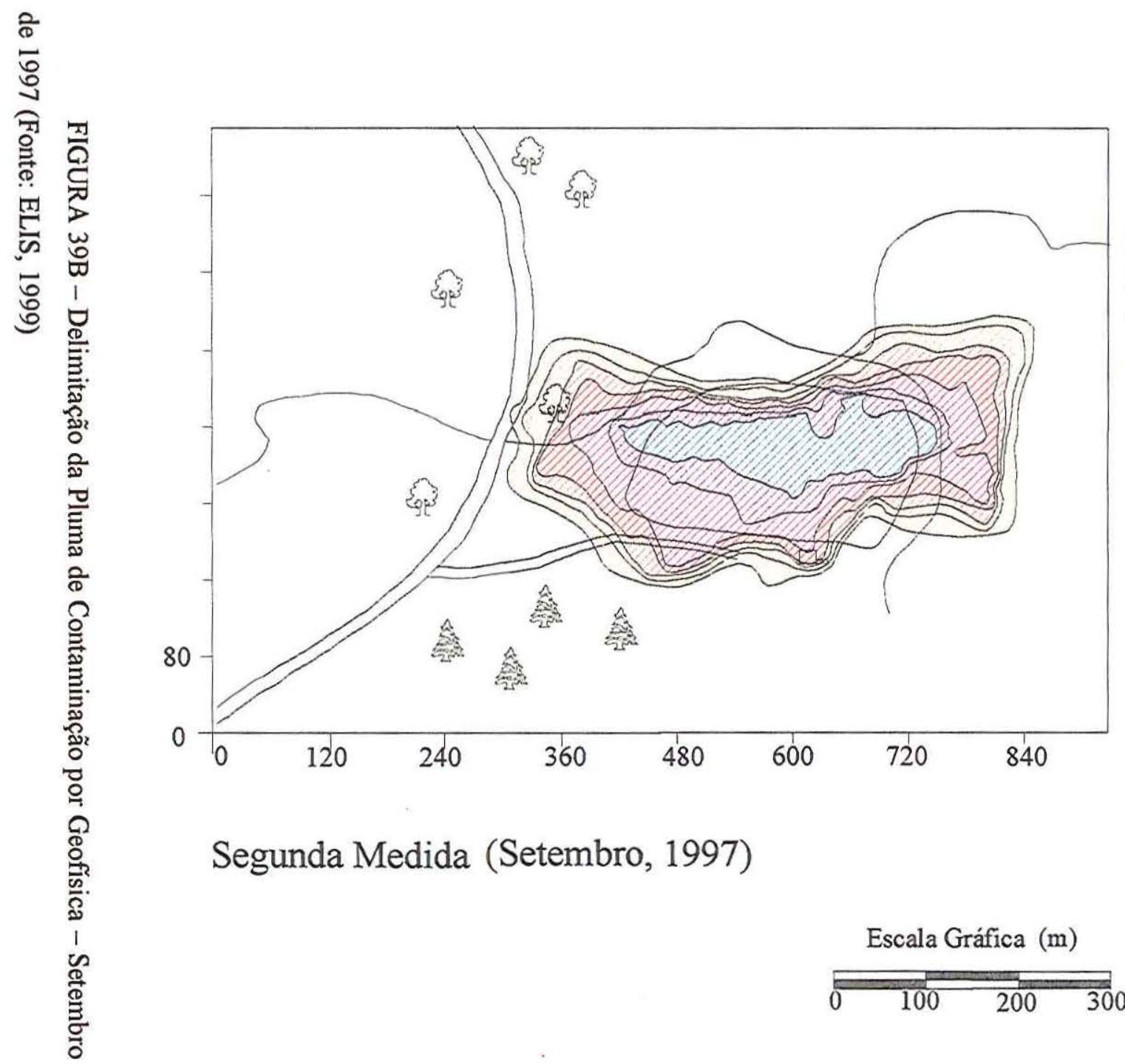

N Resistividade Aparente (ohm.m)

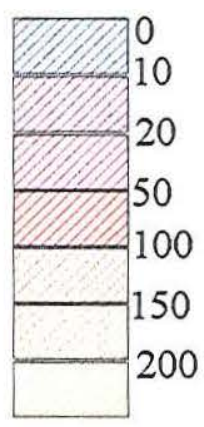

Segunda Medida (Setembro, 1997)

Escala Gráfica (m)

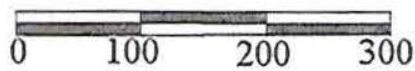




\section{CAPÍTULO VII - MODELAGEM E ANÁLISE DOS RESULTADOS OBTIDOS}

\section{Modelagem}

\subsection{Delimitação da Área de influência}

O conjunto dos dados, apresentados no Capítulo VI, permitiu a delimitação da área de influência da pluma de contaminação. Esta delimitação se deu principalmente pelo conhecimento prévio da posição da pluma e da direção, sentido e intensidade do fluxo, sem estas informações buscar-se-ia outros limites, como por exemplo, divisores de água.

\subsection{Representação dos Dados em Forma Digital}

Inicialmente digitalizou-se todos os mapas disponíveis, primeiramente, mapas na escala 1:10.000, obtendo-se as curvas de níveis (com eqüidistância de $10 \mathrm{~m}$ ), o contorno da bacia, a ocupação antrópica e as drenagens. Após digitalizou-se os mapas na escala 1:1.000 que mostraram a localização e o perímetro do Lixão e a delimitação da pluma de contaminação (obtida pelos ensaios de geofísica).

Para a digitalização foi utilizado o Software Autocad, gerando-se arquivos em formato .DXF. Os mapas que não continham informações em 3D foram importados diretamente pelo programa Visual Modflow, os arquivos que continham tais informações foram tratados por um conversor (Pgdxfcon.exe), com a finalidade de criar uma planilha em formato .TXT. Estas planilhas ou foram importados diretamente pelo Software Surfer, ou quando necessitavam de um tratamento anterior eram importados para o Excel e depois das 
alterações, salvos em formato .SKL e abertos no Surfer. Esta passagem muitas vezes foi indispensável para um resultado melhor, pois muitas vezes as passagens geraram caracteres não reconhecidos pelo Surfer.

No Surfer gerou-se arquivos em formato .GRD que foram importados pelo Visual Modflow carregando as informações tridimensionais. No Surfer também foram criados mapas de contorno e modelos tridimensionais da área quanto a: Topografia (FIGURA $40 \mathrm{e}$ FIGURA 41), Nível de Água (FIGURA 42 e FIGURA 43), Topo do Saprolito (FIGURA 44 e FIGURA 45) e Topo do Sientito (FIGURA 46 e 47).

O Visual Modflow permite que a área a ser inserida possa ter coordenadas em UTM ou coordenadas relativas, com um ponto como origem. Neste trabalho optou-se por criar um sistema georeferenciado próprio. 


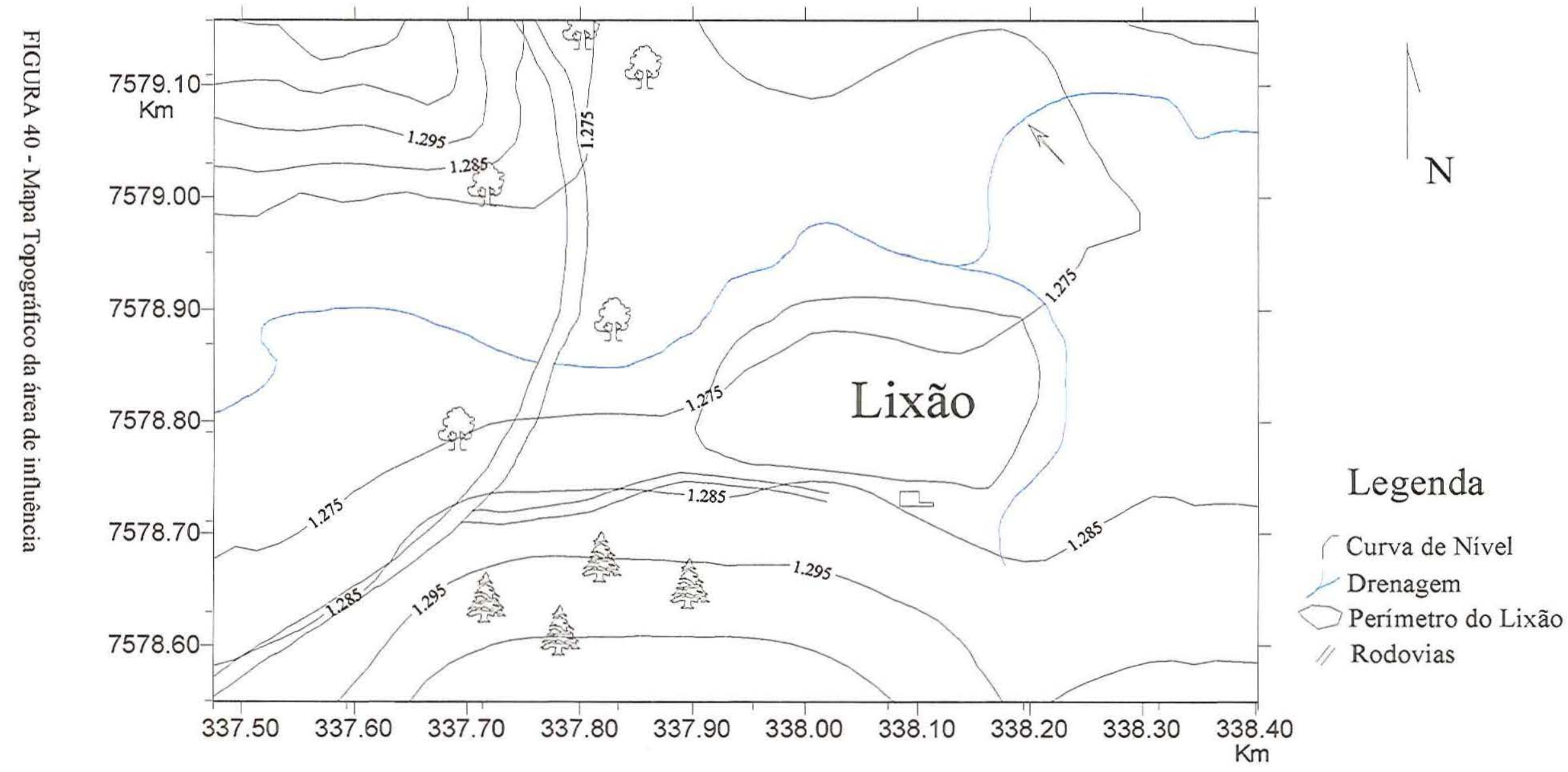




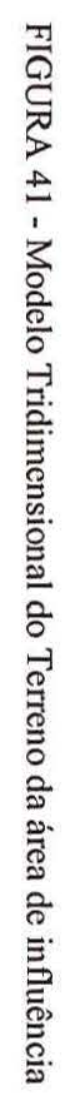

\section{Modelo Tridimensional do Terreno}

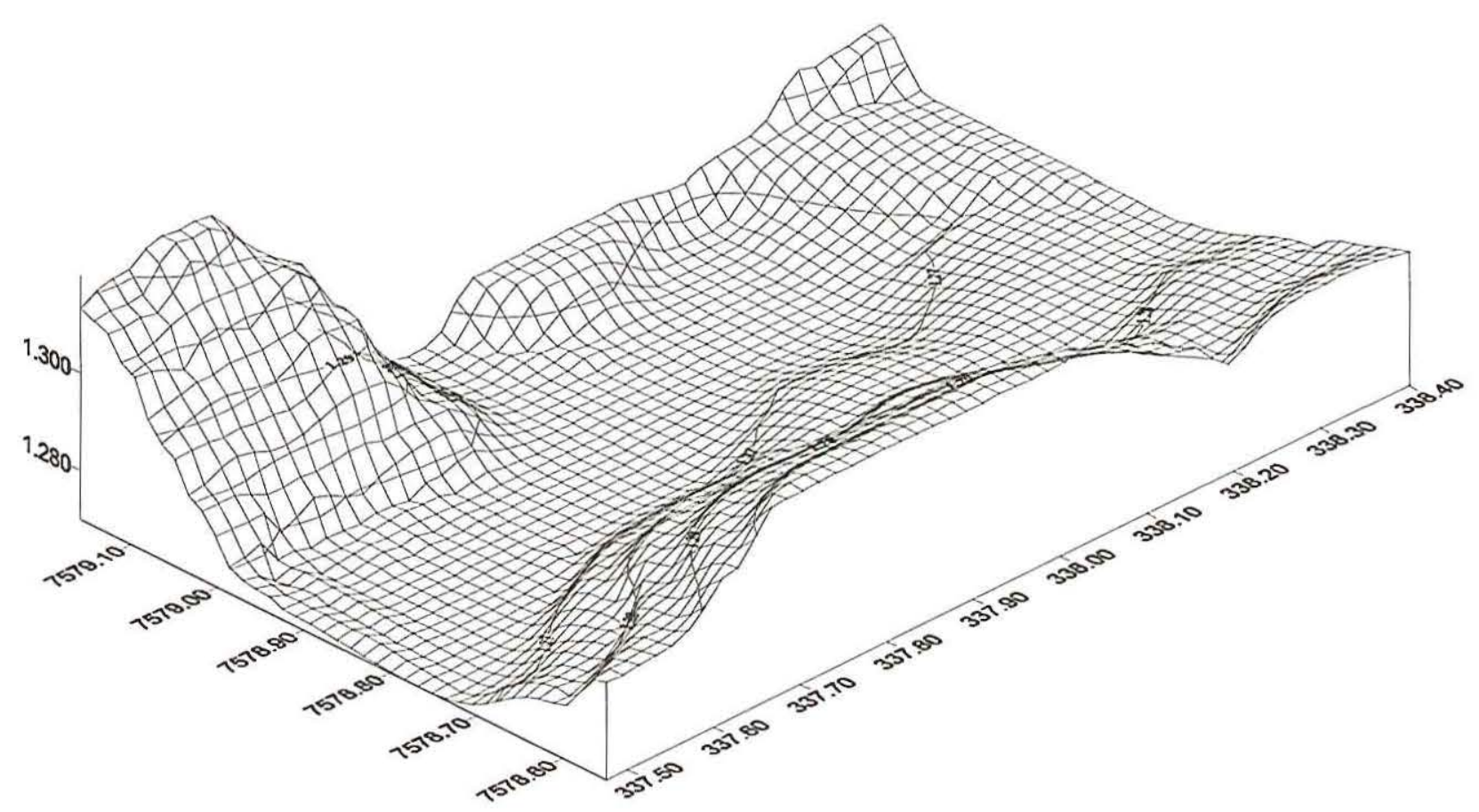




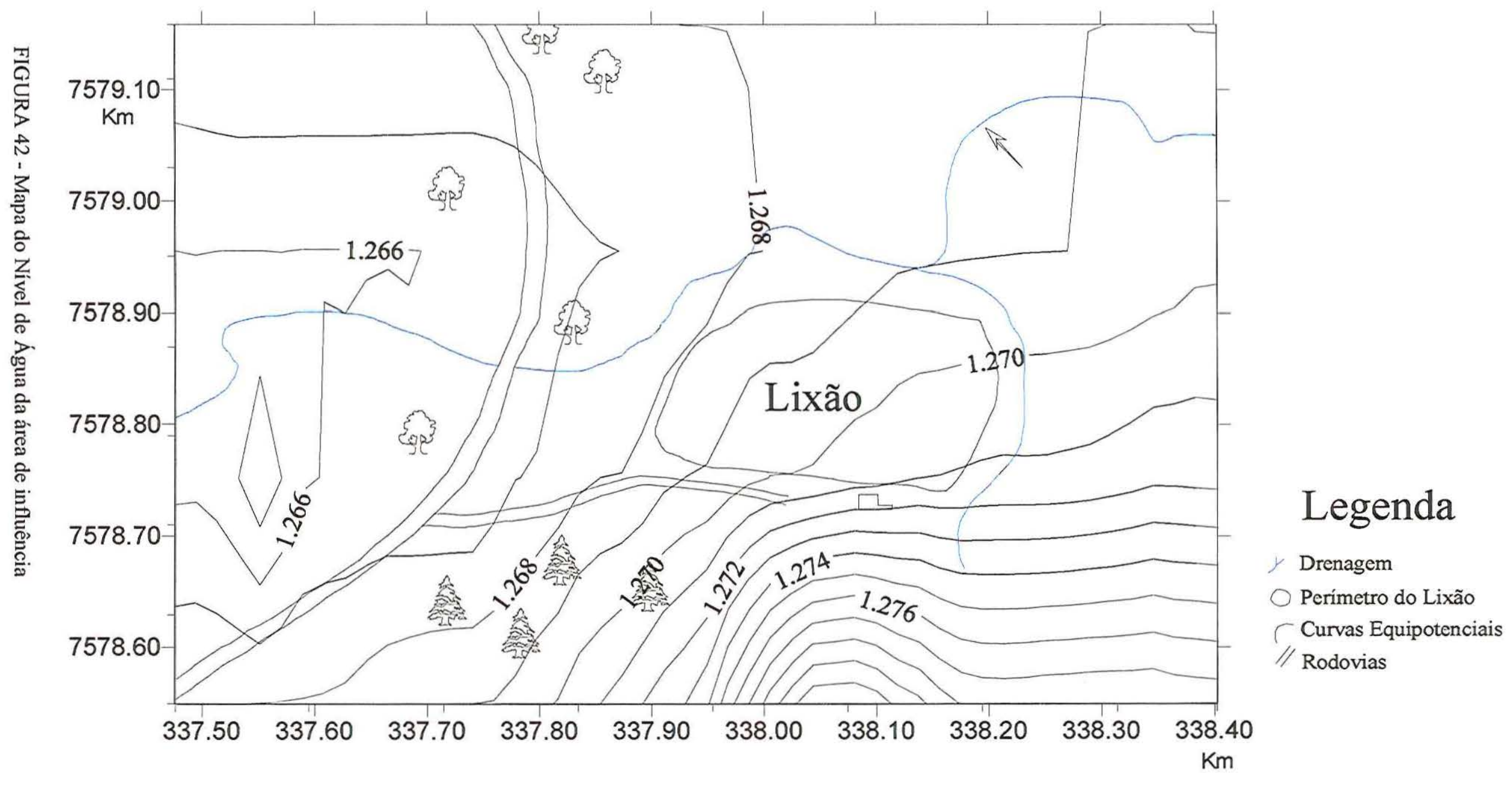




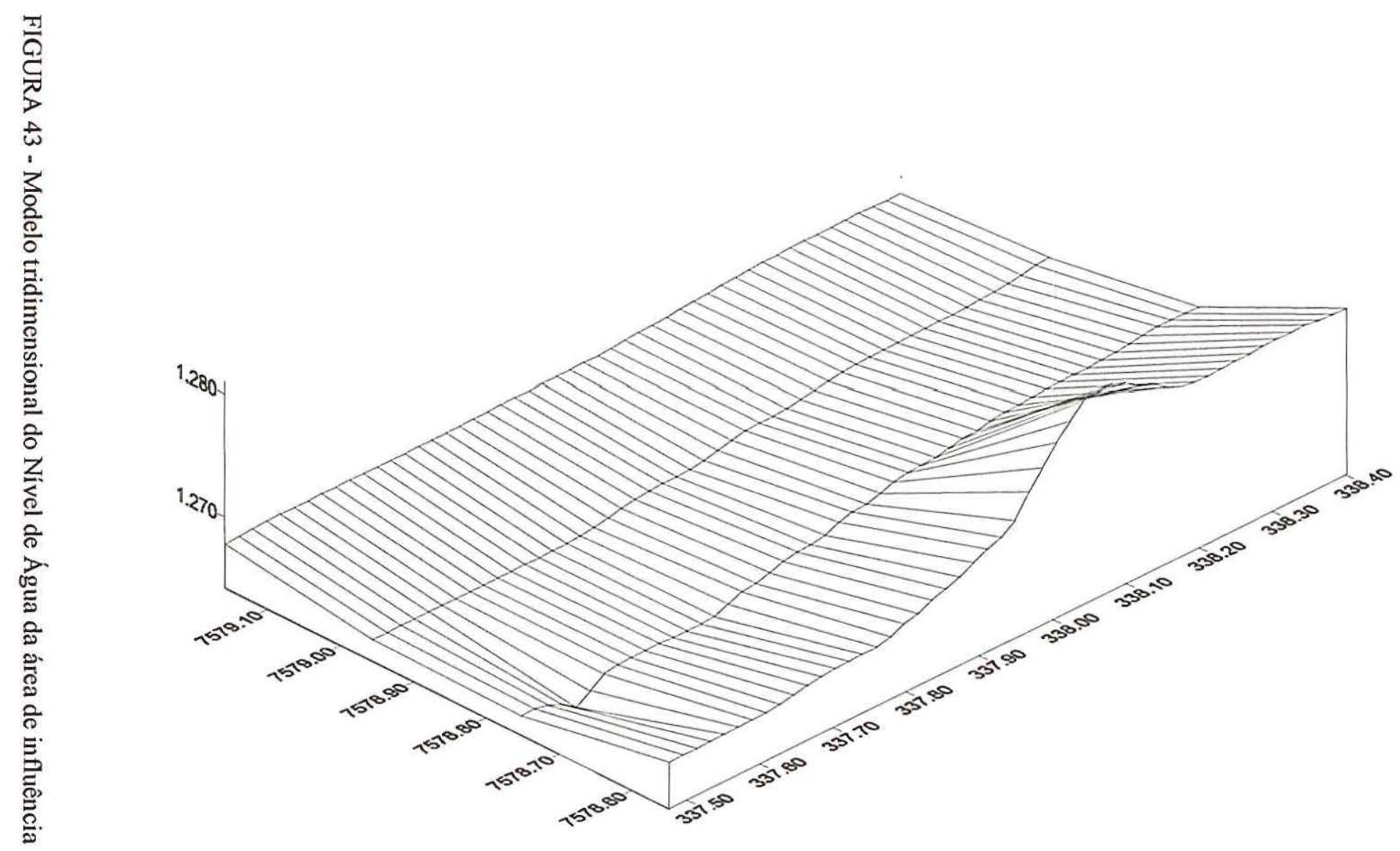

하 


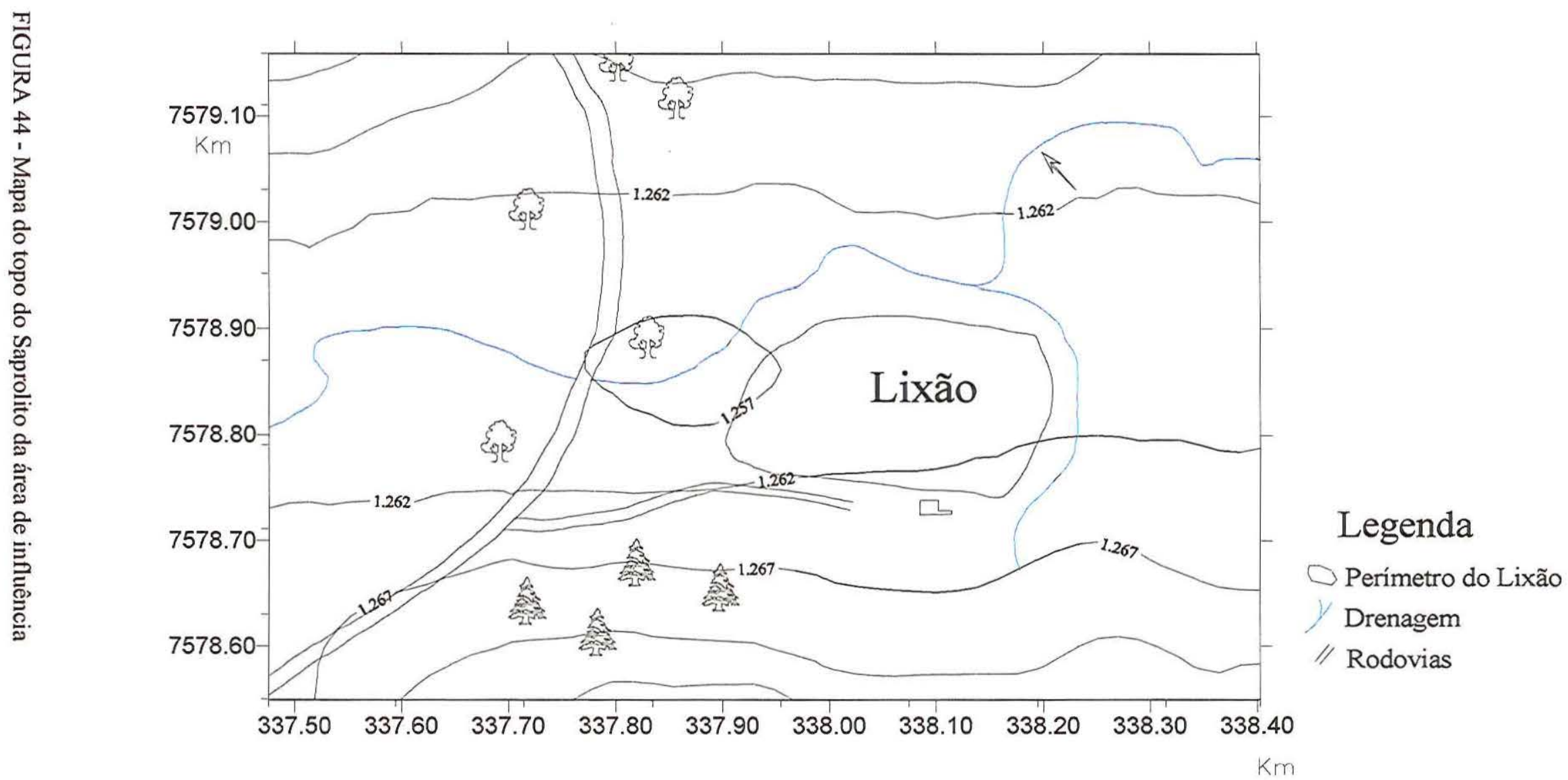




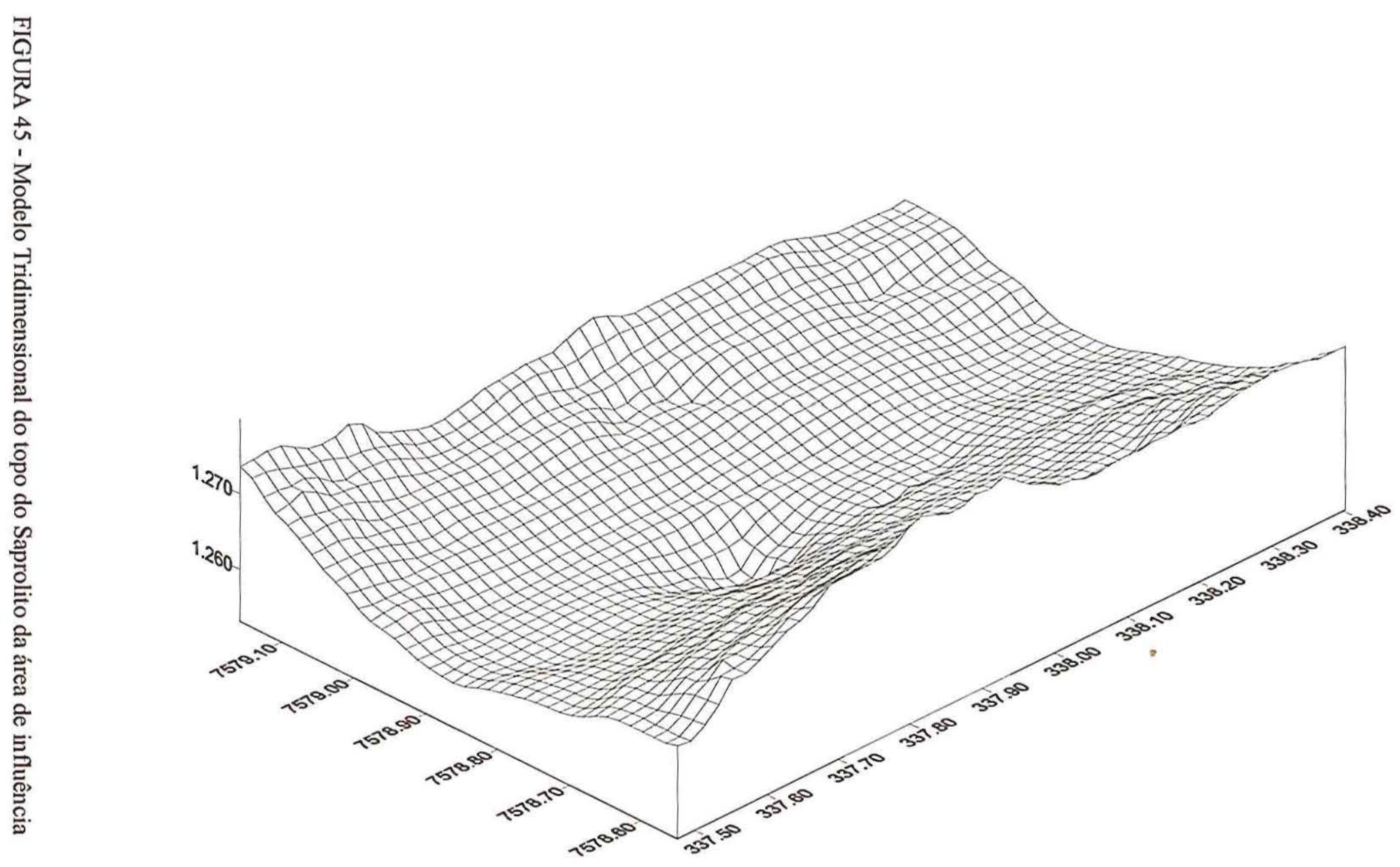




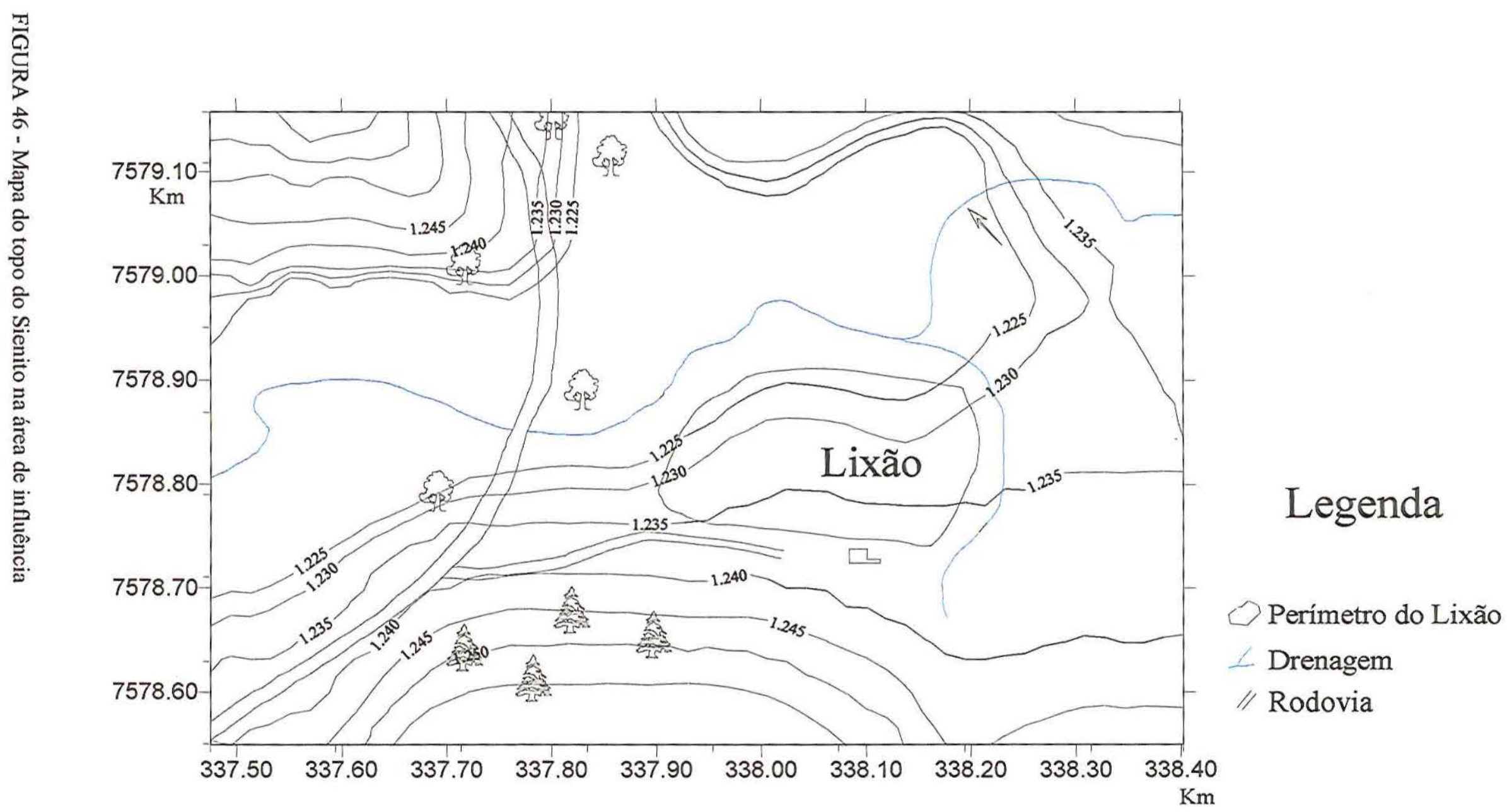




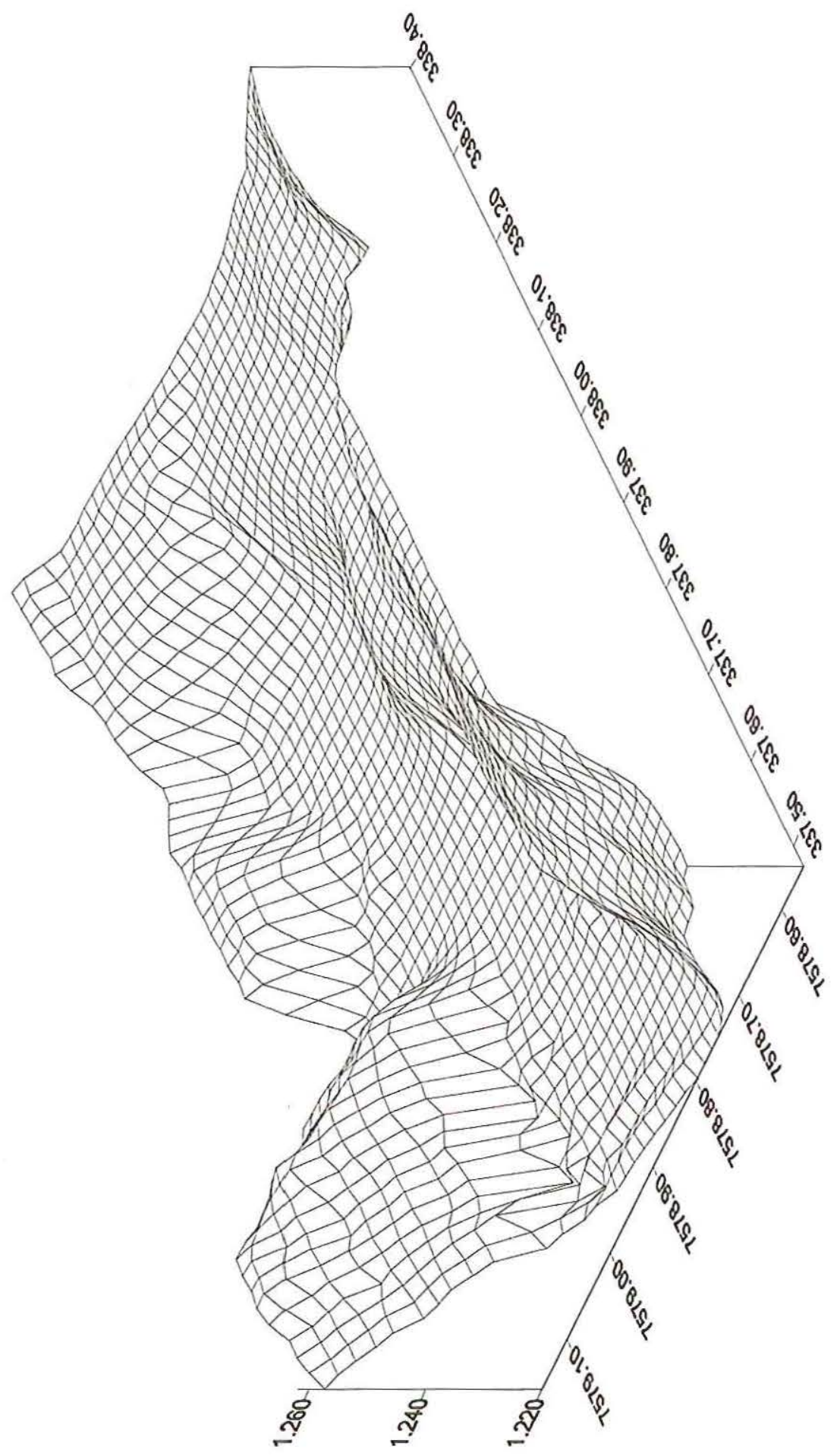

FIGURA 47 - Modelo Tridimensional do topo do Sienito da área de influência do Lixão 


\section{Discretização da Área e Entrada de Dados}

\section{Discretização Temporal}

O tempo adotado na simulação foi de 0 dias até 7300 dias, com intervalos de 1825 dias. O período assumido é função do tempo de funcionamento do Lixão, e o intervalo de tempo, relativamente grande, é devido a pequena quantidade de dados sobre a evolução da pluma (apenas 2 medidas com intervalo de aproximadamente 2 anos), uma maior discretização poderia gerar uma falsa idéia de maior precisão.

\section{Discretização Espacial}

Inicialmente, ao se criar o modelo, gera-se uma malha retangular provisória, que dependendo das características do meio físico, da pluma e das particularidades da situação simulada, pode ser refinada posteriormente. Cabe enfatizar que este passo é muito importante, pois o Visual Modflow considera que os valores na célula é igual ao valor do ponto central da mesma. A discretização deve ser tal que não exclua nenhuma feição importante do modelo e contenha o mínimo de células possível para não sobrecarregar o sistema.

A discretização vertical foi igual para todas as simulações e igual a 3 camadas, esta subdivisão foi função principalmente da condutividade hidráulica das camadas. A camada superior (Camada número 1) representa a camada de solo com condutividade hidráulica de $1,2.10^{-4} \mathrm{~m} / \mathrm{s}$, o nível de saprolito sob o solo foi dividido em duas camadas, a camada número 2 com condutividade hidráulica de $1.10^{-5} \mathrm{~m} / \mathrm{s}$ e a número 3 com condutividade hidráulica de $1.10^{-7} \mathrm{~m} / \mathrm{s}$. A camada de sienito (condutividade hidráulica de $5.4^{-8} \mathrm{~m} / \mathrm{s}$ ) é a base do modelo, considerada como impermeável.

A discretização horizontal inicial foi de 9 colunas e 7 linhas, posteriormente foi feito um refinamento da malha considerando as características do local, a localização da célula em relação ao Lixão, a drenagem, a pluma de contaminação e as particularidades da simulação. A simulação 1 (onde é realizada a modelagem da área sem considerar nenhuma modificação), foi o modelo com o menor número de células, teve 22 colunas, 17 linhas e 3 camadas, totalizando 1122 células. A simulação número 9 foi a que necessitou de maior número de células devido a presença de poços de bombeamento, esta teve 32 colunas, 26 linhas e 3 camadas, totalizando 2496 células. 


\section{Entrada dos dados}

A entrada de dados no Visual Modflow é realizada através de janelas de diálogo entre o usuário e o programa.

\section{Calibração}

Para a calibração foram escolhidos 6 pontos a partir dos resultados da geofísica. Os ensaios foram realizados em duas épocas, permitindo inserir dados considerando tempos diferentes. Na Figura 48 são mostrados os pontos adotados como pontos de observação.

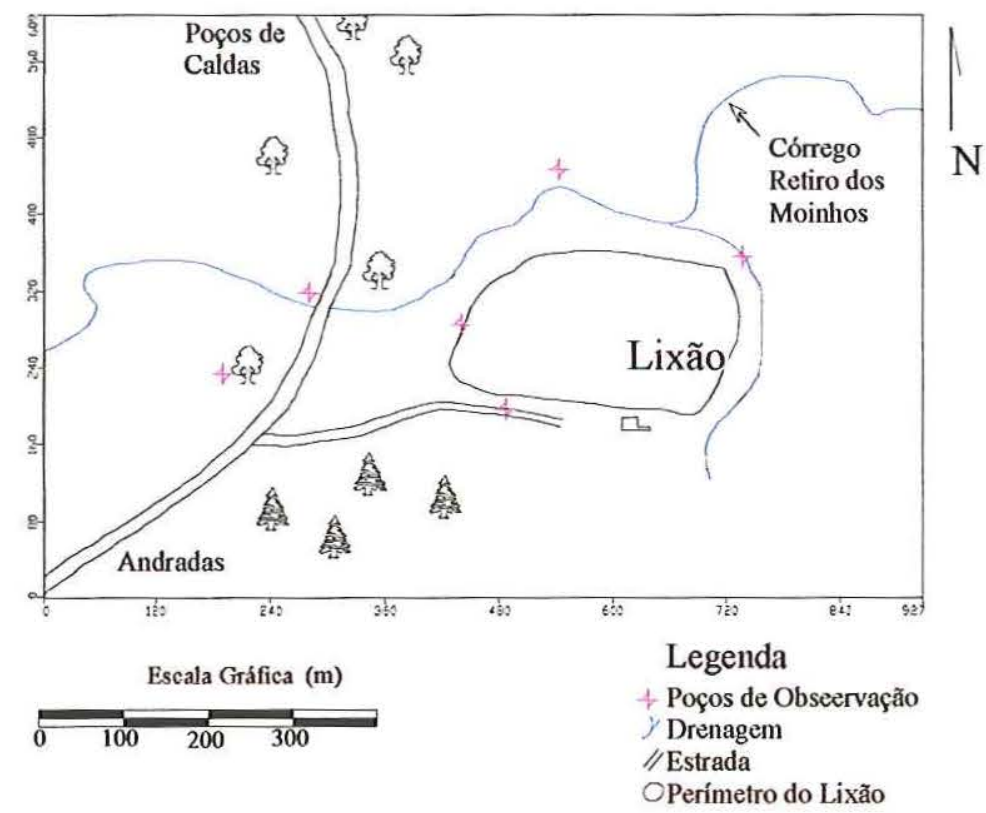

FIGURA 48 - Localização dos Poços de Observação Utilizados para Calibração.

Não há dados químicos sobre os valores de concentração dos contaminantes que formam a pluma. Os valores adotados neste trabalho são produtos de correlações com os valores de resistividade obtidos pela geofisica.

Utilizando os trabalhos de WORTHINGTON (1976) foi possivel transformar os valores de resistividade (ohm.m) em concentrações $(\mathrm{mg} / \mathrm{l})$. Estes valores são válidos para 
meio arenoso, como na caso do Lixão o meio é siltoso utilizou-se a relação proposta por URISH (1983), estas correlações são apresentadas na Tabela 6.

TABELA 6 - Correlações entre os valores de resistividade e os valores de concentração (mg/l).

\begin{tabular}{|c|c|c|}
\hline $\begin{array}{c}\text { Valores de Resistividade } \\
\text { (ohm.m) }\end{array}$ & $\begin{array}{c}\text { Correlação com } \\
\text { WORTHINGTON (1976) }\end{array}$ & $\begin{array}{c}\text { Correlação com } \\
\text { URISH (1983). }\end{array}$ \\
\hline 68 & 100 & 12 \\
\hline 34.5 & 200 & 25 \\
\hline 23.5 & 300 & 50 \\
\hline 17.5 & 400 & 100 \\
\hline 14 & 500 & 200 \\
\hline 12 & 600 & 260 \\
\hline 10.5 & 700 & 320 \\
\hline 9 & 800 & 380 \\
\hline 8 & 900 & 420 \\
\hline 7.1 & 1000 & 500 \\
\hline
\end{tabular}

É importante ressaltar que a resistividade medida é resposta de uma somatória de fatores. Devido a este fato os valores adotados podem não ter grande precisão, no entanto, servem como referência para mostrar as variações nas concentrações com a implantação de diferentes alternativas de remediação.

Os valores apresentados nas figuras 39A e 39B, nos ensaios em dois momentos diferentes, foram utilizados no processo de calibração.

O programa Visual Modflow a partir da comparação entre os dados gerados e os utilizados na calibração, cria um gráfico de erros, são apresentados os gráficos para a simulação 1, representados nas figuras 49 e 50, respectivamente para o Modelo de Fluxo e para o Modelo de Transporte. Admite neste trabalho, um erro menor que 10 para validar o modelo. 


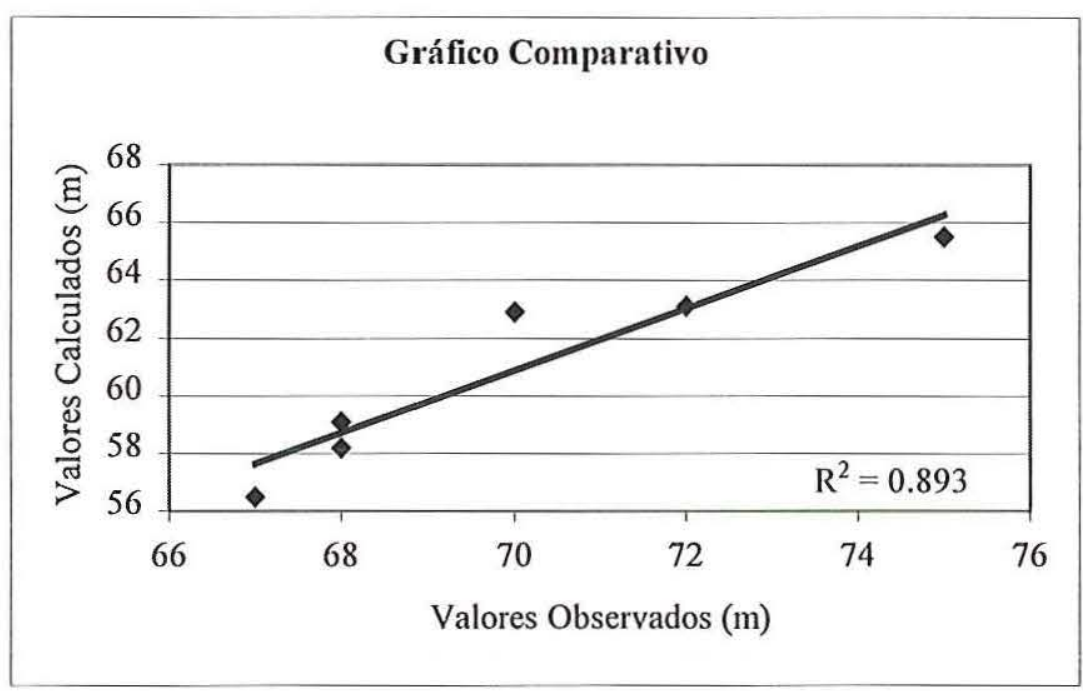

FIGURA 49 - Gráfico de erro médio para o Modelo de Fluxo. Valor de Erro = 6.05.

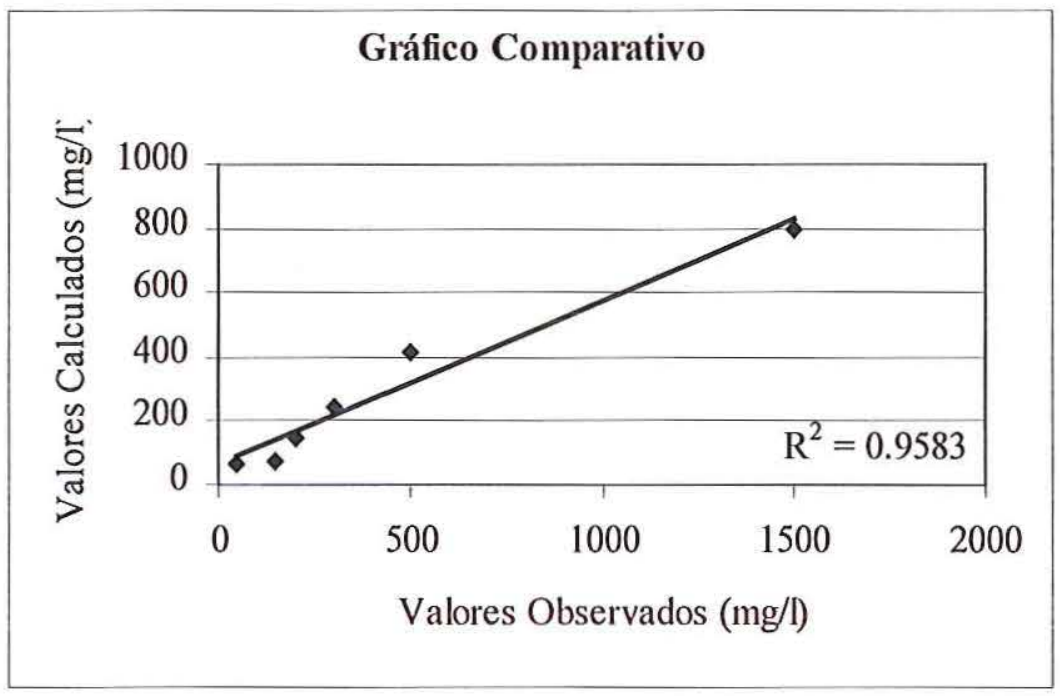

FIGURA 50 - Gráfico de erro médio para o Modelo de Transporte. Valor de Erro = 4.12. 


\section{Análise de Sensibilidade}

Após a construção do modelo, este foi rodado várias vezes alterando valores de recarga, evapotranspiração, condutância, condutividade hidráulica e coeficiente de armazenamento, dentro de uma gama plausível de valores. O objetivo da análise de sensibilidade é quantificar as incertezas no modelo calibrado causadas pelas variações dos parâmetros. 


\section{Análise dos Resultados das Simulações}

O Visual Modflow fornece os resultados na forma de mapas e perfis verticais, sendo que os mapas representam a delimitação horizontal da pluma de contaminação no topo de cada camada, nos vários intervalos de tempo do modelo, e os perfis verticais mostram a distribuição vertical dos solutos no meio físico.

Os perfis podem ser feitos paralelamente ao eixo X (linhas) e ao eixo Y (colunas), neste trabalho é apresentado um exemplo de perfil em linha e em coluna para cada simulação. As figuras $51 \mathrm{~A} \mathrm{e} \mathrm{B}$, apresentam a localização destes perfis para as simulações de 1 a 8, cabe ressaltar que devido a grade variar dependendo das particularidades de cada caso, a localização exata do perfil pode ser deslocada. Os perfis da simulação 9 estão localizados mais ao norte da área, isto foi feito com o objetivo de representar a zona de influência dos poços.

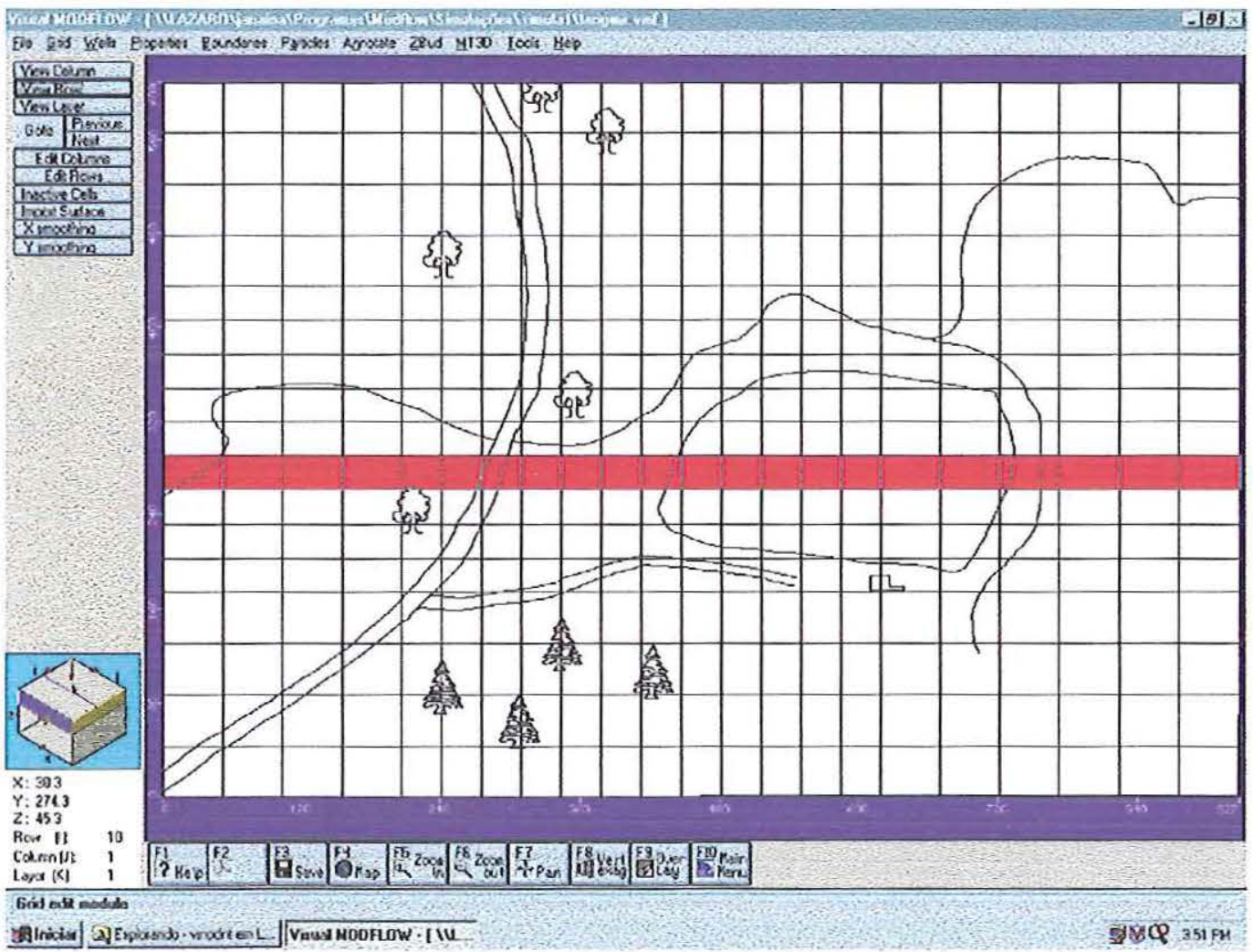

FIGURA 51A - Localização dos perfis paralelos ao eixo X (perfis em Linha), longitudinal a direção de maior espalhamento da pluma de poluição. 


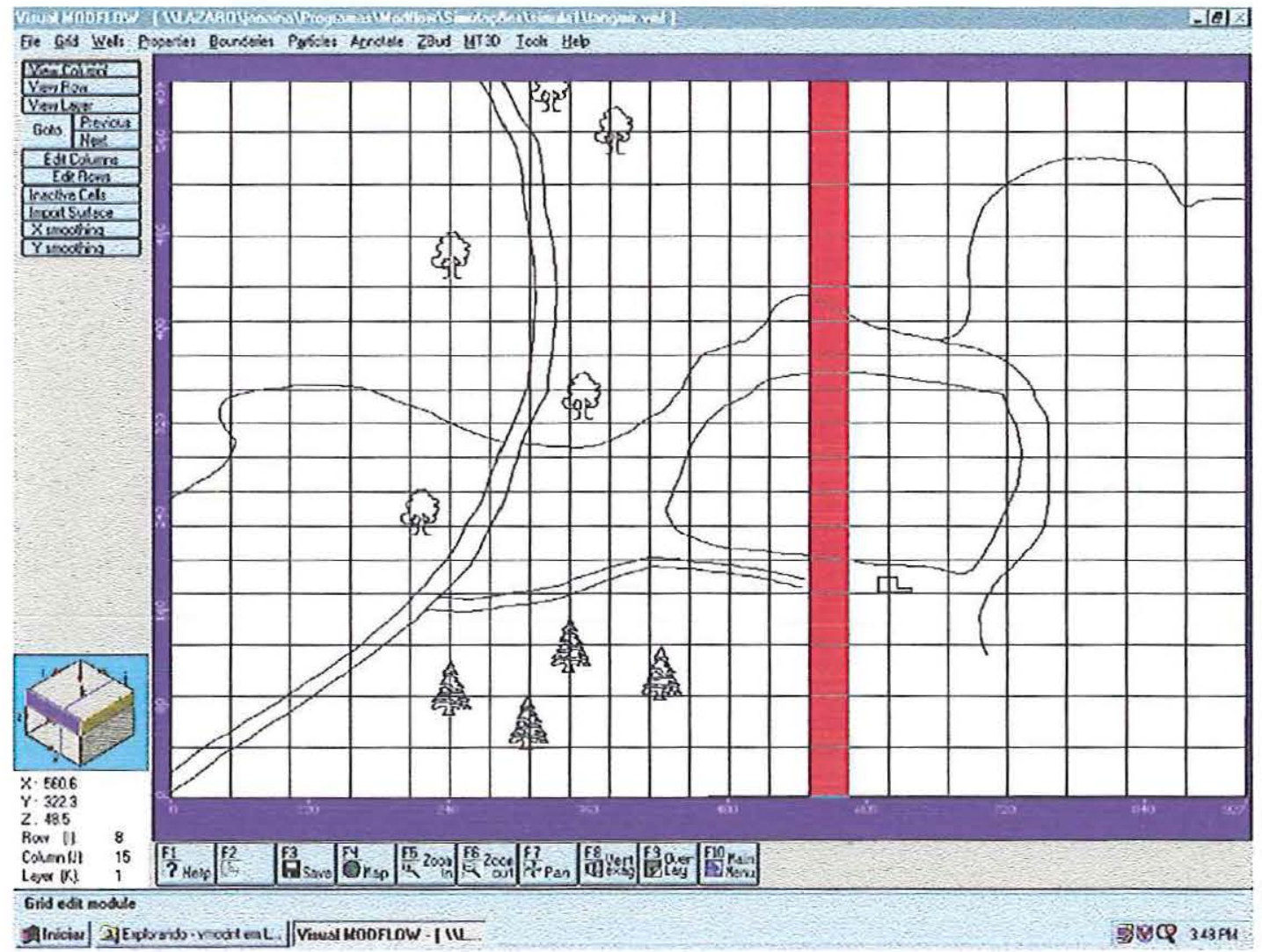

FIGURA 51B - Localização dos perfís paralelos ao eixo Y (perfís em coluna), transversal a direção de maior espalhamento da pluma de poluição. 
Simulação número 1 - Modelagem da Situação Atual

Nesta simulação as características físicas do meio são preservadas, este modelo é importante pois servirá como base para as demais situações, já que os resultados obtidos podem ser comparados diretamente com os dados obtidos em campo.

Os resultados obtidos para esta simulação são:

\section{Modelo de Fluxo}

O modelo de fluxo mostra uma direção preferencial de fluxo no sentido dos limites horizontais do modelo para o centro da área, região onde localiza-se o leito do Córrego dos Moinhos.

O Visual Modflow utiliza-se de vetores para indicar a direção, sentido e intensidade do movimento. Observa-se na Figura 52 que na margem sul do Córrego do Moinho o gradiente hidráulico favorece um fluxo mais intenso, é nesta margem que está localizado o Lixão.

Em alguns pontos os vetores cruzam a drenagem sem sofrer influência, isto é devido ao espaçamento da grade, já que para cada célula existe apenas um vetor relacionado ao ponto central da célula.

\section{Modelos de Transporte}

Por esta simulação observa-se que a pluma de contaminação formada pelo lixão sofre forte influência do fluxo atuante na área, esta característica sugere que o mecanismo de transporte dominante seja o Advectivo.

A Figura 53 mostra o caminhamento do soluto, observa-se que este é condicionado pelo fluxo de água subsuperficial da área. As figuras 54 a 62 mostram um transporte lento já que não é visível um grande deslocamento entre os tempos, principalmente entre $3650 \mathrm{e}$ 7300 dias, esta característica é mais importante na camada, para as camadas 2 e 3 o espalhamento é relativamente rápido. 0 modelo também mostra que o perímetro da pluma com o tempo no topo da camada número 1 não aumenta de maneira expressiva, no entanto nota-se um aumento na concentração de contaminante.

Na segunda camada observa-se uma situação diferente, inicialmente a pluma apresenta-se com pequeno espalhamento e, posteriormente, a pluma aparece maior em área e com os mesmos níveis de contaminação. Na camada 3 a pluma de contaminação inicial apresenta níveis de concentração que com o tempo diminui, paralelamente aparecem outros 
pontos de contaminação que se unem e formam uma pluma de contaminação com níveis de contaminação muito baixos. Estas variações são respostas de diferentes características do meio, principalmente da condutividade hidráulica e do gradiente hidráulico da células.

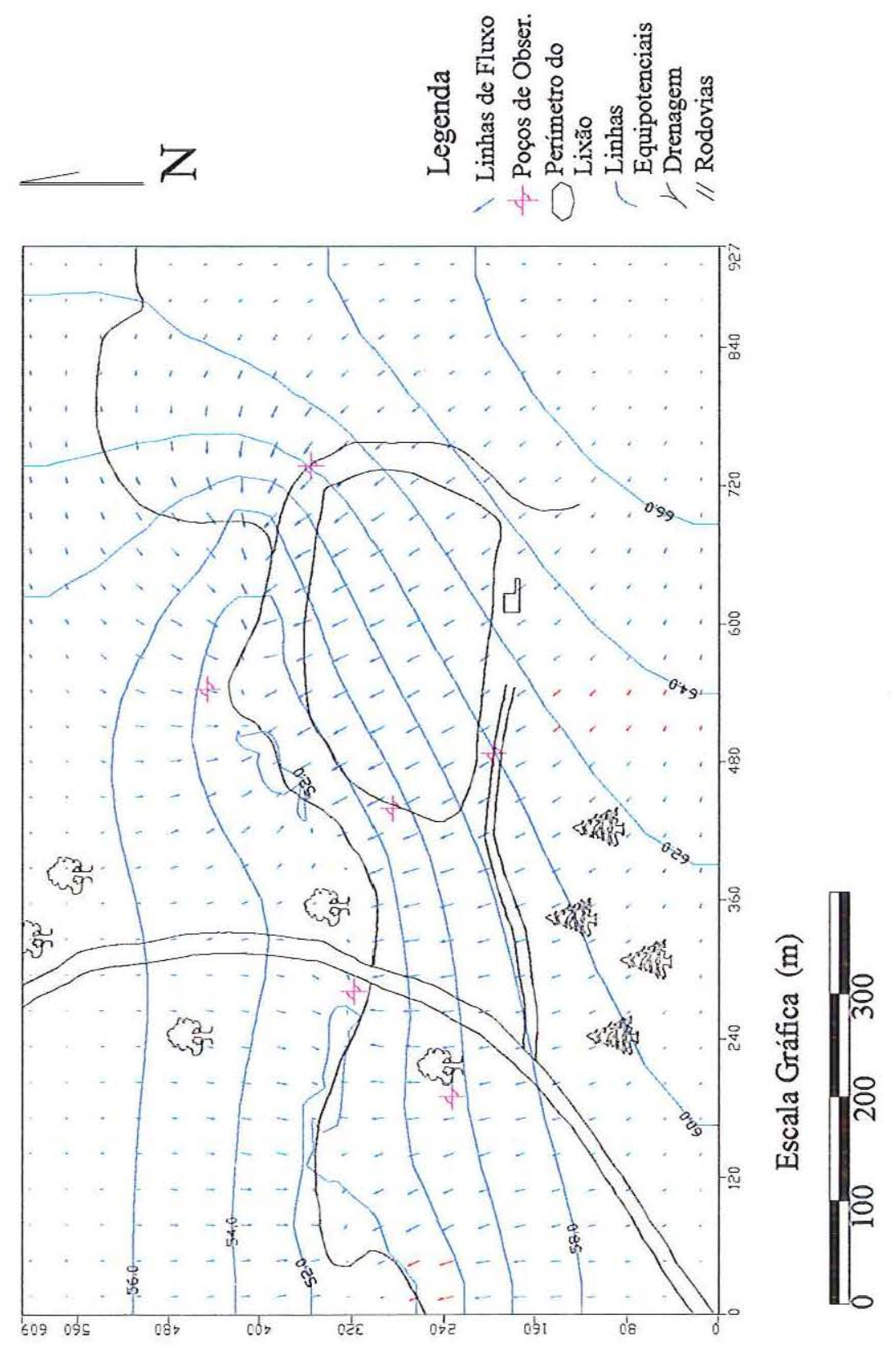

FIGURA 52 - Modelo de Fluxo das águas subsuperficiais na área de influência 


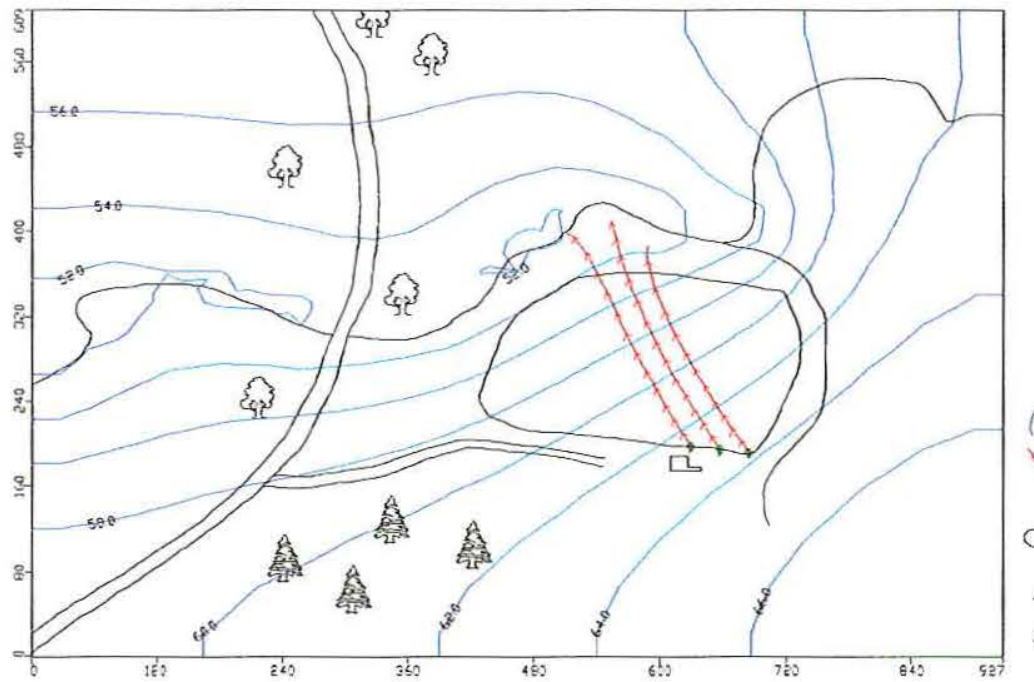

Escala Gráfica (m)

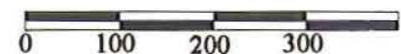

$\left.\right|_{N}$

\section{Legenda}

Linhas Equipotenciais

Caminhamento das partículas

Perímetro do Lixão

Drenagem

Rodovias

\section{FIGURA 53 - Trajetória das Partículas}

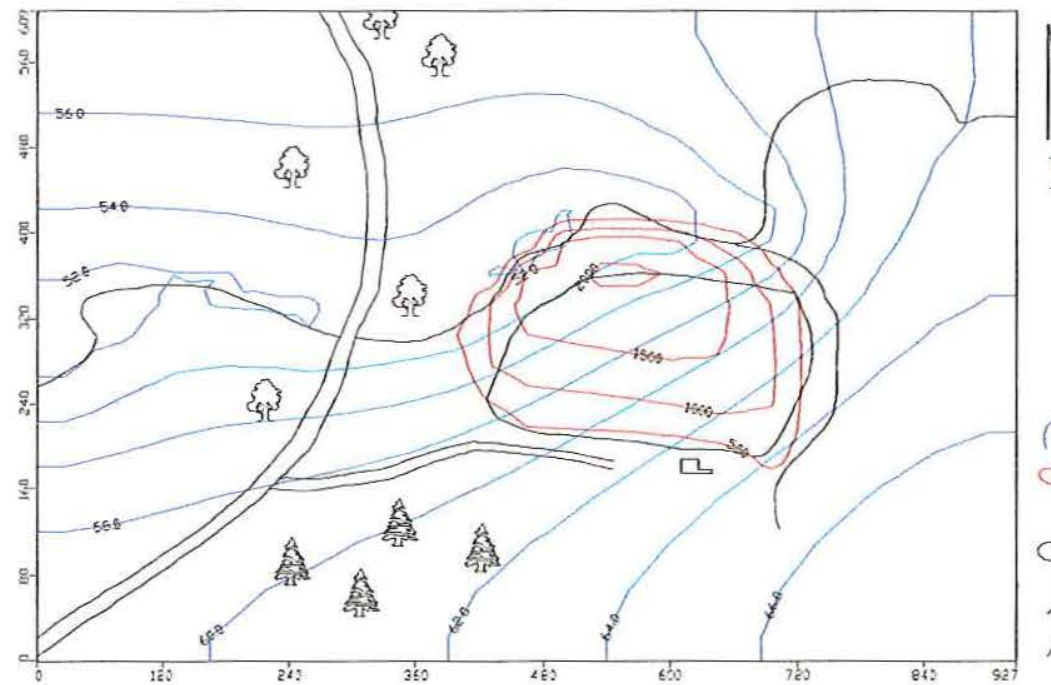

Escala Gráfica (m)

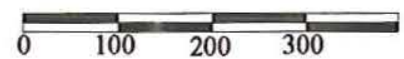

$\mathrm{N}$

\section{Legenda}

Linhas Equipotenciais

Delimitação de Níveis de

Concentração da Pluma

$\bigcirc$ Perímetro do Lixão

, Drenagem

// Rodovias

FIGURA 54 - Modelo de Transporte. Camada 1 Tempo 1825 dias. 


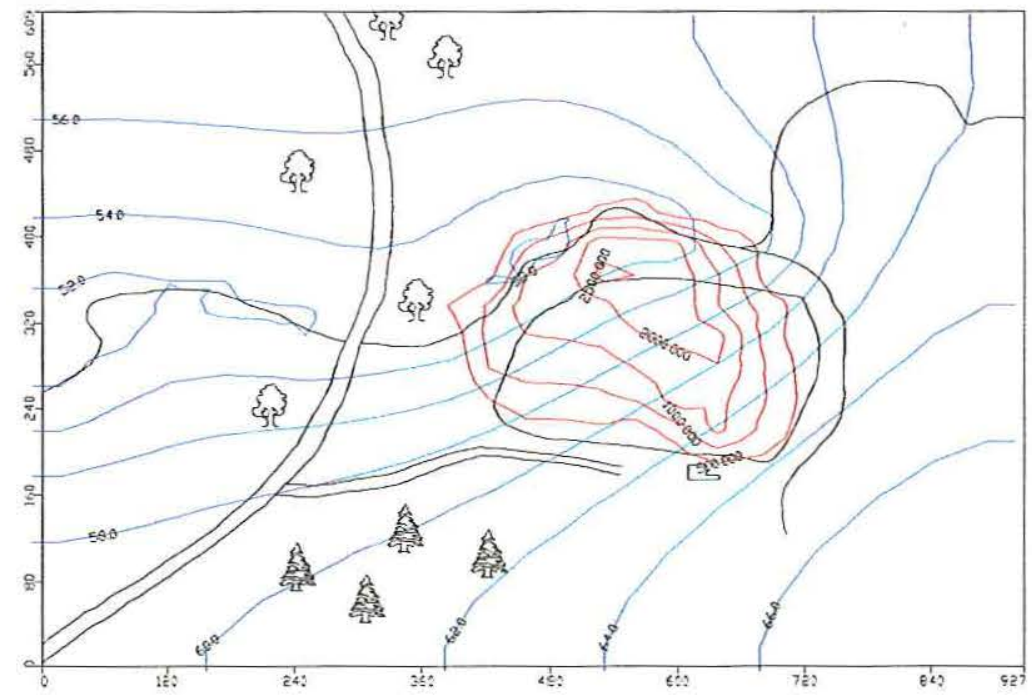

$\mathrm{N}$

\section{Legenda}

Linhas Equipotenciais

$\checkmark$ Delimitação de Níveis de Concentração da Pluma

$\checkmark$ Perímetro do Lixão

y Drenagem

// Rodovias

Escala Gráfica (m)

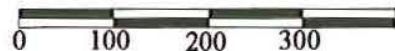

FIGURA 55 - Modelo de Transporte. Camada 1 Tempo 3650 dias.

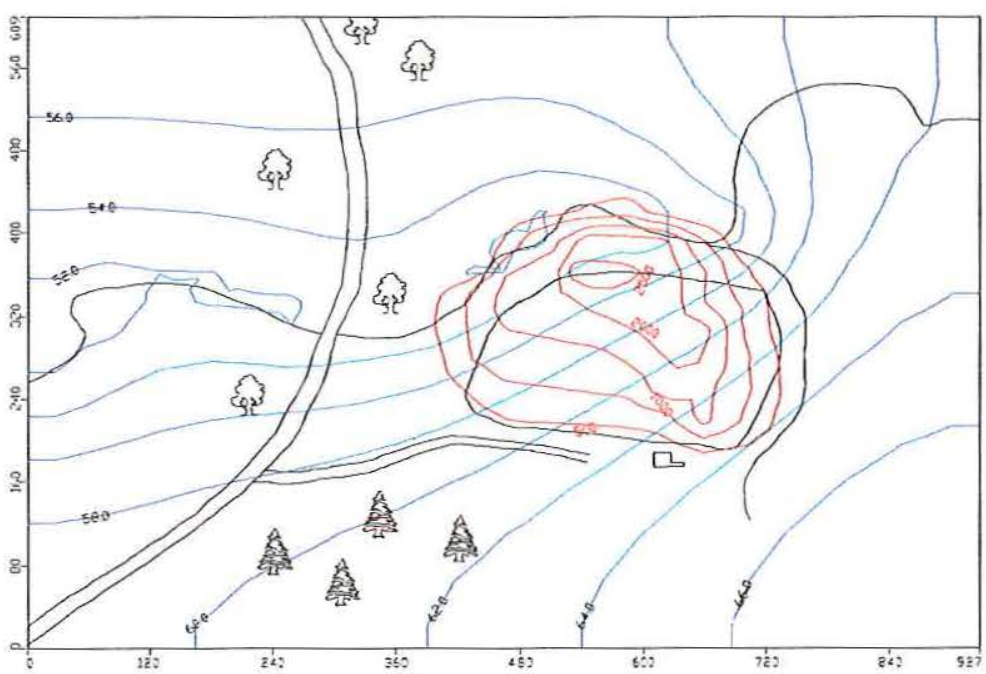

Escala Gráfica (m)

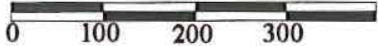

\section{Legenda}

C Linhas Equipotenciais Delimitação de Níveis dt Concentração da Pluma

$\bigcirc$ Perímetro do Lixão

$\gamma$ Drenagem

$/ /$ Rodovias

FIGURA 56 - Modelo de Transporte. Camada 1 Tempo 7300 dias. 


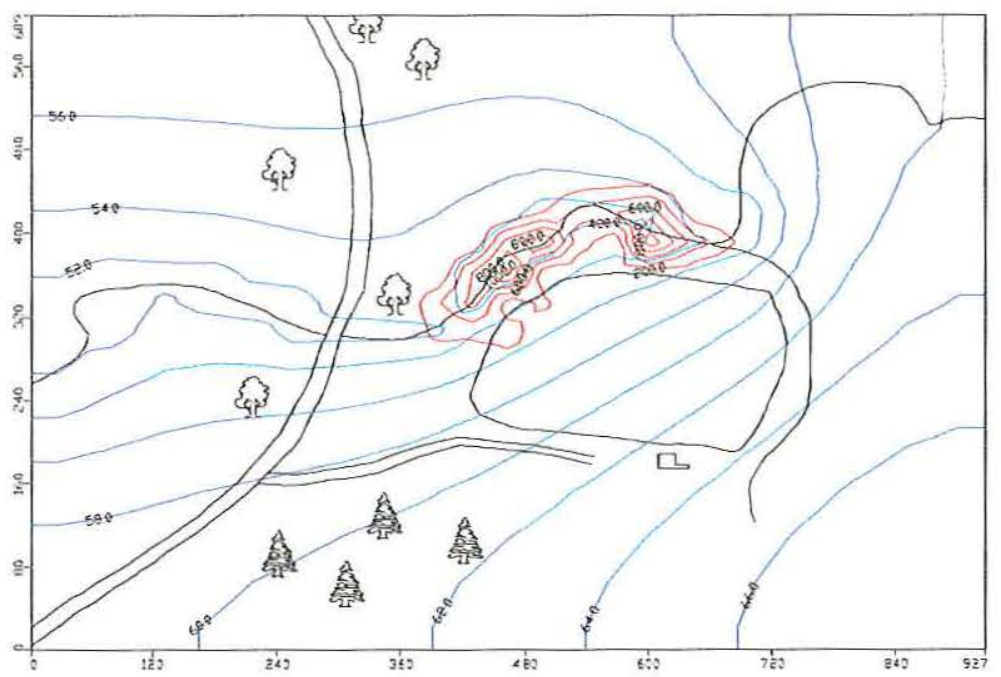

${ }_{\mathrm{N}}$

\section{Legenda}

Linhas Equipotenciais

$\checkmark$ Delimitação de Níveis de

Concentração da Pluma

Perímetro do Lixão

$\gamma$ Drenagem

// Rodovias

Escala Gráfica (m)

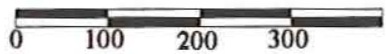

FIGURA 57 - Modelo de Transporte. Camada 2 Tempo 1825 dias.

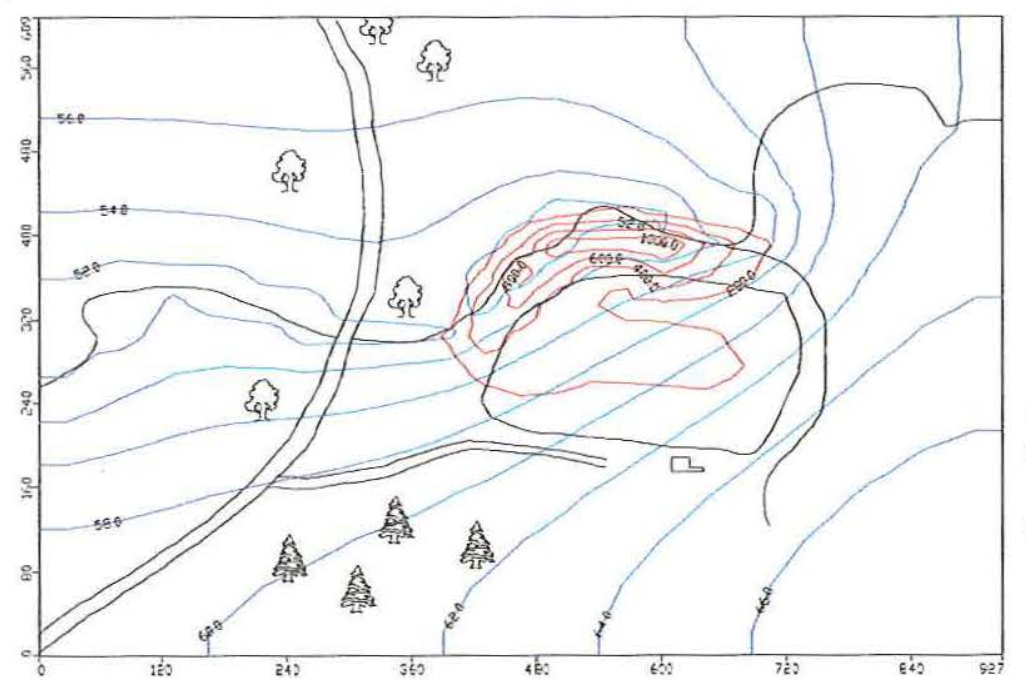

Escala Gráfica (m)

$\mathrm{N}$

\section{Legenda}

- Linhas Equipotenciais

Delimitação de Níveis de Concentração da Pluma

$\bigcirc$ Perímetro do Lixão

$\gamma$ Drenagem

// Rodovias

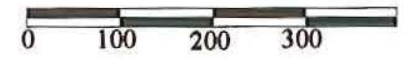

FIGURA 58 - Modelo de Transporte. Camada 2 Tempo 3650 dias. 

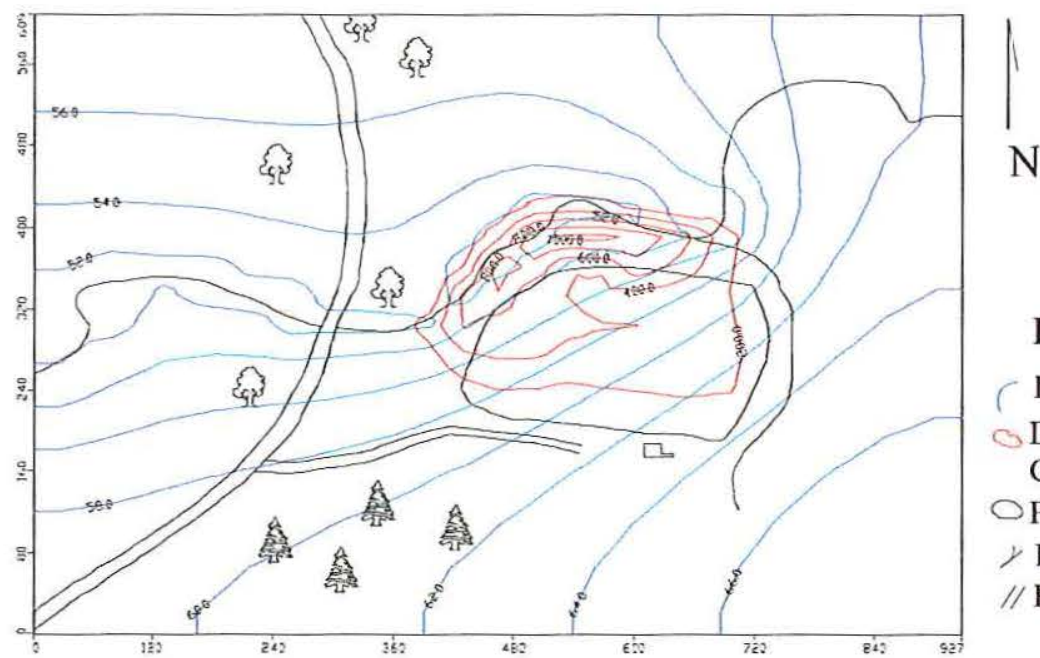

\section{Legenda}

Linhas Equipotenciais

○elimitação de Níveis de Concentração da Pluma

$\bigcirc$ Perímetro do Lixão

¿ Drenagem

// Rodovias

Escala Gráfica (m)

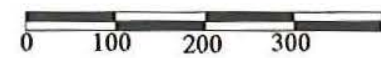

FIGURA 59 - Modelo de Transporte. Camada 2 Tempo 7300 dias.

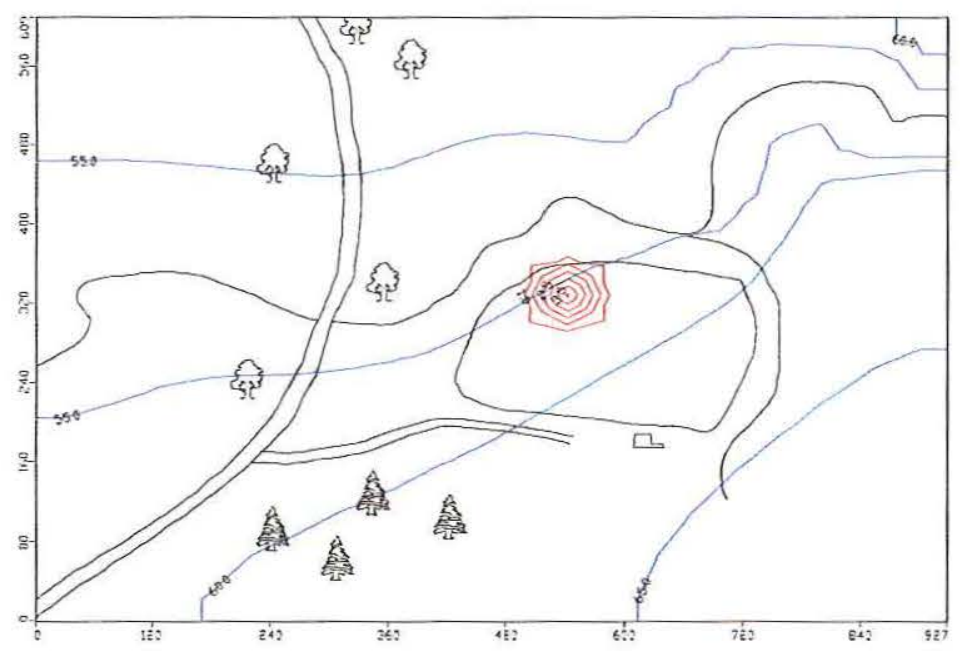

Legenda

( Linhas Equipotenciais

○elimitação de Níveis de

Concentração da Pluma

$\bigcirc$ Perímetro do Lixão

$\gamma$ Drenagem

// Rodovias

Escala Gráfica (m)

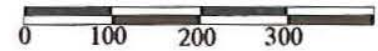

FIGURA 60 - Modelo de Transporte. Camada 3 Tempo 1825 dias. 


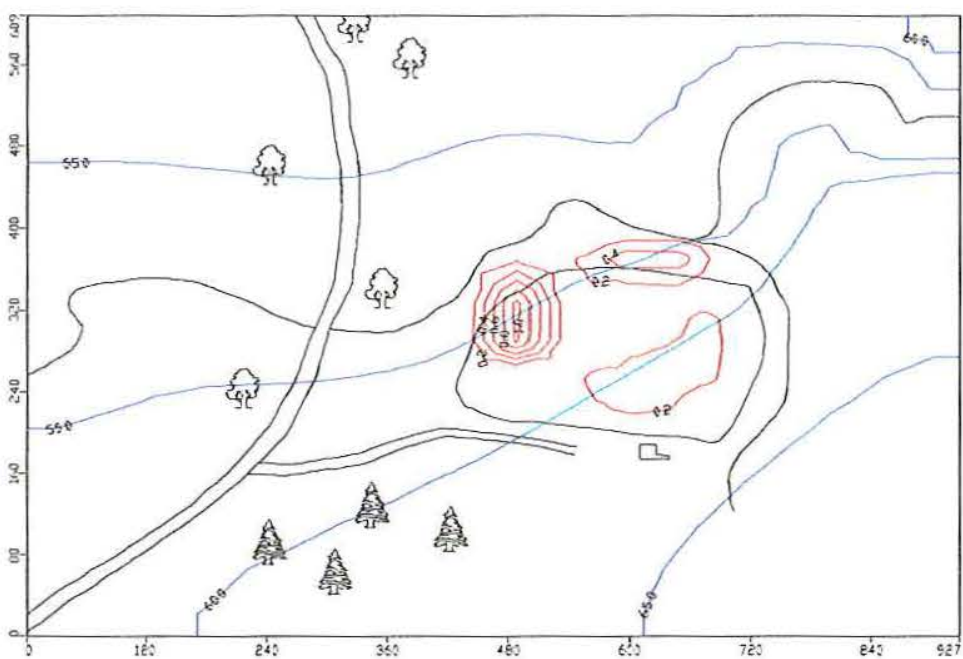

1

\section{Legenda}

Linhas Equipotenciais

$\bigcirc$ Delimitação de Níveis de

Concentração da Pluma

$\bigcirc$ Perímetro do Lixão

$\gamma$ Drenagem

// Rodovias

Escala Gráfica (m)

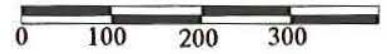

FIGURA 61 - Modelo de Transporte. Camada 3 Tempo 3650 dias.

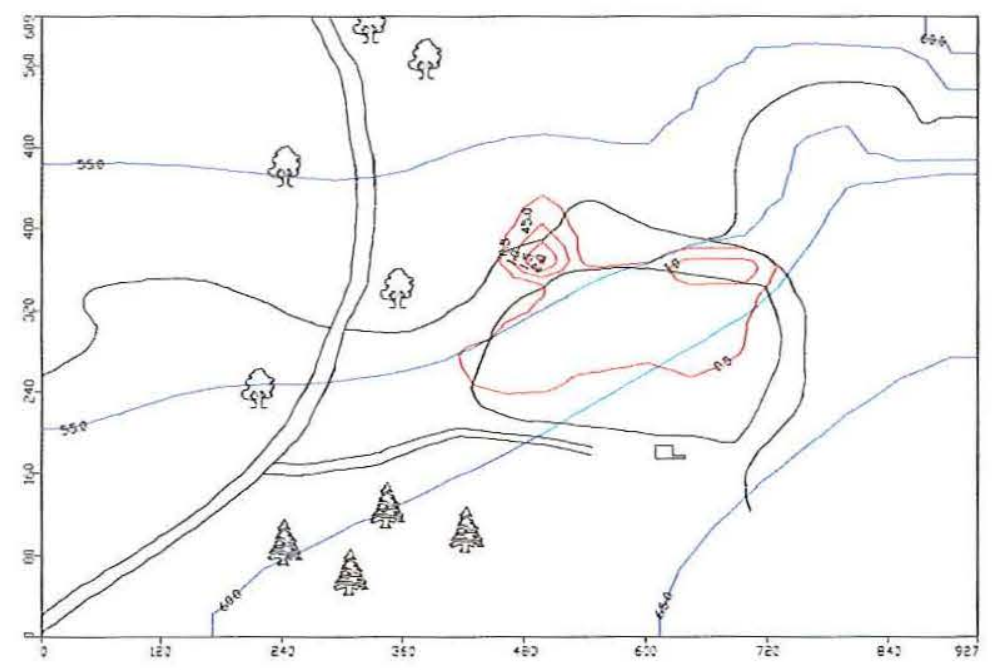

Escala Gráfica (m)

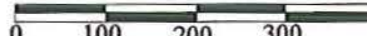

\section{Legenda}

Linhas Equipotenciais

Delimitação de Níveis de Concentração da Pluma

O Perímetro do Lixão

Drenagem

// Rodovias

FIGURA 62 - Modelo de Transporte. Camada 3 Tempo 7300 dias. 
Os perfis gerados a partir deste modelo são apresentados nas figuras 63 a 68 . Nestes é possível visualizar a distribuição dos solutos e, principalmente, a influência da drenagem no transporte do contaminante.

As figuras 63 e 64 mostram uma evolução continua da pluma, com intervalos regulares de níveis de concentração, na Figura 65 observa-se que estes espaçamentos são alterados, isto é devido a representação da pluma ao atingir a camada 2, que por apresentar características hidrogeológicas distintas, altera a velocidade da pluma de poluição.

Através dos perfís é possível observa-se que a camada 3 não é atingida de maneira significativa. 


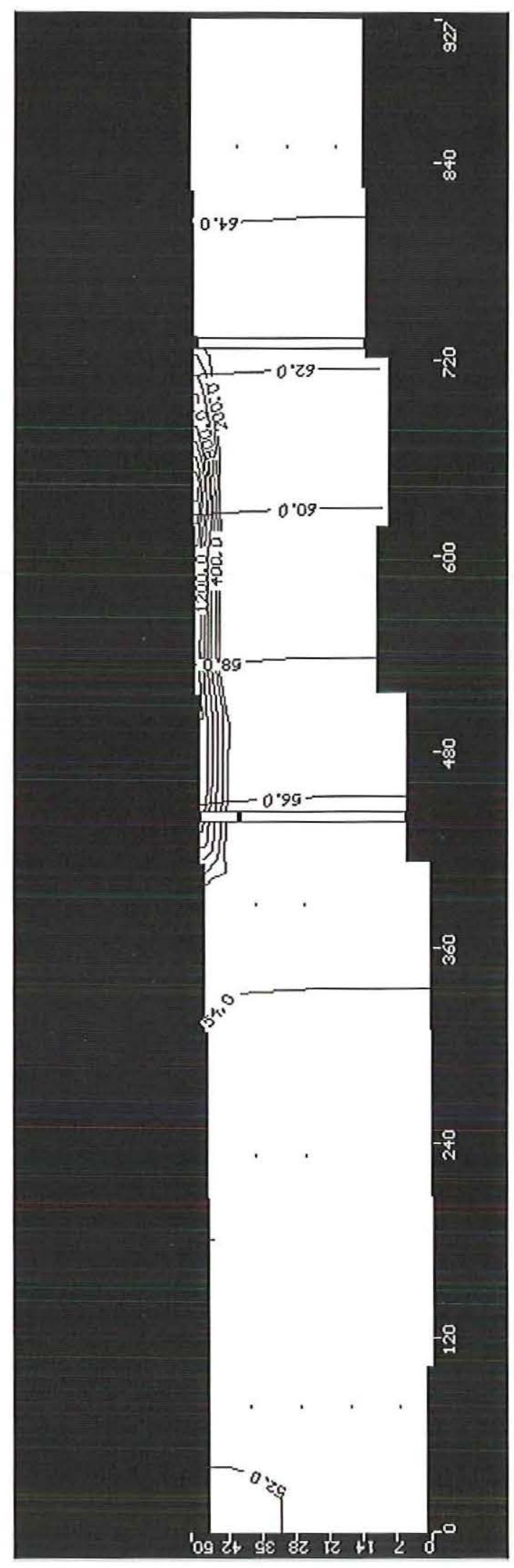

FIGURA 63 - Perfil Longitudinal a direção de maior espalhamento da pluma (Linha) Tempo 1825 dias. 


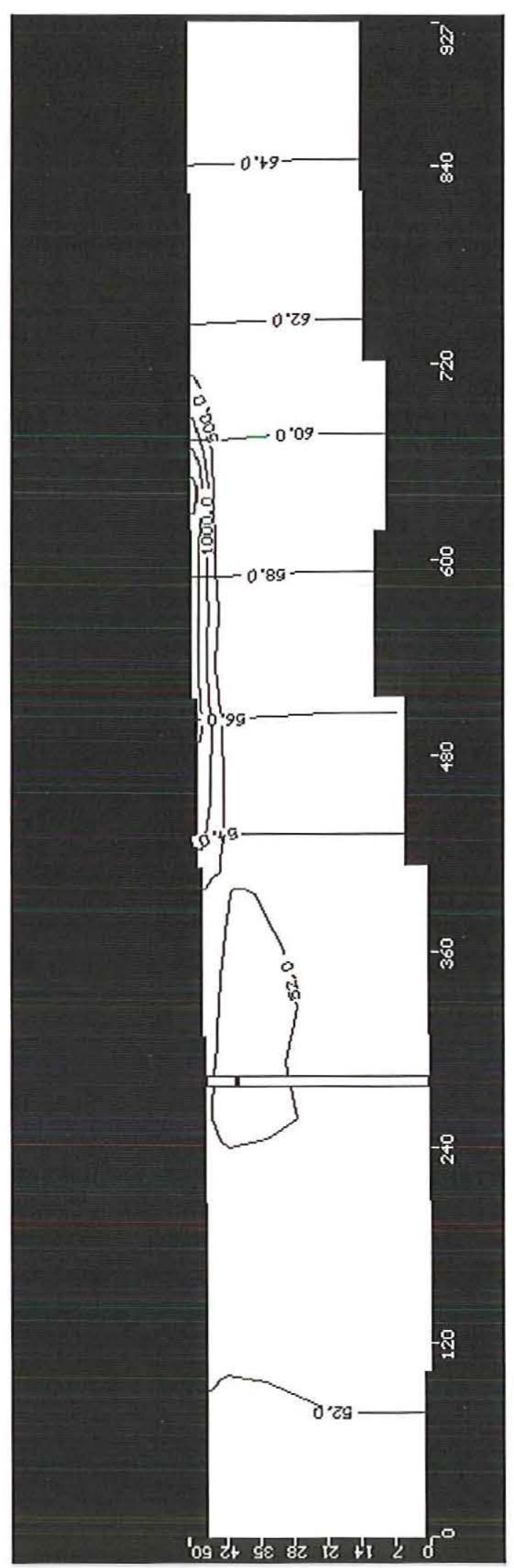

FIGURA 64 - Perfil Longitudinal a direção de maior espalhamento da pluma (Linha) na Tempo 3650 dias. 


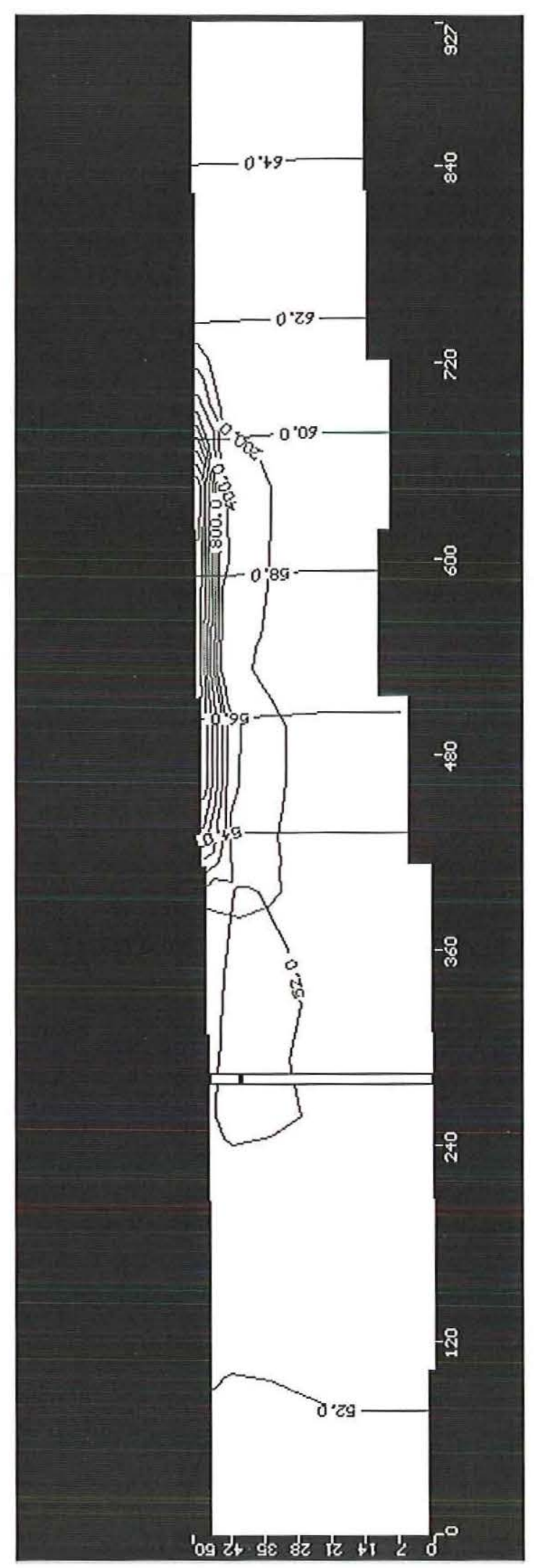

FIGURA 65 - Perfil Longitudinal a direção de maior espalhamento da pluma (Linha) Tempo 7300 dias. 


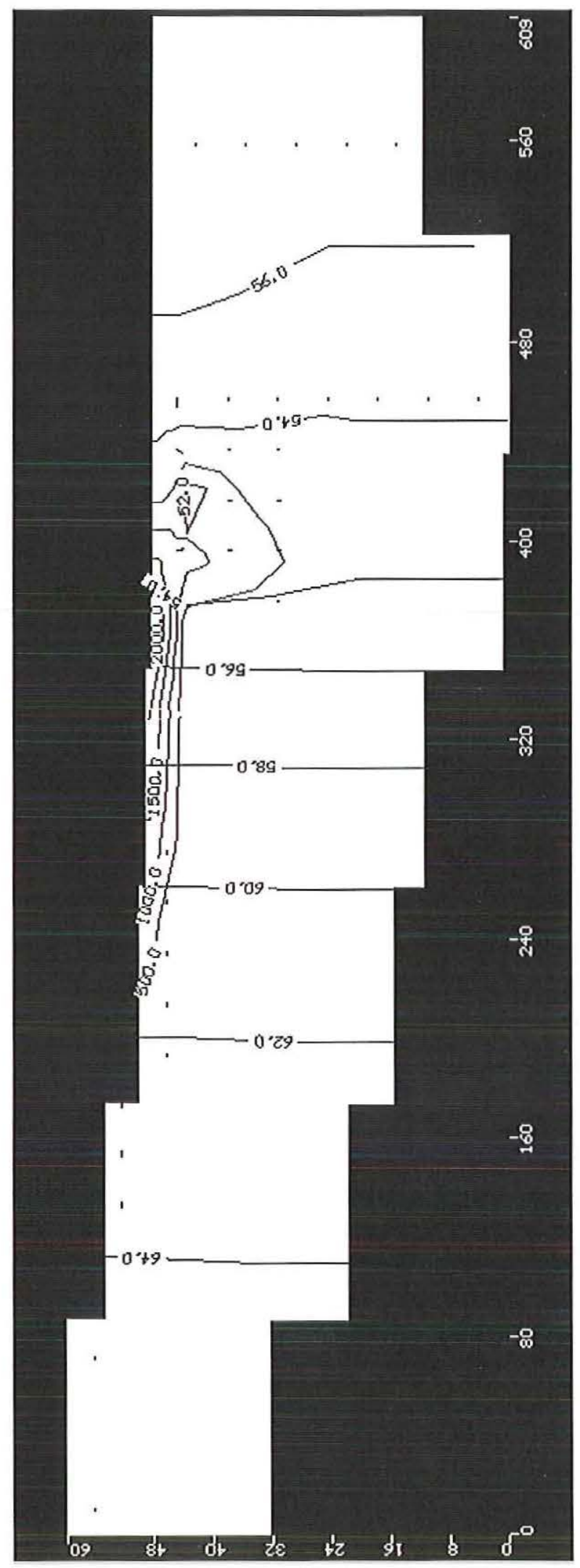

FIGURA 66 - Perfil Transversal a direção de maior espalhamento da pluma (Coluna) no Tempo 1825 dias. 


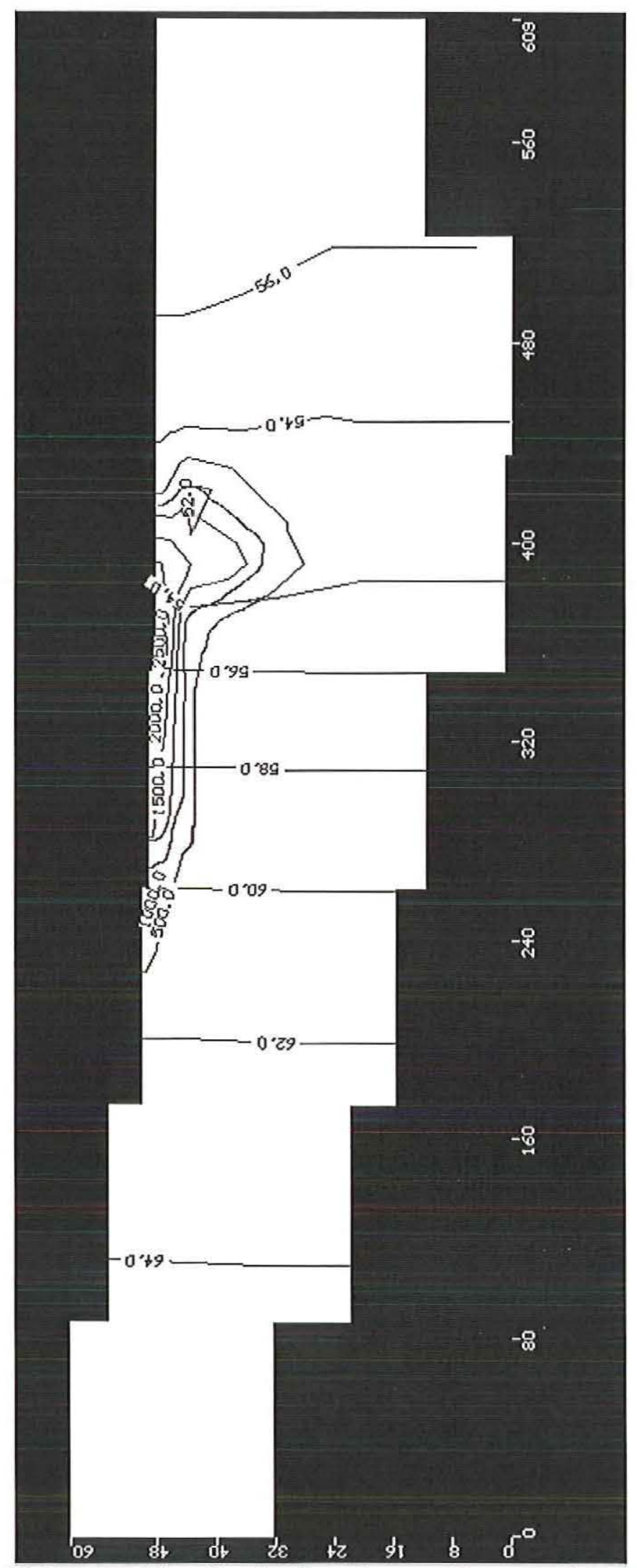

FIGURA 67 - Perfil Transversal a direção de maior espalhamento da pluma (Coluna) no Tempo 3650 dias. 


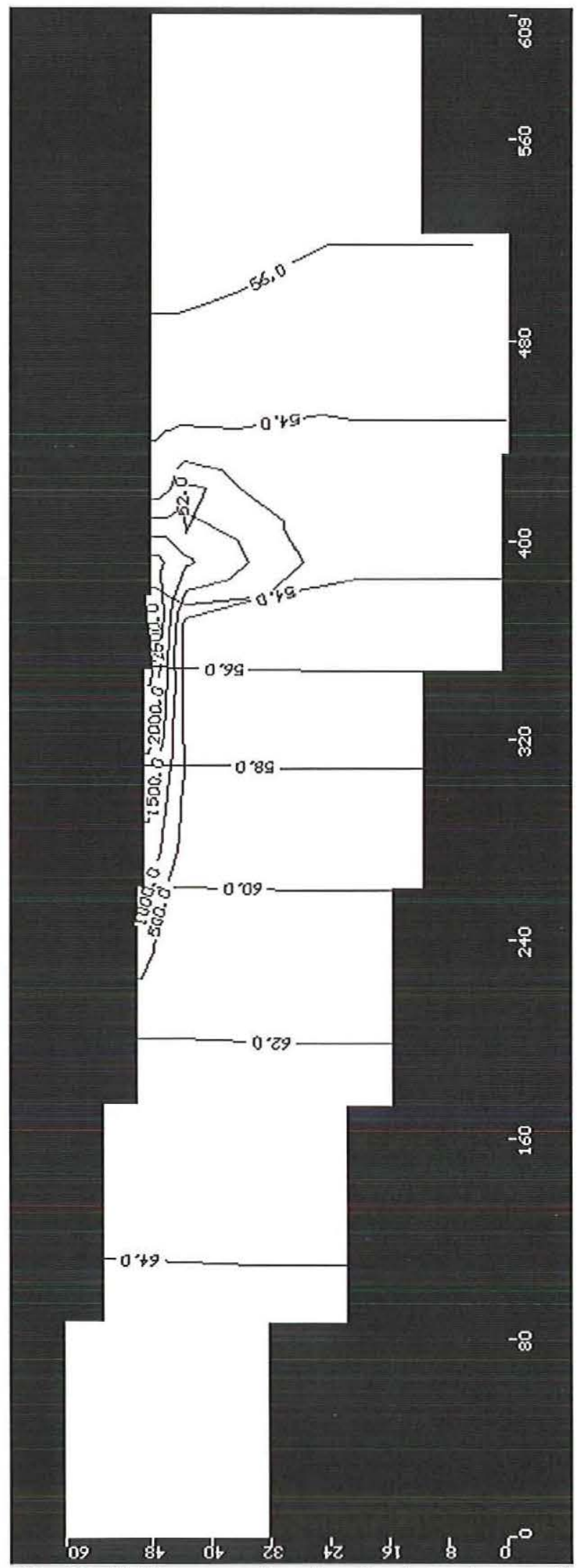

FIGURA 68 - Perfil Transversal a direção de maior espalhamento da pluma (Coluna) no Tempo 7300 dias. 
Simulação da Situação Real utilizando-se a Isoterma de Sorção Linear

As figuras 69A, 69B e 69C apresentam os resultados da mesma simulação número 1, apenas substituindo os valores da Isoterma de Sorção de Langmuir pelos da Isoterma de Sorção Linear, desta forma estes produtos puderam ser comparados entre si e com os dados obtidos em campo. Através destas comparações verificou-se que os modelos gerados aplicando a Isoterma de Langmuir representavam melhor o mecanismo de sorção atuante na área.

Observa-se que o espalhamento nesta simulação é maior que quando se considera a Isoterma de Langmuir, isto é devido a concentração de soluto na fonte ser teoricamente constante.

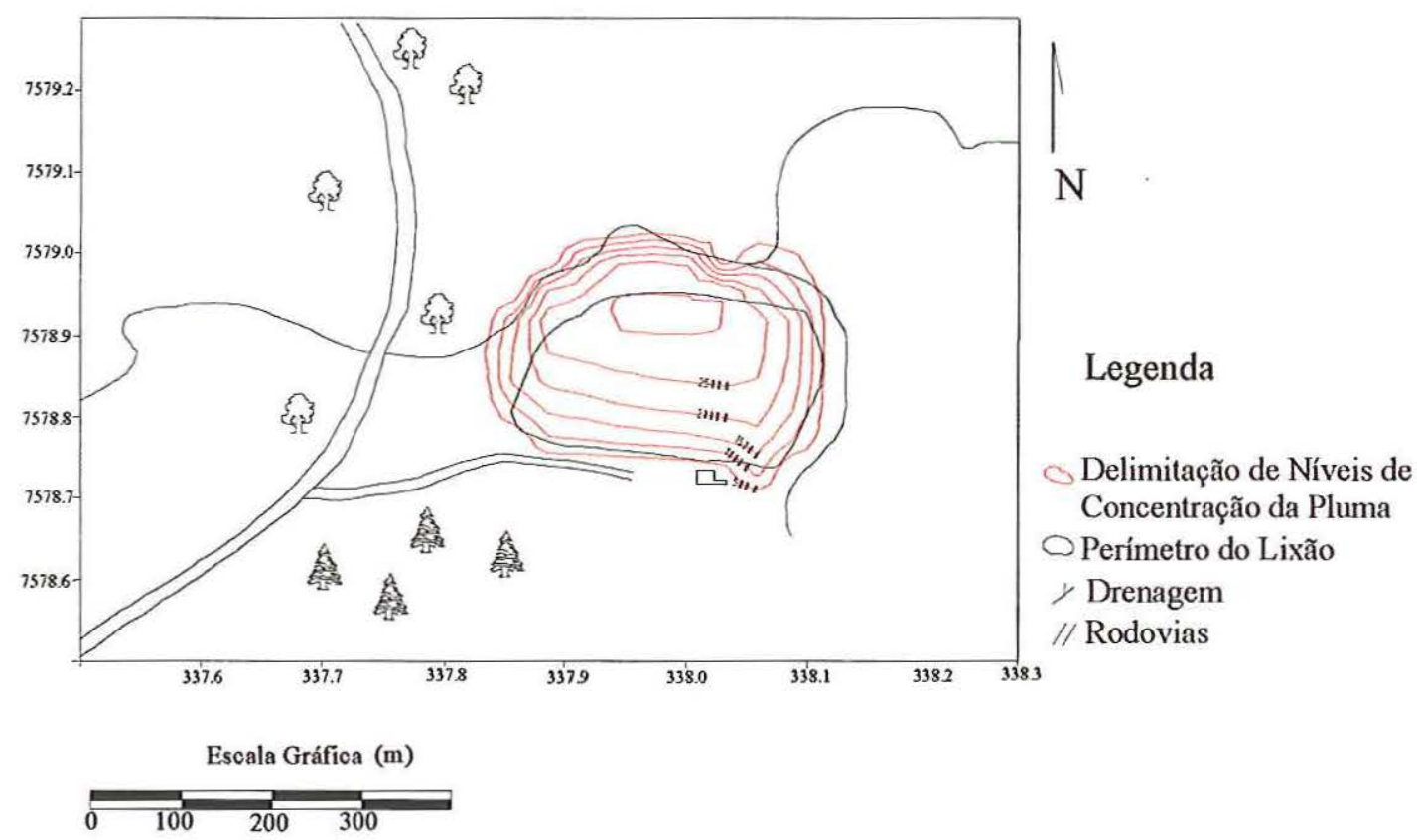

FIGURA 69A - Modelo de Transporte. Camada 1 Tempo 1825 dias. 

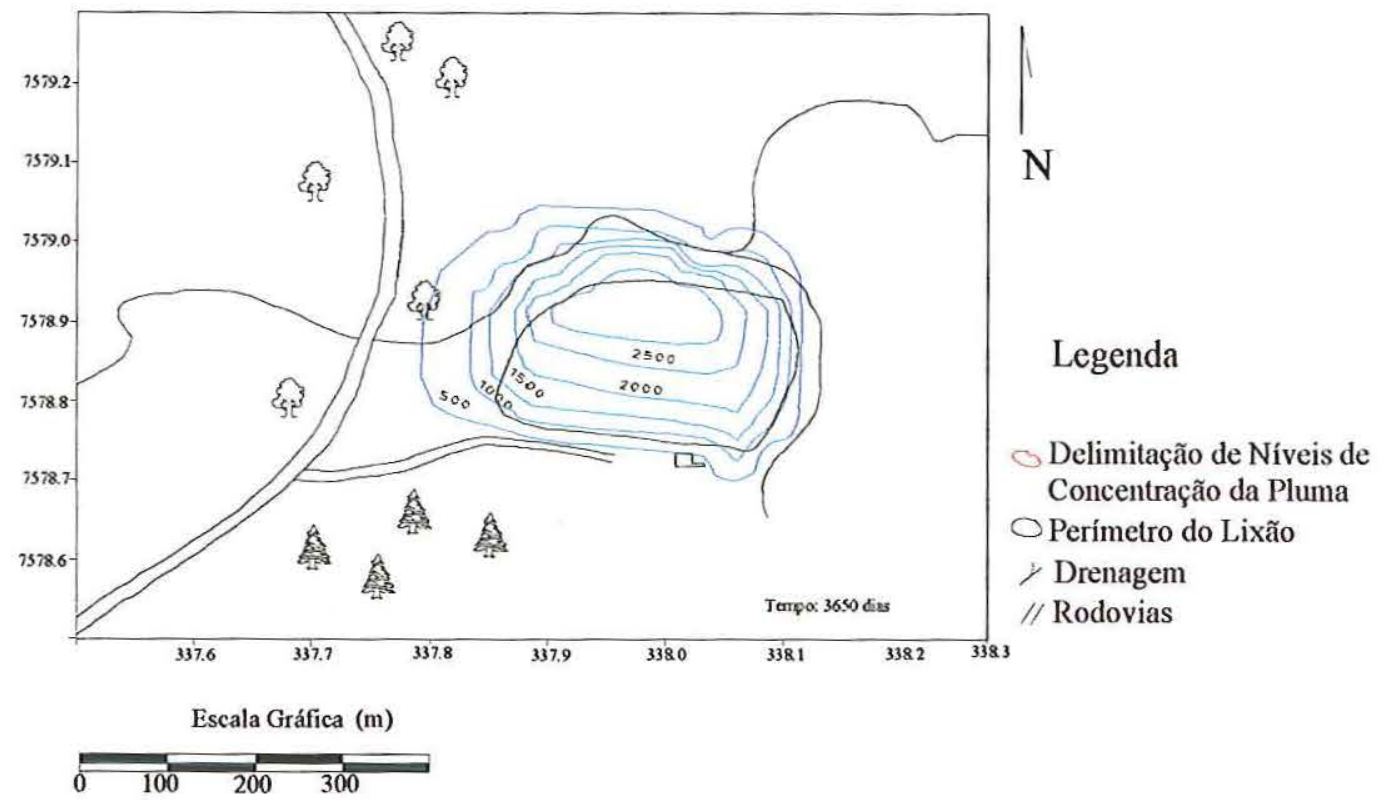

FIGURA 69B - Modelo de Transporte. Camada 1 Tempo 3650 dias.

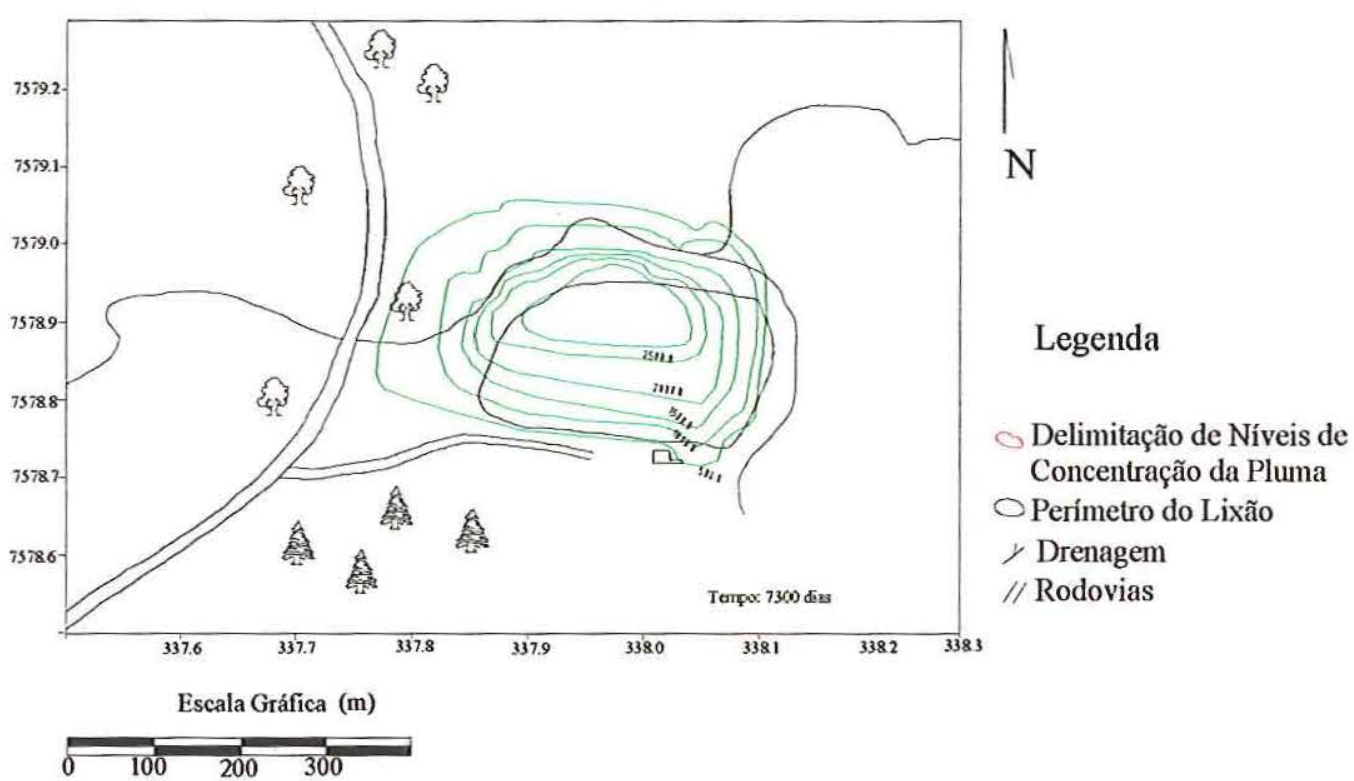

FIGURA 69C - Modelo de Transporte. Camada 1 Tempo 7300 dias. 


\section{$2^{\circ}$ Simulação: Extração dos Resíduos}

Para esta simulação procedeu-se de mesma forma que na $1^{\circ}$ simulação, tratando os dados de entrada de modo semelhante, no entanto no tempo de 5425 dias se simulou a retirada dos resíduos para se observar a dissipação da pluma de contaminação sem a contínua injeção de poluentes.

Os resultados desta simulação são:

\section{Modelo de Fluxo}

Esta alternativa de remediação não afeta o fluxo de água subsuperficial, preservando as características originais. A Figura 70 representa o fluxo atuante na área, para as condições impostas.

\section{Modelo de Transporte}

O objetivo desta simulação é observar a evolução do espalhamento da pluma de poluentes sem a fonte. 0 tempo de 5475 dias foi adotado por ser aproximadamente o tempo de funcionamento do Lixão de Poços de Caldas.

$\mathrm{O}$ modelo indica que no topo da camada 1 a contaminação em 1825 dias (período da modelagem entre os intervalos de tempo de 5475 dias e 7300 dias) cairia a valores desprezíveis. Esta diminuição nos níveis dos poluentes também é observado na camada 2, no entanto a redução não é tão acentuada com na camada 1 . Na camada 2 a concentração diminui de um pico de $1.000 \mathrm{mg} / \mathrm{l}$ para $450 \mathrm{mg} / \mathrm{l}$. Na camada $3 \mathrm{a}$ área atingida pela pluma diminui de extensão, no entanto o pico de contaminação aumenta de 1 para $6 \mathrm{mg} / \mathrm{l}$. A Figura 71 representa o caminhamento do soluto e as figuras 72 a 83 mostram a evolução da pluma de contaminação. 


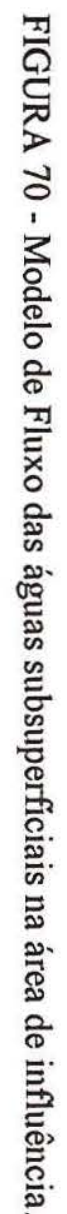

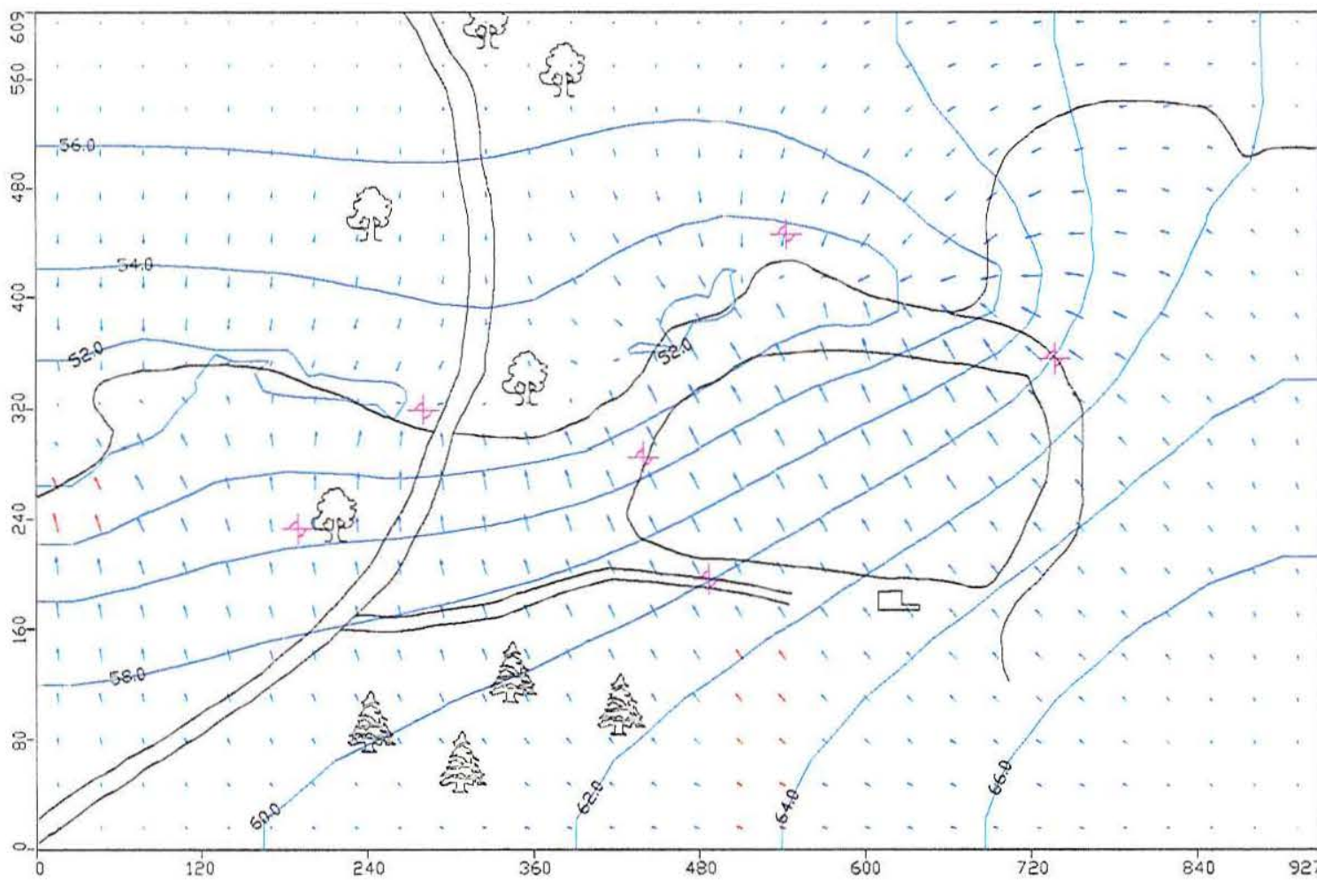

$\left.\right|_{N}$

Legenda

Linhas de Fluxo

Poços de Obser.

Perimetro do

Lixão

- Linhas

Equipotenciais

Drenagem

// Rodovias

Escala Gráfica (m)

\begin{tabular}{lll}
\hline 0 & 100 & $200 \quad 300$
\end{tabular} 


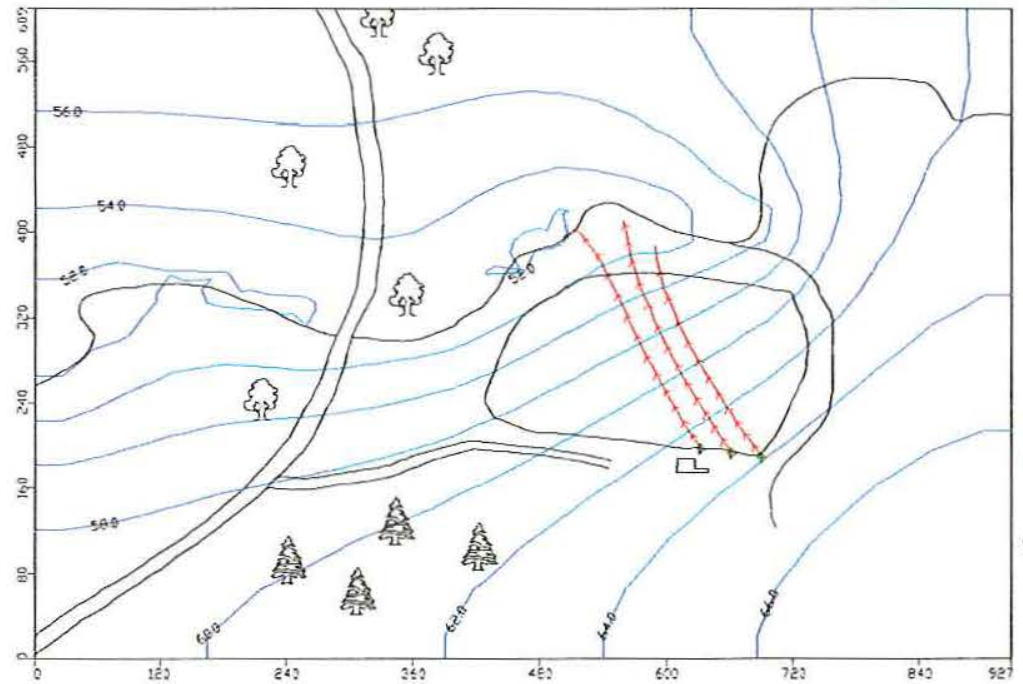

Escala Gráfica (m)

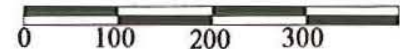

$\mathrm{N}$

\section{Legenda}

Linhas Equipotenciais

Caminhamento das partículas

$\bigcirc$ Perímetro do Lixão

$y$ Drenagem

/ Rodovias

FIGURA 71 - Trajetória das Partículas

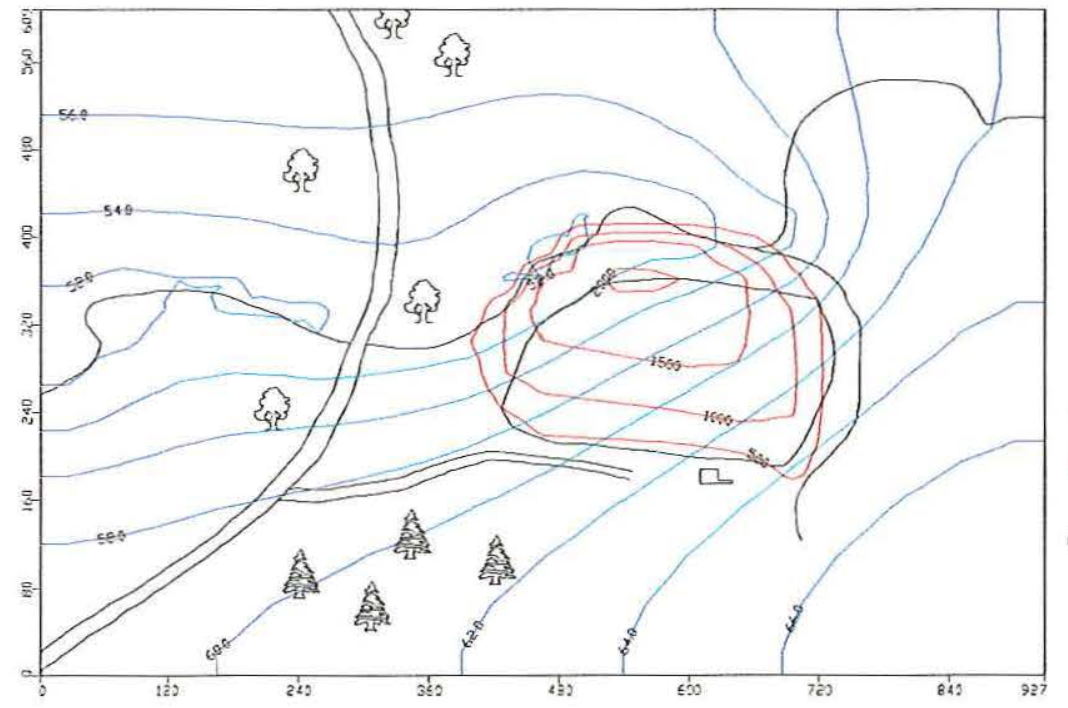

Escala Gráfica (m)

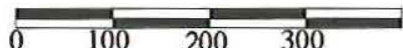

$\mathrm{N}$

\section{Legenda}

Linhas Equipotenciais

Delimitação de Níveis dı Concentração da Pluma

Perímetro do Lixão

Drenagem

// Rodovias

FIGURA 72 - Modelo de Transporte. Camada 1 Tempo 1825 dias. 

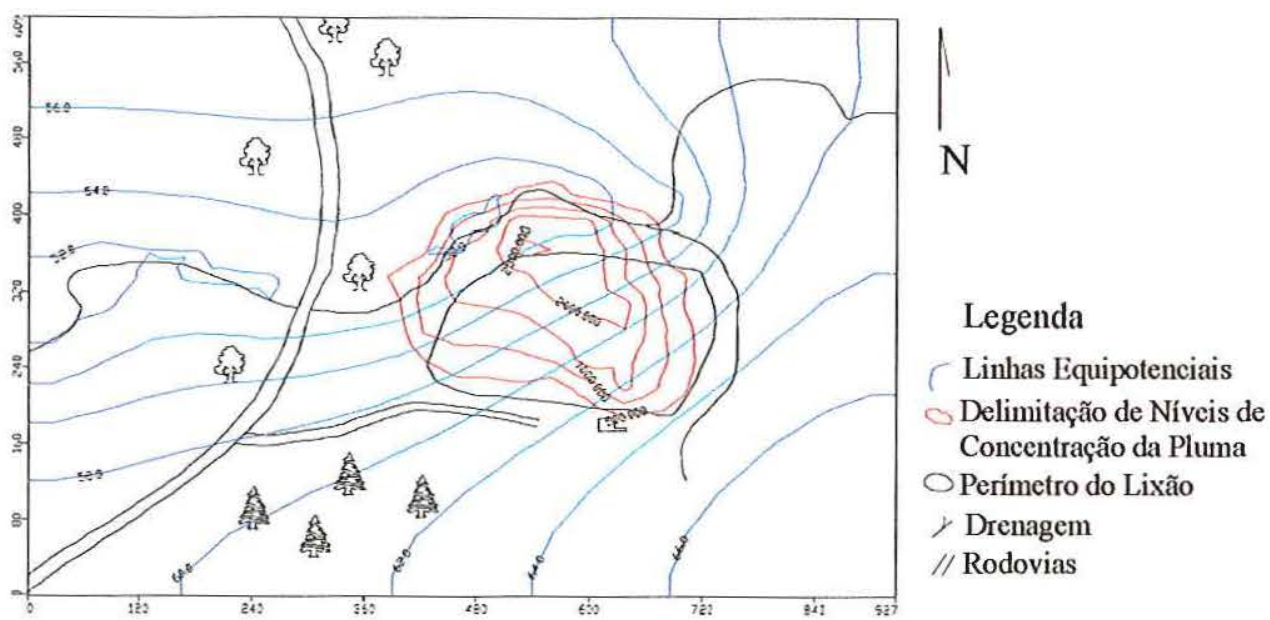

Escala Gráfica (m)

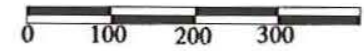

FIGURA 73 - Modelo de Transporte. Camada 1 Tempo 3650 dias.
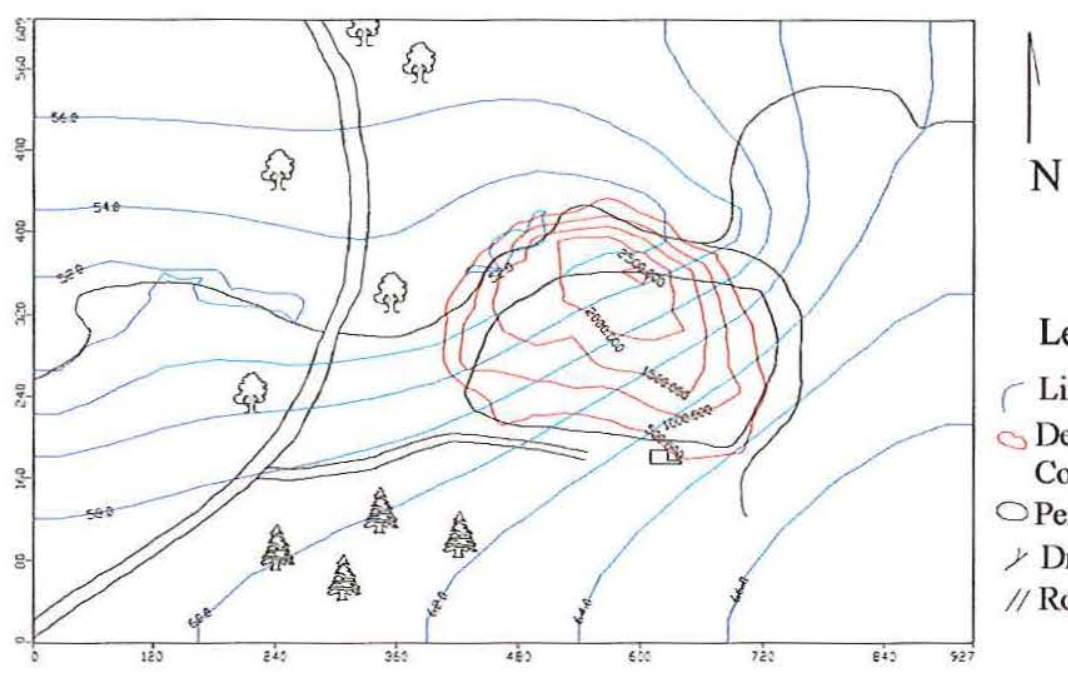

\section{Legenda}

Linhas Equipotenciais

$\checkmark$ Delimitação de Níveis de

Concentração da Pluma

Perímetro do Lixão

> Drenagem

// Rodovias

FIGURA 74 - Modelo de Transporte. Camada 1 Tempo 5475 dias. 


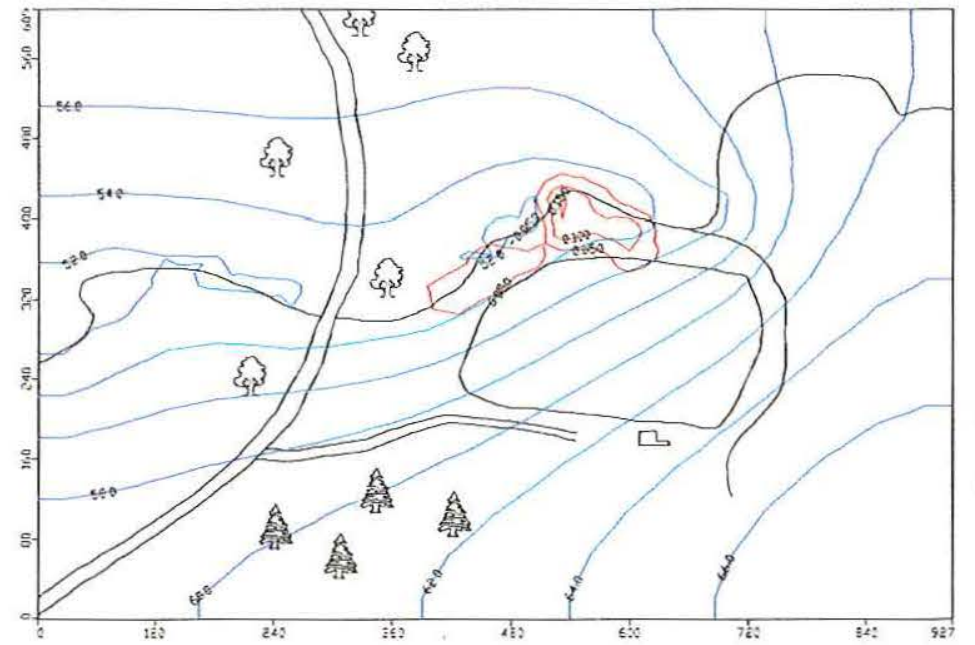

$\mathrm{N}$

Legenda

Linhas Equipotenciais

$\checkmark$ Delimitação de Níveis de

Concentração da Pluma

$\checkmark$ Perímetro do Lixão

y Drenagem

// Rodovias

Escala Gráfica (m)

\begin{tabular}{llll}
\hline & 100 & 200 & 300
\end{tabular}

FIGURA 75 - Modelo de Transporte. Camada 1 Tempo 7300 dias.

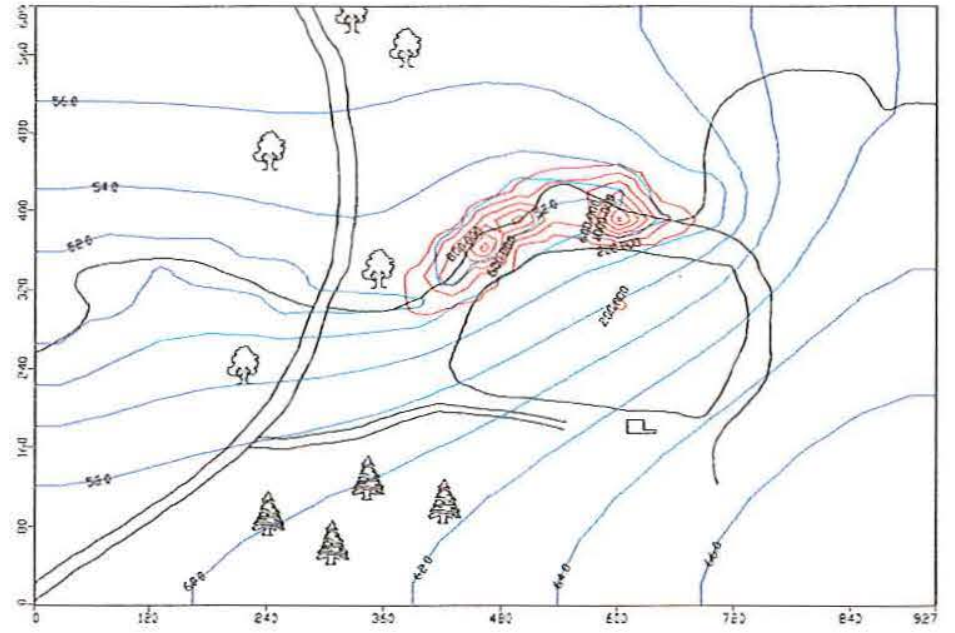

Escala Gráfica (m)

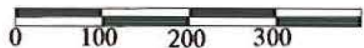

\section{Legenda}

- Linhas Equipotenciais

Delimitação de Níveis de Concentração da Pluma

$\bigcirc$ Perímetro do Lixão

y Drenagem

// Rodovias

FIGURA 76 - Modelo de Transporte. Camada 2 Tempo 1825 dias. 


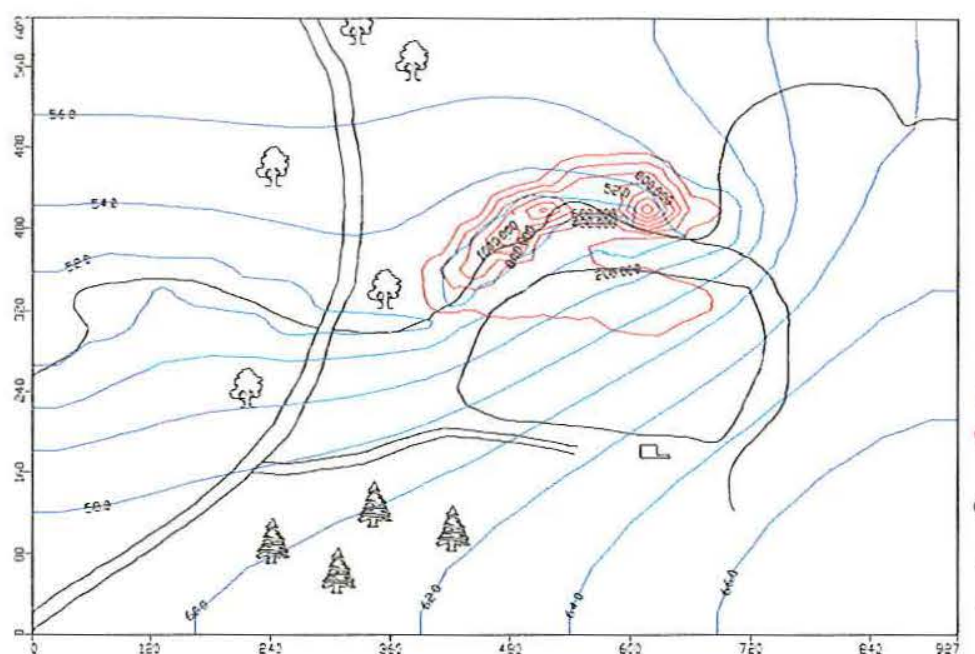

Escala Gráfica (m)

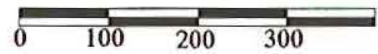

$\left.\right|_{N}$

\section{Legenda}

Cinhas Equipotenciais

○ Delimitação de Niveis de

Concentração da Pluma

$\bigcirc$ Perímetro do Lixão

yrenagem

// Rodovias

FIGURA 77 - Modelo de Transporte. Camada 2 Tempo 3650 dias.

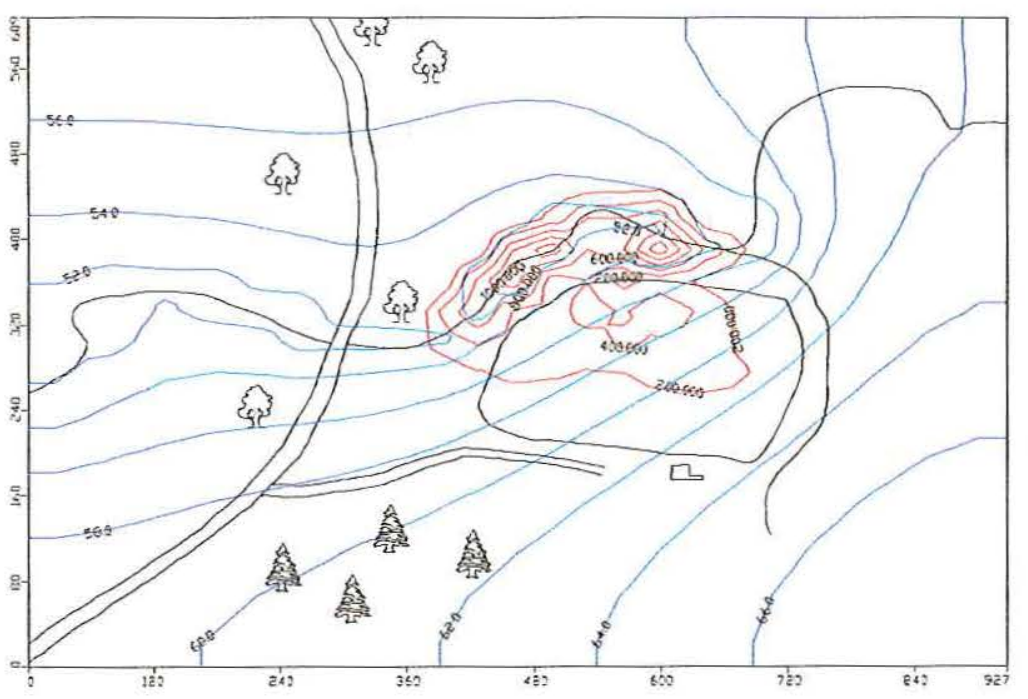

Escala Gráfica (m)

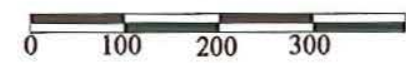

\section{Legenda}

C Linhas Equipotenciais

$\bigcirc$ Delimitação de Níveis dı

Concentração da Pluma

○ Perímetro do Lixão

y Drenagem

// Rodovias

FIGURA 78 - Modelo de Transporte. Camada 2 Tempo 5475 dias. 

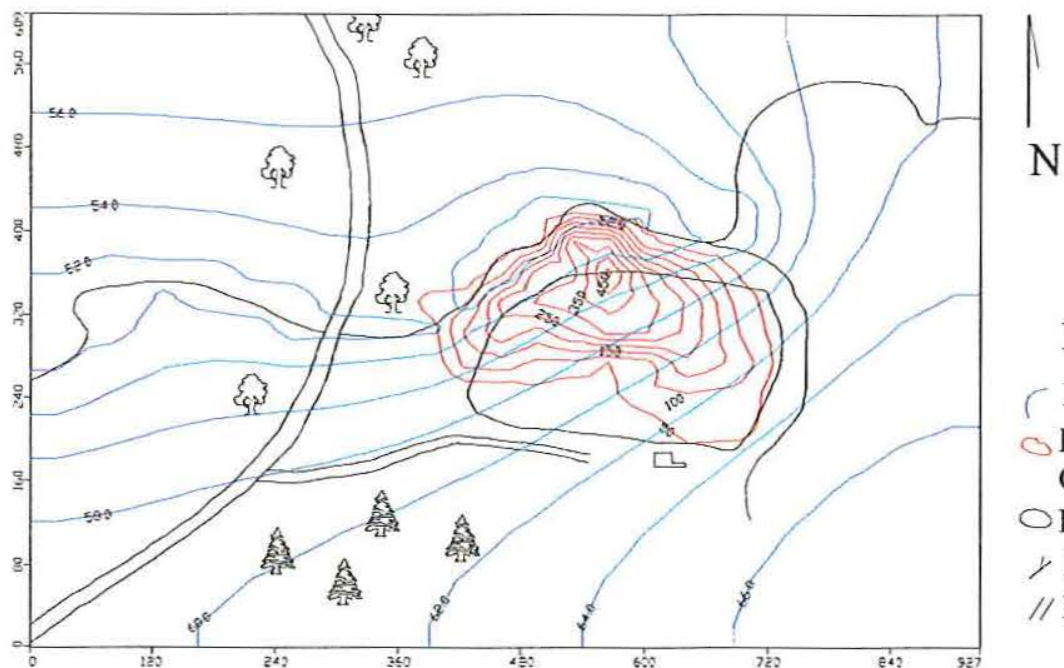

\section{Legenda}

Linhas Equipotenciais

$\bigcirc$ Delimitação de Níveis de Concentração da Pluma

O Perímetro do Lixão

> Drenagem

// Rodovias

Escala Gráfica (m)

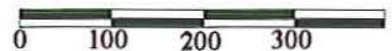

FIGURA 79 - Modelo de Transporte. Camada 2 Tempo 7300 dias.

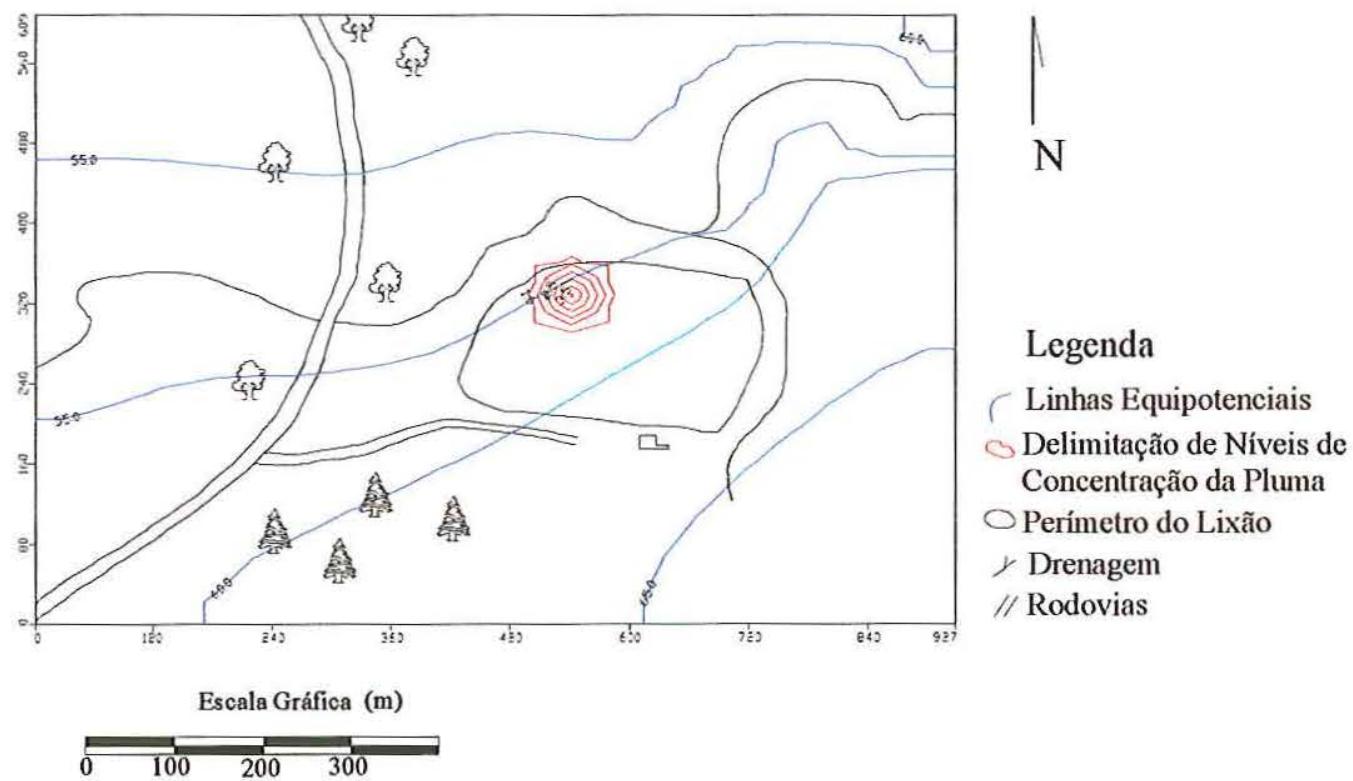

FIGURA 80 - Modelo de Transporte. Camada 3 Tempo 1825 dias. 


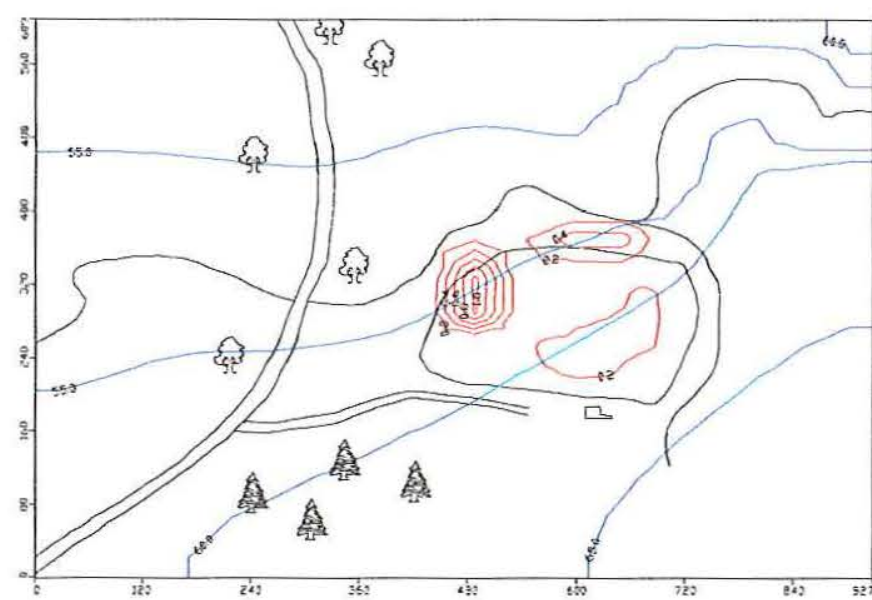

$\mathrm{N}$

\section{Legenda}

( Linhas Equipotenciais

$\checkmark$ Delimitação de Níveis de

Concentração da Pluma

$\bigcirc$ Perímetro do Lixão

y Drenagem

// Rodovias

Escala Gráfica (m)

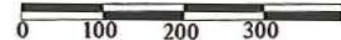

FIGURA 81 - Modelo de Transporte. Camada 3 Tempo 3650 dias.

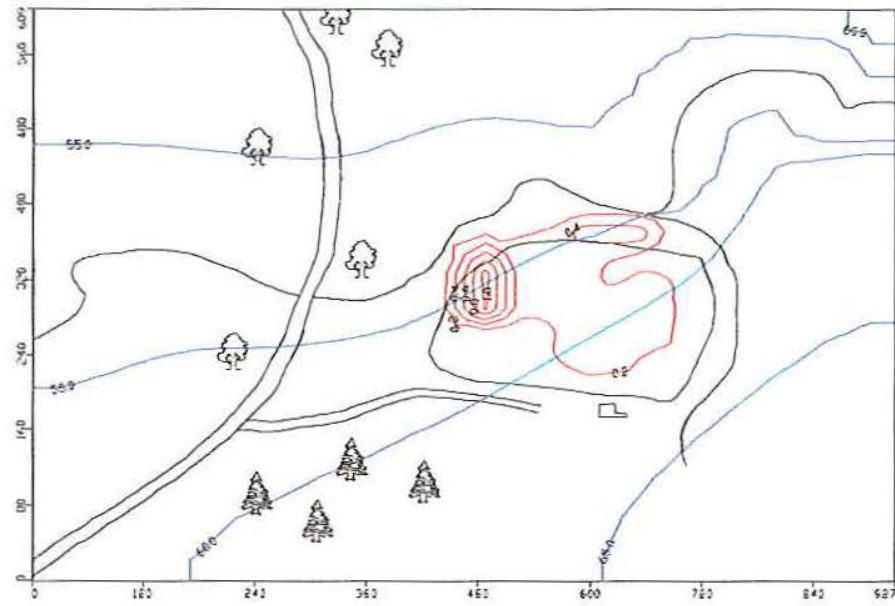

$\mathrm{N}$

\section{Legenda}

Linhas Equipotenciais

Delimitação de Níveis de Concentração da Pluma

$\bigcirc$ Perímetro do Lixão

y Drenagem

// Rodovias

Escala Gráfica (m)

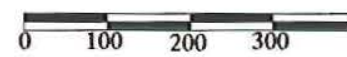

FIGURA 82 - Modelo de Transporte. Camada 3 Tempo 5475 dias. 


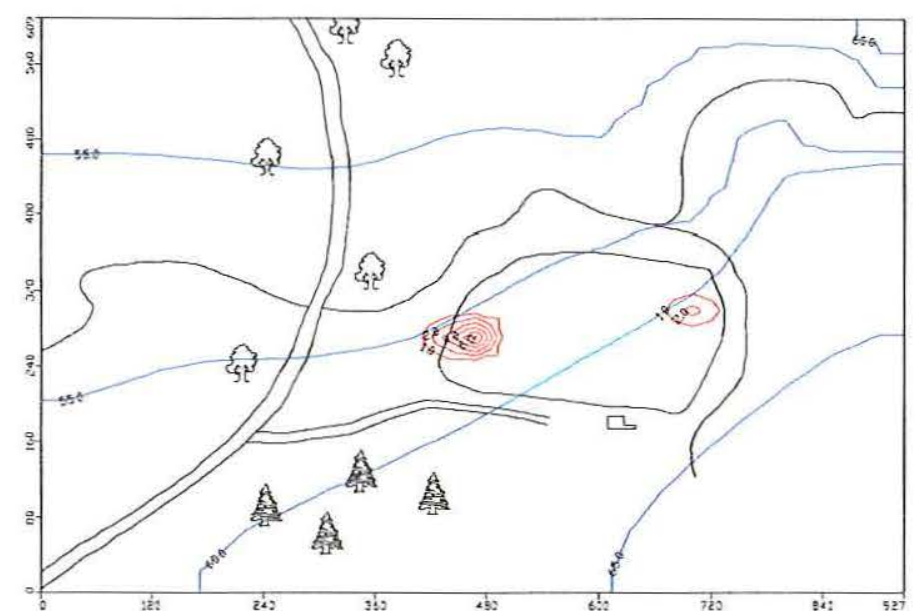

$\left.\right|_{N}$

Legenda

Linhas Equipotenciais

Delimitação de Níveis de

Concentração da Pluma

$\bigcirc$ Perímetro do Lixão

$\gamma$ Drenagem

// Rodovias

Escala Gráfica (m)

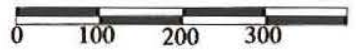

FIGURA 83 - Modelo de Transporte. Camada 3 Tempo 7300 dias.

As figuras 84 a 91 apresentam os perfis verticais da área. Observa-se que a evolução da pluma nos intervalos iniciais da modelagem são iguais a simulação 1.0 aspecto mais interessante desta situação é a mudança na configuração da geometria da pluma de contaminação após a retirada da fonte de poluição, observa-se uma diminuição dos valores de concentração principalmente na camada 1 , porém uma migração da mancha para profundidades da ordem de $35 \mathrm{~m}$. 


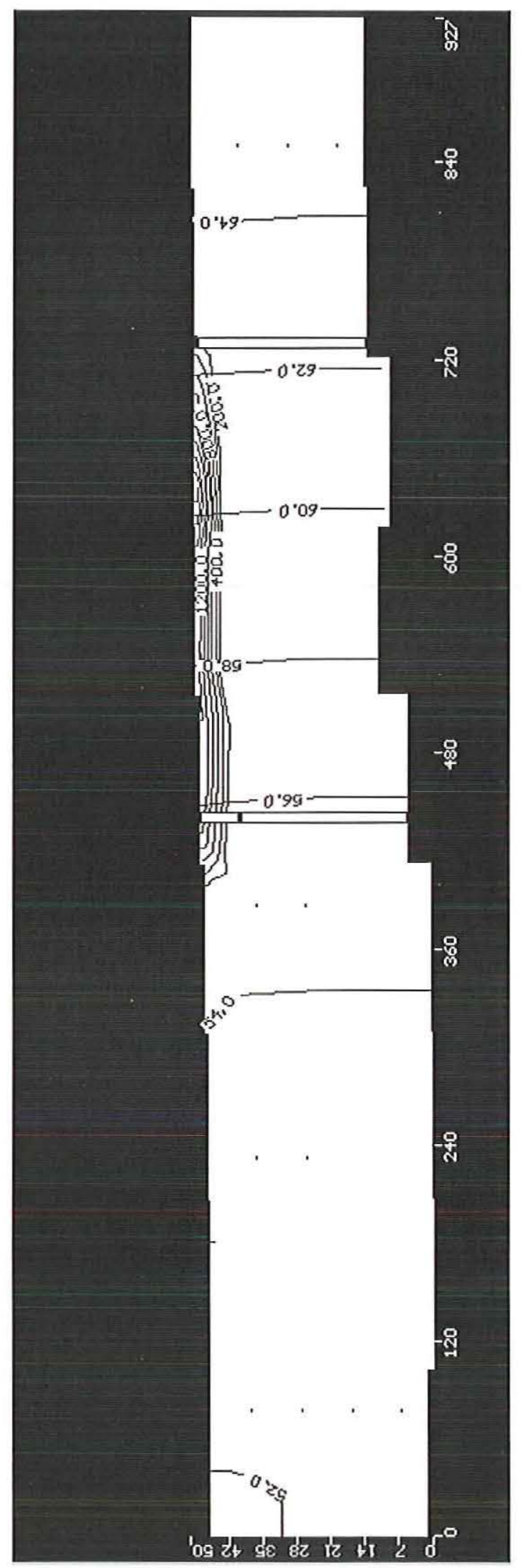

FIGURA 84 - Perfil Longitudinal a direção de maior espalhamento da pluma (Linha) Tempo 1825 dias. 


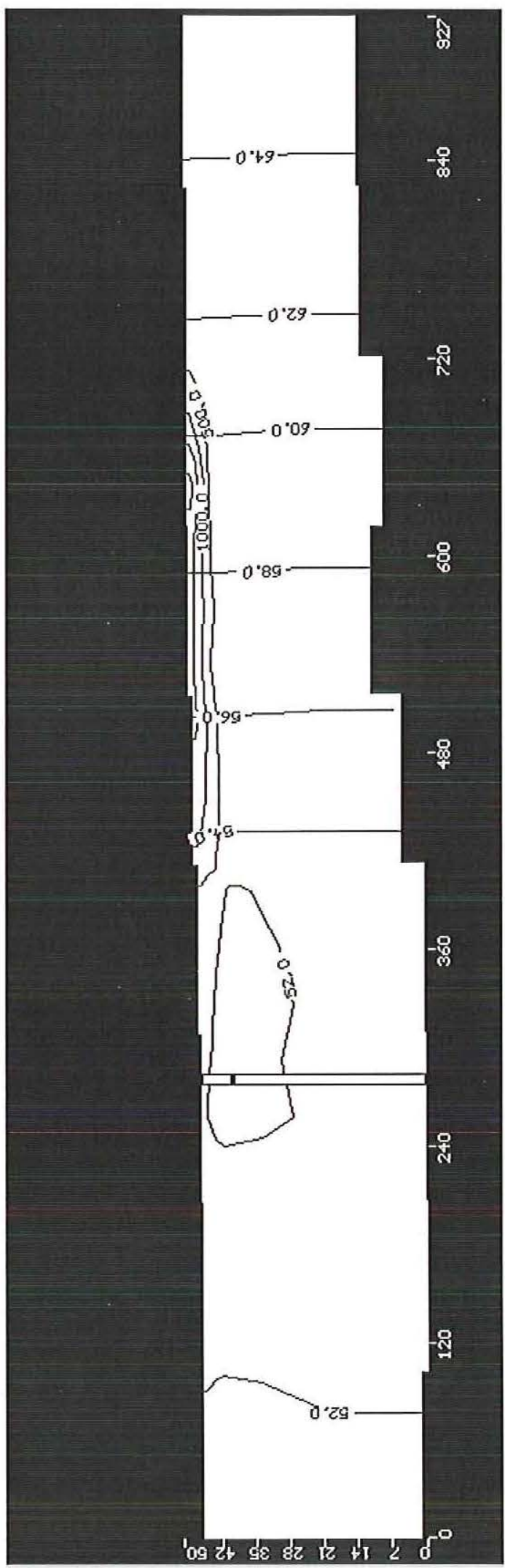

FIGURA 85 - Perfil Longitudinal a direção de maior espalhamento da pluma (Linha) Tempo 3650 dias. 


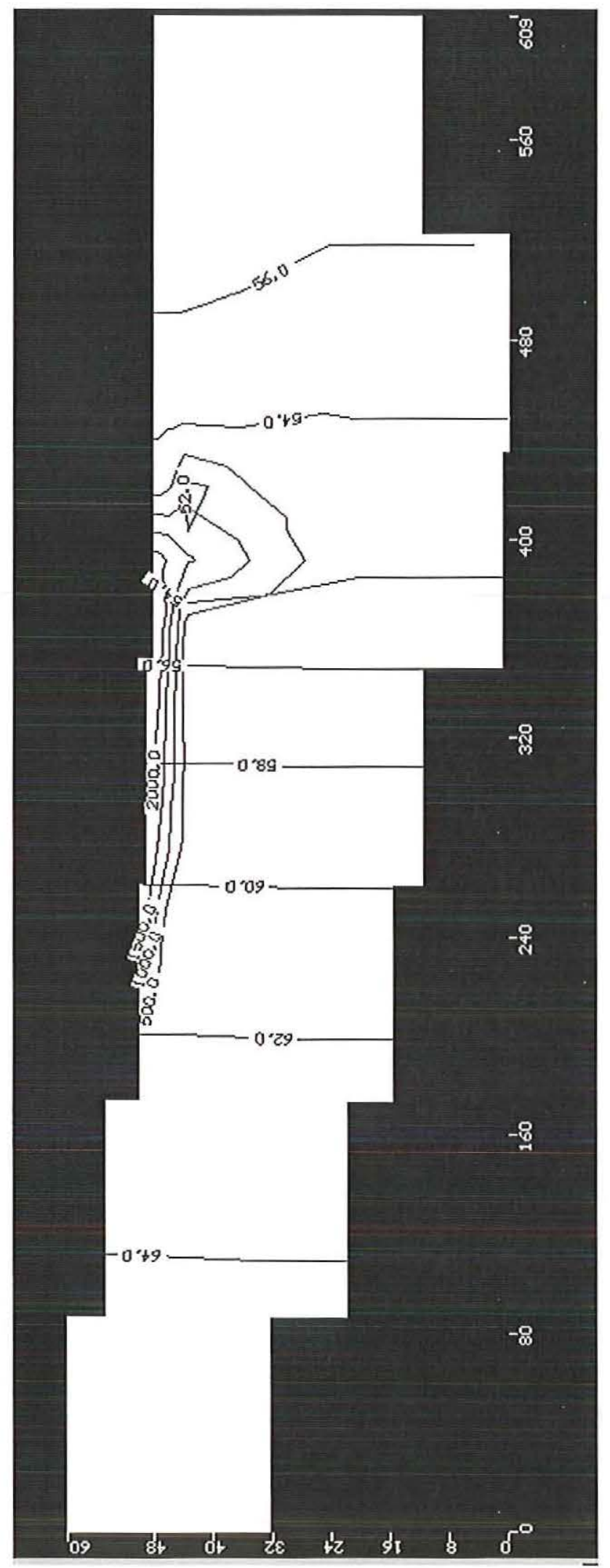

FIGURA 86 - Perfil Longitudinal a direção de maior espalhamento da pluma (Linha) Tempo 5425 dias. 


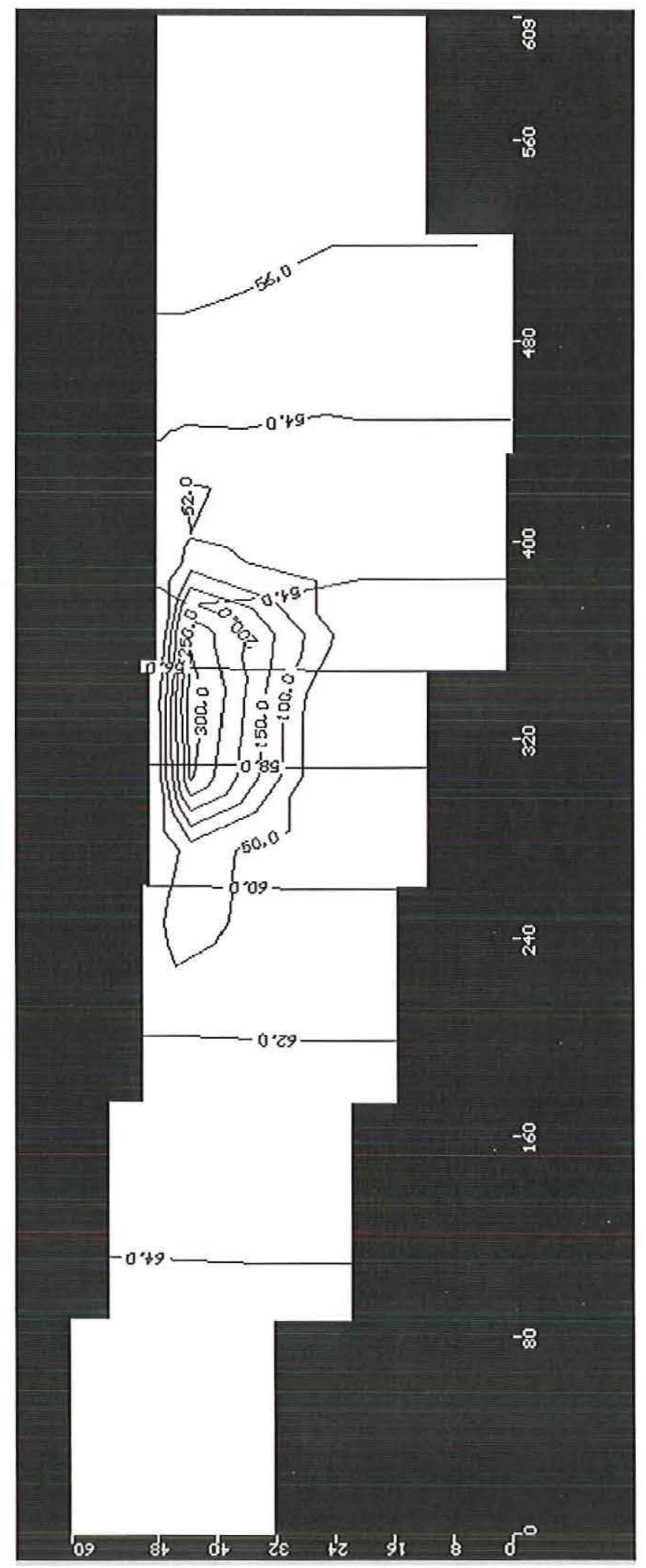

FIGURA 87 - Perfil Longitudinal a direção de maior espalhamento da pluma (Linha) Tempo 7300 dias. 


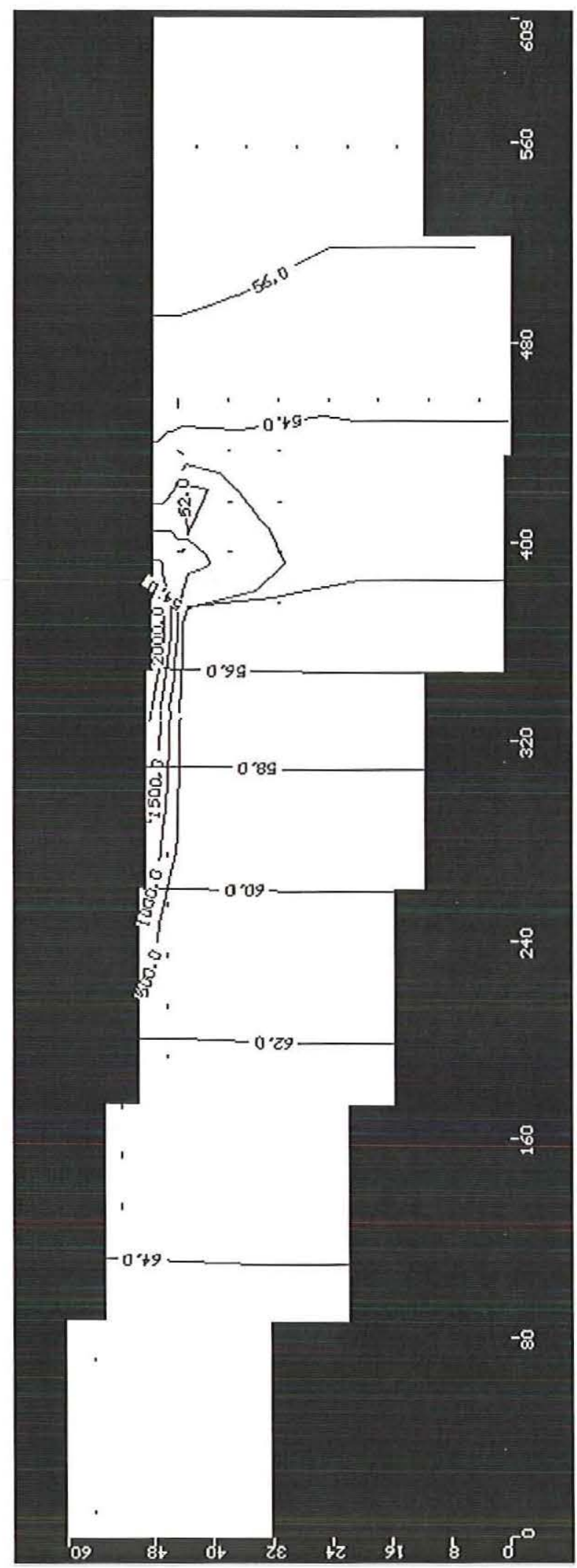

FIGURA 88 - Perfil Transversal a direção de maior espalhamento da pluma (Coluna) Tempo 1825 dias. 


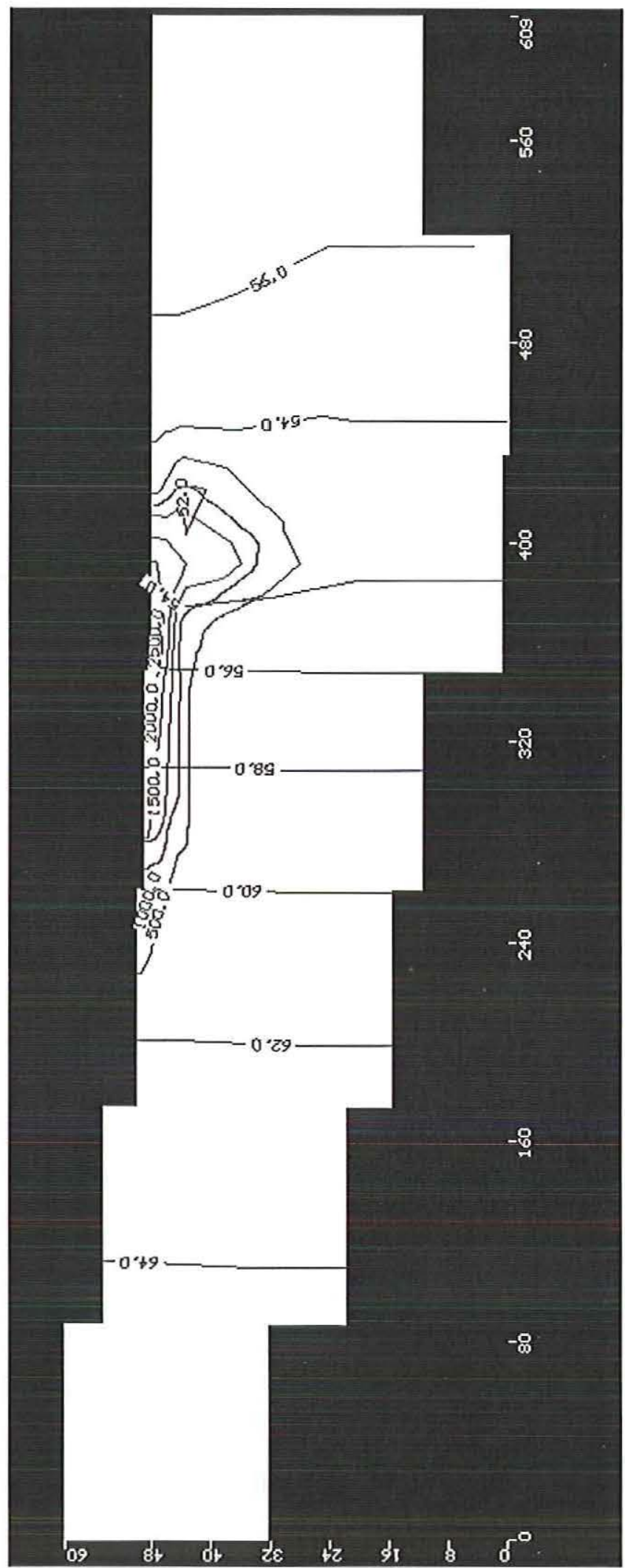

FIGURA 89 - Perfil Transversal a direção de maior espalhamento da pluma (Coluna) Tempo 3650 dias.

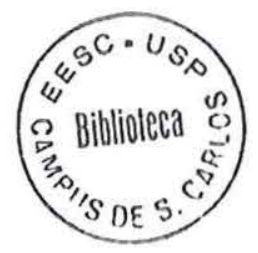




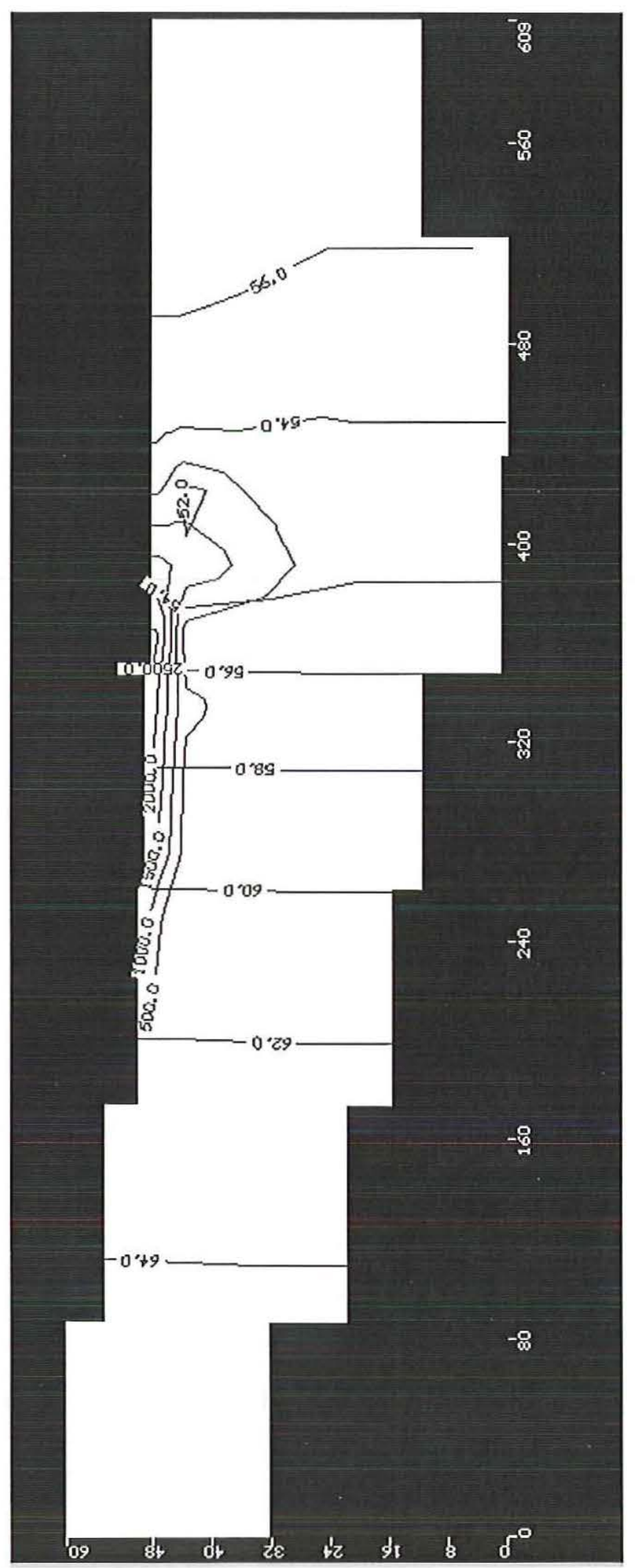

FIGURA 90 - Perfil Transversal a direção de maior espalhamento da pluma (Coluna) Tempo 5425 dias. 


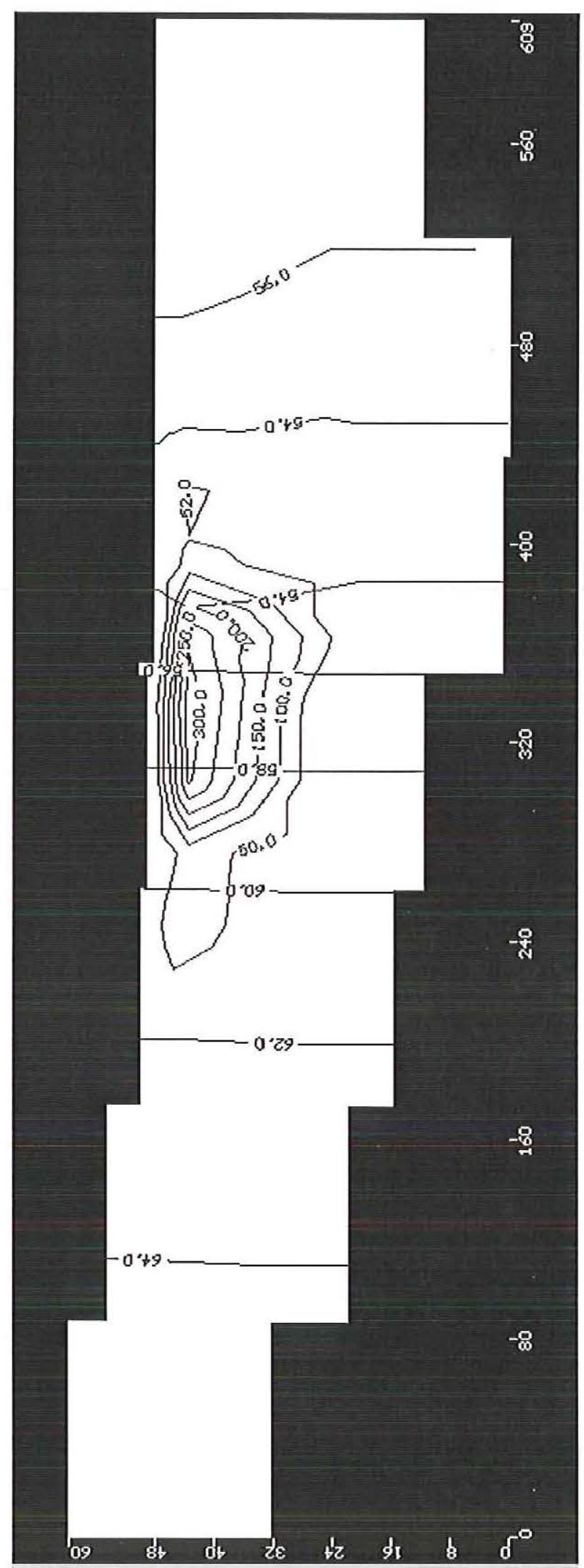

FIGURA 91 - Perfil Transversal a direção de maior espalhamento da pluma (Coluna ) Tempo 7300 dias. 


\section{$3^{\circ}$ Simulação: Utilização de Cobertura}

Neste modelo os dados que representam o meio físico são os mesmos que nos casos anteriores. Para simular um sistema de cobertura sobre o lixão existem 2 opções:

$\checkmark$ Alterar a condutividade hidráulica das células que formam o lixão. Neste caso seleciona-se as células da camada 1 que estão sobre o lixão e atribui-se o valor de condutividade desejado, a desvantagem desta simulação é que a condutividade é atribuída a toda a espessura da camada, resultando em um mascaramento da realidade; esta condutividade alterada irá influenciar o fluxo subterrâneo.

$\checkmark$ Alterar a precipitação das células, alterando a infiltração. Por esta opção mudase apenas a quantidade de água que entra no sistema preservando as demais características (neste caso adotou-se uma camada de cobertura que teria como objetivo diminuir a infiltração em 3.0x).

Os resultados obtidos são:

\section{Modelo de Fluxo}

Para simular a cobertura optou-se pela diminuição da precipitação, esta alteração no modelo original não afeta a direção do fluxo de água subsuperficial, ocasionando apenas uma redução na velocidade do fluxo. Como pode-se notar a Figura 92, o fluxo desta simulação é muito semelhante aos casos anteriores.

\section{Modelo de Transporte}

A alteração da quantidade de água que infiltra para o sistema afeta diretamente o volume de lixiviado gerado e consequentemente transportado. Observa-se que a pluma formada nesta situação, apresenta uma geometria muito semelhante a simulação 1, principalmente na camada 1, diferenciando nos valores de concentrações. A Figura 93 mostra o caminhamento das partículas e as figuras 94 a 102 mostram o resultado do modelo de transporte para os diversos tempos e camadas. 

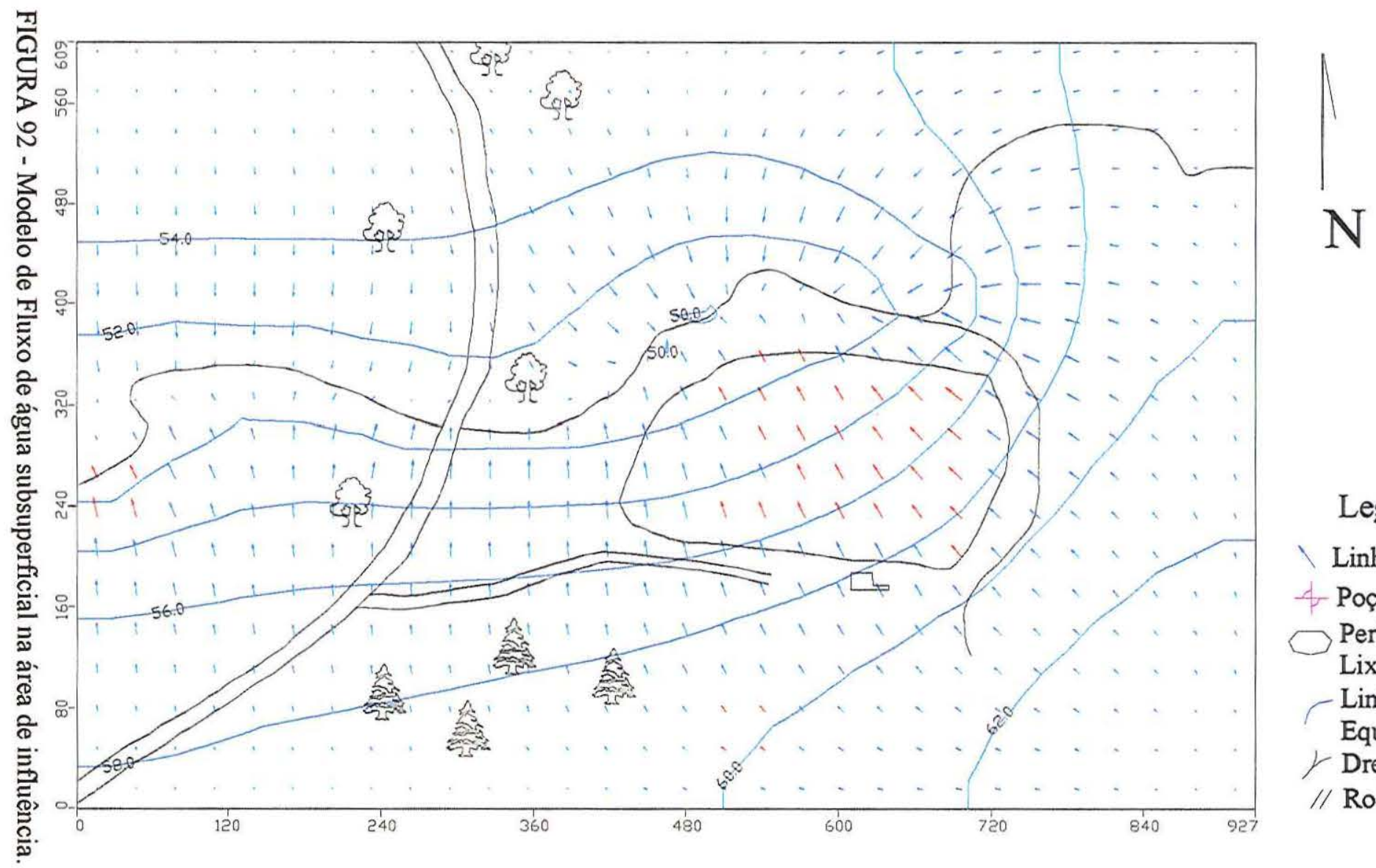

Escala Gráfica (m)

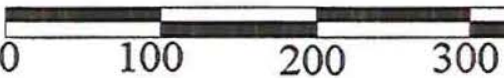

Legenda

Linhas de Fluxo

f. Poços de Obser.

Perímetro do

Lixão

- Linhas

Equipotenciais

Drenagem

// Rodovias 


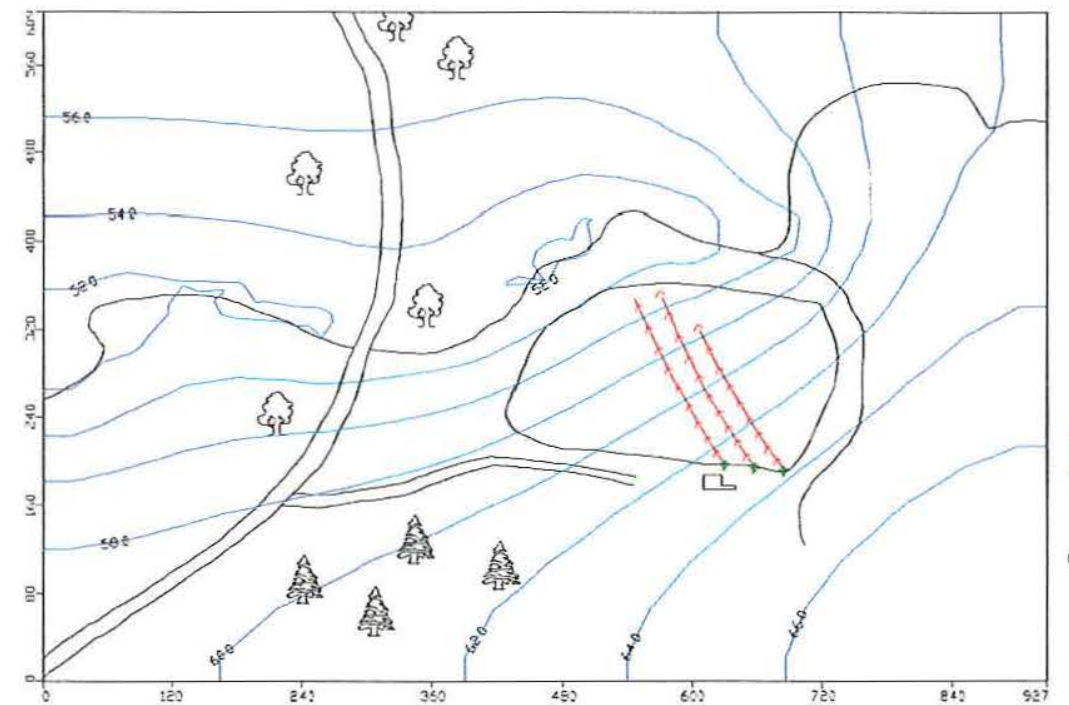

$\left.\right|_{N}$

Legenda

- Linhas Equipotenciais

Caminhamento das

partículas

$\bigcirc$ Perímetro do Lixão

$\succ$ Drenagem

// Rodovias

Escala Gráfica (m)

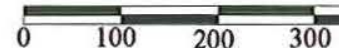

\section{FIGURA 93 - Trajetória das Partículas}
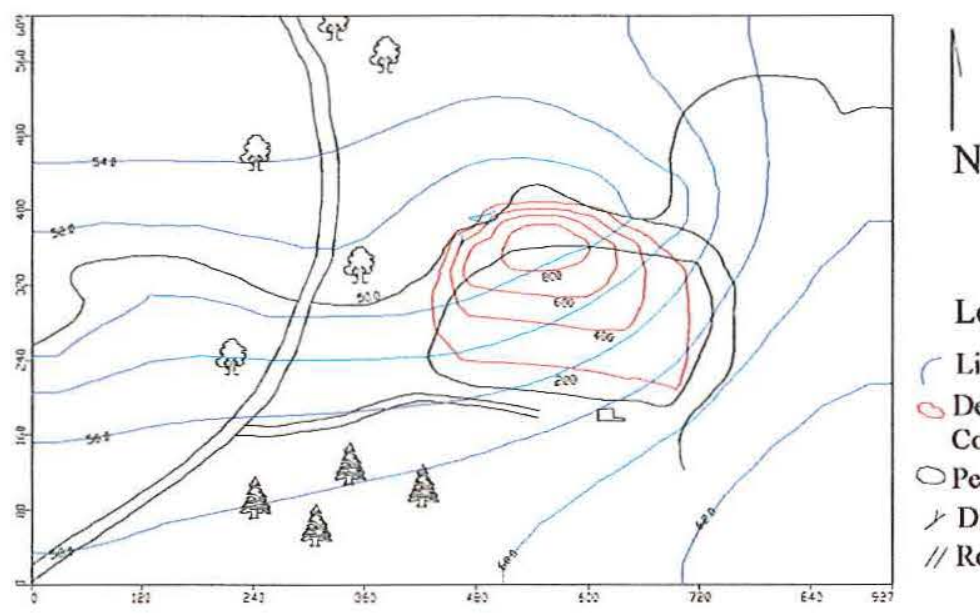

\section{Legenda}

( Linhas Equipotenciais

○ Delimitação de Níveis de

Concentração da Pluma

$\checkmark$ Perímetro do Lixão

$\checkmark$ Drenagem

// Rodovias

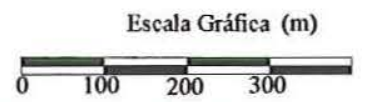

FIGURA 94 - Modelo de Transporte. Camada 1 Tempo 1825 dias. 

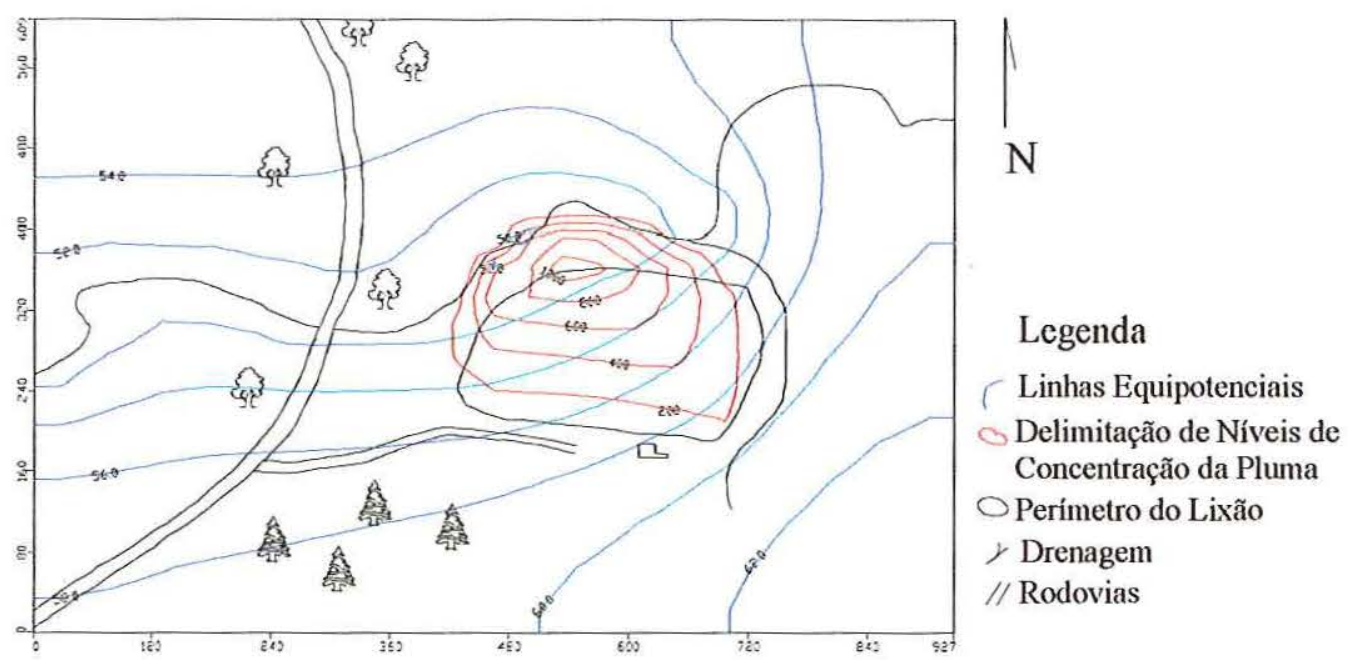

Escala Gráfica (m)

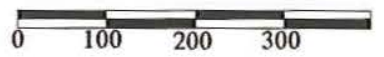

FIGURA 95 - Modelo de Transporte. Camada 1 Tempo 3650 dias.

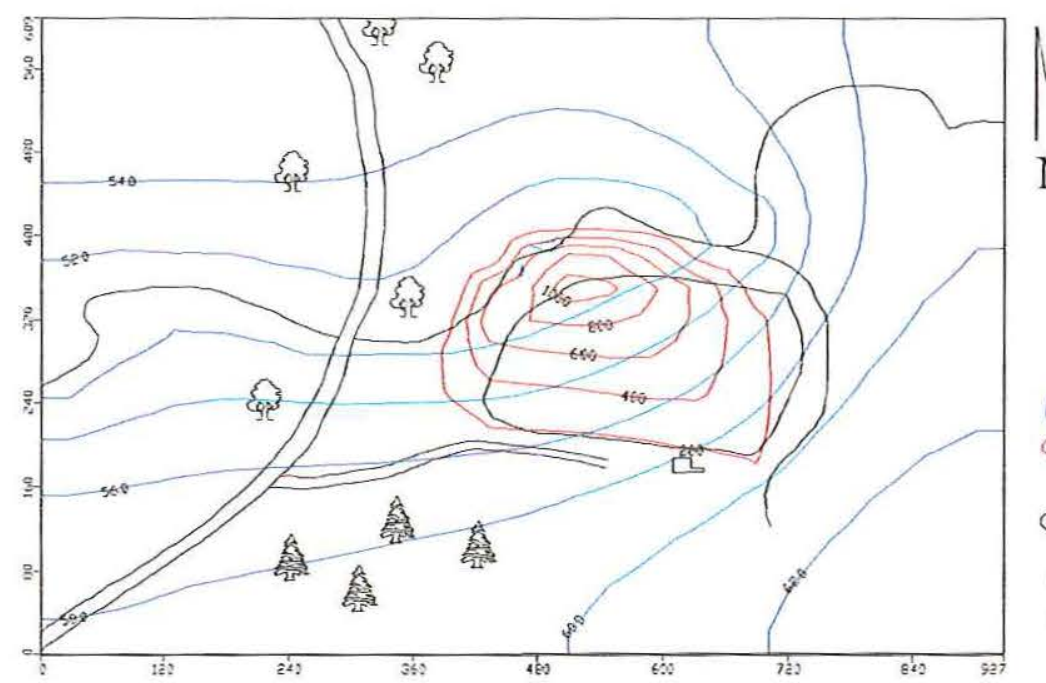

\section{Legenda}

- Linhas Equipotenciais

$\bigcirc$ Delimitação de Níveis de

Concentração da Pluma

$\bigcirc$ Perímetro do Lixão

y Drenagem

// Rodovias

Escala Gráfica (m)

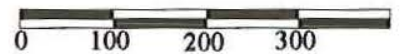

FIGURA 96 - Modelo de Transporte. Camada 1 Tempo 7300 dias. 


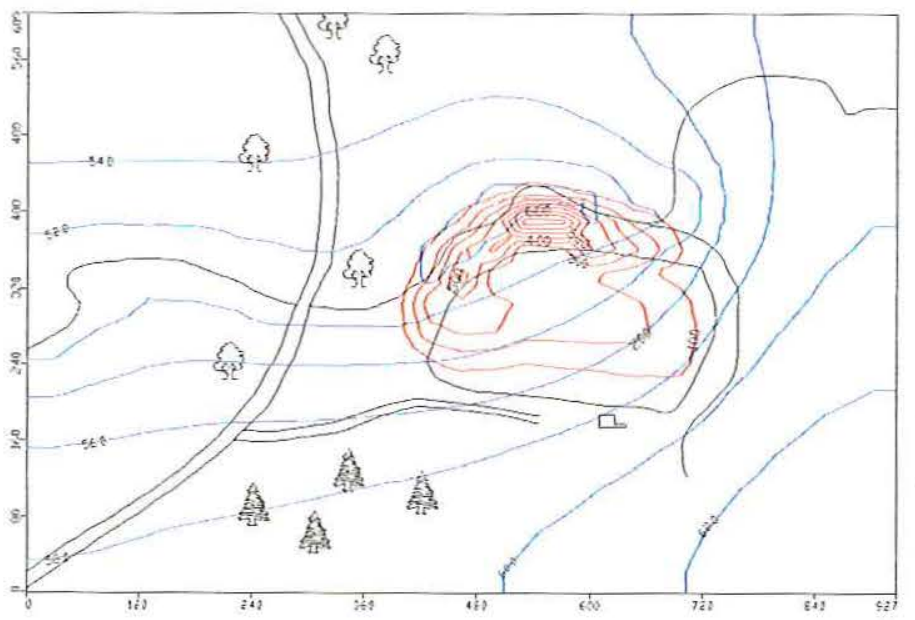

$\mathrm{N}$

\section{Legenda}

Linhas Equipotenciais

Delimitação de Níveis de

Concentração da Pluma

P Perímetro do Lixão

- Drenagem

// Rodovias

Escala Gráfica (m)

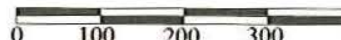

FIGURA 97 - Modelo de Transporte. Camada 2 Tempo 1825 dias.
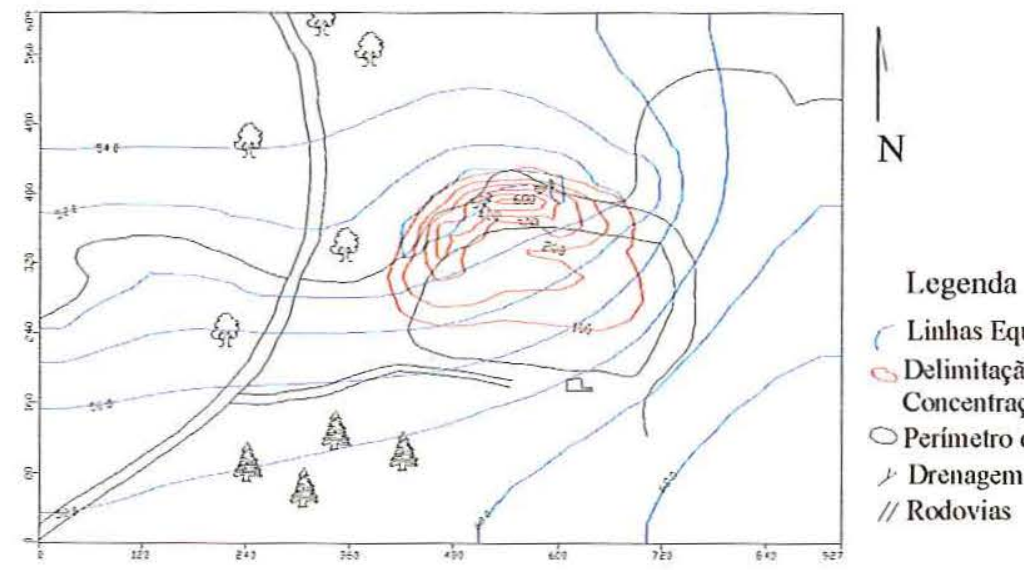

Cinhas Equipotenciais

Delimitação de Niveis de

Concentração da Pluma

$\bigcirc$ Perímetro do Lixão

y Drenagem

// Rodovias

\section{Escala Gráfica (m)}

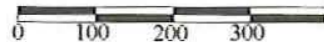

FIGURA 98 - Modelo de Transporte. Camada 2 Tempo 3650 dias. 


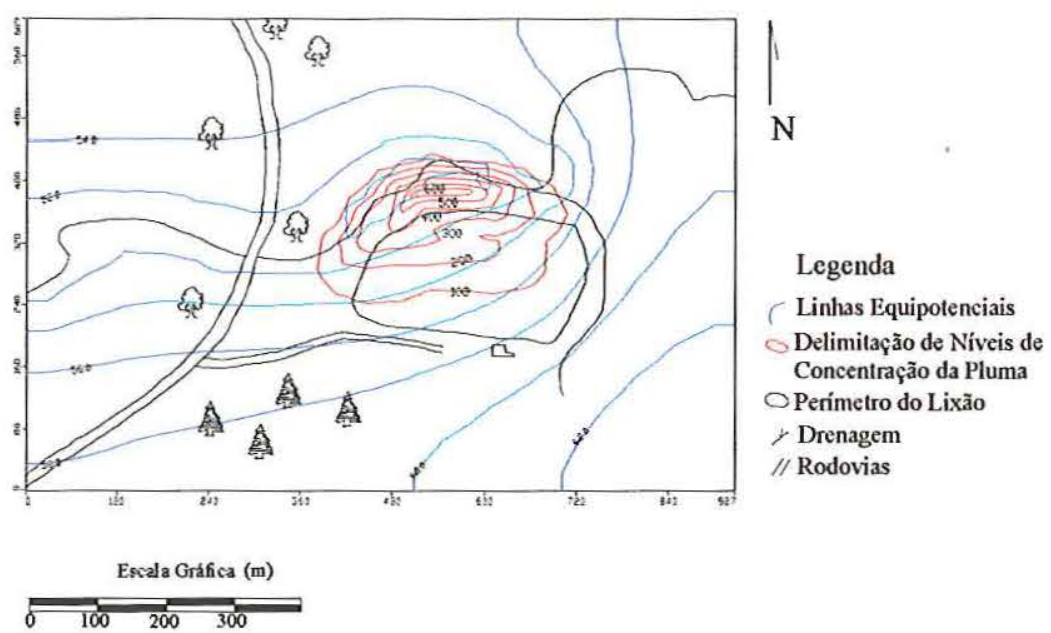

FIGURA 99 - Modelo de Transporte. Camada 2 Tempo 7300 dias.

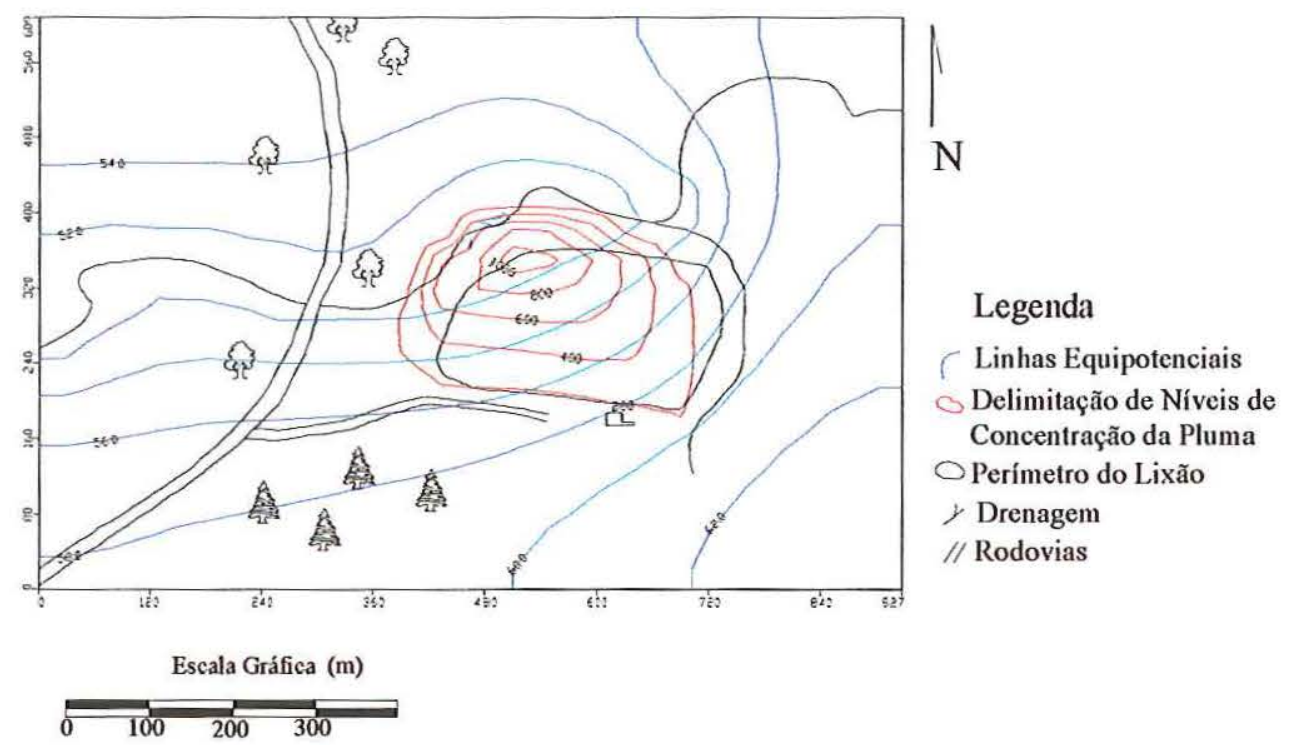

FIGURA 100 - Modelo de Transporte. Camada 3 Tempo 1825 dias. 


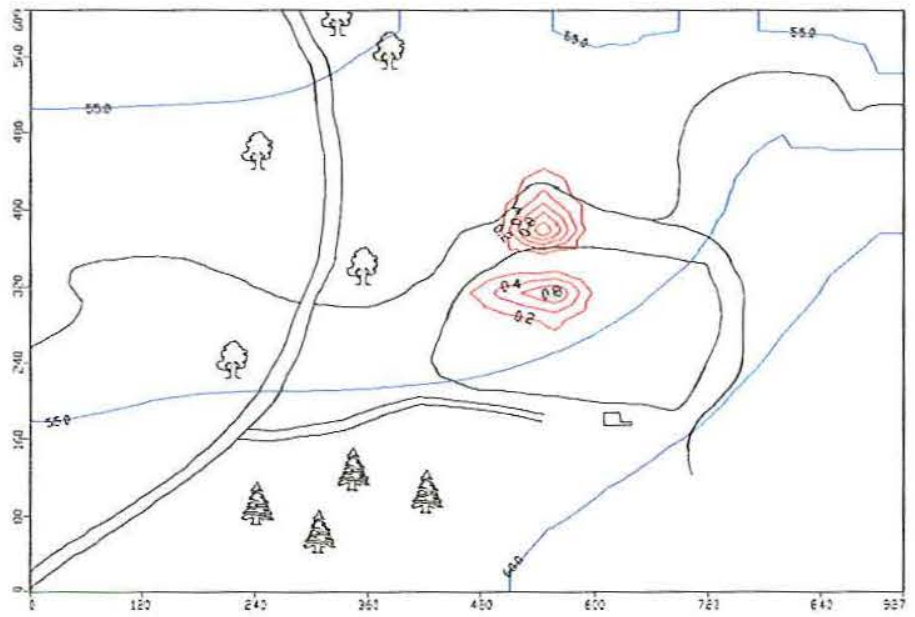

$\left.\right|_{N}$

\section{Legenda}

C Linhas Equipotenciais

$\checkmark$ Delimitação de Níveis de

Concentração da Pluma

O Perímetro do Lixão

> Drenagem

// Rodovias

Escala Gráfica (m)

\begin{tabular}{llll}
\hline & 100 & 200 & 300
\end{tabular}

FIGURA 101 - Modelo de Transporte. Camada 3 Tempo 3650 dias.

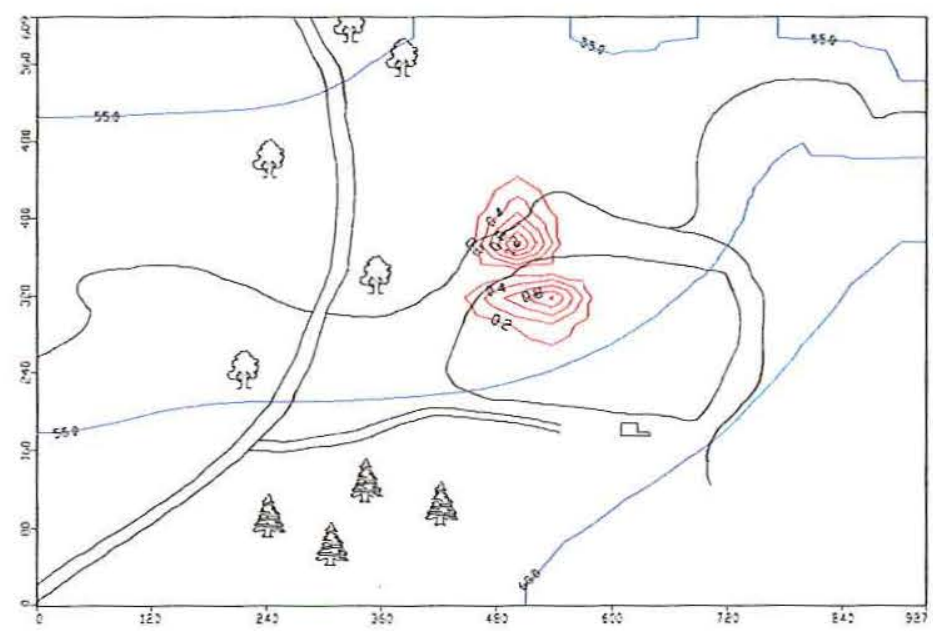

Escala Gráfica (m)

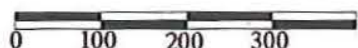

\section{Legenda}

Linhas Equipotenciais $\bigcirc$ Delimitação de Níveis de Concentração da Pluma

$\bigcirc$ Perímetro do Lixão

y Drenagem

// Rodovias

FIGURA 102 - Modelo de Transporte. Camada 3 Tempo 7300 dias. 
Assim como os mapas apresentados, a delimitação vertical da pluma de contaminação também é semelhante a situação inicial, a alteração ocorre nos níveis de concentração dos solutos os perfís são representados nas figuras 103 a 108.

A semelhança na geometria da pluma de soluto em relação a $1^{\circ}$ simulação é devido a conservação das características físicas do meio que condicionam o transporte, a redução da concentração é resultado da menor lixiviação do soluto, devido a menor quantidade de água infiltrada pela superfície do lixão. 


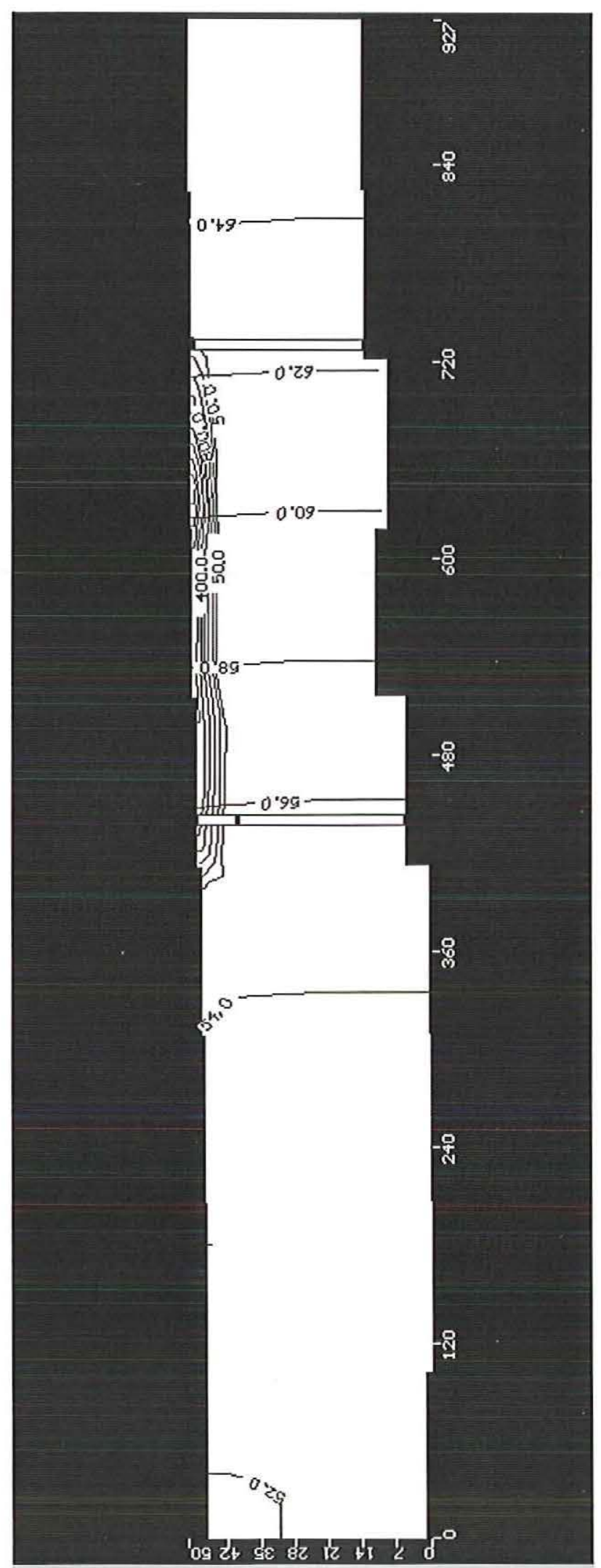

FIGURA 103 - Perfil Longitudinal a direção de maior espalhamento da pluma de poluição (Linha) no Tempo de 1825 dias. 


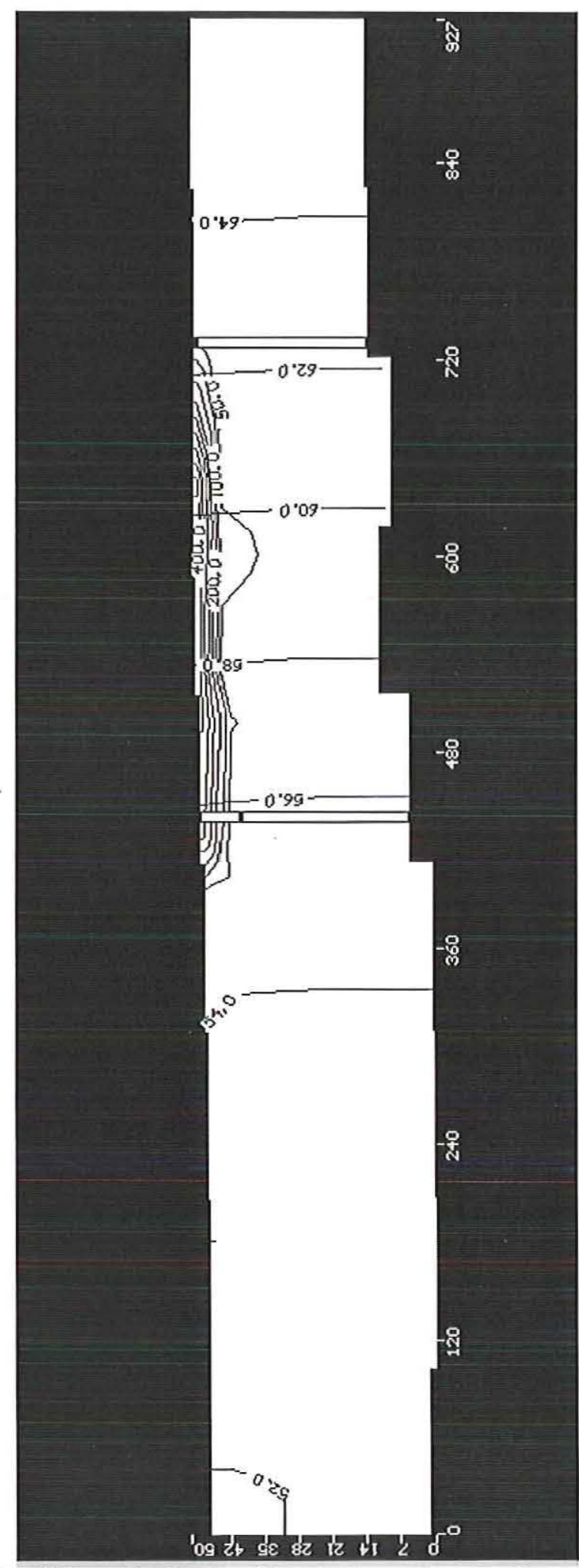

FIGURA 104 - Perfil Longitudinal a direção de maior espalhamento da pluma de poluição (Linha) no Tempo de 3650 dias. 


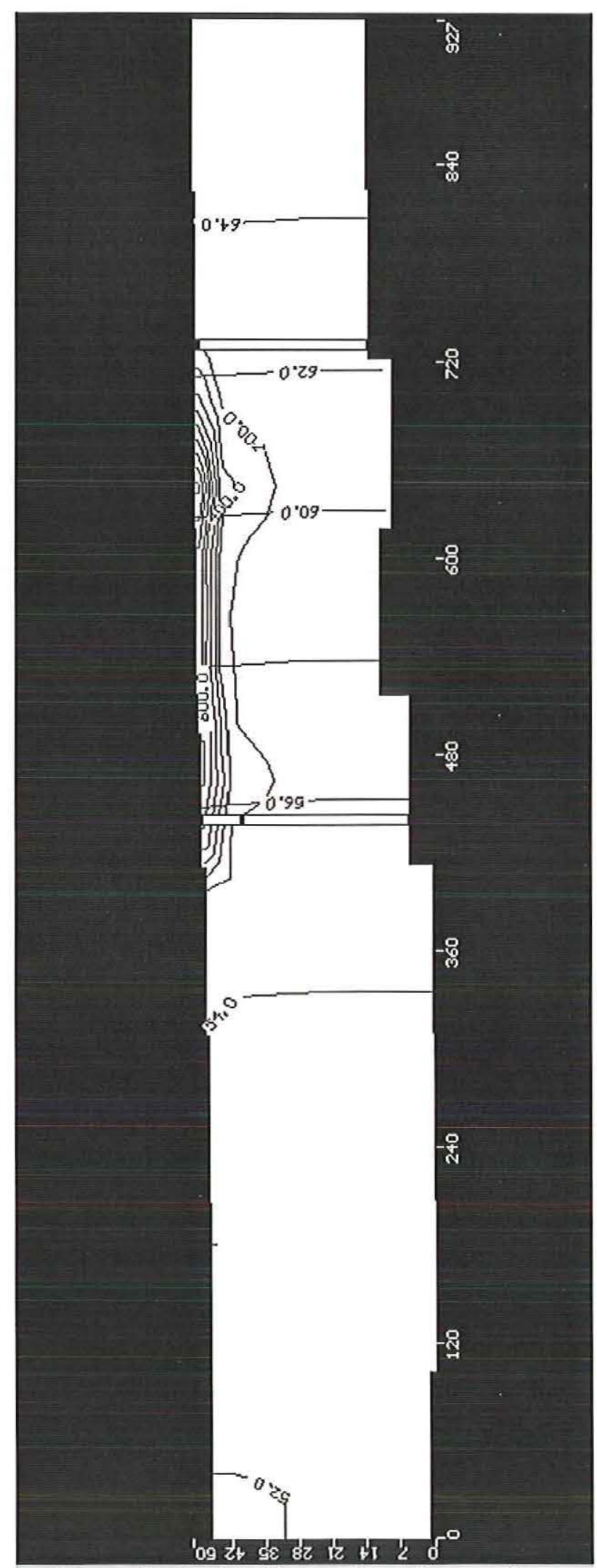

FIGURA 105 - Perfil Longitudinal a direção de maior espalhamento da pluma de poluição (Linha) no Tempo de 7300 dias. 


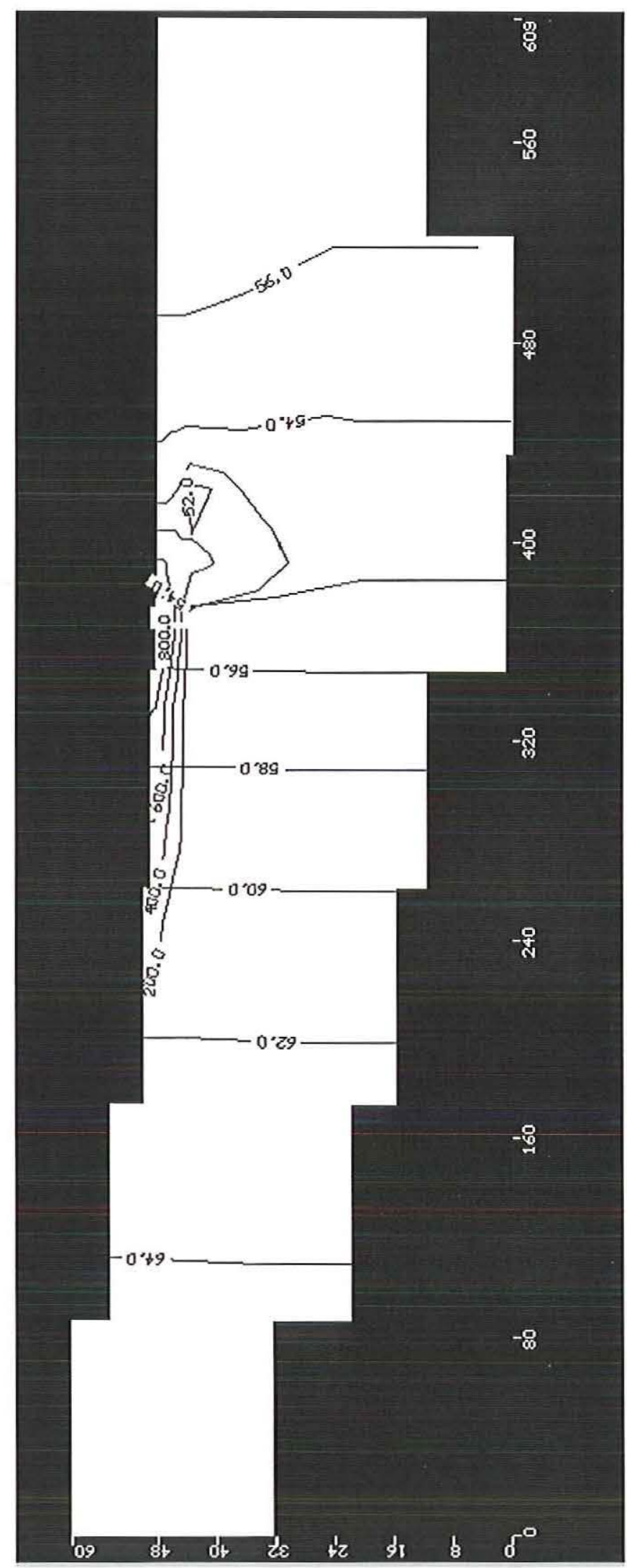

FIGURA 106 - Perfil Transversal a direção de maior espalhamento da pluma de poluição (Coluna) no Tempo de 1825 dias. 


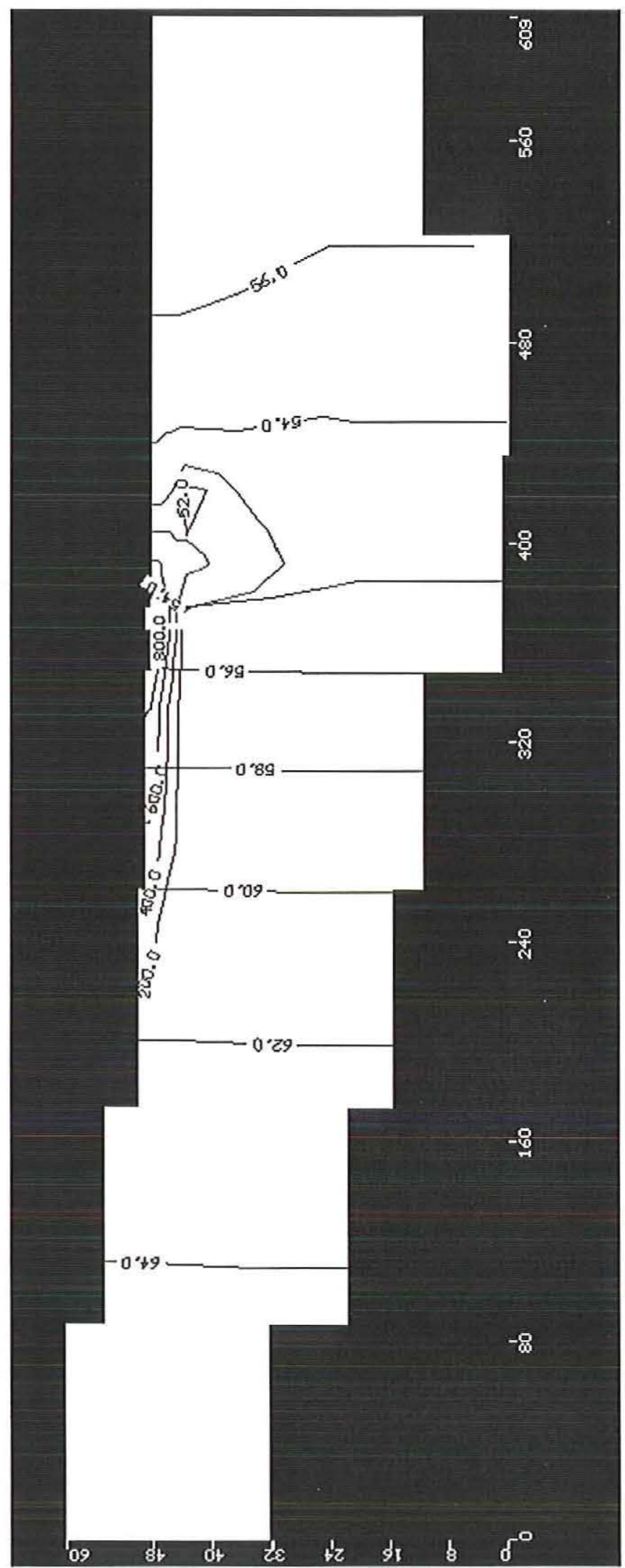

FIGURA 107 - Perfil Transversal a direção de maior espalhamento da pluma de poluição (Coluna) no Tempo de 3650 dias. 


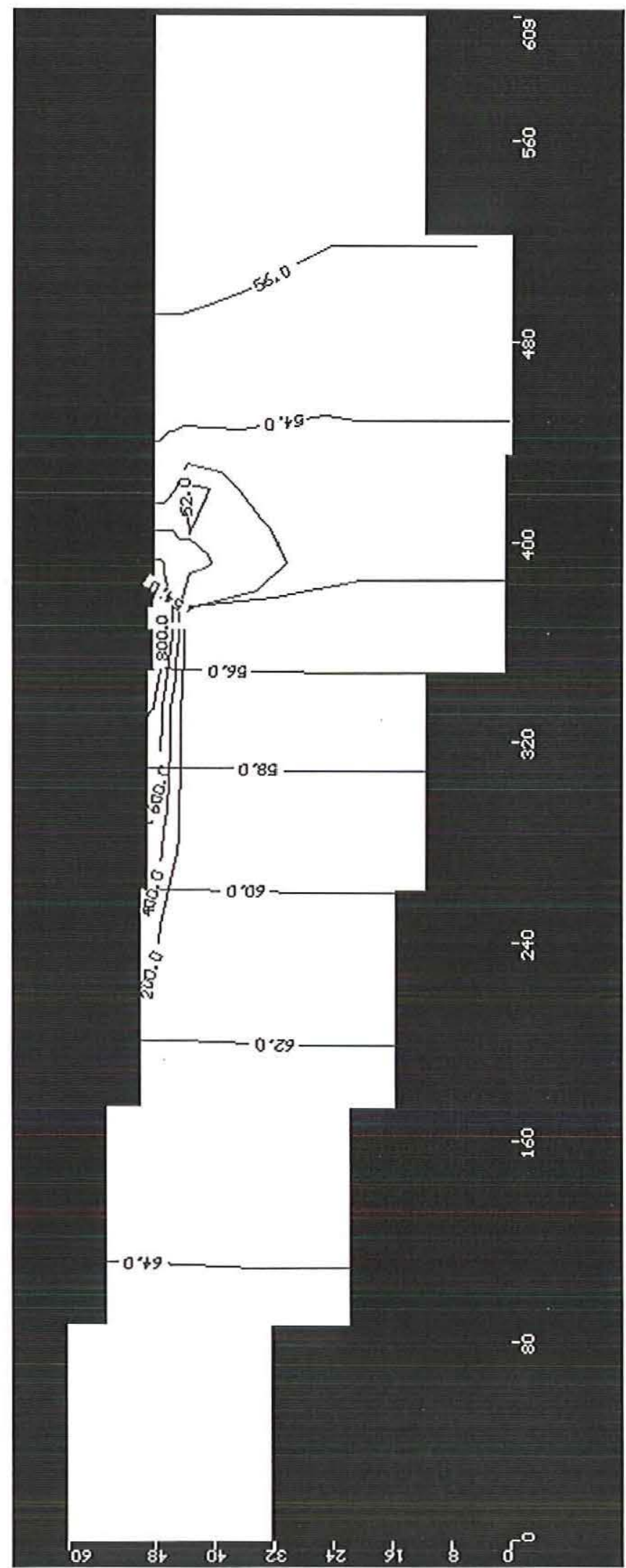

FIGURA 108 - Perfil Transversal a direção de maior espalhamento da pluma de poluição (Coluna) no Tempo de 7300 dias. 


\section{$4^{\circ}$ Simulação: Paredes a Montante no Camada número 1}

Este modelo tem como objetivo simular a construção de estruturas de contenção para verificar a variação no fluxo subsuperficial e consequentemente no transporte do contaminante.

A simulação de uma parede pode ser feita de 2 formas:

$\checkmark$ Através do "Menu" utilizando a função "Wall". Esta função permite especificar a espessura e a condutividade hidráulica da parede, esta altemativa também tem a vantagem de não exigir um rearranjo na malha, no entanto tem a limitação de só permitir a construção da parede paralelamente ao eixo X;

$\checkmark$ Seleção de células inativas. Este método permite a construção de um estrutura de contenção em $90^{\circ}$, no entanto é necessário que se adeqüe a grade, além de representar uma estrutura com condutividade infinitamente grande, não permitindo nenhum processo de transporte por entre as células.

Para se obter um resultado melhor sem aumentar de maneira excessiva o número de células do modelo, cria-se a parede através da função "Wall" e depois se completa-se a geometria desejada com células inativas.

Neste caso específico a estrutura só se estendeu a primeira camada (número 1). Para efeito de representação, a espessura da parede foi exagerada nas figuras.

Os resultados nesta simulação são:

\section{Modelo de Fluxo}

A construção de uma estrutura de contenção afeta diretamente o movimento do fluxo subsuperficial; é possível observar pela Figura 109 que a parede causa um desvio no fluxo de água subsuperficial. O objetivo desta alternativa é minimizar a quantidade de fluxo que atinge a pluma ocasiona o espalhamento desta. 

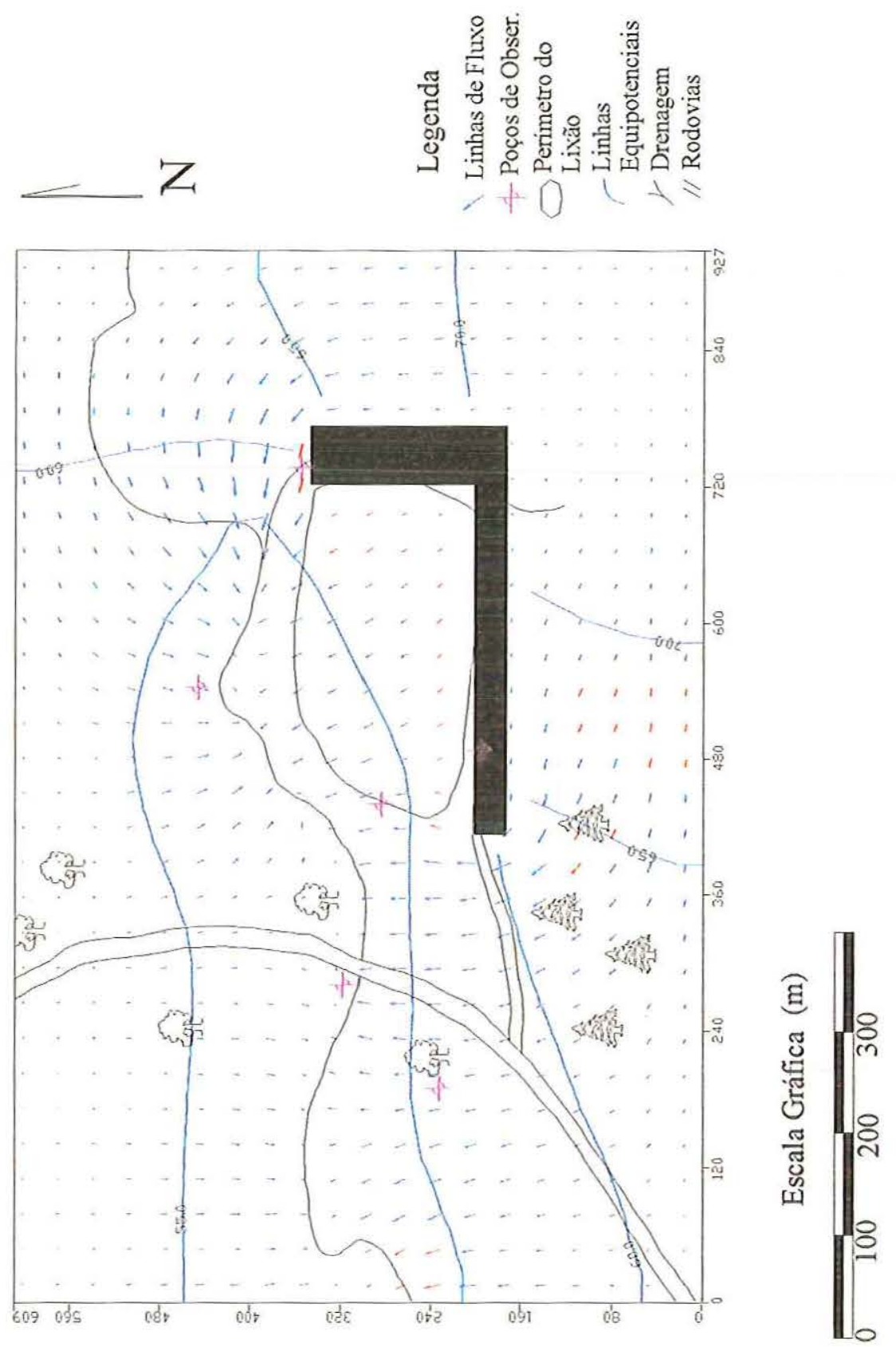

FIGURA 109 - Modelo de Fluxo de água subsuperficial na área de influência

Modelo de Transporte

As figuras 111 a 113 mostram que o espalhamento na camada 1 é um pouco menor se comparado com a situação 1, e o nível de contaminação é maior. A Figura 110 apresenta a trajetória das partículas para o caso desta simulação. 
Na camada 2, nota-se um aumento na concentração em relação a situaçãol. A maior mudança ocorreu na camada 3 , onde além da variação na geometria da pluma o pico de concentração aumenta de $2 \mathrm{mg} / \mathrm{l}$ para $150 \mathrm{mg} / \mathrm{l}$ no tempo de 7300 dias.

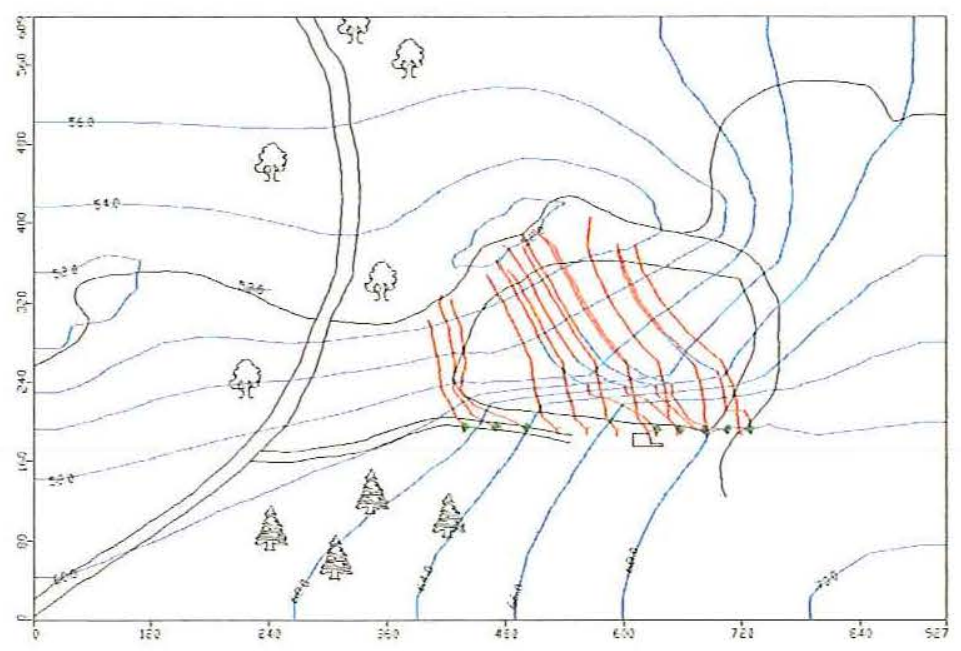

Escala Gráfica (m)

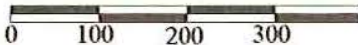

\section{Legenda}

Linhas Equipotenciais Caminhamento das partículas

$\bigcirc$ Perímetro do Lixão

$y$ Drenagem

// Rodovias

FIGURA 110 - Trajetória das Partículas

As figuras 111 a 119 representam a distribuição dos solutos na zona de influência para as camadas 1,2 e 3 .

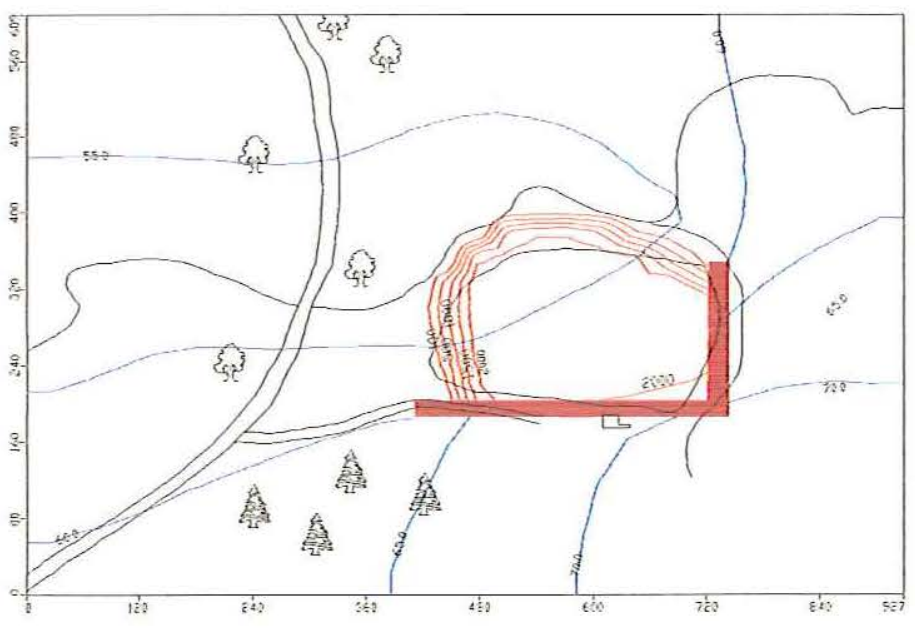

Escala Gráfica (m)

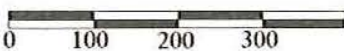

$\mathrm{N}$

\section{Legenda}

C Linhas Equipotenciais

Delimitação de Níveis de

Concentração da Pluma

Perímetro do Lixão

y Drenagem

// Rodovias

FIGURA 111 - Modelo de Transporte. Camada 1 Tempo 1825 dias. 


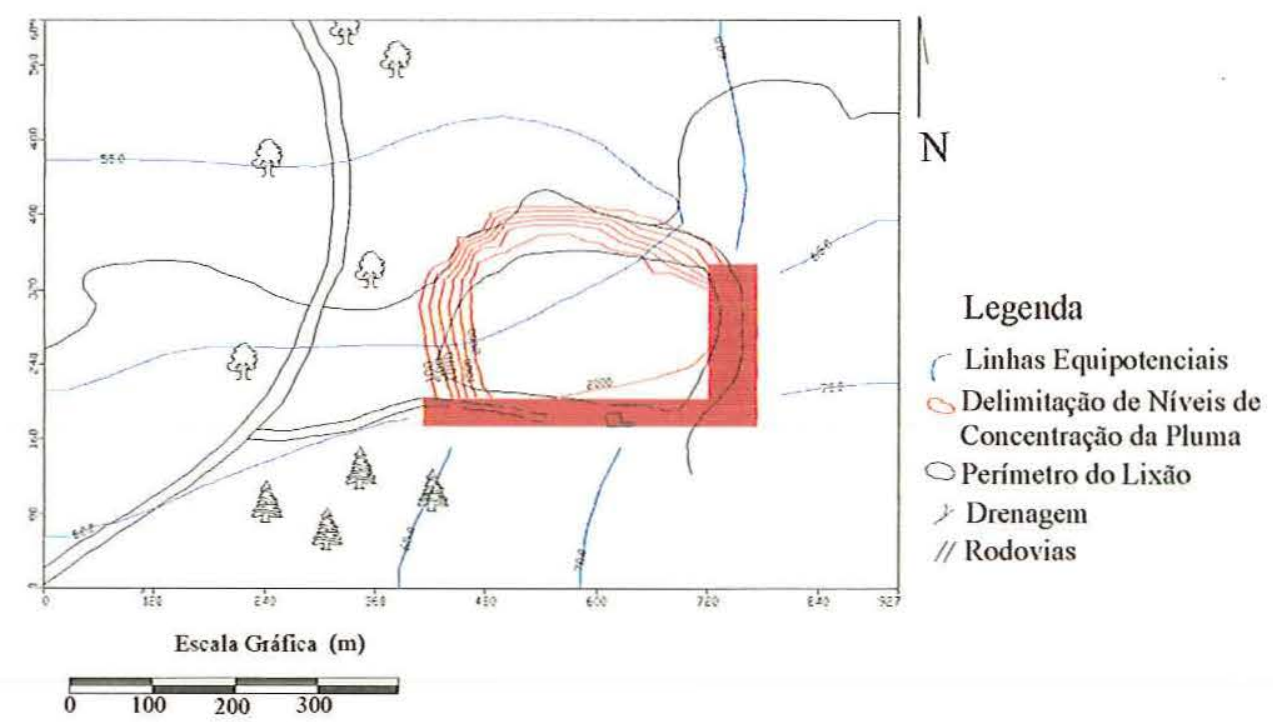

FIGURA 112 - Modelo de Transporte. Camada 1 Tempo 3650 dias.

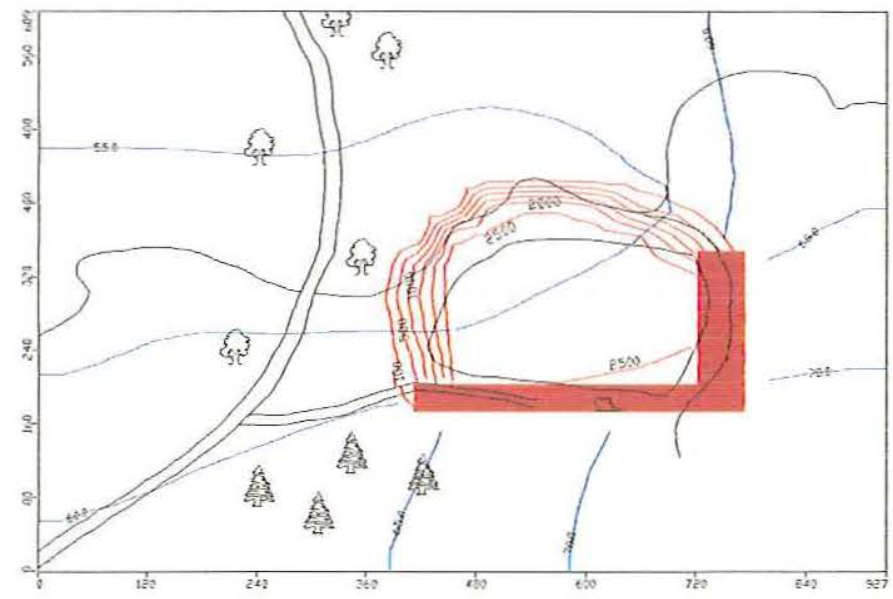

N

Legenda

( Linhas Equipotenciais $\checkmark$ Delimitação de Níveis de Concentração da Pluma

$\bigcirc$ Perímetro do Lixão

5. Drenagem

// Rodovias

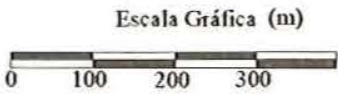

FIGURA 113 - Modelo de Transporte. Camada 1 Tempo 7300 dias. 


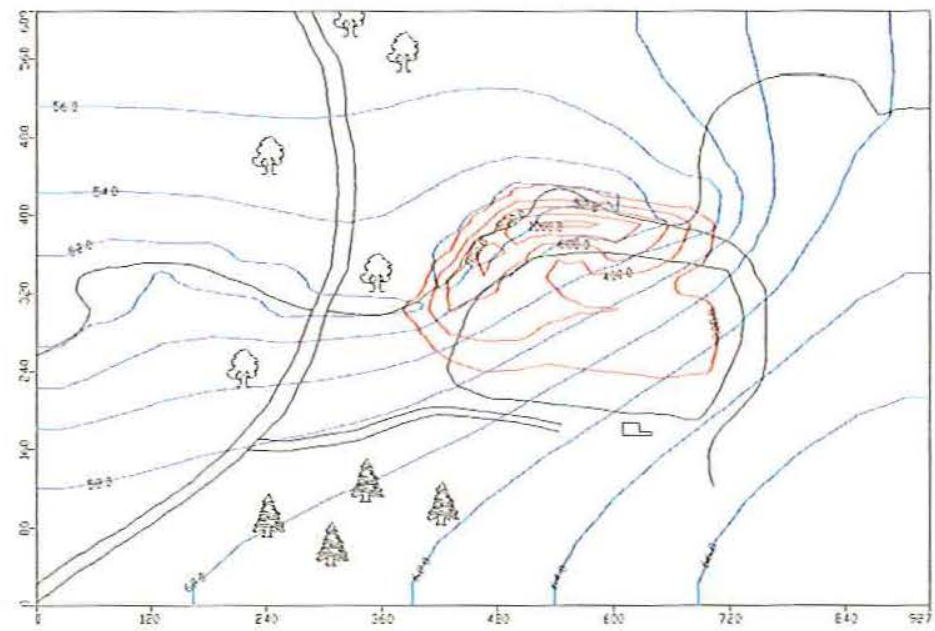

Escala Gráfica (m)

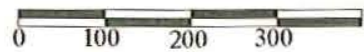

$\mathrm{N}$

\section{Legenda}

- Linhas Equipotenciais

Delimitação de Níveis de

Concentração da Pluma

Perímetro do Lixão

. Drenagem

// Rodovias

FIGURA 114 - Modelo de Transporte. Camada 2 Tempo 1825 dias.

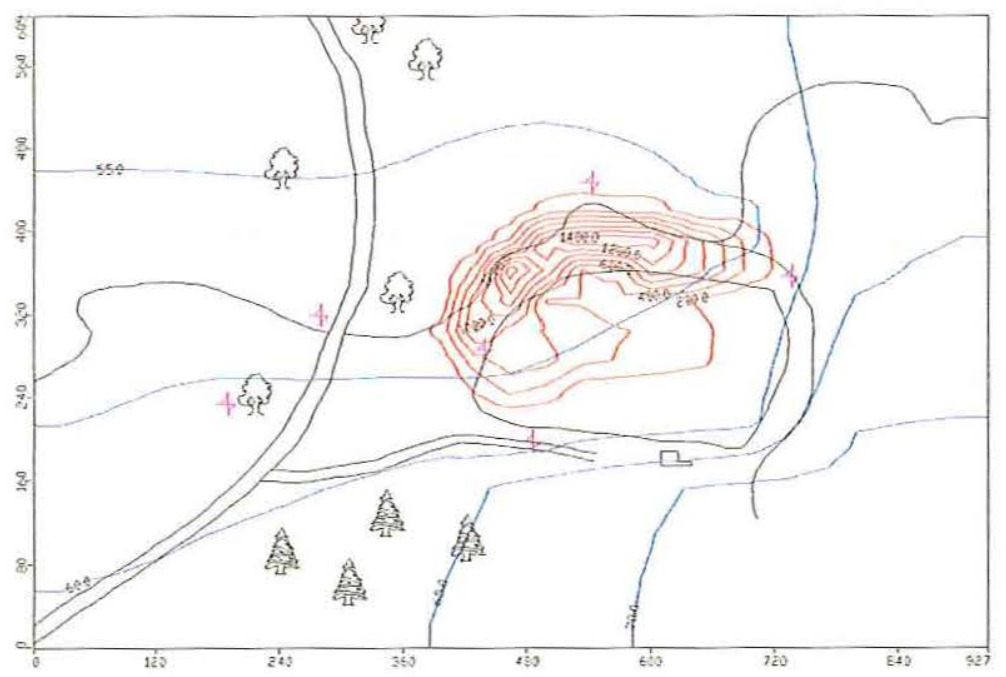

\section{${ }_{N}$}

\section{Legenda}

Linhas Equipotenciais

Delimitação de Níveis di Concentração da Pluma

$\bigcirc$ Perímetro do Lixão

, Drenagem

// Rodovias

Escala Gráfica (m)

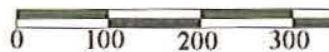

FIGURA 115 - Modelo de Transporte. Camada 2 Tempo 3650 dias. 


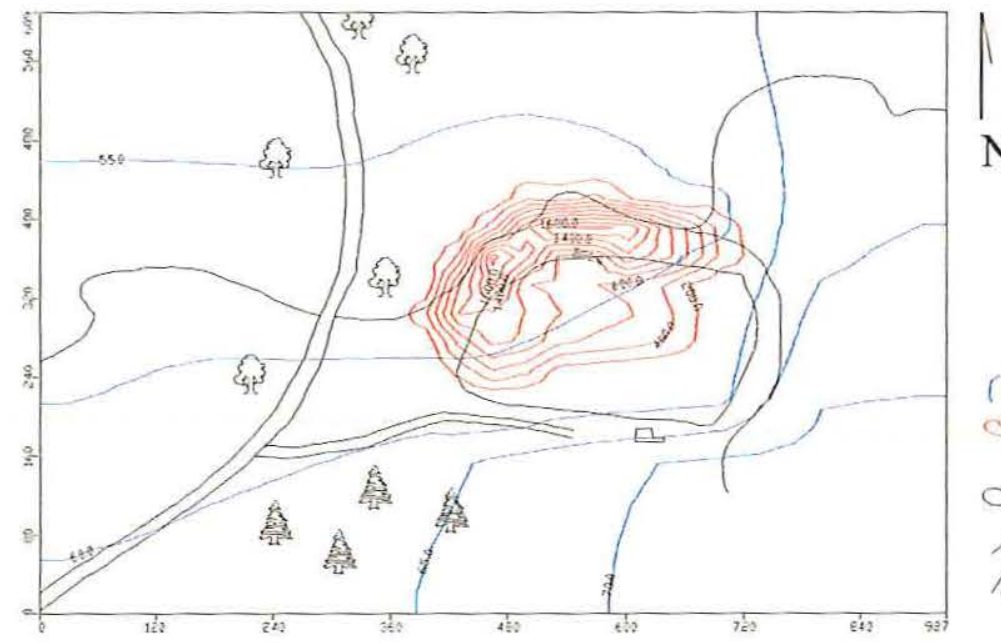

Legenda

( Linhas Equipotenciais

$\checkmark$ Delimitação de Níveis de

Concentração da Pluma

$\checkmark$ Perímetro do Lixão

Drenagem

// Rodovias

Escala Gráfica $(\mathrm{m})$

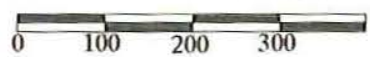

FIGURA 116 - Modelo de Transporte. Camada 2 Tempo 7300 dias.

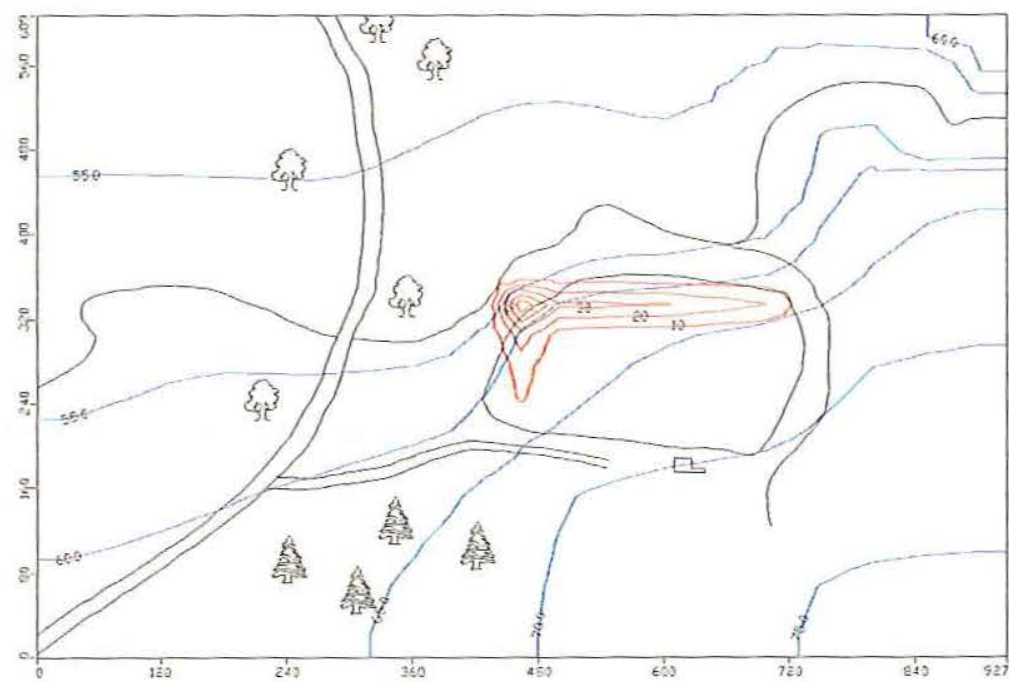

\section{Legenda}

Linhas Equipotenciais

Delimitação de Níveis de Concentração da Pluma

$\bigcirc$ Perímetro do Lixão

y Drenagem

// Rodovias

Escala Gráfica (m)

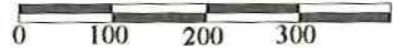

FIGURA 117 - Modelo de Transporte. Camada 3 Tempo 1825 dias. 

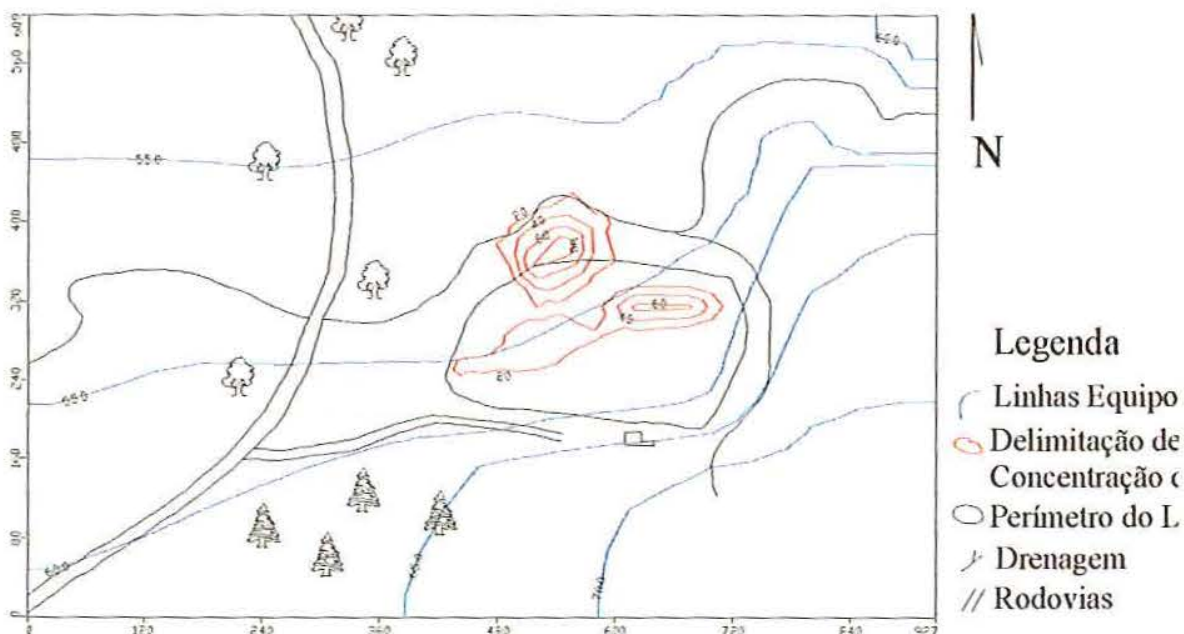

Escala Gráfica (m)

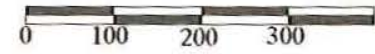

FIGURA 118 - Modelo de Transporte. Camada 3 Tempo 3650 dias.

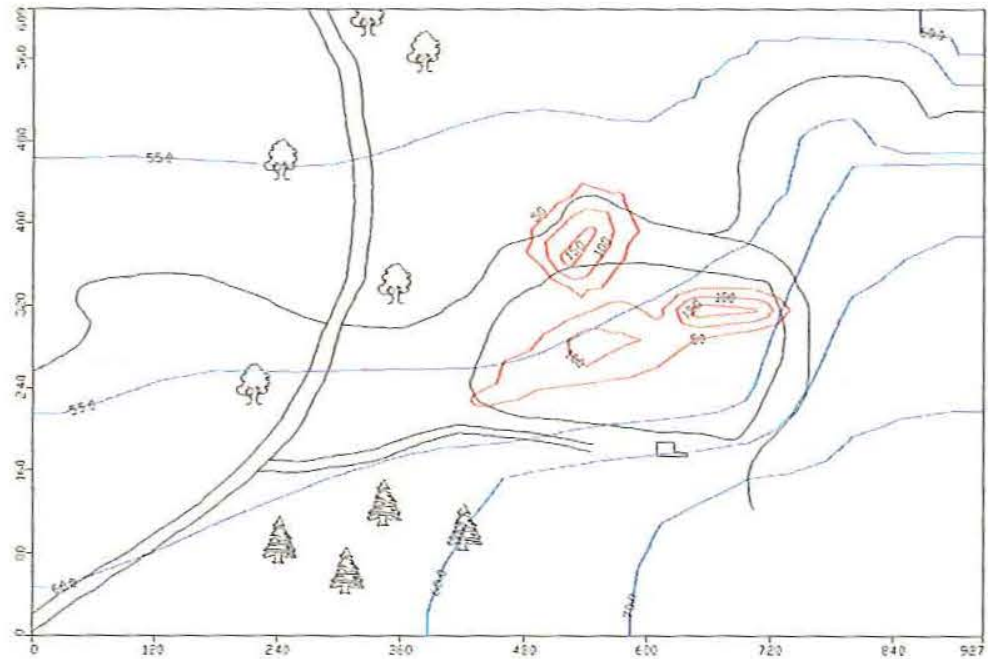

Escala Gráfica (m)

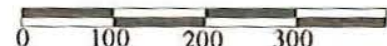

N

\section{Legenda}

( Linhas Equipotenciais

Delimitação de Níveis de Concentração da Pluma

$\bigcirc$ Perímetro do Lixão

, Drenagem

// Rodovias

FIGURA 119 - Modelo de Transporte. Camada 3 Tempo 7300 dias. 
As figuras 120 a 125 representam os perfis verticais longitudinais e transversais gerados pelo modelo. Observa-se que a parede diminui o contato do fluxo com o contaminante e desta forma diminui o espalhamento da pluma de poluentes.

As figuras 123 a 125 mostram a influência da estrutura de contenção onde observase que, próximo a parede, ocorre um transporte mais efetivo na vertical devido a alteração no fluxo original, porém observa-se nos perfis transversais o espalhamento da zona abaixo do lixão para profundidade da ordem de 30 metros. 


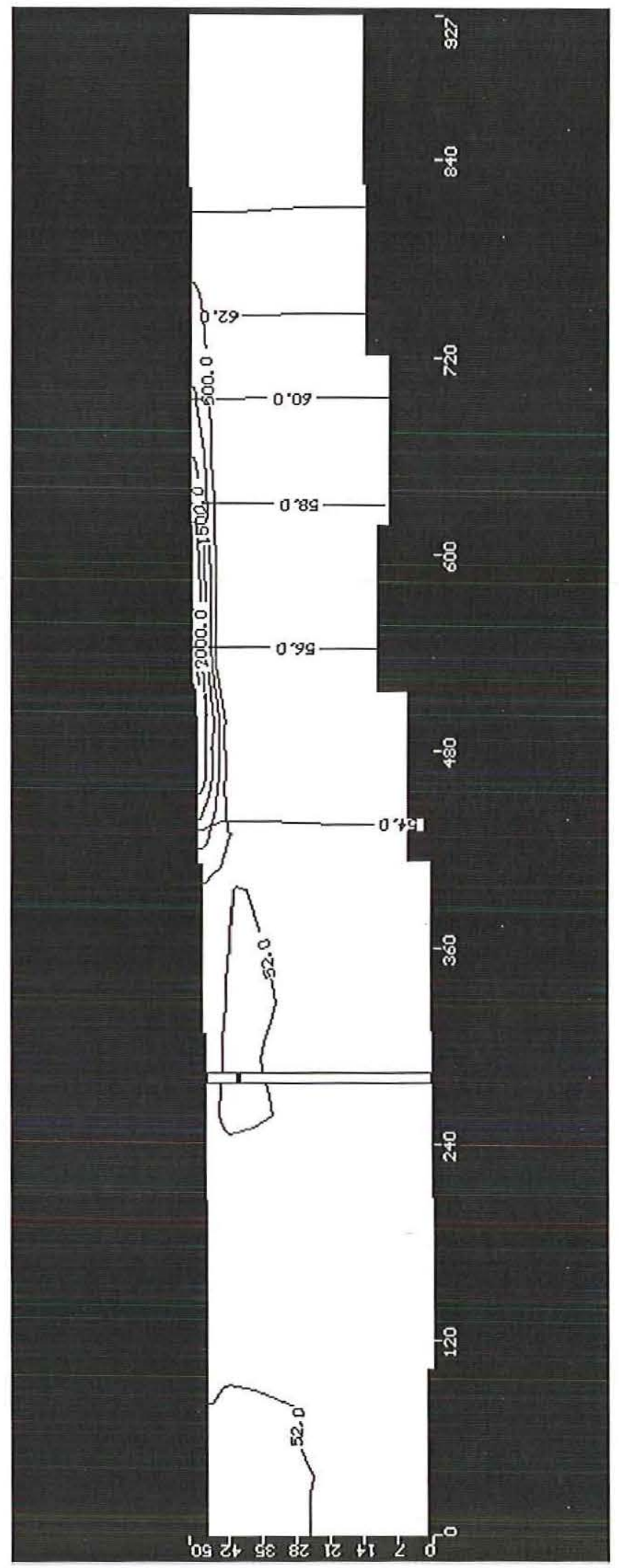

FIGURA 120 - Perfil Longitudinal a direção de maior espalhamento da pluma de poluição (Linha) no Tempo de 1825 dias. 


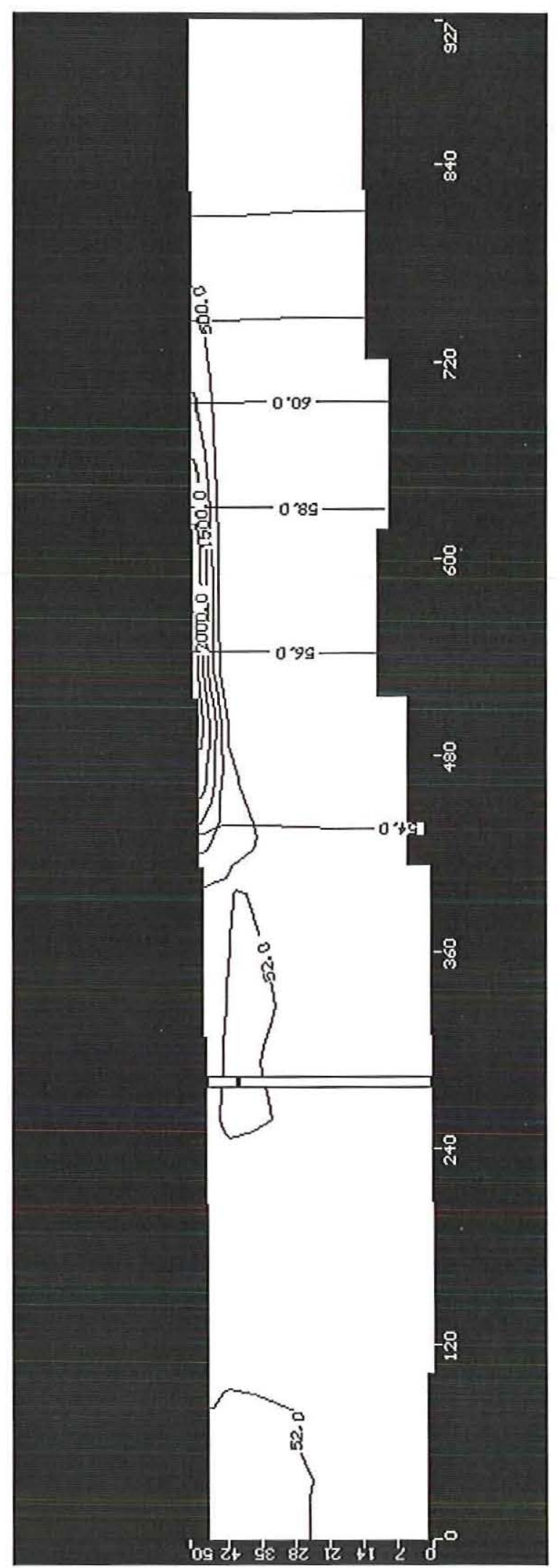

FIGURA 121 - Perfil Longitudinal a maior direção de espalhamento da pluma de poluição (Linha) no Tempo de 3650 dias. 


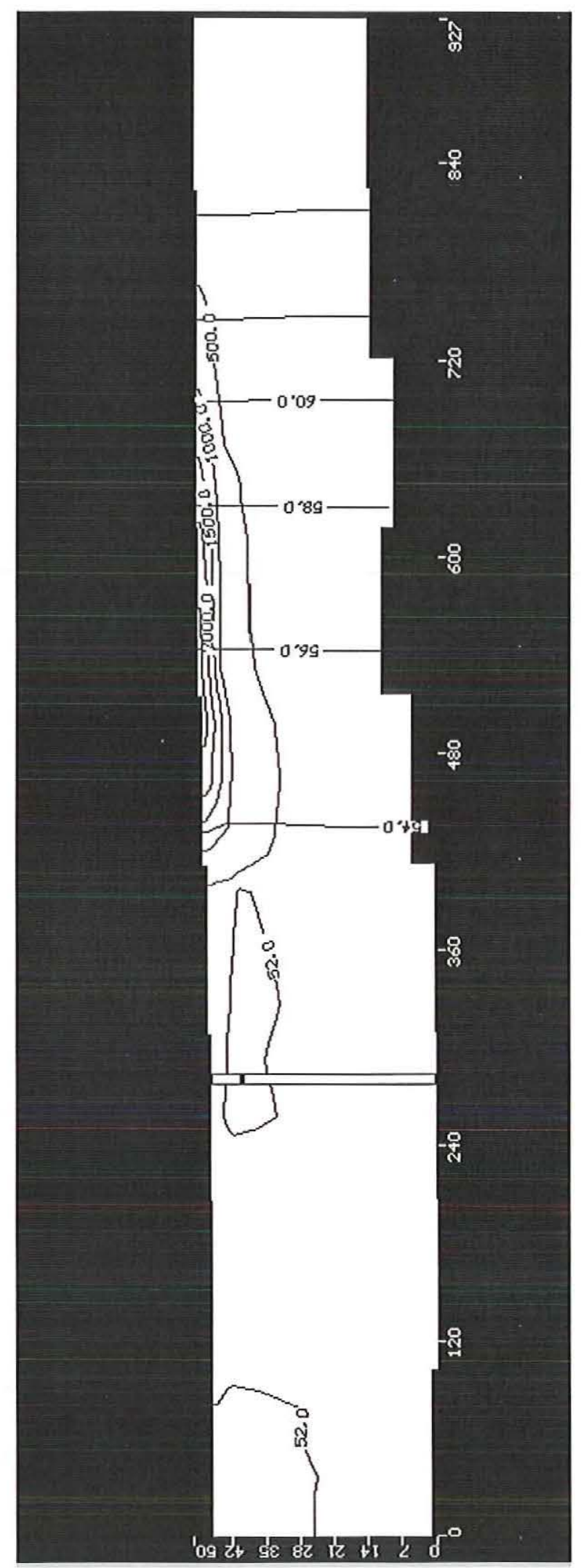

FIGURA 122 - Perfil Longitudinal a direção de maior espalhamento da pluma de poluição (linha) no Tempo de 7300 dias. 


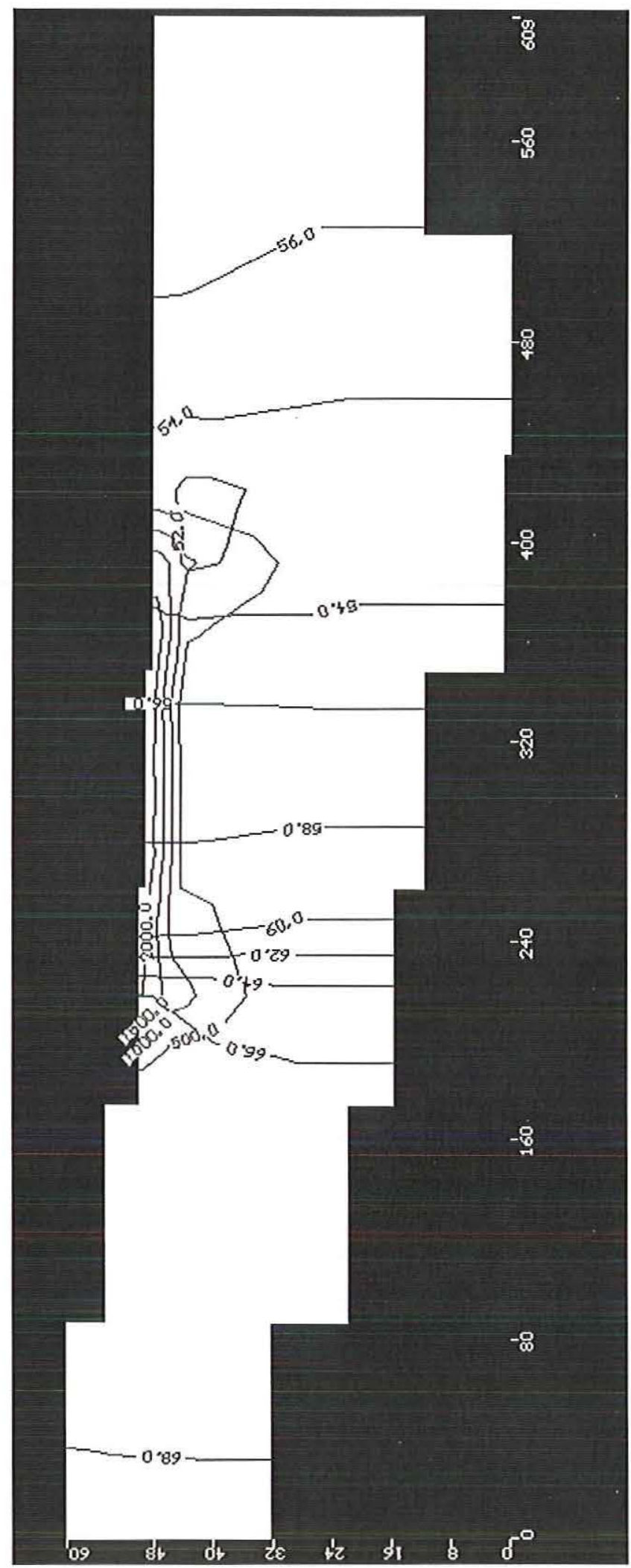

FIGURA 123 - Perfil Transversal a direção de maior espalhamento da pluma de poluição (Coluna) no Tempo de 1825 dias. 


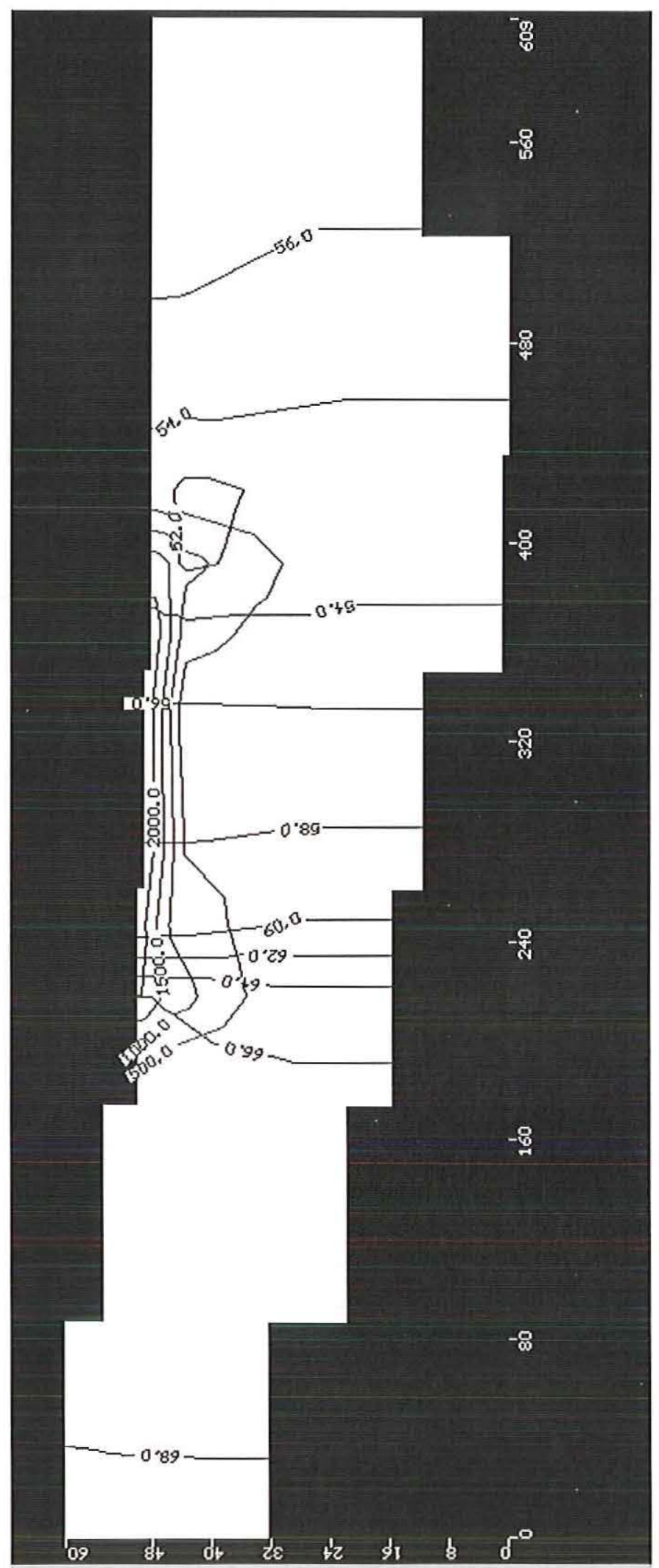

FIGURA 124 - Perfil Transversal a direção de maior espalhamento da pluma de poluição (Coluna) no Tempo de 3650 dias. 


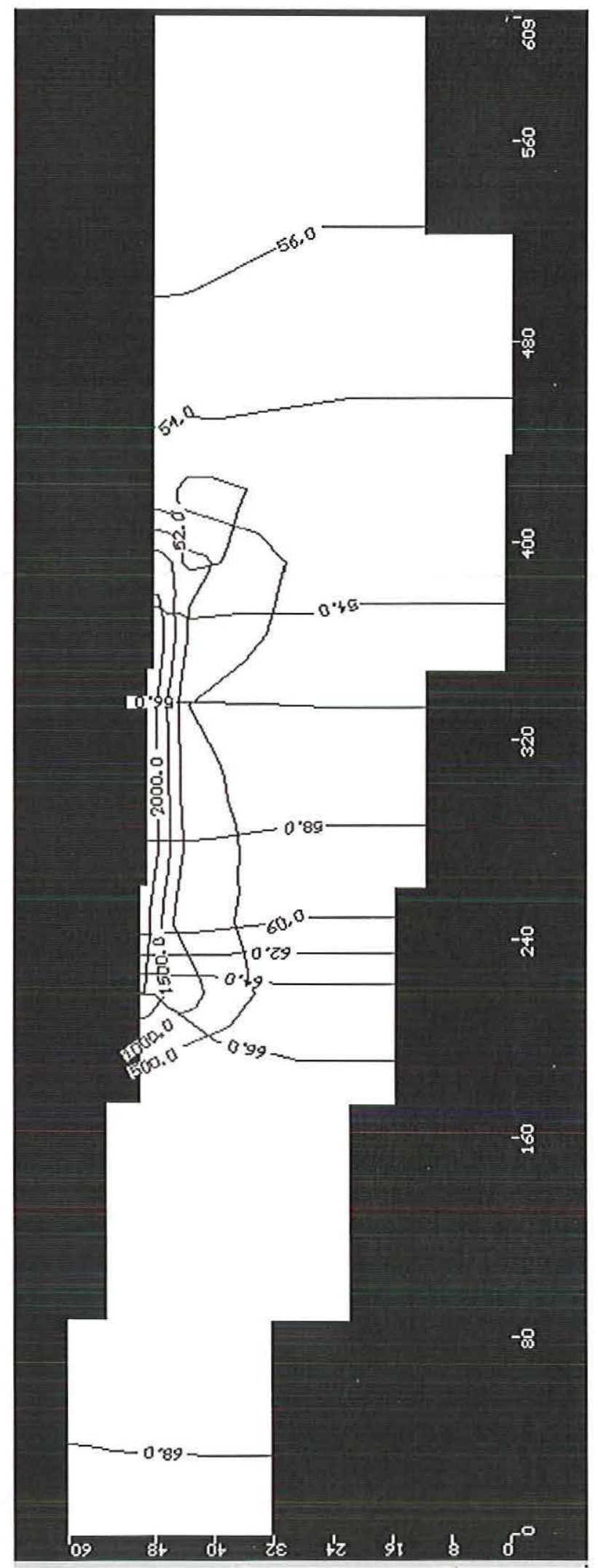

FIGURA 125 - Perfil Transversal a direção de maior espalhamento da pluma de poluição (Coluna) no Tempo de 7300 dias. 


\section{$5^{\circ}$ Simulação: Utilizando-se de Paredes Frontais}

Para esta alternativa utilizou-se os mesmos recursos, alterando apenas a posição das paredes em relação a fonte de contaminação, neste caso, a estrutura de contenção atravessa as 3 camadas. Os resultados desta simulação são:

\section{Modelo de Fluxo}

A construção desta estrutura, assim como no caso anterior, também tem como objetivo alterar o fluxo de água subsuperficial, neste caso a função é servir como barreira para a pluma de poluição e não de minimizar o contato entre o fluxo e o poluente.

Nota-se na Figura 126 que as linhas de fluxo seguem em direção ao ponto de junção entre as duas paredes. Durante esta simulação colocou-se poços para bombear esta pluma, no entanto não obteve-se sucesso para esta alternativa, pois as células ao sul do poço ficaram secas, indicando um rebaixamento muito grande mesmo com a utilização de apenas um poço com vazão baixa $\left(10 \mathrm{~m}^{3} / \mathrm{dia}\right)$.

\section{Modelo de Transporte}

Neste modelo observa-se que a pluma atinge a parede e gradativamente aumenta sua concentração e espalhamento. A influência da parede é mais visível nas camadas 2 e 3 , pois nestas a pluma tenderia a estar localizada mais ao norte da parede (simulação 1) e devido a barreira se concentra próximo a parede. Os níveis de concentração para a camada 1 é semelhante ao caso da simulação 1 , para a camada 2 nota-se um aumento na concentração principalmente no tempo de 7300 dias e um aumento ainda mais acentuado na camada 3, onde a concentração máxima chega a $80 \mathrm{mg} / \mathrm{l}$ (na simulação 1 é de $2.0 \mathrm{mg} / \mathrm{l}$ ).

Neste caso o aumento de concentração é desejado, pois indica que as paredes não estão permitindo a fuga do contaminante da região confinada. A Figura 127 apresenta o caminhamento das partículas. 

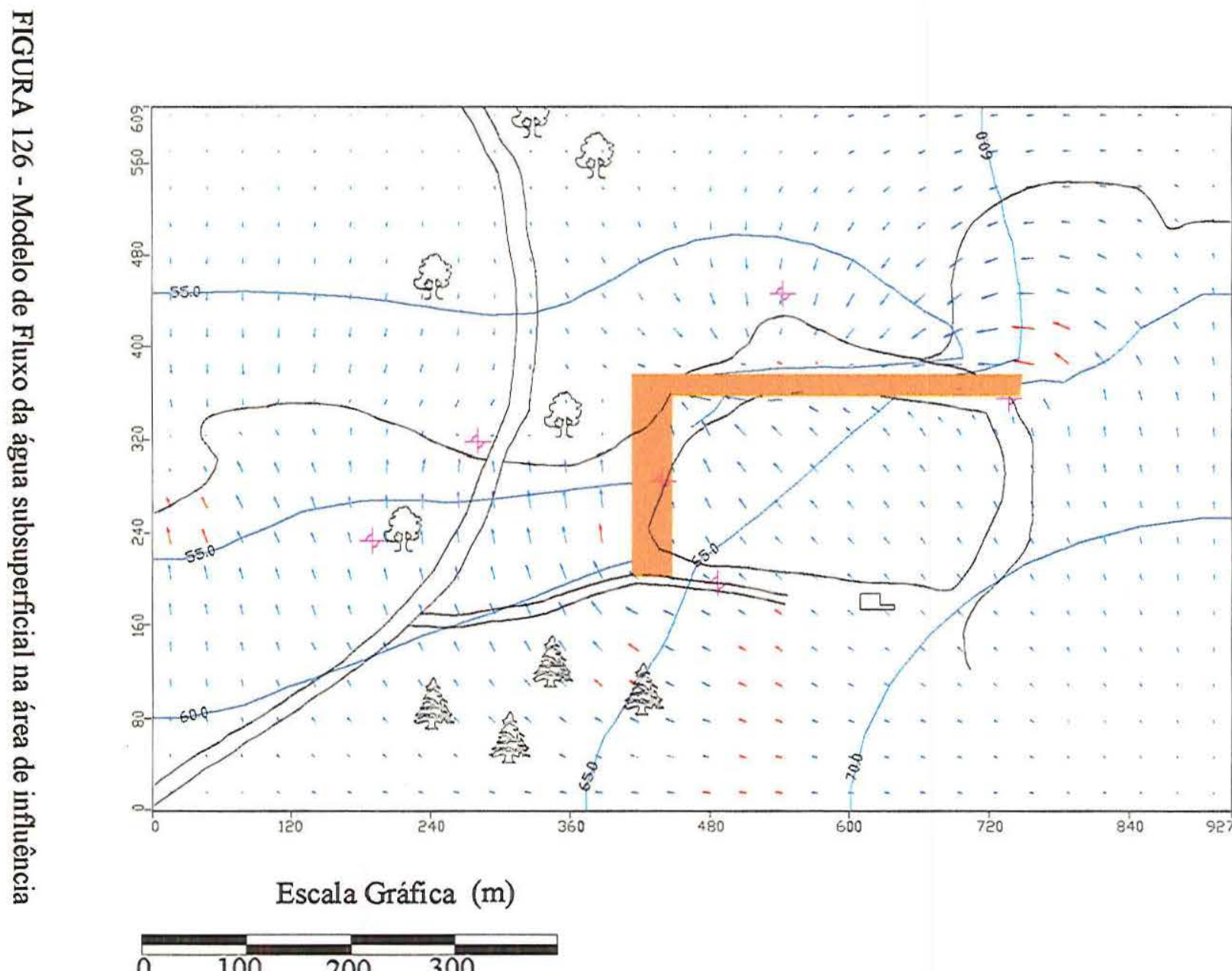

N

Legenda

Linhas de Fluxo 4. Poços de Obser. Perimetro do

Lixão

- Linhas

Equipotenciais

$\gamma$ Drenagem

// Rodovias

$0 \quad 100 \quad 200 \quad 300$ 


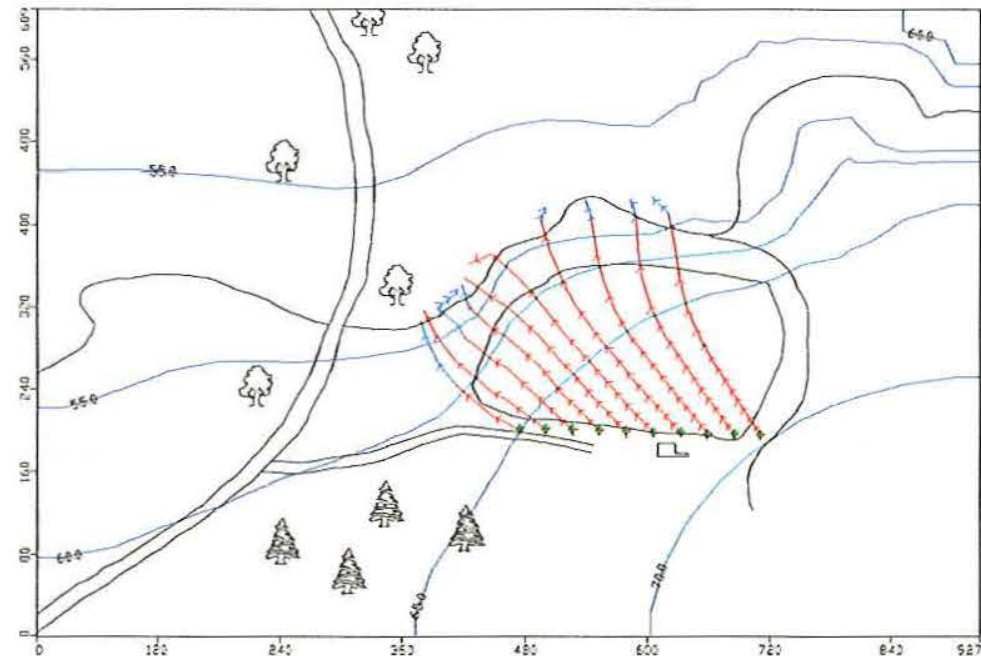

$\mathrm{N}$

\section{Legenda}

Linhas Equipotenciais

Caminhamento das partículas

OPerímetro do Lixão

y Drenagem

// Rodovias

Escala Gráfica (m)

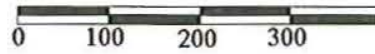

FIGURA 127 - Trajetória das Partículas

As figuras 128 a 136 mostram a distribuição da pluma de contaminação para esta simulação.

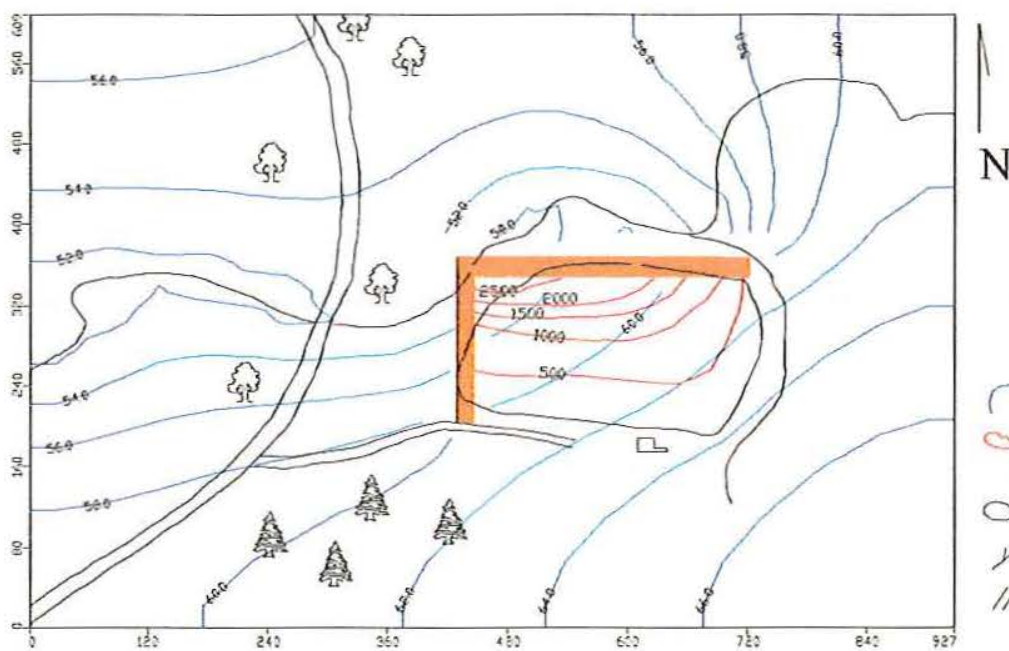

Legenda

Linhas Equipotenciais

Delimitação de Niveis de Concentração da Pluma

Perímetro do Lixão

y Drenagem

// Rodovias

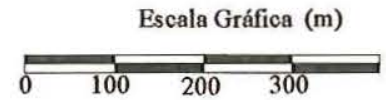

FIGURA 128 - Modelo de Transporte. Camada 1 Tempo 1825 dias. 


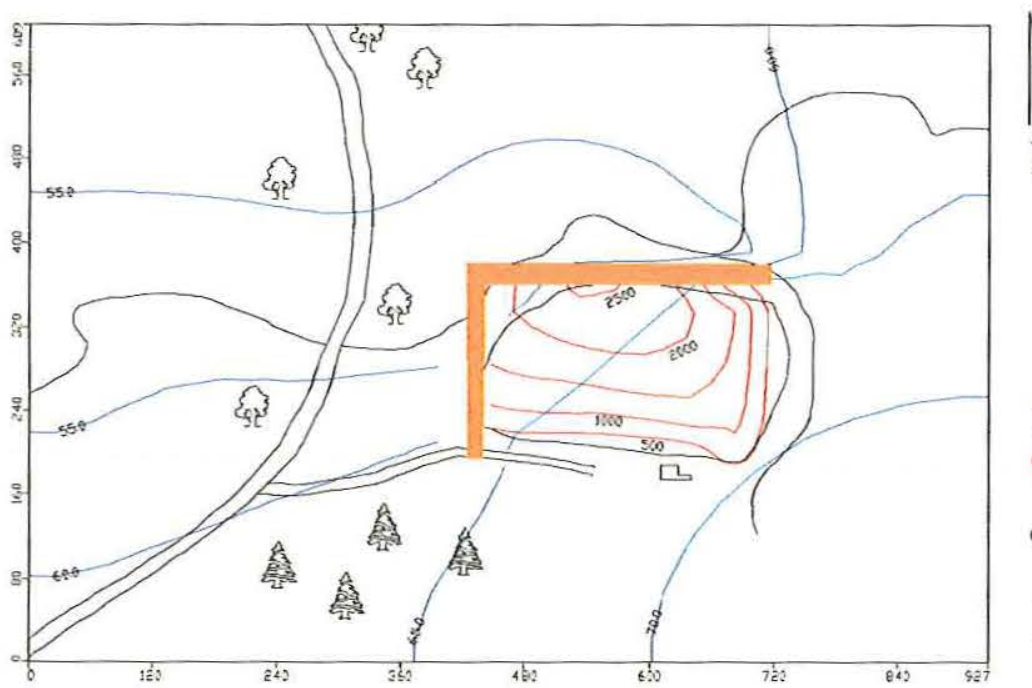

\section{Legenda}

- Linhas Equipotenciais

Delimitação de Níveis de Concentração da Pluma

$\bigcirc$ Perímetro do Lixão

> Drenagem

// Rodovias

Escala Gráfica (m)

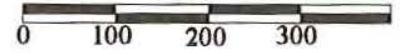

FIGURA 129 - Modelo de Transporte. Camada 1 Tempo 3650 dias.

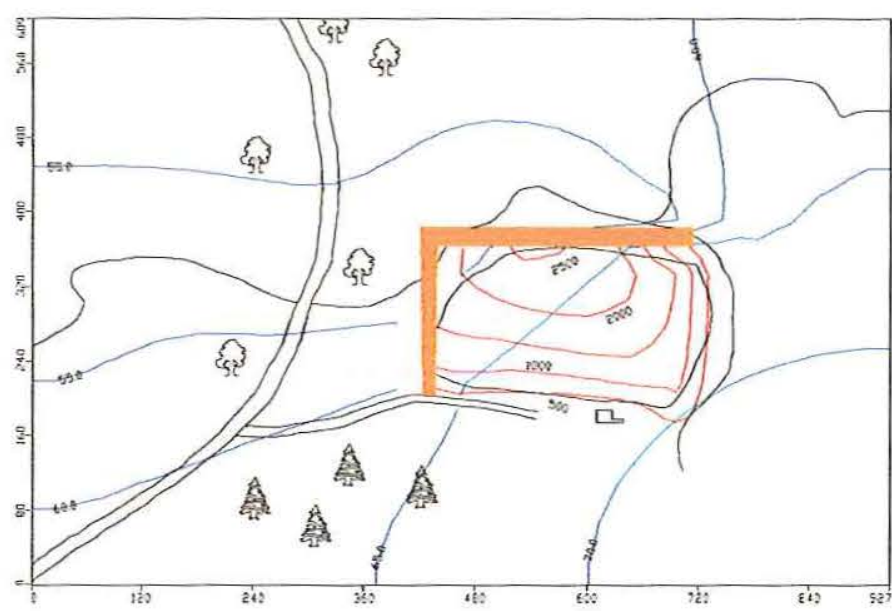

$\mathrm{N}$

\section{Legenda}

( Linhas Equipotenciais

Delimitação de Níveis de

Concentração da Pluma

○erímetro do Lixão

Drenagem

// Rodovias

FIGURA 130 - Modelo de Transporte. Camada 1 Tempo 7300 dias. 


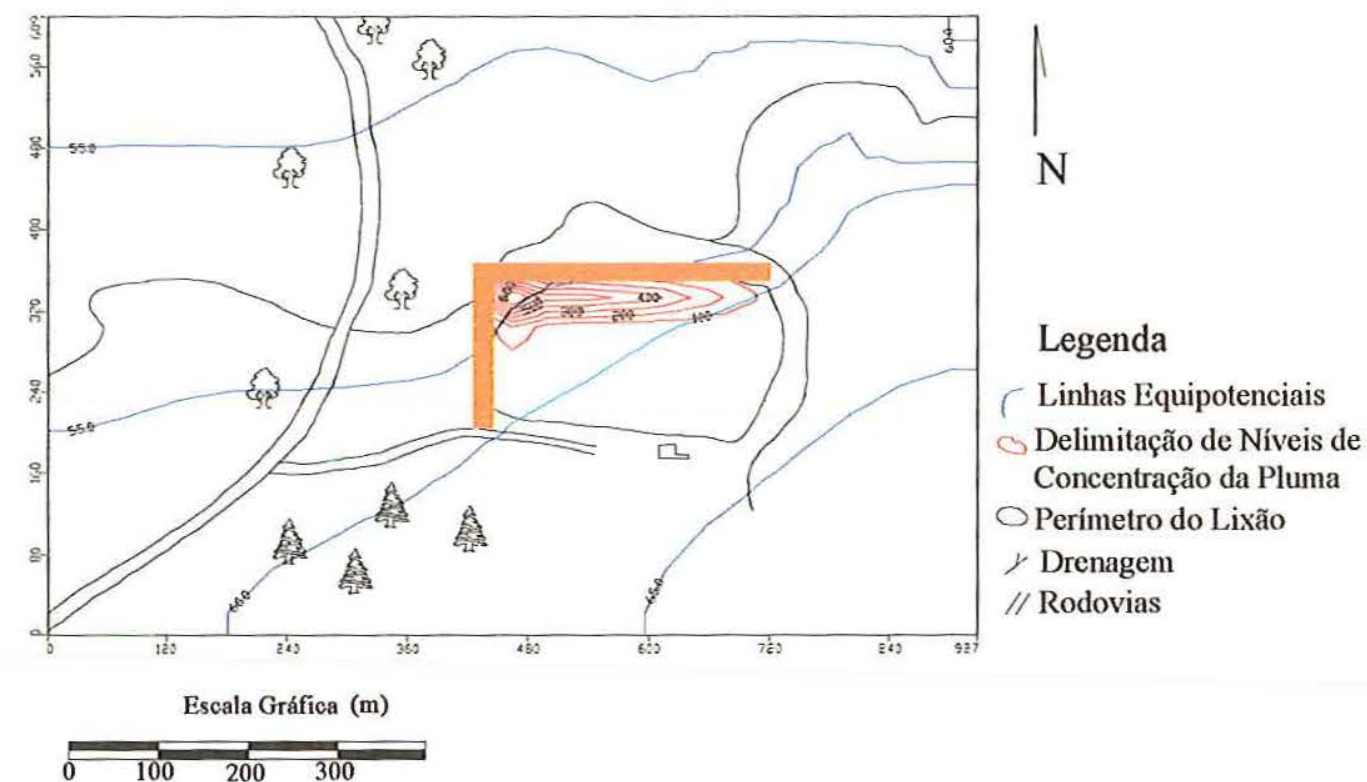

FIGURA 131 - Modelo de Transporte. Camada 2 Tempo 1825 dias.
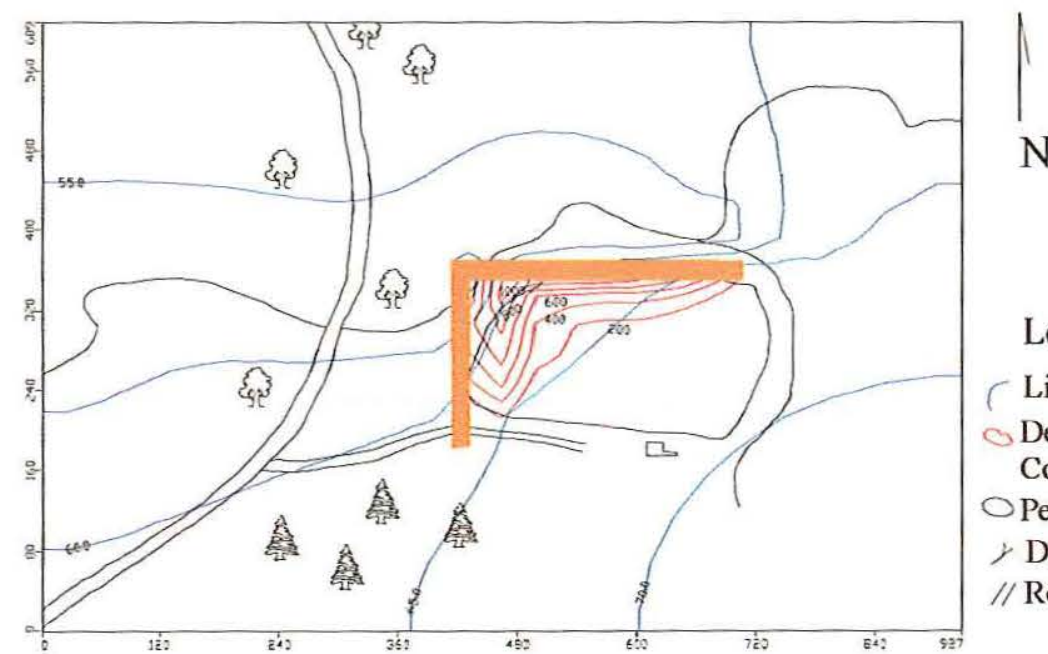

\section{Legenda}

Linhas Equipotenciais $\bigcirc$ Delimitação de Níveis de Concentração da Pluma Perímetro do Lixão

> Drenagem

// Rodovias

FIGURA 132 - Modelo de Transporte. Camada 2 Tempo 3650 dias. 


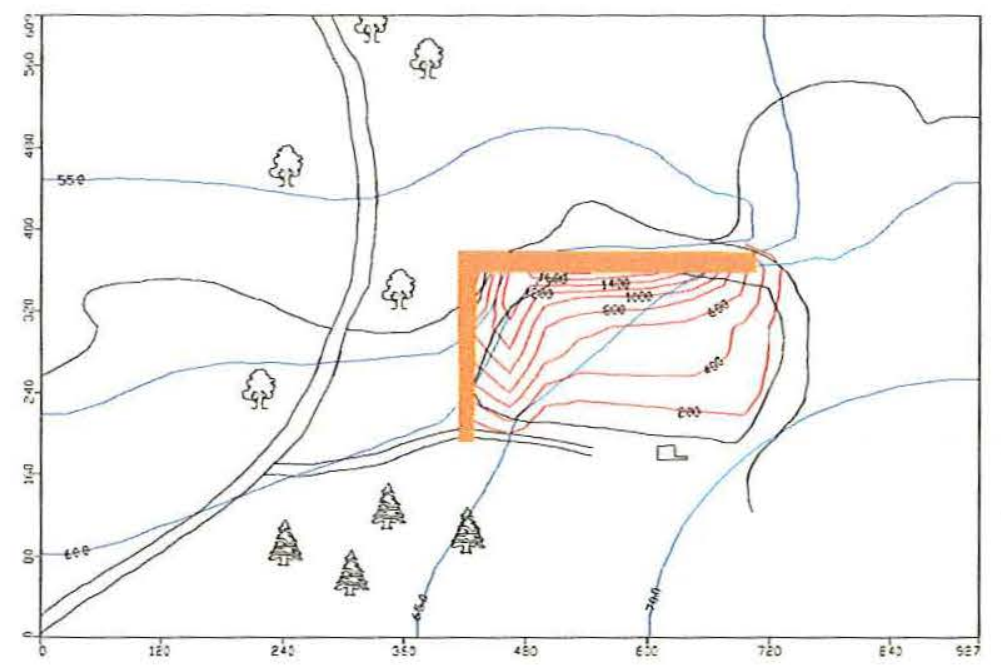

\section{$\left.\right|_{N}$}

\section{Legenda}

C Linhas Equipotenciais

Delimitação de Níveis de Concentração da Pluma

$\bigcirc$ Perímetro do Lixão

y Drenagem

// Rodovias

Escala Gráfica $(\mathrm{m})$

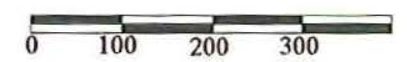

FIGURA 133 - Modelo de Transporte. Camada 2 Tempo 7300 dias.

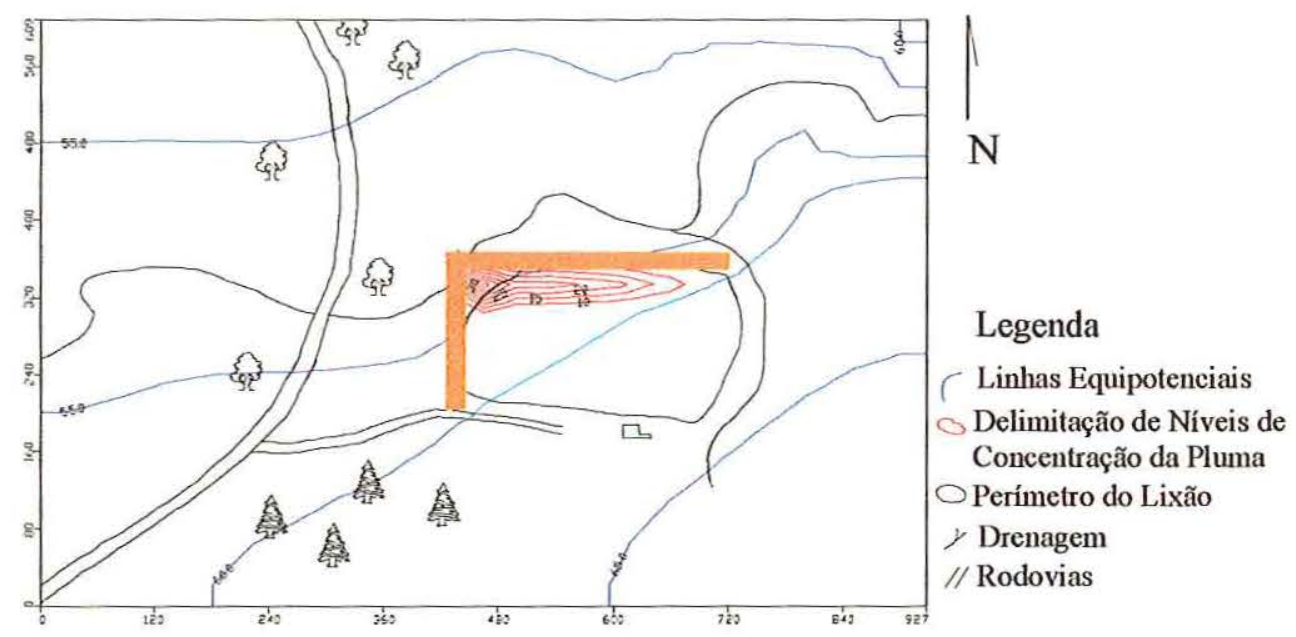

Escala Gráfica (m)

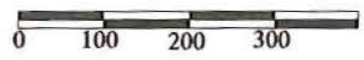

FIGURA 134 - Modelo de Transporte. Camada 3 Tempo 1825 dias. 


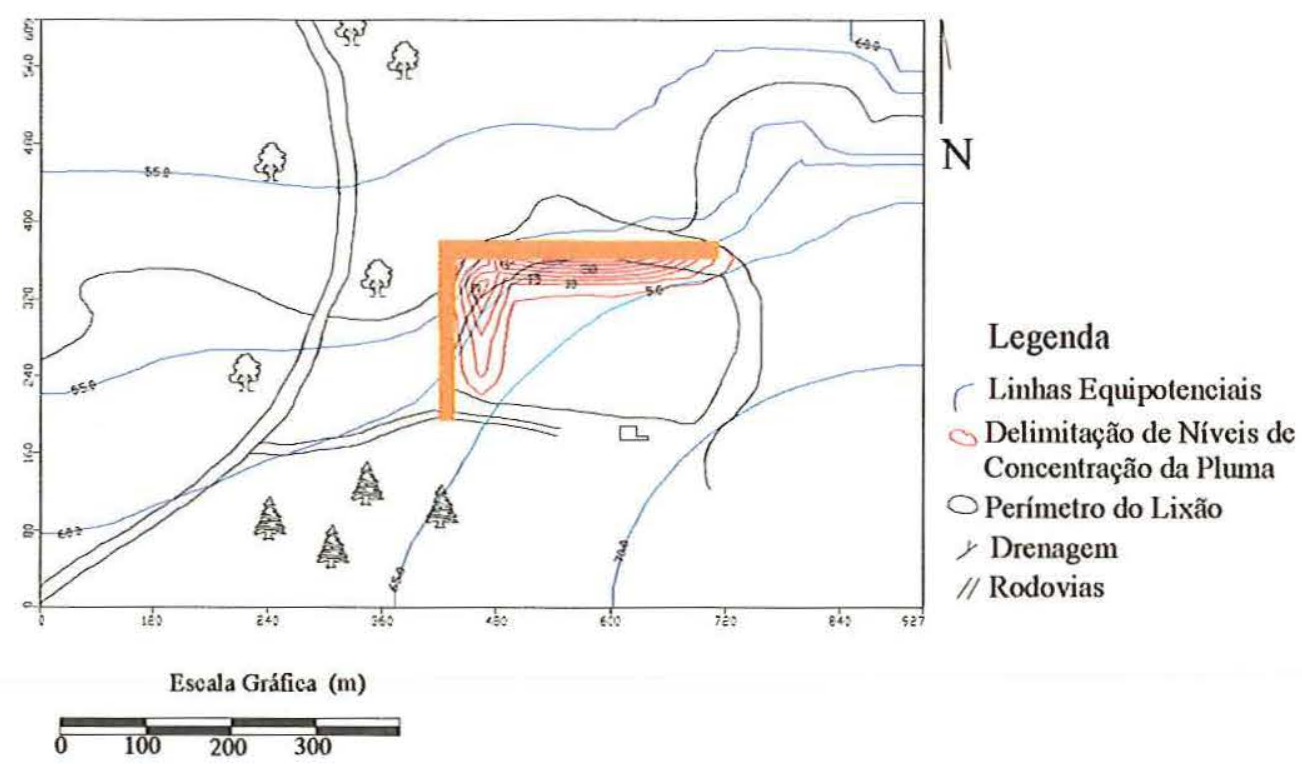

FIGURA 135 - Modelo de Transporte. Camada 3 Tempo 3650 dias.

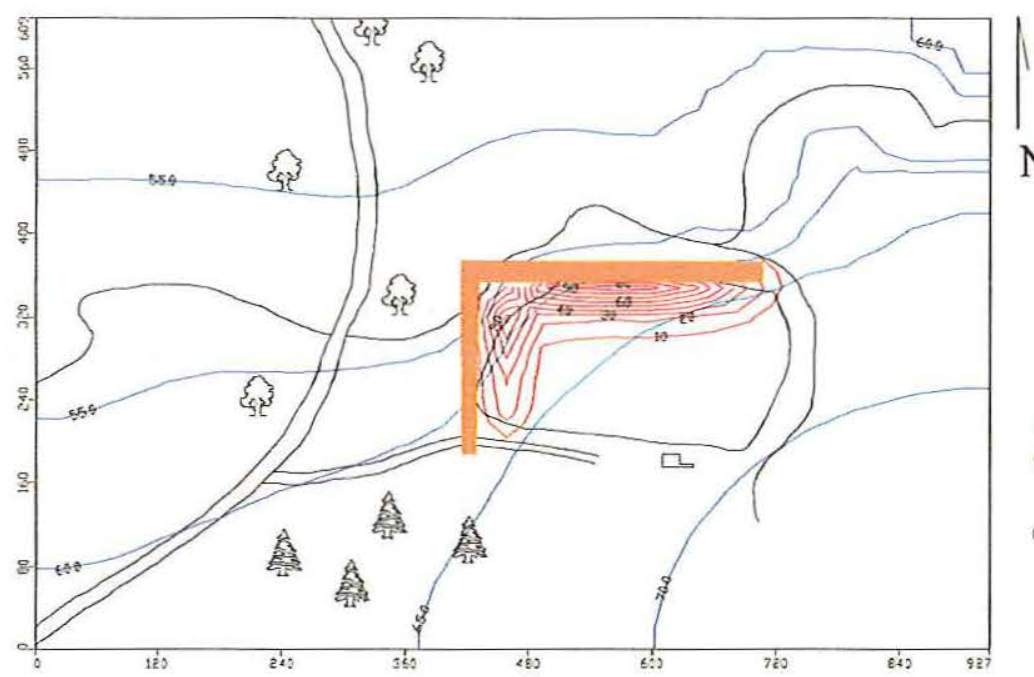

Legenda

( Linhas Equipotenciais

$\bigcirc$ Delimitação de Níveis dt Concentração da Pluma

$\bigcirc$ Perímetro do Lixão

y Drenagem

$/ /$ Rodovias

Escala Gráfica (m)

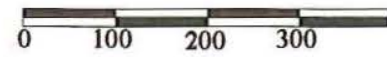

FIGURA 136 - Modelo de Transporte. Camada 3 Tempo 7300 dias. 
As figuras 137 a 142 mostram a distribuição vertical dos solutos e a influência da parede no caminhamento desta pluma. Seja na parede EW ou na NS observa-se valores da ordem de $500 \mathrm{mg} / \mathrm{l}$ a profundidades de $25 \mathrm{~m}$. Tal situação demostra a efíciência da barreira, mas por outro lado exige alta efíciência na construção da mesma, pois em caso de um rompimento o problema esta potencializado e os riscos são maiores. A frente poluente pode inclusive percolar abaixo da parede em períodos de tempo maiores (30 anos ou mais). 


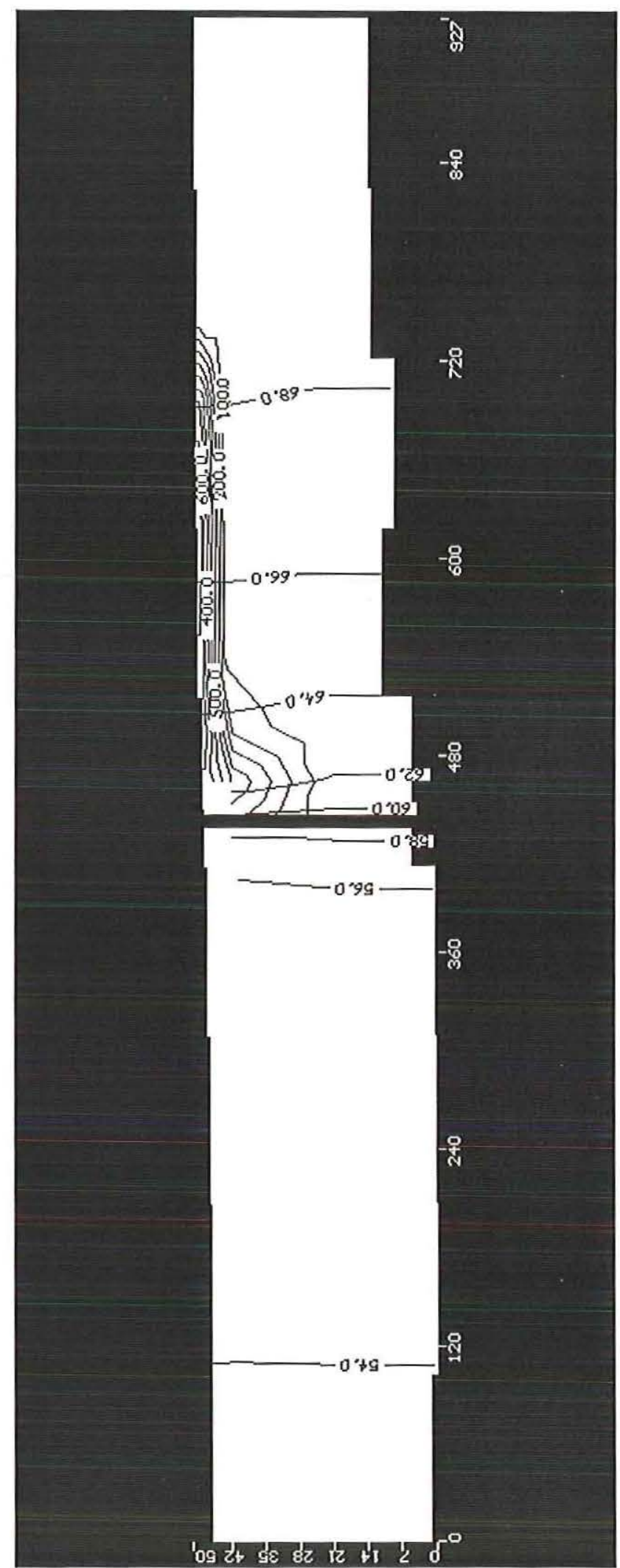

FIGURA 137 - Perfil Longitudinal a direção de maior espalhamento da pluma (Linha) Tempo de 1825 dias. 


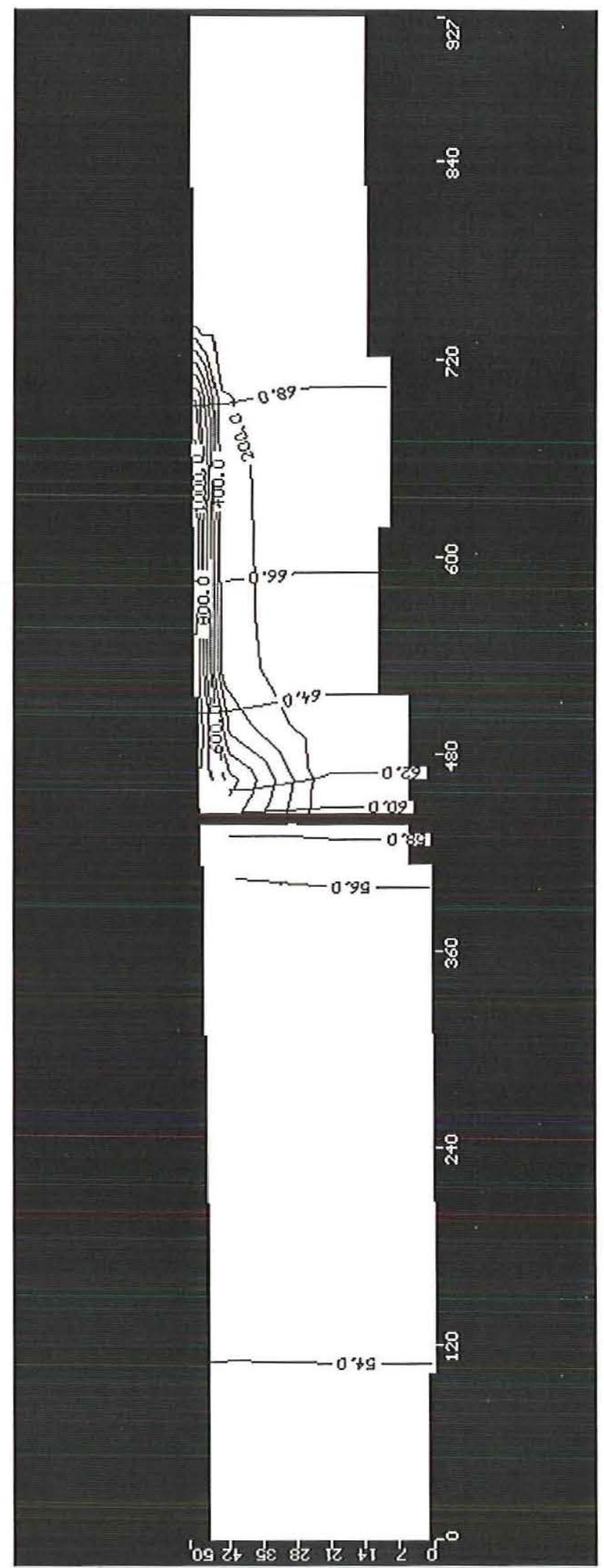

FIGURA 138 - Perfil Longitudinal a direção de maior espalhamento da pluma de poluição (Linha) no Tempo de 3650 dias. 


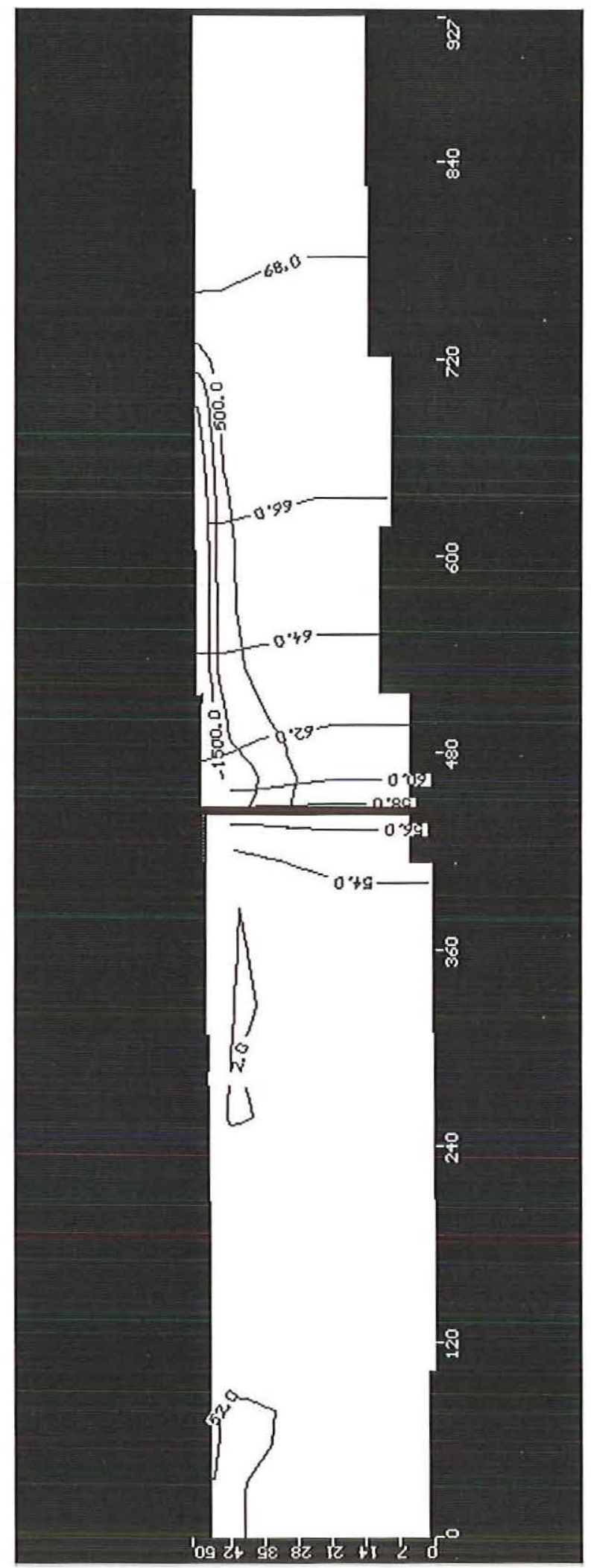

FIGURA 139 - Perfil Longitudinal a direção de maior espalhamento da pluma de da Linha no Tempo de 7300 dias. 


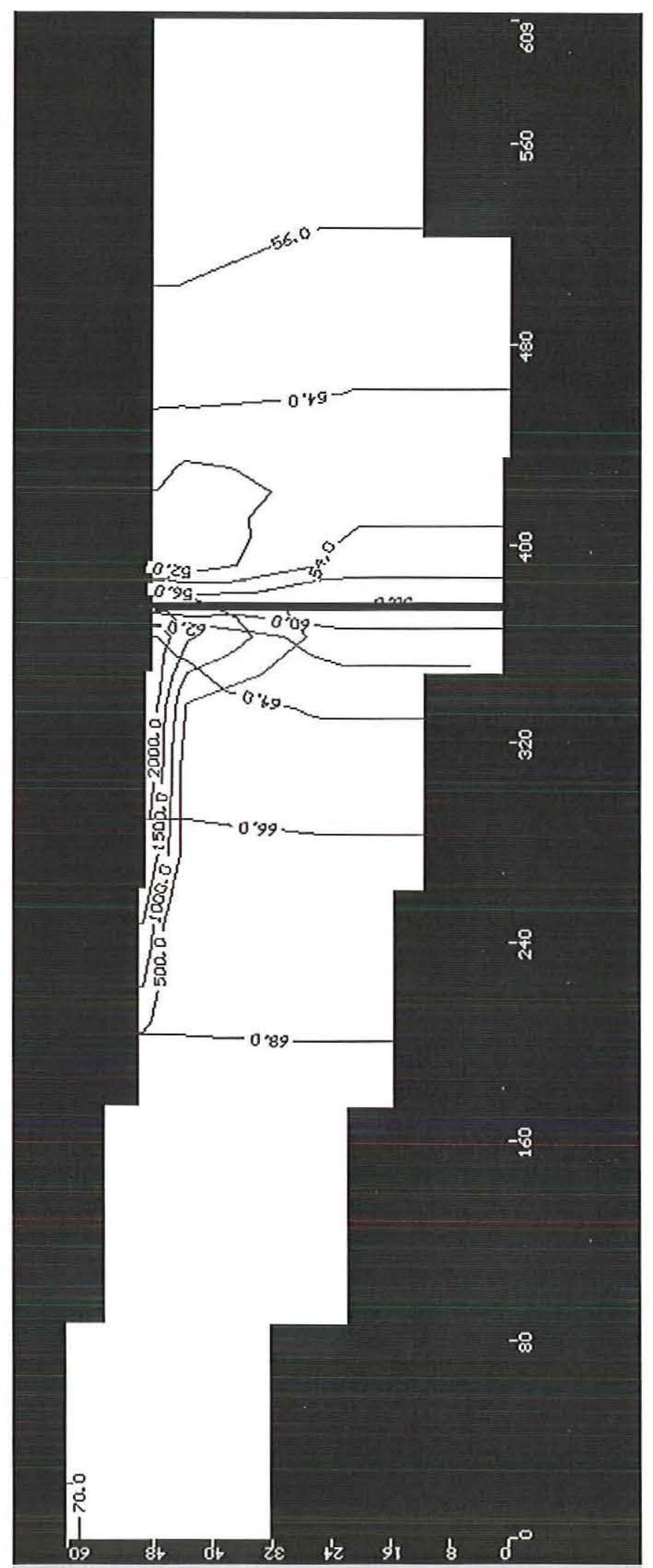

FIGURA 140 - Perfil Transversal a direção de maior espalhamento da pluma de poluição (Coluna) no Tempo de 1825 dias. 


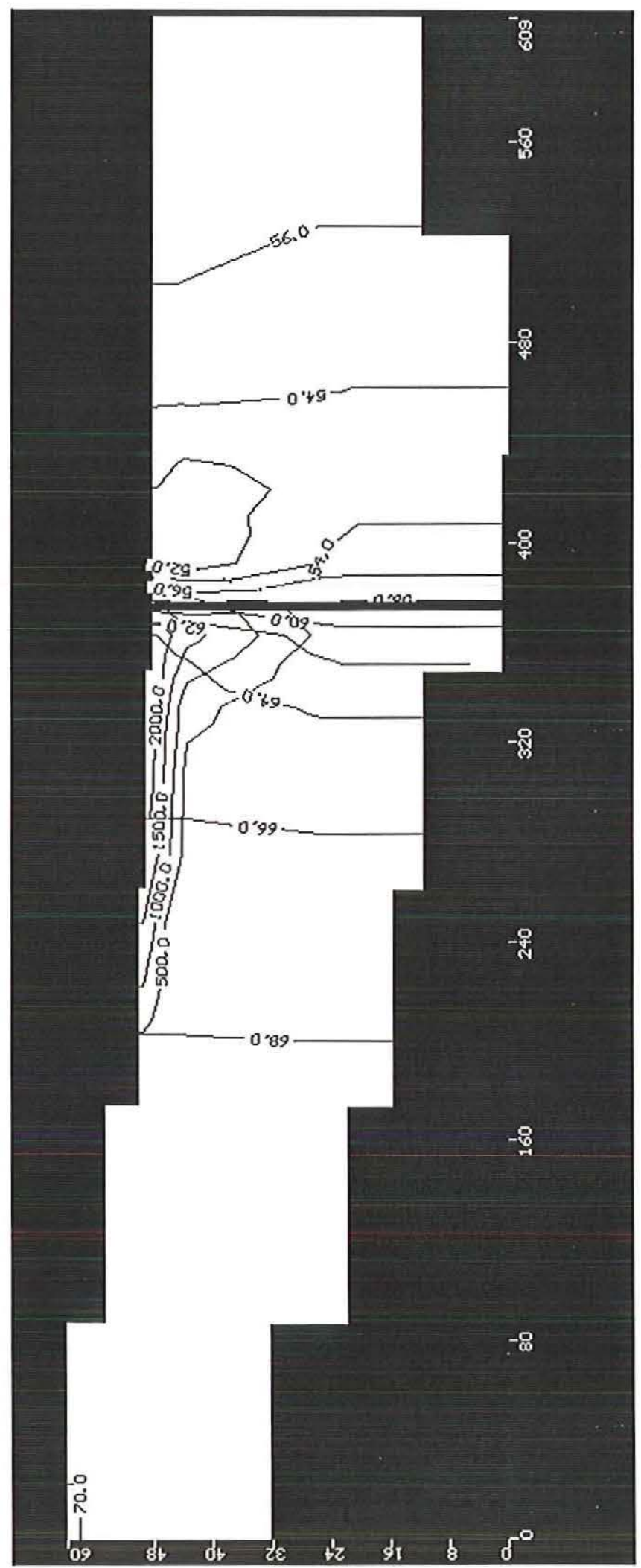

FIGURA 141 - Perfil Transversal a direção de maior espalhamento da pluma de poluição (Coluna) no Tempo de 3650 dias. 


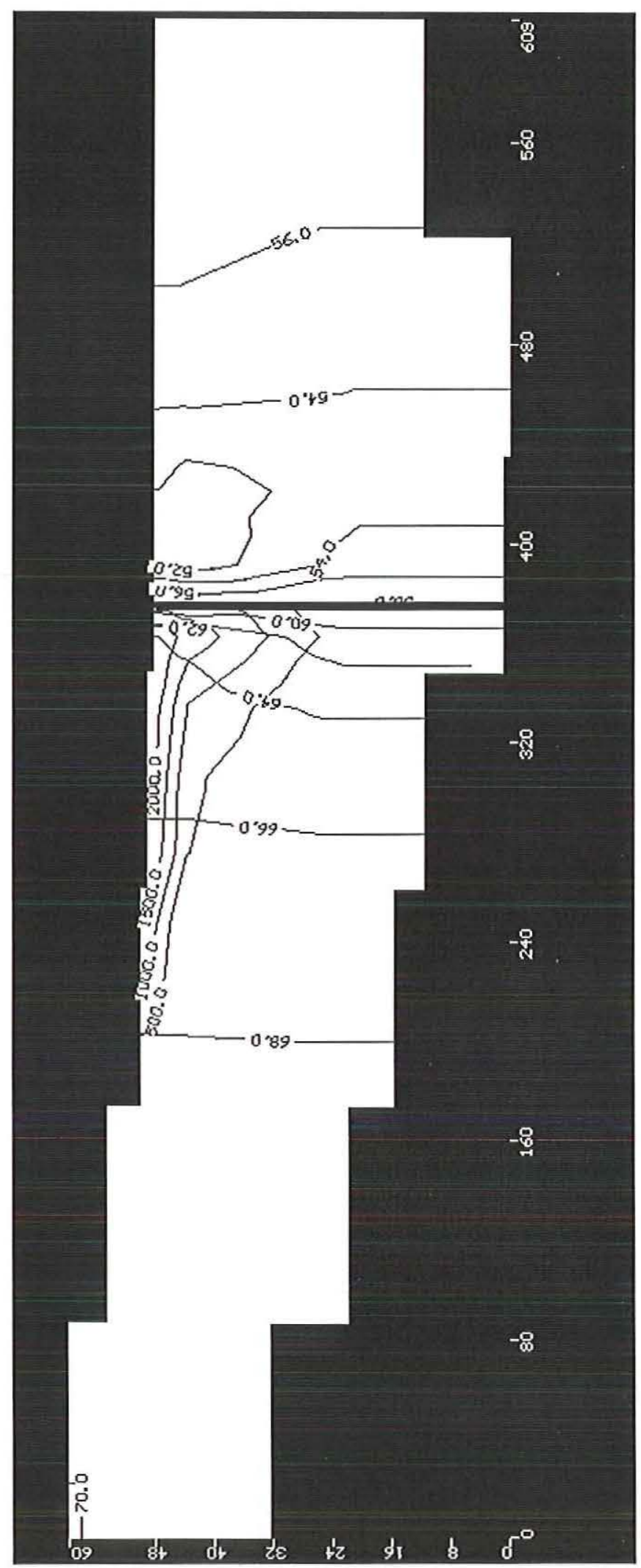

FIGURA 142 - Perfil Transversal a direção de maior espalhamento da pluma de poluição (Coluna) no Tempo de 7300 dias. 


\section{$6^{\circ}$ Simulação: Utilizando-se de parede única a montante}

Neste caso simulou-se apenas uma estrutura de contenção linear que atingiu as três camadas. Para a construção da parede utilizou-se da função "Wall" admitindo condutividade hidráulica de $1.10^{-10} \mathrm{~m} / \mathrm{s}$ e espessura de $50 \mathrm{~cm}$. Para se observar a influência da espessura da parede no modelo simulou-se várias alternativas, notou-se que $50 \mathrm{~cm}$ é uma espessura boa em função do intervalo de tempo utilizado, porém sua construção pode ser problemática.

Para efeito de ilustração, manteve-se a relação de tamanho entre a espessura da parede e a área. Observa-se que nesta escala a espessura da parede não é representada nas figuras.

Os resultados desta simulação são:

Modelo de Fluxo

Esta estrutura tem como objetivo diminuir a velocidade do fluxo que transporta o lixiviado. Observa-se na Figura 143 uma variação local na direção do fluxo próximo a barreira, onde as linhas equipotenciais tendem a ficar paralelizadas em frente a parede.

\section{Modelo de Transporte}

Nesta simulação a camada 1 não apresenta grande variação na concentração de soluto e na geometria da pluma se comparado com a simulação 1 . Na camada 2 a estrutura tem muita influência, neste caso o componente de fluxo transversal a parede ganha importância e faz com que apareçam duas concentrações importantes dentro da pluma, uma próxima a parede e outra no limite NW do Lixão, os níveis de concentração apresentam-se um pouco menor que na simulação 1 .

Na camada 3 a parede torna-se uma barreira efetiva, nesta o modelo indica apenas um ponto de contaminação próximo a parede com níveis de concentração alto (pico de $60 \mathrm{mg} / \mathrm{l})$. A Figura 144 mostra a trajetória das partículas para esta simulação e as figuras 145 a 153 representam os mapas que delimitam a pluma de contaminação. 


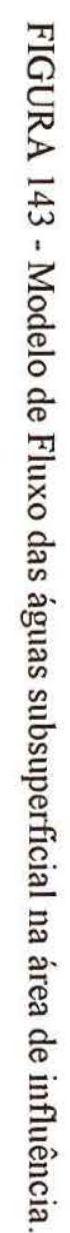

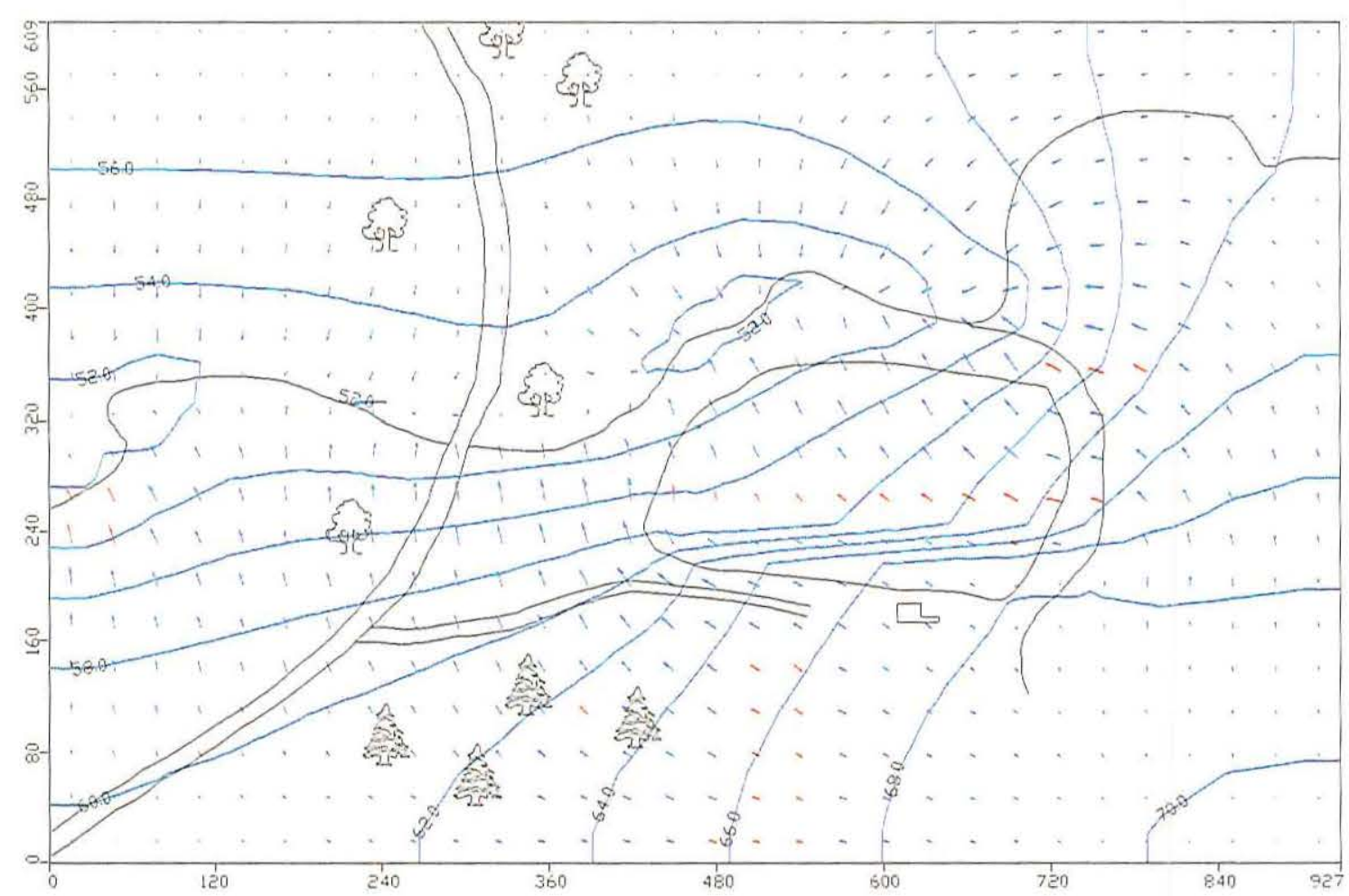

$\left.\right|_{\mathrm{N}}$

Legenda

Linhas de Fluxo

- Poços de Obser.

Perímetro do

Lixão

- Linhas

Equipotenciais

Drenagem

// Rodovias

Escala Gráfica (m)

$0 \quad 100 \quad 200 \quad 300$ 


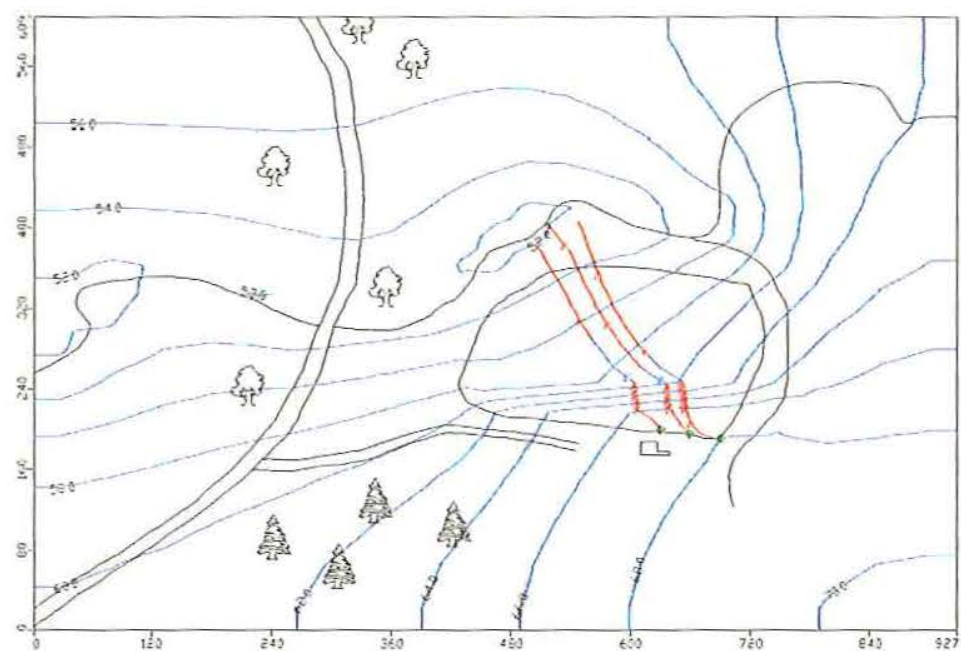

$\left.\right|_{N}$

\section{Legenda}

Linhas Equipotenciais

Caminhamento das partículas

$\checkmark$ Perímetro do Lixão

- Drenagem

// Rodovias

Escala Gráfica (m)

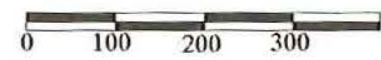

FIGURA 144 - Trajetória das Partículas
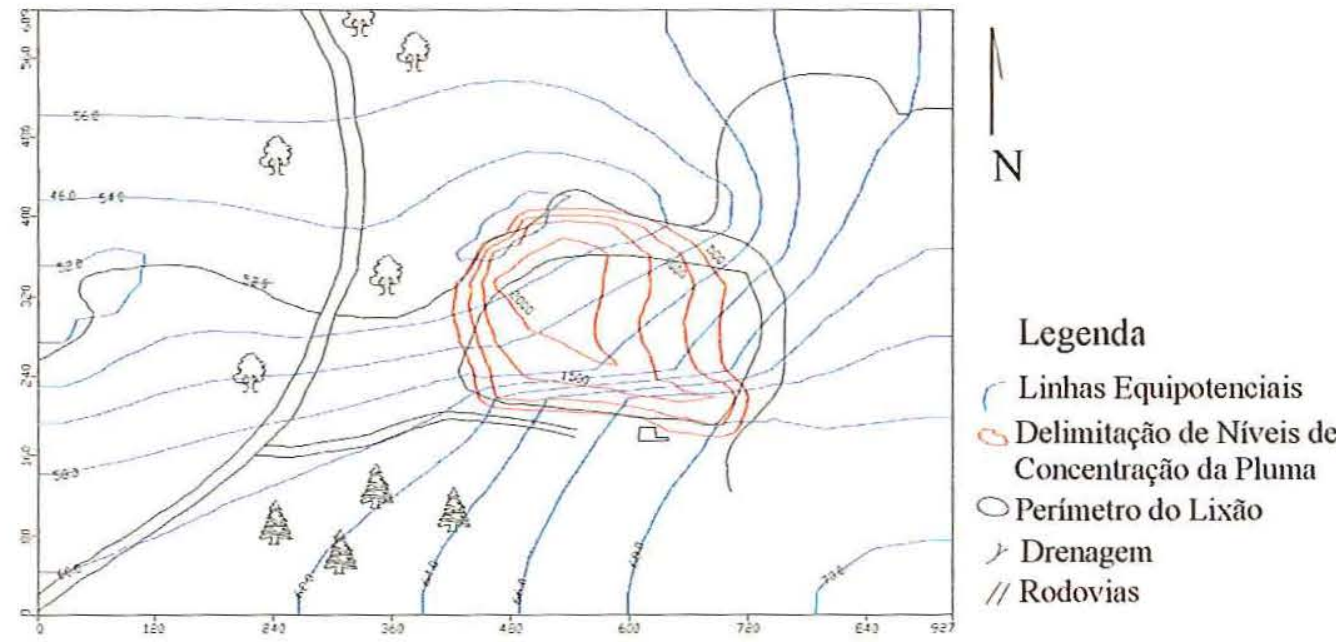

Escala Gráfica (m)

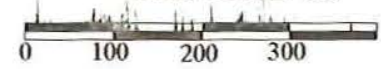

FIGURA 145 - Modelo de Transporte. Camada 1 Tempo 1825 dias. 


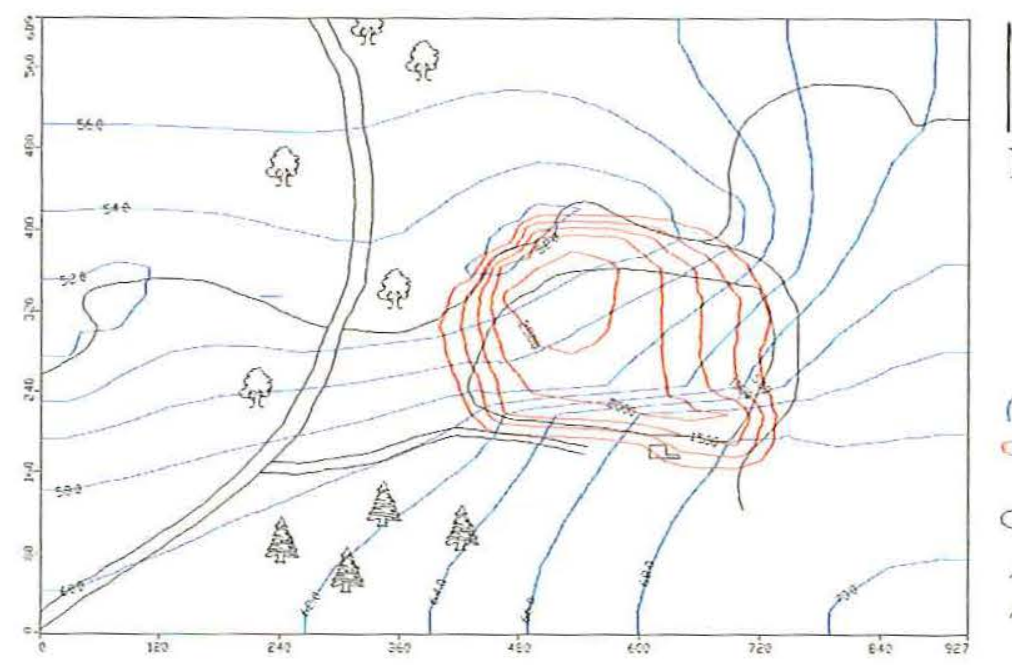

\section{Legenda}

r Linhas Equipotenciais

Delimitação de Níveis d

Concentração da Pluma

$\checkmark$ Perímetro do Lixão

y Drenagem

/ Rodovias

Escala Gráfica (m)

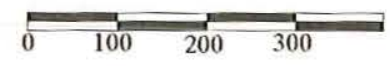

FIGURA 146 - Modelo de Transporte. Camada 1 Tempo 3650 dias.
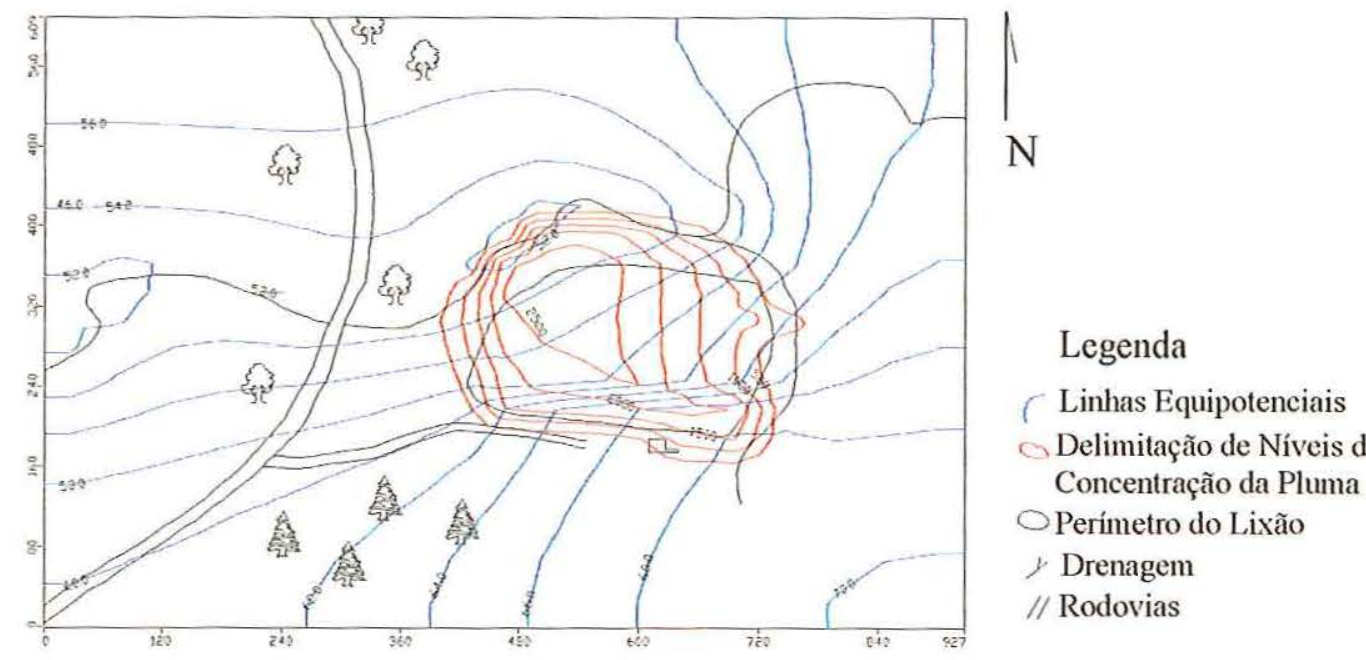

Escala Gráfica (m)

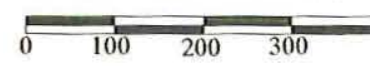

FIGURA 147 - Modelo de Transporte. Camada 1 Tempo 7300 dias. 


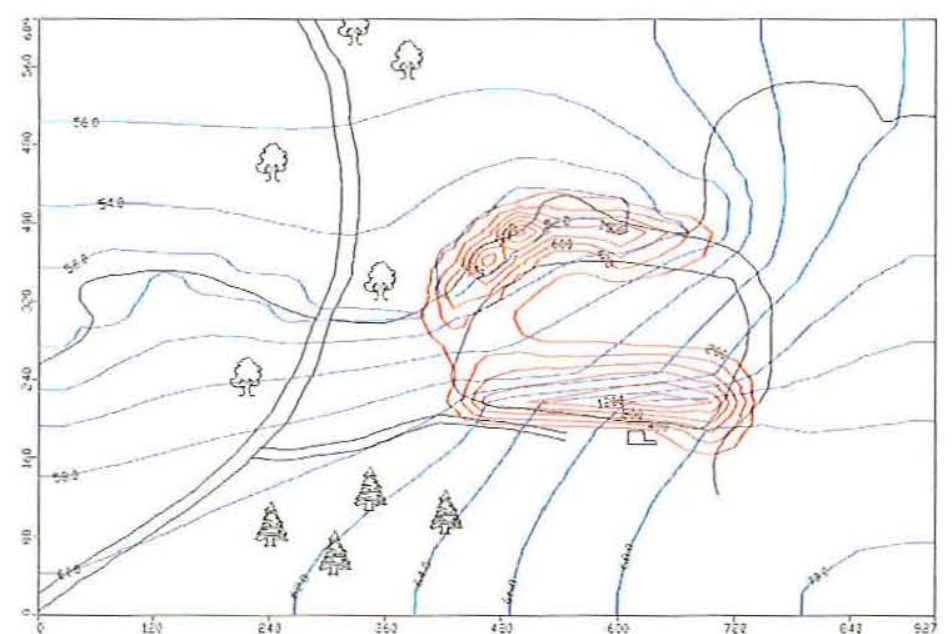

Escala Gráfica (m)

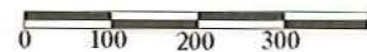

\section{Legenda}

- Linhas Equipotenciais

Delimitação de Níveis d

Concentração da Pluma

Perímetro do Lixão

Drenagem

// Rodovias

FIGURA 148 - Modelo de Transporte. Camada 2 Tempo 1825 dias.

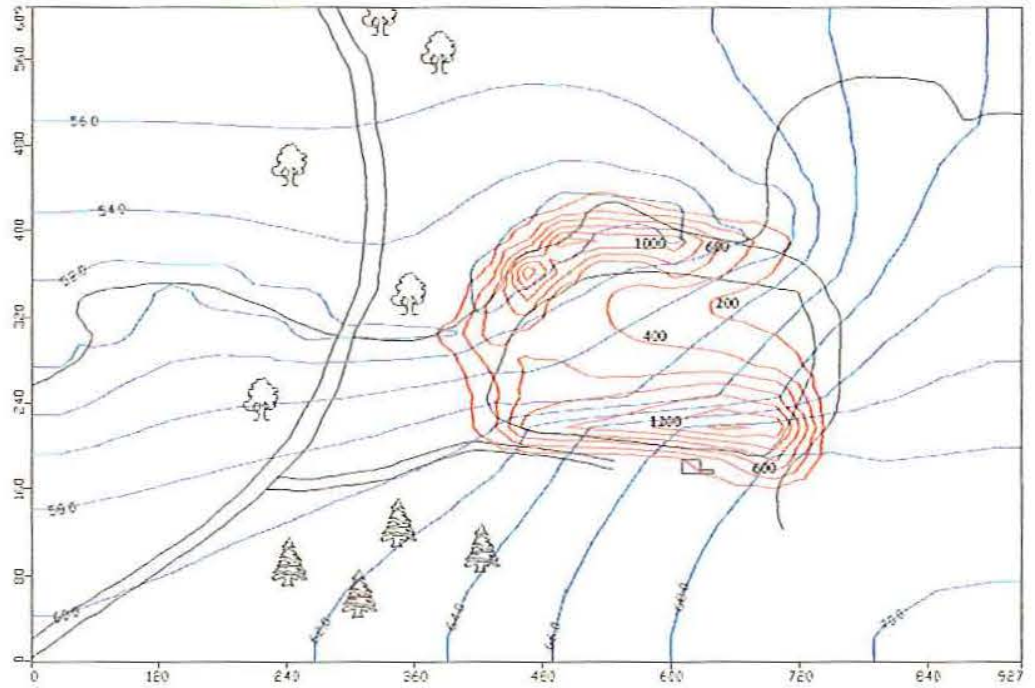

Escala Gráfica $(\mathrm{m})$

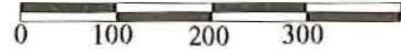

$\mathrm{N}$

\section{Legenda}

Linhas Equipotenciais

Delimitação de Níveis de Concentração da Pluma

$\bigcirc$ Perímetro do Lixão

Drenagem

Rodovias

FIGURA 149 - Modelo de Transporte. Camada 2 Tempo 3650 dias. 


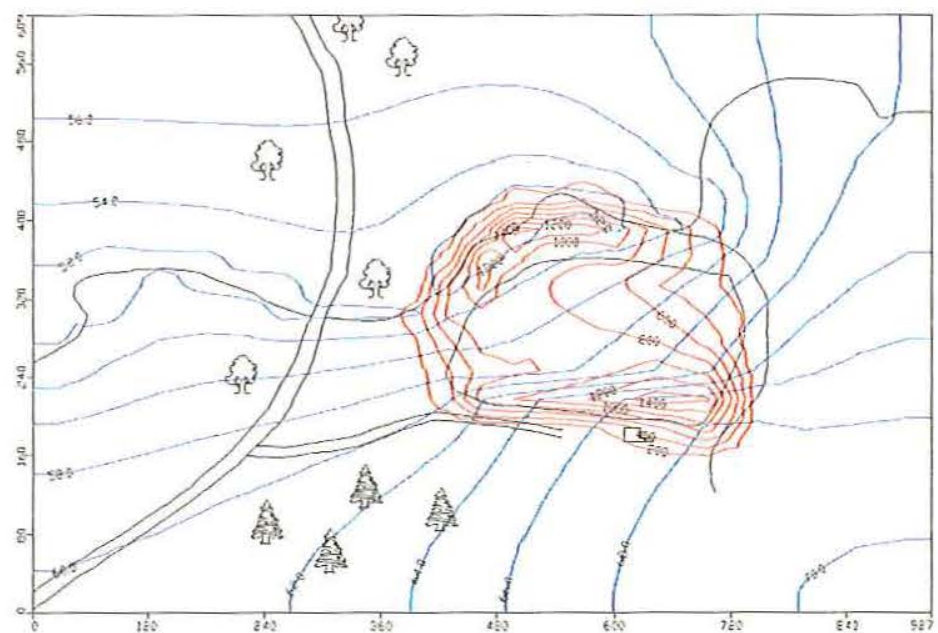

$\left.\right|_{N}$

\section{Legenda}

(Linhas Equipotenciais

Delimitação de Níveis de Concentração da Pluma

$\checkmark$ Perímetro do Lixão

y Drenagem

// Rodovias

Escala Gráfica (m)

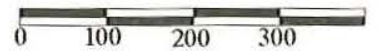

FIGURA 150 - Modelo de Transporte. Camada 2 Tempo 7300 dias.

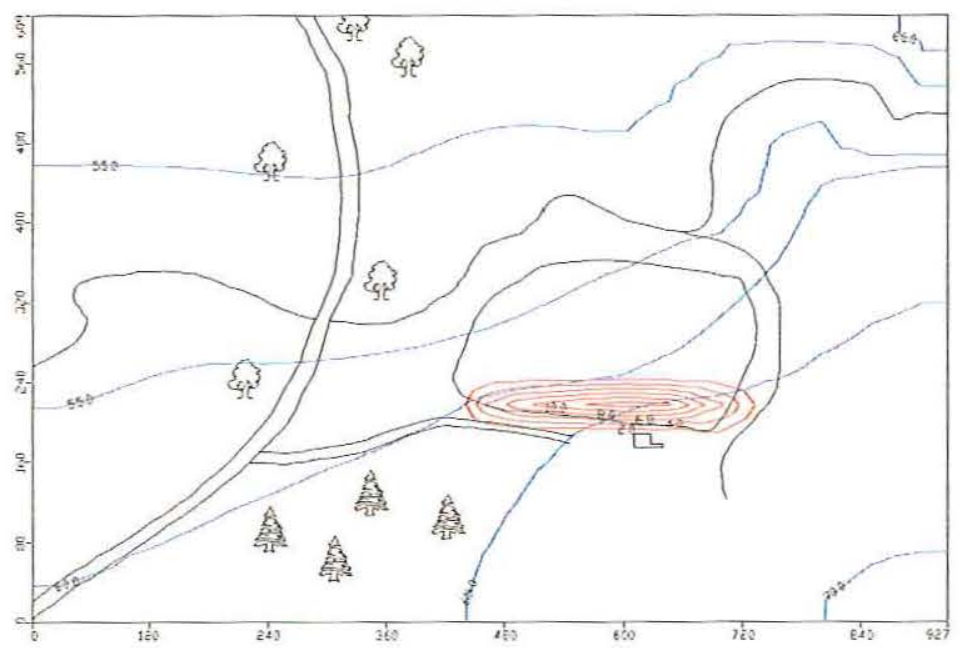

\section{Legenda}

Linhas Equipotenciais

$\checkmark$ Delimitação de Níveis de

Concentração da Pluma

$\bigcirc$ Perímetro do Lixão

y Drenagem

// Rodovias

Escala Gráfica (m)

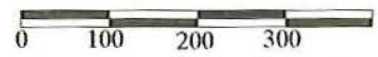

FIGURA 151 - Modelo de Transporte. Camada 3 Tempo 1825 dias.

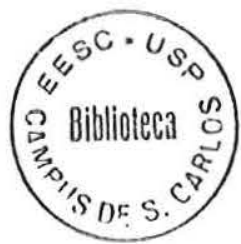



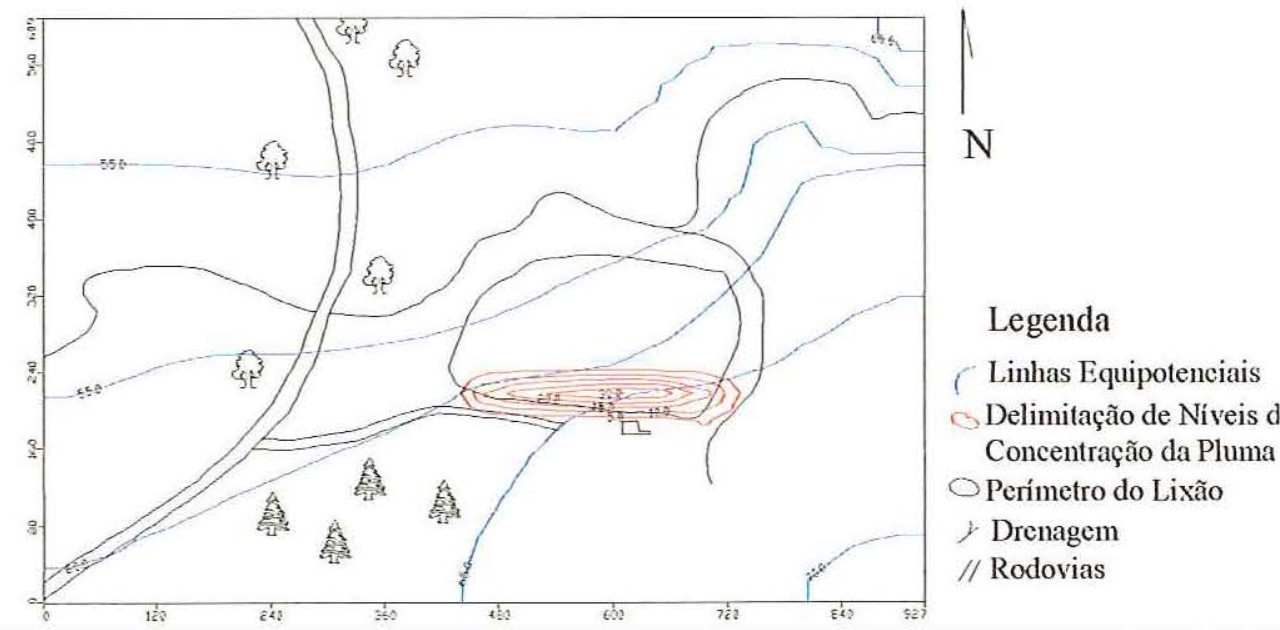

Escala Gráfica (m)

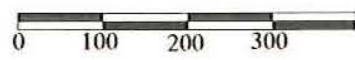

FIGURA 152 - Modelo de Transporte. Camada 3 Tempo 3650 dias.

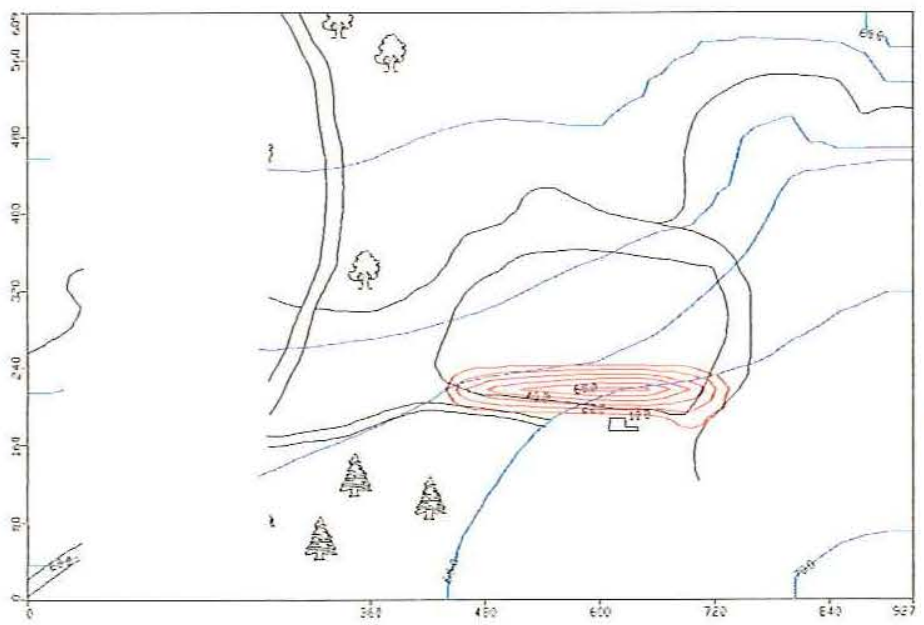

$\mathrm{N}$

\section{Legenda}

C Linhas Equipotenciais

$\checkmark$ Delimitação de Níveis de

Concentração da Pluma

$\bigcirc$ Perímetro do Lixão

> Drenagem

// Rodovias

Escala Gráfica (m)

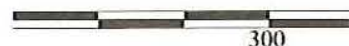

FIGURA 153 - Modelo de Transporte. Camada 3 Tempo 7300 dias. 
As figuras 154 a 159 representam os perfis verticais desta simulação. Estas figuras mostram que na seção transversal a direção de maior espalhamento da pluma, a parede afeta o nível de concentração de poluentes, principalmente nos tempos iniciais (em relação com a simulação 1). Nos perfis WE (Longitudinal a pluma) também é possível observar uma variação na geometria da pluma de poluição, a instalação da parede causa um aprofundamento da pluma a oeste do lixão (figuras 154 a 156). Na Figura 159 observa-se o avanço da pluma para o tempo de 7300 dias, demostrando a inefíciência do recurso técnico. 


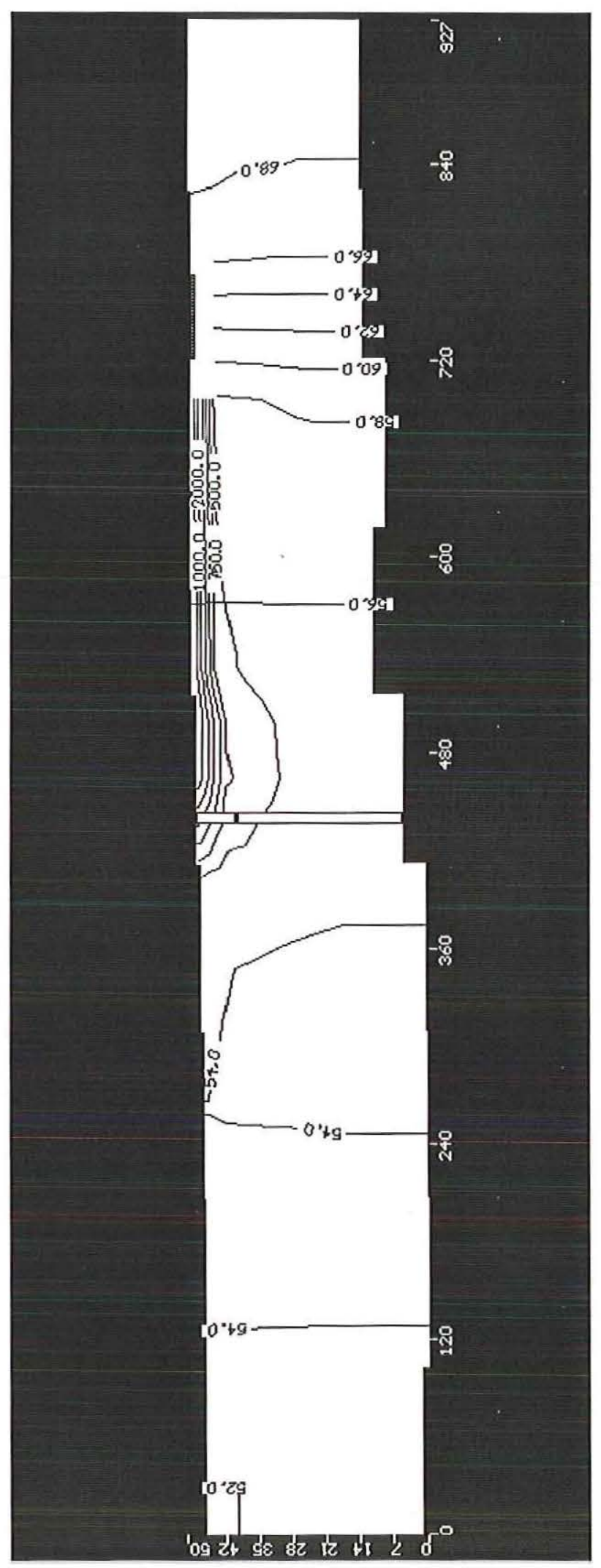

FIGURA 154 - Perfil Longitudinal a direção de maior espalhamento da pluma de poluição (Linha) no Tempo de 1825 dias. 


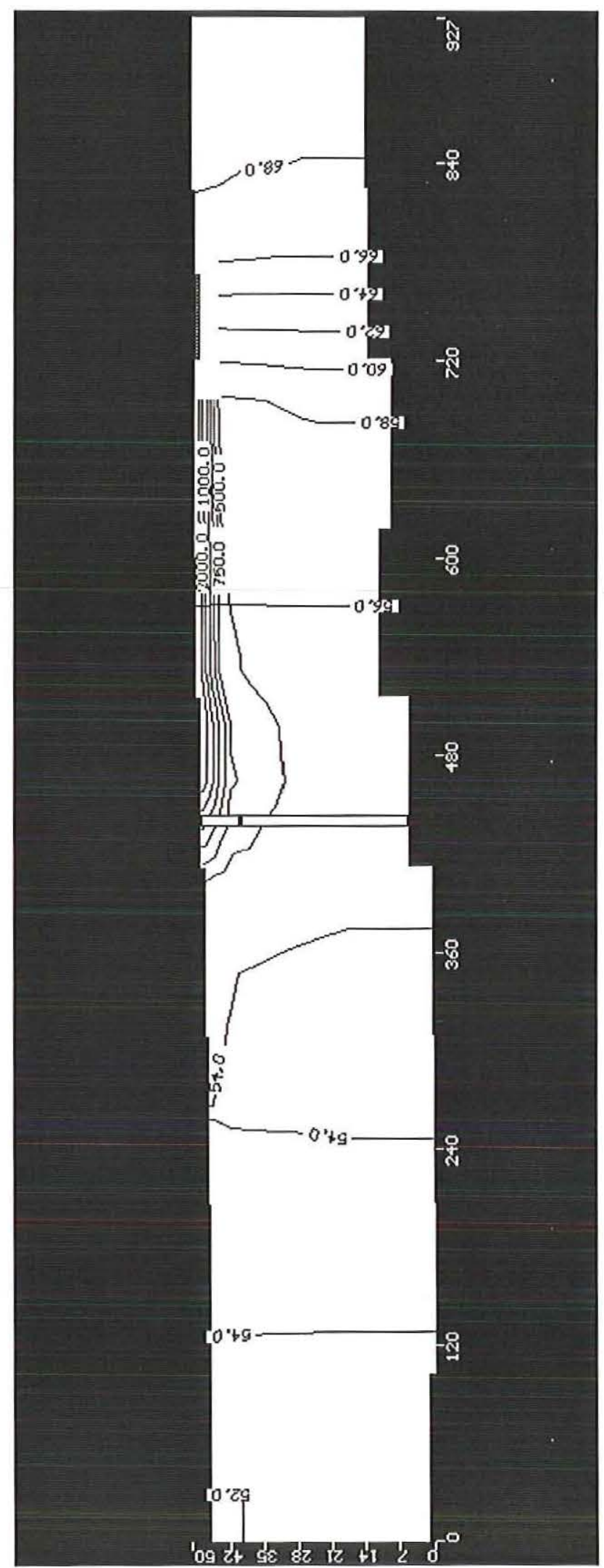

FIGURA 155 - Perfil Longitudinal a direção de maior espalhamento da pluma de poluição (Linha) no Tempo de 3650 dias. 


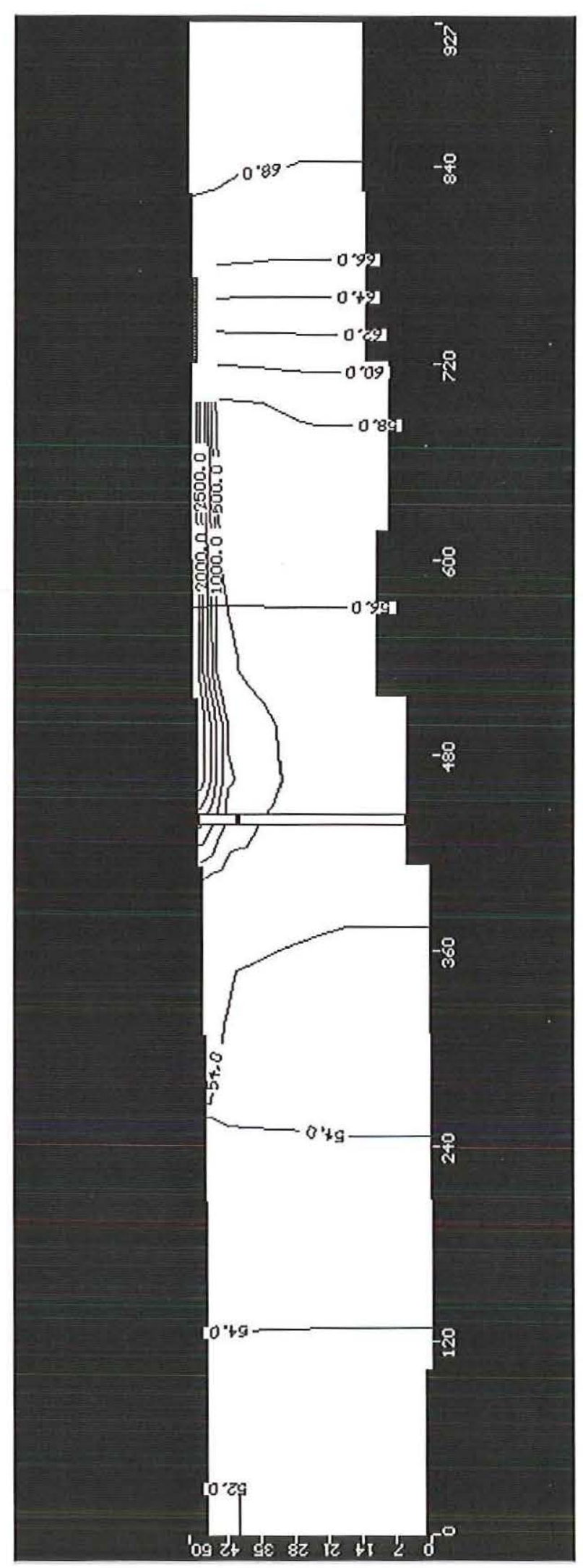

FIGURA 156 - Perfil Longitudinal a direção de maior espalhamento da pluma de poluição (Linha) no Tempo de 7300 dias. 


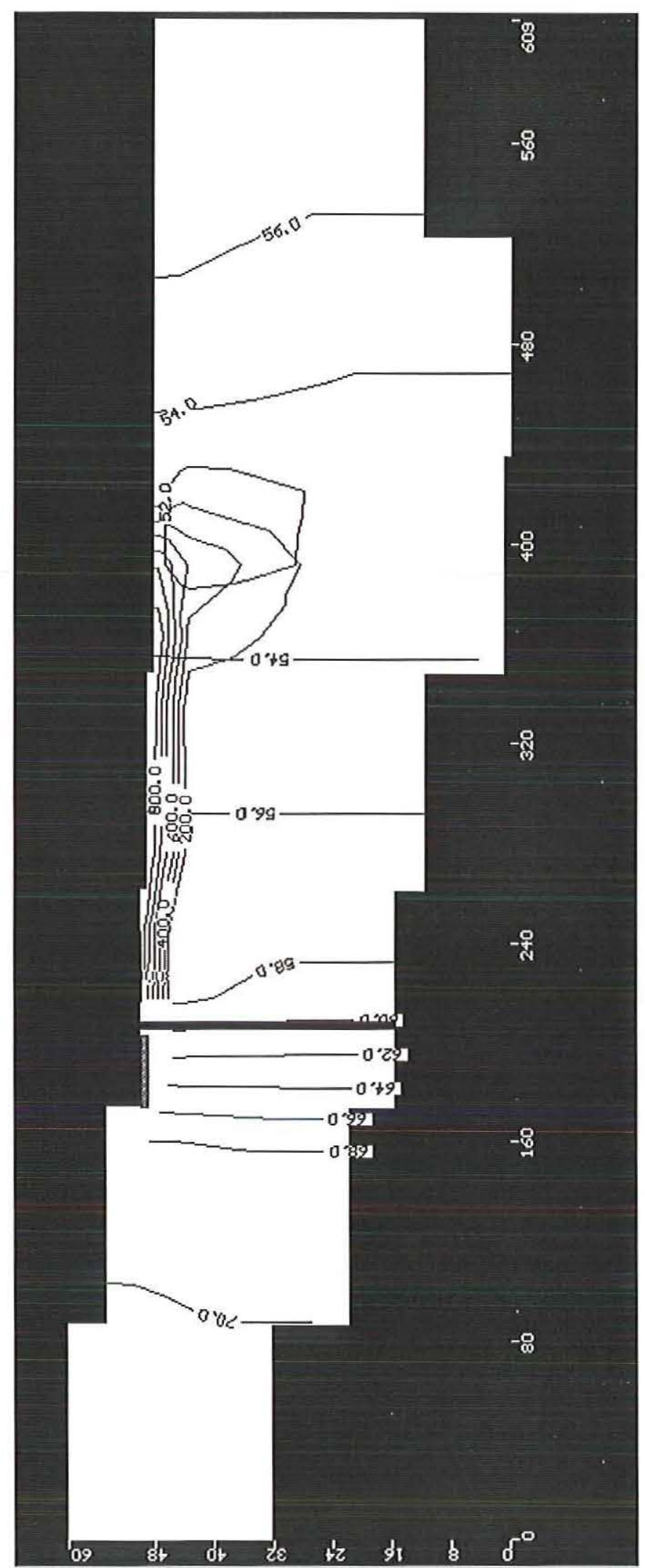

FIGURA 157 - Perfil Transversal a direção de maior espalhamento da pluma de poluição (Coluna) no Tempo de 1825 dias. 


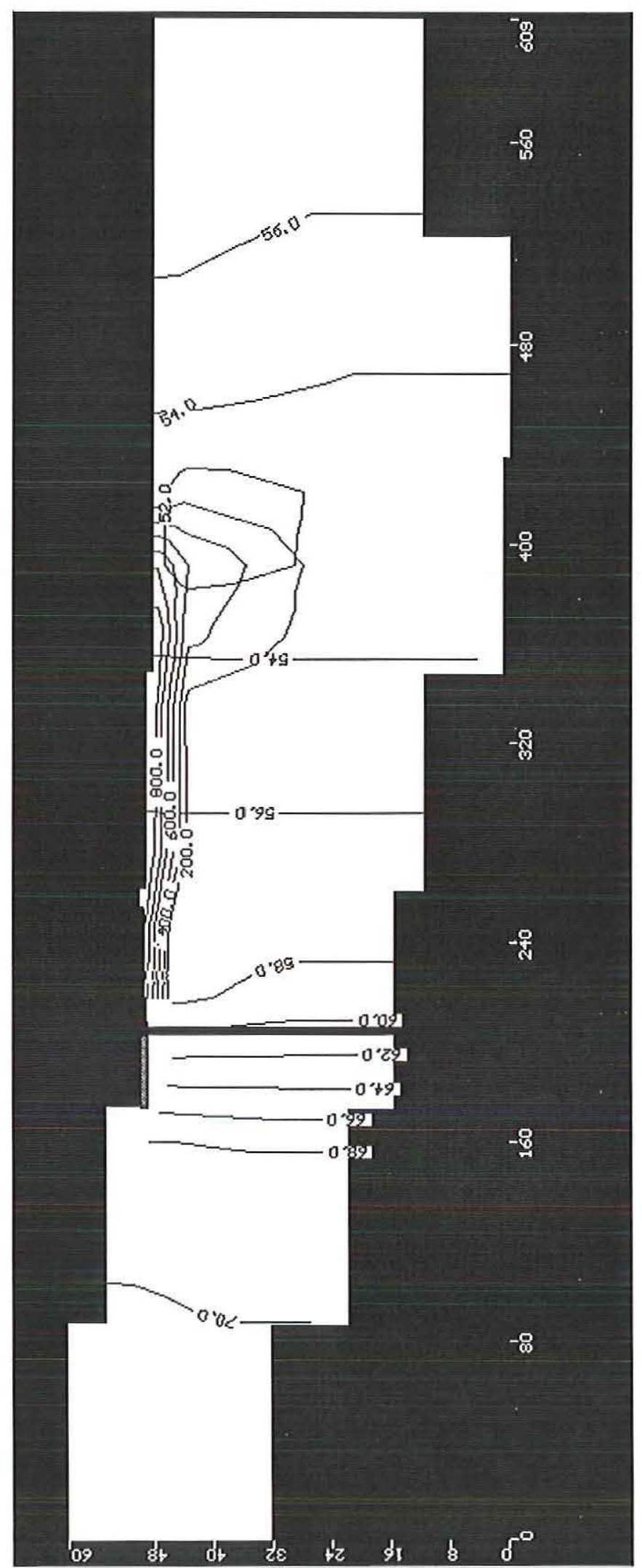

FIGURA 158 - Perfil Transversal a direção de maior espalhamento da pluma de poluição (Coluna) no Tempo de 3650 dias. 


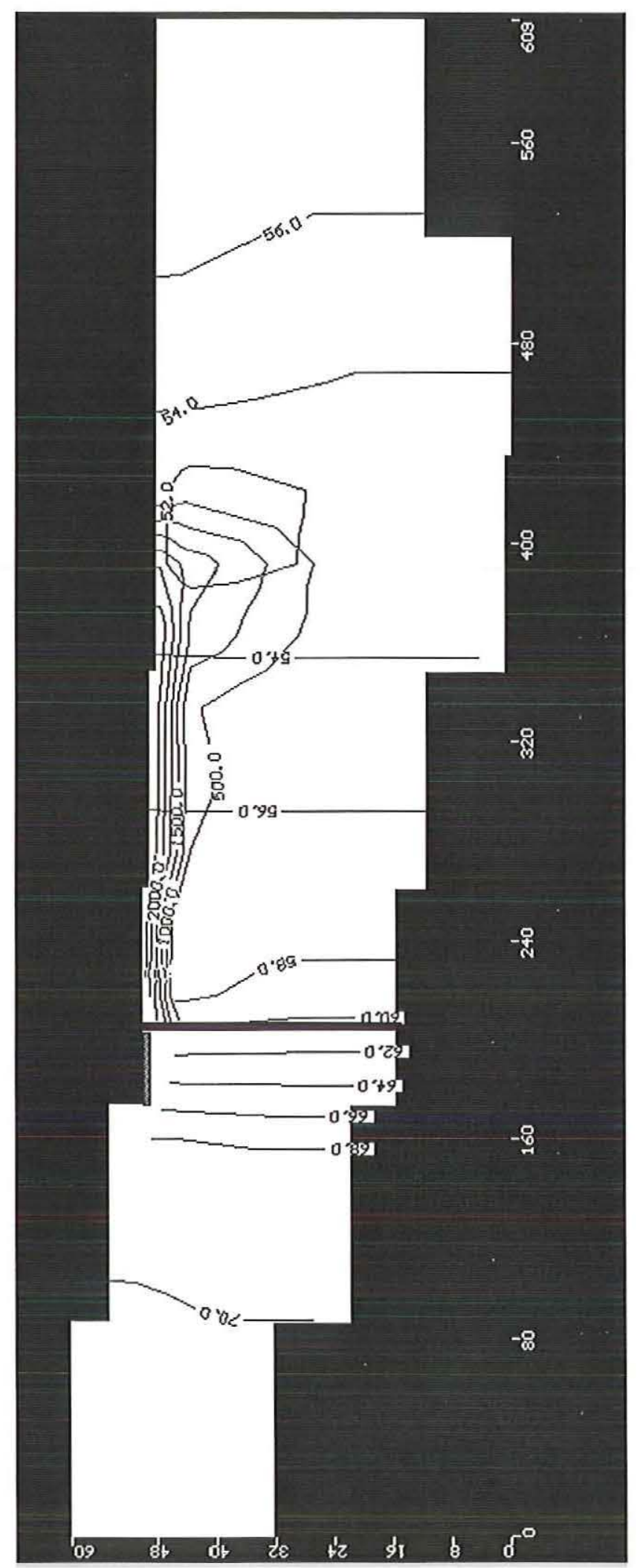

FIGURA 159 - Perfil Transversal a direção de maior espalhamento da pluma de poluição (Coluna) no Tempo de 7300 dias. 


\section{$7^{0}$ Simulação: Parede a montante e cobertura}

Para esta situação simulou-se a existência de paredes que servem como barreiras para o fluxo e de cobertura sobre o Lixão, buscando uma solução combinada. Os demais dados foram tratados de maneira semelhante aos casos anteriores e os resultados desta simulação são:

\section{Modelo de Fluxo}

Esta estrutura gera um fluxo semelhante a simulação 4 variando apenas a intensidade do fluxo nas células que formam o lixão (Camada 1). A Figura 160 ilustra o fluxo subsuperficial deste caso.

\section{Modelo de Transporte}

Nesta simulação além de minimizar o contato entre a pluma e o fluxo, também diminui-se a quantidade de água que infiltra no sistema. A geometria da pluma neste caso é muito pecualiar como mostrado nas figuras 162 a 176. Observa-se nestas ilustrações (principalmente nas referentes a camada 1) que os níveis de concentração são relativamente mais baixos que nos casos anteriores, devido principalmente a menor quantidade de lixiviado gerado. Na Figura 161 observa-se a trajetória das partículas. 


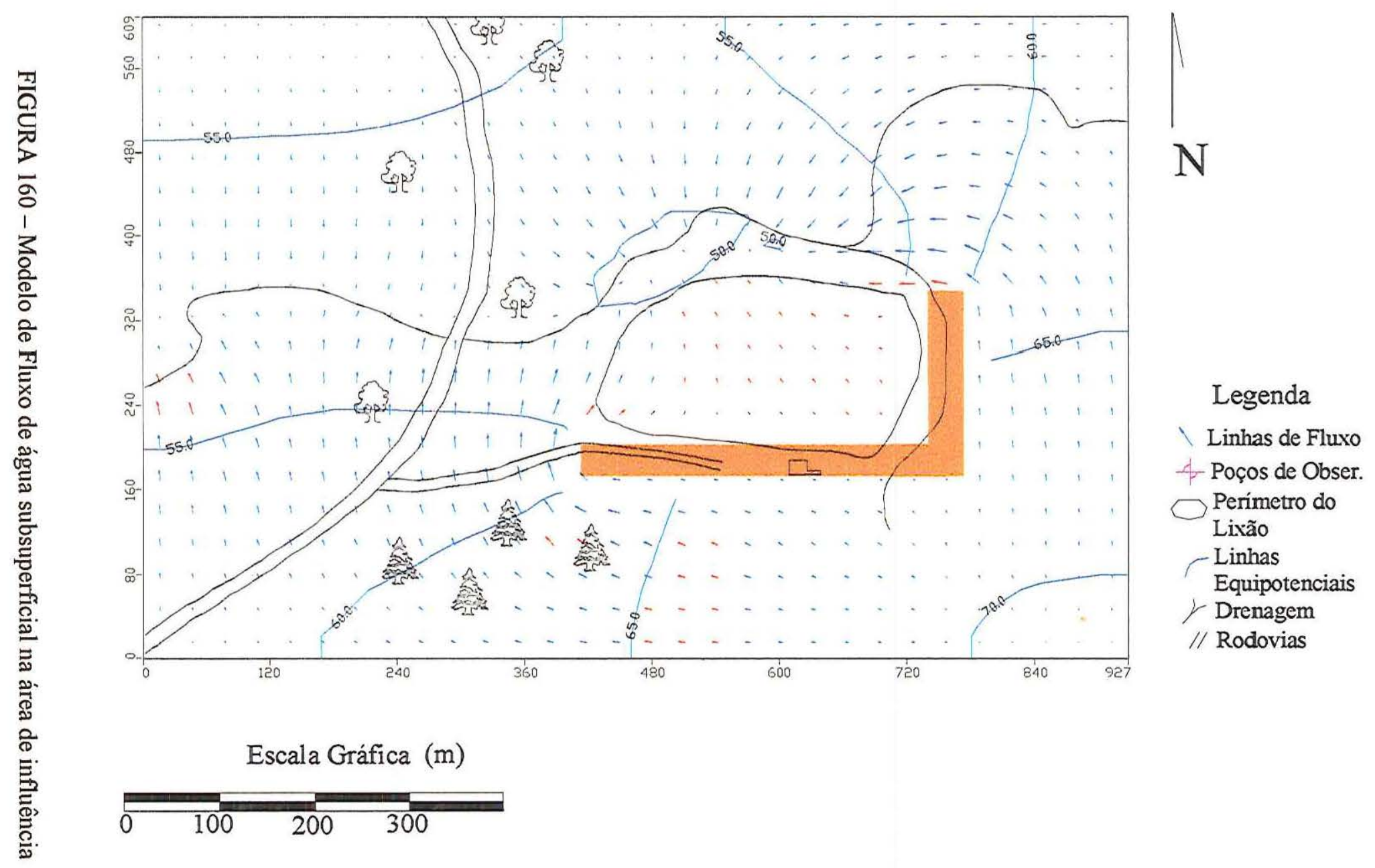




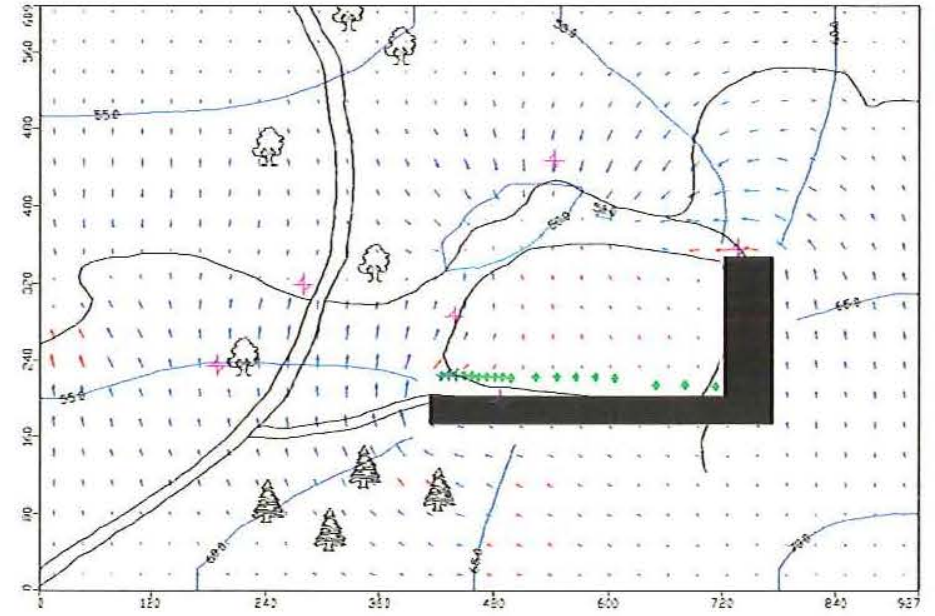

Escala Gráfica (m)

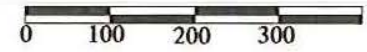

$\mathrm{N}$

\section{Legenda}

- Linhas Equipotenciais

Caminhamento das partículas

OPerímetro do Lixão

y Drenagem

$/ /$ Rodovias

\section{FIGURA 161 - Trajetória das Partículas}

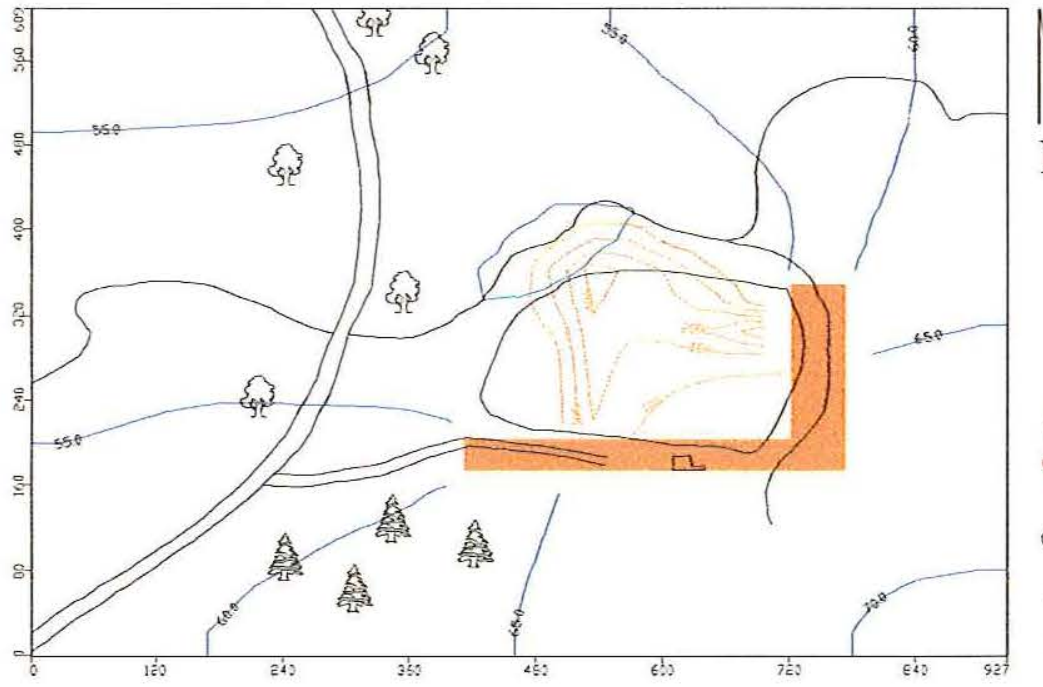

Escala Gráfica $(\mathrm{m})$

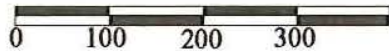

\section{Legenda}

Linhas Equipotenciais

Delimitação de Níveis d Concentração da Pluma $\bigcirc$ Perímetro do Lixão

Drenagem

/ Rodovias

FIGURA 162 - Modelo de Transporte. Camada 1 Tempo 1825 dias. 

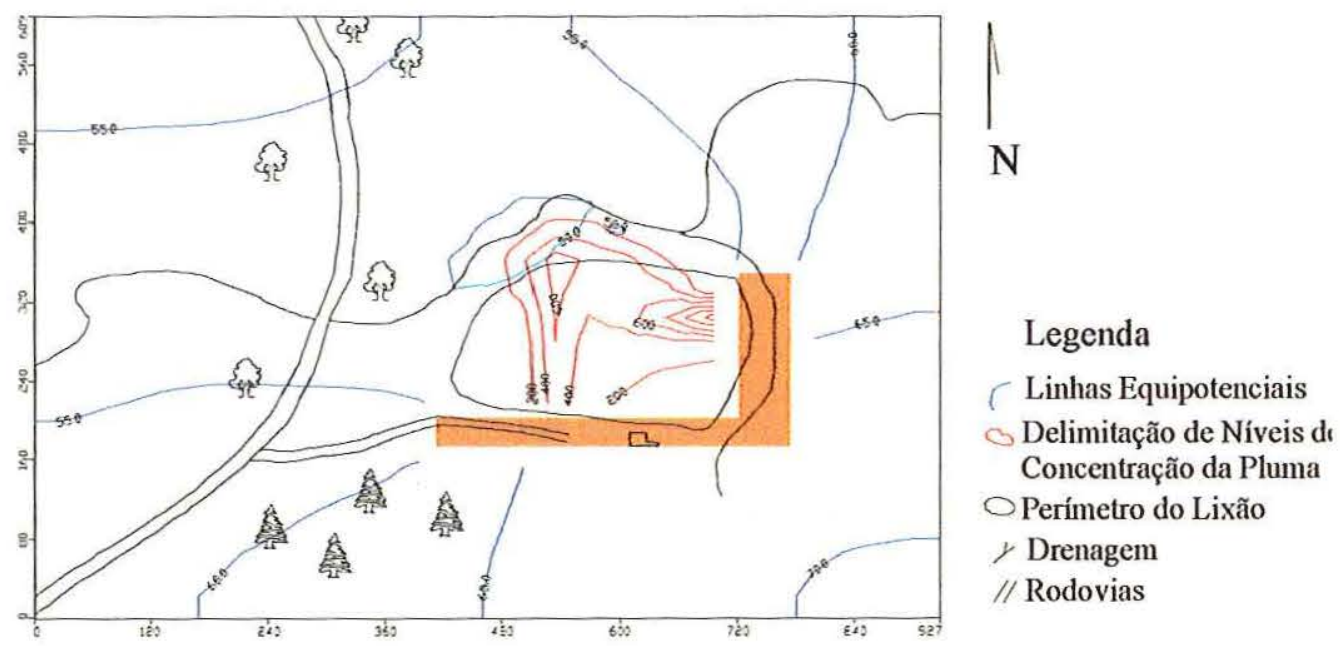

Escala Gráfica (m)

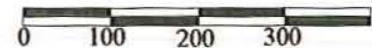

FIGURA 163 - Modelo de Transporte. Camada 1 Tempo 3650 dias.

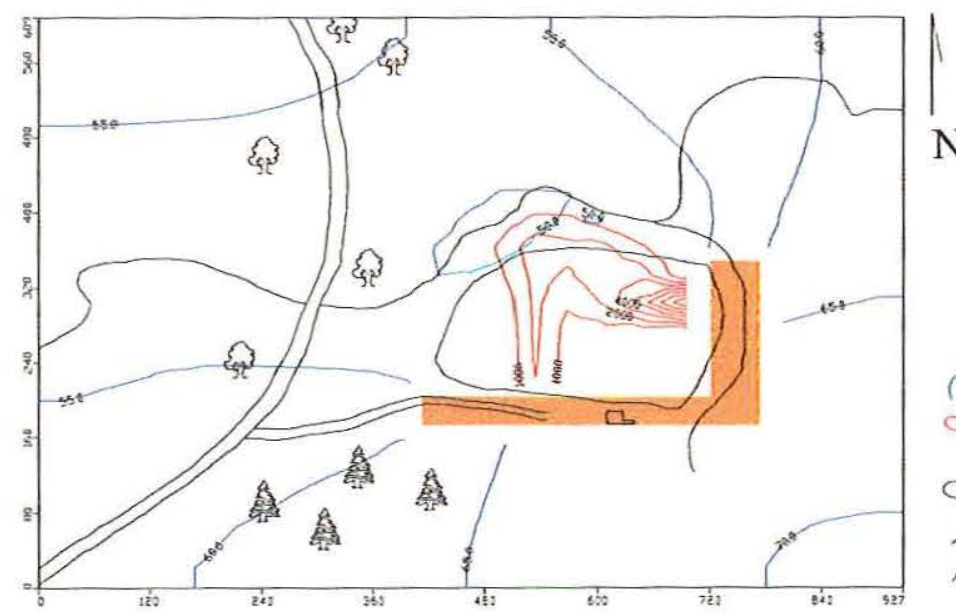

\section{Legenda}

Linhas Equipotenciais ○elimitação de Níveis de Concentração da Pluma

Perímetro do Lixão

> Drenagem

// Rodovias

Escala Gráfica (m)

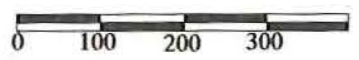

FIGURA 164 - Modelo de Transporte. Camada 1 Tempo 7300 dias. 


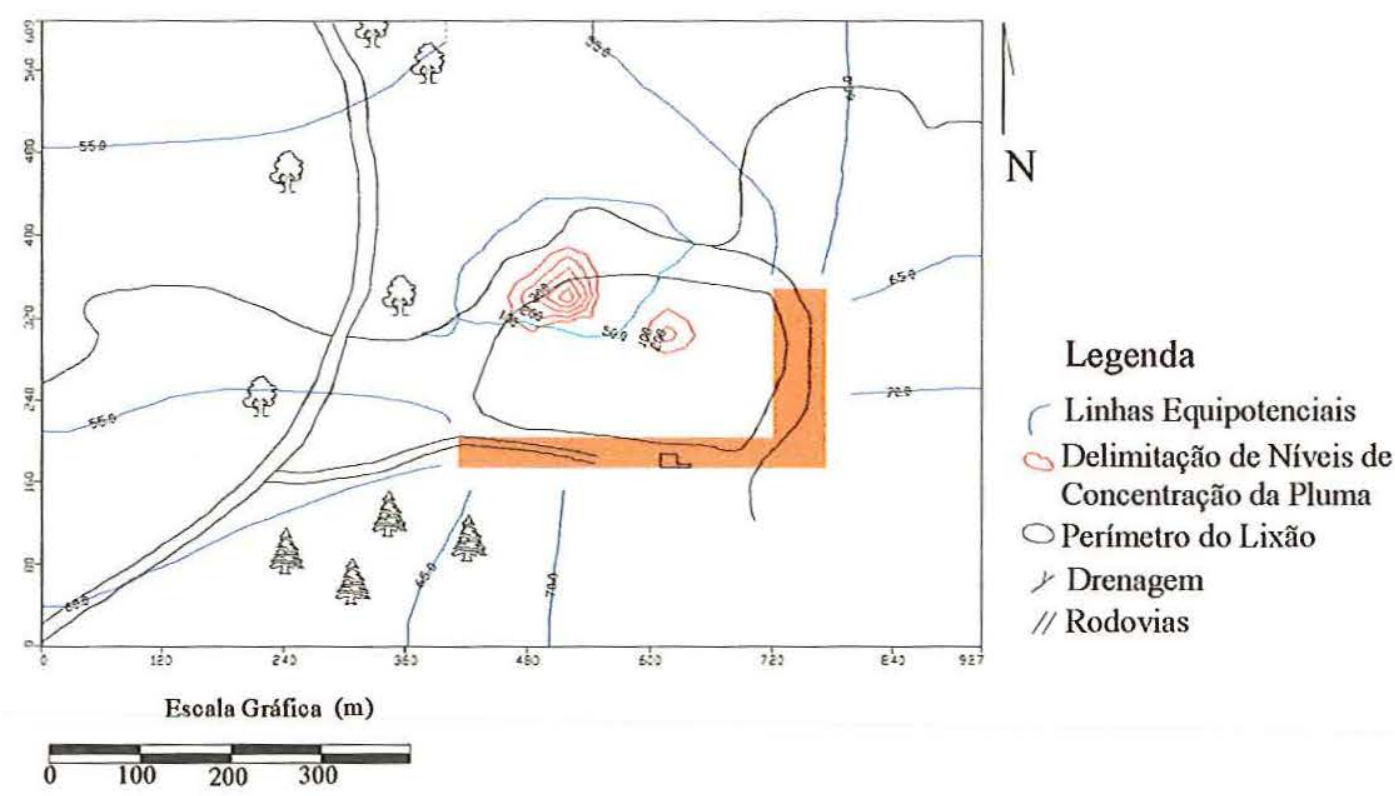

FIGURA 165 - Modelo de Transporte. Camada 2 Tempo 1825 dias.

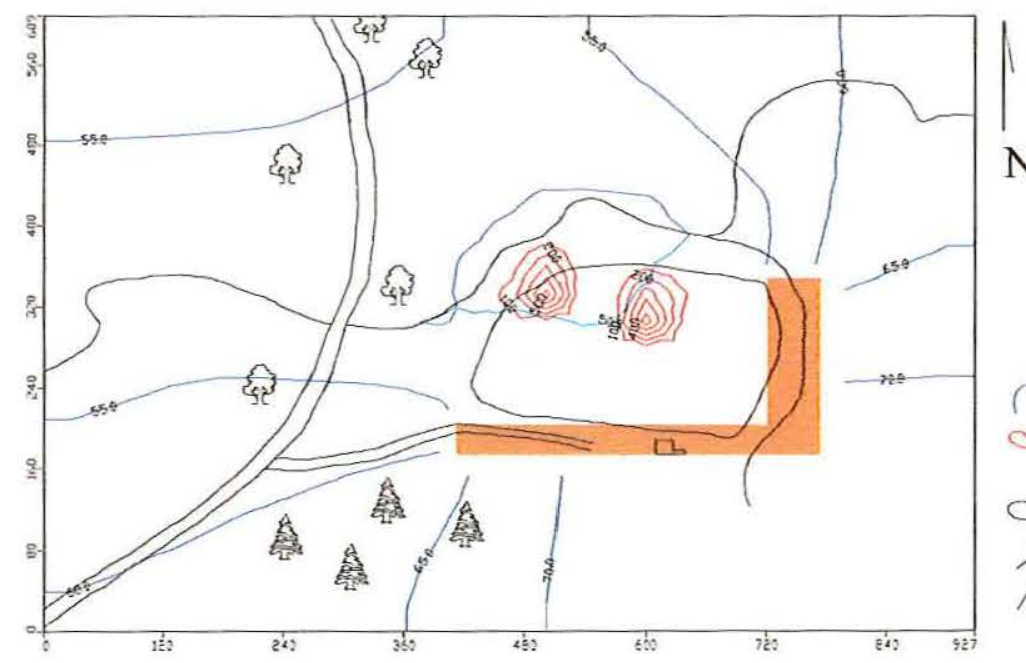

\section{Legenda}

- Linhas Equipotenciais

Delimitação de Níveis dt

Concentração da Pluma

$\bigcirc$ Perímetro do Lixão

Drenagem

// Rodovias

Escala Gráfica (m)

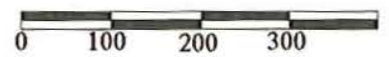

FIGURA 166 - Modelo de Transporte. Camada 2 Tempo 3650 dias. 


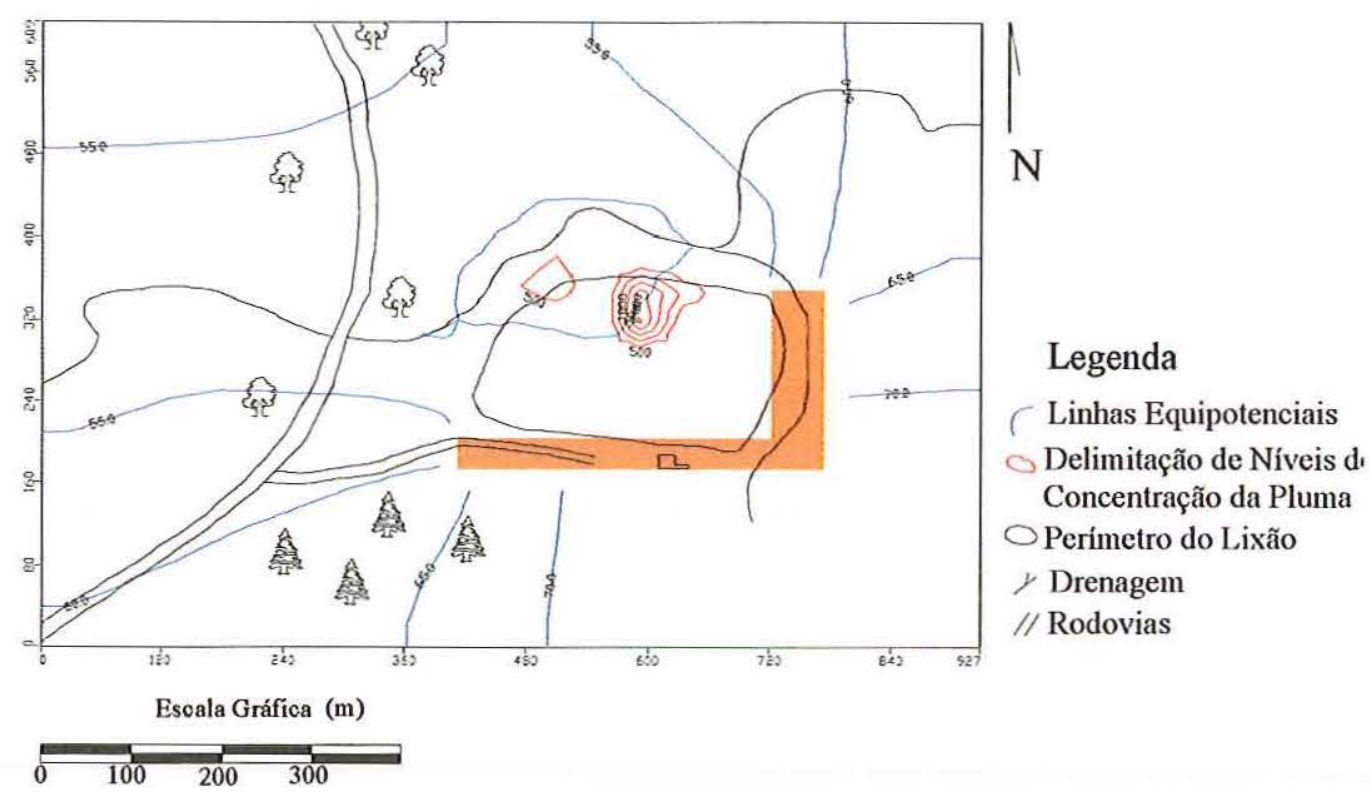

FIGURA 167 - Modelo de Transporte. Camada 2 Tempo 7300 dias.

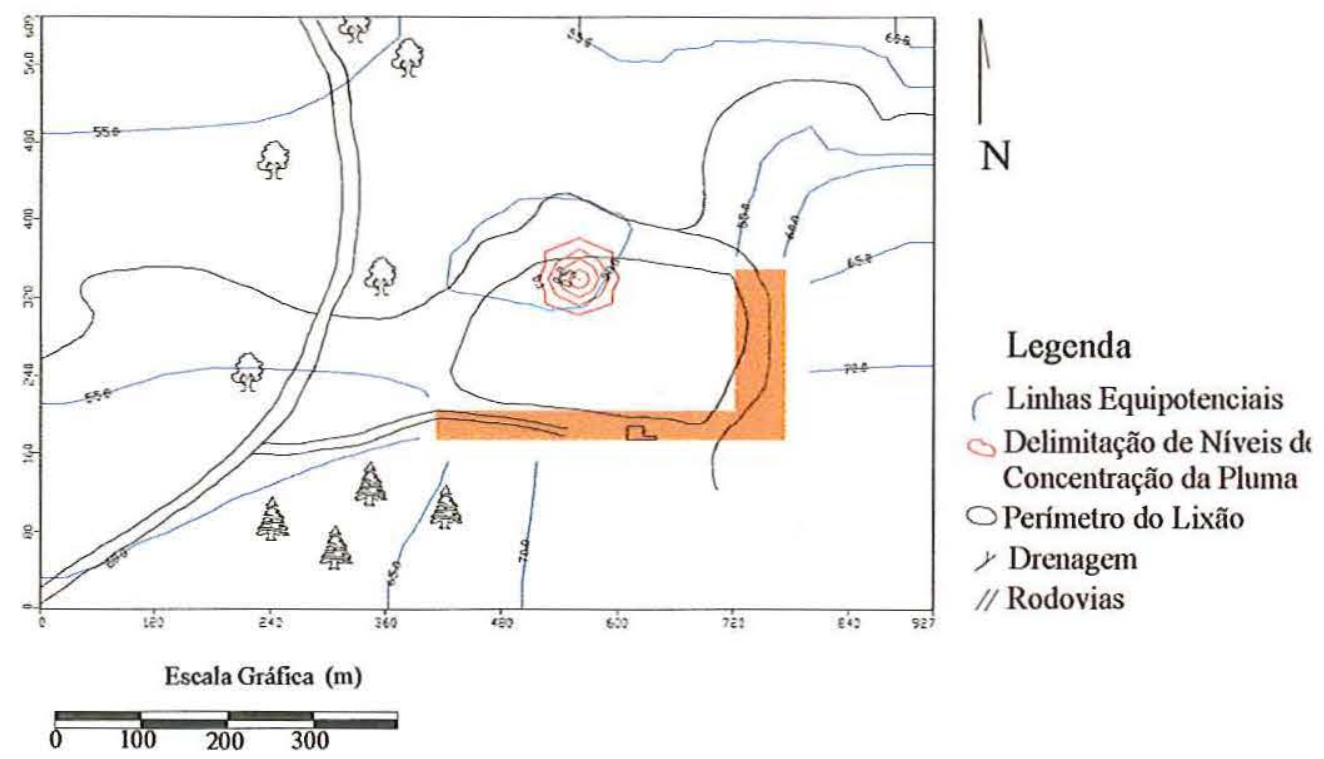

FIGURA 168 - Modelo de Transporte. Camada 3 Tempo 1825 dias. 


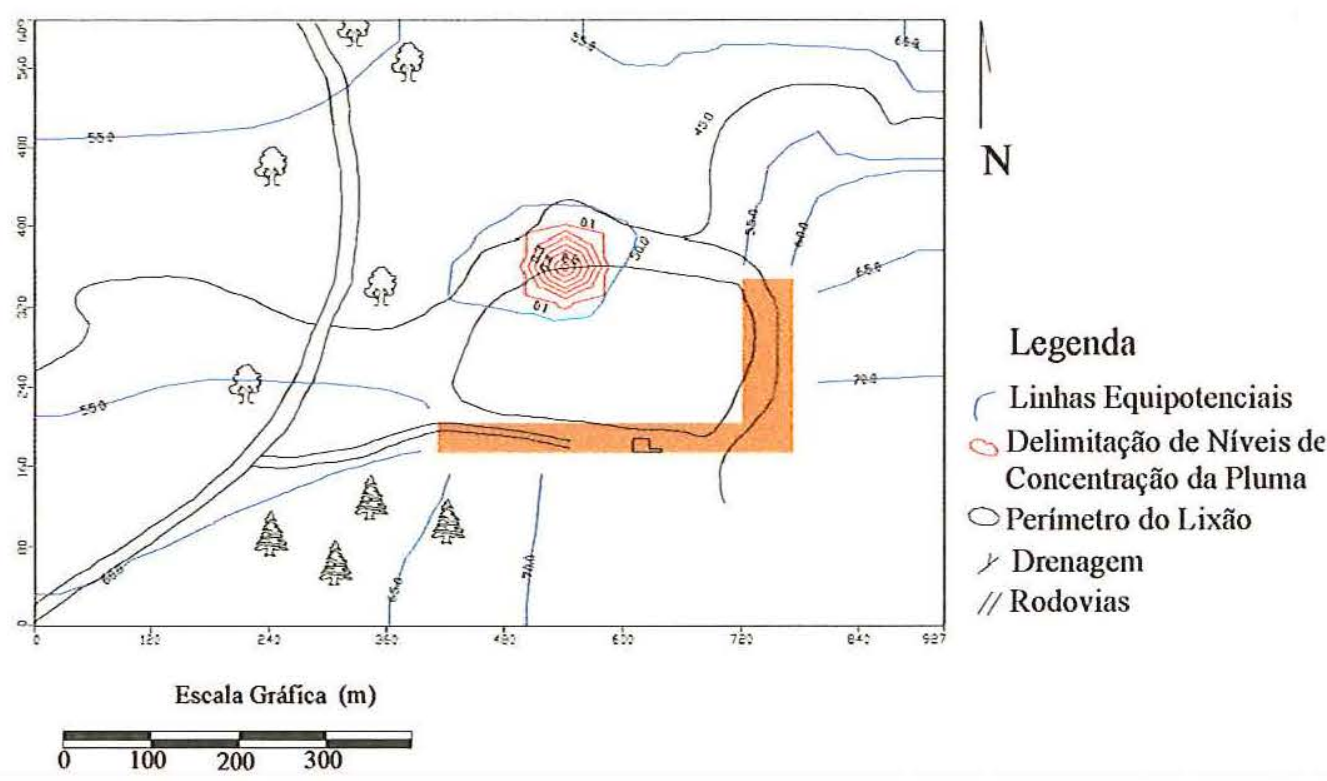

FIGURA 169 - Modelo de Transporte. Camada 3 Tempo 3650 dias.

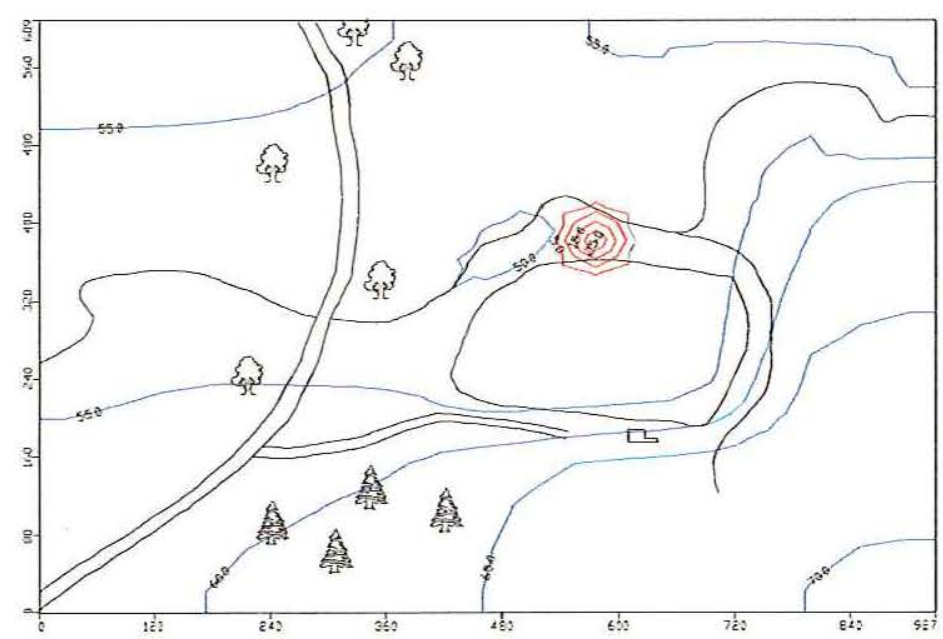

$\left.\right|_{N}$

\section{Legenda}

Linhas Equipotenciais

Delimitação de Níveis de

Concentração da Pluma

$\bigcirc$ Perímetro do Lixão

y Drenagem

// Rodovias

FIGURA 170 - Modelo de Transporte. Camada 3 Tempo 7300 dias. 
Os perfis indicam que as paredes são muito eficientes na retenção dos poluentes fazendo com que o espalhamento seja relativamente menor que o observado na simulação 1 , este fato ocorre tanto transversal como longitudinalmente ao lixão. Observa-se que a frente de poluição mantém-se restrita a proximidade da parede após 20 anos e com concentrações muito baixas, e a pequenas profundidades (os maiores níveis de concentração não atingem $10 \mathrm{~m})$ 


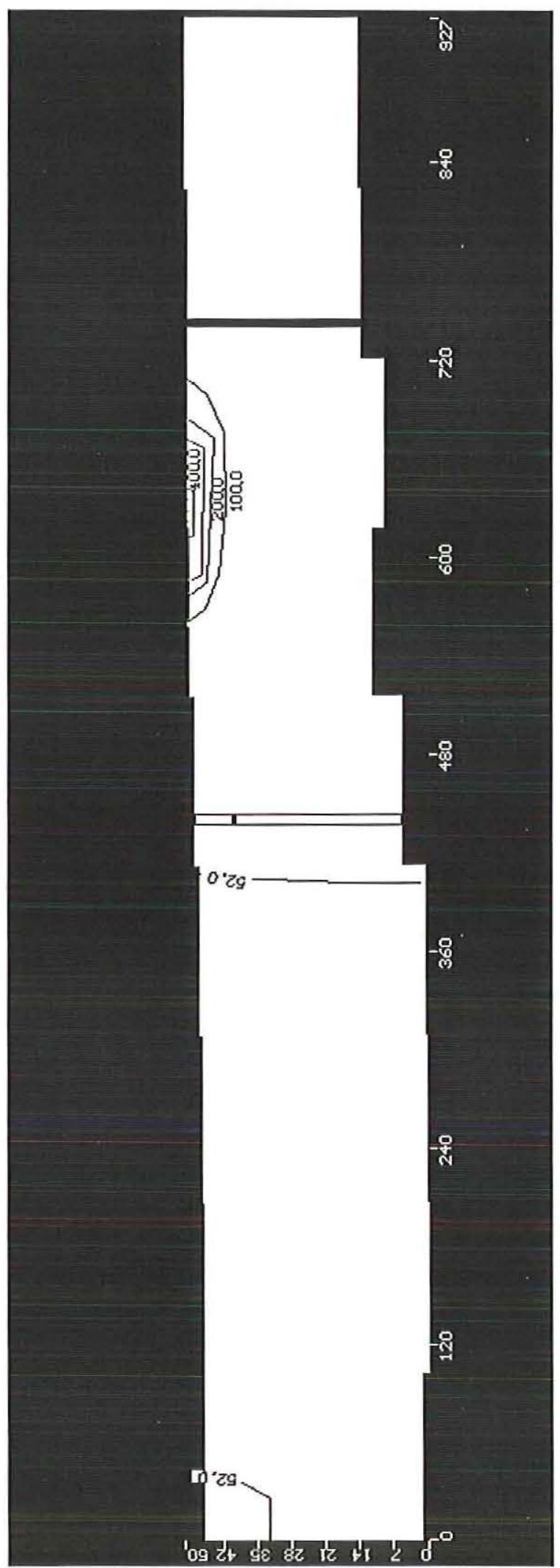

FIGURA 171 - Perfil Longitudinal a direção de maior espalhamento da pluma de poluição (linha) no Tempo de 1825 dias. 


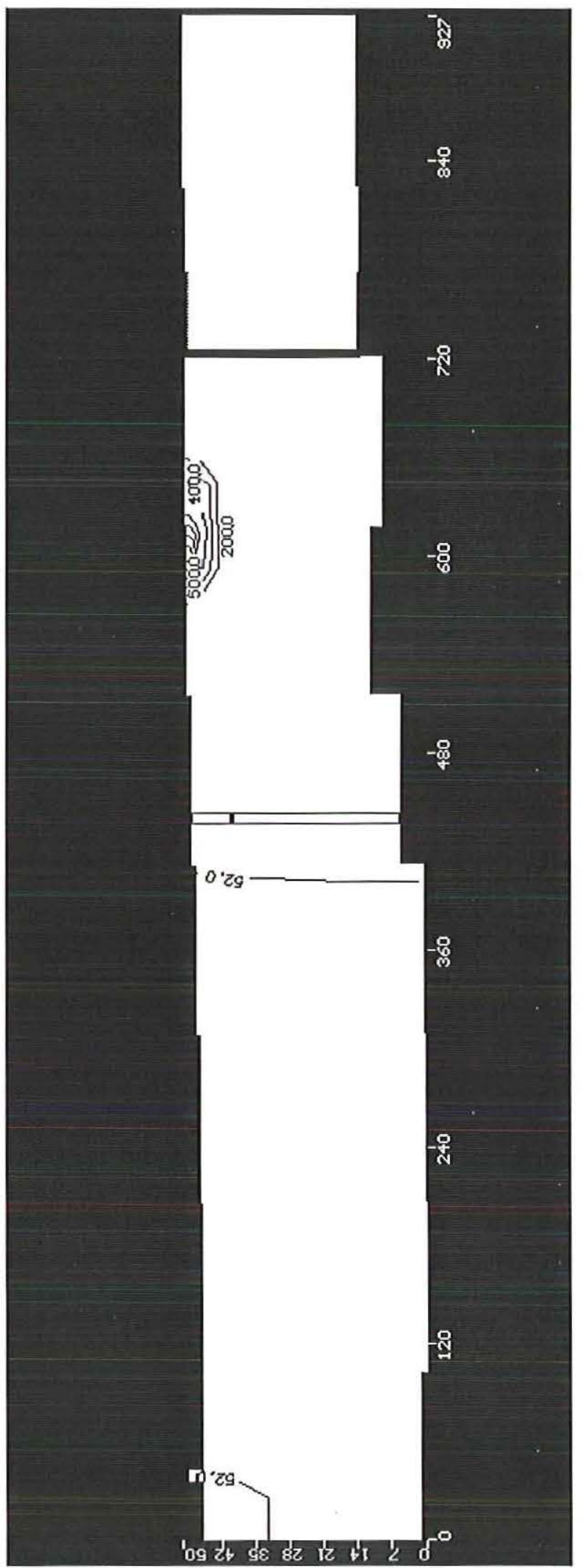

FIGURA 172 - Perfil Longitudinal a direção de maior espalhamento da pluma de poluição (Linha) no Tempo de 3650 dias. 


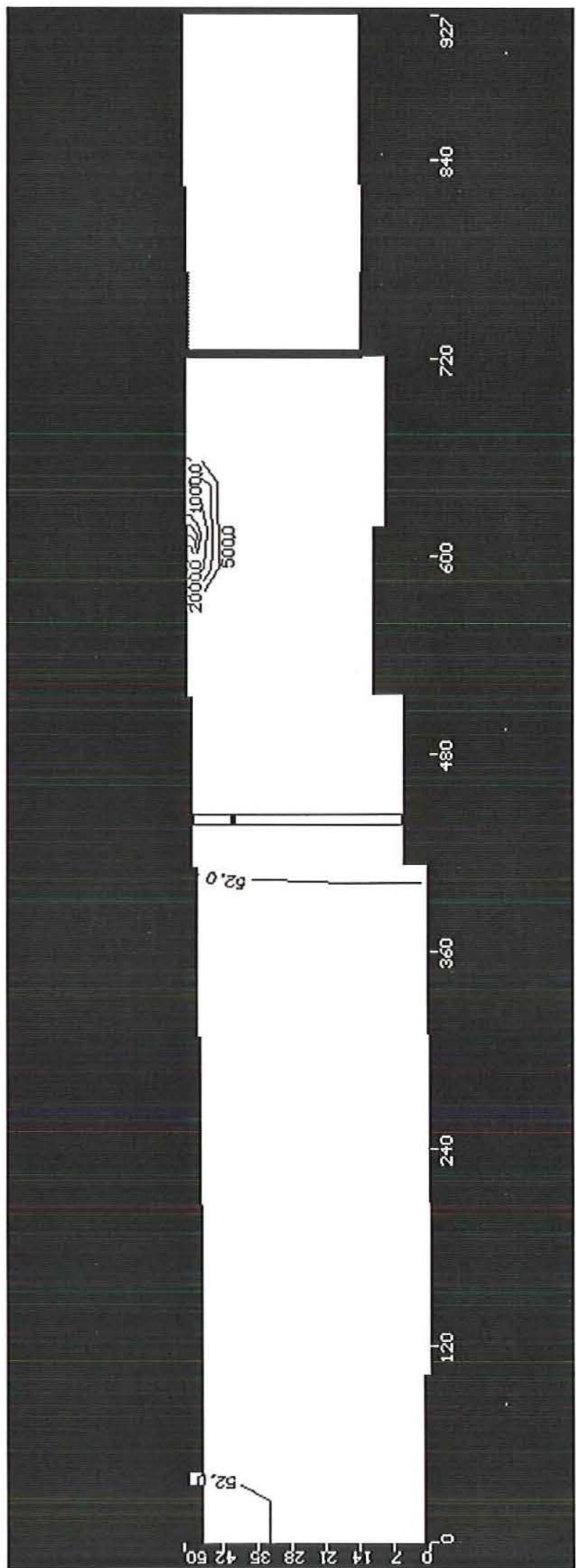

FIGURA 173 - Perfil Longitudinal a direção de maior espalhamento da pluma de poluição (Linha) no Tempo de 7300 dias. 


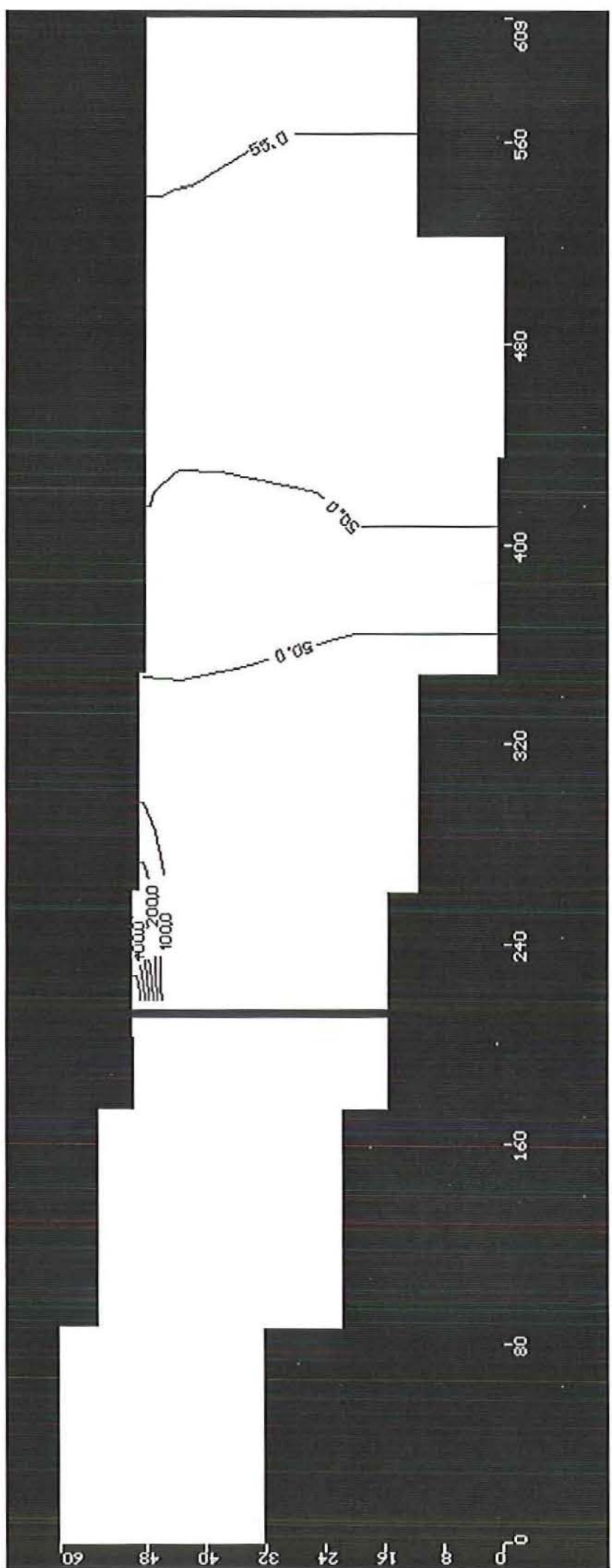

FIGURA 174 - Perfil transversal a direção de maior espalhamento da pluma de poluição (Coluna) no Tempo de 1825 dias. 


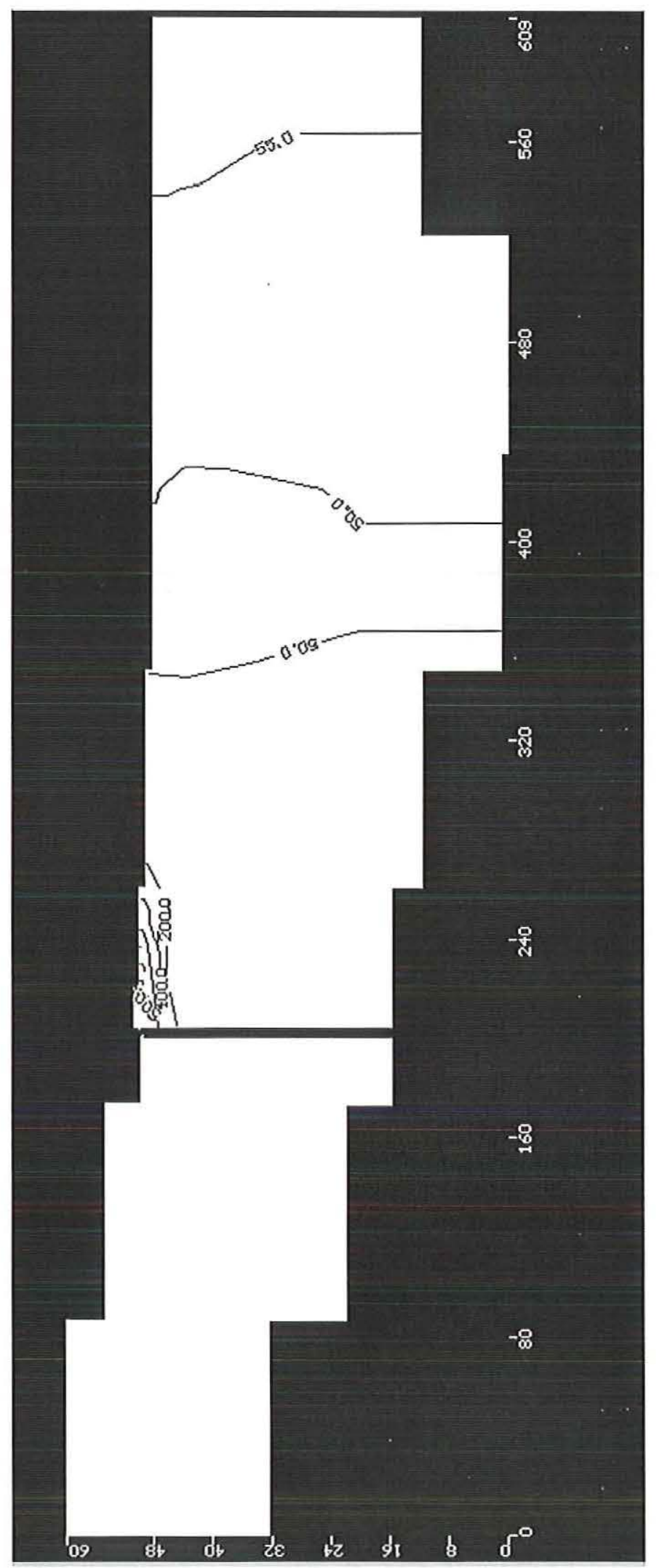

FIGURA 175 - Perfil transversal a direção de maior espalhamento da pluma de poluição (Coluna) no Tempo de 3650 dias. 


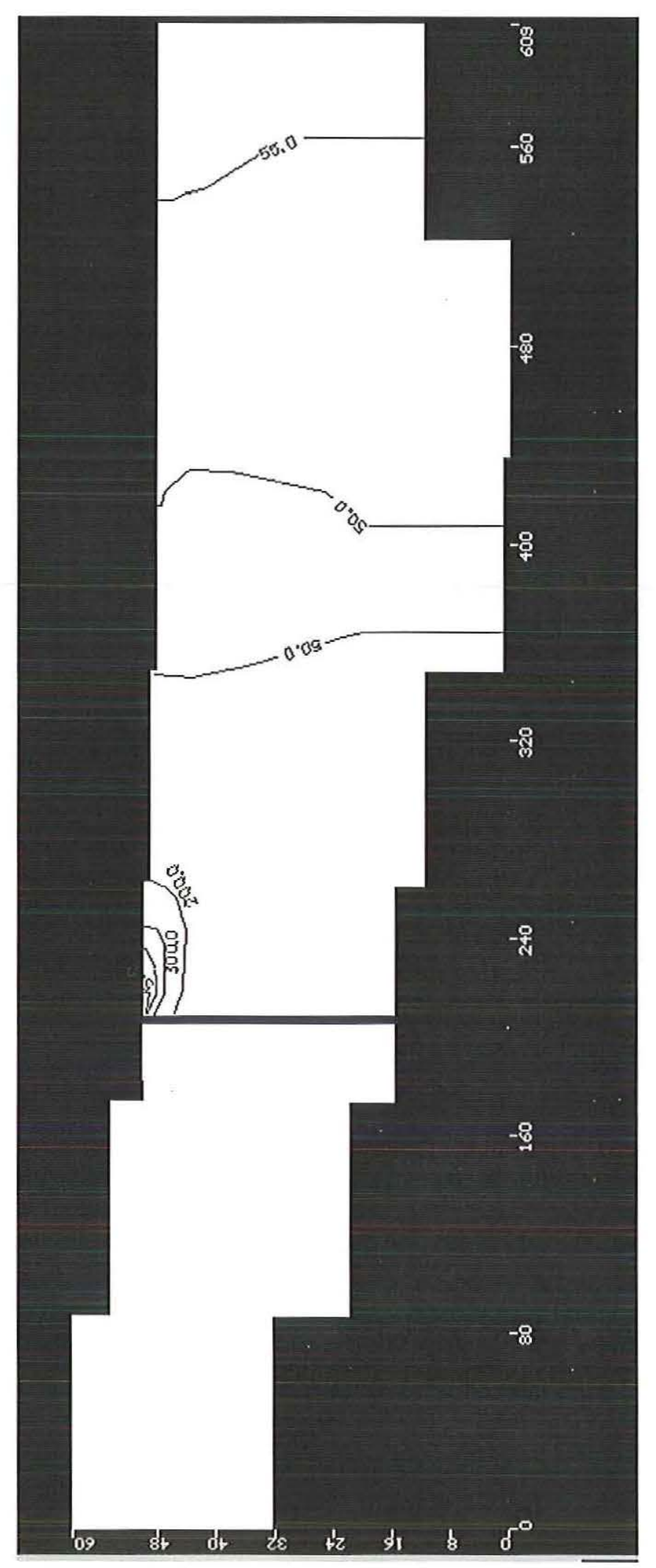

FIGURA 176 - Perfil transversal a direção de maior espalhamento da pluma de poluição (Coluna) no Tempo de 7300 dias. 


\section{$8^{\circ}$ Simulação: Paredes frontais e cobertura}

Esta simulação mantém as mesmas características básicos da simulação anterior, alterando a posição da parede em relação a fonte de contaminação. Os resultados desta simulação são:

\section{Modelo de Fluxo}

O fluxo neste modelo se comporta do mesmo modo que na simulação 5 , porém alterando a intensidade do vetor de velocidade. O fluxo pode ser visualizado na Figura 177.

\section{Modelo de Transporte}

A geometria formada pelas plumas de contaminação são semelhantes a simulação 5 , onde as mesmas estruturas de contenção foram aplicadas, a diferença observada é quanto aos níveis de concentração mais baixos, devido a presença da cobertura.

A delimitação da pluma está representada nas figuras 179 a 193. A Figura 177 apresenta o caminhamento das partículas nesta simulação. 

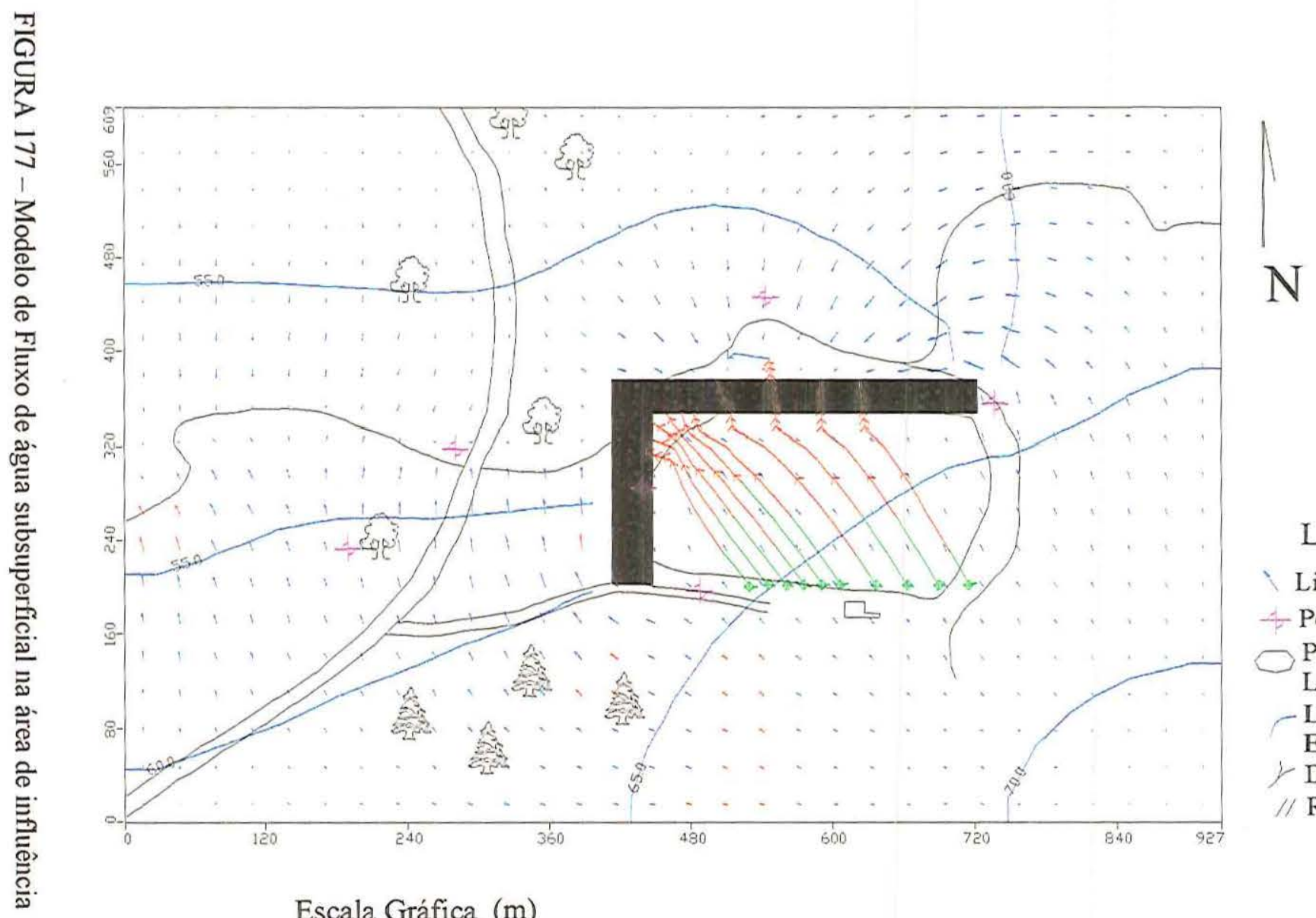

Escala Gráfica (m)

Legenda

Linhas de Fluxo

- Poços de Obser.

Perímetro do

Lixão

Linhas

Equipotenciais

Drenagem

// Rodovias

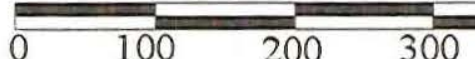




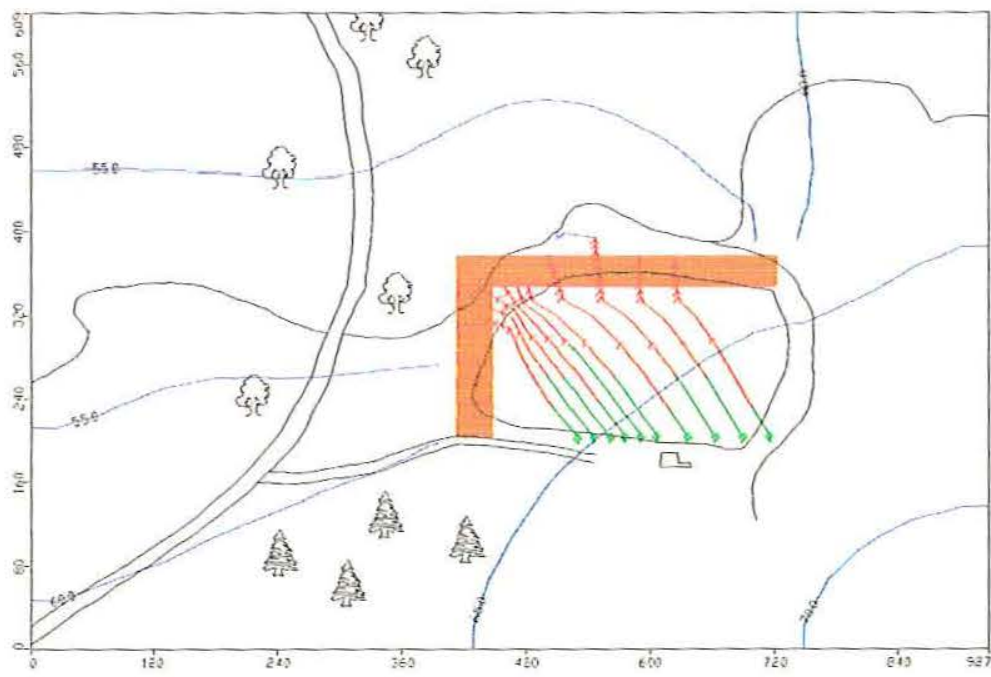

$\mathrm{N}$

\section{Legenda}

Linhas Equipotenciais

Caminhamento das partículas

$\bigcirc$ Perímetro do Lixão

> Drenagem

// Rodovias

Escala Gráfica (m)

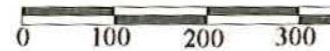

FIGURA 178 - Trajetória das Partículas

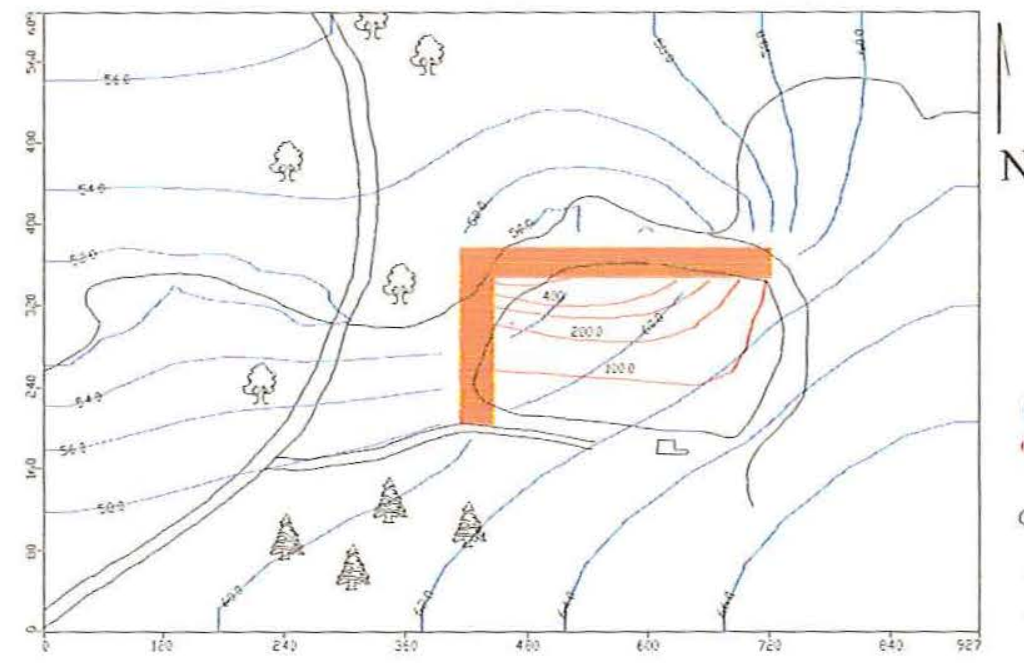

\section{Legenda}

Linhas Equipotenciais

Delimitação de Niveis de

Concentração da Pluma

Perímetro do Lixão

y Drenagem

// Rodovias

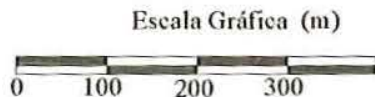

FIGURA 179 - Modelo de Transporte. Camada 1 Tempo 1825 dias. 


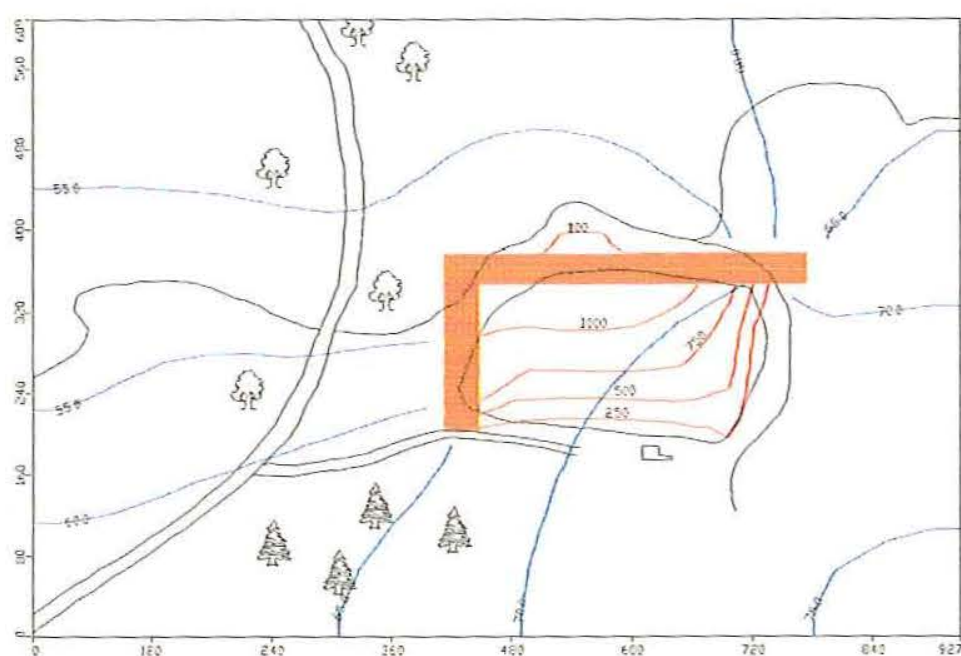

N

\section{Legenda}

Linhas Equipotenciais

Delimitação de Níveis de Concentração da Pluma

$\checkmark$ Perímetro do Lixão

$>$ Drenagem

// Rodovias

Escala Gráfica (m)

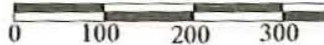

FIGURA 180 - Modelo de Transporte. Camada 1 Tempo 3650 dias.
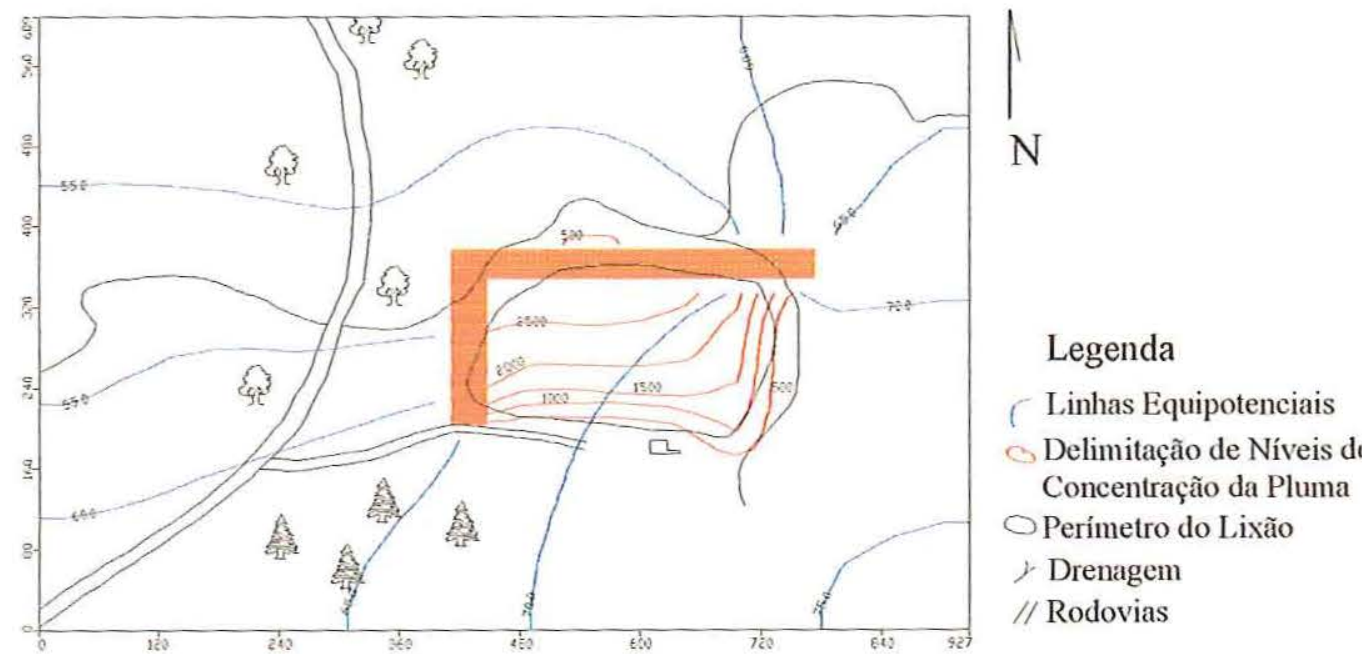

Escala Gráfica (m)

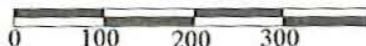

FIGURA 181 - Modelo de Transporte. Camada 1 Tempo 7300 dias. 


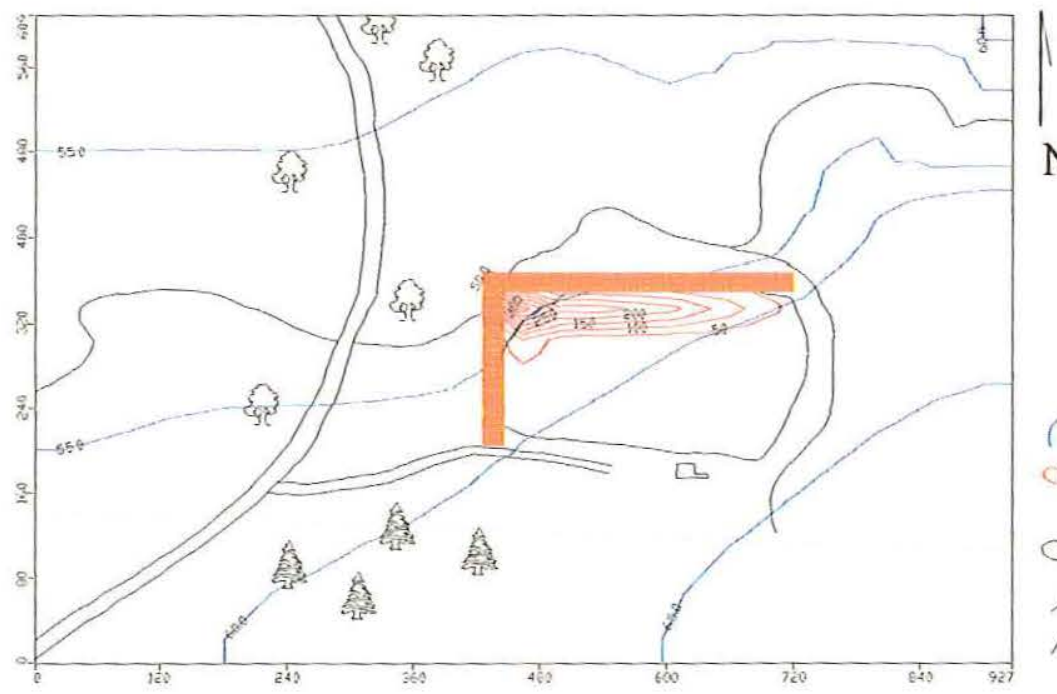

N

\section{Legenda}

Limhas Equipotenciais

Delimitação de Níveis d

Concentração da Pluma

Perímetro do Lixão

Drenagem

// Rodovias

Escala Gráfica $(\mathrm{m})$

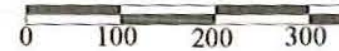

FIGURA 182 - Modelo de Transporte. Camada 2 Tempo 1825 dias.

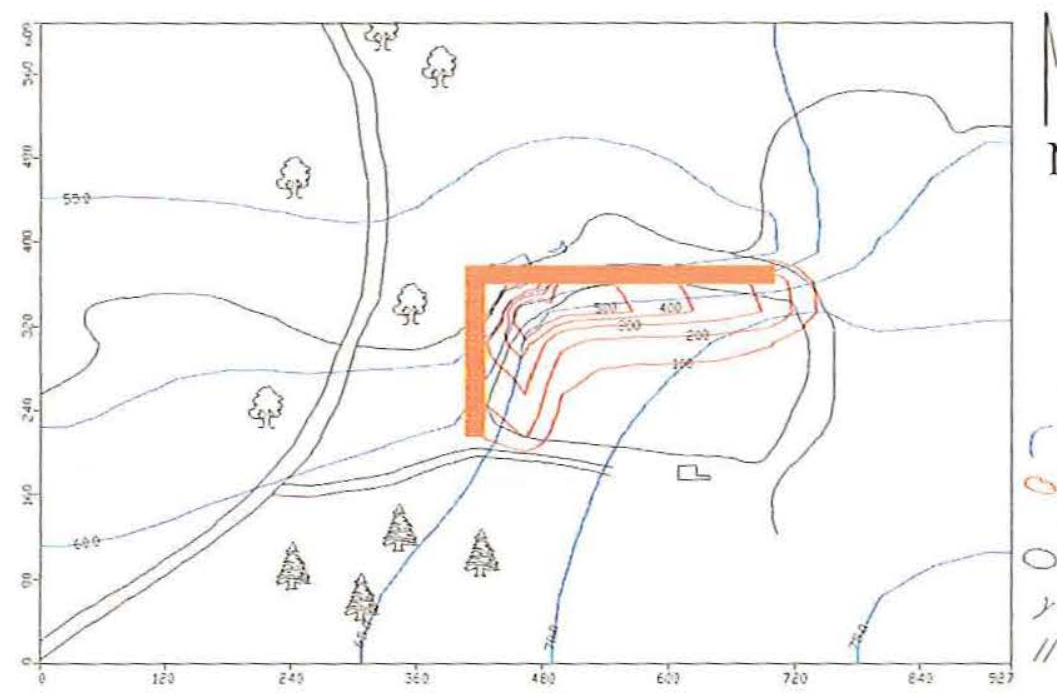

$\mathrm{N}$

\section{Legenda}

Linhas Equipotenciais

Delimitação de Níveis de Concentração da Pluma

Perímetro do Lixão

Drenagem

Rodovias

Escala Gráfica (m)

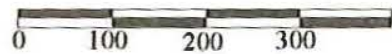

FIGURA 183 - Modelo de Transporte. Camada 2 Tempo 3650 dias. 


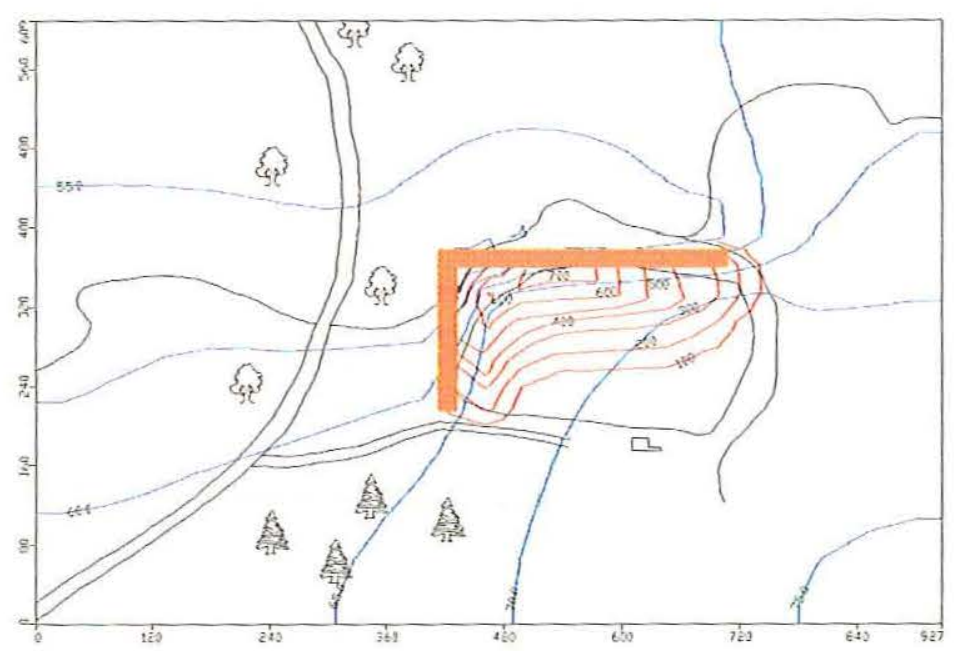

$\mathrm{N}$

\section{Legenda}

- Linhas Equipotenciais Delimitação de Níveis de Concentração da Pluma $\checkmark$ Perímetro do Lixão $\checkmark$ Drenagem // Rodovias

Escala Gráfica (m)

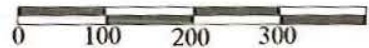

FIGURA 184 - Modelo de Transporte. Camada 2 Tempo 7300 dias.

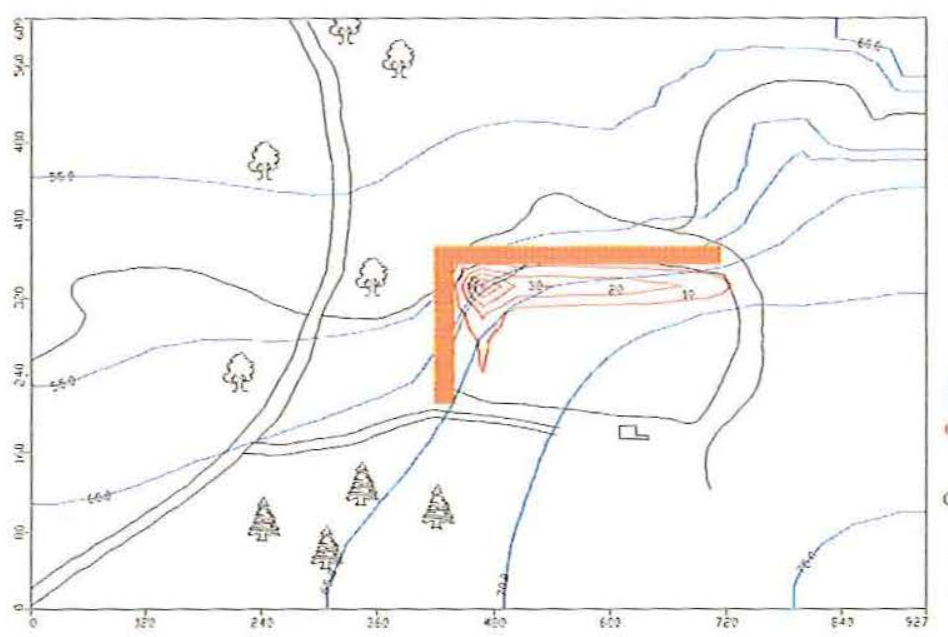

\section{Legenda}

Linhas Equipotenciais Delimitação de Níveis de Concentração da Pluma $\checkmark$ Perímetro do Lixão

Drenagem

// Rodovias

Escala Gráfica (m)

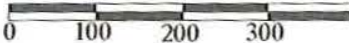

FIGURA 185 - Modelo de Transporte. Camada 3 Tempo 1825 dias. 


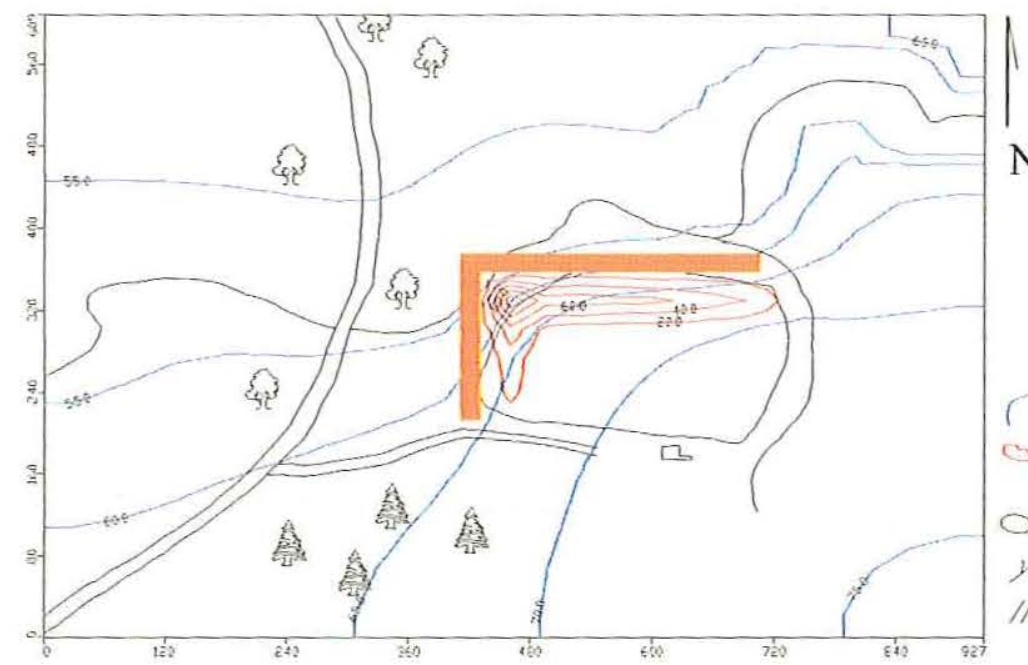

\section{Legenda}

Linhas Equipotenciais

Delimitação de Níveis de

Concentração da Pluma

Perímetro do Lixão

y Drenagem

Rodovias

Escala Gráfica (m)

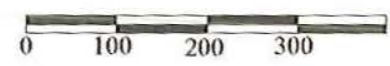

FIGURA 186 - Modelo de Transporte. Camada 3 Tempo 3650 dias.

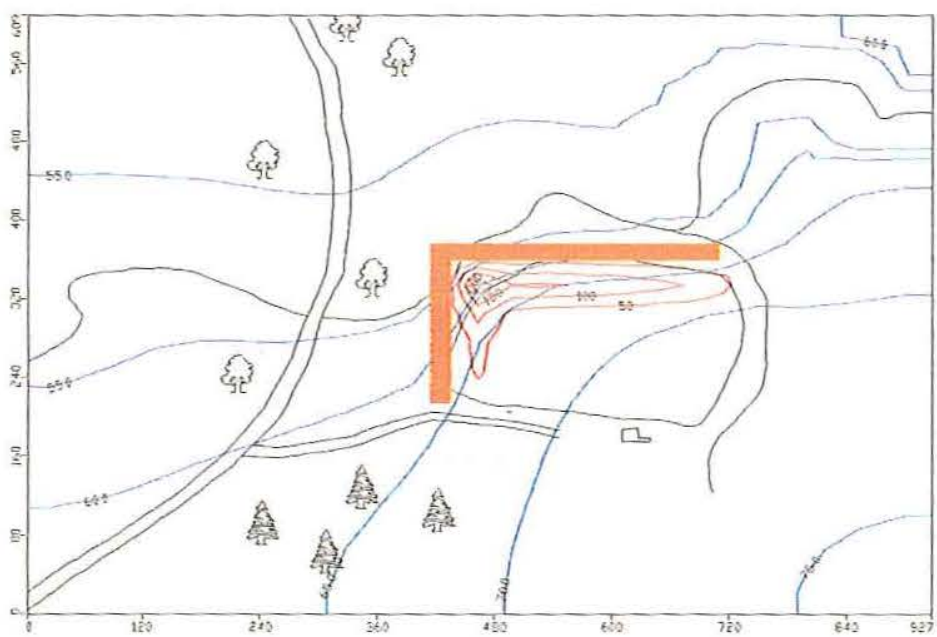

$\mathrm{N}$

\section{Legenda}

Linhas Equipotenciais

Delimitação de Níveis de

Concentração da Pluma

$\bigcirc$ Perímetro do Lixão

Drenagem

// Rodovias

Escala Gráfica (m)

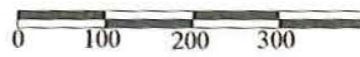

FIGURA 187 - Modelo de Transporte. Camada 3 Tempo 7300 dias.

Os perfis resultantes indicam que a estrutura é eficiente na contenção do movimento dos poluentes, observa-se que os níveis de concentração próximo as barreiras são maiores e atingem profundidades maiores (na ordem de 36m). Esta feição é mais visível nos perfís transversais a direção de maior espalhamento. 


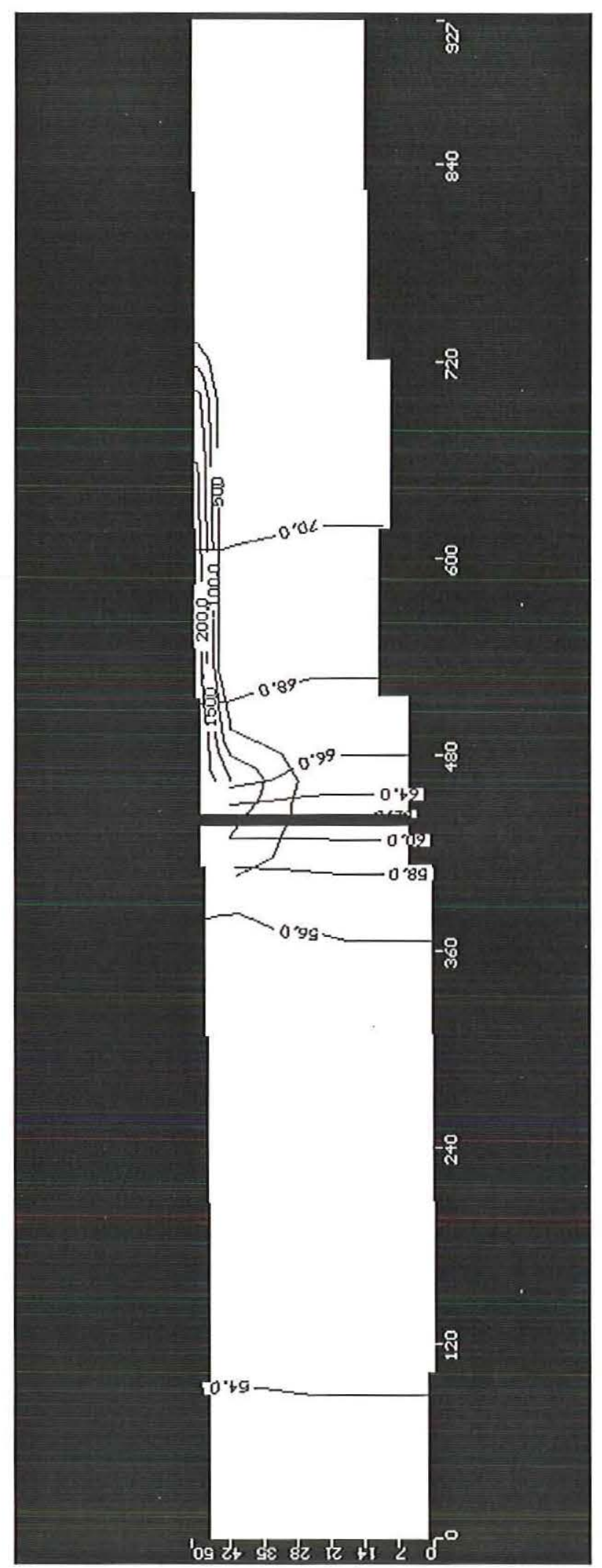

FIGURA 188 - Perfil Longitudinal a direção de maior espalhamento da pluma poluição (Linha) no Tempo de 1825 dias. 


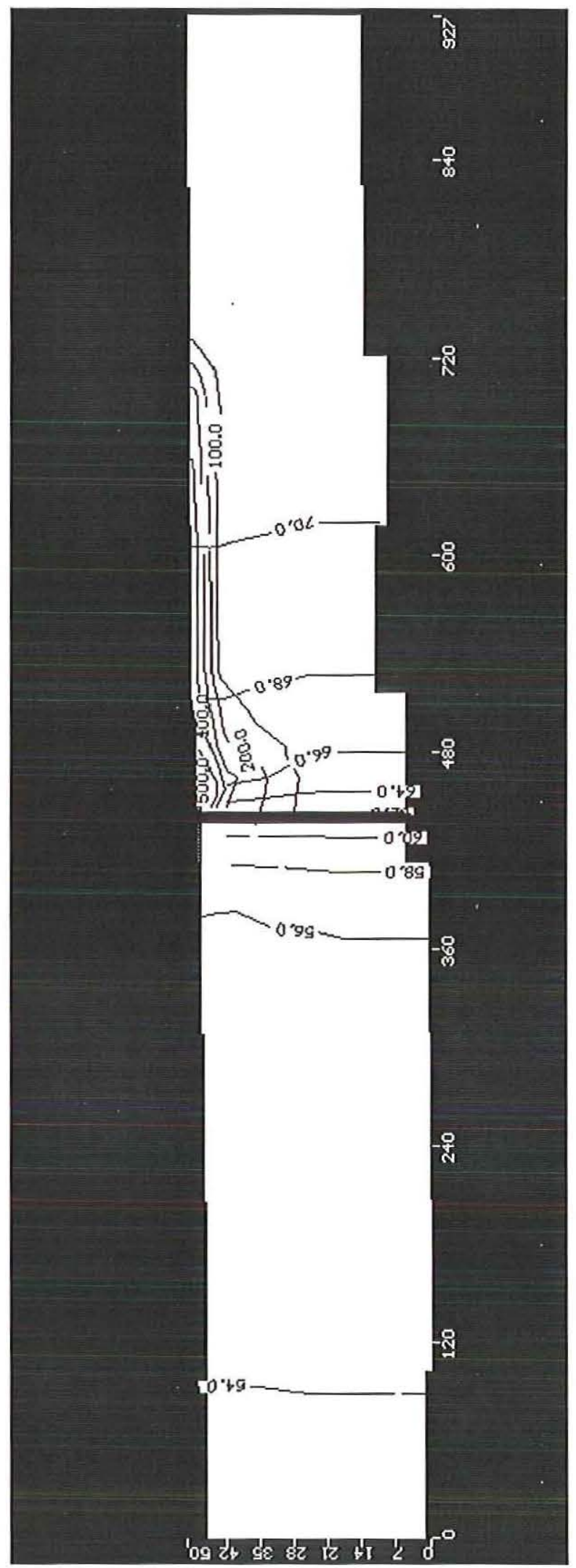

FIGURA 189 - Perfil Longitudinal a direção de maior espalhamento da pluma poluição (Linha) no Tempo de 3650 dias. 


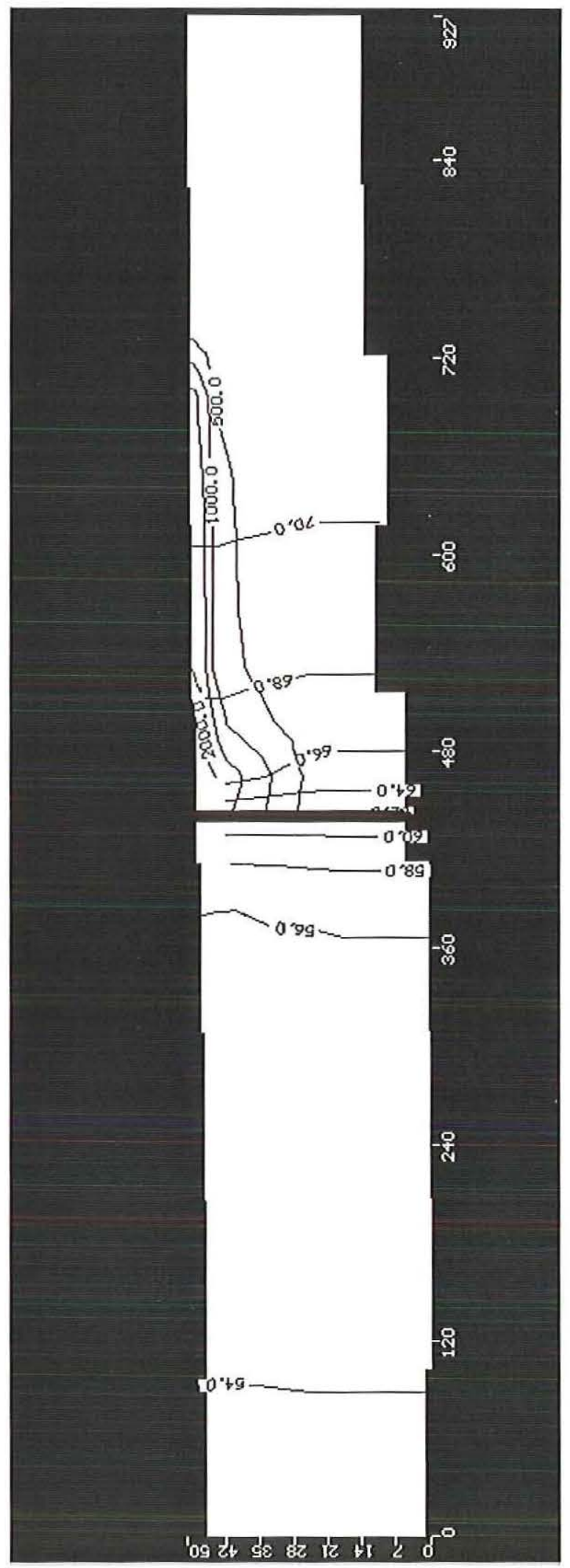

FIGURA 190 - Perfil Longitudinal a direção de maior espalhamento da pluma poluição ( Linha) no Tempo de 7300 dias. 


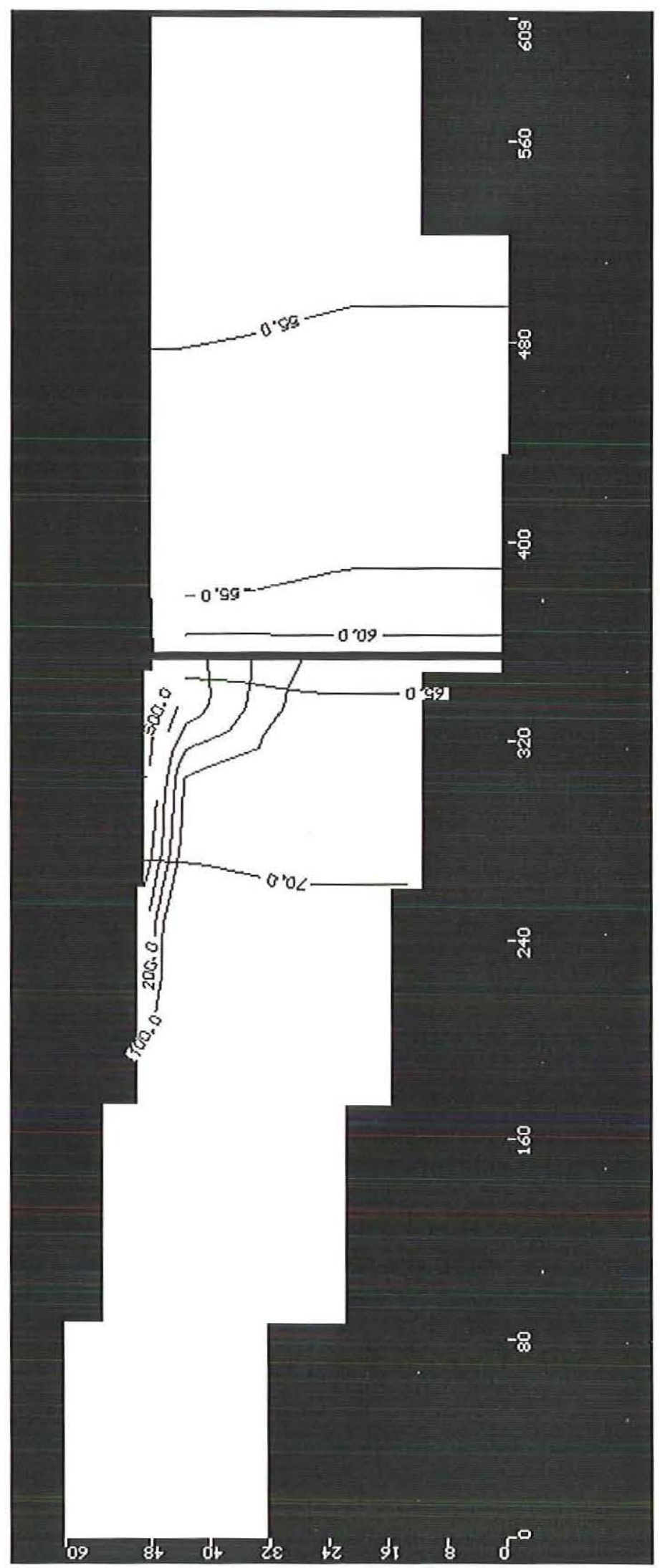

FIGURA 191 - Perfil transversal a direção de maior espalhamento da pluma de poluição (Coluna) no Tempo de 1825 dias. 


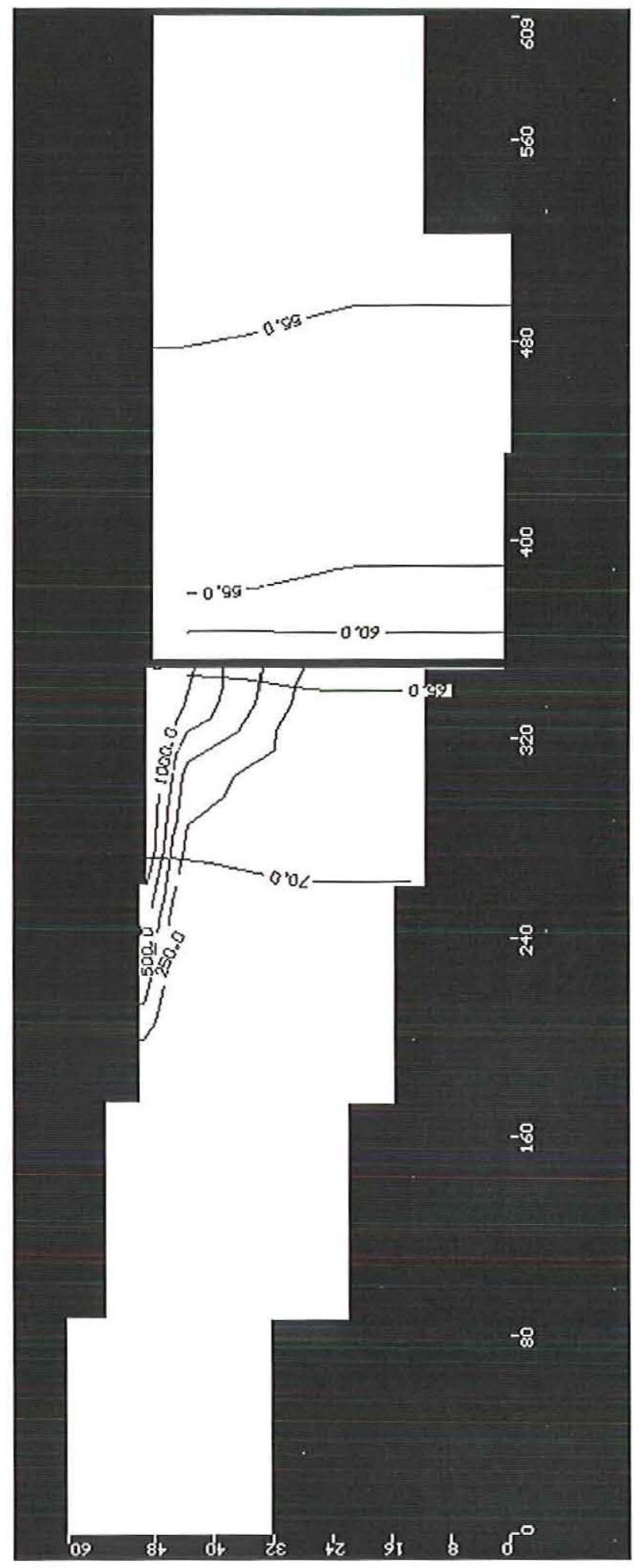

FIGURA 192- Perfil transversal a direção de maior espalhamento da pluma de poluição (Coluna) no Tempo de 3650 dias. 


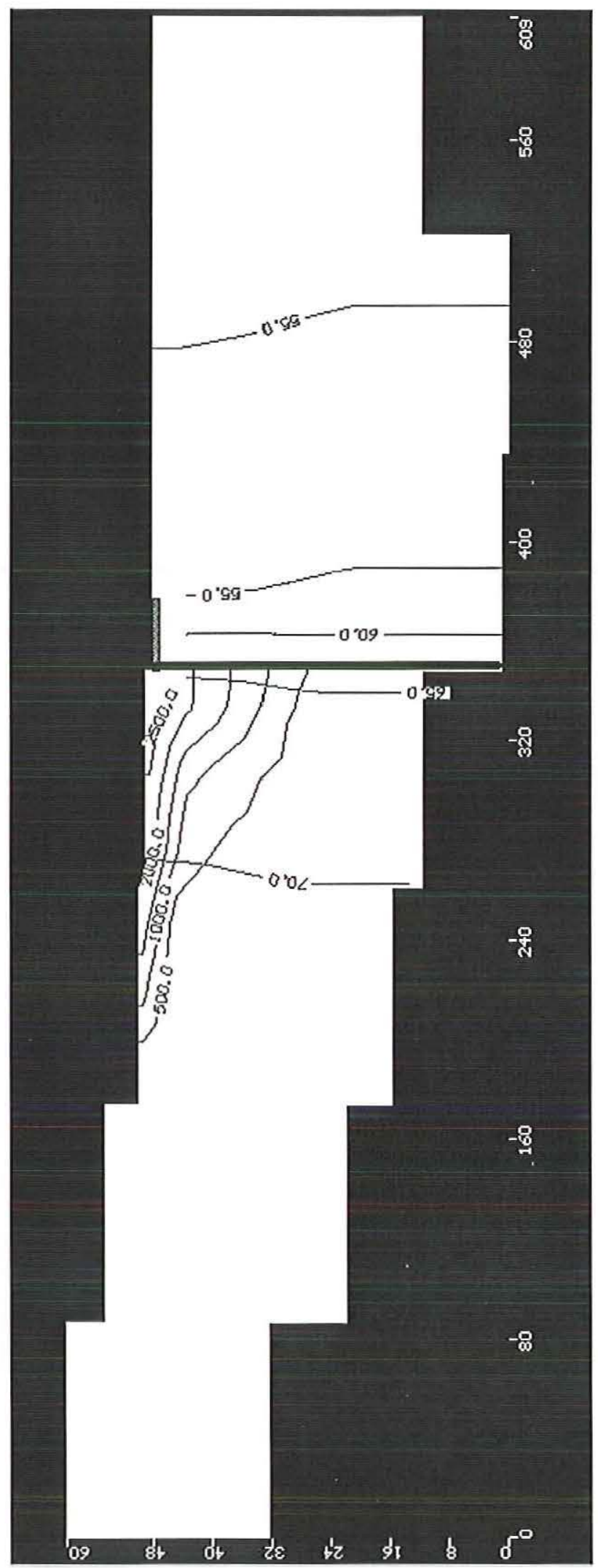

FIGURA 193 - Perfil transversal a direção de maior espalhamento da pluma de poluição (Coluna) no Tempo de 7300 dias. 


\section{$9^{\circ}$ Simulação: Utilizando Poços de Bombeamento}

Para simular os poços de bombeamento, deve-se na fase de entrada de dados, localizar e dar as características de vazão e os intervalos de tempo para o bombeamento. Para esta alternativa é necessário que se adense a malha nas proximidades dos poços, com o objetivo de representar melhor as mudanças no fluxo, além de possibilitar a introdução dos poços.

Simulou-se várias alternativas com poços, alterando a localização, número, vazão, etc. Devido a facilidade do programa em alterar estas rotinas, em muitos dos casos anteriores foi realizada a simulação com e sem poços de bombeamento.

Os resultados obtidos com poços são:

Modelo de Fluxo

A locação de poços de bombeamento altera o fluxo de água ao seu redor, estes poços tornam-se pontos de convergência das linhas de fluxo, como mostrado no Figura 194.

\section{Modelo de Transporte}

Os poços de bombeamento não afetaram de maneira efetiva o transporte dos contaminantes. A presença destes poços é mais visível na camada 3 , onde as plumas migram em direção aos poços.

A Figura 195 mostra a trajetória das partículas para esta simulação e as figuras 196 a 210 permitem visualizar a distribuição da pluma de contaminação. 


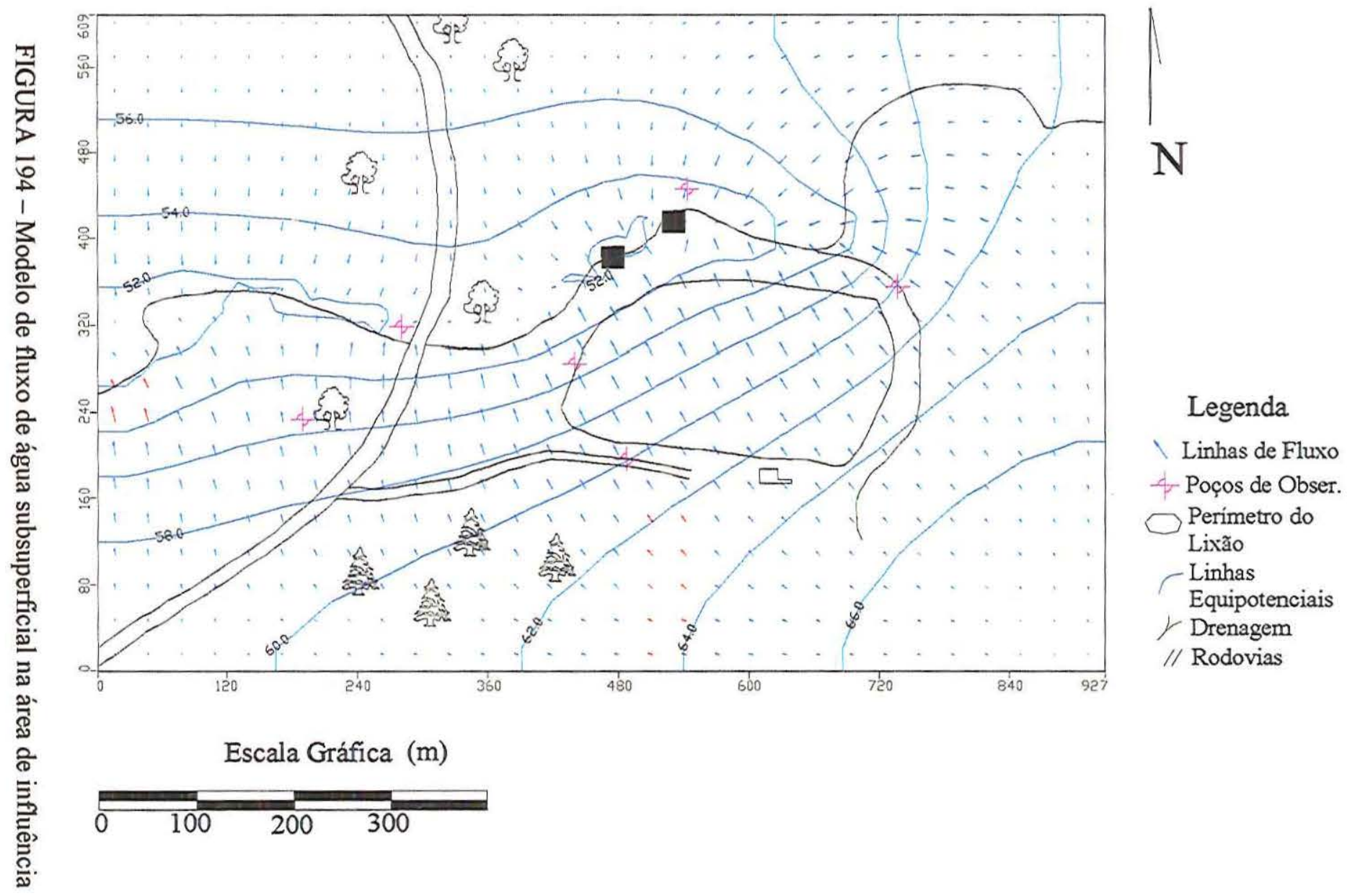




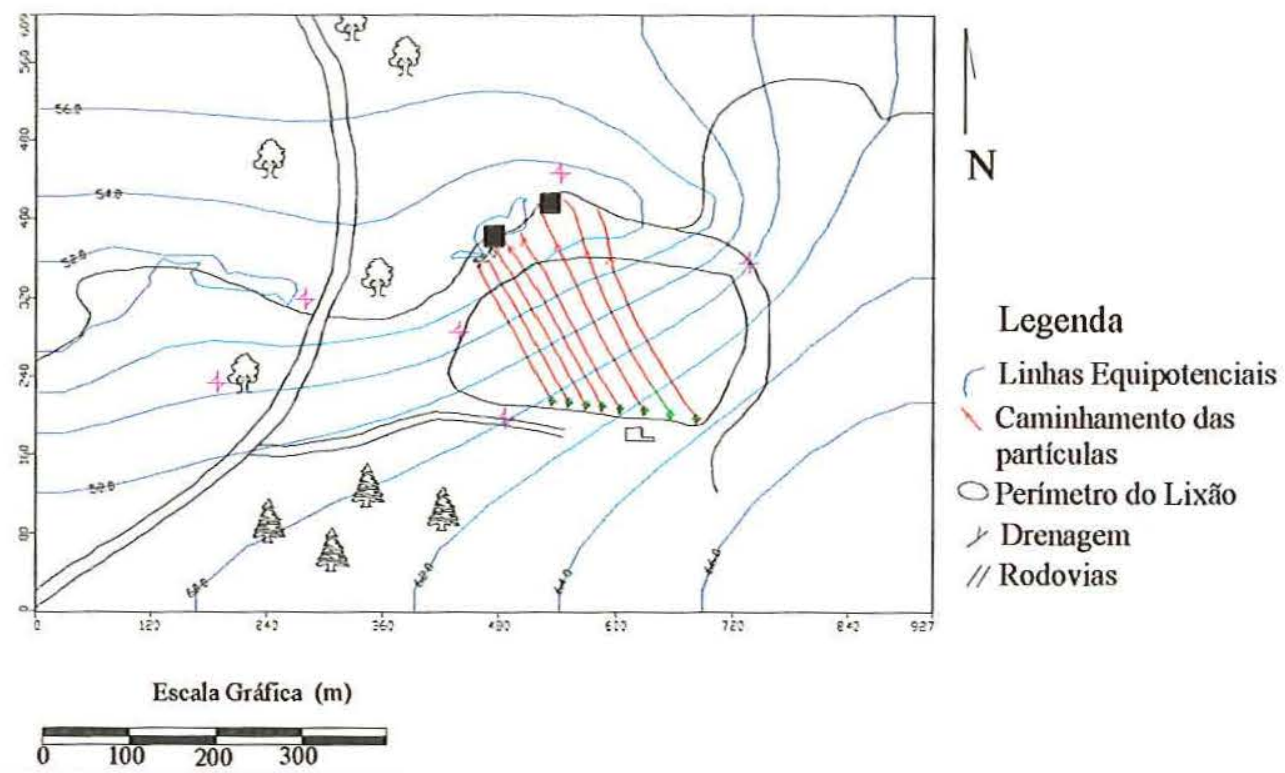

FIGURA 195 - Trajetória das Partículas
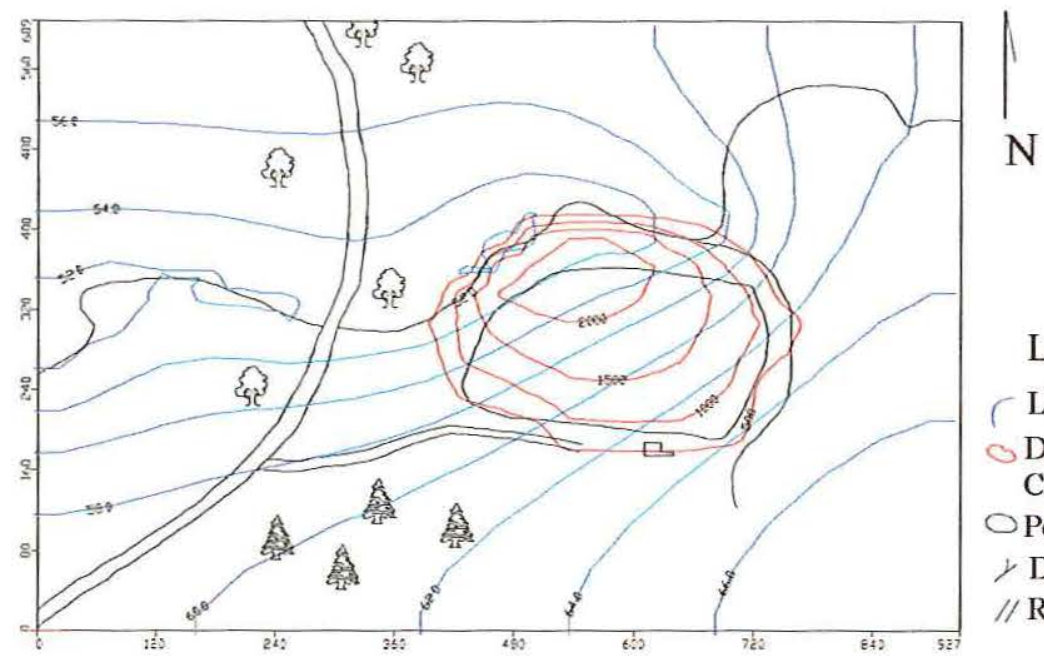

Legenda

- Linhas Equipotenciais $\bigcirc$ Delimitação de Níveis de Concentração da Pluma

$\bigcirc$ Perímetro do Lixão

> Drenagem

// Rodovias

Escala Gráfica (m)

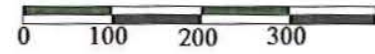

FIGURA 196 - Modelo de Transporte. Camada 1 Tempo 1825 dias. 


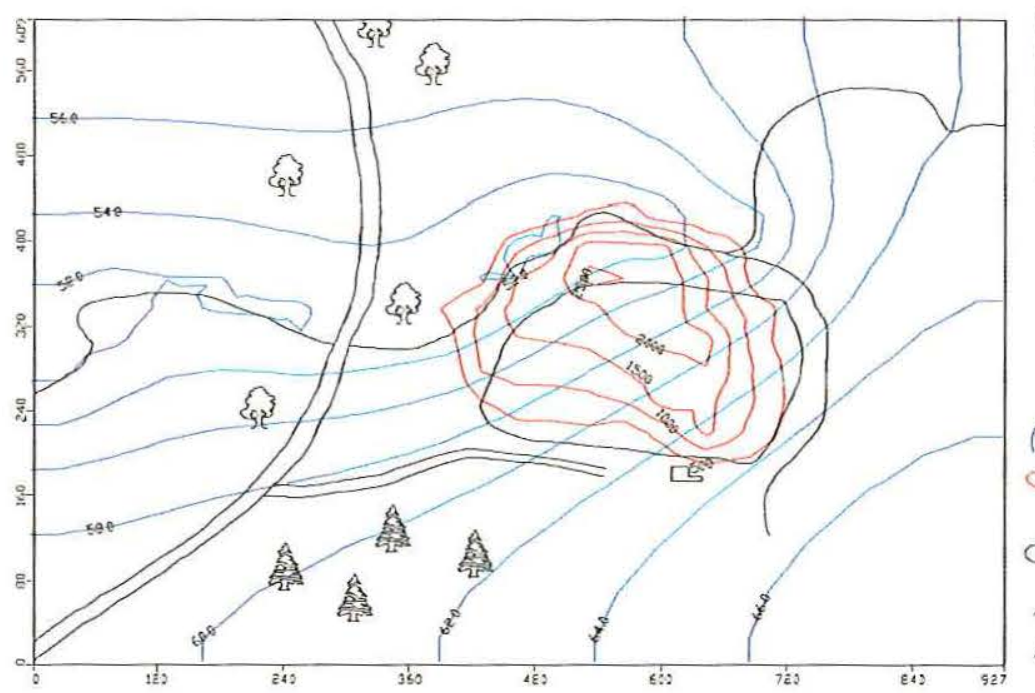

\section{Legenda}

Linhas Equipotenciais

Delimitação de Níveis de Concentração da Pluma

P Perímetro do Lixão

Drenagem

// Rodovias

Escala Gráfica (m)

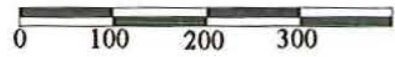

FIGURA 197 - Modelo de Transporte. Camada 1 Tempo 3650 dias.
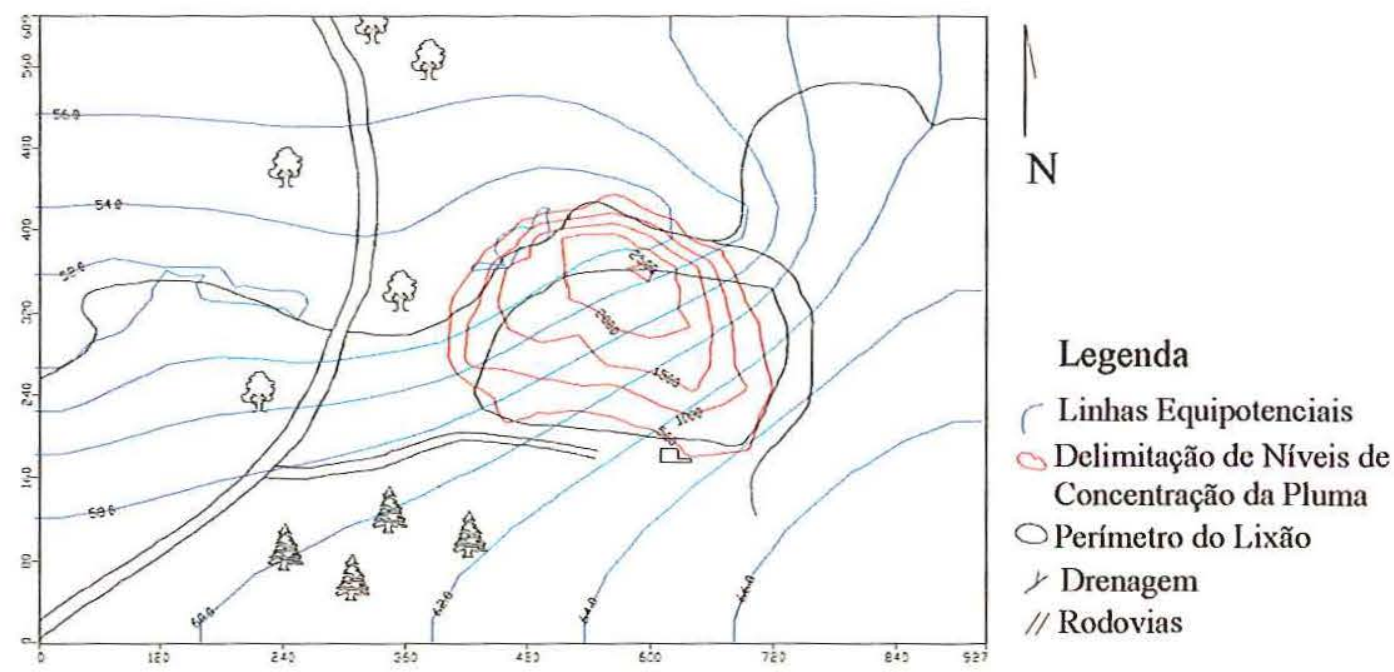

Escala Gráfica (m)

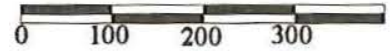

FIGURA 198 - Modelo de Transporte. Camada 1 Tempo 7300 dias. 


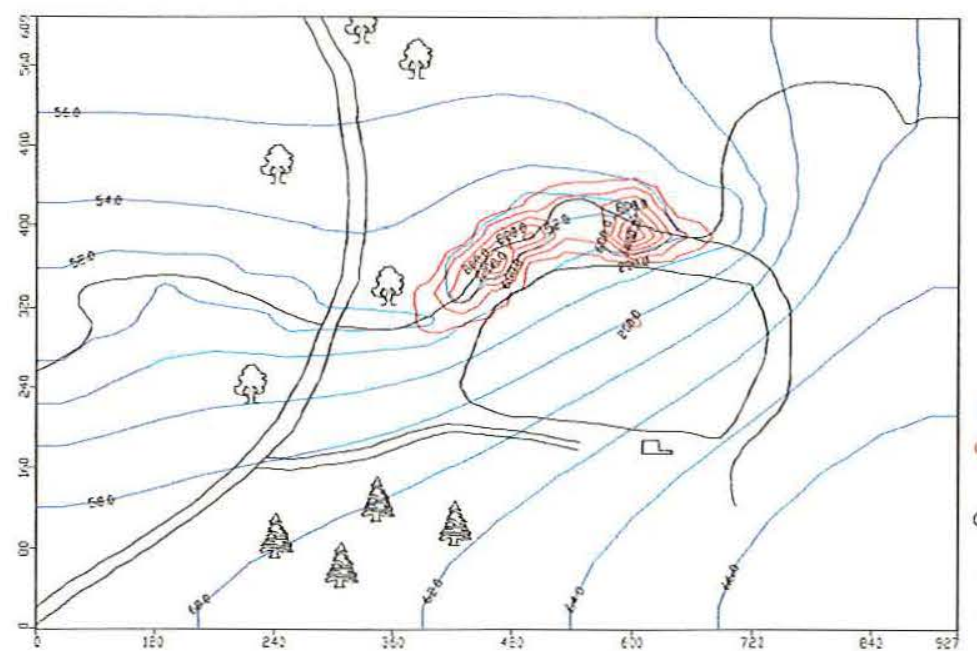

$\left.\right|_{N}$

\section{Legenda}

Linhas Equipotenciais

$\bigcirc$ Delimitação de Níveis de

Concentração da Pluma

$\bigcirc$ Perímetro do Lixão

y Drenagem

// Rodovias

FIGURA 199 - Modelo de Transporte. Camada 2 Tempo 1825 dias.

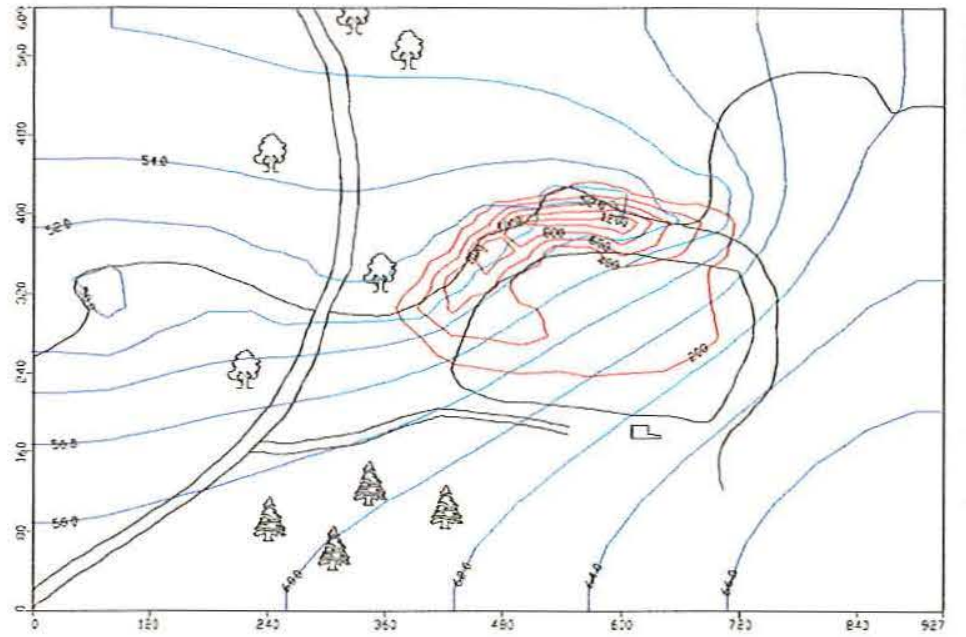

\section{Legenda}

Linhas Equipotenciais $\checkmark$ Delimitação de Níveis de Concentração da Pluma

Perimetro do Lixão

> Drenagem

// Rodovias

Escala Gráfica $(\mathrm{m})$

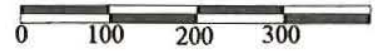

FIGURA 200 - Modelo de Transporte. Camada 2 Tempo 3650 dias. 


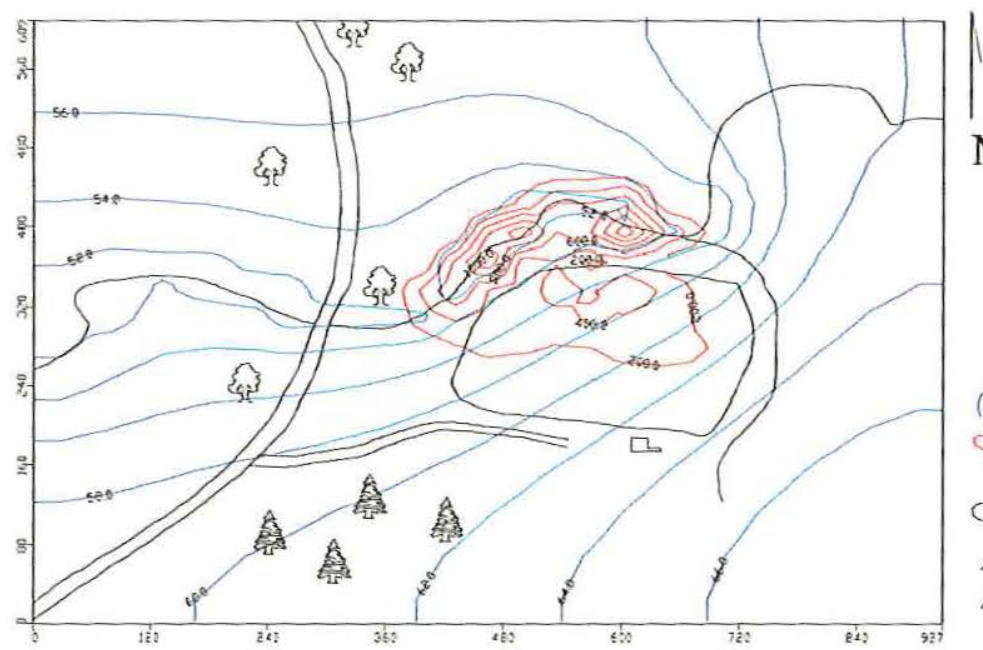

\section{Legenda}

( Linhas Equipotenciais

$\bigcirc$ Delimitação de Níveis de Concentração da Pluma

$\bigcirc$ Perímetro do Lixão

$>$ Drenagem

// Rodovias

Escala Gráfica $(m)$

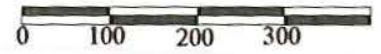

FIGURA 201 - Modelo de Transporte. Camada 2 Tempo 7300 dias.

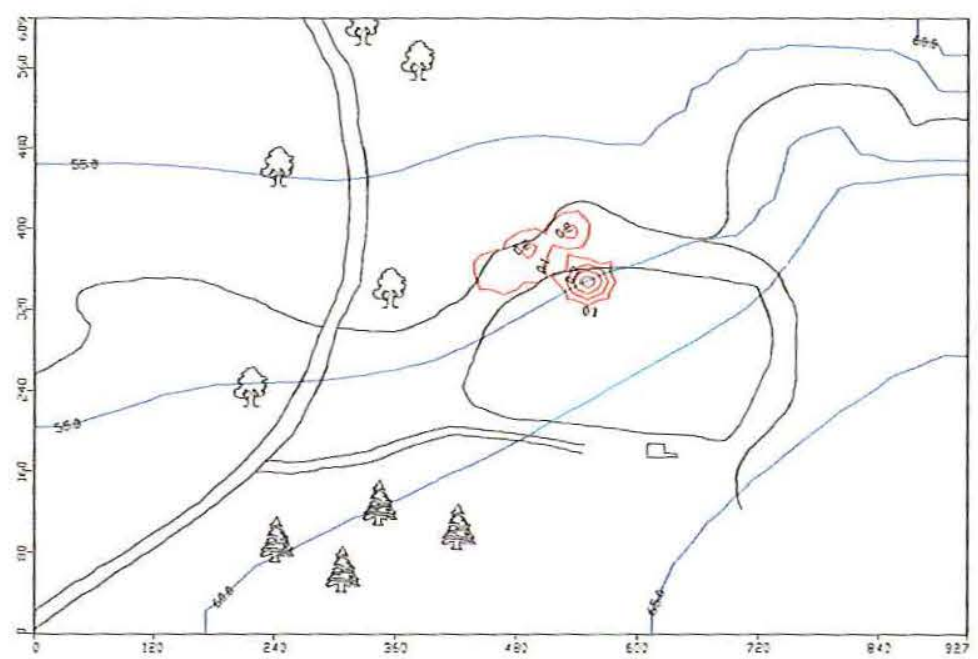

$\mathrm{N}$

\section{Legenda}

Linhas Equipotenciais

Delimitação de Níveis de Concentração da Pluma

$\checkmark$ Perímetro do Lixão

¿ Drenagem

// Rodovias

Escala Gráfica (m)

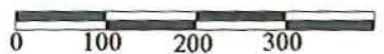

FIGURA 202 - Modelo de Transporte. Camada 3 Tempo 1825 dias. 


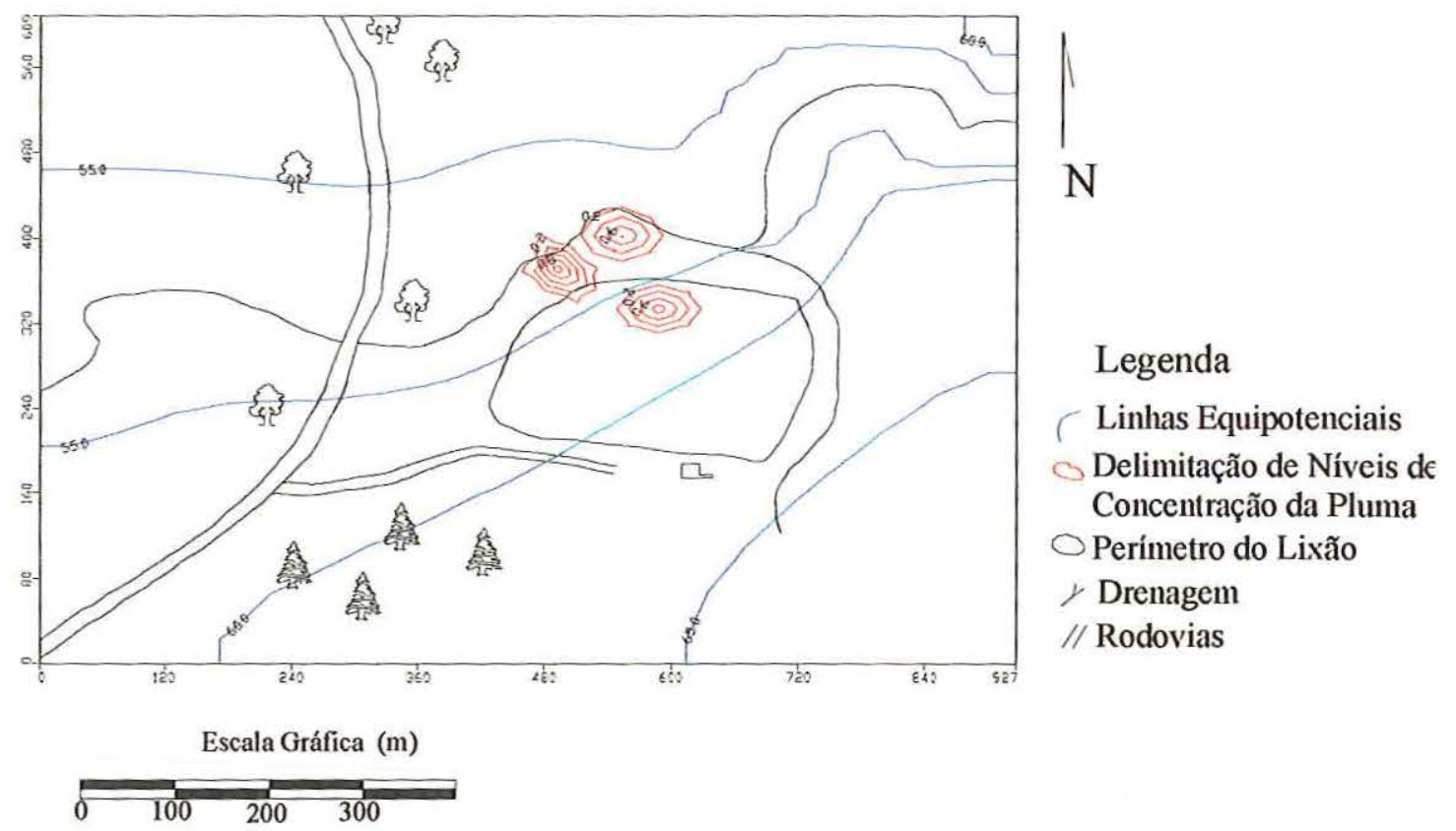

FIGURA 203 - Modelo de Transporte. Camada 3 Tempo 3650 dias.

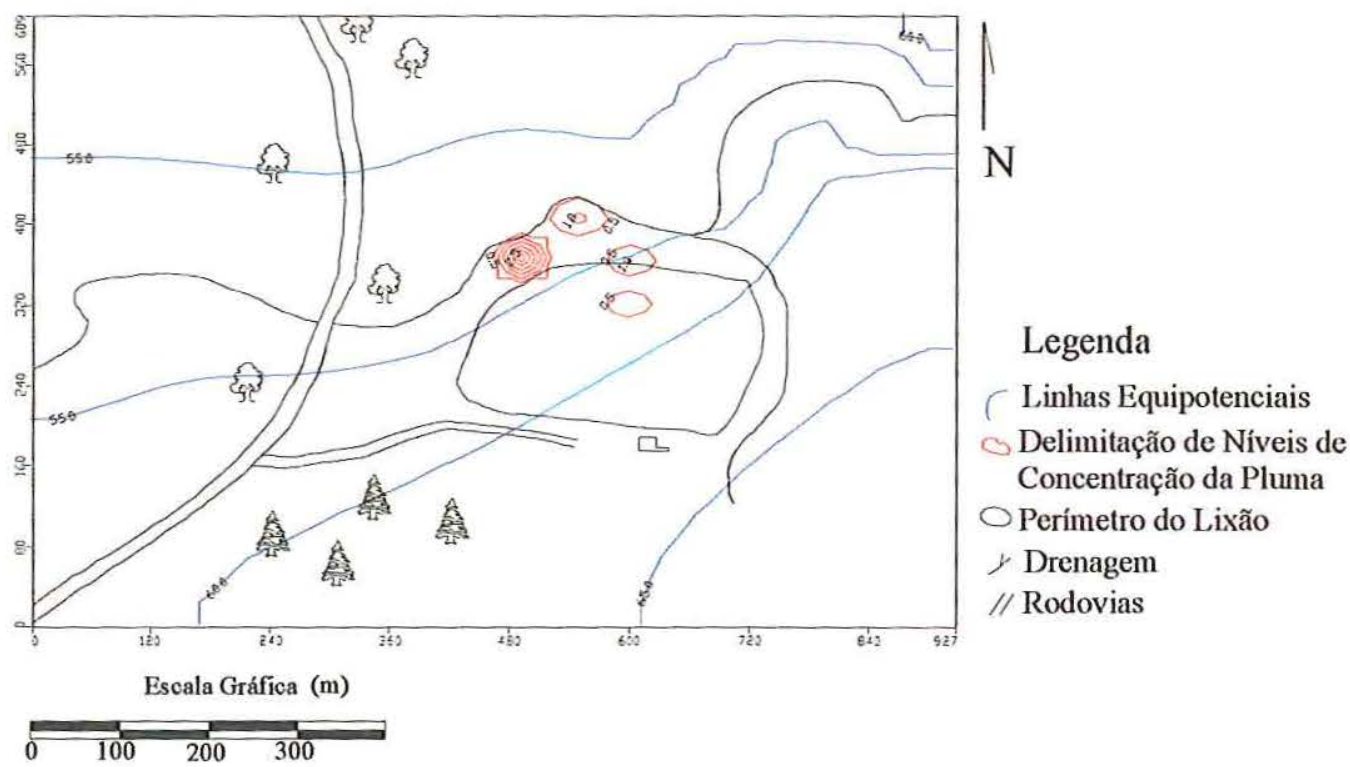

FIGURA 204 - Modelo de Transporte. Camada 3 Tempo 7300 dias.

Os perfis transversais não indicaram uma variação significativa em relação a situação atual quanto a geometria da pluma e pequena alteração em relação a níveis de concentração. Nos perfis longitudinais a influência dos poços é mais visível e sugerem que os poços devem ser executados no centro do lixão para que a pluma concentre-se abaixo dos resíduos e distante do leito do Córrego dos Moinhos. 


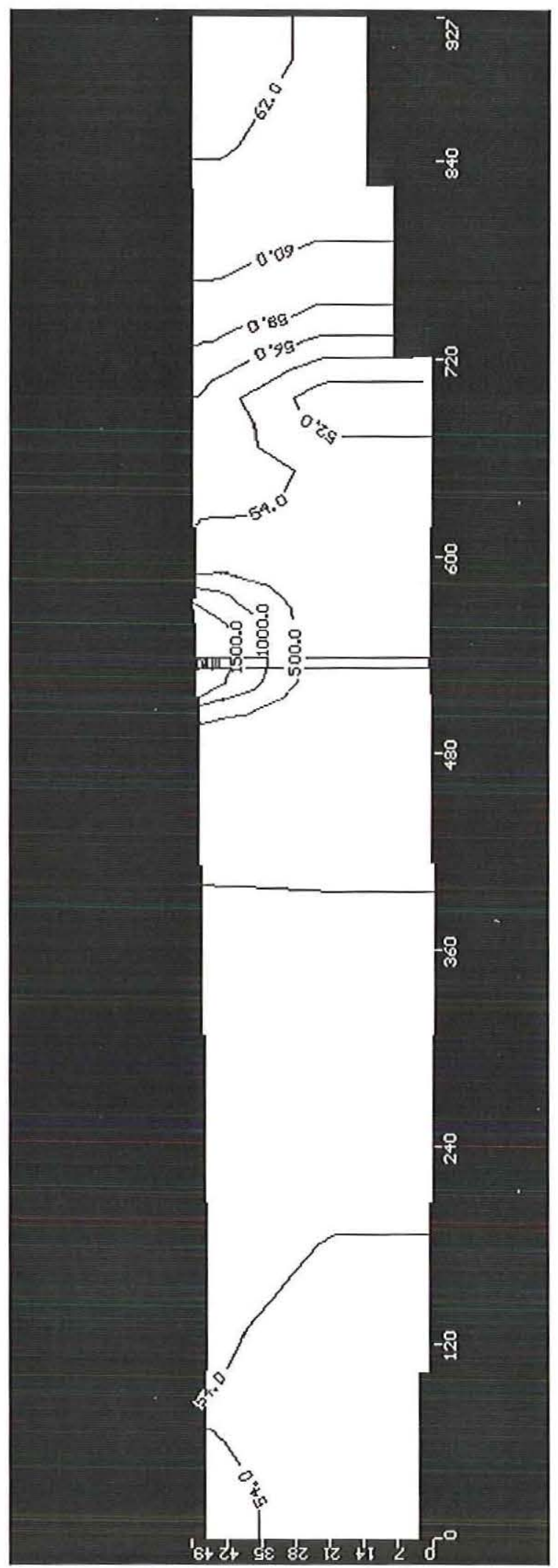

FIGURA 205 - Perfil Longitudinal a direção de maior espalhamento da pluma poluição (Linha) no Tempo de 1825 dias. 


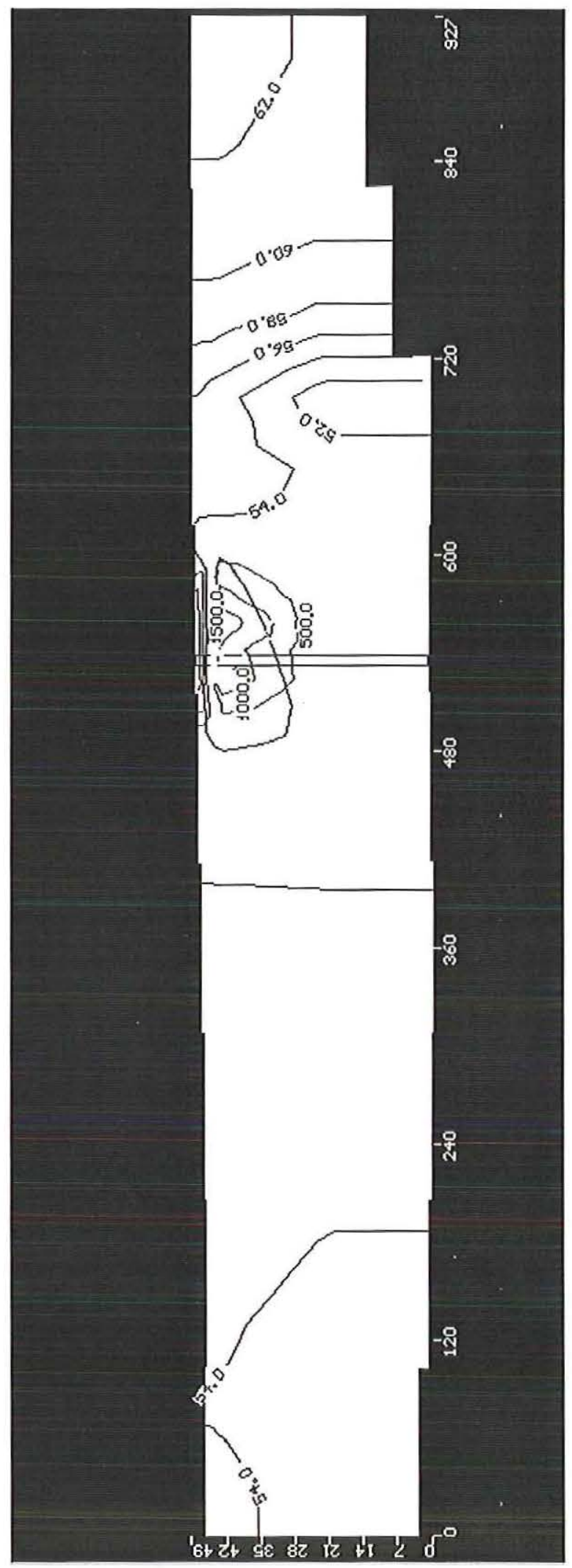

FIGURA 206 - Perfil Longitudinal a direção de maior espalhamento da pluma poluição (Linha) no Tempo de 3650 dias. 


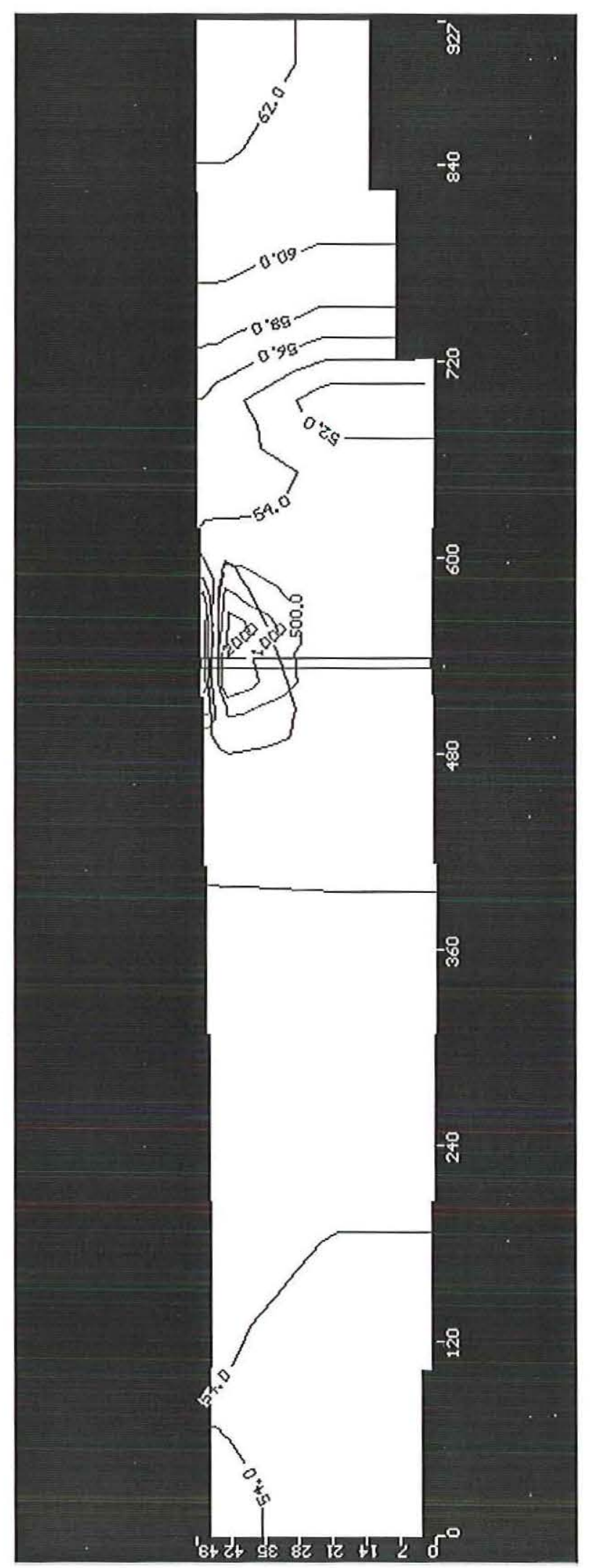

FIGURA 207 - Perfil Longitudinal a direção de maior espalhamento da pluma poluição (Linha) no Tempo de 7300 dias. 


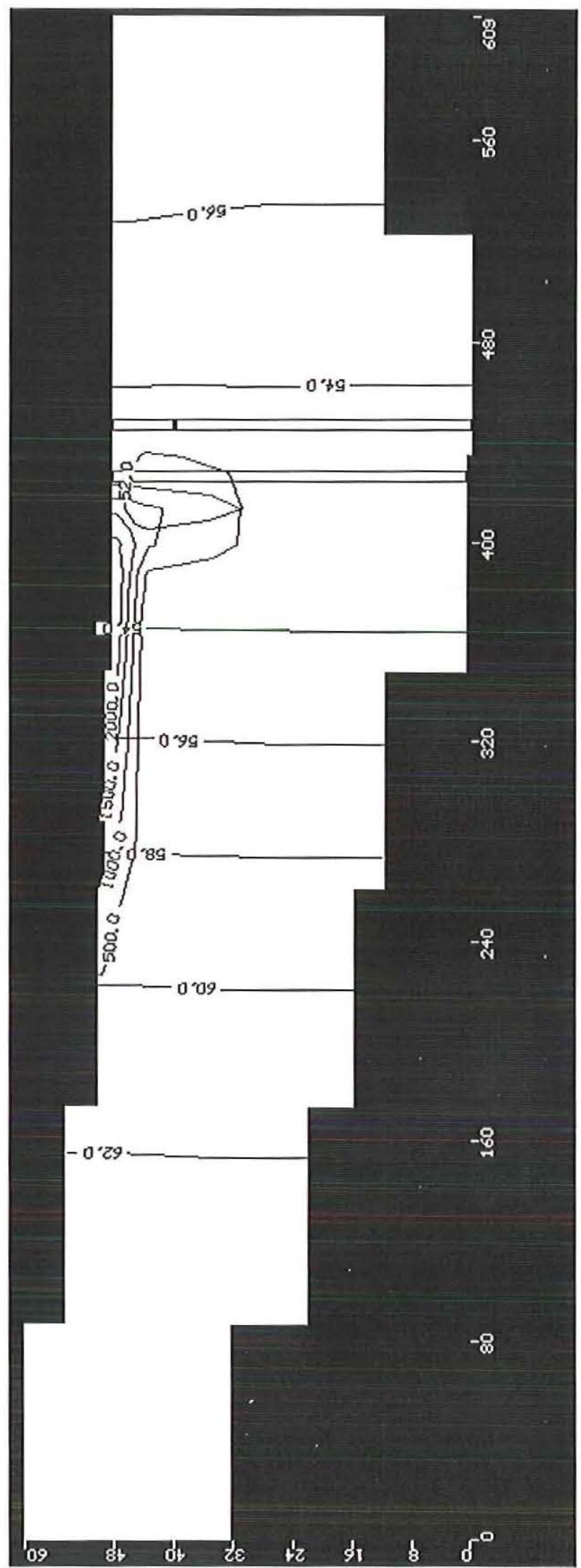

FIGURA 208 - Perfil Transversal a direção de maior espalhamento da pluma poluição (Coluna) no Tempo de 1825 dias. 


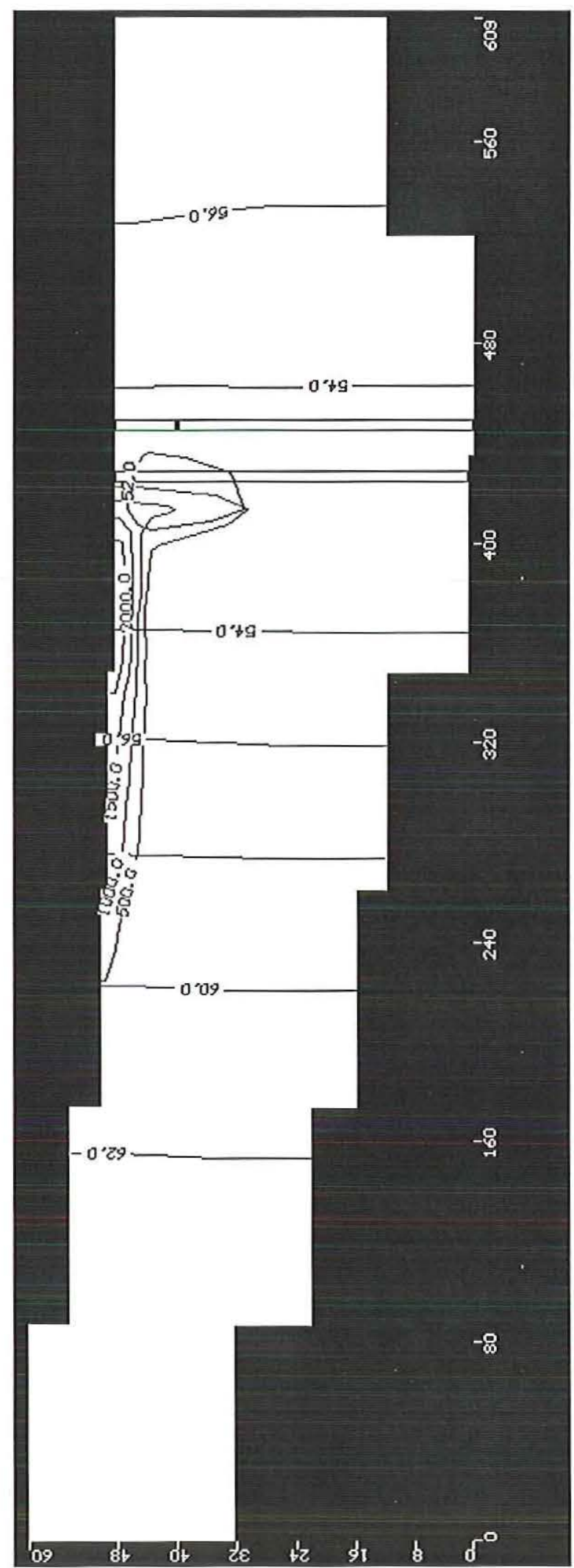

FIGURA 209 - Perfil Transversal a direção de maior espalhamento da pluma poluição (Coluna) no Tempo de 3650 dias. 


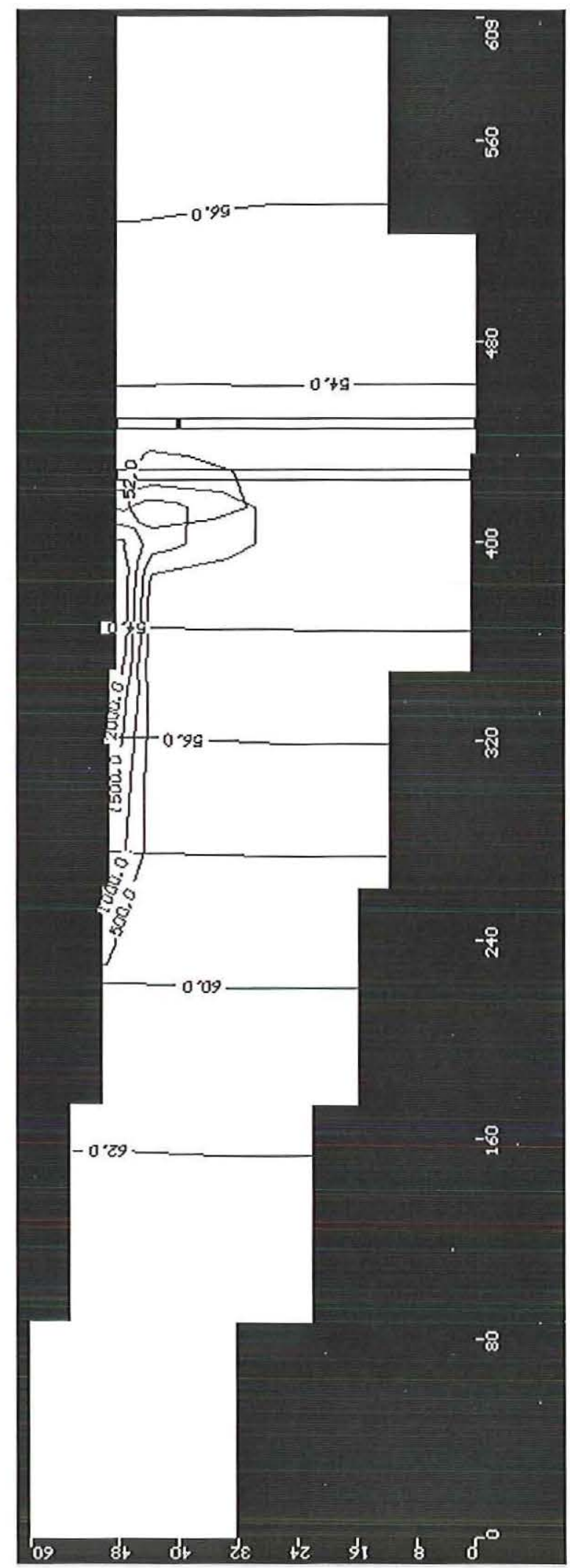

FIGURA 210 - Perfil Transversal a direção de maior espalhamento da pluma poluição (Coluna) no Tempo de 7300 dias. 


\section{CAPÍTULO VIII - CONSIDERAÇÕES FINAIS}

O conhecimento detalhado das características geológicas - geotécnicas hidrogeológicas é muito importante para o entendimento do sistema real, pois permite simplificações e a construção de um modelo representativo.

Os dados geofísicos são de grande utilidade para a modelagem, pois permitem a delimitação da pluma de contaminação sem a necessidade de um número excessivo de ensaios diretos. No entanto, seria aconselhável ter-se dados de concentração de poluentes, pois estes serviriam na calibração dos valores obtidos pela geofísica.

Alguns autores sugerem que a escolha do modelo computacional seja uma das primeiras etapas do processo de construção de um modelo, desta forma seria possível nortear a coleta de dados. Esta alteração na sequiência pode, no entanto, gerar problemas caso conclua-se que o modelo adotado não seja adequado as particularidades da área. Com o conhecimento prévio das características físicas e químicas do local a escolha do modelo pode ser direcionada, buscando o programa mais adequado para o objetivo do estudo.

O software Visual Modflow apresenta boa interação com o usuário, no entanto sua saída para impressão direta (sem necessidade de exportar para outro programa), principalmente para perfis verticais, não é satisfatória.

A utilização de poços de bombeamento não gerou os resultados esperados, mesmo utilizando vazões baixas obteve-se valores muito altos de rebaixamento. Este fato é mais visível em situações onde os poços foram utilizados como complemento a outras técnicas. 
O Visual Modflow é recomendado para casos onde o poluente seja totalmente miscível com a água e para regiões com pequena espessura de zona não saturada, que foi o caso da área estudada.

A análise de sensibilidade demostrou que dos parâmetro avaliados, a precipitação, por afetar diretamente a quantidade de água no sistema, é o fator de maior influência no modelo de transporte. A alteração deste fator sobre a área do lixão causa uma significativa variação nas concentrações observadas, das várias situações simuladas, notou-se que em média quando se diminui a precipitação em 3 vezes, os valores de concentração, para o caso específico, é reduzido para a metade.

Os resultados obtidos pela modelagem indicaram que a construção de paredes, preferencialmente a montante do lixão considerando a direção do fluxo, concomitante com a utilização de cobertura (simulação 7), é o método mais indicado, em função da relação entre custo e benefício, para a remediação e controle de poluição.

Considerando a construção da barragem, pressuposto que deu origem a este trabalho, a alternativa mais indicada é a combinação de medidas: remoção de todo o resíduo depositado e do material que forma a primeira camada (aproximadamente $2 \mathrm{~m}$ de espessura nas imediações do lixão), incluindo a área próxima aos limites da pluma de poluição e sua substituição por um material de condutividade hidráulica da ordem de $10^{-9} \mathrm{~cm} / \mathrm{s}$. Desta forma a taxa de poluente deve dispersar-se sem atingir níveis problemáticos quanto ao uso da água. 


\section{REFERÊNICA BIBLIOGRÁFICA}

ABDUL, A. S; GIBSON, T.L; RAI, D.N; (1990) - Selection of Surfactants for the removal of petroleum products from shallow sandy aquifers. Ground water 28(6): pp 920-926.

ALMEIDA FILHO, R.; PARADELLA, W. R. (1977) Estudo do Maciço Alcalino de Poços de Caldas através de imagens Landsat com ênfase em mineralizações radioativas - Dissertação (Mestrado em Sensoriamento Remoto) INPE. 1V. 130p.

ANGELL, K.G. (1992) - In situ Remedial methods: air sparging. Natl. Environ. J.2 (1):pp 2023.

ANDERSON, M. P. \& WOESSNER, W.W. (1992) Applied Groundwater Modeling Simulation of Flow and Advective Transport, San Diego, Academic Press.

ANON (1989) - Cleaning up sites with on-site process plants. In: Environmental Science and Technology, 23, pp 912 - 916.

ATTEWELL, P. (1993) Ground Pollution. Environment, Geology, Engineering and Law. London.. Chapman \& Hall. 251p.

BAEHR, A. L; HOAG, G. E; MARLEY, M. C. (1989) - Removing volatile contaminants from the unsaturated zone by inducing advective air-phase transport. J. Contam. Hydrol. 4(1):pp $2-6$.

BENSON, C.H. \& DANIEL, D.E. (1994) - Minimum thickness of compacted soil liners: I. Stochastic models II. Analysis and case histories.In: Journal Geotechnical Eng., 120(1): pp $129-172$.

BENVENUTO, C. (1995) - A concepção e a construção de aterros sanitários. In: Simpósio sobre Barragens de rejeitos e disposição de residuos. Ouro Preto, Anais. pp 551- 561. 
BOSMA, T.N.P; SCHNOOR, J.L; SCHRAM, G; ZEHNDER, a J.B; (1988) - Simulation model for biotransformation of xenbiotics and chemotaxis in soil columns. J. Contam. Hydrol. 2:pp225-236.

BRANCO, S. M. (1991) - A água e o homem. In: PORTO, R.L.L.(org) Hidrologia Ambiental. São Paulo. EDUSP. pp 3- 25.

BRANDL, H. (1992) - Mineral liners for hazardous waste containment. Géotechnique, (I): pp 57 $-65$.

BROWN, R. (1992) - Air Sparging: A Primer for Application and Design. Trenton, N.J. Groundwater technology, Inc.

BRUN, P; AUDIGUIER, M; BILLIOTTE, D (1994) - Experimental and numerical study of the infiltration phenomena in a compacted clay designed for the short period radioactive wastes. In: Engineeering Geology. 37 pp 123 - 1336.

BUSCHECK, T. PEARGIN, R. (1991) Summary of a nationwide vapor extraction system performance study. In: Proceedings of Petroleum Hydrocarbons and Organic Chemicals in Ground Water:Dublin, Ohio: National Ground Water Association.. 394p.

CAIRNEY, T. (1993) - Contaminated Land - Problems and Solutions. Lewis Publishers.

CARLSTRON FILHO, C.; CORRÉA FILHO, D; BOTTURA, J. A. (1978) Caracterização Hidrogeotécnica Baseada em Dados Piezométricos e características Hidrodinâmicas do Maciço da Mina de Urânio Osamu Utsumi, Poços de Caldas, MG. In: Anais do $2^{\circ}$ Congresso Brasileiro de Geologia de Engenharia. Associação Brasileira de Geologia de Engenharia. São Paulo. V2, pp 297-309.

CAVAlCANTE, J. C. et al.; (1979) Projeto Sapucaí - Estados de São Paulo, Rio de Janeiro e Minas Gerais. Relatório Final de Geologia - Brasilia - DNPM/SP, CPRM (Série Geologia, 4 Seção Geológica 2). 229p. 
CETEC (1987) Avaliação hidrológica e hidroquímica dos arredores de Poços de Caldas. Relatório Belo Horizonte, 139p.

CHAPUIS, R.P. (1990) - Sand-bentonite liners: Field control methods. Canadian Geotechnical Journal. 27(2).

CHAPUIS, R.P; POULIOT, G. (1996) - Determination of bentonite content in soil-bentonite liners by X-ray diffraction. In: Canadian Geotechnical Journal. 33 (5):pp 760-769, 1996.

CHRISTENSEN, T.H; COSSU; STEGMANN, R (1991) Landfilling of Waste: Barriers. E \& FN SPON (ed).

CHRISTENSEN, T.H; COSSU; STEGMANN, R (1991) Landfilling of Waste: Leachate. E \& FN SPON (ed).

CHRISTOFOLETTI, A. (1970) Análise morfométrica das Bacias hidrográficas do Planalto de Poços de Caldas - MG. Tese (Livre Docência). Fac. De Filosofia, Ciências e Letras de Rio Claro. 1v. 215p.

CHRISTOFOLETTI, A. (1973) A unidade morfoestrutural do Planalto de Poços de Caldas MGSP. Notícias Geomorfológicas. V13. P77-85.

CLEARY, R. W.; UNGS, M. J. (1994) Prince user guide version 3.0. Princeton analytical models of flow and mass transpor. Waterloo Hidrogeologic Software. Waterloo.

CONWAY, R.A; ROSS, R.D. (1980) Handbook of Industrial Waste Disposal. Van Nostrand ReinHold.

COOKSON, Jr. J.T. (1995) Bioremediation Engineering. Design and Application. McGraw-Hill Publishing Company.

COOPER, H.H.; JACOB, C. E. (1946) A Generalised graphical method for évaluation formation constants and summarizing well field history. Am. Geophy. Union Trans. 27, 526-534. 
DANIEL, D.E., (1993) - Clay liners. In: Geotechnical Practice for Waste Disposal. D. E. Daniel (ed.) Chapman \& Hall, Londres.

DANIEL, D.E. (1995) - Pollution prevention in ladfills using engineered final covers. Waste Disposal by Landfill. Balkerma, Rotterdam.

DESTRIBATS, J. M; PREZ, E; SOYEZ, B. (1994) La depollution des sols en Place. Techniques et exemples. Paris. Études et Recherches des laboratories des ponts et Chaussés.. 120p.

DERBY, O. A. (1987) On nepheline - rocks in Brazil, with special reference to the association of phonolite and foyaite. Quartely Journal of the Geological Society of London, 43:p.457473.

DI MAIO, C. \& FENELLI, G. B; (1994) - Residual strength of kaolinite and bentonite: the influence of their constituint pore fluid. Géotechique, 44 (4): 217 - 226.

DOMENICO, P. A.; SCHWARTZ, F.W. (1990) - Physical and Chemical Hydrogeology. Wiley. 824 p.

ELLERT, R. (1959) Contribuição à geologia do Maciço Alcalino de Poços de Caldas. Boletim (Geologia 18) da Faculdade de Filosofia, Ciências e Letras da Universidade de São Paulo, n18, 237: 5-63p.

ELIS, V.R. (1999) Avaliação da Aplicabilidade de métodos Elétricos de Prospecção Geofísica no Estudo de áreas utilizadas para Diposição de Resíduos. Tese (Doutorado em Geociências e Meio Ambiente, IGCE). Rio Claro, SP. Unesp. 264p.

ETCHEBEHERE, M. L.C. (1990) Modelo de Exploração Mineral Aplicado à Pesquisa de Fontes Termais no Planalto de Poços de Caldas - MG- SP. Dissertação. Instituto de Geociências e Ciências Exatas de Rio Claro - UNESP - SP. 158p. 
ETCHEBEHERE, M. L.C. et al. (1992) Análise Estrutural Apliada à prospecção de Fontes Termais no Planalto de Poços de Caldas (SP/MG). In: YOCITERU HASUI \& JOSÉ AUGUSTO MIOTO (Coordenadores): Geologia estrutural Aplicada. ABGE - Votoratim AS. 439-459p.

EVANS, J.C; (1997) - In situ Remediation oh the Geoenvironment - Proceedins of the Conference. Geotechnical Special Publication. No 71.ASCE.

EPA. (1990) - Insitu treatment of Contaminated Ground Water. Washington, D.C: EPA, Technology Innovation Office.

FAILEY, A.R.; SCRIVENS, A.J. (1994). Contaminated Land. Assessment and Redevelopment. Stanley Thormes (ed).

FERNANDEZ, R.M. (1994). Geomembranas usuales in México. In: XVIII Reunion Nacional de Mec. De Suelos. La Geotecnia y su relación con el medio Ambiente. V (1). P 99-118.

FOGEL, S.; FINDLAY, M.; MOORE, A. LEAHY, M. (1987) Biodegradation os chlorinated chemicals in Groundwater by methane oxidizing bacteria. NWWA Confere Petroleum Hydrocarbons and Organic Chemicals in Groundwater - Prevention, Detection, and Restoration.1987. Dublin (Ohio). Proceedings... Dublin, National Water Well Association. p 167-185.

FOLKE, D.J. (1982) Fifth Canadian Colloquim: Control of contaminant by the use of liners. Canadian Geotechnical Journal 19(3), p 320 - 344.

FAILEY, A.R.; SCRIVENS, A.J. (1994) Contaminated Land. Assessment and Redevelopment. Cheltenham: Stanley Thormes.. 96p.

FREEZE, R.A. \& CHERRY, J.A. (1979) Groundwater. Englewood Cliffs, New Jersey: Prentice Hall, Inc. 604p. 
FREEZE, R. A.; MASSMANN, J. ; SMITH, L.; SPERLING, T.; JAMES, B. (1990) Hydrogeologic decision analysis: 1. A framework. Groundwater 28 (5), 738-766.

GARDA, G. M. A., (1990) Alteração hidrotermal no contexto da evolução geológica do Maciço Alcalino de Poços de Caldas MG-SP. Dissertação (Mestrado). São Paulo, USP. 213p.

GOUVENOT, D; BOUCHELANGHEM. A; (1994)- Engineered Barriers for Underground Water Propection. In: XIII, New Delhi, India. pp 1633 - 1636.

HARRIS, S; HERBERT, S; (1994) - ICE Design and practice Guide. Contaminated land. Investigations, assessment and remediation. Thomas Telford (ed). 78p.

HOIGNÉ, J; (1988) - The Chemistry of Ozone in Water - process Technologies for Water Treatment. New York: Plenum Publishing Corporation.

HUNT, J.R; SITAR, N. UDELL, K.S. (1988a) Nonaqueous phase liquid transport and cleanup, I: Analysis of mechanisms. Water Resources Res. 24(8). p 1247-1258.

HUNT, J.R; SITAR, N. UDELL, K.S. (1988b) Nonaqueous phase liquid transport and cleanup, II: Experimental studies. Water Resources Res. 24(8):pp 1259-1269..

HUTZELER, N.; MURPHY, B.; GIERKE, J. (1989) State of Technology Review: Soil Vapor Extraction Systems. EPA/600/2-89/024. Cincinnati: EPA Risk Reduction Engineering Laboratory..

INSTITUTO DE PESQUISA TECNOLOGICA - IPT (1995). Manual de Gerenciamento Integrado do Lixo Municipal.São Paulo. 278p

JAVANDEL, I; TSANG, C.F; (1986) - Capture-Zone Type Curves: A tool for Aquifer Clean-up. In: Ground Water. v (24) No 5. pp 616-625. 
JESSBERGER, H.L., (1995) - Waste containment with compacted clay liners. In: Geoenvironment 2000, v 2, Containment, Remediation and Performance in Environmental Geotechnics. Y.B. Acar e D. E. Daniel (eds) Geotechnical Special Publication No46/ ASCE. pp 463-483.

JESSBERGER, H.L.; MANASSERO M.; SOYEZ, B. STREET, A. (1995) - Engineering waste disposal (geotechnicss of landifill design and remedial works). Waste Disposal Landfill. Balkerma, Rotterdam.

JOHNSON, P.; STANLEY, C.; KEMBLOWSKI, M; BYERS, D.; CORTHART. J. (1990) A practical approach to the design, operation and monitoring of in situ soil-venting systems. Ground Water Monit.. Spring-Verlag Berlim Heidelberg. 159p.

KALTEZIOTIS, N; SARSBY, R.W; ZERVOGIANNIS, H; (1994) - Compacted Clay soil for landfill Liners. In: XIII ICSMFE. New Delhi. India. pp1591 - 1594.

KAYABALI, K (1996) - Engineering Geological Aspects of Replacing o Solid Waste Disposal site with a Sanditary landfill. In: Engineering Geology. V (4). pp 203-212.

KEENE, P. (1987) - Sanitary landfill treatment, Interstate Highway 84. In: Environmental Geotechincs and Problematic Soils and Rocks. Balkema, Rotterdam.

KENNEY, T.C.; VAN VEEN, M.A.; SUNGAILA, M. A. (1992) Hydraulic conductivity of compacted bentonite-sand mixture. In: Canadian Geotechnical Journal. 29(3): pp 364-374.

KING, B.R; LONG. G. M; SHELDON, J. K (1992) Practical Environmental Bioremediation. Lewis Publishers.

KIRKWOOD, R.C; LONGLEY, A.J; (1995) Clean Technology and the Environment. Blakie Academic \& Professional. 
KOMINE, H.; OGATA, N. (1996) Prediction for swelling characteristic of compacted bentonite. In: Canadian Geotechnical Journal, 3 (1): pp 11-22.

LAGE FILHO, A. L. (1996) Caracterização ecológica e limnológicas da Bacia Hidrográfica do Ribeirão das Antas no período de menores precipitações (Poços de Caldas - MG) EESC.USP. 196p.

LANDVA, A; KNOWLES, D; (1992) - Geotechnics of waste fills. Theory and Practice. ASTMSTP. 1070.

LEITE, A. L.; (1996a) - Avaliação de liners compostos de materiais inconsolidados das formações Botucatu e Serra Geral quanto ao processo de difusão molecular. Revisão Bibliográfica - Seminários Gerais em Geotecnia. EESC - USP. SP

LEITE, A. L. (1997) A difusão molecular do $\mathrm{K}^{+}$e $\mathrm{CL}^{-}$em solos naturais compactados: Uma perspectiva para uso em liners. Dissertação (Mestrado). EESC - USP 144p.

LEITE, J.C (1996b) - Avaliação de materiais inconsolidados para uso em liners. Seminários Gerais em Geotecnia. EESC - USP. SP

LEITE, J.C.; ZUQUETTE, L.V. (1995) - Prevenção da contaminação e poluição de aqüíferos: a utilização de liners. Geociências, São Paulo, 14(1): pp 167 - 178.

LIORET, A; ALONSO, E.E; (1994) - Unsaturated flow Analysis for the design of a Multilayer Barrier. In: XIII ICSMFE, New Delfi, India. pp 1529 - 1632.

LIPORACI, S. R. (1996) Procedimentos e metodologias de Mapeamento Geotécnico: Aplicação na cidade e parte do Munícipio de Poços de Caldas (MG) Escala 1:25.000 - Visando o planejamento do uso e ocupação do Meio Físico. Dissertação (Mestrado) EESC -USP. IV. $214 \mathrm{p}$.

MANZANO, A.R; (1991) - Utilización de Geosintéticos en Rellenos Sanitarios. In: Simpósio Geotecnia y Medio Ambiente. Sociedd Mexicana de Mec. de Suelo. pp 101-114. 
MASSMANN, J; FREEZE, R.A (1987) - Groundwater Contamination from Waste Management Sites: The interaction between Risk - Based Engineering Design and Regulatory Policy 1, Methodology. In: Water Resources Research. V (2), No 2. pp 351-367.

MASSMANN, J; FREEZE, R.A (1987) - Groundwater Contamination from Waste Management Sites: The interaction between Risk - Based Engineering Design and Regulatory Policy 2, Results. In: Water Resources Research. V (2), No 2. pp 368-380.

MARTIN, K; BASTOCK (1993) - Waste Minimization: A chemist's Approach. Royal Society of Chemistry.

MATSUZAKI, S. S. (1998) Aplicação de Modelos computacional de escoamento de água Subterrânea no Lixão de São Carlos. Dissertação (Mestrado). EESC - USP. 113p.

MEANS, J.L; HINCHEE, R.E; (1994) - Emerging Technology for Bioremediation of Metals. Lewis Publishers.

NATIONAL ACADEMY PRESS. (1995) Alternatives For Ground Water Cleamup. Washington, D. C.,. 315p.

NUCLEBRAS - Empresas Nucleares Brasileiras (1975) Mapa Geológico do Planalto de Poços de Caldas. Escala 1:50.000. Rio de Janeiro (inédito)

OLDENBURG, C.M; PRUESS, K; (1993) - On numerical Modeling of Capillary Barries. In: Water Resouces Research, v (29), No 4. P 1045-1056.

PEJON, O. J. (1992) Mapeamento Geotécnico Regional da Folha de Piracicaba - SP (Escala 1:100.000): Estudo de Aspectos Metodológicos, de Caracterização e de Apresentação de Atributos Dissertação (Mestrado). EESC. USP. 2V.

PREFEITURA DE POÇOS DE CALDAS (1997) Análise Geológico-Geotécnica da Área do Aterro Sanitário do Município de Poços de Caldas. Relatório Interno. 
PORTO, M.F.A. (1991) - Estabelecimento de parâmetros de controle da Poluição. In: PORTO, R.L.L.(org). Hidrologia Ambiental, São Paulo. EDUSP, pp 375-390.

QUIGLEY, R.M; FERNANDEZ, F; CROOKS, V.E; (1987) - Engineered Clay Liners: A Short Review. In: Environmental Geotechnics and Problematic Soils and Rocks. Balkema. Rotterdam. pp 63-74.

REED, S.C; MIDDLEBROOKS, E.J; CRITES, R.W. (1988) Natural Systems for Waste Managment \& Treatment. McGraw-Hill Publishing Company.

RHYNER, C.R; SCHWARTZ, L.J; WENGER, R.B; KOHRELL, M.G. (1995). Waste Management and Resource Recovery. Lewis Publishers.

ROWE, R.K; BOOKER, J.R; (1987) - New theorical Models for Waste Disposal sites with clay liners. In: Environmental Geotechnics and Problematic Soils and Rocks, Balkema, Rotterdam. pp 409-419.

ROWE, R.K. (1988) - Contaminant migration through groundwater - the role of moddeling in the desing of barries. Eleventh Canadian Geotechnical Colloquim. Canadian Geotechnical Journal, 25(4): pp 778-798.

ROWE, R.K.;QUIGLEY, R. M.; BOOKER, J.R., (1995) - Clayey Barrier Sustems for Waste Disposal Facilities. E \& FN SPON, Londres.

ROWE, R.K.; MEMBER, A.S.C.E; BADV, K; (1996) - Advective - diffuse Contaminant Migration in Unsaturated Sand and Gravel. In: Journal of Geotechnical engineering. $v$ (122), No 12. pp 965 - 975.

SALOMONS, W; STIGLIANI, W.M; (1995) - Biogeodynamics of Pollutants in Soils and Sediments. Risk Assessment of Delayed and Non-Linear Responses. Ed. Springer.

SARSBY, R.W; (1995) - Waste Disposal by Landfill. A.A.Baalkema, Rotterdam. (ed). 
SAUTY, J.P; (1980) - An Analysis os Hidrodispersive Transfer in Aquifers. In: Water Resoures Research, v (16). No 1. pp 145 - 158.

SCHALCH, V.; LEITE, W. C. de A.; FANTINI Fr., W; AGUIAR, E. M. de; FERNANDES Jr, J. L. (1992) Aterros sanitários: Considerações sobre a escolha do Sítio, Projeto, Implantação, Operação e Monitoramento. In: 7o Congresso Brasileiro de Águas Subterrâneas, Belo Horizonte. MG. pp 123 - 127.

SCHWILLE, F. (1988) Dense chlorinated solvents in porous and fractured media: Model experiments. Transl. From german by J. F. Pankow. Chelsea, MI: Lewis Publishers. P. 146.

SHARMA, D.H; LEWIS, S.P. (1994) Waste Containment Systems, Waste Stabilization, and Landfill - Design and Evaluation. New York. Wiley Interscience. 1994. 585p.

SMITH, L; HINCHEE, R. (1993) - In situ Thermal Technologies for Site Remediation. Ann Arbor, Mich. Lewis Publishers.

SMITH, J.A.\& JAFFÉ, P.R., (1994) Benzene transport through landill liners containing organophilic bentonite. Journal Envir. Engng., 120 (6): pp 1559 - 1577.

SOESILO, J.A; WILSON, J. R; (1995) Hazardous Waste Planning. Lewis Publishers (ed).

STEWART, J.P; NOLAN, W.T. (1987) Infiltration testing for Hydraulic Conductivity of soil liners. In:Geotchnical testing Journal. 10(2): pp 41-51.

STONER, D.L (1994). Biotechnology for the Treatment of Hazardous Waste. Lewis Publishers. (ed.)

SUTHERSAN, S.S (1997). Remediation Engineering: Design Concepts. Boca-Raton, Florida. Lewis Publishers.. 362p. 
TCHOBANOGLOUS, G; THEISEN, H; ELIASSEN, R; (1977) Solid Waste - Engineering Principles and Management Issues. McGraw-Hill Publishing Company

TESTA, S.M; (1994) Geological Aspects of Hazardous Waste Management. Lewis Publishers.

TRAVIS, C.C; COOK, S.C; (1989) Hazardous Waste Incineration and Human Health. CRC. PRESS.

TRESSOLDI, M; (1996) - Avaliação da influência de tapetes impermeabilizantes na Migração de Contaminantes. In: $8^{\circ}$ congresso Brasileiro de Geologia de Engenharia. RJ. V (2). pp 659 -670 .

UDELL, K.S; STEWART, L.D (1989) - Field Study of In Situ Steam Injection and Vacuum Extraction for Recovery of Volatile Organic Solvents. UCB-SEEHRL 98-2.

ULBRICH, H. H. G. J. (1984) A petrografia, a estrutura e o quimismo do nefelina Sienito do Maciço Alcalino de Poços de Caldas MG-SP. Instituto de Geociências de SP - Usp. Tese (Livre Docência). 2v.

ULBRICH, H. H. G. J.; ULBRICH, M. N. C. (1992) O Maciço Alcalino de Poços de Caldas (MG-SP): características petrográficas e estruturais. In: Congresso Brasileiro de Geologia $37^{\circ}$ SP. Anais.... Impressão DNPM, Roteiro de Excursão 5v, 94p.

URISH, D. W (1983) - The Practical application of Surface Electrical Resistivity to Detection of Ground-Water Pollution. GROUNDWATER - March-April. v. 21, No. 2. pp.144-152.

U.S. ENVIRONMENTAL PROCTETION AGENCY (USEPA). (1984) Slurry Trench Construction for Pollution Migrant control, EPA -34012-40-001, USEPA, Cincinnati, Ohio.. 217p.

U.S. ENVIRONMENTAL PROCTETION AGENCY (USEPA - EPA). (1990) In situ treatment of Contaminated Ground Water. Washington, D.C: EPA, Technology Innovation Office. $78 \mathrm{p}$. 
VAN DER HEIJDE, P. K. M. (1987) Quality assurance in computer simulations of groundwater contamination. Environmental Software. 2 (1) 19-28.

VAN DER HEIJDE, P. K. M.; PARK, R.A. (1986) U. S. EPA Groundwater Modeling Policy Study Group. Report of findings and discussion of selected groundwater modeling issues. International Ground Water Modeling Center. Holcomb Res. Inst. Butler Univ. Indianapolis.

VANN REE, C.C.D.F.; WETSTRATE, C.G.; BREMMER, C.N.(1992) Design aspects and permeability testing of nature clay sand - bentonite liners. In:Geotechnique, XLII (1), 1992.

VIRARAGHAVANT, T. (1987) - Land waste disposal systems. Environmental Geotechnics and Problematic Solis and Rocks, Balkema Rotterdam, 421 - 426.

WISE, D.L; TRANTOLO, D.J. (1994) - Remediation of Harzardous Waste contaminated soil.Wise \& Trantolo (ed). Dekker. 929p.

WILSON, D. J; CIARKE, A.N. (1994) Hazardous Waste site Soil remediation: Theory and Application of Innovative technologies. New York: Marcel Dekker. 567p. (ed)

WILSON, J. T. \& WILSON, B.H. (1985). Biotransformation of trichlorothylene in soil. Applied Environmental Microbiology, v. 49, p242-243.

WORTHINGTON, P.F. (1976). Hydrogeophysical Equivalence of Water Salinity, porosity and Matrix Conduction in Arenaceous Aquifers. GROUNDWATER. July-August. V.14, No.4. pp.224-232.

XANTHAKOS, P.P. (1979) Slurry Walls. New York.. Mc Graw-Hill Book Company.. 622p. 